\title{
Über dieses Buch
}

Dies ist ein digitales Exemplar eines Buches, das seit Generationen in den Regalen der Bibliotheken aufbewahrt wurde, bevor es von Google im Rahmen eines Projekts, mit dem die Bücher dieser Welt online verfügbar gemacht werden sollen, sorgfältig gescannt wurde.

Das Buch hat das Urheberrecht überdauert und kann nun öffentlich zugänglich gemacht werden. Ein öffentlich zugängliches Buch ist ein Buch, das niemals Urheberrechten unterlag oder bei dem die Schutzfrist des Urheberrechts abgelaufen ist. Ob ein Buch öffentlich zugänglich ist, kann von Land zu Land unterschiedlich sein. Öffentlich zugängliche Bücher sind unser Tor zur Vergangenheit und stellen ein geschichtliches, kulturelles und wissenschaftliches Vermögen dar, das häufig nur schwierig zu entdecken ist.

Gebrauchsspuren, Anmerkungen und andere Randbemerkungen, die im Originalband enthalten sind, finden sich auch in dieser Datei - eine Erinnerung an die lange Reise, die das Buch vom Verleger zu einer Bibliothek und weiter zu Ihnen hinter sich gebracht hat.

\section{Nutzungsrichtlinien}

Google ist stolz, mit Bibliotheken in partnerschaftlicher Zusammenarbeit öffentlich zugängliches Material zu digitalisieren und einer breiten Masse zugänglich zu machen. Öffentlich zugängliche Bücher gehören der Öffentlichkeit, und wir sind nur ihre Hüter. Nichtsdestotrotz ist diese Arbeit kostspielig. Um diese Ressource weiterhin zur Verfügung stellen zu können, haben wir Schritte unternommen, um den Missbrauch durch kommerzielle Parteien zu verhindern. Dazu gehören technische Einschränkungen für automatisierte Abfragen.

Wir bitten Sie um Einhaltung folgender Richtlinien:

+ Nutzung der Dateien zu nichtkommerziellen Zwecken Wir haben Google Buchsuche für Endanwender konzipiert und möchten, dass Sie diese Dateien nur für persönliche, nichtkommerzielle Zwecke verwenden.

+ Keine automatisierten Abfragen Senden Sie keine automatisierten Abfragen irgendwelcher Art an das Google-System. Wenn Sie Recherchen über maschinelle Übersetzung, optische Zeichenerkennung oder andere Bereiche durchführen, in denen der Zugang zu Text in großen Mengen nützlich ist, wenden Sie sich bitte an uns. Wir fördern die Nutzung des öffentlich zugänglichen Materials für diese Zwecke und können Ihnen unter Umständen helfen.

+ Beibehaltung von Google-Markenelementen Das "Wasserzeichen" von Google, das Sie in jeder Datei finden, ist wichtig zur Information über dieses Projekt und hilft den Anwendern weiteres Material über Google Buchsuche zu finden. Bitte entfernen Sie das Wasserzeichen nicht.

+ Bewegen Sie sich innerhalb der Legalität Unabhängig von Ihrem Verwendungszweck müssen Sie sich Ihrer Verantwortung bewusst sein, sicherzustellen, dass Ihre Nutzung legal ist. Gehen Sie nicht davon aus, dass ein Buch, das nach unserem Dafürhalten für Nutzer in den USA öffentlich zugänglich ist, auch für Nutzer in anderen Ländern öffentlich zugänglich ist. Ob ein Buch noch dem Urheberrecht unterliegt, ist von Land zu Land verschieden. Wir können keine Beratung leisten, ob eine bestimmte Nutzung eines bestimmten Buches gesetzlich zulässig ist. Gehen Sie nicht davon aus, dass das Erscheinen eines Buchs in Google Buchsuche bedeutet, dass es in jeder Form und überall auf der Welt verwendet werden kann. Eine Urheberrechtsverletzung kann schwerwiegende Folgen haben.

\section{Über Google Buchsuche}

Das Ziel von Google besteht darin, die weltweiten Informationen zu organisieren und allgemein nutzbar und zugänglich zu machen. Google Buchsuche hilft Lesern dabei, die Bücher dieser Welt zu entdecken, und unterstützt Autoren und Verleger dabei, neue Zielgruppen zu erreichen. Den gesamten Buchtext können Sie im Internet unterhttp://books.google.com durchsuchen. 
This is a reproduction of a library book that was digitized by Google as part of an ongoing effort to preserve the information in books and make it universally accessible.

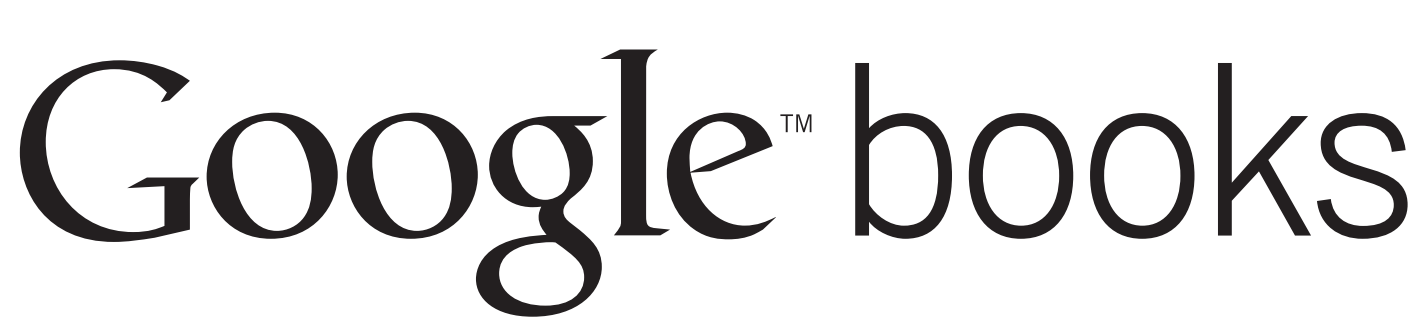

https://books.google.com

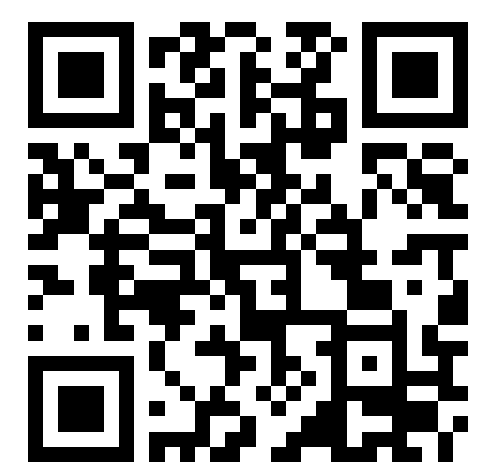



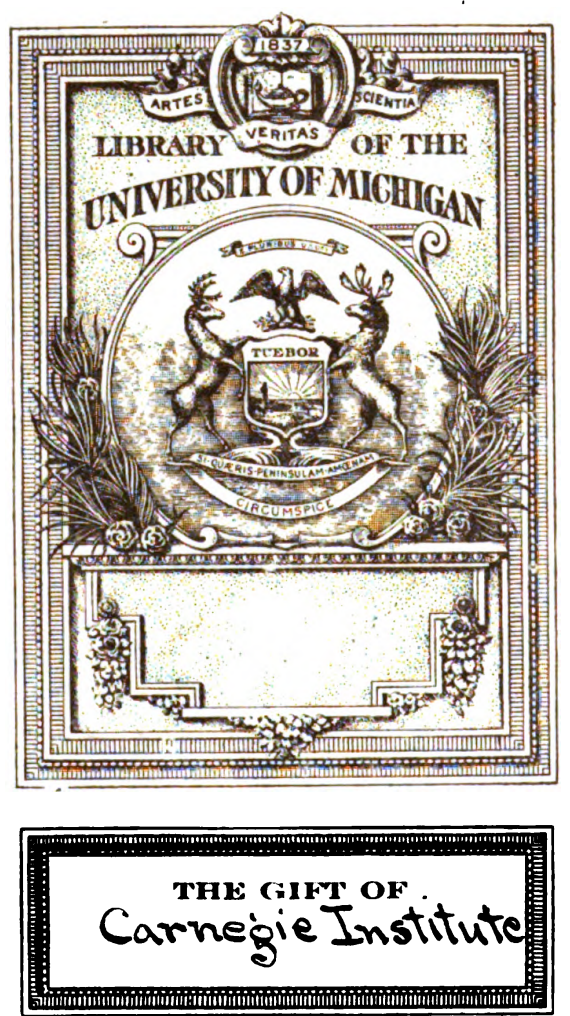
AS

32

142.

$w_{i}, 13$ 

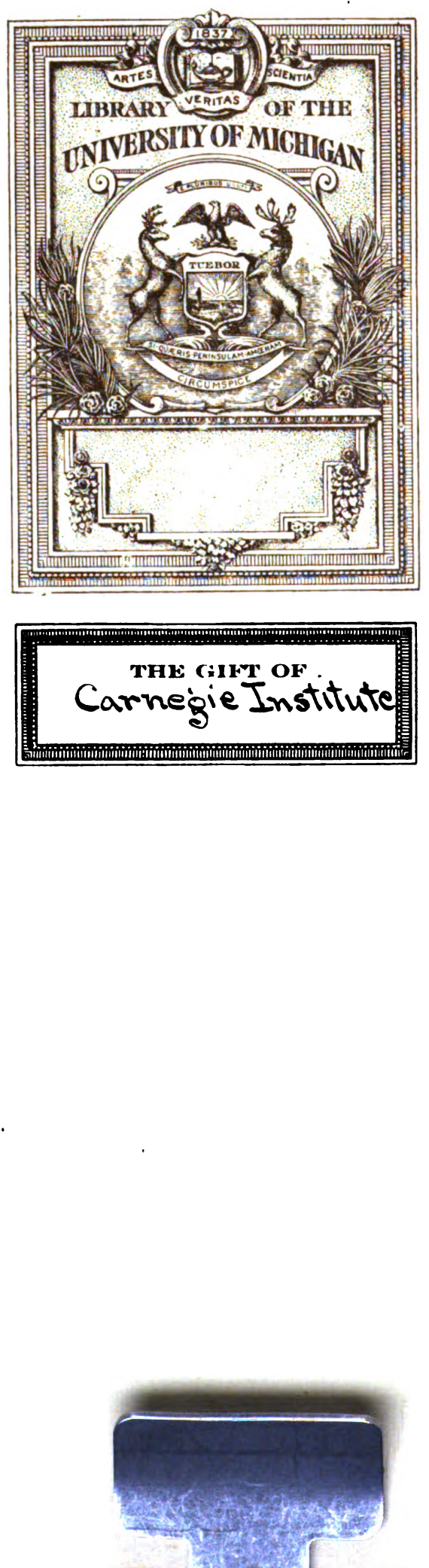

Digitized by GOOgle 
AS

32

142

$20,1 ?$

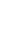

Digitized by $\mathrm{OOg} e$ 




$$
\begin{aligned}
& \text { Carreque inatitution of } \\
& \text { EXPLORATIONS IN TURKESTAN }
\end{aligned}
$$

\author{
EXPEDITION OF 1904
}

\title{
PREHISTORIC CIVILIZATIONS OF ANAU
}

Origins, Growth, and Influence of Environment

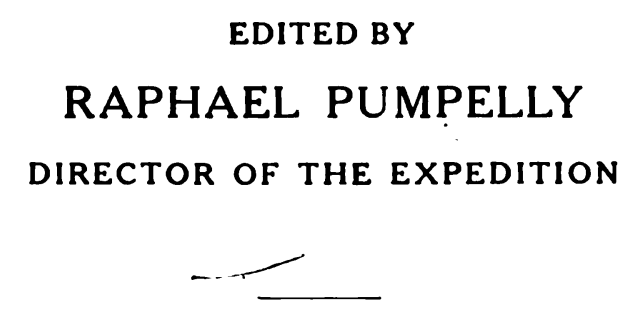

IN TWO VOLUMES-VOLUME ONE

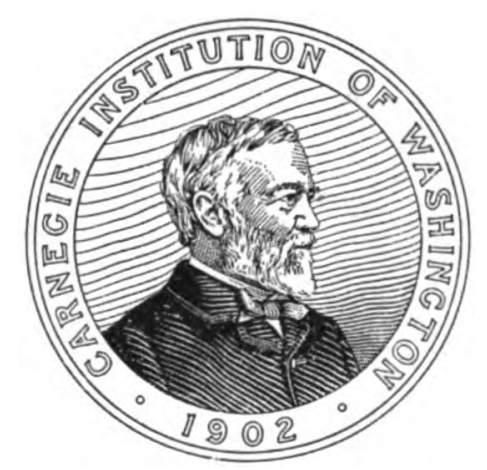

WASHINGTON, D. C.

Publishod by the Carnegie Institution of Washington 1908 


\section{TABLE OF CONTENTS.}

\section{FIRST VOLUME.}

Part I. ancient anau and the Oasis-world. R. Pumpelity.

Chapter I. Evolution of the Environment of Centrili-Asian Civilizations............

Undrained Central Asia: The beginning of Central Asia $\ldots \ldots \ldots \ldots \ldots \ldots \ldots \ldots \ldots \ldots$

A series of great and small landlocked basins containing residuary seas; these seas are gages recording cyclical climatic changes. General trend toward aridity..

Influence of Glacial period. Several phases of the Glacial period recorded in the high

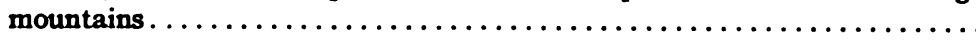

Undrained Asia contrasted with oceanic basins; river-brought detritus graded and distributed by wind instead of water; loess......................

Characteristics of loess as an inexhaustible soil; its influence on history of China and of

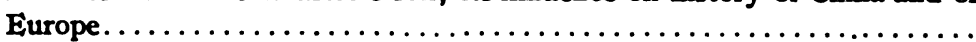

Richthofen's theory of origin of loess confirmed; all loess brought by wind...........

Expeditions of 1903 and 1904 show two sources from which wind derives the dust, viz, Ist, directly from products of deflation and of disintegration; 2d, from alluvions or dry deltas and dry flood-plains $\ldots \ldots \ldots \ldots \ldots \ldots \ldots \ldots \ldots$

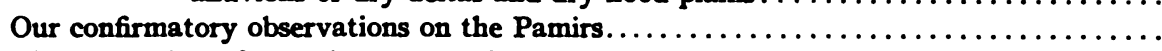

Bird's-eye view of organic processes in undrained Asia ............................

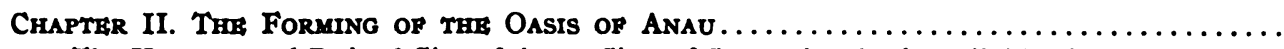

The Kurgans and Ruined City of Anau, Sites of Successive Ancient Civilizations...........

They consist of slowly accumulated layers of the débris of occupation (culture-strata); their bottoms stand 20 feet below the surface of the oasis-plain...........

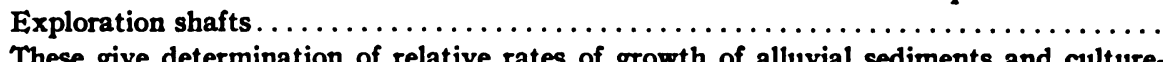

These give determination of relative rates of growth of alluvial sediments and culturestrata, 20-2I; and of alternating growth and degradation of the alluvial

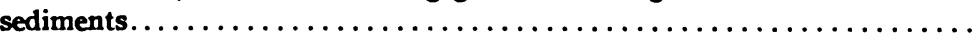

Deformation of the kurgans by wind and water through long time. Three distinct growths of alluvial strata with two intermediate degradations, since

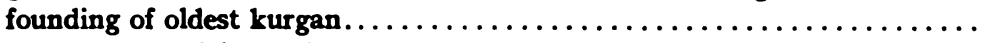

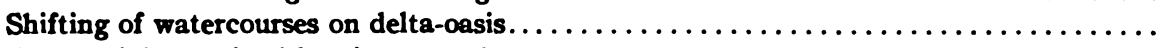

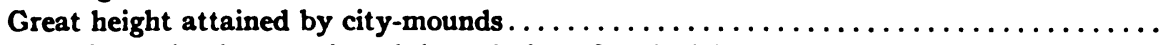

$\checkmark$ Agencies active in growth and degradation of oasis-delta $\ldots \ldots \ldots \ldots \ldots \ldots \ldots \ldots$

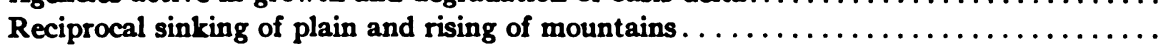

Block-uplifts shown in the mountains and sinking of plains shown in artesian well at

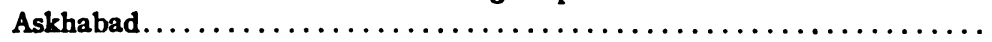

Unloading ou mountains; loading on delta; zonal distribution of sediments on delta.....

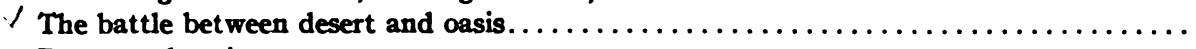
Dunes and oasis.

Surface conditions continue in depth, the delta alluvions dove-tailing with surrounding dune-sands.......................................

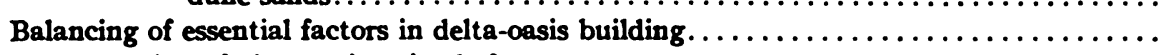

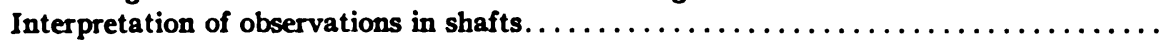

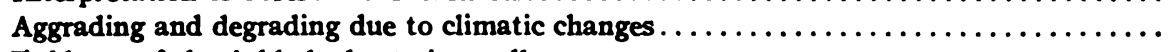

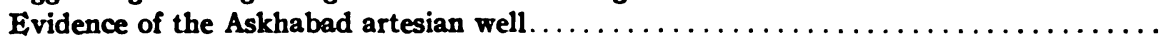
Table showing physiographic history of the Anau delta-oasis....................

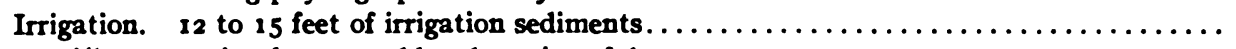

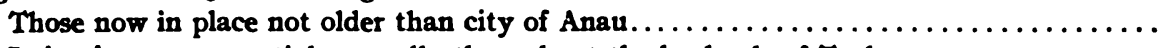
Irrigation now essential generally throughout the lowlands of Turkestan $\ldots \ldots \ldots \ldots \ldots$ Its introduction reversed the order of delta-building processes $\ldots \ldots \ldots \ldots \ldots \ldots \ldots \ldots$

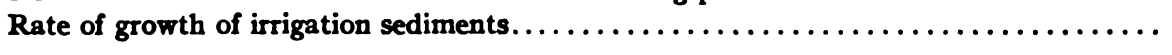




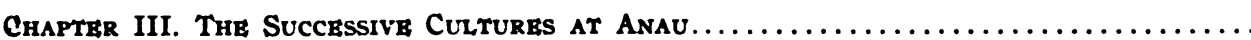

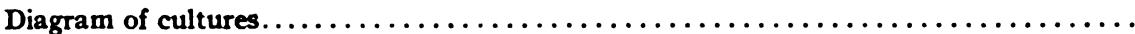

Culture I (Eneolithic), North Kurgan. Negative and positive characteristics........... Area of the site.................................................. A settlement of houses of unburnt bricks from the beginning, with hand-made painted

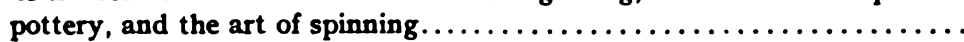

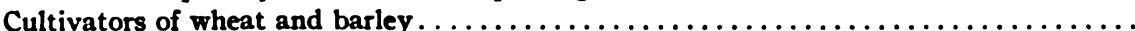
Children buried in "contracted position" under house-floors. . . . . . . . . . . . . . . . . . .

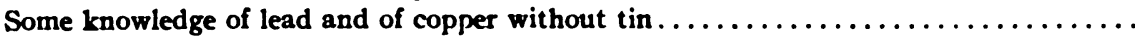
Duerst's discovery that domestication of animals began in this culture period-ox, horse,

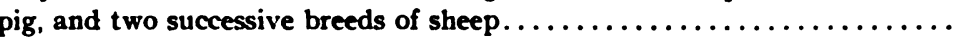

Culture II, North Kurgan. Negative and positive characteristics....................

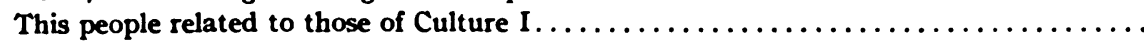
More knowledge of copper; no tin; more highly developed hand-made pottery and ornament, and lapis lazuli; they bring shepherd's dog, goat, and camel; sheep become hornless. Period ends in time of aridity $\ldots \ldots \ldots \ldots \ldots \ldots \ldots$

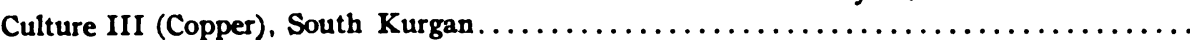

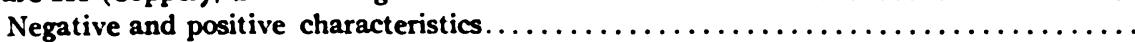
Begins with founding of South Kurgan during favorable stage of climatic cycle........ Fully developed Copper Age of Central Asia. Pottery wheel-made and rarely painted.. Tin rare and in small percentages, unintentionally present in a few objects of copper,

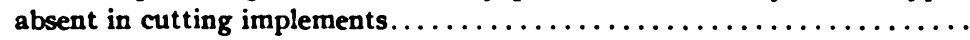
Localities of tin ores and copper ores in Central Asia ......................... General presence of arsenic and antimony in the copper $\ldots \ldots \ldots \ldots \ldots \ldots \ldots \ldots \ldots$

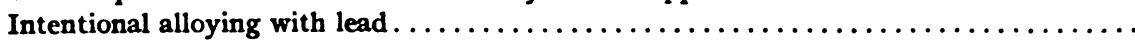
Evidences of intercourse with Western Asiatic spheres of culture................. Arrow-point of Armenian obsidian; winged and bird-headed lion-griffin; the copper sickle The flint-edged sickles of early Egypt . . . . . . . . . . . . . . . . . . . . . . . . . . . . . Persistence of traditional forms of implements; figurines of Ishtar type............

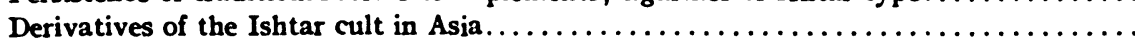

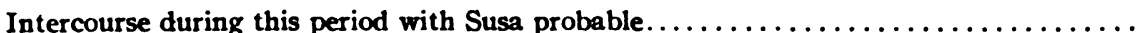
Culture III ends apparently with a conflagration and near arid extreme of climate..... After this the South Kurgan was long unoccupied...........................

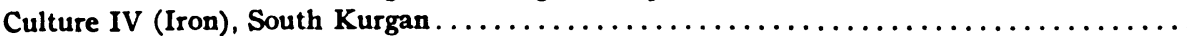
Overlies Culture III, with 8 feet of intervening débris of wastage- "mixed layers." Iron age, sickles with rivet-holes; three-edged copper arrow-point ........ This culture founded during climatic reaction from aridity $\ldots \ldots \ldots \ldots \ldots \ldots \ldots$ Scythic invasion of Persia ..........................................

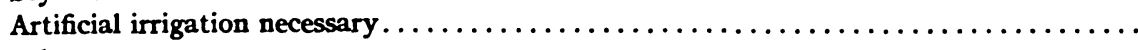
Chronology.

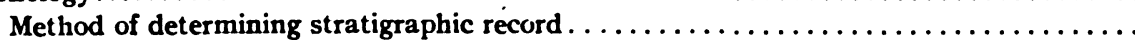

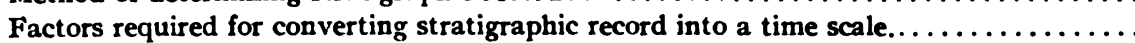
Geological and archeological factors used in determining the stratigraphic equivalence of the intervals between the cultures........................... Equivalence in feet of culture-strata of the interval between end of Iron Culture (IV)

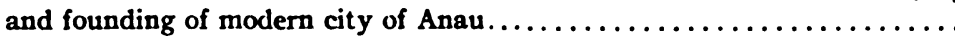
Interval between Copper III and Iron Culture IV $\ldots \ldots \ldots, \ldots, \ldots, \ldots, \ldots, \ldots, \ldots, \ldots$

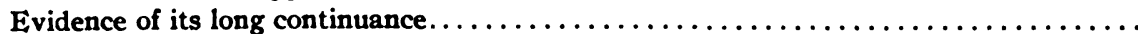
Geological estimation of duration of this interval.................................

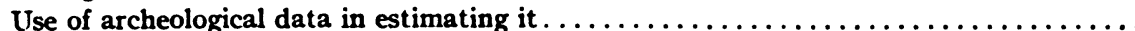

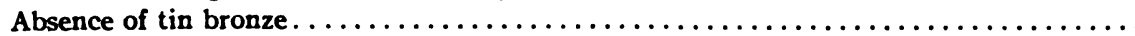
End of Copper Culture probably not later than 2200 B. c..................... No data for estimating interval between Culture II (North Kurgan) and Culture III (South Kurgan)

Conversion of stratigraphic column into a time scale.... Glazed pottery appears first with Sassanian coins at ancient Merv.................. Rate of growth of culture-strata since introduction of glazed pottery $\ldots \ldots \ldots \ldots \ldots$.

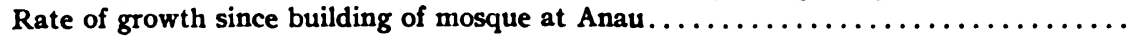
Rate of growth before building of mosque.

Paces. 37-62 37 38 38 38 39 39 40 41 42 43 
Chapter III. The Successive Cul,tures at Anau.-Continued.

Chronology.-Continued.

Average of these rates in city of Anau 2.5 feet per century.......................

Culture-strata of the kurgans much more compacted and rate of grcwith taken at 2 feet per century

Results of author's study of rates of growth of village mounds at Egyptian temples show in the six cases studied rates ranging from 1.35 to 1.9 feet, an average of 1.66

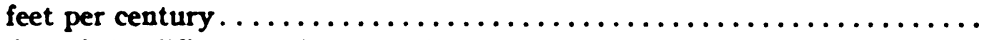
Estimated dating of the different cultures at Anau.............................

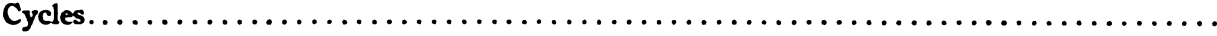

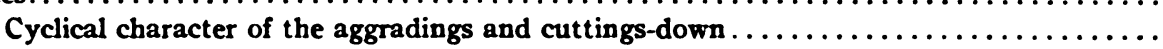

Reasons for ascribing them to climatic changes rather than to orogenic movements.....

Geological evidence from Ghiaur Kala confirmatory of historical evidence............

Parallelism with rise and decay of civilizations and with biological changes...........

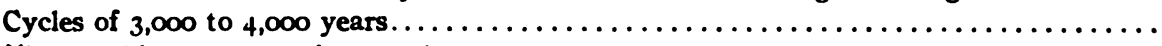

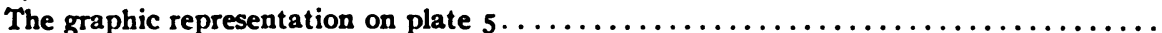

Relation of cycles to the successive civilizations of the North and South Kurgans....

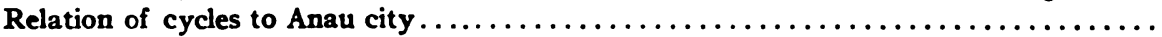

The 2,200-foot Askhabad well possibly a time scale in glacial geology $\ldots \ldots \ldots \ldots \ldots \ldots$.

Chapter IV. Hypothesis of the OAsis-world $\ldots \ldots \ldots \ldots \ldots \ldots \ldots \ldots \ldots \ldots \ldots \ldots \ldots \ldots$ The two earliest civilizations, I and II, distinguished by complete absence of axes, spear-

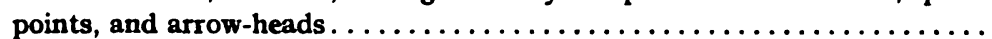

This indicates absolute isolation from Europe and Africa since a time earlier than the invention of these implements. .

Therefore Anau Cultures I and II wholly native to the region of inner-continental isolation This isolation must date from one of the stages of the Glacial period. . . . . . . . . . . .

The post-glacial progressive trend towards aridity caused segregation of peoples, first into larger groups and later into smaller ones on isolated oases or in high mountain valleys, causing differentiation in evolution of social organization and

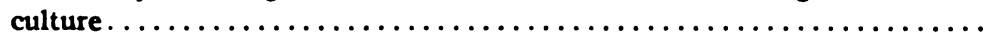

The earliest culture at Anau presupposes a long-continued previous evolution..........

Cultures I and II show inheritance from a still earlier stage common to both, knowing town life and cultivation of wheat and barley $\ldots \ldots \ldots \ldots \ldots \ldots$

People of Culture III (South Kurgan) were related to those of I and II, but they show, in stone arrow-points and objects of foreign cults, influence of cultures from

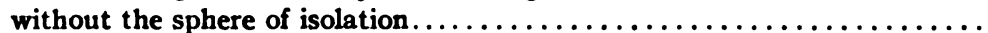

No evidence of Mediterranean influence. . . . . . . . . . . . . . . . . .

Evidence of a regionally widespread autochthonous culture-evolution ..............

The gradual shrinkage of habitable areas and disappearance of herds of wild animals; mankind concentrated on oases necessarily begins the evolution of agriculture.

Growing need leads to beginning of irrigation, to broader development of agriculture and conquest of arid regions, rendering possible the centralized, imperial civilizations of Elam and Babylonia . . . . . . . . . . . . . . . . . . . .

The fundamental essentials of civilization that were native to the sphere of isolation were agriculture, domestication of animals, use of copper and lead, the arts

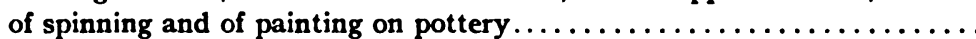

The intervention of the Glacial period and its reaction on inner-continental conditions were the initial, conditioning factors in the evolution of the intellectual and social life of man.

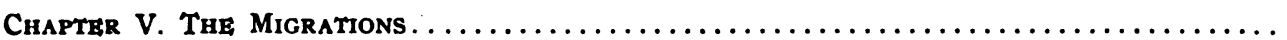
Since cultivation of cereals began long before 8000 B. C. (before founding of North Kurgan), and since domestication of animals was accomplished successively between 8000 and 6800 B. C., that is, after the founding of North Kurgan, it follows-

I, that the agricultural stage preceded the nomadic shepherd stage in Asia............

II, that before domestication of animals, mankind in Central Asia was sharply divided into settled agriculturists on oases, and hunters wandering within a limited

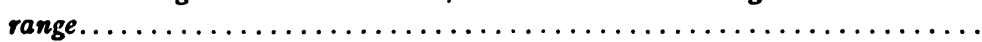


Chapter V. The Migrations.-Continued.

reos.

Climatic deterioration caused unrest and migrations of agriculturists, but caused nomadic shepherds merely to expand over the semi-arid regions .............

This expansion of nomads covered all Inner Asia by the III millennium B. c......... Duerst's identification of the second breed of sheep and the domestic pig of Anau I with the domesticated sheep and pig of late neolithic stations in Europe indicates Transcaspia as ultimate source of these domestic animals............

They appear in Europe contemporaneously with immigrants of round-headed Asiatic

(Galcha) type, and with introduction of wheat and barley.............
These early immigrants brought no other oasis industries, except perhaps spinning, nor metals, but adopted European neolithic culture................

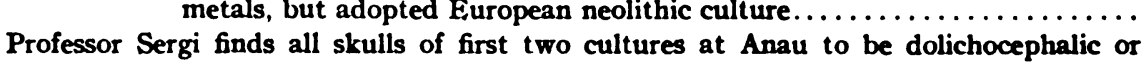
mesocephalic, with total absence of the round-headed element ..........

It is, therefore, a fair hypothesis that the chain of transmission of animals and cereals and spinning included round-headed Asiatic nomadic shepherds........

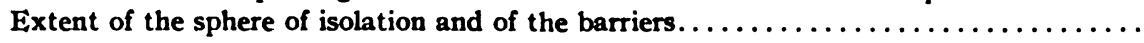

Organized town life with agriculture and breeding of animals first appears among a longheaded people and apparently originated by these.................

Since the II Culture at Anau was started during the trend toward the arid extreme of the cycle and introduced lapis lazuli and the camel, it is probable that this migration came from the East; and the presence in Asia Minor of bones of the turbary sheep makes it possible that migrations of the oasis peoples extended

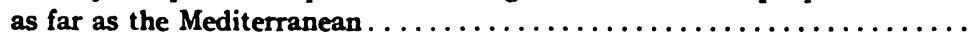

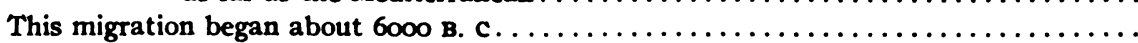

The great migrations were probably checked by the favorable climatic period down to the III millennium B. c. . . . . . . . . . . . . . . . . . . . .

Hypothesis that peoples of the hunting stage received the art of breeding and of planting from the oasis stock during the VI millennium B. c.; that they expanded during the favorable climate of the $V$ and IV millenniums, and that the renewed trend towards aridity in the IV and III millenniums saw the beginnings of the great waves of westward migrations.............

The migrations of the nomadic stocks were chiefly over Eurasian steppes and north of the Black Sea; those of the oasis stock along routes through Mesopotamia

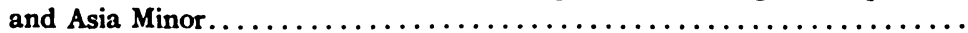

Relation of Anau Cultures I and II to early Babylonia and Susiana . . . . . . . . . . . .

Duerst identifies breed of longhorned cattle established at Anau with that brought to Babylonia before time of Sargon of Accad-in IV millennium B. c. or earlier-in the pre-Semitic Sumerian time.

The Babylonian symbol for the domestic ox $\boldsymbol{\psi}$ belongs in the pre-transitional, pictographic form of writing, which was used before the introduction of writing into Babylonia.

Since agriculture preceded domestication and breeding, it is probable that the origins of these fundamental elements antedated the Chaldean and Babylonian civilizations.

De Morgan's excavations at various points in Susiana found, in pre-Sargonic strata, no traces of stone arrow or spear-points, but abundance of sickle-flints and of

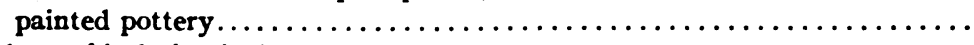

Hence the sphere of isolation included Chaldea . . . . . . . . . . . . . . . . . . . . . .

Hence also a genetic relationship of the cultures of Anau I and II and pre-Semitic Chaldea

Their origin and evolution was within the sphere of isolation that began in the Glacial

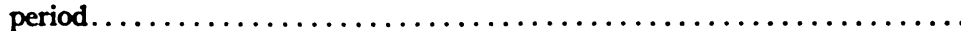

Evidence to show that these cultures were evolved east of Mesopotamia and on or near

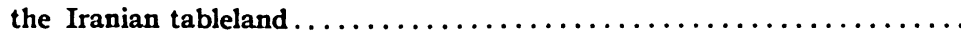

The evolution of agriculture on the oases necessarily preceded the controlling of the Euphrates, the accomplishment of which may have been contemporaneous with the earlier stages of the North Kurgan Copper Culture of Anau III... .

List of Works Consulted in Preparing Part I.
67

67

67

68-69 
Part II. The Archeological, Excavations in anau and Old Merv. Hubert Schmidt.

Chapter vi. The Archeological, Excavations at anau, $\ldots \ldots \ldots \ldots \ldots \ldots \ldots \ldots \ldots$

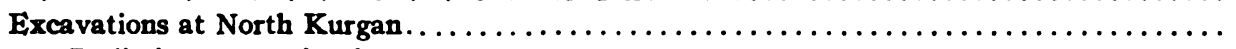

Preliminary examination $. \ldots \ldots, \ldots, \ldots, \ldots, \ldots, \ldots, \ldots, \ldots, \ldots, \ldots, \ldots$

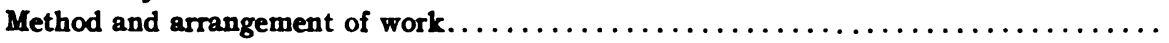

The work and finds at the separate localities on North Kurgan ..................

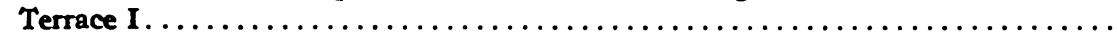

Walls and rooms; pivotal door-stones; bake-ovens; fireplaces............

Skeletons of children buried in "contracted position" and burial gifts; lapis

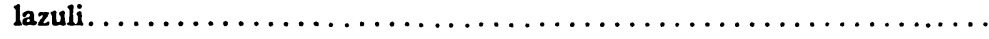

Early recognition of stratigraphic distinctions in pottery, varieties of gray and red monochrome above (group $x$ ) and coarse and fine painted (group $y$ ) below

Terraces IV and V.

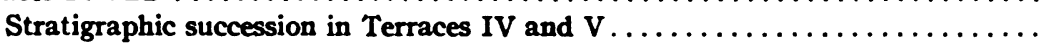

Determined by the stratigraphic distribution of skeletons and pottery.......

Painted pottery in the upper strata (group $z) \ldots \ldots \ldots \ldots \ldots \ldots \ldots \ldots \ldots$

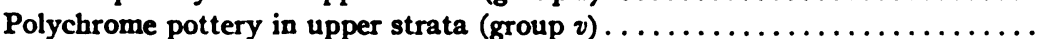

Determination of a change from an older to a younger different culture at 25 feet above the plain, the older one characterized by pottery group $y$, the

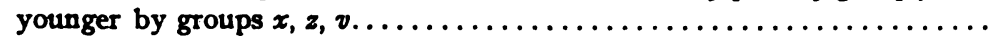

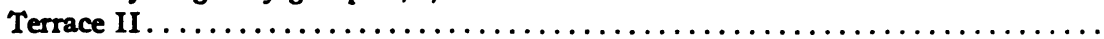

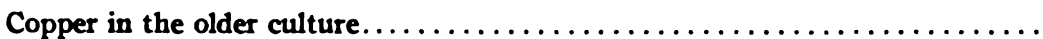

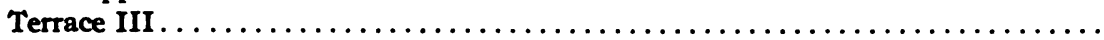

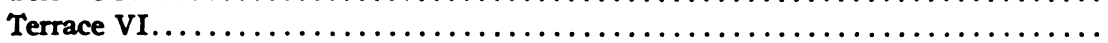

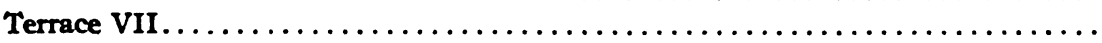

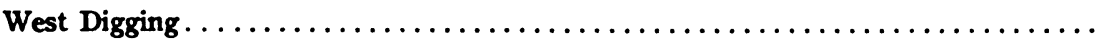

North Digging: Culture-strata down to 24.5 feet below level of plain: skeleton in "contracted position" at - I I feet; painted pottery of group $y$ extends to bottom strata, but in depth associated with a distinct painted variety

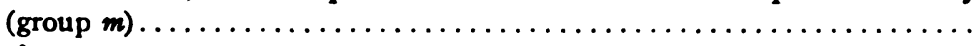

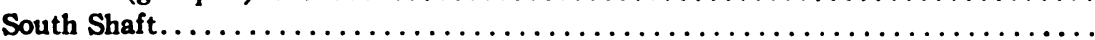

West Shaft: shows wide extent of strata of the older culture with pottery of group $y$

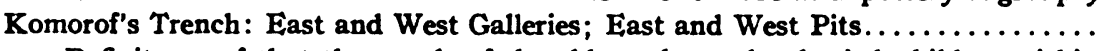

Definite proof that the people of the older culture also buried children within

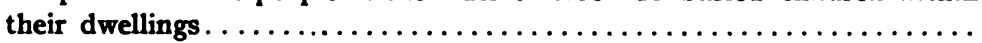

Other finds; character of culture; relative chronology $\ldots \ldots \ldots \ldots \ldots \ldots \ldots \ldots \ldots$ 103 $^{104}$

The excavations at the South Kurgan $\ldots \ldots \ldots \ldots \ldots \ldots \ldots \ldots \ldots \ldots \ldots \ldots \ldots \ldots$ 104-120

General summary and $\operatorname{method} \ldots \ldots \ldots \ldots \ldots \ldots \ldots \ldots \ldots \ldots \ldots \ldots \ldots \ldots \ldots \ldots$

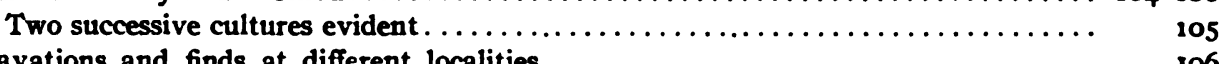

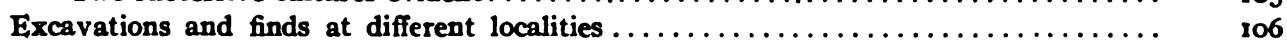

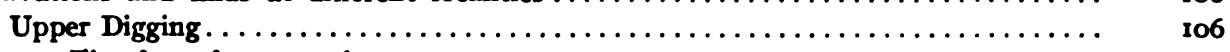

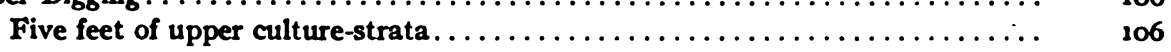

Wheel-made pottery of upper culture (group $I$ ) and iron knife.......... I06

Superior hand-made pottery (group 2) in mixed strata below upper culture... $\quad$ I08

Below 37 feet 7 inches above level of plain only wheel-made pottery of red, gray and whitish-green varieties (groups 3-5) characterizes the older culture of

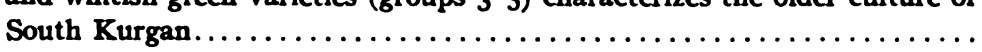

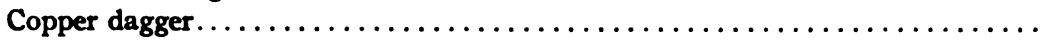

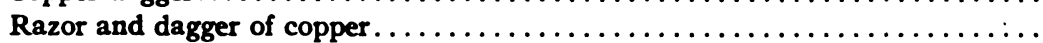

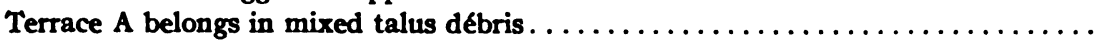

Copper three-edged arrow-point and iron sickle $\ldots \ldots \ldots \ldots \ldots \ldots \ldots \ldots \ldots \ldots \ldots$

Outer Digging. The two cultures and the intermediate "mixed" zone represented.

Terrace B...

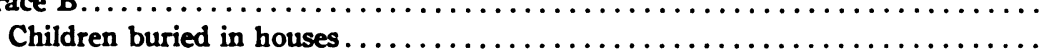

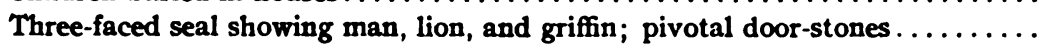

"Clay chest" ..................................................... II

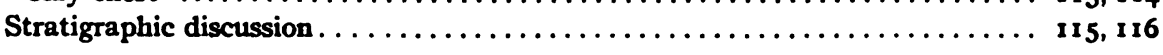


Chapter Vi. The Archiological Excavations at Anau.-Continued.

The excavations at the South Kurgan.-Continued.

Excavations and finds at different localities-Terrace B.-Contimed.

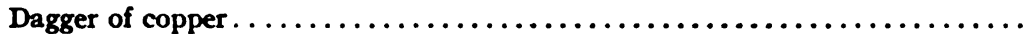

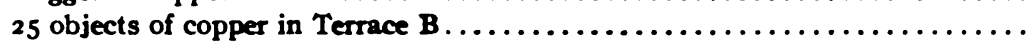

Beads; turquoise; vessels of marble and alabaster; human and animal figures

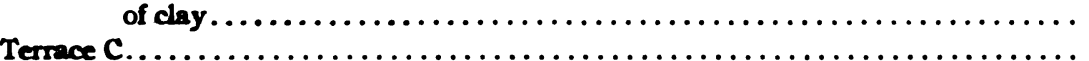

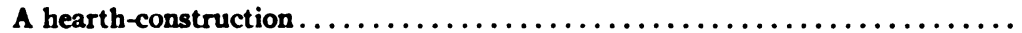

8 objects of copper; beads of agate, turquoise, etc. ; stone vessels............

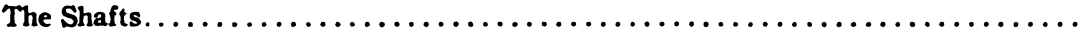

116

118

118

$118-120$

119

120

120

Chapter VII. Resul, Ts.

Results in North Kurgan. Two successive civilizations.

$121-173$

Upper Culture II, above 25 feet above the plain; houses of air-dried bricks; bottomless "bake-oven" pots; burial of children in contracted position in houses; red and gray monochrome pottery (group $x$ ); painted pottery (groups $z$ and $v$ )

Lower Culture I, below 25 feet above the plain; house walls observed down to 18 feet below surface of plain (fireplaces down to -28 feet - R. P.); walls, pithoi, and skeleton graves at all levels. . . . . . . . . . . . . . . . . . . .

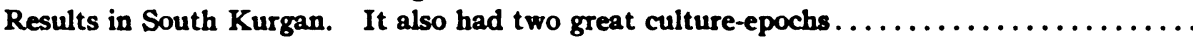

The Younger Culture represented on the top and on low extension; characterized by pottery (groups I and 2), by iron imflements (knife and sickle), and by younger copper forms (three-edged arrow-point) $\ldots \ldots \ldots \ldots \ldots \ldots \ldots$

The Lower Culture III has its top between 38 and 41 feet above the plain. The people of this culture also buried children in a contracted position in their houses Stratigraphic analysis of upper 12 feet of this culture:

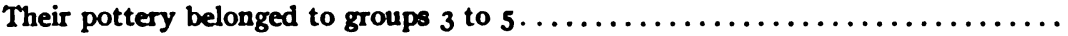

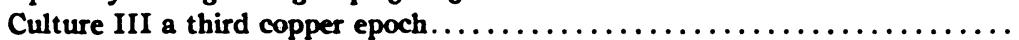

Origin and mode of growth of the two kurgans. . . . . . . . . . . . . . . .

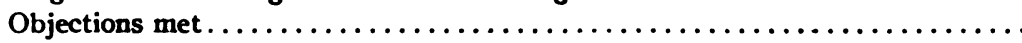

Analytical description of the finds from North and South Kurgans . . . . . . . . . . . . .

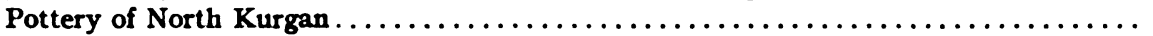

Pottery from the middle strata, Culture $I \ldots \ldots \ldots \ldots \ldots \ldots \ldots \ldots \ldots \ldots$

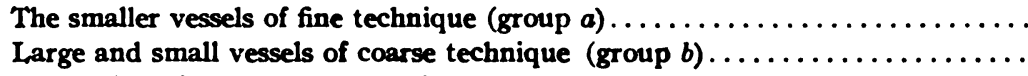

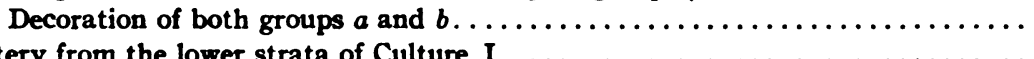

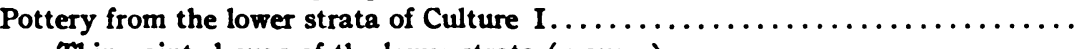

Thin painted cups of the lower strata (group $c) \ldots \ldots \ldots \ldots \ldots \ldots \ldots$

Pottery from the upper strata, Culture II $\ldots \ldots \ldots \ldots \ldots \ldots \ldots \ldots \ldots \ldots \ldots$

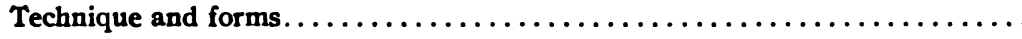

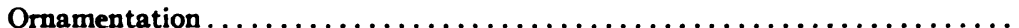

The younger painted pottery of Culture II $\ldots \ldots \ldots \ldots \ldots \ldots \ldots \ldots \ldots$

Pottery of South Kurgan .....................................

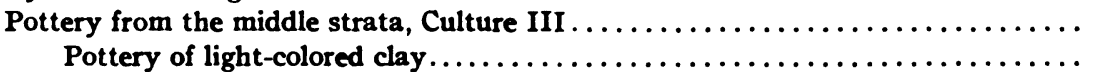

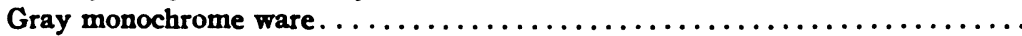

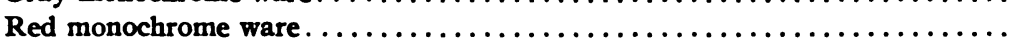

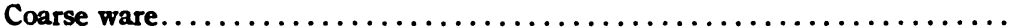

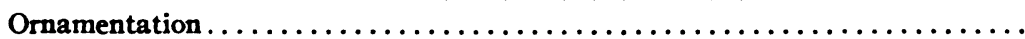

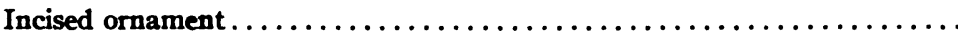

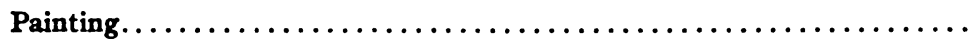

Pottery from the lower strata of Culture III $\ldots \ldots \ldots \ldots \ldots \ldots \ldots \ldots \ldots \ldots$

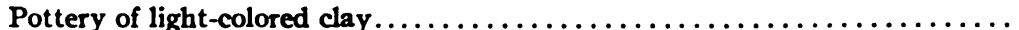

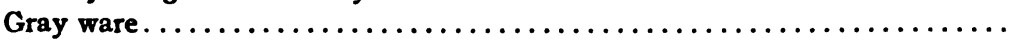

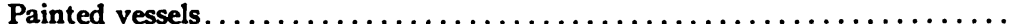

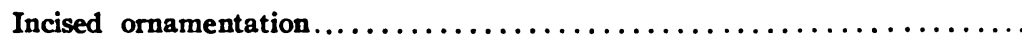


Chapter VII. RESur.Ts.-Continued.

Analytical description of the finds from North and South Kurgans. - Continued.

Pottery of South Kurgan.-Continued.

Pottery from the upper strata, Culture IV $\ldots \ldots \ldots \ldots \ldots \ldots \ldots \ldots \ldots \ldots \ldots . .145-149$

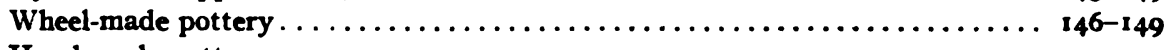

Hand-made pottery................................... 149

The minor antiquities of metal, bone, clay, stone, and faience of both kurgans $\ldots \ldots \ldots \ldots 149^{-173}$

Copper ornaments from middle and lower strata of North Kurgan, Culture I....... 150

Copper objects from upper strata of North Kurgan, Culture II............... 15 I

Copper ornaments and implements from lower and middle strata of South Kurgan, Cul-

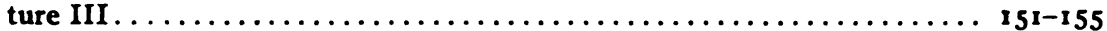

Copper from upper strata of South Kurgan, Culture IV ................... 155-157

Lead from North Kurgan $\ldots \ldots \ldots \ldots \ldots \ldots \ldots \ldots \ldots \ldots \ldots \ldots \ldots \ldots \ldots \ldots \ldots, \quad{ }_{157}$

Ornaments of stone, clay, and faience (beads, etc.):

From lower and middle strata of North Kurgan, Culture I............. 157

From upper strata of North Kurgan, Culture II .................... 158

From middle and lower strata of South Kurgan, Culture III............. 159, 160

From upper strata of South Kurgan, Culture IV....................... 160

Of uncertain position in South Kurgan . .......................... 162

Useful objects of stone, clay, and bone from Cultures I and II, North Kurgan (whorls,

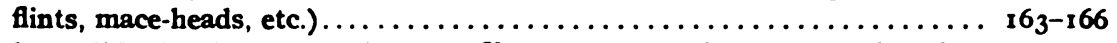

From Culture III, South Kurgan (whorls, flints, arrow-heads, mace-heads, slingstones, seals, and stamps, vessels of marble and alabaster) $\ldots \ldots \ldots \ldots \ldots$ 166-170

From Culture IV, South Kurgan (whorls, etc.) .................... 170

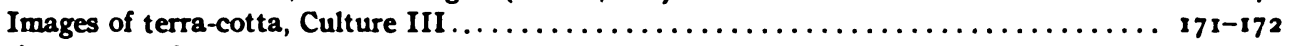

Fragments of glazed pottery in South Kurgan........................ 173

Chapter Vili. Results.

Comparative summary of the four cultures. ........................... $175^{-177}$

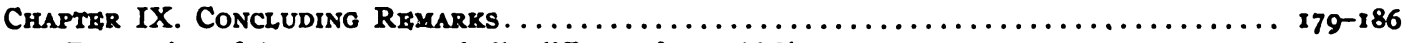

Decoration of Anau pottery wholly different from old European systems............. 179

The only possible comparison would be with that of lowest strata at Susa......... $\quad 179$

Painting of pottery an essential characteristic of oldest cultures of Turkestan and Persia, which were probably not far different in age ....................

Comparison of Anau with ancient Europe in regard to elements of culture and social peculiarities Burial in contracted position in Europe, Africa, and Palestine . . . . . . . . . . . . . . .

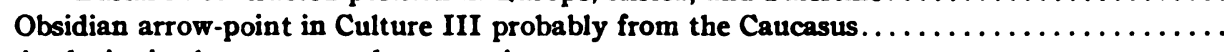

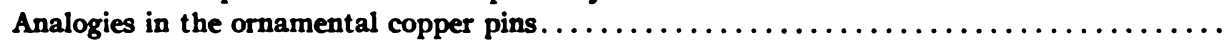

The sickle in Culture III has analogous forms only in VI city of Troja $\ldots \ldots \ldots \ldots \ldots \ldots \ldots$

A knife-blade in Culture III resembles one in Altai-Ural bronze age ..................

Insufficiency of the established equations for chronological determinations . . . . . . . . . . .

The seal with a man, a lion, and a griffin clearly from Western Asia $\ldots \ldots \ldots \ldots \ldots \ldots \ldots$

The three-edged copper arrow-point of Culture IV.$\ldots \ldots \ldots \ldots \ldots \ldots \ldots \ldots \ldots \ldots \ldots \ldots$

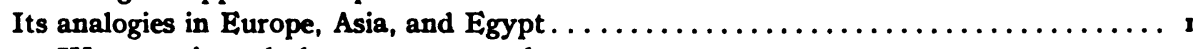

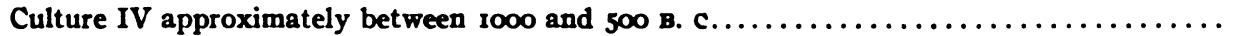

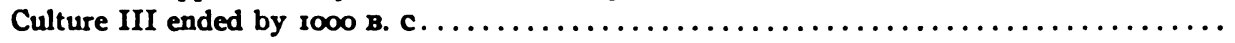

Its brilliant period corresponds with flourishing period of Mycenean culture or earlier .......

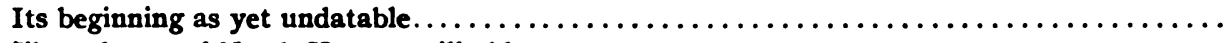

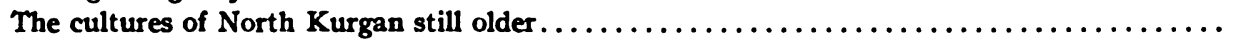

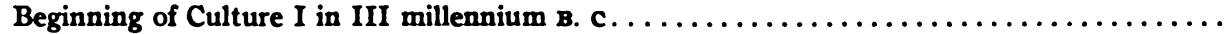

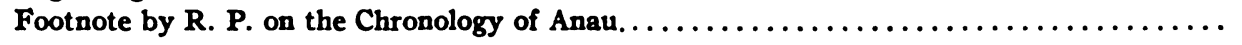

179

179

180

181

181

182

182

182

182

183

$183^{-186}$

186

186

186

186

186

186

186

Chapter X. The Excavations in Ghiaur Kala (Old Mgrv) $\ldots \ldots \ldots \ldots \ldots \ldots \ldots \ldots \ldots$ 187-201

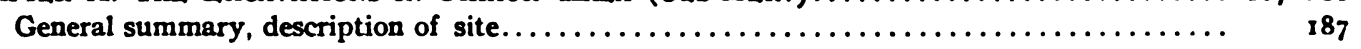

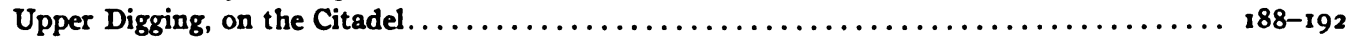

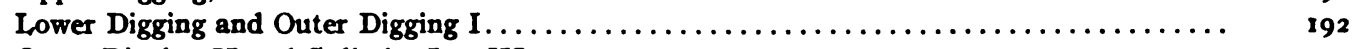

Outer Digging II and Galleries I to III. . . . . . . . 193 
Chapter X. The Excavations in Ghuur Kala (Otd Mgrv). - Continued.

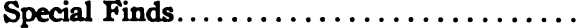

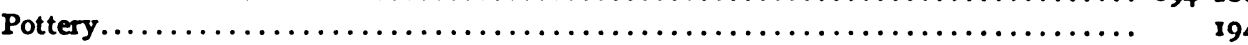

Glazed pottery $\ldots \ldots \ldots \ldots \ldots \ldots \ldots \ldots \ldots \ldots \ldots \ldots \ldots \ldots \ldots \ldots \ldots \ldots \ldots \ldots$

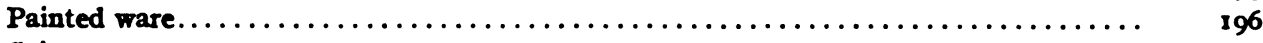

Coins.......................................... 196-197

The observed culture of Ghiaur Kala was Sassanide . . . . . . . . . . . . . . . 197

Inscriptions in Uigur and Pehlevi................................ 197

Metal objects: gold, bronze, iron............................. 198

Beads of stone, clay, glass, and faience. . . . . . . . . $199 \ldots \ldots \ldots \ldots \ldots \ldots \ldots$

Terra-cotta figures......................................... 200

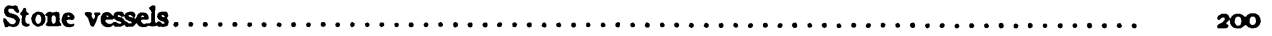

Sling implements. . . . . . . . .

Miscellaneous. ...................................................

Catalogug of Special Find $\ldots \ldots \ldots \ldots \ldots \ldots \ldots \ldots \ldots \ldots \ldots \ldots \ldots \ldots \ldots \ldots \ldots \ldots \ldots \ldots 20210$

Special finds from North Kurgan. . . . . . . . . . . . . . . . . . . . . . . . . . .. 202-204

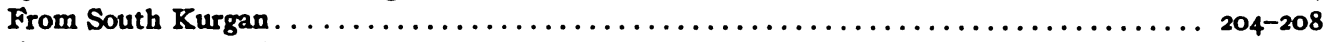

From Ghiaur Kala (Old Merv) $\ldots \ldots \ldots \ldots \ldots \ldots \ldots \ldots \ldots \ldots \ldots \ldots \ldots \ldots \ldots \ldots \ldots \ldots$

Ceapter XI. Noth on the Occurrence of Glazed Wark at aprosiab and the Large Jars at Giunur Kara. Homgr H. KidDER.

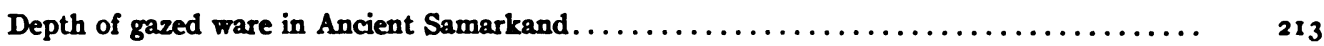

Great jars in Ghiaur Kala...................................... 214-216

Part III. Deascription of thi Kurgans of the Merpv Oasis. Ellisworth Huntington.

Chapter Xil. A Reconnaissance of the Kurgans of this Mgrv Oasis

$219-232$

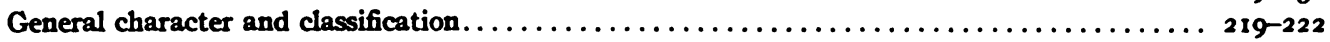

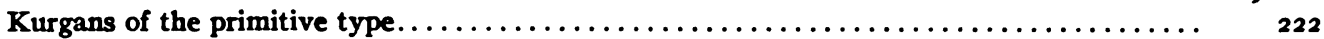

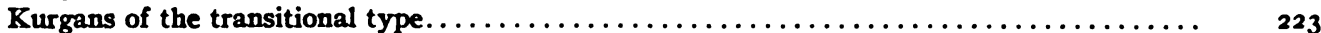

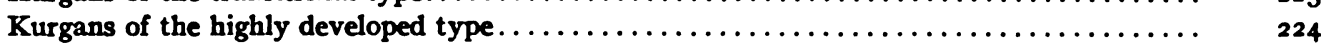

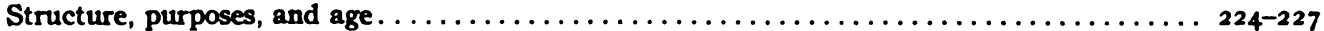

Distribution of ancient populations of the Merv Oasis.................. $228-232$

Part IV. Chemical analyses of Mgtallic Implemgents. F. A. Gooch.

Chaptgr XiII. The Analysis of the Metallitc Implemgents and Products of Corrosion..... 235-240

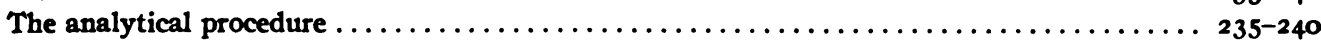

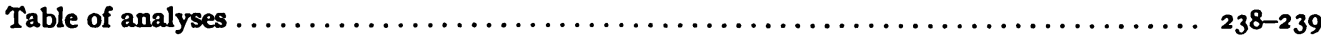


SECOND VOLUME.

Part V. Physiography of Cenmtral-Asian Degserts and Oases. R. Whllegs Pumpelliy.

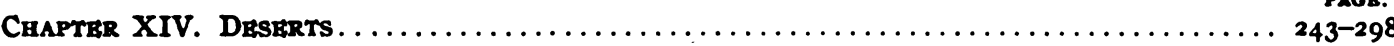

The desert basin as an organic whole. . . . . . . . . . . . . .

The essential characters of a desert basin . . . . . . . . . . . . . . . . . . . 243-244

The three agencies of erosion and transportation, ice, water, and wind; and the five deposition zones, glacial, alluvial, lacustrian, flying sands, and loess arising

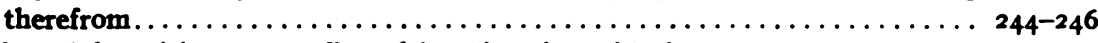

The interlapping of deposition zones effected by climatic oscillations........... 247

The cyclical development of an ideal desert basin $\ldots \ldots \ldots \ldots \ldots \ldots \ldots \ldots \ldots \ldots \ldots$ 247-250

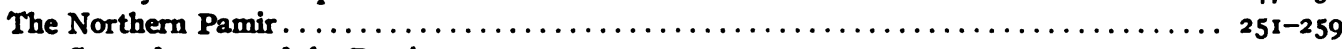

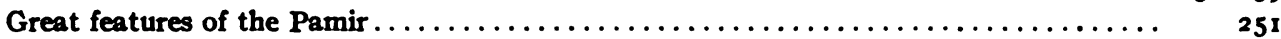

The basin of Great Kara Kul. . . . . . . . . . .

Tentative reconstruction of Quaternary sequence of events ................ 259

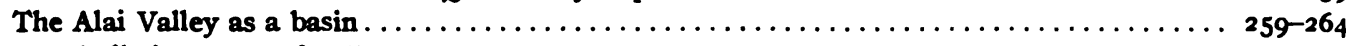

A distinct type of valley. . . . . . . . . . . .

Glaciology and evidences of mountain movement . . . . . . . . . . . . . . $\ldots \ldots 1-264$

A tentative reconstruction of events in the Alai Valley . . . . . . . . . . . . . . . 264

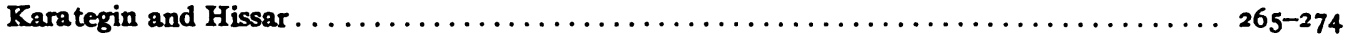

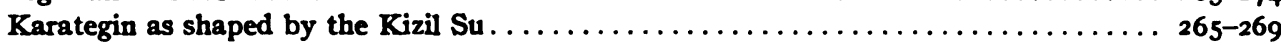

Great features of the Hissar Valley........................... 270-274

Tentative reconstruction of erosion cycles in Karategin and Hissar............. 274

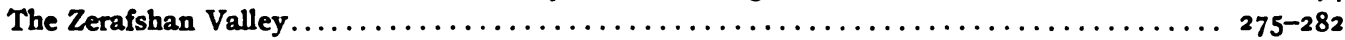

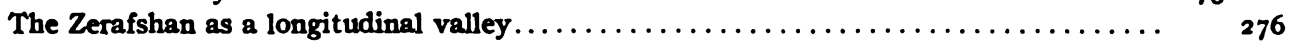

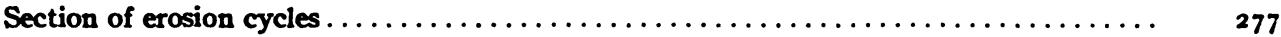

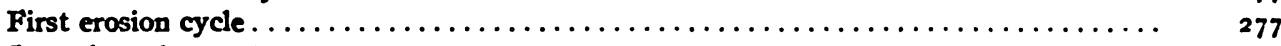

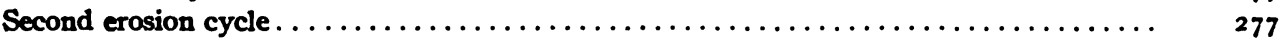

Third erosion cycle.................................. 278-279

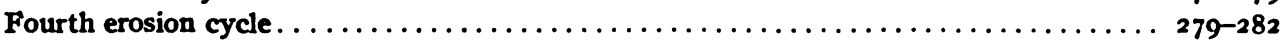

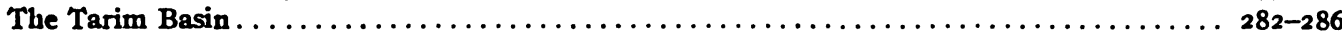

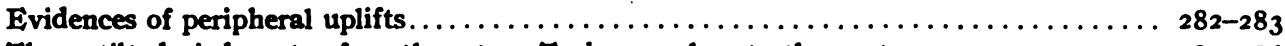

The uptilted piedmonts of northwestern Tarim as a key to the past . . . . . . . . 283-286

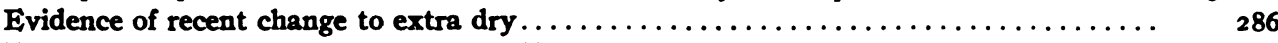

Tentative reconstruction of the past in Tarim $\ldots \ldots \ldots \ldots \ldots \ldots \ldots \ldots \ldots \ldots \ldots \ldots . \ldots \ldots$

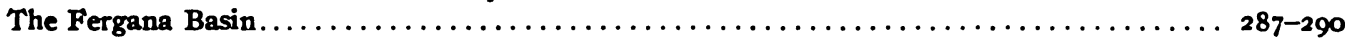

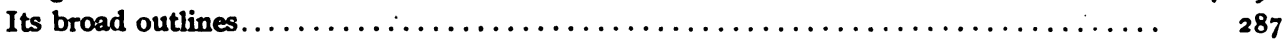

Alai erosion cycles based on the Taldic profile $\ldots \ldots \ldots \ldots \ldots \ldots \ldots \ldots \ldots \ldots \ldots \ldots .287$

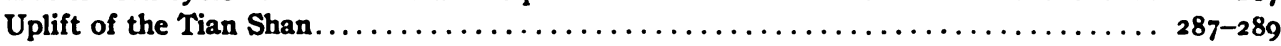

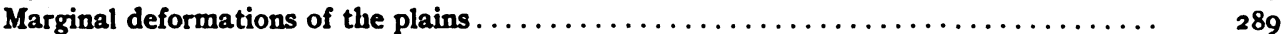

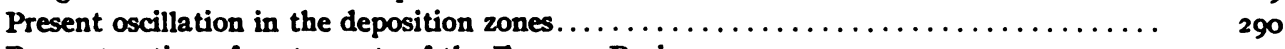

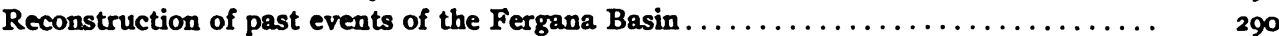

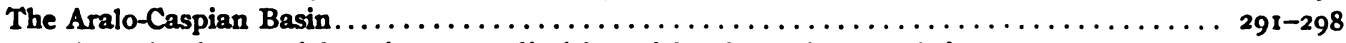

Complications and functional peculiarities arising from shape and size . . . . . . . 291-292

The lacustrian zone (Aralo-Caspian Sea expansions) . . . . . . . . . . . . . . . . 292-294

Recent developments in the alluvial and the flying-sands zones . . . . . . . . . . 294-295

Recent changes in the course of the Oxus........................ 295-297

Tentative reconstruction of the past in the Aralo-Caspian Basin . . . . . . . 298

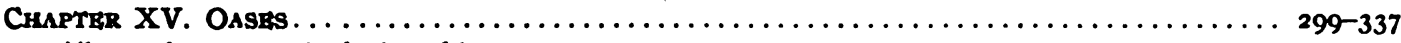

The oasis as a geological problem................................ 299-307

Man as a geologic factor of excavation, transportation and deposition, and a director of alluvial depositions................................ 299-301 
Chapter XV. OAsas.-Continued.

The oasis as a geological problem.-Conlinued.

Physiographic classification of oases.

$301-303$

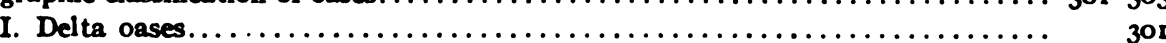

(a) Of rivers..................

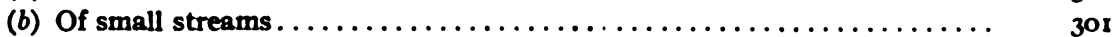

II. River-bank and flood-plain oases.............................. $3^{02}$

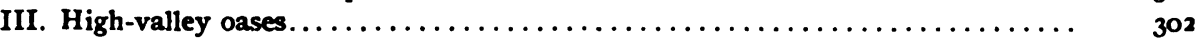

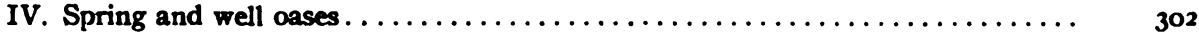

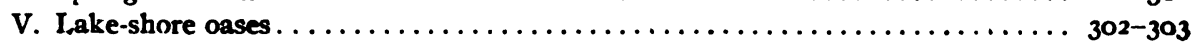

Relations between erosion and burial in the obliteration of kurgans (oasis culture deputits) $303-307$

The ancient Alai Valley route from Bactra to Kashgar....................... 307-310

Objective criteria of ancient long-used routes......................... 307

The three controlling factors of trade routes......................... $307-308$

Advantages of the Alai Valley route $\ldots \ldots \ldots \ldots \ldots \ldots \ldots \ldots \ldots \ldots \ldots \ldots \ldots \ldots \ldots, 308-310$

Oases of the Zerafshan .......................................... 310-316

River-bank (type II) oases of the lower Zerafshan ........................ 310-311

Afrosiab ............................................... 314

High-valley (type III) oases of the upper Zerafshan $\ldots \ldots \ldots \ldots \ldots \ldots \ldots \ldots \ldots \ldots 3^{11-316}$

Hissar................................................... 316-317

Abandoned oases of Fergana...................................... $\mathbf{3}_{17} \mathbf{7}-\mathbf{3 2 0}$

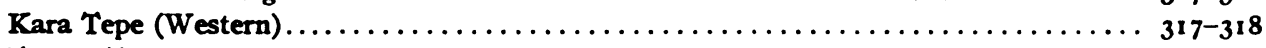

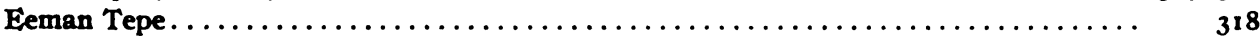

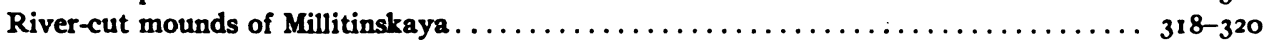

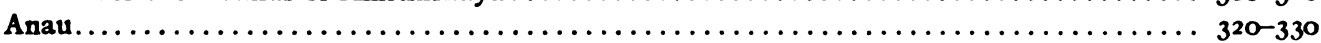

Peculiarities of Anau as an oasis of type $I b \ldots \ldots \ldots \ldots \ldots \ldots \ldots \ldots \ldots \ldots \ldots \ldots, \quad 320$

The building of a tilting delta $\ldots \ldots \ldots \ldots \ldots \ldots \ldots \ldots \ldots \ldots \ldots \ldots \ldots \ldots, \quad 3^{21}$

Erosion cycles of the Anau $\mathrm{Su}$ in the mountains........................ 322

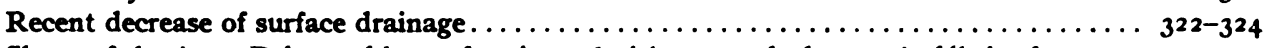

Shape of the Anau Delta and its surface irregularities wrought by man's débris of occupa-

tion and his control of alluvial depositions................... 324-327

The ancient and the modern dunes of Kara Kum and the interbedding of the delta mar-

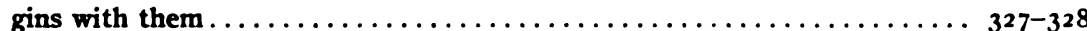

Analysis of shaft sections of the deposits from man, water, and wind $\ldots \ldots \ldots \ldots \ldots \ldots .328-330$

Physiographic reconstruction of the past in Anau...................... 330

Oases of the Murg-ab Delta ..................................... 330-337

The river Murg-ab and the type peculiarities of the Merv oases, past and present . . . . 330-333

Irregularities of the delta surface wrought by man's débris of occupation and his control

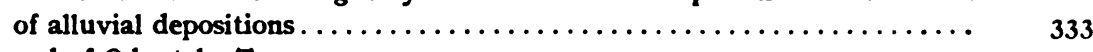

The great mound of Odontche Tepe............................... 334

Analysis of shafts at Ghiaur Ka!a. The deposits from man, water, and wind . . . . $334-336$

The stratigraphic order [( 1 ) loess, (2) dune-sand, (3) alluvium] explained by climatic change to dry and recession of the delta $\ldots \ldots \ldots \ldots \ldots \ldots \ldots \ldots \ldots, 336-337$

Part Vi. Antmal, Remarns from the Excavations at Anau, and the Horsz of anau in its Relation to the Races of Domestic Horses. J. Ul, isch Duerst.

Chapter XVI. Introduction and Description of Material.

Chapter XVII

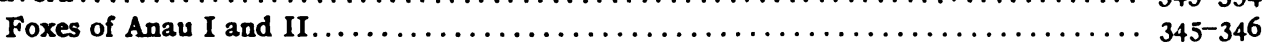

Wolf of Anau I anatomically compared............................. $346-347$

Domestic Dog of Anau II anatomically compared with prehistoric and recent domestic and wild dogs $\ldots \ldots \ldots \ldots \ldots \ldots \ldots \ldots \ldots \ldots \ldots \ldots \ldots \ldots, 348,354$

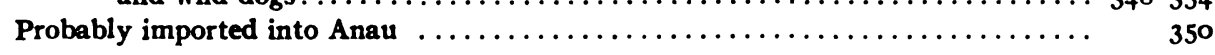

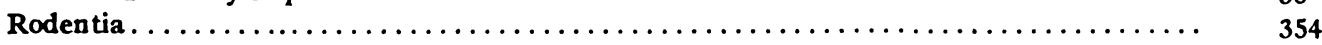

Remains of mouse. $\ldots \ldots \ldots \ldots \ldots \ldots \ldots \ldots \ldots \ldots \ldots \ldots \ldots \ldots \ldots \ldots \ldots \ldots, \quad 354$ 
CHAPran $\mathrm{x}$

Artiodactyla ......

The pig of Anau I (Sus palustris Rü timeyer) anatomically compared with prehistoric and recent wild and domestic pigs. ....................... $355-358$

Identical with Torfschwein (turbary pig) of European neolithic and bronze-age stations. . 355

Cavicornia ........................................... $359-382$

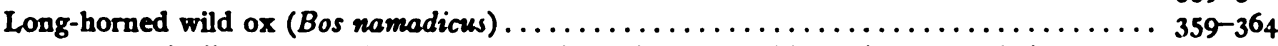

Anatomically compared with fossil and prehistoric bovids of Eurasia and Egypt . . . 359-369

Domestic long-horned cattle (Bas tourus macroceros) of Anau I . . . . . . . . . . . . .

Anatomically compared with wild and domestic cattle of Eurasia and Egypt.... 364-369

Domesticated out of the wild Bos namadicus of Anau I . . . . . . . . . . . . .

Identical with the long-horned Apis of easly Egypt.................. 369

Ovina. Wild sheep of Anau I (a) (Ovis vignei arkal) anatomically compared with Eurasiatic forms................................... 370-372

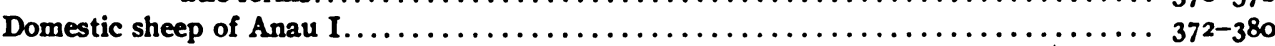

Progress of domestication out of Ovis vignei arkal shown in changes in size, and in character of bone structure........................ 372-373

Towards end of Anau I a smaller breed established identical with Ovis aries palustris Rütimeyer, the Torfschaf of European neolithic and bronze-age stations. Anatomically compared with the wild ancestor and with domestic sheep of

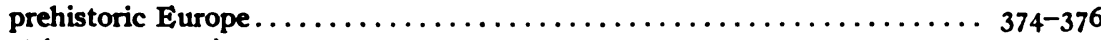

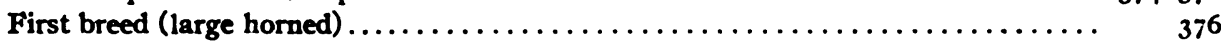

Hornless breed of Anau II . . . . . . . . . . . . . . . . . . . . . . .

Tabies of anatonical comparisons.................. 374, 375, 377-379

Capra hircus rütimeyeri Duerst. Domestic goat of Anau II, anatomically compared.... 380-381

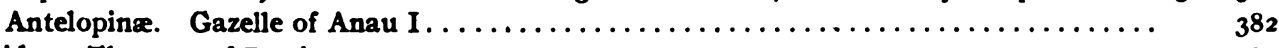

Cervidx. The stag of Persia $\ldots \ldots \ldots \ldots \ldots \ldots \ldots \ldots \ldots \ldots \ldots \ldots \ldots \ldots \ldots \ldots \ldots \ldots \ldots \ldots \ldots, 382$

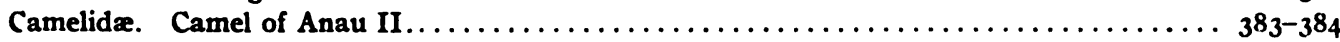

Perissodactyla. Horse of Anau... . . . . . . . . . . . . . . . . . . . . . . . . $384-399$

Distinguishing anatomical characteristics of Western and Oriental horse groups and asses. 386

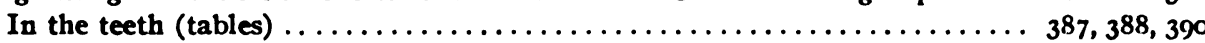

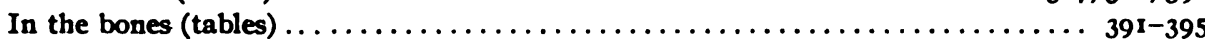

Type and relations of the horse from Anau. . . . . . . . . . . . . . . . . . $396-399$

The diluvial horse differentiated into three types: Desert type (Equus caballus pumpellii),

Steppe type (Equus caballus germanicus seu robustus) and Forest type

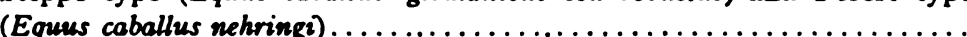

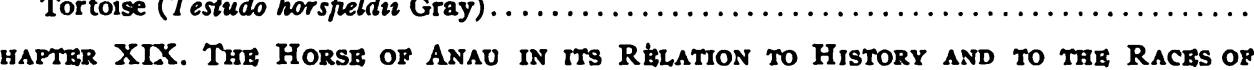

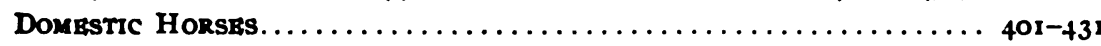

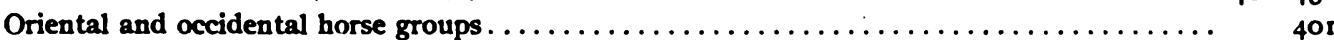

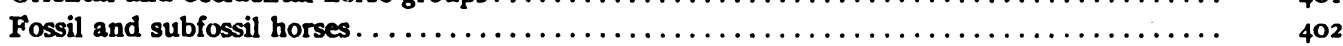

Horse of the Quaternary period of Europe . . . . . . . . . $402 \ldots \ldots \ldots \ldots \ldots \ldots$

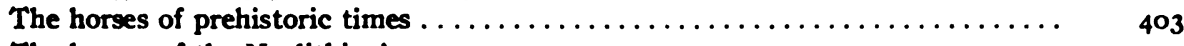

The horses of the Neolithic Age. . . . . . . .

Craniological differences between the ass and horse................... 404-4:0

The horses of Europe in the Copper, La Tène, Hallstadt, and Roman periods . . . . . . . . . 4 410

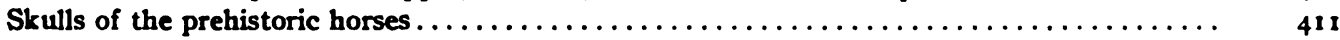

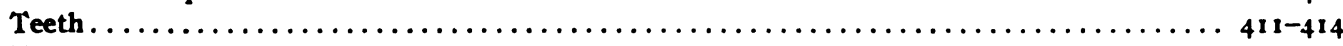

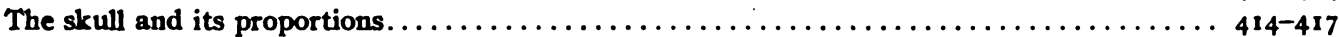

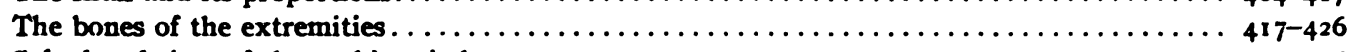

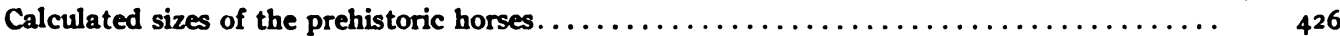

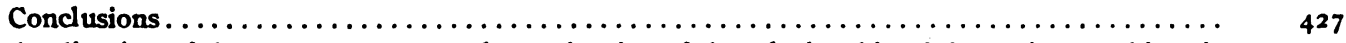

Application of the measurements to determination of the relationship of the various prehistoric horses among themselves and to the horse of Anau............. 427

The Tertiary horses of Europe. $\ldots \ldots \ldots \ldots \ldots \ldots \ldots \ldots \ldots \ldots \ldots \ldots \ldots \ldots \ldots \ldots \ldots \ldots ., 428$

Only one type of wild horse over Europe and Asia in Pliocene and Pleistocene time; probably

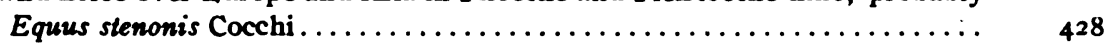

Equus przewalskii its last wild representative. ....................... 428 
Chapter XiX. The Horse of anau in its Various Rerations.-Continued.

With post-glacial changes of climate began parallel regional differentiation of vegetation and

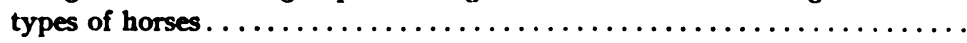

The horse of Anau (Equus caballus pumpellii) brought to Europe in the bronze age........

Used later in ennobling Roman horses. .

Genealogical chart of the races of domestic horses $\ldots \ldots \ldots \ldots \ldots \ldots \ldots \ldots \ldots \ldots \ldots \ldots, 431$

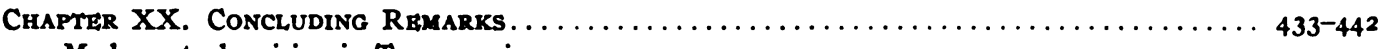

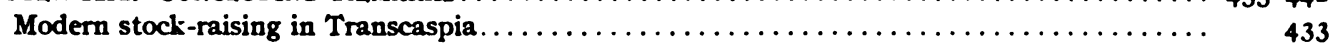

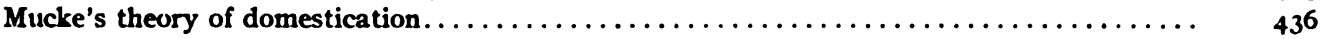

Changes in re!ative percentages of different animals bred, due to secular climatic change. .... 438

Importation of turbary sheep into Europe. . . . . . . . . . . . . . . . . . . . . . . 439

Their occurrence at Schweizersbild discussed $\ldots \ldots \ldots \ldots \ldots \ldots \ldots \ldots \ldots \ldots \ldots \ldots \ldots \ldots$

Dispersion of Anau cattle over the prehistoric world $\ldots \ldots \ldots \ldots \ldots \ldots \ldots \ldots \ldots \ldots \ldots \ldots \ldots \ldots$

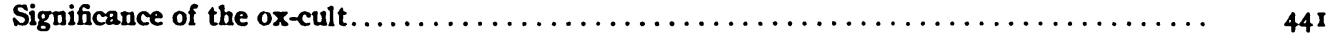

Part VII. Description of Some Skulls from the North Kurgan, Anau. G. Sergi.

Chapter XXI. Skullos prom anau.

Representatives of the two oldest cultures differ absolutely from Mongolian type; closely

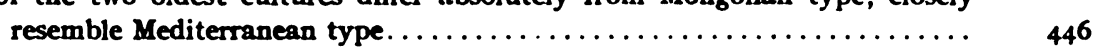

$\therefore$ Table of measurements . . . . . . . . . . . . . . . . . . . . . . . . . . . . . . . . . . 446

Part ViII. Some human Remains found in the North Kurgan, anau. Th. Molidison. 1 ,

Chapter XXII. Description of Some Human Remanns Found in the North Kurgan, Anau . . . . . . . . .

Enumeration of the bones from five adult individuals............. $44 \ldots \ldots \ldots \ldots$

The bones of individual I, from Culture II, described and racially compared . . . . . . . . . 450-46I

The bones of individual II, III, IV, and $V$ described $\ldots \ldots \ldots \ldots \ldots \ldots \ldots \ldots \ldots \ldots \ldots . \ldots 462$

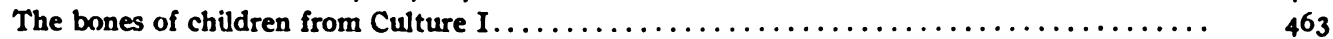

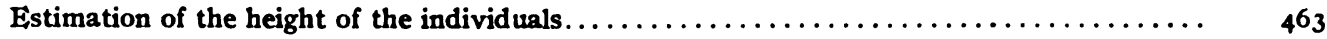

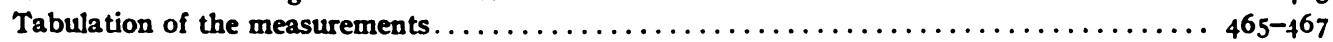

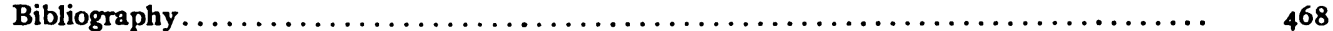

Part IX. Whrat and Barley from the North Kurgan, anau.

H. C. SchrLLLenberg.

Chaptgr XXIII. The Rgmains of Plants frox the North Kurgan, Anau ........ $471-473$

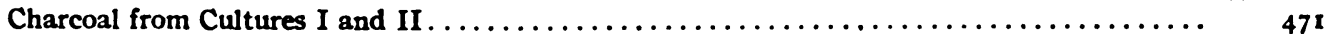

Casts and siliceous skeletons of wheat and two-rowed barley from Culture I. . . . . . . 471-473

Appendix to Professor Schellenberg's report, and note by R. P.............. 473

Part X. Stone Implegments and Skelgtons Excavated in ANaU.

LANGDON WARNER.

Chapter XXIV............................................. 477-494

Report on the larger stone implements of the Kurgans at Anau.............. 477-482

Summary of work done in Terrace II, North Kurgan . . . . . . . . . . . . . . . . . . 482-484

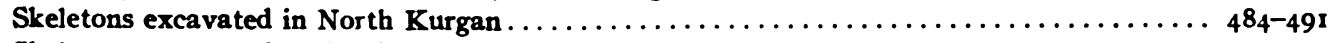

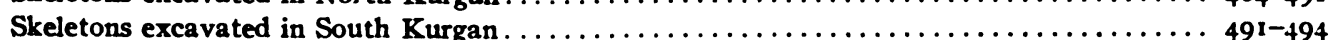

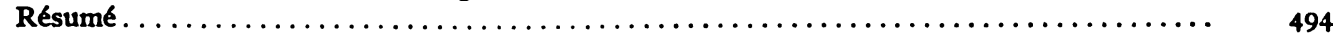




\section{LIST OF ILLUSTRATIONS.}

\section{FIRST VOLUME.}

PuATB.

1. Sections of walls in Komorof's Trench, North Kurgan, Anau. $\ldots \ldots \ldots \ldots \ldots \ldots \ldots \ldots \ldots$

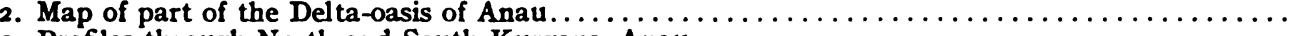

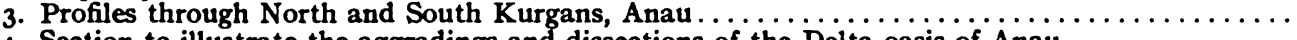

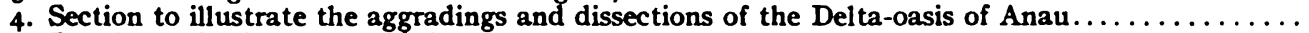

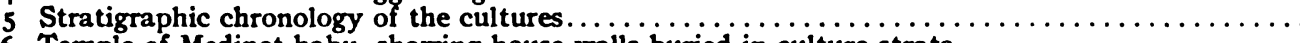

6. Temple of Medinet-habu, showing house-walls buried in culture-strata............................... 7. East and west profile from North Kurgan through city of Anau, and north-south section through
North Kurgan, Anau. $\ldots \ldots \ldots \ldots \ldots \ldots \ldots \ldots \ldots \ldots \ldots \ldots \ldots \ldots \ldots \ldots \ldots \ldots \ldots \ldots \ldots \ldots \ldots \ldots \ldots \ldots \ldots \ldots \ldots \ldots$

8. Plan of excavations, South Kurgan, Anau.

9. Pottery from North and South Kurgans, Cultures I II and

10-12. Pottery from middle strata, South Kurgan, Culture III.

13-15. Pottery from middle strata, South Kurgan, Culture II 16. Pottery from 16. Pottery from lower strata, South Kurgan, Culture III.

17. Pottery from upper strata, South Kurgan, Culture IV.

18. Hand-made pithoi from North and South Kurgans.

19. Wheel-made pottery from middle and upper strata, South Kurgan, Cultures III and IV

20. Pithoi from North Kurgan, Cultures I and II

21. Pithoi from North Kurgan Culture I........

22. Designs on painted pottery from lowest strata, North Kurgan, Culture I, group $r$.

23. Designs on painted pottery from middle strata, North Kurgan, Culture I, groups $a a$ and $a \hat{\beta}$.

24. Designs on painted pottery from middle strata, North Kurgan, Culture I, groups a $\beta, b$, and a

25. Designs on painted pottery from middle strata, North Kurgan, Culture I, group ar and group b

26, 27. Designs on painted pottery from middle strata, North Kurgan, Culture I, group b.

28. Designs on painted pottery from middle strata, North Kurgan, Culture I, group a $a$ and group $b$

29, 30. Designs on painted pottery from middle strata, North Kurgan, Culture I, group b.........

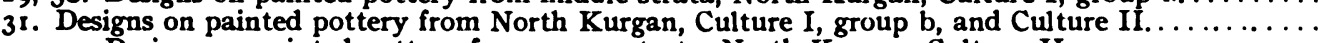

32, 33. Designs on painted pottery from upper strata, North Kurgan, Culture II . . . . . . . . . .

34. Designs on painted pottery from lower strata, South Kurgan, Culture III

35. Designs on painted pottery from South Kurgan, Culture III and between III and IV $\ldots \ldots \ldots$

36. Objects of copper from Cultures I and II North Kurgan...

Kurgan

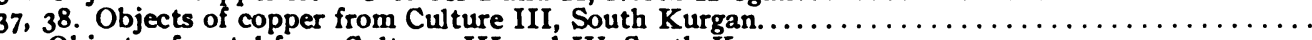

39. Objects of metal from Cultures III and IV, South Kurgan .

40. Beads and ornaments, Cultures I and II, North Kurgan

41. Beads and other articles from South Kurgan

42. Beads from South Kurgan; whorls and flints from North Kurgan

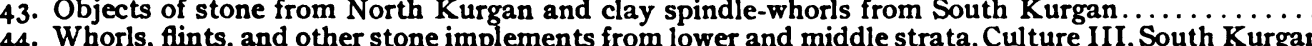

45. Objects in stone, clay, and bone, from middle and lower strata, Culture III, South Kurgan.....

45. Whorls, flints, mace-head, and bone implement, chiefly from upper strata or iron culture, South Kurgan. Terra-cotta figures of religious significance, Culture III, South Kurgan..........

47. Objects of terra-cotta, Culture III.

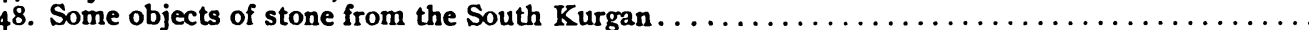

49, 50. Pottery from Ghiaur Kala (Old Merv).

51. Pottery and objects of metal from Ghiaur Kala (Ö̈ Merv)

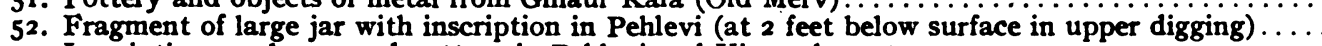

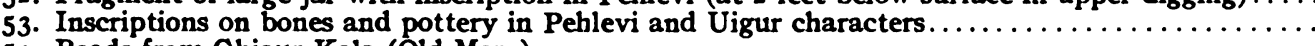

54. Beads from Ghiaur Kala (Old Merv)

55. Terra-cotta figures from Ghiaur Kala (Oid Merv)

56. Objects in clay and stone from Ghiaur Kala (Old Merv)

57. Kurgans of the Merv Oasis, Classes I, II, and III

58. Kurgans of Class III (highly developed type) and late Mohammedan ruins $\ldots \ldots \ldots \ldots \ldots \ldots \ldots$

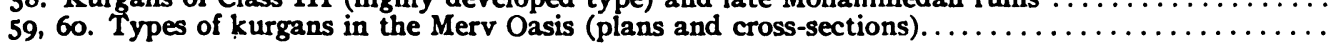

TEXT-mours.

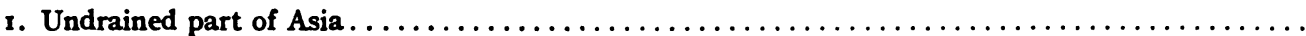

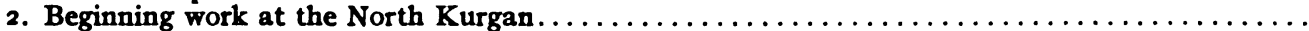

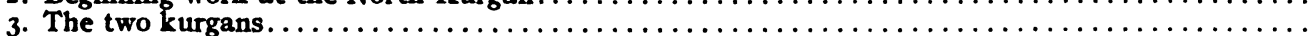

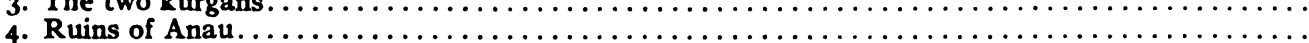

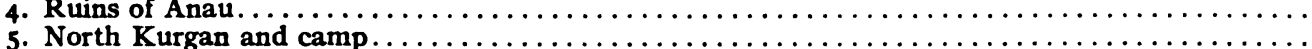

6. The South Kurgan......

6. The South Kurgan.

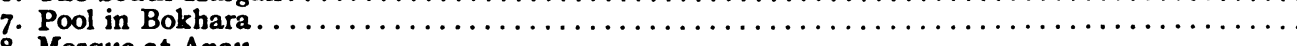

8. Mosque at Anau. . . . . . . . . .

9. Persian windlass

10. Section of a wall in the North Kurgan.

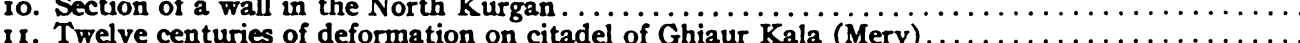

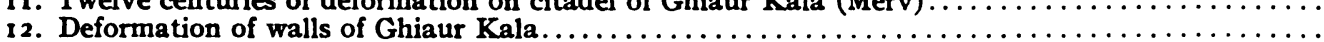

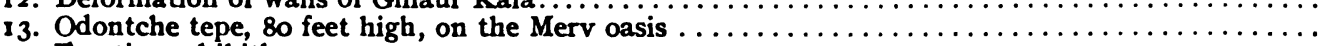

14. Erecting a kibitka

15. Ideal section of a delta-oasis on an uptilting piedmont.

16. Starting a shaft in the City of Anau...

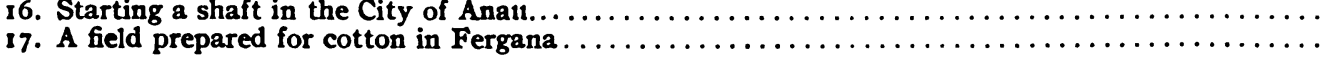


TEXT-FIGURE.

18. Diagram of cultures of the Anau sites

19. Turkoman woman baking bread.

20. Explanatory diagram of village-mound culture-strata at Medinet-habu $\ldots \ldots \ldots \ldots \ldots \ldots$

21. Geological column of the Askhabad well

1. Geological column of the Ask

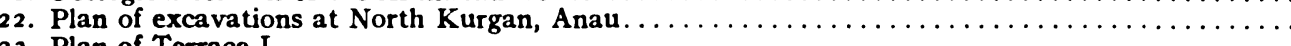

23. Plan of Terrace I

24. Vertical section and projection of finds, Terrace $I$

25. Incrusted cabinet in Terrace I

, pivotal door-stones, and grindstones, Terrace $I$

27. Pithoi $c$ and $d$ in position and skeleton $\beta$.

28. Plan of Terraces IV to VIII.

29. Vertical section and projection of finds, Terraces IV to VIII

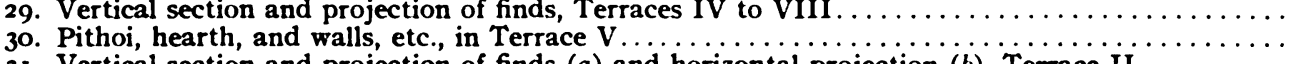

.

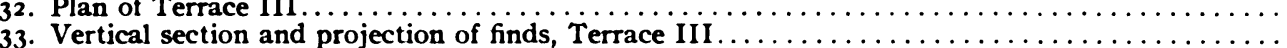

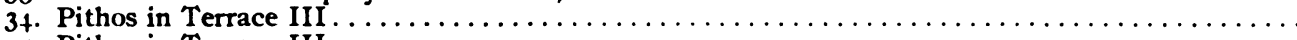

35. Pithos in Terrace III.

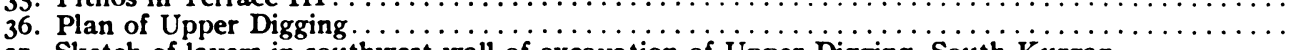

37. Sketch of layers in southwest wall of excavation of Upper Digging, South Kurgan ...........

38. Projection of finds in Upper Digging

39. Pithos $b$ in Upper Digging.

40. Pithos $c$ in Upper Digging.

41. Pithos $d$ in Upper Digging.

42. Plan of Terrace $B$

43. Vertical section and projection of finds, Terrace $B$

44, 45. Objects in position, Terrace $B \ldots \ldots \ldots \ldots$
46 . Clay chest in Terrace $B$, details of construction

47. Clay chest in Terrace B.

48,49 . Sketches of strata in walls of Terrace $B$

5o. Plan of Terrace C.

51. Sketch of fireplace in Terrace

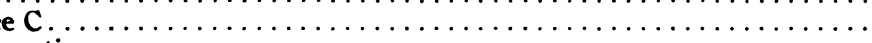

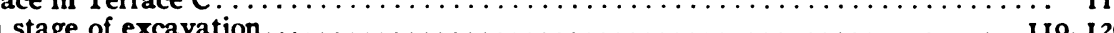

54. Fireplace in stage of excavation; skeleton in position $\ldots \ldots \ldots \ldots \ldots \ldots \ldots \ldots \ldots \ldots \ldots \ldots \ldots \ldots$

ANALYSIS OF FORM AND ORNAMENTATION OF POTTERY.

North Kurgan, Culture I.

55-58. Profiles, smaller vessels in fine technique.................

59-62. Profiles, large and small vessels in coarse technique $\ldots \ldots \ldots \ldots \ldots \ldots \ldots \ldots \ldots \ldots \ldots \ldots \ldots$

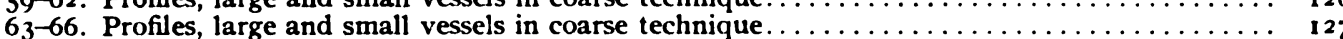

67-103. Decorative designs on pottery of middle strata, groups $a$ and $b \ldots \ldots \ldots \ldots \ldots \ldots \ldots \ldots$

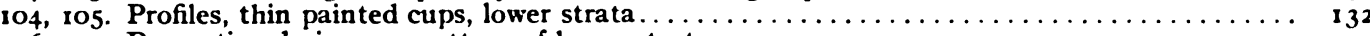

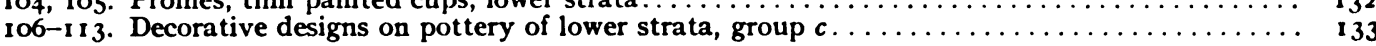
North Kurgan, Culture II.

114-131. Profiles, red monochrome ware $\ldots \ldots \ldots \ldots \ldots \ldots \ldots \ldots \ldots \ldots \ldots \ldots \ldots \ldots \ldots \ldots \ldots \ldots$

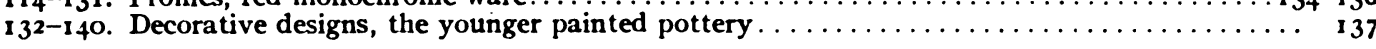
South Kurgan, Culture III.

141-179. Profiles, light-colored clay, middle strata $\ldots \ldots \ldots \ldots \ldots \ldots \ldots \ldots \ldots \ldots \ldots \ldots \ldots$ 138- 4 0 180-189. Profiles, light-colored clay, and gray and red monochrome, middle strata $\ldots \ldots \ldots \ldots \ldots$. $\ldots 1$ 190-199. Profiles, light-colored clay and gray ware and painted vessels, lower strata.......... I44 South Kurgan, Culture IV.

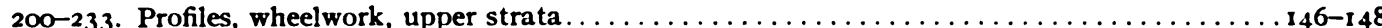

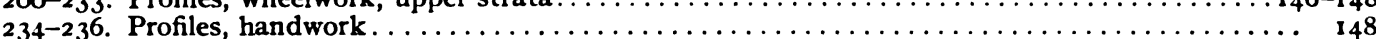

OBJECTS OF COPPER.

North Kurgan, Culture I.

237. Spiral and tubes.

(5)

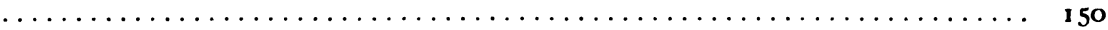

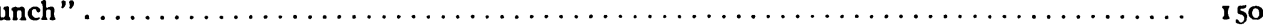

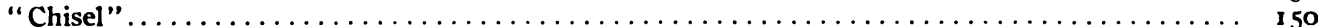

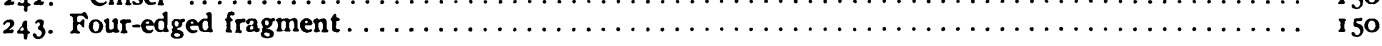

North Kurgan, Culture II.

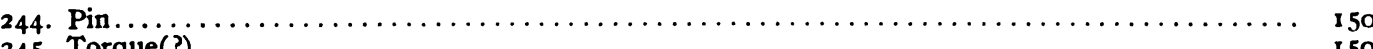

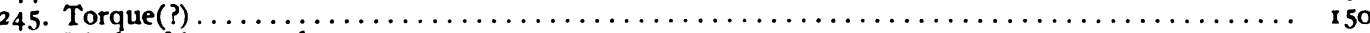

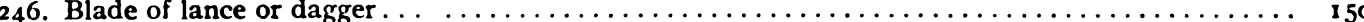

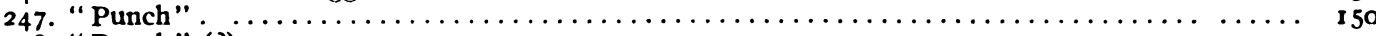

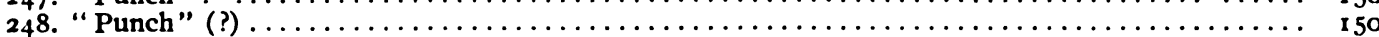

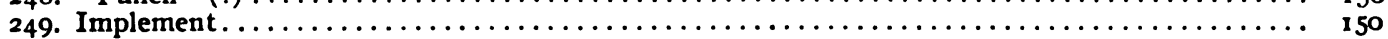


250. Pin

251, 252. Pins with spiral heads

253-255. Pins.

256-257. Ornamental disks.

258. Ornamental disk.

259, 260. Buttons

261. Small ring..

262. Piece of large ring

263, 264. Punches (?)

265-267. Chisels (?)

268. Aw] or punch

269. Tweezers

270. Rod

271,272 . Blades of knives

273. Razor-shaped blade.

274. Sickle.

275. Dagger or lance blade.

276-278. Dagger b'ades.

279. Blade of dagger or lance.

280. Blade of dagger or lance.

281. Flat arrow-point

282. Piece of double tube

283. Copper band

284. "Hilt"

285. Trough-shaped object. South Kurgan, Culture IV.

286. Wire

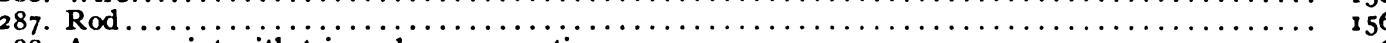

288. Arrow-point with triangular cross-section $\ldots \ldots \ldots \ldots \ldots \ldots \ldots \ldots \ldots \ldots \ldots \ldots \ldots \ldots \ldots \ldots \ldots \ldots$

South Kurgan, Culture IV.

OBJECTS OF IRON.

289. Iron sickle.

290. Piece of iron sickle.

291. Small bar of iron.

292. Piece of iron knife.

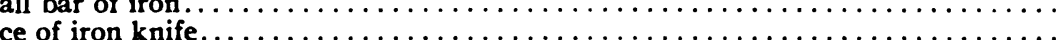

OBJECTS OF LEAD.

North Kurgan, Culture I.

293. Spirals of lead.

North Kurgan, Culture I.

\section{ORNAMENTS OF STONE AND CLAY.}

295. Turquoise beads

158

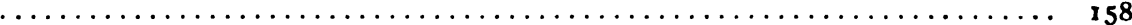

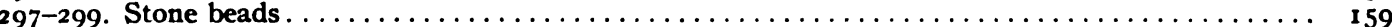

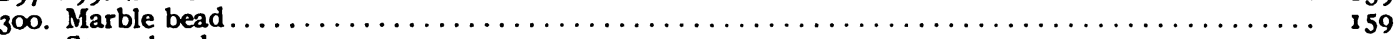

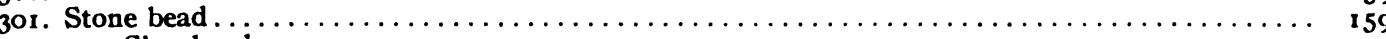

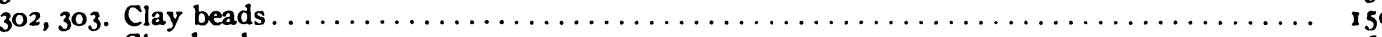

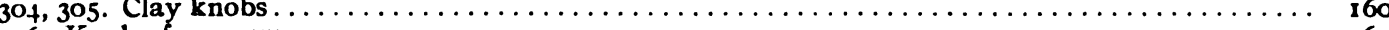

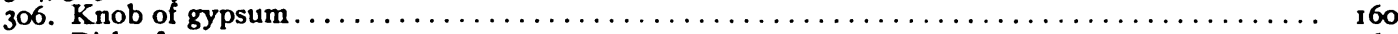

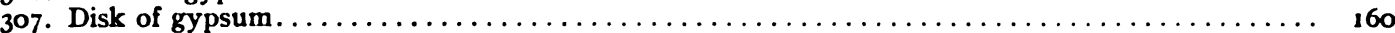

North Kurgan, Culture II.

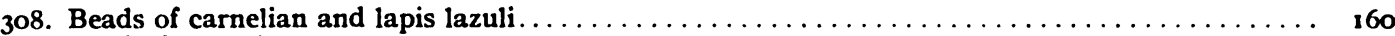

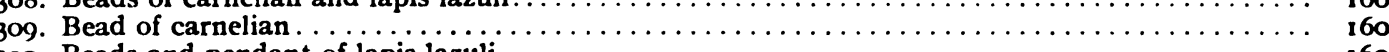

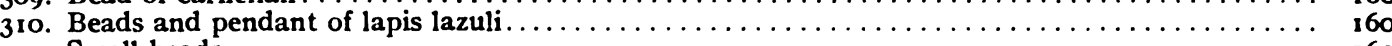

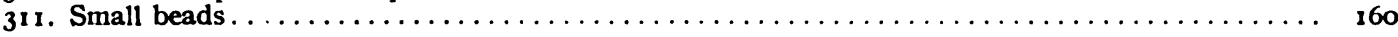

South Kurgan, Culture III.

31 2, 313. Beads.

(16r

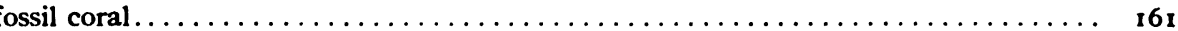

315. Bead of alabaster $\ldots \ldots \ldots \ldots \ldots \ldots \ldots \ldots \ldots \ldots \ldots \ldots \ldots \ldots \ldots \ldots \ldots \ldots \ldots \ldots \ldots \ldots \ldots \ldots$

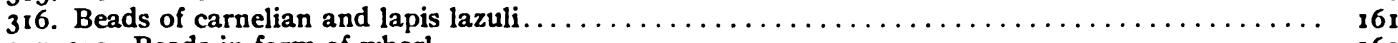

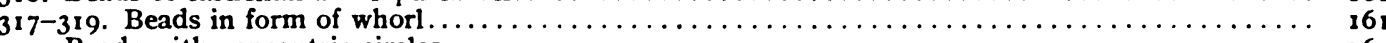

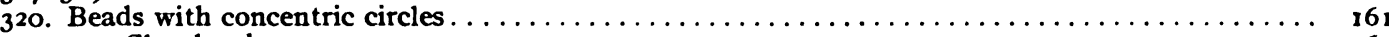

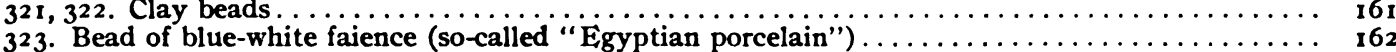

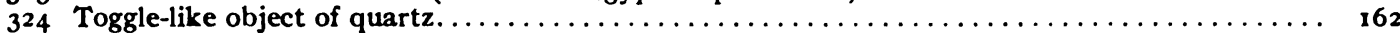

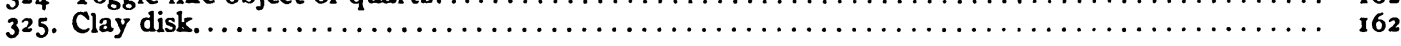


TEXT-FIOURE.

ORNAMENTS OF STONE AND CLAY-continued.

South Kurgan, Culture IV.

326. Bead of turquoise.

327. Bead of bluish-white glass.

328. Stone bead

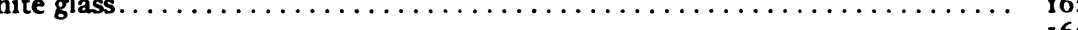

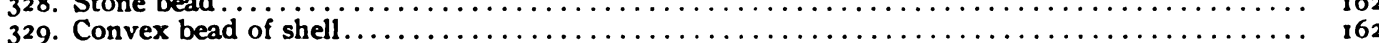

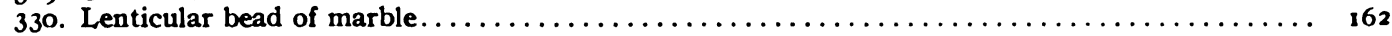

Doubtful Whether Belonging to Cultures III or IV.

331, 332. Turquoise beads.

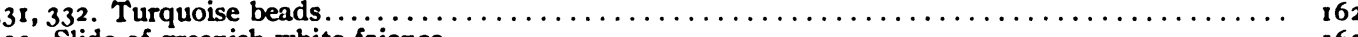

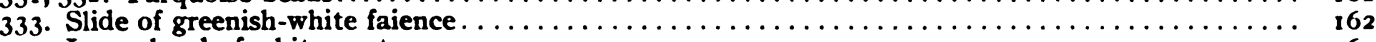

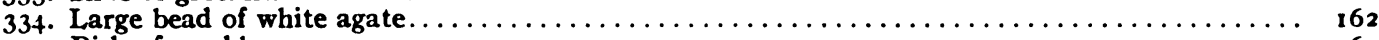

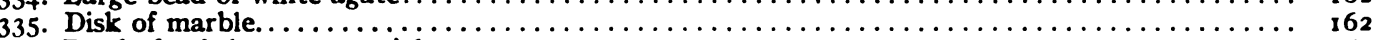

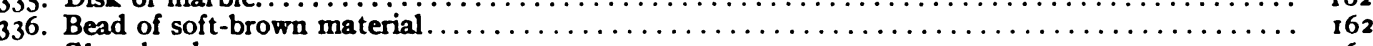

(62

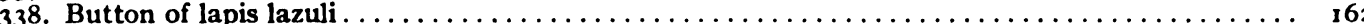

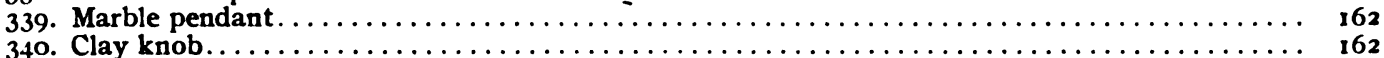

USEFUL OBJECTS OF STONE, CLAY, AND BONE.

North Kurgan, Cultures I and II.

34I-35I. Spindle-whorls, North Kurgan, Cultures I and II

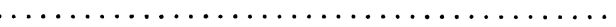

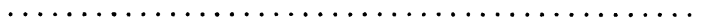

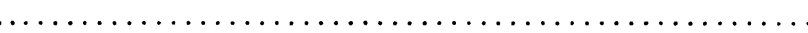

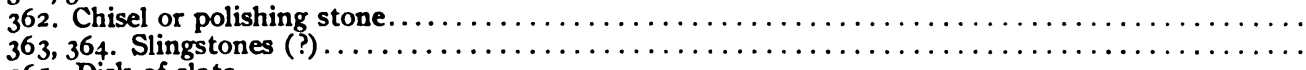

365. Disk of slate.

South Kurgan, Culture III.

367-380. Whorls.

381. Flint knife.

.

382. Flint scraper

383. One-edged saw.

384,385 . Flint arrow-points.

386. Arrow-point of obsidian

387. Unfinished mace-head (?)

388-390. Mace-heads (?)

391. Unfinished mace-head (?)

392-396. Slingstones

392-396. Slingstones . Arrow-point (?) bone.

397. Arrow-point (?) bone

399. Hoe-shaped implement of stone

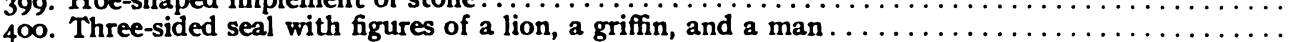

401. Stamp with concentric rings

402. Stamp (clay).

403. Stone stamp.

404-408. Vessels of marble, alabaster, etc........... South Kurgan, Culture IV.

409-411. Whorls.

412. Flint knife.

413. Two-edged saw.

415. Unfinished lenticular mace $($ ? $)$

415. Awl-shaped implement of bone.

417,418 . Clay wheels.

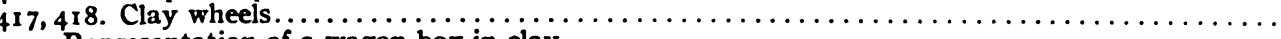

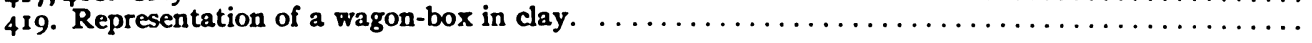

420. Plan of Ghiaur Kala

421. Plan of inner city of Ghiaur Kala.

422. Plan and vertical section of the Upper Digging on the citadel . . . . . . . . . . . . . . . .

423. Elevation of sides of Upper Digging at $2 \mathrm{I}$ feet depth, to show layer of ash and rubbish at bot-

$$
\text { tom of excavation. }
$$

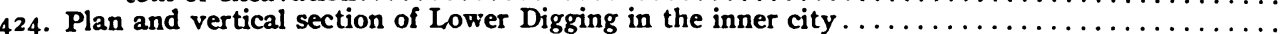

424. Plan and vertical section of Outer Digging I in the outer city.

425. Plan and vertical section of Outer Digging $I$ in the outer city.

426. Water basin found in Outer Digging $I$.

427. Details of the water basin in Outer Digging $I$.

428. Great jars found in Outer Digging II

429. Ornamentation of the great jars.

430. Sketch-map of Merv Oasis. 
SECOND VOLUME.

PLATE.
FACHO PAGB.

61. Map of Central Asia (Samarkand to Kashgar) $\ldots \ldots \ldots \ldots \ldots \ldots \ldots \ldots \ldots \ldots \ldots \ldots \ldots \ldots \ldots \ldots \ldots$

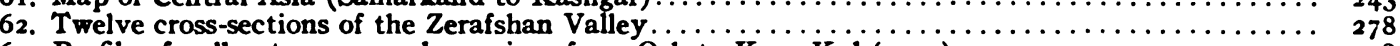

63. Profile of valley terraces and moraines from Osh to Kara $\mathrm{Kul}(1903) \ldots \ldots \ldots \ldots \ldots \ldots$

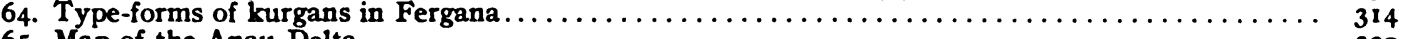

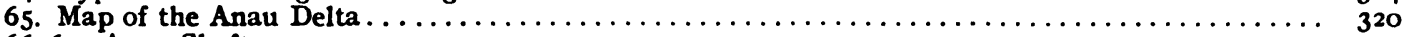

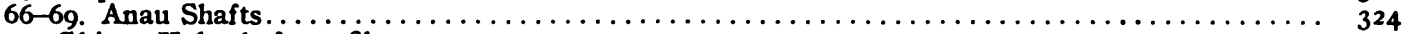

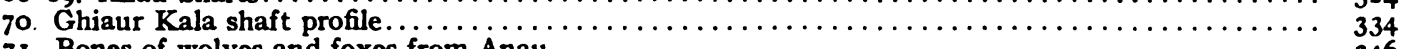

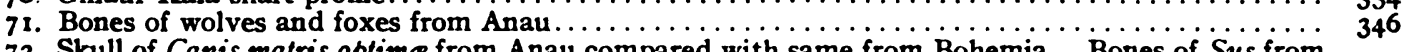

72. Skull of Canis matris optima from Anau compared with same from Bohemia. Bones of Sus from

73. Bones of Bos namadicus from Anau $I$, Bos brachyceros (Bohemian turbary), and camel from Anau II 346 74. Comparisons of basioccipital bones of Ovibos, Bubalus, and Taurus, and teeth of Yak, Bison, Bos,

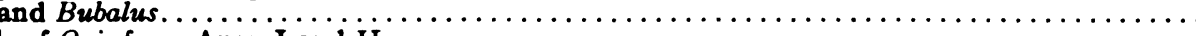

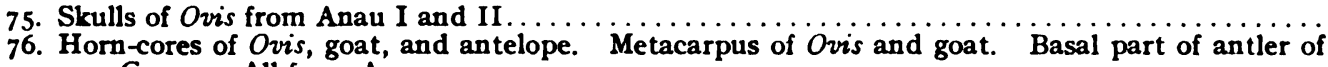
Cervus. All from Anau.

77. Bones of Equus from Anau I and II and Solutré, and camel from Anau II . . . . . . . . . . .

78. Bones of Bos from Anau and Bizino, and skull of goat from Crete...

79 Egyptian Canis (marble, in the Louvre) and long-horned cattle (tomb of Manofer, 2600 B.

79 Egyptian Canis (marble, in the Louvre) and long-hormed cattle (tomb of Man

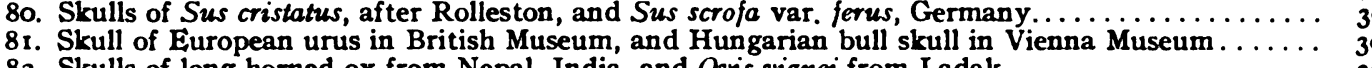

82. Skulls of long-horned ox from Nepal, India, and Ovis vignei from Ladak..........................
83. Assyrian and Babylonian representations of wild bull and long-horned ox. Horn-cores and skull of Ovis aries palustris (from England)

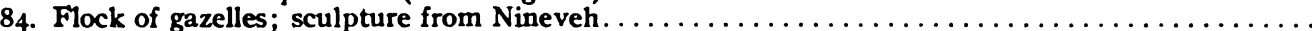

85. Map showing distribution, ancient and modern, of Bos taurus macroceros Duerst..................

87. Norma lateralis of skull of horse from pile-dwellings at Auvernier, Switzerland, compared with same view of skull of Egyptian prehistoric ass of Abadieh (IV dynasty).

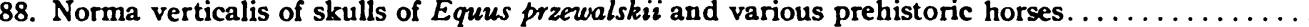

89. Norma lateralis of skulls of Equus przewalskii and two prehistoric horses. . . . . . . . . . . .

90. Comparisons of metacarpi medii and metatarsi medii, Anau horse . . . . . . . . . . . . . .

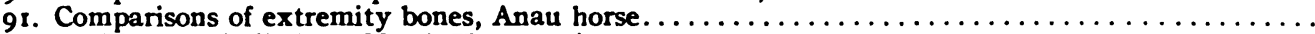

92, 93. Human skulls from North Kurgan, Anau.

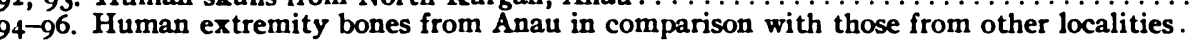

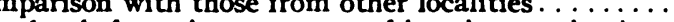

TEXT-pIGURB.

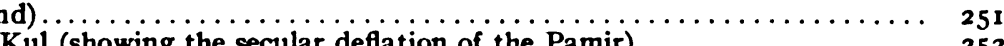

432. A granite ridge at Kara Kul (showing the secular deflation of the Pamir) $\ldots \ldots \ldots \ldots \ldots 25$

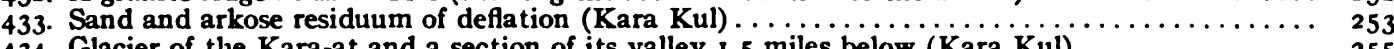

434. Glacier of the Kara-at and a section of its valley 1.5 miles below (Kara Kul) . . . . . . . . . 255

435. A pool, where Kara Kul sediments have caved in over melting lobes of glacier ice.........255

436. An ice dome and its third and fourth epoch moraines in the foreground (Kara Kul) ....... 256

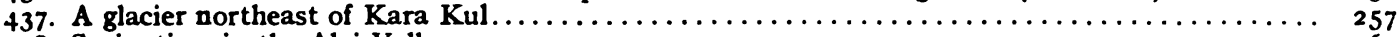

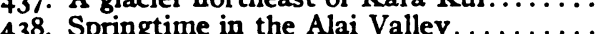

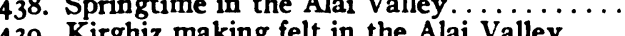

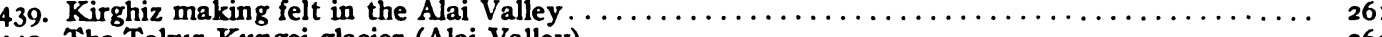

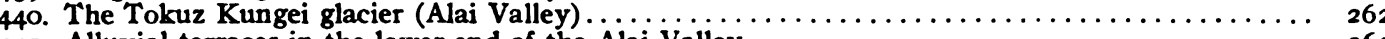

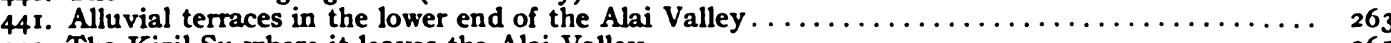

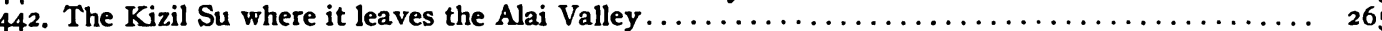

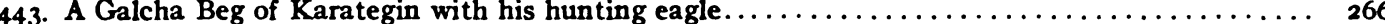

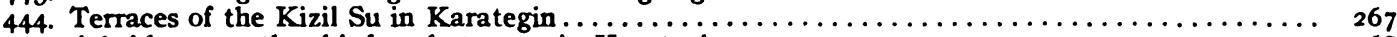

445. A bridge over the third-cycle terrace in Karategin $\ldots \ldots \ldots \ldots \ldots \ldots \ldots \ldots \ldots \ldots \ldots \ldots \ldots \ldots \ldots \ldots \ldots$

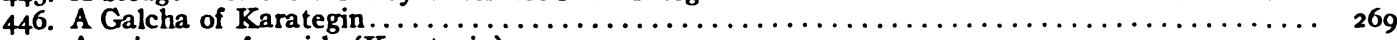

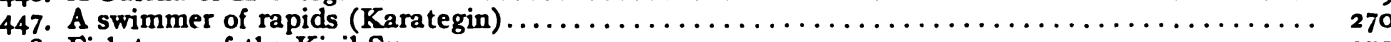

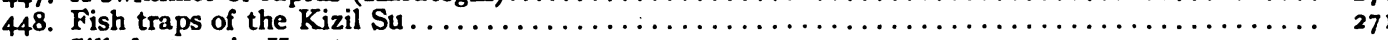

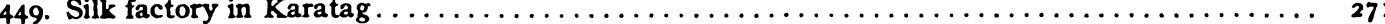

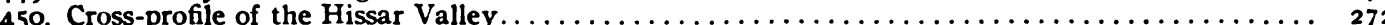

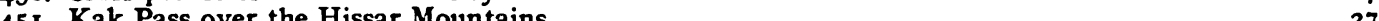

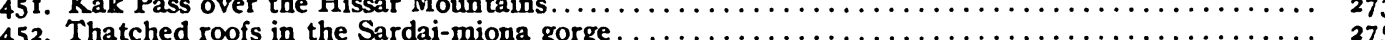

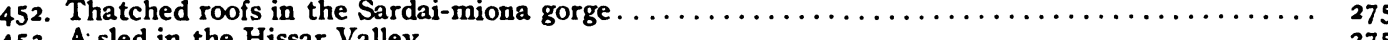

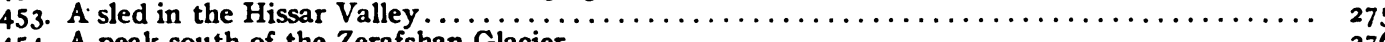

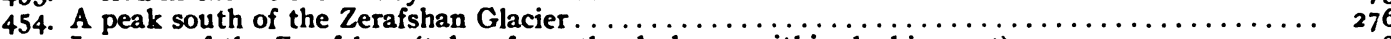

455. Ice cave of the Zerafshan (taken from the darkness within, looking out) $\ldots \ldots \ldots \ldots 278$

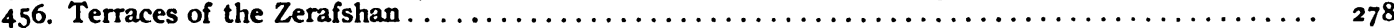

457. Section of glacier-thrusted alluvium in the Zerafshan Valley 45 miles below the glacier...... 279

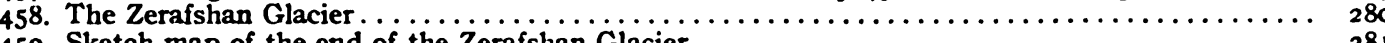

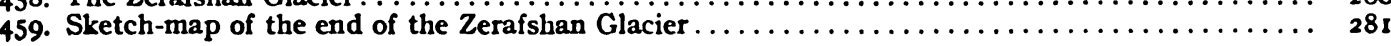


TEXT-MIOURE.

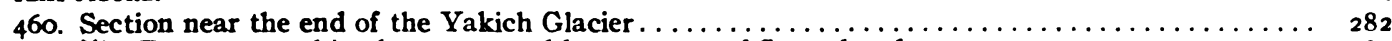

461. The Dargum canal in the up-warped loess-steppe of Samarkand . . . . . . . . . . . . . . . .

462. Vertical section of interlapping loess and alluvium in a $100-$ foot cliff of Obu-siob canal at crossing of road from Samarkand to Kundi Sufi.

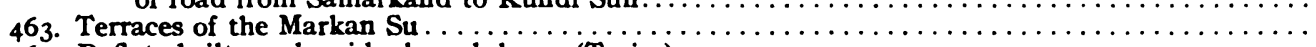

464. Deflated silts and residual sand-dunes (Tarim) $\ldots \ldots \ldots \ldots \ldots$

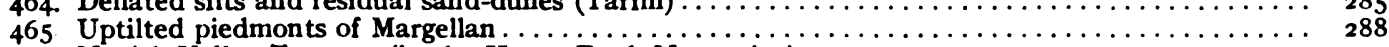

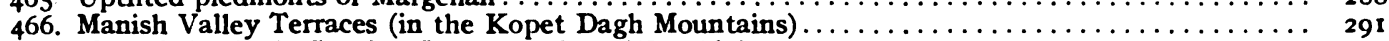

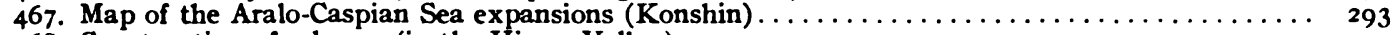

468. Construction of a house (in the Hissar Valley) $\ldots \ldots \ldots \ldots \ldots \ldots \ldots \ldots \ldots \ldots \ldots \ldots \ldots \ldots$

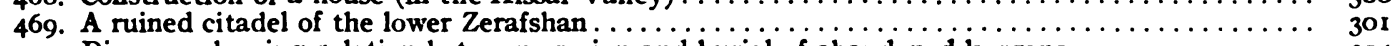

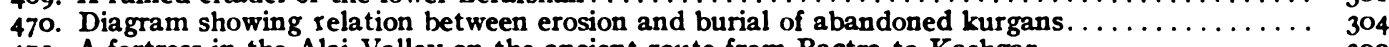

471. A fortress in the Alai Valley on the ancient route from Bactra to Kashgar...................

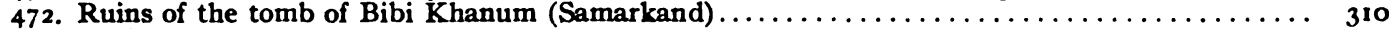

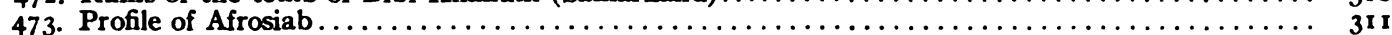

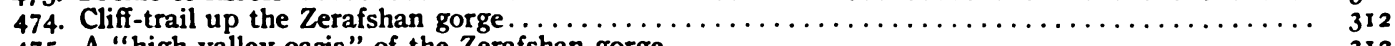

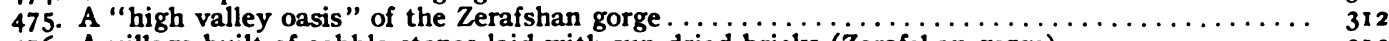

476. A village built of cobble-stones laid with sun-dried bricks (Zerafshan gorge) $\ldots \ldots \ldots \ldots \ldots \ldots$

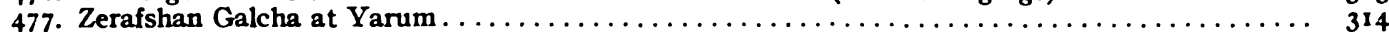

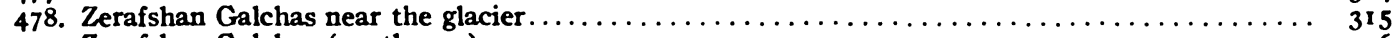

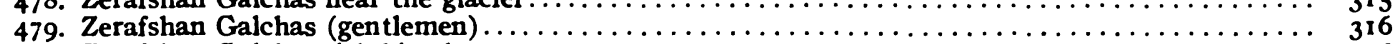

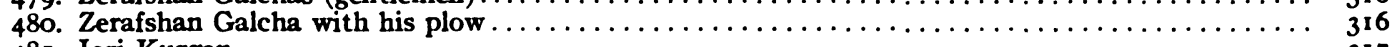

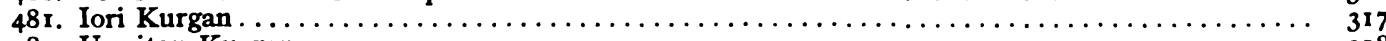

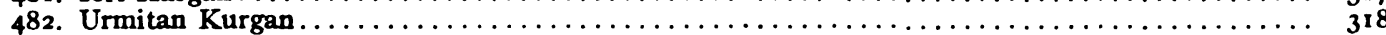

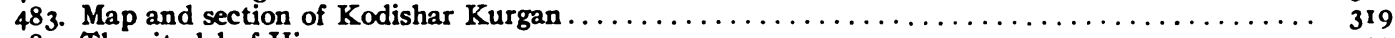

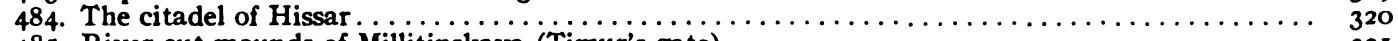

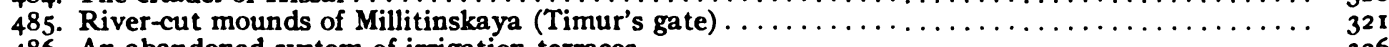

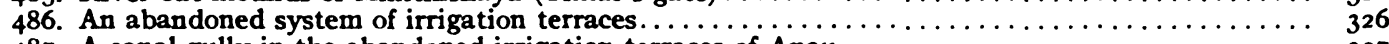

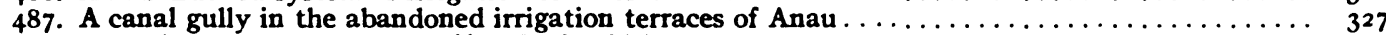

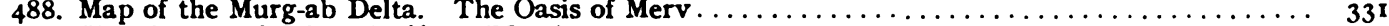

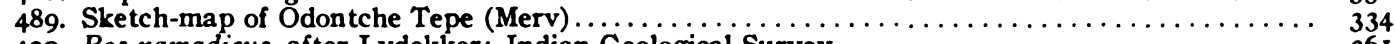

490. Bos namadicus, after Lydekker; Indian Geological Survey ........................

491. Teeth of Equus caballus pumpellii compared with teeth of other subfossil horses...........

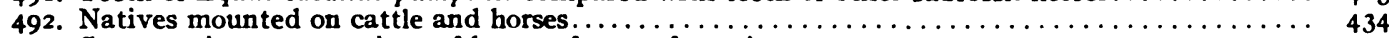

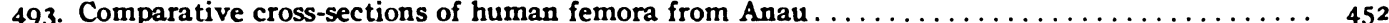

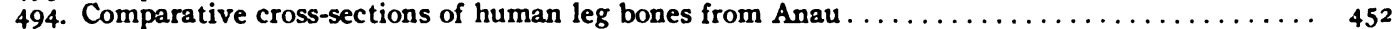

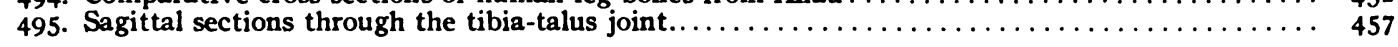

STONE IMPLEMENTS FROM THE NORTH AND SOUTH KURGANS.

496-502. Stone implements from North and South Kurgans $\ldots \ldots \ldots \ldots \ldots \ldots \ldots \ldots$

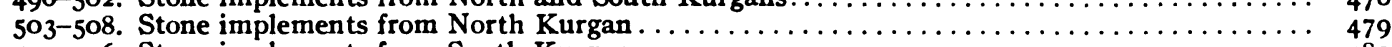

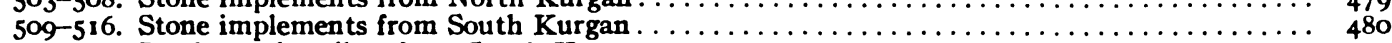

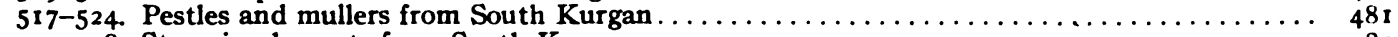

525-528. Stone implements from South Kurgan $\ldots \ldots \ldots \ldots \ldots \ldots \ldots \ldots \ldots \ldots \ldots \ldots \ldots \ldots \ldots \ldots \ldots \ldots$

529 , 530. Stone implements from South Kurgan $\ldots \ldots \ldots \ldots \ldots \ldots \ldots \ldots \ldots \ldots \ldots \ldots \ldots \ldots \ldots \ldots \ldots \ldots \ldots$

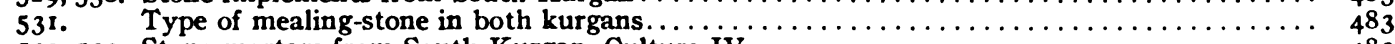

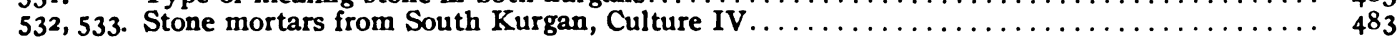

\section{SKELETONS FROM THE NORTH AND SOUTH KURGANS.}

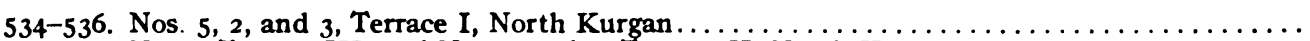

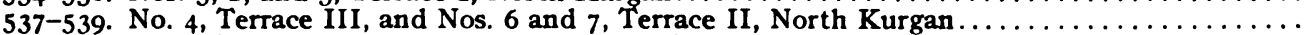
540-542. No 8, Terrace VIII, and Nos. II and 14, Terrace II, North Kurgan................

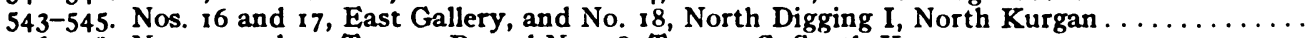
546-548. Nos. 19 and 23 , Terrace B, and No. 28, Terrace C, South Kurgan $\ldots \ldots \ldots \ldots \ldots \ldots \ldots \ldots$

\section{ERRATA.}

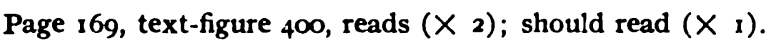

Page 169, text-figure 402 , reads $(X 0.5)$; should read $(X 0.75)$.

In legend of plate 48 , preceding page 175 , figs. 6 , 10, and 12, read (See p. 166); sliould read (See p. 168). Fig. 9 reads (See p. 116); should read (See p. 168.)

Page 413, text-figure 49ra, M2, at left-hand end of figure, should read M3. 


\section{PREFACE.}

I am often asked why, having passed my life till nearly threescore and ten in geological work, I turned to archeology, and what led me to choose remote Central Asia as a promising field. To answer this fully here would carry me beyond the restricted limits of a preface; I shall therefore state the reasons as briefly as possible.

My geological explorations through Central and Northern China and Mongolia during 1863 had given me a great amount of material towards a skeleton geological map of the Chinese empire. I learned then that the successive dynasties had caused to be made exhaustive reports on the resources of the empire, covering not only those of the vegetable kingdom and the exact localities of all useful minerals, but including also fossil bones from caves in limestone, as well as certain fossil shells of well-defined species, both of which classes of objects belong in the Chinese materia medica. Topographical phenomena of extraordinary interest.were also recorded. These printed "geographies" formed a great number of volumes. Here was a great mass of information adapted to supplementing the material I had gathered on my journeys. To utilize it I employed for several months three able native scholars, courteously found for me by the foreign office, to extract all items of a long series of classes of entries. The voluminous notes thus obtained were kindly translated for me by Mr. S. Wells Williams, then Secretary of our legation, aided by some of my missionary friends, and from them I was able to fill in my skeleton map and construct a "hypothetical geological map" of China, which Baron von Richthofen, in publishing the results of his later and far more extensive explorations, was good enough to say was remarkably good in its broad outlines. Extracts were made also from other works, and from maps, including even commented volumes of the writings of Confucius.

In studying all this material I was naturally struck, as I had been on my journeys, by the great contrast between fertile China and arid Mongolia, and by the reaction of the latter upon the former as shown in the repeated attempts of vast Turanian hordes from the Mongolian table-land to overrun China. I was impressed, too, by a note on a Chinese map of the Tarim basin stating that here a large number of cities (between 100 and 200, I think) were buried by sand in the early centuries of our era. Then, too, on native Chinese maps the desert of Gobi or Shamo was called Han-hai (dried sea), and was by native writers said to have been formerly an inland sea. 
In studying the great map compiled by Klaproth from caravan itineraries and other sources, I was puzzled by the great number of lakes dotted over the plains between the Aral Sea and the Siberian steppes-bodies of water without outlets and with no inlets of appreciable size. Their continued existence in an arid region seemed inexplicable. And when later I crossed Mongolia, the poverty of the pasturage-barely supporting the present very sparse population of Mongols, even on Tamtchin-tala, the very cradle of Genghis Khan and his hordes - seemed evidence of a marked change in natural conditions since the times when these same plains poured forth the successive waves of humanity that first threatened China, and ultimately conquered that country and devastated the Eurasian continent.

I passed the winter of $1864-65$ in Irkutsk, where I learned from Russian officers, who had campaigned on the plains north of the Aral Sea, that the countless lakes still existed, but that they were continually and slowly shrinking in size. Some of them on the Siberian borderland, which had been lakes in the eighteenth century, had actually dried up and were now the sites of towns.

It occurred to me that if the vision were reversed, one looking back through time would see the lakes gradually enlarging and coalescing till in some remote century they might appear as a large inland sea. There seemed to me to exist a relation between the buried cities of the Tarim basin, the diminished pasturage and population of Mongolia, the vanished Han-hai (dried sea) of the Gobi, the shrinking of the lakes of the Aralo-Caspian undrained depressed area, and the overwhelming movements of barbarian hordes toward China and Europe.

The subject had the fascination of a mirage, in which dissolving glimpses of a vanishing world mirrored the parallel progress of nature and man toward desolation within and destruction without. A great inland sea shrinking to disappearance presupposed former conditions favorable to its creation and to the maintenance, on its border, of a vegetation and population incompatible with the present aridity. What might have been the origin of such a sea and how far back in the perspective of geological time, and what the cause of the apparently progressive change?

Agassiz's beautiful theory of a polar ice-cap in the glacial period had already been established, and it seemed possible that climatic influences that could produce such continental accumulations of ice might also have caused the Caspian and the Aral to coalesce and expand to form a large inland sea, and that with the passing away of the climate of the glacial period there would necessarily begin the shrinkage of the sea and the progressive desiccation of Central Asia. And in this fateful progress should we see a resulting struggle for life lasting fifteen centuries, from the third cen- 
tury B. C., during which the peoplés of an area as large as Europe, driven by nature from their home lands, drenched the soil of Asia and Europe with blood, gave dynasties to China, and overthrew the Greek and Roman Empires, recasting the whole racial and social complexion of the world?

The home of our Aryan ancestors was then-in the sixties-thought by such authorities as Lassen and Max Müller to have been in High Asia. Reading these speculations, I recalled the fact that on a native map in an old Chinese commentary of the historical book of Confucius, there was the legend at a point in the Tarim basin: "Here dwell the Usun, a people with blue eyes and red hair." And with this the problem assumed an added fascination.

The reader who know seven the elements of the Aryan problem of fifty years ago will understand how quickly it became a controlling factor in my dream. To the idea that the progressive shrinkage of an inland sea indicated a progressive desiccation that forced destructive radial migrations was added the thought that migrations similarly forced might have brought to Europe the Aryan peoples, Aryan culture, and Aryan languages. In this form the dream remained for many years the background of a busy life until r89r, when, in discussing it with the Director of the Russian Geological Survey, Mr. Tschernyscheff, I learned that strata containing shells of the glacial period had actually been found in a position that seemed to really point to an inland sea of that period. Then my dream assumed the form of what seemed to me a legitimate hypothesis, worthy of being tested. It had before this been too subjective in character.

Among the friends with whom I had talked on the subject in the early eighties, Messrs. Henry Adams and Alexander Agassiz had given me much encouragement. So, after Mr. Carnegie had founded the Institution for scientific research that bears his honored name, I suggested to Mr. Agassiz, who was a Trustee, that the Institution should send an expedition to Central Asia to reconnoiter. This the Executive Committee agreed to do, on the condition that I should go myself.

It is one thing for a man of scientific training to live in the enjoyment of framing an attractive but only subjectively supported hypothesis, and it is a quite different thing to find himself, as I then found myself, face to face with the duty of testing it on the ground. Fortunately for the enterprise, Professor W. M. Davis was sufficiently interested to volunteer, at my request, to take charge of the physical-geographical part of the reconnaissance. I had little doubt that Mr. Davis would find evidence toward confirmation of the physical side of the hypothesis; but it was not without much anxiety that I faced the uncertainties of a search for traces of long-since-vanished peoples and cultures, which, even if once existent, might well have been obliterated. 
Up to this time I had done practically no reading in connection with the subject and was ignorant of the amount of thought and effort that during forty years had been devoted to Central Asia. The Russian General Staff had covered an immense area with good topographic surveys, and the Imperial Geological Survey had already mapped the geology in considerable detail. And I found that the so-called "Aryan problem" was no longer the simple hypothesis of the school of Max Müller and Lassen; it had become a hotbed of controversy in which, as a result of speculative activity, from the original linguistic seed had arisen a surprising variety of forms, into the analysis of which entered linguistic, anthropological, historical, and geographical considerations without number.

In St. Petersburg my plans were facilitated in the most generous manner by individual men of science, by the Imperial Academy of Sciences and the Geological Survey, by the ministers of War and Agriculture, and by Prince Hilkof, Minister of Ways and Communications. So thoroughly was this aid planned and executed that throughout our travels and work in 1903 and 1904 the different members of the expeditions met uniformly with the most open hospitality and the most cordial assistance.

The reconnaissance expedition of 1903 consisted of Professor Davis, with Mr. Ellsworth Huntington as his assistant, my son Raphael Welles Pumpelly, and myself. We remained together through Southern Turkestan, as far as Tashkent; separating there, Mr. Davis and Mr. Huntington, at first together and later separately, took in the regions of Issikul, and the Western Tian Shan Mountains from Kashgar to Lake Balkash, while my son and I examined the country from the Syr-darya to the heights of the Pamir. During the following winter Mr. Huntington made observations in Sistan on the Persian-Afghan frontier and in northeastern Persia. In the various reconnaissances there was accumulated a great amount of information bearing directly on the objective points of the investigation and forming the subject-matter of the volume published in 1905.* In their respective areas Messrs. Davis, Huntington, and R. W. Pumpelly established independently positive proofs of at least three distinct glacial and interglacial epochs of the glacial period and obtained abundant evidence of the deep-reaching reaction of these upon the topography of the mountains and plains.

We were also able to appreciate highly the work of the Russian geologists-to mention only Tschernyscheff, Karpinski, Muschketof, Bogdanovitch, Andrusof, and Nikitin in the pre-quaternary geology of Turkestan. Both this and the careful work of Andrusof and Sjogren on the east and west shores of the Caspian, and of Konshin in delineating phases of the expansions of the Aralo-Caspian-the accuracy of which we were able to

*Explorations in Turkestan, with an account of Eastern Persia and Sistan. Expedition of 1903 under the direction of Raphael Pumpelly. Carnegie Institution of Washington, Publication No. $26,1905$. 
observe at several points - have been of great use in working up the results of our expeditions of 1903 and 1904.

My personal attention was, in I903, directed more especially to the observations connected with the character and distribution of sites of former occupation, and their present environment and archeological promise. These sites abound to such an extent that one might call Southern Turkestan, with the valleys of the Tedjend, Murg-ab, Oxus, Zerafshan, and Fergana, a cemetery whose graves are the wasted and half-buried mounds of vanished cities.

The results of 1903 made me most anxious to probe these mounds with the spade, and a grant was generously made for this purpose by the Trustees of the Carnegie Institution.

Realizing that our problem was both geological and archeological and that pottery would probably be our most characteristic as well as most enduring fossil document, I sought an archeologist who should be expert in the subject of prehistoric pottery as well as in systematic excavation. And the success of the expedition of 1904 is largely due to the fundamental and systematic work of Dr. Hubert Schmidt of the Royal Museum für Völkerkunde at Berlin. Trained under Dörpfeld in excavations at Troy, and experienced in the whole field of European and Mediterranean archeology, he had studied critically the finds from the successive cultures of Troy and edited the museum catalogue of the Schliemann Collection, of which he had the charge. The government allowed him to join the expedition on the condition that the museum should receive duplicates of such finds as might be granted by Russia.

The right to excavate in Turkestan having been given by the Russian government-the first concession granted to a foreigner-the expedition rendezvoused at Tiflis in February, 1904, and proceeded to Askhabad, and encamped on the neighboring oasis of Anau. Here were a recently ruined city and two great mounds, one of which I had selected the previous year as a promising point for exploration because pottery of seemingly great age was exposed in a trench made twenty years previously in search for treasure.

The personnel of the party, besides my wife and myself, consisted of Dr. Schmidt, archeologist; Mr. Ellsworth Huntington, assistant and interpreter; Mr. Langdon Warner and Miss Hildegard Brooks, assistants to Dr. Schmidt; and Mr. R. W. Pumpelly, physiographer and surveyor. The work began at four o'clock in the morning and, except an hour for breakfast and two for rest in the mid-day heat, continued till six p. $\mathrm{m}$.

The method of excavations, adopted by Dr. Schmidt first at the northern mound (kurgan) and later at the southern one, consisted in sinking large pits, maintaining a level bottom, which was deepened about two feet daily. 
The surface of the oasis plain was taken as datum, and the position of the floor of the pits above or below this datum was determined daily. Such objects as vessels, fireplaces, and skeleton-burials were photographed in situ, and all fragments of pottery and bones of animals that had served the ancient inhabitants as food were, in each pit, placed in baskets which bore tags marked with the date and the name of the pit. Thus the height above the base of the mound and position in the horizontal plane of every object found was recorded. Much of the earth was sifted to save small objects.

All small objects were produced for record-entry each evening. These were simple articles, chiefly beads, whorls, small implements of flint, ornaments and implements of copper, generally wholly altered to carbonate or oxide; to these were added toward the end small, rough, terra-cotta figurines of woman and of cow or ox.

These simple objects had little beauty; the interest they aroused lay in the fact that we were unearthing cultures of a remote past and in an untouched field, far distant from the sites of classical civilization. We realized, therefore, that since the whole mound consisted of the slowly upward-growing débris of town life every object had played its part in the daily life of vanished peoples; that considered collectively, in connection with their observed positions in the column of débris (culture-strata), they formed a continuous record-precious documents of a long-continued prehistory.

The importance of considering even apparently insignificant objects as documents containing a story, and of recording their vertical and horizontal position in the column of culture-strata, became evident at every stage of the analysis of our results. It was, for instance, this procedure that enabled Professor Duerst to trace the transition of the Bos namadicus, pig, and sheep from the wild to the tame state and to date, in terms of stratigraphic growth of the mounds, the beginnings of domestications and the establishment of successive breeds of these animals.

Again, it was the appreciation of the potential possibilities latent in everything so recorded that caused Dr. Duerst to send to Professor Schellenberg a small porous fragment of burnt clay that was accidentally present in a bag of bones. In this apparently worthless clod that botanist found the evidence that the people of the oldest Anau settlement were cultivators of wheat and two-rowed barley; and my consequent search in our carefully labeled potsherds showed the casts and siliceous skeletons of the chaff of these cereals in pottery from the base of the mound. From this Dr. Duerst and I were able to draw independently the inference that the agricultural stage preceded domestication and the nomadic shepherd stage of civilization. 
It seemed to me that an examination of the abundant animal bones seen in the trenched mound in 1903 might prove of value in several respects and possibly throw some light on European relations. Consequently all that were found were collected, and each day's findings sacked and duly labeled as to stratigraphic position. About half a ton of these were forwarded to Dr. Duerst of Zürich, to whom, as Dr. Schmidt informed me, the German museums submitted subfossil animal remains for study. As a comparative anatomist, Dr. Duerst was especially interested in the domestic animals from the comparative side and from that of their origins. The results of his exhaustive study of the bones from Anau, to which he devoted his whole time during nearly three years, and his far-reaching conclusions are given in the second volume of this publication.

While Dr. Schmidt was conducting the archeological work, an independent physiographic investigation was carried on by $R$. W. Pumpelly and myself - a search for local geological records of changes in the attitude of nature toward man. This had long been to me a coordinate part of the Central Asiatic problem. The reader will see how important were the results obtained in this study of the operation of geological and climatic forces during the present epoch as recorded in mountain movements and in alternate aggradation and degradation of the delta-oasis.

Our workmen were the local Turkomans, a people speaking a Turkish dialect, very near to the Osmanli, but who had become racially much influenced by infusion of Persian blood through mothers captured in raids on to the Iranian plateau. These Turkomans, before they were with difficulty conquered by Russia, were the terror of Central Asia. Themselves Sunnite Mohammedans, they had (besides the feud between Iran and Turan, traditional from remote time) the fanatical hatred of the Shi-ite Persians. In swift raids they exterminated Persian villages, saving only women to sell as slaves in Bokhara and Khiva. Since their subjection they have been peaceable, and are esteemed by the Russians for their bravery and honesty, qualities which we, too, had every reason to admire in our workmen. We paid them from 25 to 40 cents a day for labor that was always well and persistently performed.

Our work at Anau was stopped by inroads of a vast army of grasshoppers, which not only filled our pits faster than they could be removed, but were spread through the irrigation ditches over the surface of the oasis in thick masses.

From Anau we moved to Merv, where we hoped to find sites of great antiquity and to make explorations preliminary to future excavation. The wasted walls and citadel of Ghiaur Kala (City of the Infidel) seemed the most promising, but here, while we reached in our pits only down to culture- 
strata of the third century A. D., our exploring shafts showed that the base of culture was probably not older than a few centuries B. $\mathbf{C}$.

There can be little doubt that among the great number of wasted mounds on the large Merv oasis some are exceedingly ancient, but intense heat and the prevalence of dysentery among the personnel and beginning mortality among the workmen put an end to excavating, and we removed to the more healthy altitude of Samarkand, where, after a hasty examination into the local archeological possibilities, I disbanded the expedition. Mr. Huntington was left to make a rapid survey of the distribution of mounds on the Merv oasis, and Mr. R. W. Pumpelly started an expedition on his own account, for physiographic observation, through the mountains of Bokhara and over the Pamir to Kashgar in Chinese Turkestan, the results of which are incorporated in his chapters in the second volume.

It was my intention to defer publication of the results of the expedition of 1904 until after that proposed for 1905. But the condition of unrest in Russia during the winter of 1904-05 caused the Trustees of the Carnegie Institution to postpone the work, and the preparation of the reports was immediately begun, and continued till 1907 .

While each one of the investigators was expected to work up his material, there devolved upon me, as initiator and director of the expeditions, the duty of presenting an independent discussion of the results as a whole. I found myself confronted with the task of translating and editing the contributions of the experts, and of drawing my own conclusions from these and from my own observations. To do this I surrounded myself with a library of six hundred or more volumes, covering many of the more important as well as latest writings in the sciences related to our work and problems, besides many borrowed from libraries. Literally living in this problem, for nearly four years, my whole time, reading, and thought has been devoted to acquiring such a general survey of the field as would enable me to discuss the subject of our results and of their wider bearing in the light of the present condition of archeological and ethnological knowledge.

Besides incidental inspection of the museums of Tiflis and Tashkent, numerous visits for study were made to those of Moscow, St. Petersburg, Berlin, Vienna, Zürich, Schafhausen, Cairo, Athens, London, Naples, and Rome, and to those of Paris, including M. De Morgan's systematically collected finds from Susiana - to me perhaps the most important of all - and in connection with my chapter on chronology a special journey was made, together with R. W. Pumpelly, to Egypt to study the rate of growth of Egyptian village mounds in comparison with those of Anau.

Of the two alternatives-confining the reports, my own included, to a record of observations and finds - or having each contributor go further and, 
treating his subject from the comparative point of view, draw his conclusions as to the bearing of his results on the general question of Eurasian problems-the latter seemed preferable. For, with the whole chain of observation and thought fresh in the mind, it would seem to be the province of the individual investigator to state his inferences, even if only as working hypotheses.

I confess to having written a chapter on the Aryan problem in the light of an extended study of the whole field and of our own results. But this I have suppressed because it seemed a premature as well as a hazardous venture for one not already an authority on the subject; and the word Aryan is mentioned only incidentally. The various parts, however, of the volume contain abundant material for both use and controversy in this connection. In drawing my own conclusions I have tried to keep before the reader a current statement of the objective facts from which such inferences were drawn.

The reader may be surprised that no traces of writing are noted among the finds from Anau, especially since it is assumed that the people who carried the proto-cuneiform script into Chaldea came from an eastwardlying region within the area of isolation. It must be frankly confessed that such traces were not looked for. But even had these earlier peoples of Anau I and II possessed the art of writing, it would probably have been used only on wood, bark, or skins; for the straight and curved lines of the earliest proto-cuneiform script of Chaldea are proof that in its pre-Chaldean stage it must have been used on materials different from the clay tablets on which it was possible to develop the later cuneiform. And all traces of organic substances have disappeared, except only charcoal and niter-saturated bones. And while we might perhaps expect the strata of Anau III, which show evidence of Chaldean relations, to contain inscribed clay tablets, these might easily be confused with the containing earth mass and thus escape eyes that were not looking for inscriptions.

And now what relation do the results bear to the dream that gave rise to the expeditions? On the physical side, Messrs. Davis, Huntington, and R. W. Pumpelly have traced in High Asia the records of several great glacial expansions during the glacial period. The climatic conditions, which during that period so greatly expanded these glaciers and buried Russia under thousands of feet of ice, presumably produced also the inland sea whose shore lines are still visible.

The evolution of civilization has been traced backward to a time when, before its datings in Babylon and Egypt, man at Anau already lived in cities, cultivated wheat and barley, began the domestication and breeding of the useful animals which are our inheritance, and possessed the funda- 
mental industrial arts, including a certain amount of metallurgical knowledge. Evidence has been traced of a progressive desiccation throughout long climatic cycles in whose favorable extremes civilizations flourished which disappeared in the arid extremes. And that the climatic conditions under which these civilizations vanished gave rise to very early migrations and to a constructive reaction upon the outside world would seem to follow from the early appearance, in Babylonia and Egypt and in the late stone age in Europe, of wheat and barley and of breeds of domestic animals which Dr. Duerst identifies with those first established on the Transcaspian oases.

I have in Chapter IV attempted to show that Central Asia was, from one of the epochs of the glacial period onward, isolated from Africa and Europe and that, excepting the elements of the lowest generalized form of human culture, all its cultural requirements were necessarily evolved and differentiated within the region of isolation. Before the supposedly Central-Asian Sumerians fused with the Semites on the Euphrates they had been trained in a struggle with nature which had culminated in the ability to conceive and execute great undertakings, as shown in the work of controlling the great river. Their field of thought was doubtless confined largely to economic effort and organization. Into the fusion, the contemplative nomadic shepherd Semites brought a new range of speculative thought, and out of the union arose the highly developed Babylonian civilization. And to the extent that this entered into the origins of preclassic Figean and Mycenæan cultures, so far did it carry the contribution of the fundaments of civilization from the Central-Asian oases to the Mediterranean.

The earlier reactions of the oasis cultures on the outside world were, therefore, both as regards migrations and ideas, essentially constructive in character. The later and greater migrations were of a different character. The growth of great nomadic populations, to whose outward movement these were due, could not have begun until after the development of the art of breeding the animals upon the possession of which alone life on the arid plains of Asia depended. I have shown, in the chapter on migrations, that during climatic conditions which depopulated the oases the grasses of the arid plains would permit the expansion and differentiation of nomadic shepherd peoples till all Central Asia should be occupied, and that later there came a time when-in the progressive desiccation through an arid extreme of a climatic cycle and some thousands of years after the beginning of domestication and breeding of animals-the populations, swollen to the limit of the supporting capacity of the pasturage, would be forced to seek outlets into more favored regions.

The great continental unrest which variously affected different parts of the West, being caused by the decreasing capacity of the pasturage to 
support nomadic shepherd life, could not have begun until all of Central Asia had become peopled up to the limit of that capacity.

We may imagine the great area to have been by this time portioned out among peoples of varied racial origin and having different degrees of culture, varying from nomads in the arid regions to more or less settled pastoral peoples with elementary agriculture in the more favored lands north of the Black Sea. The waves of movement, beginning in the drier eastern region, should seem to have progressed outward, the central peoples pushing the next outer ones outward, and so on till the climatically favored peripheral regions, including Europe, were successively submerged by one migration after another, ending with the purely Turanian inroads of our era.

These migrations were destructive wherever they came in contact with cultures higher than their own.

The reader will see that in tracing back to Central Asia the source of the fundamental elements of western civilization, in finding the traces and cause of the inland sea, in discovering evidence of progressive desiccation (and in this the cause of the migrations that revolutionized the world), the dream has to this extent been realized.

On the other hand, as regards the Aryan problem, we have contributed only some fragments which may be useful in further speculation. The solution of the great problem awaits much more extended archeological, anthropological, and philological research.

Our indebtedness is indeed very great for aid and hospitality received on this expedition, as it was in that of 1903 . In England our ambassador, the Hon. Joseph H. Choate, smoothed the way through Turkey with a letter from the Turkish ambassador. Prince Hilkof again placed at our disposal for the season a commodious private car. In St. Petersburg my plans were again generously furthered in many ways by Messrs. Tschernyscheff, Director, and Karpinski, Bogdanovitch, and Andrusof, members of the Imperial Geological Survey, while General Artamonof, of the General Staff, kindly aided me in getting War Office maps of Turkestan. I am under deep obligation to Count A. Bobrinski and Mr. Latichef, of the Imperial Archeological Commission, and Professor W. Radlof, President of the Central Committee for Central-Asiatic excavation, for the obtaining from the Government permission to excavate. Mr. Salemann kindly examined the few Uigur and Pehlevi inscriptions found at Merv, and to Mr. Markof we owe the important determination of the coins found at Merv.

In Tiflis the personnel of the expedition were delightfully entertained with dinners and a ball by the Georgian Prince and Princess Begtabegof. In Turkestan at Kraznovodsk we enjoyed again the hospitality of Colonel and Madame Volkovnikof. At Askhabad General Ussakofski, governor of 
Transcaspia, and Madame Ussakofski entertained us socially. And all the details connected with organizing and continuing our work at Anau were carefully managed by General Ussakofski and the district Natchalnik Colonel Kukol-Yaznopolski, while the required government supervision was courteously executed by Mr. A. Semencf.

At Bairam-ali (Merv) the Director of the Imperial Domain, Mr. Yeremief, gave us a house for all the members of the expedition, and Madame Yeremief made our stay pleasant socially in their beautiful house.

Here, too, we were aided in many ways by Herr von Brandt, assistant to the Director. At Bokhara we had, as on the previous expedition, reason to be grateful to Baron Tscherkesof for aid in visiting Old Bokhara and for aid in obtaining from the Ameer permission for $\mathrm{R}$. W. Pumpelly to travel in the remote parts of the Khanate and in taking the steps that insured for him the hospitable reception extended to him throughout his journey.

We shall never forget the unbounded kindness shown us at Samarkand by General Medinski, the Governor, and Mademoiselle Collins, who took Mrs. Pumpelly and Miss Brooks and myself at once into the charming Government House and in every way made our stay delightful. And after our departure General Medinski perfected the arrangements for my son's expedition.

To Professors Hoernes, of Vienna; Heierli, of Zürich; Pigorini and Colini, of Rome, I am indebted for kindly given aid in examining the collections in the great museums of those cities. And in Paris I have to thank Mr. Hubert, of the Museum of St.-Germain-en-Laye, not only for guidance through the collections, but also for undertaking to have the metallic implements from Anau reproduced in wax, which was most artistically executed by M. Champion.

To Professcrs Sayce and Flinders Petrie and Mr. Reissner I owe many thanks for instructive interviews in connection with Babylonian and Egyptian archeology. And to the many hours spent with Professor Sergi during repeated visits to Rome and the deep interest taken by him in our work in Turkestan I owe not only much encouragement and instruction, but also his impcrtant contribution to these volumes.

Dr. William James, Jr., very kindly volunteered his services in preparing from Mr. Langdon Warner's photographs and sketches of the skeletal remains the drawings that are reproduced in Mr. Warner's report.

No small part of the success of the expedition of 1904 is due to the volunteer work of Mr. Warner and of Miss Hildegard Brooks. Miss Brooks, in addition to other duties, acted as assistant to Dr. Schmidt, recording the lists of finds and asscrting the great mass of fragments of pottery that were collected daily. 
Lastly; at Merv and Samarkand Mr. Homer Kidder rendered valuable volunteer assistance.

It should be mentioned that the topographic work was executed on a plane-table with telescopic alidade specially constructed by Messrs. Buff \& Buff.

To avoid misunderstanding it may be added here that the word culture is used as a synonym for civilization, and that the term culture-strata (Kulturschichte of the Germans) stands for the débris slowly accumulated during occupation of an inhabited site.

It should also be added here that I presented the outlines of our results in my presidential address at the Ottawa meeting of the Geological Society of America in December, 1905; and that some changes from that address, in connection with the question of culture gaps and datings, are due to later and more extended analysis.

It is desirable to refer here to a point that was overlooked on pages 55 and 56 , in advancing a law of vertical growth of sites built of air-dried bricks. It is this: Aside from the contribution of bones and potsherds, the accumulating débris is derived chiefly from the wasting surface of roofs and walls. This is roughly proportionate to the area of these surfaces. In primitive and small sites the houses had, as a rule, only one story, but in larger cities of advanced culture, such as were Merv and Memphis, houses of two or more stories were frequent, and the rate of growth was correspondingly much more rapid.

Dublin, N. H., October I, 1908.

R. P. 
Digitized by GOOgle 
PART I.

ANCIENT ANAU AND THE OASIS-WORLD.

By Raphael Pumpelly.

[Chapters I-V; Plates 1-6.] 



\section{CHAPTER I.-EVOLUTION OF THE ENVIRONMENT OF CENTRAL-ASIAN CIVILIZATIONS.}

The beginnings of Central Asia, as part of the Great Continent, lie far back in the Tertiary period, during a time when Mother Earth was in travail, giving birth to her last-born - the new order of continental and organic forms. In the throes of the contracting terrestrial crust there had been slowly born great mountain masses, ranges whose ice-capped giants now mark the boundary between north and south, extending half-way around the earth, through the Pyrenees, Caucasus, and Himalayas to China. The Eurasian continent was born, but in its infancy a great sea extended from the Atlantic through the Mediterranean to southeastern Asia. Later, during the Middle Tertiary, this connection was broken, leaving a great interior sea called the Sarmatic, which once extended from Austria to beyond the Aral. In the progressive development of land and climate, during Pliocene or late Tertiary time, this sea in turn broke up into separate landlocked basins of fresh and brackish water, the deposits and faunæ of which are designated as belonging to the Pontic Stage.

In these changes we see the evolution of Central Asia as an interior region. Differentiated from the periphery of the continent by mountains that intercepted the moisture from the ocean on the south, and otherwise climatically at a disadvantage on account of its geographical relation to the laws of atmospheric circulation, this vast region entered upon an independent course of development.

When this inner-continental area ceased to send its waters to the ocean, it was predestined to a course of evolution whose progress must inevitably culminate in the desert-waste conditions ruling there to-day. Each of the geological periods mentioned had its characteristic land and water organic life, among which were prophetic ancestral forms in the genealogy of the mammals of to-day.

The cause of this differentiating evolution is as simple as it is fatefully majestic in its progress. The moisture, carried by the high currents of air in their course from the equator to the pole, is largely condensed in rising over the great altitudes of lofty mountain ranges. To the north of the highlands, the plains receive but a slight annual precipitation, and this is so distributed in the seasons as to produce the minimum of vegetation in respect to the amount of precipitation received during the year. Under these conditions a forest growth is impossible, and the surface must be more or less grass-covered or bare according to the amount of effective precipitation, which in turn may perhaps have varied during different periods with a possible varying in height of the intercepting mountains.

Under such conditions the region would vary in character between semi-arid and arid. Whether semi-arid or arid, the hot air rising from plains, barren of 
vegetation and heated by the sun of spring and summer, prevents local rainfall, and the residuum of moisture that escaped condensation on the mountains is carried on to the colder regions of the north. It is only during the winter that this residuum is precipitated on the plains as snow, and even this melts away by March, awaking to life a varied desert flora, which in turn vanishes under the burning April sun. Thus, excepting the relatively ineffective winter snows, the whole of

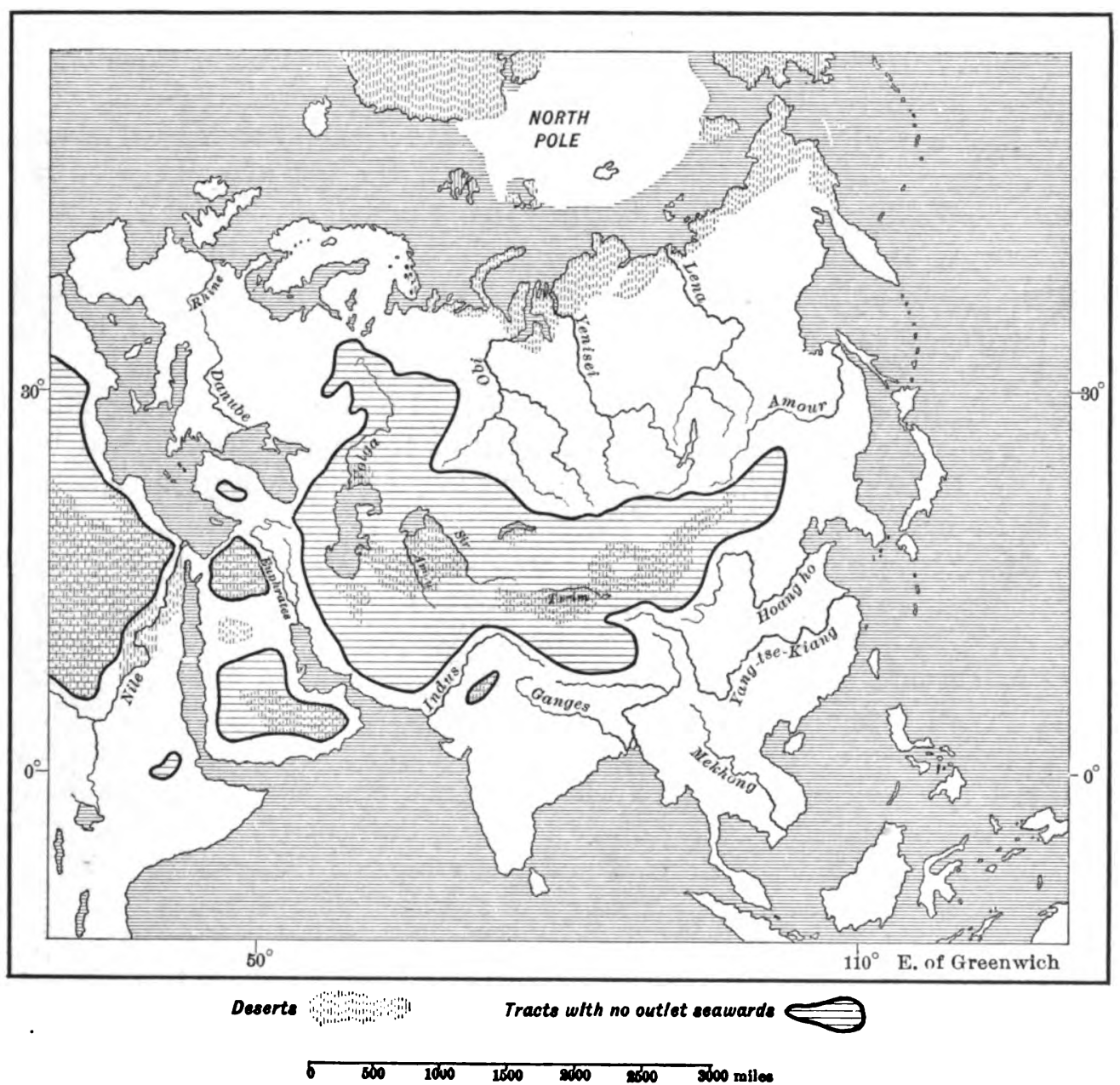

Fig. 1.-Undrained Parts of Asia. (From Élisée Reclus, The Earth and its Inhabitants.)

this vast inner-continental region receives waters only from the precipitation over the high mountains that separate it from the peripheral zone, and from such mountains as rise sufficiently high within its own area.

Central Asia, from the western border of Manchuria to the western end of the Black Sea, is a series of great and small landlocked basins. From these no water flows to the ocean, excepting that which the Black Sea loses through the canyon of the Bosporus, which was not opened to the Mediterranean until the present 
geological epoch. This great landlocked area is divided into two basin-systems; one is the higher-lying Gobi on the east, inclosed on the west between the mountain masses of the Kuen-Lun and Tian Shan.

The western system of landlocked basins covers a great part of Western Asia. Extending west from the Tian Shan ranges, it is limited on the south by the Persian plateau and the Caucasus, and on the north by the low Siberian elevation that forms the water divide toward the Arctic Ocean. On the west, from a hydrographic but not from a climatic point of view, this system includes the Black Sea, with the areas drained by the Volga, Don, and Dnieper (a large part of Russia), and by the lower Danube. The Persian plateau itself forms an independent high-lying system of arid landlocked basins.

Of this great western system a part near the Caspian Sea lies below the level of the ocean. A large part of the whole system is so situated in reference to the barriers that separate it from the oceans that, given a sufficient quantity of water and the closing of the Bosporus Channel, there would be a landlocked sea several hundred feet deep and larger than the Mediterranean. It is potentially a sea, of which the Black Sea, Caspian, and Aral remain as three larger residuary bodies of water. This is due to climatic conditions, under which the precipitation over the region, together with the water brought by the streams from without, is offset by the intense evaporation over the heated arid surface. With a sufficiently longcontinued inflow of water in excess of evaporation, and a restoration of the barrier at the Bosporus, the Black Sea and the Caspian would coalesce, and, after extending to include the Aral, would rise till an overflow should be reached, either into the Mediterranean or into the Arctic Ocean, and our potential sea would become a reality. If, on the other hand, there should exist a sufficiently long-continued condition in which evaporation should be in excess of inflow of water, then a time would come when, instead of a sea, there would be only a region of barren deserts. Our basin is, therefore, potentially both a sea and a desert. At present the two controlling factors-water and evaporation-are about in a state of equilibrium.

The existing residuary seas are, therefore, in the rising and lowering of their surfaces, gages recording the cyclical climatic changes as they occur over the great catch-basins that supply them with water. Of these catch-basins, the northern and western ones are the great hydrographic systems of European Russia and the smaller river systems, chiefly of the Caucasus. The rest lie almost wholly in the lofty mountain chains that stretch with increasing height and area as they go eastward to High Asia. The vast masses of snow and ice, constantly accumulating on these heights, feed perennially the few larger and countless smaller streams that flow toward the central basin region. Without these Turkestan would be an absolutely desert and practically lifeless region.

I imagine that the general trend of the climatic conditions over the central continental area was from the beginning toward aridity. The mountains that separated it from the ocean were of slow growth, and mountains of moderate altitude are compatible with a moderate amount of precipitation over the interior region beyond them. The grassy plains of Mongolia and of the Central Western 
United States are illustrations of this. The early condition of Turkestan and northern Persia, during much of Pliocene time, may well have been one in which at first forests existed, at least on the piedmont hills and plains, while the rest of the region that was not still occupied by the residuary seas consisted of broad grassy steppes extending to Europe and of interior areas of deserts. Parallel with the growing elevation of the moisture-intercepting mountains progressed the regional desiccation. The progressive effect of this would be continued shrinkage of the water areas, conversion of much of the central plains into deserts, narrowing of the grass-covered zones towards the mountains, and change in the character and extent of the forested areas. After the Miocene sea had been shut off from the ocean, it dried up, as is shown in the Sarmatic strata by the widespread deposits of gypsum and salts resulting from the evaporation of the saline waters.

That the basin was reoccupied more than once by a more or less extensive landlocked sea is shown in successive formations characterized by changes in organic forms, and by old beach and water lines. There is little doubt that these expansions of the water area record the climatic changes that mark the advent and phases of the glacial period. An effect of these changes, which were of mundane extent, was doubtless an increase of precipitation over a large part of the central region. In the glacial period a large part of Russia west of the Ural Mountains was covered to a depth of several thousand feet by ice, a large part of which in melting went toward filling the central basin.

Our exploration in 1903, as shown in the reports of Professor Davis and Messrs. Huntington and R. W. Pumpelly, has proved the existence of several successive glacial epochs in the mountains of High Asia during the glacial period, and that glaciers existed on a greatly extended scale throughout the mountains bordering the great basin on the south and east. Each of these epochs of glacial expansion must have had its echo in a corresponding expansion of the water area, and in a reaction on the climate of the basin region itself in the direction of local precipitation and amelioration of the desert conditions.

During the glacial and interglacial phases of the glacial period, there must have existed a continuity of broad and alternately tundra and grass-covered steppes along the whole length of Central Asia into Europe.

The great "central" basin-system resembles the ocean in that it is the sink into which all the solid and dissolved products of the destruction of the surrounding country are brought. In the ocean all such detritus is classificd by gravity, wave-action, and currents, which distribute the graded material over wide areas. On the dry surface of the desert plains this classification and distribution is begun by the rivers and finished by the winds. While in the ocean the sand is deposited to become stratified beds of sandstone, and the clays to form ultimately beds of slate, in the arid basin the sand accumulates in moving hills, and the finest silts are borne off by the winds to form the remarkable and economically important deposits of loess.

For the general reader, I will explain that loess is, with slight exceptions, the most important soil in the world, owing to its great depth, its fertility, and 
self-fertilizing power. It is, in itself, an unstratified, even-textured, yellowish or yellowish-brown earth of very fine grain. It consists largely of exceedingly fine particles of silica with an admixture of equally finely comminuted silicates, some oxide of iron, and a varying amount of calcareous material which often segregates into concretions of irregular form. It generally contains also various soluble salts of the alkaline earths and alkalis. While it will maintain vertical cliffs apparently for centuries in a dry climate, in which the dwellings of whole villages are excavated, it can be crumbled between the fingers. It is rendered porous by innumerable tubular channels left by the decayed stalks and roots of grasses, and roots of trees may penetrate it to a depth of 100 feet or more.

Loess has played, and still plays, such an important part in the history of man that I shall devote several paragraphs to a description of the manner in which it is formed, and I do so not only because of its importance in connection with the past history of Turkestan, but also because of its general interest.

The most striking illustration is offered by northern China, where it covers a great part of the surface, both on the hills and on the lowlands. Its fertility seems to be inexhaustible, a quality it owes partly, as Richthofen remarks, to its depth and texture, partly to the salts brought to the surface after rains by capillary attraction acting through the tubular channels left after the decay of successive generations of the grass stems inclosed during its accumulation, and partly to the increment of fresh dust that is still brought by winds from the interior. Its self-fertilizing ability is shown by the fact that crops have been raised continuously, through several thousand years, on its immense areas in China, and practically without fertilizing additions. It is on these lands that dense populations accumulate and grow up to the limit of its great life-supporting capacity, the only check being in the fact that in this region of light rainfall, a drought lasting through several successive years produces at times famines that may exterminate many millions of people.

China offers, too, another striking illustration of the influence of this remarkable soil on the history of its fortunate possessors. At repeated intervals of a few centuries, its population has been decimated and over large areas almost annihilated by overwhelming invaders or by civil wars, as in the Tai-Ping rebellion of the past century. In southern China, where there is no loess, the area that can be cultivated is absolutely dependent on the amount of available fertilizers, and since the population is so dense and the holdings are too small to admit of the keeping of live stock, the only available fertilizer is that produced by man. The result of this is that population recuperates rapidly in the loess-covered provinces where cultivation is dependent only on the ability to prepare the soil and to plant the seed; while in the south the ability to support population waits on the slow increase of fertilizing humanity.

Again, great events in our own history are directly connected with the distribution of this wind-borne soil-events which have shifted and radically changed the populations of Europe and have caused the downfall of empires and replaced civilizations by semi-barbarism. For from north of the Caspian to Austria extends 
a continuous zone of loess lands covered with grass. From the time when the domestication of the horse and ox made possible the movements of organized bodies of men, these grassy plains have been used as an easy road for the migration of whole populations and for the devastating irruptions of barbarian hordes.

To turn again to the more peaceful side of the subject, southern Russia, Hungary, Austria, and the valley of the Rhine enjoy great profit from this fertile soil; and this is true to an even greater extent in the United States over the loesscovered areas of Iowa, Missouri, and Dakota, where it compensates for the lighter rainfall.

All previous geologists had considered it to be a sedimentary deposit, laid down in still water, and this was the view also of the writer after seeing it in some of the connected basin-like depressions of northern China and Mongolia in 1863 . But later Richthofen, in his extensive exploration of China, found it mantling mountains several thousand feet high and containing there only remains of land animals and land snails. He found also that waters eroding this mantle deposited it in basins and on flood-plains, where it then often contained pond and river shells. As a result of his studies he found that the loess had been brought by winds. In developing his theory Richthofen showed that certain widely existing conditions were necessary to the formation of this product, so important to man. These conditions he explained in connection with the broad and fundamental theory, mentioned above, of the effect of climatic conditions in the "central" parts of continents as contrasted with the coastal or "peripheral" zones. All water is brought by winds from the oceans, and, generally speaking, by far the greater part of the moisture that is not precipitated in the coastal regions is condensed on the mountain ranges bordering the interior. The streams that flow from these mountains toward the central area sustain vegetation only where they can be spread over the land, leaving practically the whole vast area in a more or less arid state, excepting where more or less precipitation occurs over a zone near the mountains.

It was in the action of the winds on the unprotected surface of these plains that Richthofen found the source of loess. Wind not only takes up dust, but it wears away slowly and surely all soft, unprotected rocks, and, following lines of weakness, it removes thick strata of harder texture, leaving masses carved into fantastic forms, towers, and pinnacles, often hundreds of feet high, to prove the gigantic scale on which it can work with the aid of time. The products of this action may be classed as dust, sand, and still coarser material. The wind itself makes this classification. Separating the sand and dust from the coarser detritus, it carries the dust afar, while the sand is moved slowly forward, piling up into wave-like dunes, which progress by drifting away from the windward slope to accumulate on the lee side. As long as the dust is borne over a barren surface, it is ever at the mercy of the wind; but in many places near the borders of the arid region, as in northern China and southern Mongolia, there is sufficient precipitation to permit the ground to be covered with grasses adapted to such a climate. Once caught in this grass it remains to nourish the growth that is to continue the process 
of accumulation. The extremes of this process were, therefore, accumulation of the dust in the form of mantling loess on the borders of the "peripheral" zone, and barren stony steppes in the interior, with seas of sand-dunes following between. The dense dust-storms that during the seasons of predominant winds from the interior darken the air of northern China and southern Turkestan, are proof that the process outlined above, in the sense of Richthofen's theory, was at least one source of the loess of China and Mongolia, and his conception must stand as a beautiful and well-conceived explanation.

The writer, in reviewing the first volume of Richthofen's great work "China," in 1876 , recognized the validity and strength of the argument and was led to suggest additional sources of wind-borne loess.* These were: first, the silts (chiefly glacierground) brought by rivers into desert regions, where after desiccation they became the prey of the winds; second, another important source would be where a region which had long been protected by heavy vegetation should, through the chemical action of infiltrating waters carrying free oxygen and organic acids, become disintegrated and decomposed, either in mass or broken up into polygonal blocks surrounded by clay detritus. Such a state exists often to depths of 100 to 300 feet in regions that have not been glaciated. When in consequence of a climatic change toward aridity such a region should lose its protecting vegetation, it would offer to the action of the winds an immense store of loosely aggregated material ready for easy and rapid removal. On the other hand, in the oncoming of a glacial epoch, such a condition would explain the origin of the greater part of the glacial till and large and small bowlders transported in the slow movement of the great ice-cap. This modification was accepted by Richthofen and reproduced in the second volume of "China."

The expedition of 1903 offered opportunities for studying the loess of Turkestan and observing the way in which it was formed, and certain facts were noted that explain some points that have been considered by many to be inconsistent with Richthofen's theory. These observations showed clearly that all loess is primarily brought by wind and arrested by grasses under the protection of continued generations of which it slowly accumulates. But there are two sources from which the wind derives the dust. One is from the bare surface of deeply disintegrated mountains, as on the Pamirs, and the uninterrupted deflation by the winds of the rocks of the desert, which are perpetually disintegrating under the influence of the great daily changes of temperature. The other is from the floodplains and dry deltas of rivers and from the shores of retreating lakes, as I had suggested in the paper referred to. This brings in water as an intermediate factor in transportation, in connection with the origin of loess in certain regions. In every case, however, the process nuust be in an arid or more than semi-arid climate, where extensive rock areas or widespreading flood-plains are in a state of desiccation. On the Pamirs we found the mountains buried in the unmoved products of their own disintegration. In this worst of desert regions, rocks at the surface crumble

* The Relation of Secular Rock Disintegration to Loess, Rock Basins, and Glacial Deposits. American Journal of Science, February, 1879. 
to dust continuously under the effects of the great and sudden differences of temperature between day and night, and between the sun-warmed and shadecooled sides of the block. R. W. Pumpelly found the surface of the older moraines wind-swept to a floor of even smoothness, the large and small blocks of rock being represented only by flat surfaces flush with the floor, in which they produce the effect of a mosaic. Here we observed both factors at work in the process of loess transportation, for the waters from the early melting snows bring down great quantities of the finer products, which are soon dried on the dry deltas and plains, and all through the day cyclonic columns of the dust are seen moving rapidly across the field of vision to disappear beyond the mountains. Again, in the great Alai grass-covered valley, ro, 00 feet above the sea, at the northern foot of the Pamirs, we observed all stages of the process. Moraines of $I, 000$ to $I, 500$ or more feet high, and stretching Io to 15 miles across the valley and belonging to the earlier glacial epoch, are mantled to a depth of several feet with loess, while the younger moraines, though abundantly grass-covered, have only a thin covering. The streams that descend from the snows and glaciers of the lofty Trans-Alai valleys have flood-plains several miles wide, which are nearly dry except during the spring floods. Here one can often see the fine dust carried by the wind from the floodplains to the grass-covered moraines, and there can be no doubt that the loess on the moraines was brought by the winds from the neighboring flood-plain. In view of this it would seem probable that a great part, perhaps the greater part, of the loess of many regions has undergone previous transportation by water. The loess of China owes its origin, doubtless, both to deflation of the Mongolian deserts and to wind-sifting of the flood-plain of the Yellow River, which carried an immense load of glacial flour during the glacial period.

Loess, whether originally a product of deflation or of glacial grinding, must, where its whole pre-eolian existence has been passed in desert conditions, retain a greater or less amount of the soluble products of disintegration and decomposition. For, even when leached and transported by water, more or less of these constituents remain in the silts left dry by evaporation, not only on desert depressions and dry deltas, but on broad flood-plains as well.

The structure and constitution of a loess-mass vary according to the conditions under which it was built up: where it is deposited on an elevation, it grew up after covering this, as a homogeneous formation, unstratified and free fron interbedded detritus; where it forms on mountain declivities, it contains layers of detritus washed down from above; where it borders an aggrading flood-plain it alternates with occasional gravels; and where it forms on the "dry deltas" of streams emerging from the nountains, it assimilates the fine sediments, which, like itself, are retained by the grass, and impresses loess characteristics upon the resultant product.

We have seen that the lofty mountains intercept most of the moisture brought by air-currents from the ocean, and that the fiery column of air rising from the heated barren plains prevents precipitation except in winter; but there is a zone between the deserts and the mountains on which sufficient moisture falls in spring 
to nourish the grasses of a semi-arid region. In Mongolia, where the intercepting mountains are low, the zone is broad. In Turkestan it is narrow or in places now almost wanting. During the cold glacial period it was wide.

I will ask the reader now to consider this central region as an organic whole. Let him imagine himself looking down over this great expanse and, foreshortening space and the vista back through untold centuries, able to view the successive phases of its life during a short period of geological time.

First, we are in the glacial pericd; on the south we see the giant mountains from the Caucasus to China covered with snow and, on the higher masses, great domes of ice and far-reaching glaciers. Far away in the northwest is the cap of continental ice spread thousands of feet thick over nearly all of Furopean Russia. Between these limits our sight wanders over the blue waters of a sea greater than the Mediterranean and fed by the larger rivers that flow from the snow and icecapped regions. The rivers are building great deltas where they enter the sea, while above these they spread their silts far and wide over the aggrading plains.

Remember that while we look, in our time-perspective, millenniums are as seconds. Even now the glacial period has passed, and the reaction has begun; and we look down upon the beginning of a general trend toward desolation. The ice-cap is gone from Russia and the great glaciers on the southern mountains are diminishing in extent. Evaporation is now more rapid than inflow of water, and the sea is shrinking and breaking up into smaller basins. With each lapse of thousands of years, we see the larger rivers grow smaller, while many of those coming from the southern mountains fail to reach the receding sea. Those great gyrating columns that are coursing across the surface of the earth show that the dried silts have become the prey of the winds. And now, looking closer, we see at their work all the controlling agencies that are the life of the great geographic organism that we call an arid inner-continental region. We can see that the floodplains and deltas and the drying beds of seas are covered with dried silts of clay, sands, and gravels. The winds are working these over and classifying them according to size of grain. The finest material is easily lifted and carried afar; and it is this that forms those massive yellow clouds that are darkening these plains in their progress, and those gyrating columns-vortices :n the heart of the sweeping whirlwind. Of the coarser silts the winds move only the sands, and these only slowly, along the surface of the plain, where we see them forming great seas of sand-waves or dunes, in places more than 100 feet high. These waves progress as each high wind, lifting sand from the windward side, deposits it on the lee side. As the winds vary in direction during the seasons, so does the progress of the dust and of dunewaves. But it is an important fact for us that both dust and dunes make an absolute progress during the year in the direction of the predominant winds. Watch those columns and clouds of dust. As the wind falls they dissipate, settling on the surface to wait to be borne on the wings of the next windstorm. Look now towards the grass-covered plains bordering the deserts. No clouds rise from these; on the contrary, the volumes of dust that fall remain under the protecting vegetation; the grass is nourished perennially by the dust, and under this reciprocal 
process the surface rises slowly during the centuries to form great thicknesses of the soil we call loess. Look back again over the region. While the sand, from which was separated the dust we have just seen deposited to form loess, lags still scores of miles behind in its advance, we see the grassy plains bordered by a sea of high sand-dunes. They, too, have been arrested in their overwhelming progress by the slight growth of grasses and plants that are compatible with a soil of sand, under the slight precipitation near the border zone. Both the loess and the dunes grow continually in height.

We have seen a cycle of geological activity quite different from that which takes place on the periphery of a continent where the silts are distributed by ocean currents over great submarine areas. Here, on the contrary, the waste from the degrading mountains, which was spread by rivers over the plains, is returned by the winds to pile up on the piedmont zone, and this is obviously true not only of the solids, but of the soluble alkaline and earthy salts as well.

All this conforms strictly to Richthofen's theory that loess was a product of deflation of desert-surfaces, wind-borne till it found protection on the grasscovered zone. Here, however, we see that water intervened as an earlier transporting agent, and that on the plains evaporation restored to the fine silts the salts that had been leached out.

Let us return to our panorama. It is still that of many thousand years ago, and the grassy steppes across all Central Asia teem with herds of wild ruminants and horses and other animals that during early glacial and interglacial time were common to the Eurasian continent. I will ask the reader to look, at the same time, toward the edge of the plains. At short intervals we see streams emerging from the mountains through canyons on to the plain, where they spread out evenly over large fan-shaped deltas that slope radially outward from the apex at the canyon mouth. These are the delta-oases, of which I shall have more to say. Casting our eyes along the southern border of the plains, from the Caspian Sea eastward we see grassy loess-plains fringing the southern mountains, and filling out the great embayments between the spurs of the Tian Shan ranges in the east. But everywhere both these plains and the deltas are hemmed in by the sea of dunes.

During our foreshortened time-scale, our present glance sees also the effects of later climatic oscillations. It is perhaps a period of diminishing regional precipitation. The zone of vegetation narrows, the scant protecting plant life disappears from the dunes, and they advance over the edge of the loess-belt, and encroach also on the shrinking delta-plains. With a period of renewal of precipitation, vegetation resumes its former area, and the loess deposits expand over the dunes.

The processes which we have reviewed have been operating with fluctuating intensity since Tertiary time. The maximum of intensity existed probably as a consequence of the glacial period. Glacial epochs were accompanied by swollen rivers with broad flood-plains, expansions of the seas with extensive marshes, and by great extent of loess-steppes. During interglacial epochs the conditions were reversed, and subsequent to the last glacial epoch there began the general trend 
toward the present condition of aridity-a trend that was interrupted by oscillations, in some of which the aridity may have exceeded that of to-day-a process in which the seas, while responding to the oscillations, have in the main shrunken gradually to the volumes compatible with the present equilibrium between precipitation and evaporation. Parallel with this progress toward aridity, under the diminished precipitation and lessening to disappearance of the ameliorating climatic reaction of the once-expanded water areas, was the shrinkage of the loess zones. The grassy steppes, which had once teemed with life and permitted the distribution of ruminants and the horse across all Asia to Europe, gradually became broken up into disconnected areas by the increased intensity of desert conditions. The expanding deserts cut off the connection between the faunæ of southern Turkestan and Persia on the one hand and those of Europe on the other, and allowed the evolution of regional varieties. And there must have been a similar reaction upon the distribution of man.

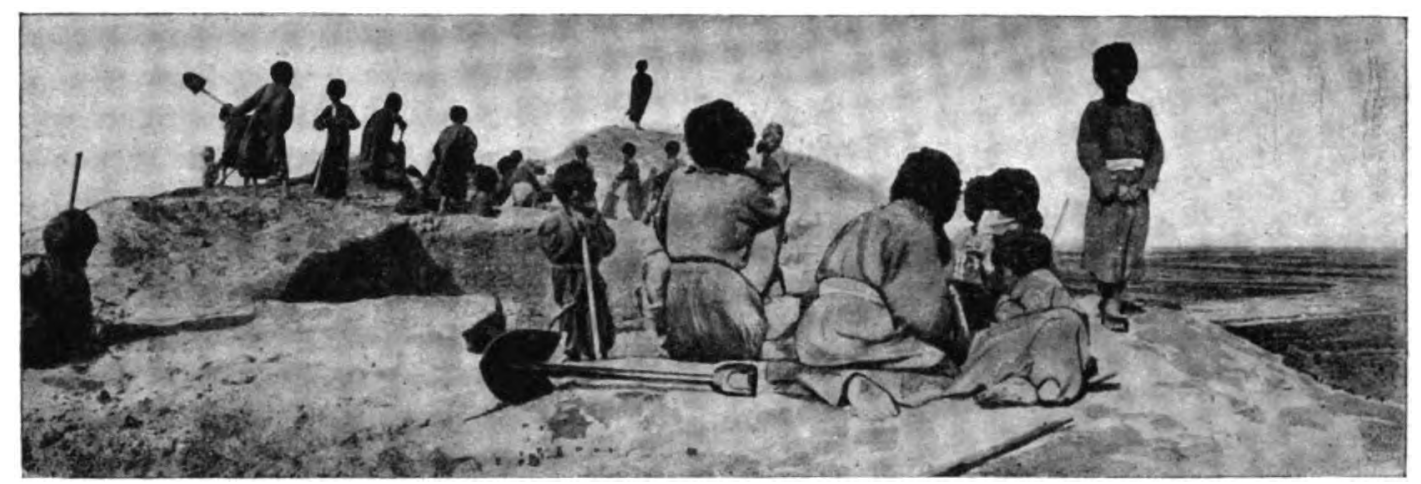

Fig. 2.-Beginning Work at the North Kurgan.

After this, a continued progress towards extreme aridity advanced the desert sea of sands till its dune-waves, rolling ever nearer to the mountain, completely submerged long stretches of the narrowed loess-zone between the now restricted deltas at the mouths of mountain streams. The teeming herds of ruminants and horses disappeared over vast areas, and life was restricted to the mountains and to the borders of the few remaining streams and the deltas.

When this stage had been reached, in early prehistoric time, and long before the introduction of irrigation, the condition of southern Turkestan and northern Persia may be summed up as one of deserts, relieved only by oases in high valleys and on the deltas at the mouths of streams emerging from the mountains, or where larger rivers died out on the plains or entered the shrunken seas. The delta-oases have been the home of man from early prehistoric time till now, throughout Turkestan and northern Persia. On one of these, at Anau near Askhabad, 300 miles east of the Caspian, we made, in 1904, excavations and physiographic studies. 
Digitized by GoOgle 


\section{CHAPTER II.-THE FORMING OF THE OASIS OF ANAU.}

\section{KURGANS.}

Near the middle of the oasis of Anau two hills with rounded contours rise, one 40, the other 50 feet above the plain; they stand one north of the other and half a mile apart. A mile to the east and nearly equidistant from the two hills stand the ruins of the walled city of Anau. These hills are not natural elevations; they are the time-wasted, wind- and water-carved remnants of long-forgotten cities. Together with the neighboring ruined citadel, they represent an almost continuous series of successive cultures whose local beginnings seem to antedate the predynastic remains of Egypt.

The structure of the North Kurgan was well exposed in a trench that had been made in it 20 years or more ago by General Komorof. When I saw it during a brief visit on the journey of reconnaissance in 1903 , its stratified character had been clearly brought to light by the action of the winds on the sides of the trench. The horizontal stratification was especially marked by thin layers of ash and charcoal and burnt earth. Bones of animals and potsherds of hand-made plain and painted ware were visible in all parts of the sides of the trench. There was no doubt in my mind that we had before us the slowly built-up accumulation of the debris of many generations of population. It was this that decided me to begin on this hill the work of excavation in 1904. Our excavations exposed the same stratified structure throughout the South Kurgan.

These hills are town-sites. The inhabitants lived in houses built of air-dried bricks, and the hills are made up of the débris of mud-houses continually wasting under wind and rain, and continually repairing, largely with material brought from without. Remnants of house-walls are present throughout the mass, but being of the same material as the earth-layers they are generally very indistinct, though after a few days' exposure by the spade the outlines of the bricks often become clearly defined. In the trench in the North Kurgan, a continuous layer of redburnt earth, apparently marking a conflagration, extends almost entirely through the hill, while still higher a well-defined horizon is marked by continuous ash-layers and by a change in the density of the earth from more compact below to a somewhat looser and honeycombed structure above. This horizon marks also a change in culture. On the accompanying sketches (plate I) by R. W. Pumpelly only some of the more clearly defined ash-layers and walls are accurately platted, the bases and dimensions of the walls having been carefully measured.

In our excavations the structure described above was everywhere evident. Under Dr. Schmidt's plan and direction the work was done by sinking wide pits. 
The excavation consisted in maintaining a strictly horizontal floor which was sunk I or 2 feet daily. His report shows how the hill was made up of houses, and how, in sinking, house-floors were exposed, one immediately underlying the other, and all marked by hearths and inserted bake-oven pots, and by the skeletons of children, which it was the custom of these people to bury under the dwellings.

In order of age the North Kurgan is the oldest and the ruined city of Anau the youngest. $v$ The North Kurgan had been abandoned before the founding of the South Kurgan, and this in turn before the city was started; and I shall show that there is evidence of several time-gaps of greater or less duration in the sequence of the cultures.

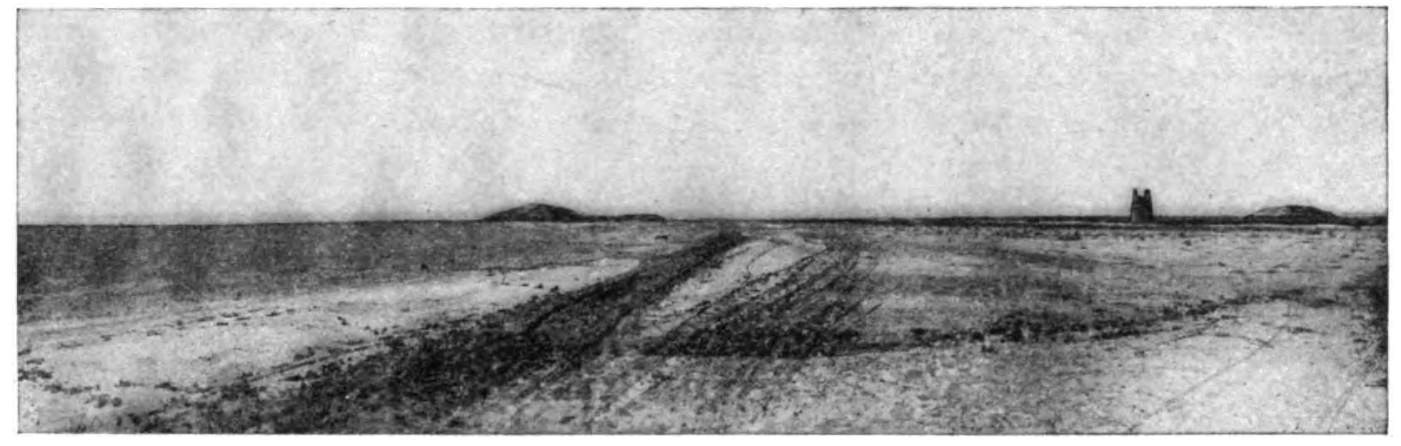

Fig. 3. - The Two Kurgans.

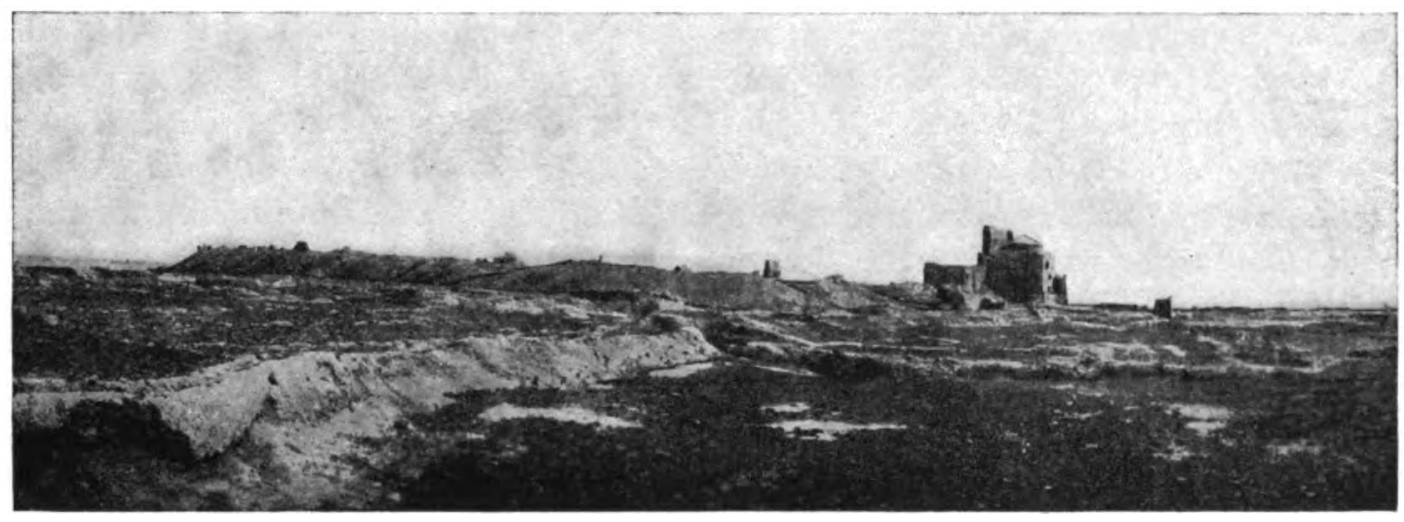

Fig. 4.-Ruined City of Anau.

The city of Anau was abandoned only during the past century. Its gates are gone, its walls have crumbled, and of the houses built of burnt bricks only dilapidated walls are standing. The surface of the interior is irregular, great depressions marking the places where were once extensive pools. These water-basins form one of the charms of the cities of Turkestan, where they are inclosed in paved steps that descend from terraces on which stand widespreading trees and tea-housesthe lounging and gossiping centers of daily life. In Anau only the gaping depressions remain to mark how rapidly desolation may obliterate the traces of busy life. 
. 


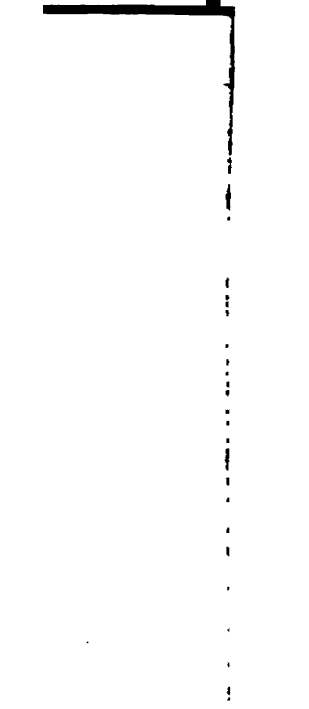

Digitized by GoOgle 
One remnant of departed beauty remains-the ruins of a superb mosque whose lofty façade, fully 70 feet high, is still brilliant with enameled tiles, decorated with richly colored arabesque designs of fifteenth-century Persian artists. We did not excavate this city, but my shafts, sunk to the bottom of its culture-strata, showed that these were based i 5 feet below the level of the surrounding plain. The average surface of the interior of the city is 38 feet above the base; and the floor of the mosque, which stands on the edge of the city, is 29 feet above the base of the culture-strata. The chronological bearing of these data is treated in chapter III.

We have seen how, with the slow trend of climatic change towards aridity life-sustaining areas became gradually restricted to the desert-bound oases. Let

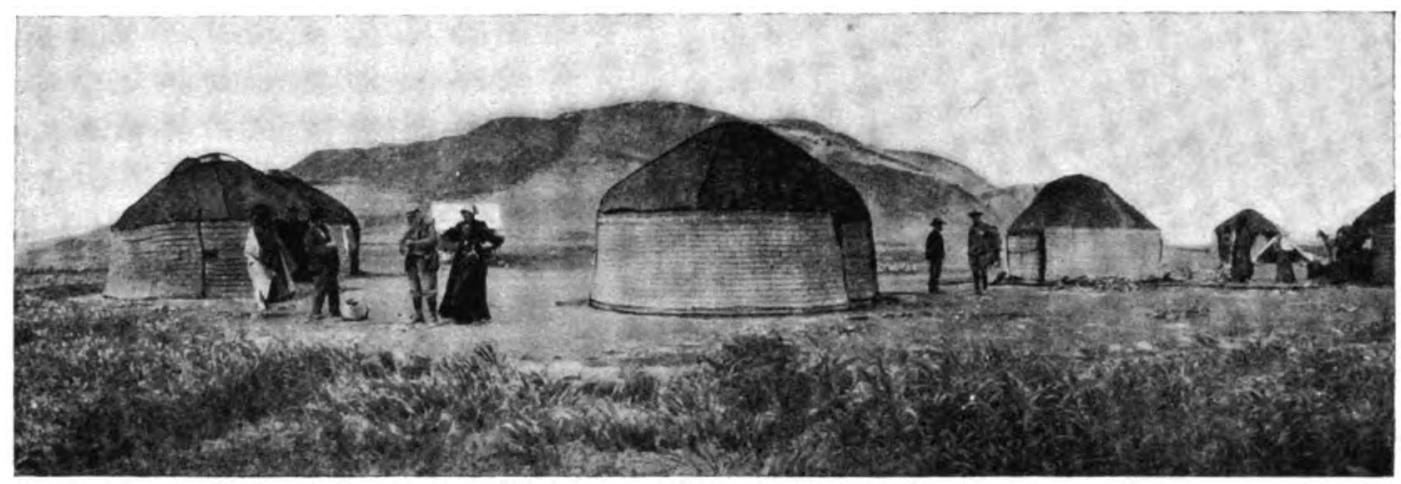

Fig. 5. - The North Kurgan and Camp.

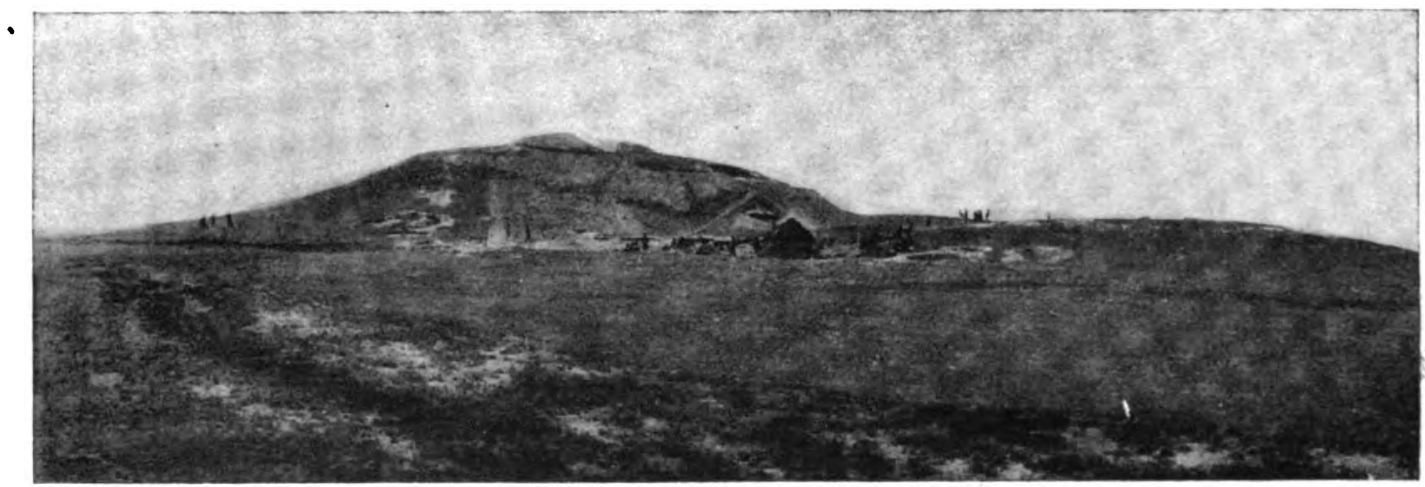

Fig. 6. -The South Kurgan.

us now consider the relations that existed on the oasis of Anau, between its cultures and their environment. In doing this it will be necessary to describe the manner of growth of this delta-oasis, beginning with a description of the methods employed in the study.

During the brief visit made to the northern one of these kurgans in 1903 , the evidently great age of the mound impressed me with a belief that its base would be found to be buried to a greater or less depth in the plain. Our excavations of 1904 proved this to be true. The base of the visible mass of the North Kurgan 
was found to be at 20 feet below the surface of the plain, while a shaft (North Kurgan west shaft I) 200 feet distant disclosed culture-strata down to a depth of 28 feet, belonging to a part that had been overgrown by the rising alluvial growth. Not only was this true of the North Kurgan, but it was found that the much younger South Kurgan also was based 20 feet deep. On the other hand, the base of the younger city of Anau was found to stand only I $_{5}$ feet deep. The fact that two kurgans, between the beginnings of which the time-interval could be reckoned only in thousands of years, had been buried to the same depth, clearly presented a physiographic problem of great interest. It seemed, too, that its solution should aid in correlating the history of the successive cultures of the region with the course of natural events.

I decided, therefore, to attack this problem with shafts, while Dr. Schmidt was directing the purely archeological excavations. From the beginning the shafts

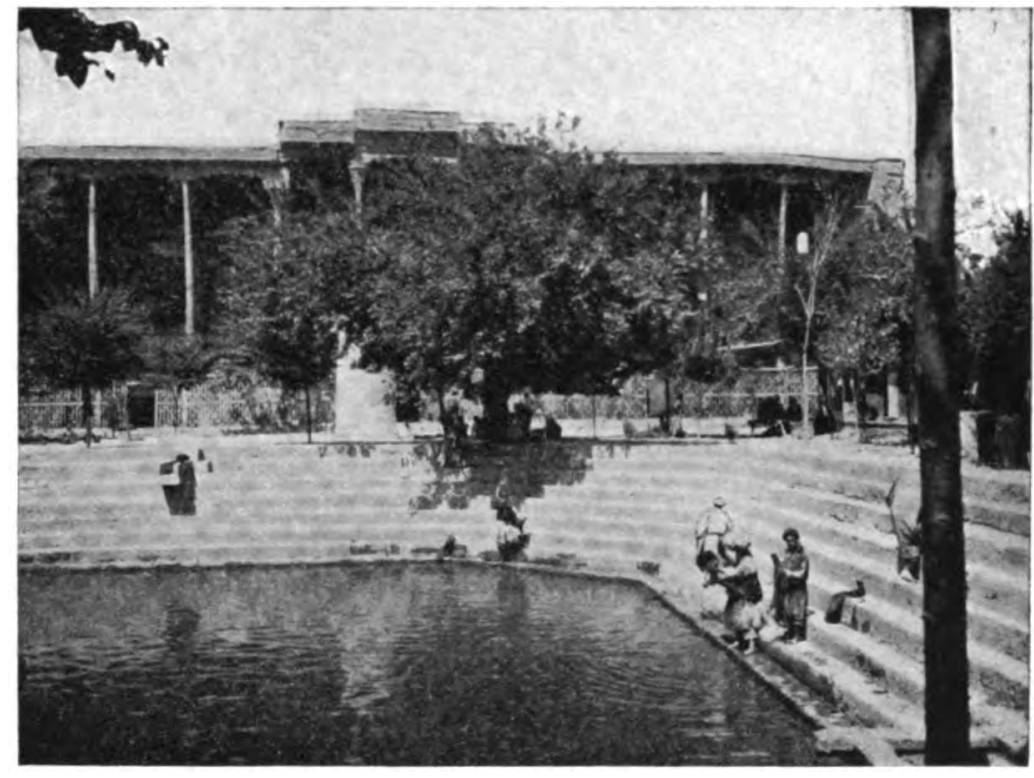

Fig. 7.-A Pool in Bokhara.

showed that the records left by man and those buried by nature ran parallel, and that a study of each was essential to a good understanding of the other. They showed also that much of the physical history of the region, as well as of its human record, could be read only underground. It was found that during the existence of the two kurgans there had been a succession of alluvial growths with intervening degradations, succeeded in the end by a considerable thickness of irrigation silts. There were, therefore, three kinds of growths-natural sediments, irrigation sediments, and culture-strata. It was clearly desirable to obtain some light on the relative rates of these growths, for, having this, if we should be able to determine the rate of either one in years, it could be applied to all, including the culture-strata.

There were sunk 24 shafts. Nine were intended to determine the thickness of the culture-strata and the character of the underlying natural formations. Two 


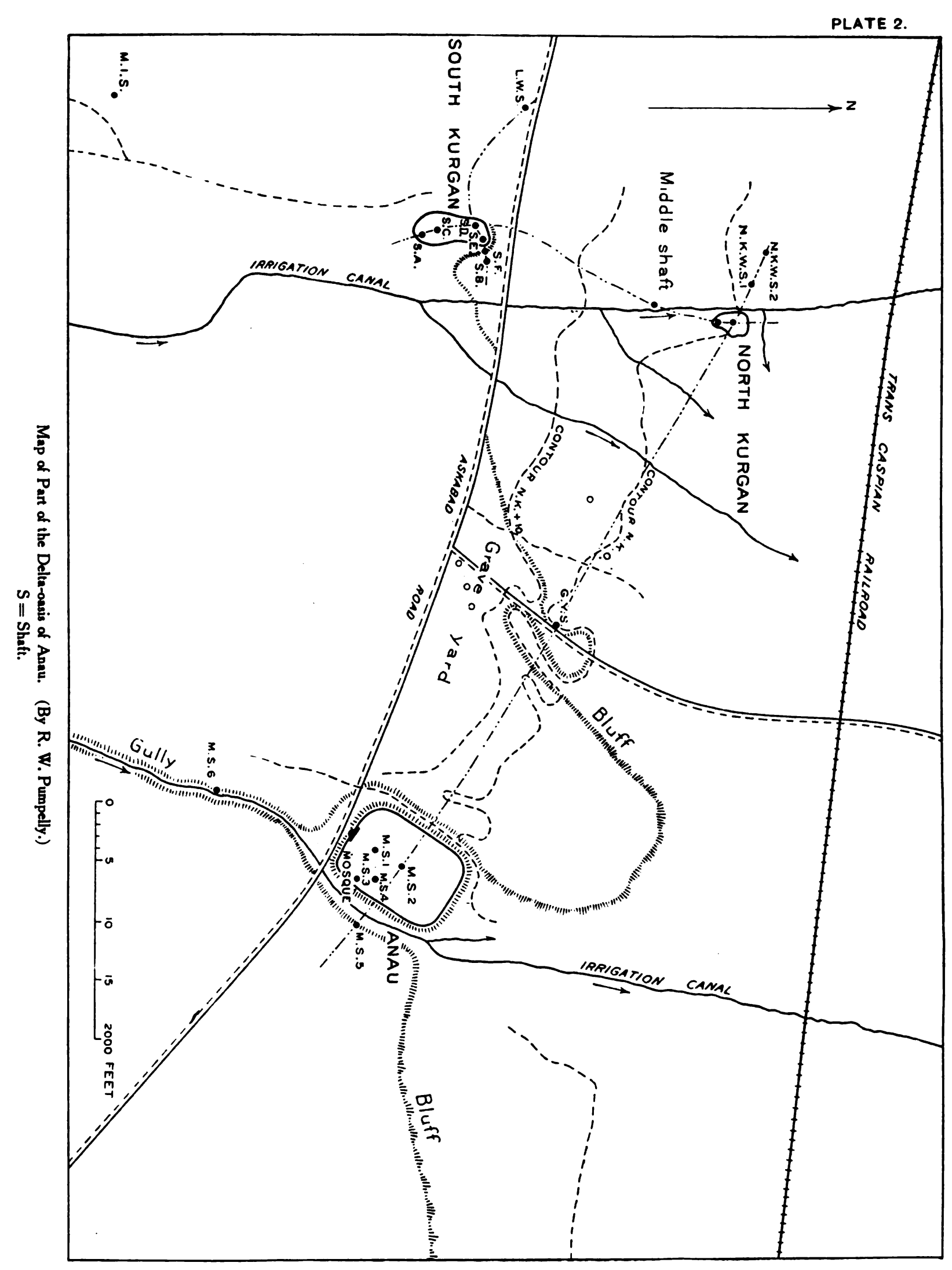


Digitized by GOOgle 
of these were sunk in the North Kurgan, 3 at the South Kurgan, and 4 in the city of Anau. Of the remaining I 5 some were placed to determine the later relations of culture-strata to natural and irrigation sediments, while others pierced the plain at what were thought to be desirable points. R. W. Pumpelly undertook the study of the details of structure shown in these shafts, as he had also assisted in deciding as to where they should be placed, and in his report in this publication is given the full description of his observations. He also treats at length the subject of oases in connection with the general physiography of Turkestan. The information obtained from these shafts is of the greatest interest, and it was a cause of much regret that we were not able to sink more of them. The intense and increasing heat made work very difficult; and added to this was the vast quantity of grasshoppers, which accumulated in the pits so rapidly that they at last forced the abandonment of work.

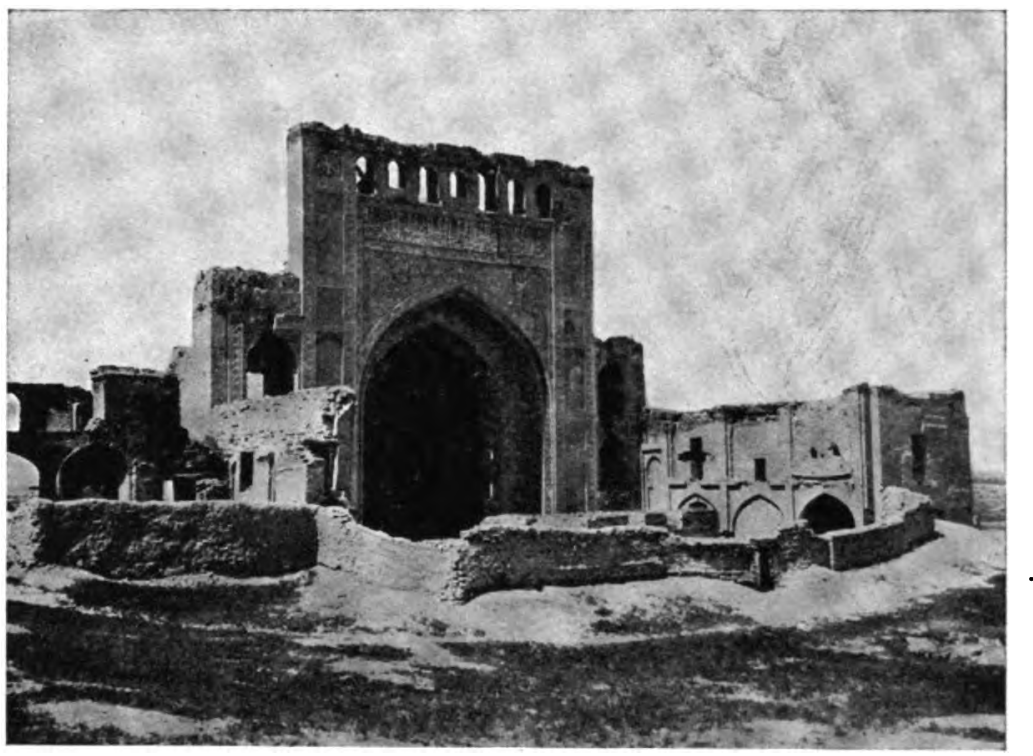

Fig. 8. - The Mosque at Anau.

The shafts sunk within the North Kurgan ("east" and "west galleries," as well as north digging II) penetrated the underlying natural alluvial formation at a depth of 20 feet below the level of the plain. But North Kurgan west shaft I, over 200 feet west of the kurgan, after sinkirg through 7 feet of irrigation sediments, passed through culture in place, with standing walls and pottery of the earliest strata of the kurgan, to the depth of 28 feet below the surface of the plain. It was, therefore, clear that the settlement had started on an eminence raised somewhat above the surrounding country. It was found that the North Kurgan stood on a loesslike formation with interbedded alluvial strata characteristic of the delta structure. The indications were clear that the delta-plain had been dissected before the kurgan settlements were started. At the South Kurgan, shafts A and C, sunk through the culture-strata and into the underlying natural formation, found the base of 
culture at 20 feet below the surface of the plain. In shaft $D$, sunk through the culture-strata on the low northern extension of the kurgan, the base of culture was found also at 20 feet below the surface of the plain, allowance being made for the inclination of the plain in going north. But fragments of pottery and wash, derived from the lower culture-strata, found at 30 feet below the surface in shafts $\mathrm{F}$ and $\mathrm{E}$, prove that this kurgan also was founded on an elevation. Shaft $\mathrm{C}$ disclosed the fact that the main mass of the South Kurgan was, like that of the northern one, founded on loess.

The first important results of the underground studies came from shafts sunk at and near the South Kurgan, and shown on plates 2 and 3. We were fortunate in finding in these the data for calculating the relative rates of growth of the sediments in aggrading the delta on the one hand, and of the culture-strata on the other. A low plateau extends out from the main and high part of the kurgan. Now while

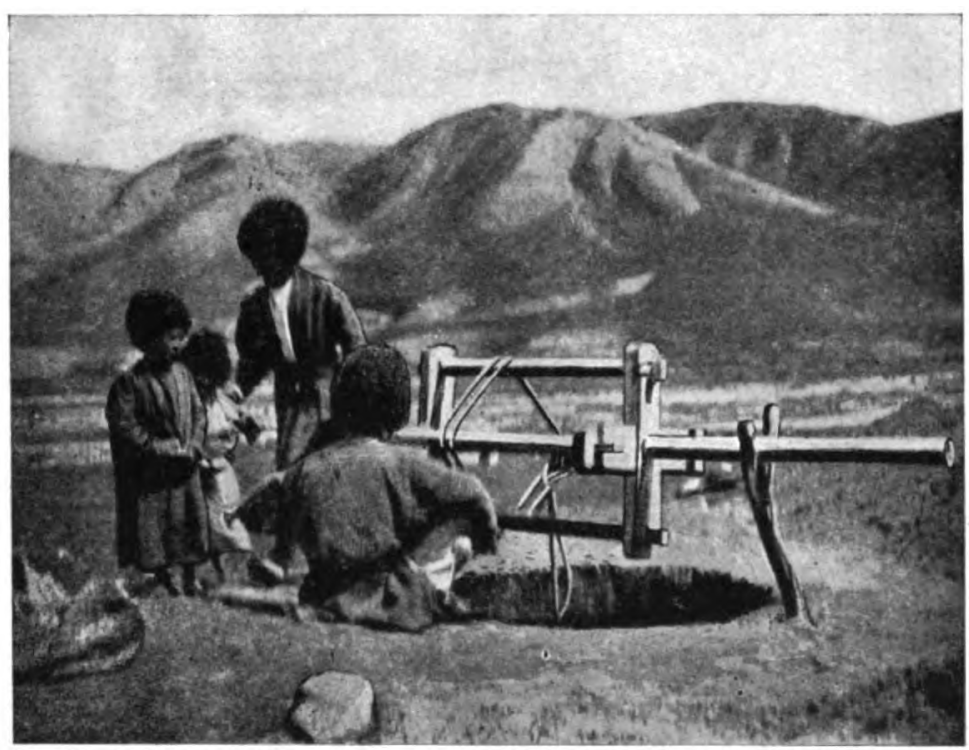

Fig. 9.-A Persian Windlass.

shaft $\mathrm{C}$, sunk to the bottom through the heart of the high part, is wholly in culturestrata, shaft $\mathrm{D}$ in the projecting plateau, after sinking through culture-strata, enters natural sediments, below which it passes again through culture-strata till it finds the base of culture at the same level as under the main body of the kurgan in shaft C. As we recognize geological horizons by their characteristic fossils, so here we recognize the cultures to which these strata belong by their characteristic pottery in which they abound. We find interbedded in the natural sediments in shafts $\mathrm{E}$ and $\mathrm{F}$ a layer of wash, $\mathrm{W}$, which contains pieces of the lower culture that was cut in shaft $D$. After the depositions of this pottery the natural sediments grew 19 feet in height, submerging the settlement and rising to the level at which it is covered by culture-strata in shaft $D$, which is 16 feet below the beginning of the pure iron culture (culture IV). Now the evidence in shaft $\mathrm{C}$ is that the main body of the kurgan grew uninterruptedly from its base 52 feet, 
to reach there the level 16 feet below pure iron culture. If we assume that these 19 feet of sediments began to grow contemporaneously with the founding of the kurgan, the relative rates of growth would be $52: 19=1: 2.733$. It is possible, however, that the whole thickness of the 7 feet of submerged culture-strata contributed to the layer of "wash" with pottery in shafts E and F; therefore, if we subtract these lowest 7 feet of culture-strata, shown in shaft D, from the $5^{2}$ feet in the main body of the kurgan, we have the rates: $45: 19=1: 2.368$, say 2.37. But, everything considered, it would 'seem proper to take I to $2.5, i$. e., I of natural

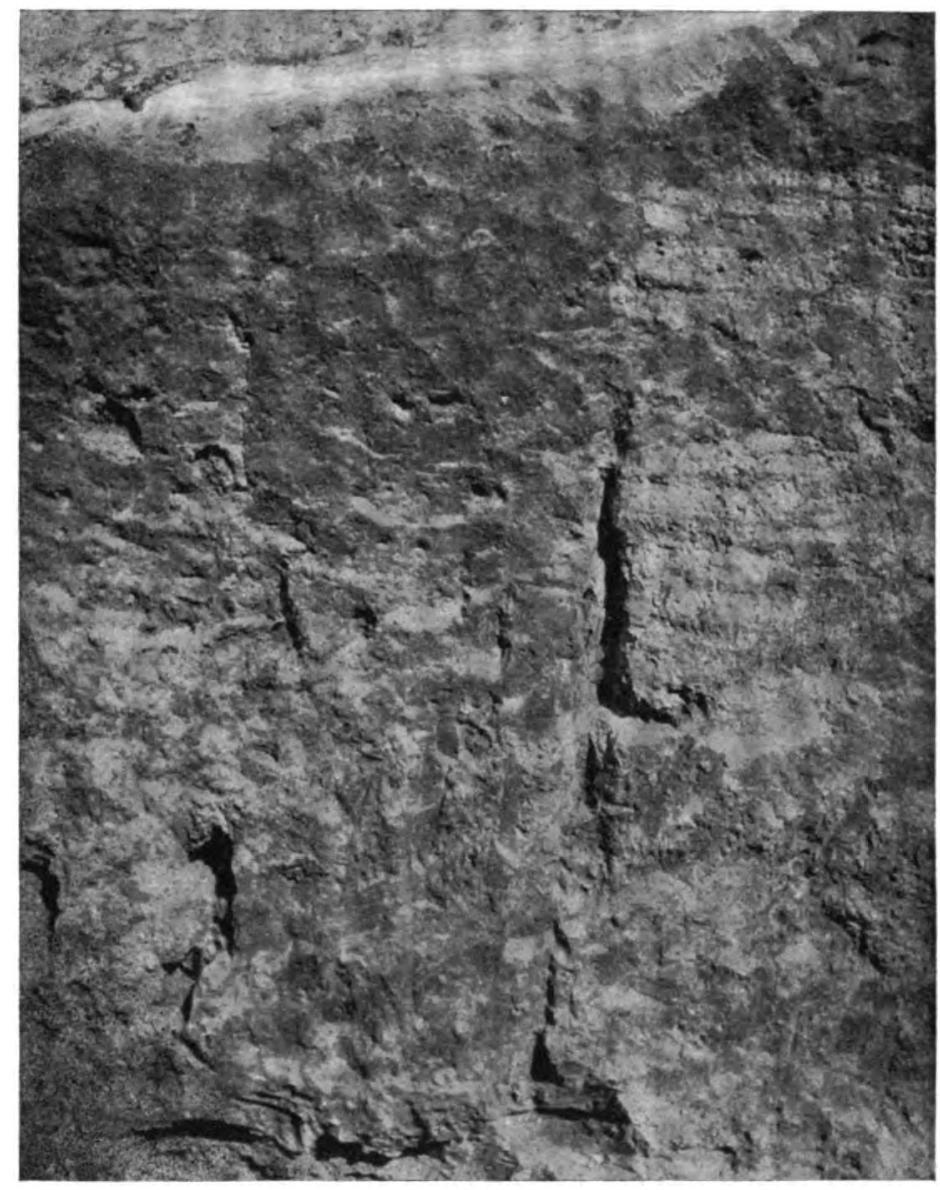

Fig. 10.--Section of a Wall in the North Kurgan.

sediments to 2.5 of culture-strata, as the relative rates of growth in connection with the closely compacted culture-strata of the three older periods. This ratio being obtained from the parallel accumulations of a considerable period of time has, as we shall see later, for our purpose both an archeological and a geological value.

After the sediments had reached the height shown in shaft $D$, there came a change, and this part of the plain was dissected, for a little farther eastward, in shaft $B$, we find a new series of sediments marking a renewed aggrading. Now when this new growth had reached the level indicated on the section by an arrow in shaft $B$, it received fragments of the pottery peculiarly characteristic of the 
uppermost or pure iron culture of the kurgan, i.e., of that part of culture IV which begins 8 feet above the top of culture III, for under IV is classed an interval of 8 feet of débris of wastage during which little or no culture seems to have existed; and from this level it continued to grow upward a further 7 feet, after which irrigation was introduced. Now we have archeological and stratigraphical evidence that the introduction of the artificial irrigation which produced these sediments was about contemporaneous with the founding of the city of Anau and the abandonment of the South Kurgan.

Our ratio, I to 2.5 , is equivalent to a growth of 17.5 feet of culture-strata between the time of deposition of the iron-culture pottery in shaft $B$ and the

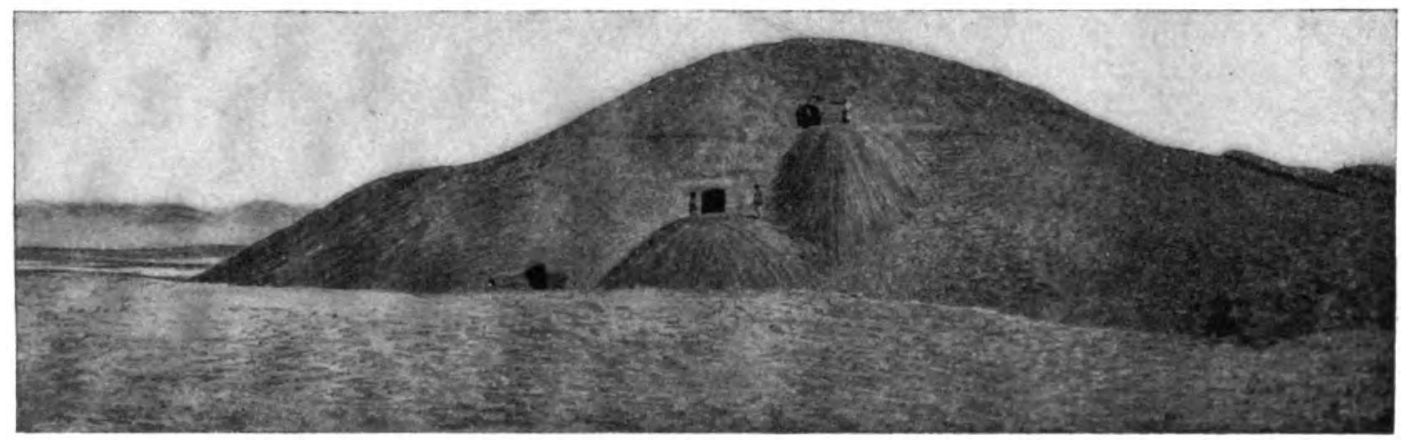

Fig. 11.-Tweive Centuries of Deformation on Citadel of Chiaur Kala, Merv.

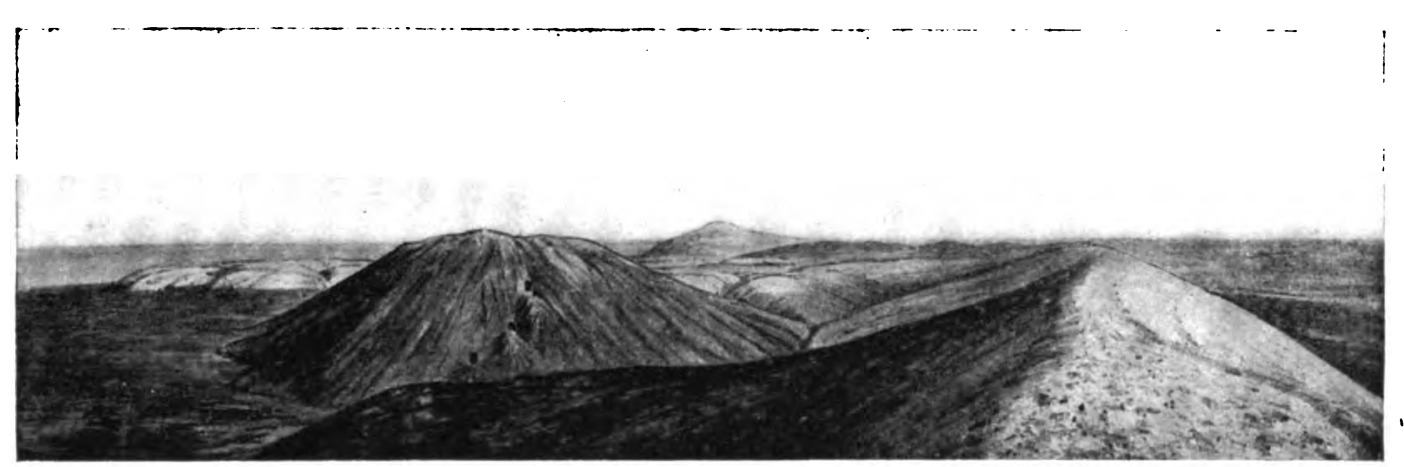

Fig. 12.-Deformation of the Walls of Ghiaur Kala during about Twelve Centuries.

apparently contemporaneous ending of the life of this culture and beginning of irrigation, while there are only 4 feet of iron culture now standing on the top of the kurgan. The great deformation that this hill has suffered is evidence that it has lost a considerable amount of its original height, and it is likely that the difference between the 17.5 feet of iron culture required by our ratio, and the 4 feet now standing, is a minimum measure of that wastage. I have, therefore, in the column of cultures, added this 13.5 feet to the present thickness of culturestrata of the South Kurgan.

Let us turn now to the record of the shafts near the North Kurgan. We have seen that while the main mass of the kurgan is based at a depth of 20 feet 


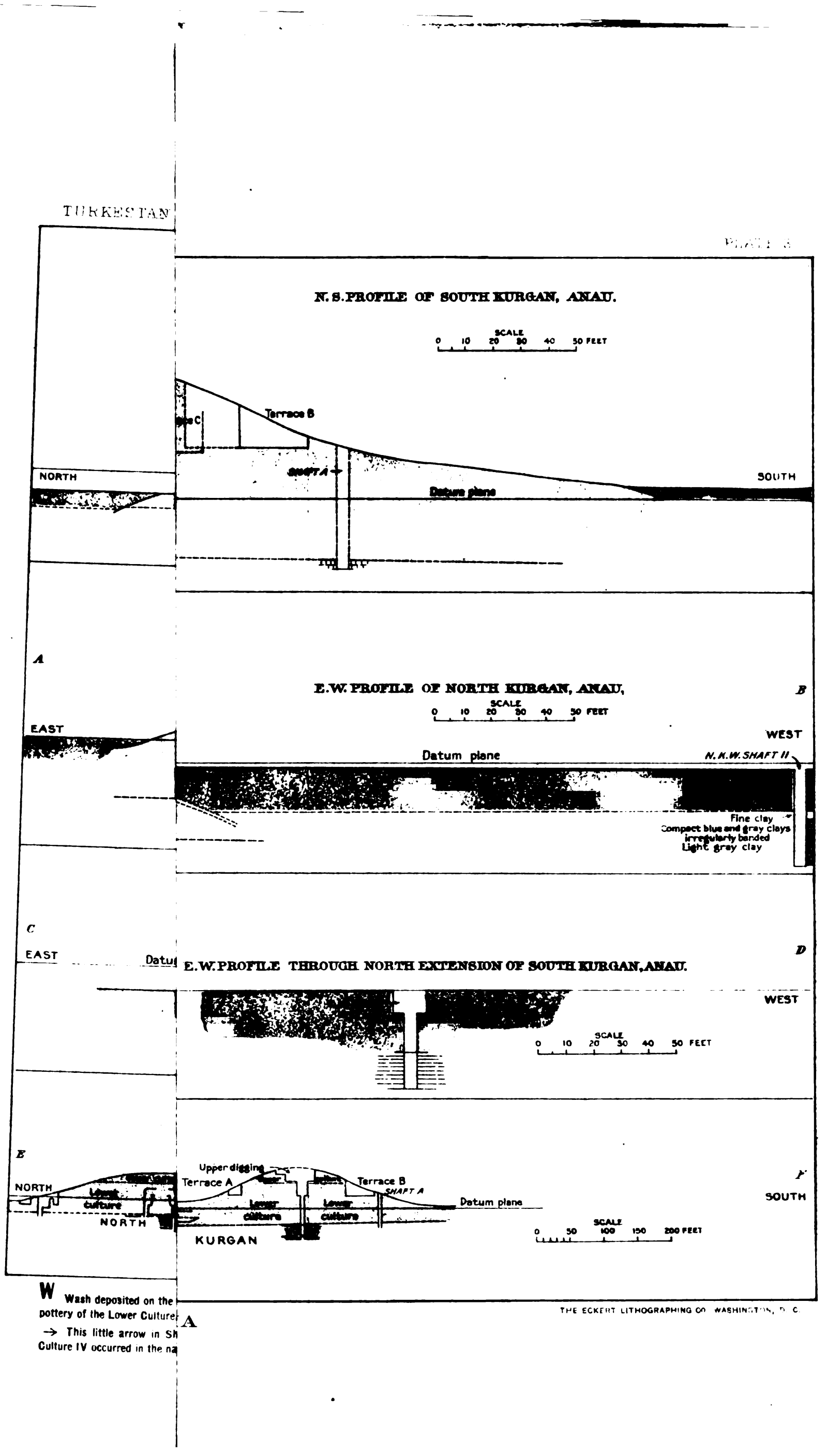



below the present surface of the plain, its western extension, which is overgrown and hidden by the alluvial strata and irrigation silts, extends to a depth of at least 27 feet, where its culture-strata contain the pottery that belongs only in the lower culture. North Kurgan west shaft II, after sinking through 15 feet of irrigation silts, was continued to -30 feet* through alluvial strata. Down to -22 feet these contained fragments of the pottery peculiarly characteristic of the upper culture II, $i$. e., of the strata above the level of 45 feet above the base of the main mass of the kurgan; while from -25 to -27 feet there was found only the pottery of the lower culture. The conditions under which the pottery was found at -19 feet were such as would seem to exclude the possibility of its having been washed into place. The pieces were sharply angular and they were found by R. W. Pumpelly to be associated with bones and charcoal-conditions indicating contemporaneity of age for the pottery, bones, charcoal, and alluvial clay.

Now we have seen that in shaft F, at the South Kurgan, pottery of the lower culture of that kurgan was found in alluvial strata at 26 feet below the level of the plain, i. e., 7 feet deeper under the surface than the level at which the upperculture pottery of the North Kurgan was found in the shaft near the North Kurgan. Therefore, the whole of the growth from -26 feet upward occurred after the founding of the South Kurgan. Assuming that the pottery, bones, and charcoal were left by man on the plain when it stood -19 to -20 feet at the North Kurgan, we have evidence that the alluvial growth in shaft $F$ of the South Kurgan is a younger growth than that in the west shaft il of the North Kurgan, for artefacts of the younger South Kurgan could not become naturally buried at a deeper horizon than those of the older kurgan in alluvial strata of the same growth. On this evidence the alluvial strata, which are shown in shafts $\mathrm{D}, \mathrm{E}$, and $\mathrm{F}$ to have overgrown the older settlement on the extension of the South Kurgan, must belong to a younger growth than that of the strata in North Kurgan west shaft II, and degradation must have intervened between the two. We have not found either pottery or charcoal in any of our shafts at a greater depth than 27 feet below the surface. And these traces of man's occupation of the region were so abundantly scattered over the contemporary surface that we find them in all shafts at various depths down to 27 feet. We have, therefore, evidence of three separate growths of alluvial strata between the founding of the North Kurgan and the beginning of irrigation, and of two intervening degradations.

While these growths and degradations doubtless affected the whole surface of the oasis to a certain extent, the full extent of their action was apparently limited to the principal channel or channels through which the water found its way from the mountains to the desert. This is still faintly shown by careful observation in the topography of the present surface, and it is recorded also in the character of the sediments pierced by our shafts. The "irrigation canal," a small distributing ditch, shown on plate 2 as passing by the east side of the South Kurgan and to the west of the North Kurgan, follows a broad but only

* The surface of the plain is the datum. 
faintly depressed trough. This probably marks the course of the valley in which ran the river, on the eastern bank of which the settlement at the North Kurgan was started, and on the west side of which the South Kurgan was founded at a very much later date.

One of the essential incidents of growth in all these oasis-deltas is the more rapid growth of the banks of the stream than of the general surface; for the stream, when in flood, is loaded with silt, the greater part of which is deposited as soon as the velocity is diminished in spreading over the banks on to the plains. On the steepest grades, on "fans" formed where mountain gorges debouch on to steep declivities, the torrent in depositing its load of large and small boulders builds up on each side a high and narrow dike, and maintains only a narrow channel between these. But on the gentle grades of an oasis surface and where the silts are less differentiated in size of grain, the resulting relative increase of height near the stream is only slightly marked. When in the course of time the valley of the stream is filled up by alluvial deposits during the process of "aggrading," these embankments it has formed no longer contain it and the waters seek a new course over the lower surface outside. Such would appear to have been the cause of the abandonment of the South Kurgan and of the founding of the now ruined city of Anau, a mile away to the east, on what is now the chief watercourse of the delta.

NorE.-It is, in fact, because of this shifting from side to side, this bursting of the natural embankments of a delta's distributary channels, and of the shifting of the axes of maximum growth, that deltas and fans everywhere present such an aspect of symmetry, and it may be said that no great area of alluvial plains, such as the steppes of Central Asia, ever obtained without a wonderful transmigration of rivers and streams and revolutional changes in hydrography, such as must often have been sudden and catastrophic to man, especially to the sedentary population.

There can be little doubt that the above law, so universal to alluvial growth, had an important effect upon the history of Anau. The earlier generations of the North Kurgan had no difficulty in keeping their water-supply at hand, for the Anau-Su then flowed by in a well-defined channel incised in the plain, but when the flood-plain of this channel had aggraded to - 20 feet, as shown in North Kurgan shaft 1 , the stream could have had little or no natural obligation to flow by the North Kurgan. But though the inhabitants may have had to exercise their ingenuity, it could not have been for long, because -20 feet is the ultimate height to which filling attained here at this period, and marks the beginning of cutting-down, and a long period during which the stream again flowed in a well-defined channel by the North Kurgan. The South Kurgan was founded on the other side of this same channel, and as with the first kurgan, its earlier generations had no doubt but that their water would flow to them forever, of its own accord, but in the course of about a thousand years after the beginning of this kurgan, the flood-plain had again aggraded, to fill the little valley, and this time surely overflowed the neighboring lands in flood time. From this time on for about I,500 years, this embarrassing state of affairs continued, while the neighborhood of the stream aggraded till the basal layers of the South Kurgan were buried to a depth of 12 feet in natural sediments, when at about 2600 B. C. the stream began to cut down again. We must credit these primitive people with no little amount of ability, for they succeeded in forcing the stream to flow by their town during a period of 1,500 years; and it must have been a much more vigorous flow than at present, and would naturally have deflected from side to side in order to maintain an even surface to the fan. 
It is only after understanding these facts that we have been able to explain the reason why the regions only a quarter of a mile to the east and west of the axis of this channel and its growth were depressions to a depth of about 15 feet when the next cutting-down began. These depressions afterwards afforded excellent areas for irrigation and became filled with irrigating sediments, so that they are no longer evidenced on the surface. However much difficulty there may have been in preventing their stream from permanently bursting out to either of these depressions, the people of the South Kurgan had no more difficulty after it had begun to reexcavate the little valley, so that although the kurgan was soon afterwards abandoned and left unoccupied during the "period not represented by culture-strata," the stream continued there in loneliness unused until the reoccupation of the town by the people of the iron culture, who found it refilling the valley with sediments. When the founders of Anau City arrived, the valley was only 8 feet deep at the South Kurgan and must have been even shallower at the apex of the fan, so that there was no difficulty in deflecting the stream to the new city.-R. W. P.

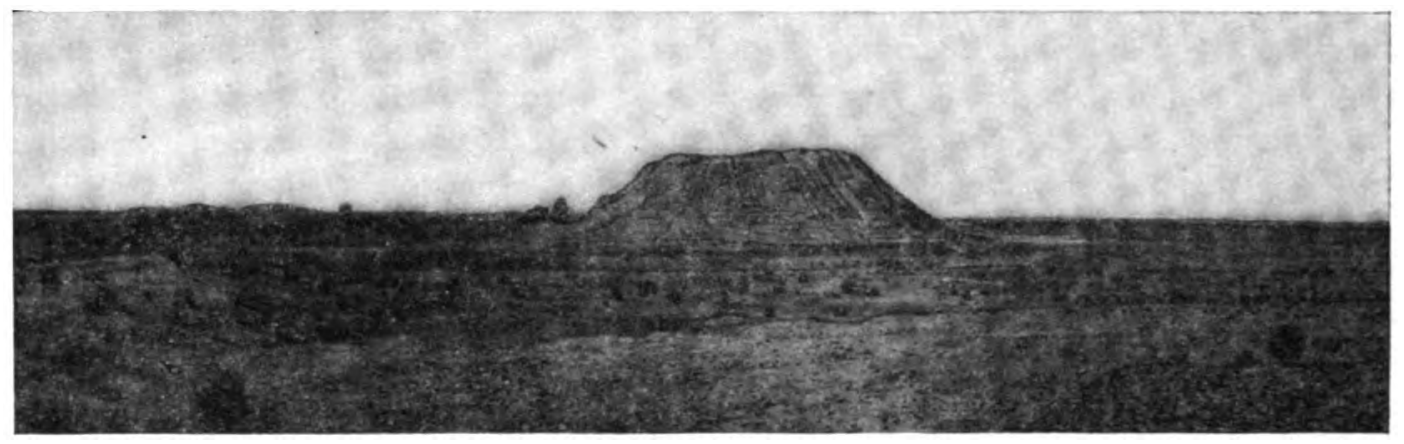

Fig. 13.-Odontche Tepe, 80 feet high, on Merv Oasis.

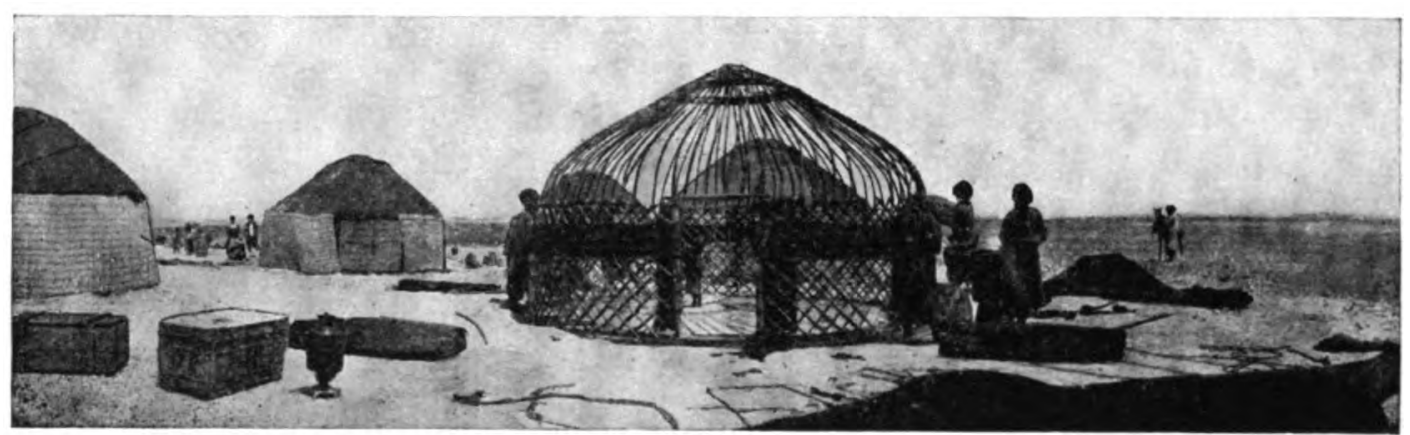

Fig. 14. - Erecting a Kibitka.

This occurred at about the time that the alluvial growth reached its maximum height as shown in shaft $B$, for this growth stopped at the beginning of irrigation, and irrigation began at about the time of the founding of Anan. It is, indeed, not unlikely that a similar diversion of the stream caused the abandonment of the North Kurgan and the subsequent choice of the site of the South Kurgan.

The fact that a settlement had attained to a height of 50 or 60 feet above the plain would perhaps seem to us a reason for choosing a new site, but such does not appear to have been a motive in Central Asia. Height was apparently much 
appreciated, for we find hills of pure culture growth 80 feet high which have been occupied till within a thousand years. The reason for this preference may have been partly the strategic advantage offered, but it is doubtless also to be sought in the very marked relief, found at even a slight elevation, from the burning summer atmosphere of the plain, as stated by Mr. Huntington in his report on the distribution of kurgans on the oasis of Merv.

Let us now consider the agencies that have been active in these processes of cutting-down and rebuilding. They form one of the most interesting illustrations of the law of compensation in the grand cyclical action of forces that have modeled the relief of the surface of our planet.

A great mountain range, the Kopet Dagh, several hundred miles long, forms the sharply defined southern edge of the desert plains of Western Central Asia. It rises everywhere abruptly from this plain to a height of from 5,000 to 10,000 feet; and its height is sufficiently great to cause it to receive abundant precipitation and a heavy covering of winter snows. Within this mountain system the trunk valleys, after following a longitudinal course, turn sharply and, after cutting through the border range and piedmont hills, discharge their waters onto the

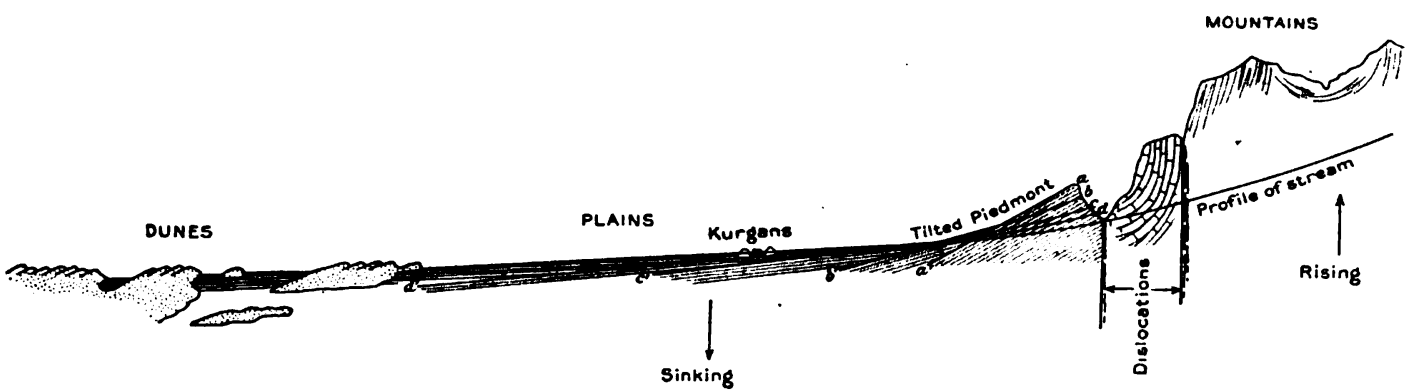

Fig. 15.-Ideal Section of a Delta.oasis on an Uptilting Piedmont. (By R. W. Pumpelly.)

plains. The mountain masses, lacking the protection of a heavy forest growth, are subjected to rapid disintegration and decay, and the resulting detritus is carried by the torrential rivers down to the plains.

In a coastal region these waters would flow onward to the ocean, and the silts they had brought from the mountains would ultimately complete the same course, to be deposited at the mouth of the river, to form there a submarine delta. But in an arid "central" region, such as is Turkestan, the conditions are different. The precipitation is confined to the mountains, and on leaving these the rivers enter a desert region of rapid evaporation, where there is no compensating rainfall. The valley ends at the mouth of the mountain gorge. Thus all the coarse and fine materials brought by the torrential rivers from far and near in the mountains, as well as those carried down by smaller streams from the declivities bordering the lowland, and from the piedmont hills, are deposited within a zone along the edge of the plain at the base of the Kopet range. The rock-mass of the mountains is, therefore, being continually removed and loaded onto this long zone.

Now, two connected phenomena are observed to result from this process. On the one hand, the zone of deposition is continually and proportionately sinking 
under the increasing load; and on the other hand the mountains are continually rising to maintain their height. The strain established in the rigid crust, between the sinking zone of deposition and the rising mountain range, finds relief in the development of fractures along the range, as well as others which permit a differential uplifting of great block-masses-a fact which had before us been observed by Muschketof. The evidence of this compensatory maintenance of hydrostatic equilibrium is strikingly recorded both in the Kopet range and in the zone of deposition. All along the range the lines of fracturing are visible on a large scale in well-developed faultings; and the border of the alluvial plain is bent sharply upward, having been dragged up by the rising mountains. Deep longitudinal valleys are carved by erosion along the lines of weakness offered by these faultplanes. On the mountainward side of the valley rise the older rocks of the range, while on the other is a steep wall, formed often by the basset edges of beds of conglomerate which are the up-bent representatives near the mountains of the alluvial strata of the plains. On the other hand, the sinking of the zone of deposition is proved in the deep artesian well southeast of Askhabad. This boring remained to a depth of 2,195 feet in a pure delta-formation and was still in this when boring was stopped. The plain at Askhabad is 820 feet above the Caspian; the bottom of this trough is, therefore, more than 1,400 feet below the level of the ocean.

Two factors were necessary to the growth of the deltas-precipitation in the mountain region to supply the water to bring down the products of disintegration, and a rising movement of the highland to maintain a grade necessary for the transportation of these products by water.

The delta is broadly divided into three zones of deposition-that of quickly dropped coarse detritus at the apex; the main body of the delta, the rapidly descending broad surface of which receives sediments from the overflow during the floods; and the outer, more or less flat, border, which receives both the finest material and all of the materials that are carried or rolled down through the channel or channels through which the water that does not overflow the delta finds its way, to be lost beyond on the bordering plain.

This bordering zone belongs not only to the delta but to the desert as well; and it is here that is waged the eternal struggle between the desert with its breath of fire and its overwhelming sea of sand on the one hand, and the life-bringing waters on the other. The sands from the desert encircle the whole delta with a wall of great wave-like dunes. That they do not bury it when they are not themselves arrested by sparse grass on their surface is due wholly to the ability of the waters to prevent the formation of barkhans and dunes on its surface; for the water, spreading in flood-time over the even surface of the fan, distributes and assimilates annually a great part of the sand that lies in ripples on the surface; while another part, finding no irregularities to form the starting points of dunes, is blown to join the sandhills on the opposite side.

The delta streans maintain channels through the dunes bordering the foot of the delta; and through this the excess waters of the floods find their way to spread out among dune-locked depressions, where on evaporating they leave their 
clay sediment to form the takyrs (adobe flats). The area occupied by the deltaoasis, or living delta, is proportional to the amount of water available for keeping the dunes in check. It is evident that during a continued decrease in the annual supply of water the delta will die at its borders and the dunes advance, diminishing the area of the oasis. After that, only a long-continued increase in water-supply could recover for the oasis its lost area by burying the bordering dunes in takyr and thus extending the foot of the living delta.

The continued process of aggrading on the three zones of the delta is, therefore, of a very complex nature and dependent on varying factors; at the apex, there remains the greater part of the coarsest material-boulders, cobble, gravel, and coarse sand; the middle zone receives in overflow much of the finer silts; while the rest of the finest silts accumulate on the lowest slopes as far as the dune-barrier; and here, too, as well as beyond in the dune-locked depressions, are deposited the coarse and fine sediments rolled along its bottom or carried in suspension by the stream.

These are the contribution from the mountains. Parallel with this is the contribution from the desert on the north. As we have seen, a part of the sand from the desert is distributed and assimilated by the living delta. Besides this the desert whirlwinds come laden with fine dust, and where this falls on the delta it remains caught in the vegetation, and it, too, enters as a loess-constituent into the delta structure. It is, therefore, clear that the zone of deposition and depression along the base of the mountains is being continually loaded, not only with the products of current destruction of the neighboring mountain masses, but also with materials brought from the desert. And while much of this came originally from the mountains near at hand, much must also have originated in the distant highlands of Afghanistan and the Pamirs.* Thus it is probable that the load on part of the zone of depression may be greater than that removed from the neighboring mountain masses.

We may extend this analysis still further, to a picture of the internal constitution and structure of the zone of depression as a whole. Ever since Central Asia became a "central region," without efflux of its waters to the ocean, it has necessarily been an area of desert wastes with a climate the aridity of which was tempered probably only during periods of glacial expansion. Of equally long duration has been the activity of the processes I have outlined. Deltas have continually grown up at the mouths of streams emerging from the mountains, and where the streams were separated by short intervals their deltas merged together; where the intervals were greater the sands, as they were stopped in their onward course by the mountain barrier, piled up in hills which rose high above the intervening living deltas.

* The Tejend and Murg-ab are rivers of considerable size, which rise in Afghanistan and have sufficient volume and grade to maintain their course farther out onto the desert before spreading out to be lost in evaporation. It is probable that, during a not very remote period of greater precipitation, the Oxus, instead of emptying into the Aral Sea, followed a southerly route to the Caspian, along the so-called Ungus, midway between the Kopet range and the Aral Sea. The Oxus would then have received the waters of the Tejend and Murg-ab with their silts, and its flood-plains would have contributed to the loading of the zone of depression along the base of the Kopet Dagh. 
Since the position of the mountain streams and the activity of the agencies described have been, generally speaking, constant, it follows, as shown by $\mathrm{R}$. W. Pumpelly in his report, that the conditions now visible on the surface of the zone of depression continue in a general way in depth. Therefore, a longitudinal section in the axial plane of the trough of depression should show the delta structure extending downward to the extreme depth, while the whole of the intervals would appear occupied by wind-borne materials from the desert and from the floodplains, mixed with detritus brought by cloudbursts from the declivities. While the building-up process was constant, orogenic and climatic changes would be recorded by dovetailings of sand and delta interbeddings where the two kinds of columns meet. And periods of adequate local precipitation would probably be marked by beds of sandy loess that had formed over the dune-sands. A similar set of conditions should appear in the downward extension of the foot of the delta in the relation between takyr strata and dune-sand. Indeed, this condition was observed by R. W. Pumpelly in a shaft at Bal Kuwi on the desert, a few miles north of Anau.

We have seen that the essential factors in the process of delta-building are precipitation to facilitate movement of detritus, and mountain-rising to maintain the grade needed for transportation through and beyond the highlands. Of these factors we may, I think, take the rising of the mountains to average a constancy adequate to the maintenance of a relatively constant grade. On the other hand, we shall probably be right, in deahing with considerable periods of time, if we assume that precipitation is a factor of more varying intensity. It is evident that, other things remaining equal, the amount of detritus brought from the mountains will be proportionate to the amount of precipitation to supply the volume of water needed to move it. After this detritus emerges from the mountains, the manner in which it builds up the delta depends largely on the relation between the secularly maintained volume of water and the established grade. The tilting of the edge of the plain favors erosive action and deepening of the channels of watercourses across the deltas. Such a channel having been established across a delta, all the material that is not dropped on account of its coarseness at the apex near the mountain is carried onward. Where the floods can overflow the banks, they deposit silts on the general surface. But the greater part of the detritus carried goes to the gently inclined and dune-barred foot-plain of the delta, where it spreads out, forming an alluvial plain around the lower slope of the fan. We may call the upper edge of this aggrading plain the grade-contour line or alluvial shore. The mouth of the valley will always be at this shore-line and move with it upstream or downstream.

If there were no differential movement and the plains did not yield and sink under the accumulating load, the rising surface of the plain would extend into the mountains, and the valleys would gradually become filled with the sediments. On the other hand, if the zone of deposition sank gradually throughout its width, the valley would always end at the mouth of the mountain gorge. But the slower sinking of the border is shown in the up-tilted strata of old delta sediments along 
the piedmont border, through which the stream has maintained its valley. It is therefore evident that the plains have been sinking relatively to the dissected piedmont on the border. Now, the position of the valley mouth and of the alluvial shore-line on the delta is dependent on two factors-the rate of sinking on the one hand, and the rate of aggrading, that is, the rate of accumulation of silts, on the other hand.

It is also evident that as long as the rate of aggradation exceeds the rate of sinking, the alluvial shore-line will move towards the apex of the delta, carrying the valley mouth with it, and will tend to bury the dissected border; and that when the rate of aggrading falls short of the rate of sinking of the plains, the dissected border will tend to widen; that is, the piedmont valley will be prolonged outward, as the alluvial shore-line retreats to the foot-plain of the delta or to the dune-locked basins beyond.

It so happens that the Anau kurgans, standing as they do on the side of a valley that has been repeatedly aggraded and dissected, were critically situated in their relation to the zone of sinking on the one hand, and to the dissected piedmont on the other. Thus, the area occupied by the kurgans belongs potentially to the zone of marginal deformation on the one hand, and to the zone of sinking and of secularly maintained alluviation on the other hand.

Let us now apply these principles to an interpretation of the facts observed in the shafts at Anau and their bearing on the history of the successive ancient settlements. Obviously the valley on which the North Kurgan was founded was cut down when the zone of depression was sinking at a faster rate than the rate of alluviation. Conversely, the refilling of this valley is indicative of a period during which the surface of secular alluviation rose more rapidly by aggradation than the rate at which the accumulating strata beneath were sinking. In a later chapter, in treating of the cyclical character of these aggradings and dissectings of the valley and their relation to the changes of cultures, $\mathrm{I}$ have given reasons for assigning them to climatic changes causing secular fluctuations in the precipitation over the mountains of the highlands. In future we shall reason on the hypothesis that each cutting-down of the valleys represents a period of abnormally low precipitation, while the refilling represents a reversion to greater precipitation with more rapid alluviation.

The information that was obtained in the shafts is brought together on plate 4 , in which the essential facts are represented correctly in the vertical scale, while the positions of the valley walls are necessarily idealized. During a dry period preceding the founding of the North Kurgan, a valley had been cut in the deltaplain, the surface of which dated from loess-forming time. Then came a period of increased precipitation, during which the valley was refilling, throughout the life of the oldest culture and into that of the second. During part of the second culture-the latter part of the life of the North Kurgan-there occurred a dry period, during which the valley was reexcavated. When under renewed precipitation it began to refill again, the South Kurgan was started on the west side of the valley on the original loess-plain. This growth of sediments continued till it rose higher than the previous aggrading, overflowing not only the terrace 


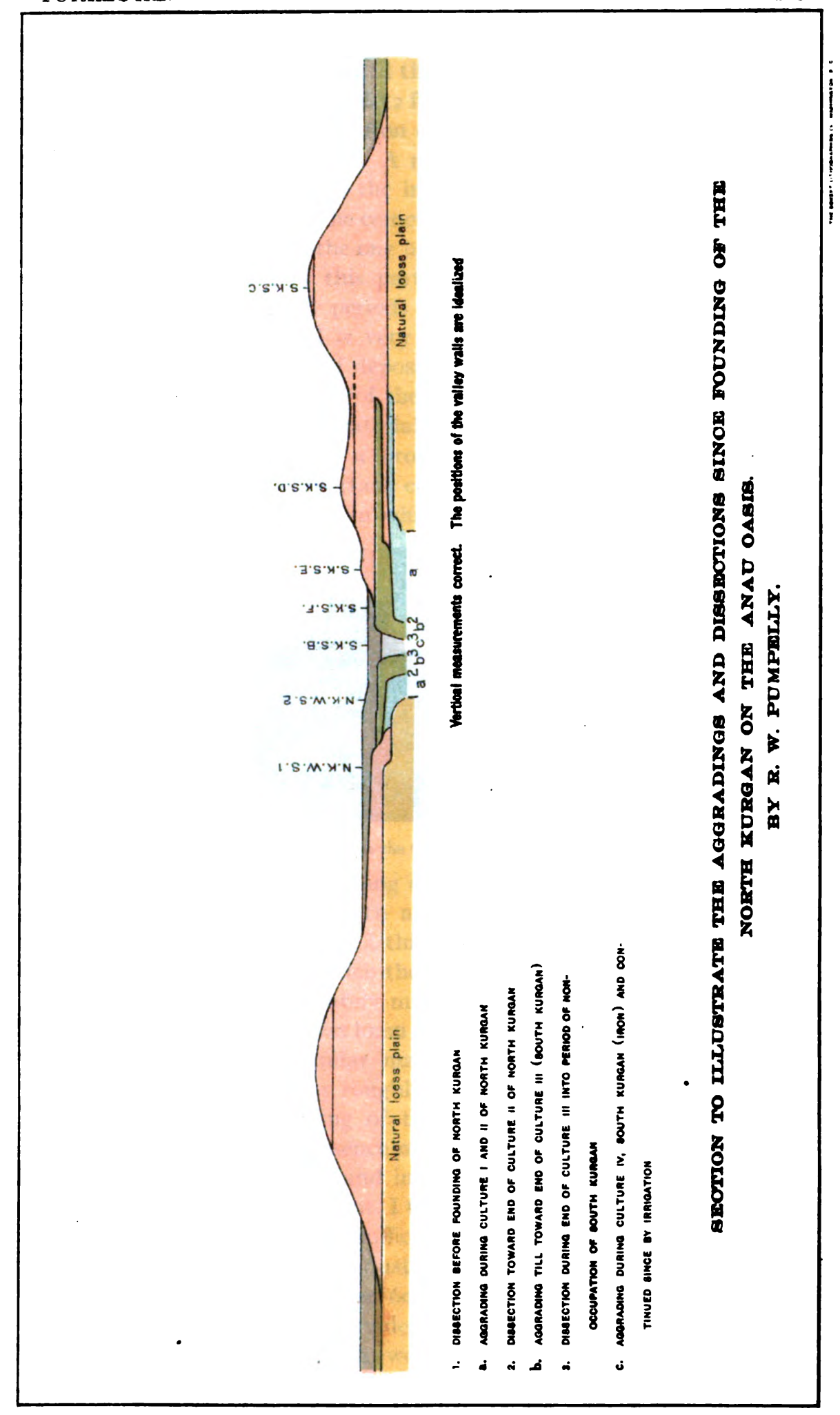


Digitized by GoOgle 
of this and the general plain, but also a part of the earlier culture of the growing South Kurgan, and it continued to grow until the brilliant period of the life of this kurgan was drawing to a close at a height of 52 feet above its base. Then followed a change to dryness, causing the reexcavation of the valley, and lasting through a period when the site was not occupied. A reverse change caused the refilling (shaft B) that followed, which lasted till the introduction of irrigation and coincided with the life of the iron culture. The coincidence is thus very marked between the founding and growth of culture on the one hand and the condition of precipitation that permitted the aggrading of this part of the delta. And equally well marked is the relation between the dry periods and the disappearance of cultures.

The record in the Askhabad Well is very interesting, for it gives a section extending 2,200 feet down in the zone of deposition and depression, and reaching down to nearly 1,400 feet below the level of the ocean. Below the upper 60 feet, with the exception of layers of coarse material aggregating less than 7 per cent of the volume, it consists uniformly of a brown loam, which indicates clearly that loess-dust enters into it as an important constituent. Of the upper 60 feet, 50 consist of more or less coarse material in which the brown loam is absent.

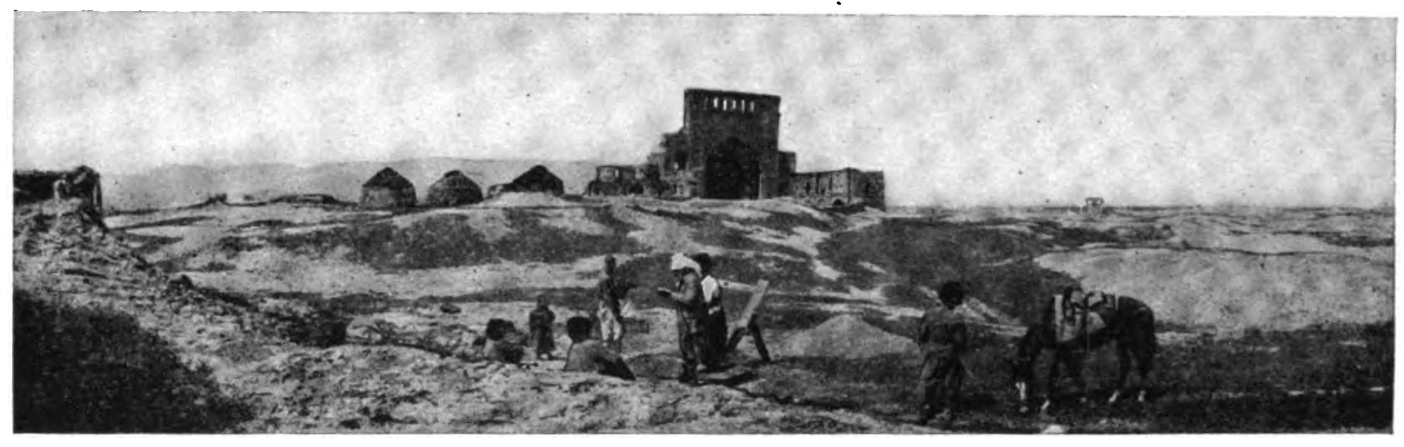

Fig. 16.-Starting a Shaft in the City of Anau.

The conditions that permitted the forming of these great thicknesses of brown loam were apparently those belonging with a greater amount of both general and local precipitation. They presuppose, I think, a degree of moisture that does not now obtain, under the influence of which there was a perennial growth of grass sufficient to allow the accretion of intimately mixed alluvial silts and loess-dust.

I imagine that the top of the brown loam at -60 feet in the well is approximately contemporaneous with the similar material under the North and South Kurgans; and that its greater depth may roughly correspond to the depth to which degradation extended before the refilling of the valley occurred, during which the North Kurgan was started. The absence of the brown loess-dust constituent, both from the upper 50 feet in the well and in the sediments deposited at Anau after the starting of the North Kurgan, point, I think, to a diminished precipitation over the piedmont zone, $i$. e., diminished sufficiently to cause a deficiency in the growth of grass required to retain the loess-dust.

When we compare, further, the upper 60 feet in the well with the whole of the column below, we see that there is evidence of a great change from a longcontinued different condition. And when we consider together the apparent 
decrease in vegetation indicated by the absence of the loess constituent, and the evidence, both geographical and archeological, of regional desiccation, the change would seem clearly to have been towards aridity. The successive degradations and rebuildings recorded in our shafts show that this period was one of fluctuating climate-a time in which the periods of greater precipitation affected the mountain regions without causing local rainfall after winter on the zone of deposition.

The time needed for the accumulation of the observed 2,200 feet of sediments in the Askhabad Well can be estimated only in geological chronology. It doubtless extends well back in the Pleistocene period, and it is not unlikely that the conditions shown between the depths of 500 and 900 feet mark the last great glacial advance.

Looking upon the loess-forming condition shown below-60 feet as typical of the piedmont plains of southern Turkestan generally, and probably of northern Persia as well, we see correspondence with the conditions that permitted the existence of the herds of ruminants and horses that in Pleistocene time ranged from Mongolia to southeastern Europe. And that these animals existed in a wild state at Anau at the time when the North Kurgan was settled is proved by Dr. Duerst's study of the bones collected during our excavations.

In the following table, constructed by R. W. Pumpelly, an attempt is made to illustrate the physiographic history of the Anau delta-oasis:

Physiographic History of the Anau Delta-oasis.

\begin{tabular}{|c|c|c|c|c|c|c|c|c|c|}
\hline \multirow{2}{*}{\multicolumn{3}{|c|}{ Tnk. }} & \multicolumn{6}{|c|}{ Physiography. } & \multirow{2}{*}{ ArCREOLOOY. } \\
\hline & & & \multicolumn{2}{|c|}{ Mountains. } & \multicolumn{2}{|c|}{$\begin{array}{l}\text { DisLocation ZONE, } \\
\text { BORDER OF PLAINS. }\end{array}$} & \multicolumn{2}{|r|}{ Plains. } & \\
\hline \multicolumn{3}{|c|}{ Preglacial. } & Quiet. & Old. & Quiet. & & & & \\
\hline \multicolumn{3}{|c|}{$\begin{array}{l}\text { Quaternary glacial } \\
\text { period differen- } \\
\text { tially reccorded, } \\
\text { with local epochs } \\
\text { in mountain val- } \\
\text { leys according to } \\
\text { uplift. }\end{array}$} & & $\begin{array}{l}\text { Young. Rap- } \\
\text { id dissection } \\
\text { to deep val- } \\
\text { leys. }\end{array}$ & & $\begin{array}{l}\text { Tilting border, bur- } \\
\text { ied in general } \\
\text { rapid aggrada- } \\
\text { tion. }\end{array}$ & & $\begin{array}{l}\text { Aggrading rapidly } \\
\text { with grasssteppes } \\
\text { over large areas. } \\
\text { stationary aread- } \\
\text { bills, and loess. }\end{array}$ & $\begin{array}{l}\text { ternary life over } \\
\text { the steppes of } \\
\text { Asia. } \\
\text { Primitive Man. }\end{array}$ \\
\hline \multirow{7}{*}{ 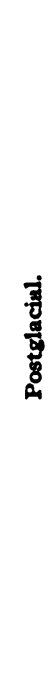 } & 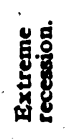 & $\begin{array}{l}\text { Reac- } \\
\text { tionto } \\
\text { extra } \\
\text { dry } \\
\text { c1i. } \\
\text { mate. }\end{array}$ & $\frac{3}{8}$ & $\begin{array}{l}\text { Slow diwsec- } \\
\text { tion. }\end{array}$ & & $\begin{array}{l}\text { Rising of tilting } \\
\text { border to form } \\
\text { a dry piedmont } \\
\text { transversely dis- } \\
\text { sected by valleys. }\end{array}$ & $\ddot{0}$ & $\begin{array}{l}\text { Aggradation slow } \\
\text { Desert steppes. } \\
\text { Moving sand. }\end{array}$ & \\
\hline & \multirow{6}{*}{ 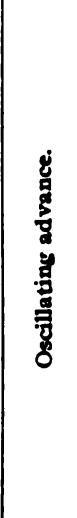 } & $\begin{array}{l}\text { Pa r r- } \\
\text { tial } \\
\text { recov- } \\
\text { ery of } \\
\text { prect- } \\
\text { pita- } \\
\text { tion. }\end{array}$ & 离 & $\begin{array}{l}\text { I.ess slow } \\
\text { dissection. }\end{array}$ & 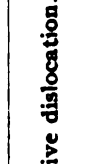 & $\begin{array}{l}\text { Valley fills to }-28 \\
\text { feet and contin- } \\
\text { ues filling to }-20 \\
\text { feet }\end{array}$ & a & Grass. & $\begin{array}{l}\text { Aneolithic Man } \\
\text { founds North } \\
\text { Kurgan. }\end{array}$ \\
\hline & & Dry. & 鄫 & \begin{tabular}{|} 
Slow dissec- \\
tion.
\end{tabular} & 4 & $\begin{array}{l}\text { Valley reexcava- } \\
\text { ted to below -35 } \\
\text { feet. }\end{array}$ & के & Desert. & Culture-gap. \\
\hline & & $\begin{array}{l}\text { Recov. } \\
\text { ery. }\end{array}$ & है & $\begin{array}{l}\text { Less slow } \\
\text { dissection. }\end{array}$ & & $\begin{array}{l}\text { Valley filled again } \\
\text { to - } 12 \text { feet. }\end{array}$ & & Grass. & \multirow{2}{*}{$\begin{array}{l}\text { Foundation and } \\
\text { growth of South } \\
\text { Kurgan. Copper }\end{array}$} \\
\hline & & Dry. & & \begin{tabular}{|c|} 
Slow dissec- \\
tion.
\end{tabular} & & $\begin{array}{l}\text { Valley reexcava- } \\
\text { ted. }\end{array}$ & & Desert. & \\
\hline & & $\begin{array}{l}\text { Recov. } \\
\text { ery. }\end{array}$ & & $\begin{array}{l}\text { I.ess slow } \\
\text { dissection. }\end{array}$ & & $\begin{array}{c}\text { Valley fills to } \\
\text { - } 15 \text { feet and }\end{array}$ & & Grass. & Iron \\
\hline & & Dry. & & & & $\begin{array}{l}\text { then overflows } \\
\text { with irrigation. }\end{array}$ & & Desert. & Anau. \\
\hline
\end{tabular}




\section{IRRIGATION.}

Except in two instances our shafts show a thickness of from 12 to 15 feet of sediments deposited from the waters of irrigation over the surface of the delta. An effect of the artificial distribution of water has been to cover the delta with a system of a few broad terraces on which the inclination is more gentle than that of the underlying surface of the natural sediments. Generally speaking, the differences of thickness of irrigation sediments, shown in the ranging from 12 to I 5 feet, are due to the relative positions of the shafts on these terraces.

We have seen in discussing the record of shaft B that its 12 feet of irrigation material did not begin until 7 feet of natural sediments had grown over the pottery peculiarly characteristic of the upper (iron) culture of the South Kurgan. Now, according to the deduced ratio of rates of growth of natural

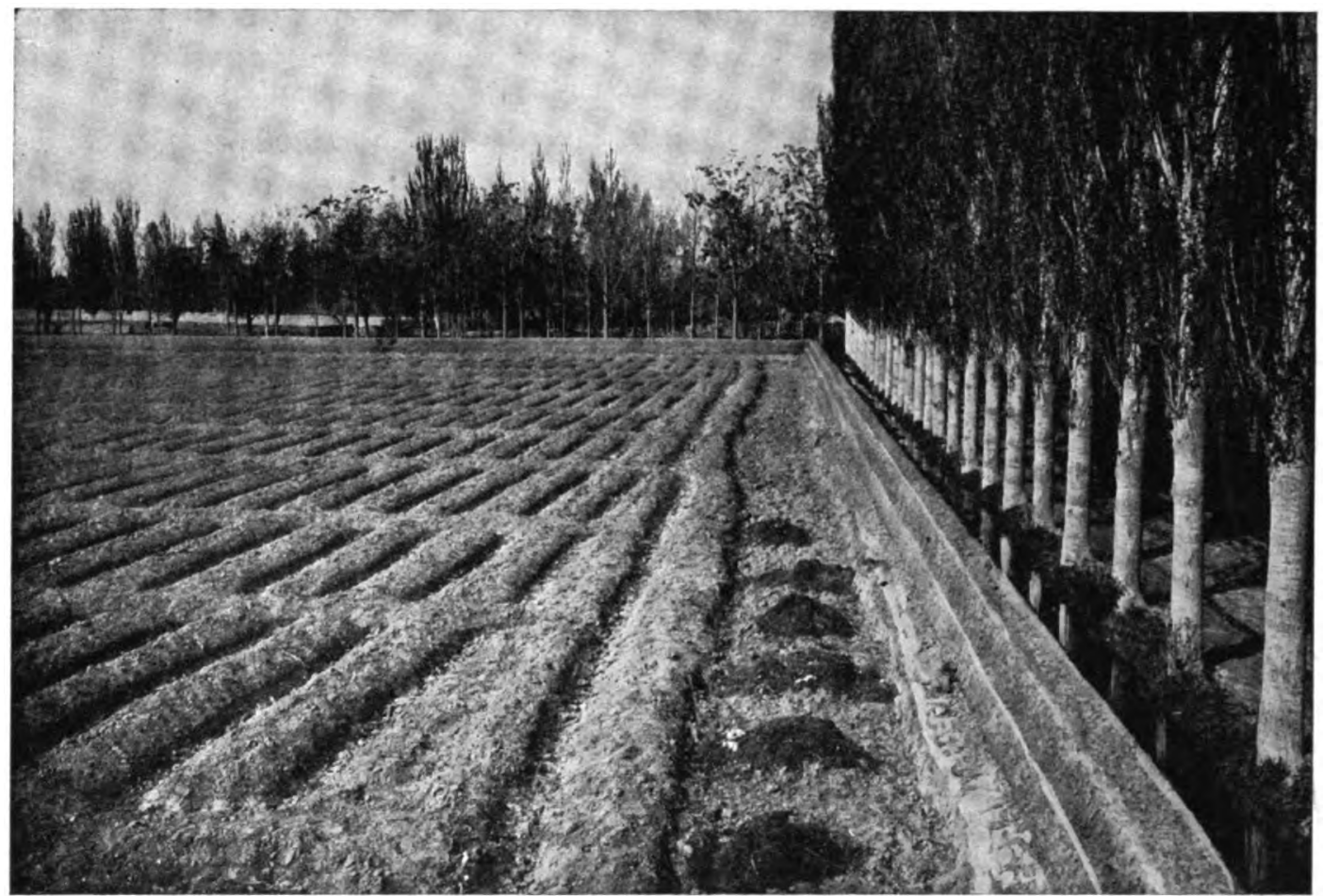

Fig. 17.-A Field Prepared for Cotton Planting in Fergana. (Photograph by Emil Steinert.)

sediments and culture-strata, viz, I to 2.5 , these 7 feet represent, as we have seen the time-equivalent of 17.5 feet of culture-strata, which would include not only all of the uppermost or pure iron-culture strata represented at the South Kurgan but at least 13 feet more that have disappeared under the action of time and weather. Therefore, this irrigation material was not deposited until after the abandonment of the South Kurgan.

The city of Anau was started on natural sediments, while 15 feet of growth of irrigation sediments stands in its immediate neighborhood on a level with its base. It is, therefore, evident that this growth is not older than the founding of the city or later. 
The introduction of irrigation would seem to indicate that in the climatic progress towards aridity, a stage had been reached at which agriculture was too precarious or, as now, impossible without artificial watering.

We are not in a position to determine whether irrigation was practised by the people of the South Kurgan during either the later or the earlier period. In two of our shafts we found 22 feet or more of irrigation silts, which may possibly include material due to irrigation during the iron period of the South Kurgan.

We can not well suppose that the people of the copper period were without knowledge of the principle of artificial watering, since we have evidence, among our finds, that there was more or less intercommunication between Anau and the Babylonian sphere of culture. But the deep cutting-down that occurred after the disappearance of the copper culture was doubtless accompanied by more or less degradation, or at least by such a dissection of the surface explored by our shafts that we might very easily have missed any surviving traces of artificial watering.

If we look at the present climatic conditions ruling throughout Turkestan, we find that irrigation is now almost everywhere essential. The only exceptions are the high valleys and the piedmont borders of the more lofty ranges. At a few points, as near Samarkand, grain is planted on the mere chance of there coming once in two or three years enough rain to mature a scanty crop, but along the piedmont plain of the Kopet Range there is no local precipitation after March.

But we seem to be now in an arid extreme of the present climatic cycle. Moreover, it is not unlikely that the climatic conditions, as regards vernal precipitation over the border zone in which Anau lies, have been on a descending scale as a whole, each arid extreme becoming more arid than the preceding one; and this would be in agreement with our hypothesis.

The arid extremes of the climatic fluctuations, which coincided with the disappearance of the different cultures of the kurgans, and seem to have caused these interruptions, were very probably less dry than is now the case, but they were doubtless sufficiently severe when the city of Anau was founded to render the previously practised system of agriculture useless for the maintenance of population and of domestic animals. Not until the introduction of the artificial distribution of water was it possible, thenceforth, to maintain a continuity of civilized life.

That even as late as the date of this improvement, apparently about the fourth century A. D., the volume of water brought in the streams was considerably greater than to-day is shown throughout Turkestan by the much greater extent of the irrigation canals and oases during the earlier centuries of our era and down to medieval times.

The introduction of irrigation reversed the order of the delta-building processes. By bringing all the water under control through the season in which it carries sediments, and distributing it evenly over the delta, the aggrading shore-line was kept back at the apex, instead of receding towards the desert, and the delta was continually built up over its whole extent. That this has been the case ever since irrigation began is shown by the fact that, since the first layers of irrigation 
sediments were deposited over the old channel shown in shaft $B$, there has been no recurrence of dissection. Had irrigation not come to the rescue, the aggrading shore-line would have receded desertward, and the prolonging channels would have carried the sediments onward to form barren takyrs on the dune-covered plain.

At present practically only the excess of water in the high floods carries fine sediments beyond the delta, for the water that is allowed to escape after the irrigating season is nearly clear. Thus practically all the detritus is retained in the delta. The coarser material is rolled along in the ditches; the rest is distributed over the fields, where it accumulates as a creamy white formation of even texture, of evenly mixed clay and very fine sand. The marked characteristic of this formation is an entire absence of stratification. This is doubtless due to growth of vegetation and the annual comminution of the soil through the processes of cultivation, for while the annual increment of sediment is only a small fraction of an inch, the yearly manipulation breaks up the ground to a depth of several inches.

At present our only way of estimating rate of growth of irrigation sediments is by comparison with that of the accumulation of culture-strata. Both the city of Anau and the irrigation formation started on the natural surface of the delta; and, while in the city the culture-strata have grown to a height of 38 feet, the irrigation formation has risen on each side to a thickness of 15 feet, which would give a ratio of $I$ of irrigation to nearly 2.5 of the loosely compacted culture-strata of the city of Anau. 


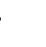

Digitized by 1009 le 


\section{CHAPTER III.-THE SUCCESSIVE CULTURES AT ANAU.}

We have come now to a general review of the more salient characteristics of the different cultures exposed in our excavations. For the detailed description of the finds from these, the reader is referred to Part II, by Dr. Schmidt.

After a mutual agreement as to the location of points for attacking the kurgans, the archeological part of the work was left wholly to Dr. Schmidt, who kept a current record in such a manner that the derivation of nearly every object collected is known, both as to the particular excavation in which it occurred and as to the
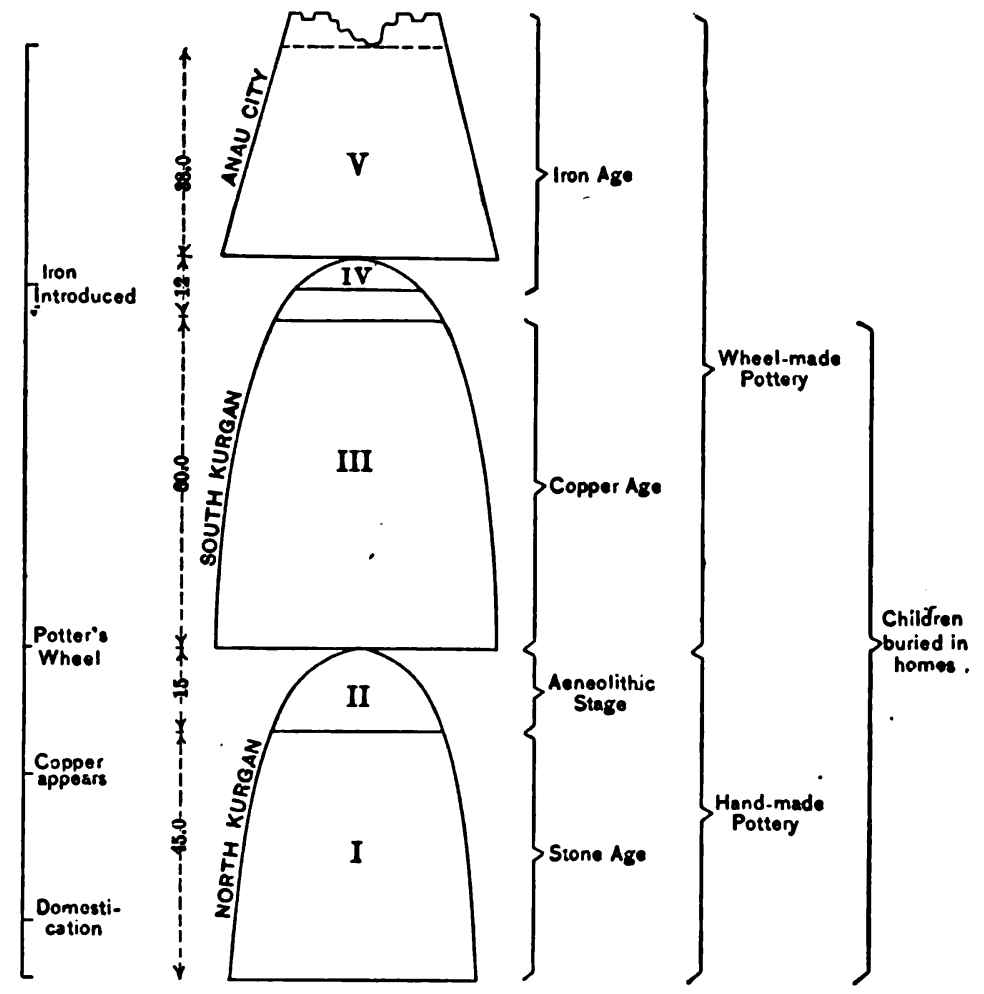

Fig. 18.-Diagram of the Cultures of the Anau Sitea.

height above or below the datum-plane, which represented the level of the plain on the side of the kurgans. In the same manner I had all the bones of animals that were found in the North Kurgan collected and preserved, and labeled in such a manner that in every case the derivation was recorded to show the horizontal and vertical position in the kurgan. This collection, aggregating nearly half a ton, was studied by Dr. J. Ulrich Duerst of Zïrich, to whose report in this publication the reader is referred. 


\section{Culture I.-Anau North Kurgan.}

\section{CHARACTERISTICS OF THE EARLIEST CULTURE.}

No potters' wheel.

No glazed ware nor glazed beads.

No burnt bricks.

No handles to vessels.

No incrusted ware.

No gold or silver found.

No tin.

No celts.

No arrow-points of stone or metal.

No spear-points of stone or metal.

No lapis lazuli found.

No representations of men, animals, or plants.

No dog.

No camel.

No goat.
They had hand-made painted ware, with only geometrical designs.

They cultivated wheat and barley.

They had rectangular houses of air-dried bricks.

They made awls and straight-edged flakes of flint and mace-heads of stone.

They had bone awls.

spindle-whorls.

some knowledge of copper and lead. mealing-stones.

turquoise beads.

only wild animals at first, out of which were locally domesticated the longhorned ox, the pig and horse, and successively two breeds of sheep. burials of children in contracted position in homes.

They hunted the following wild animals, probably all for food: ox, sheep, gazelle, deer, horse, fox, wolf, boar.

A horizontal section through the North Kurgan, taken at the level of the plain, would have an area of less than 2 acres. This, however, does not at all represent the size of the settlement at the time of its foundation; for the shaft sunk about 330 feet west of the center of the kurgan went through culture-strata, showing a breadth of at least 480 feet between this shaft and the east side of the hill. No other shafts were sunk to show what extent of settlement lies buried beneath the younger growth of alluvial sediments, but it would seem to have occupied at least 5 acres, and possibly nearly ro.

In this settlement the inhabitants appear, from the beginning, as dwellers in rectangular houses, built of air-dried uniform bricks. They were skilled in making hand-made pottery, both coarse ware and finer for special uses. These potters possessed already a definite stock of geometrical designs, which are analyzed by Dr. Schmidt. The reader will see the forms of this pottery represented on plates 18 (figs. I-6), 20 (fig. I), and 21, while plates 22-30 inclusive and plate $3 \mathrm{I}$ (figs. I and 2) exhibit practically the whole range of ornamental design possessed by the potters of this culture. It would be interesting to know what range of designs they had, if any, in woven stuffs or in basket work; for this is, I think, the oldest painted ornamentation that has come to light out of buried antiquity. They had also the art of spinning, for whorls abound from the lowest strata upward. The abundant mealing-stones show that they ground a vegetable food.

But the most important fact, as we shall see in discussing its broader significance, is that they cultivated cereals from the beginning, as is shown by Professor 
Schellenberg's discovery of the casts of chaff of wheat and barley, which was used always in mixing the clay for the thick pots shown on plates 20 (fig. I) and 2 I (fig. I).

At first, besides cultivating the soil, they hunted wild animals, and while the bones of these, as well as those of the animals which they domesticated later, show that they ate the flesh of these, including the pig and probably also the fox and wolf, these bones are not sufficiently abundant to prove that meat formed by any means the chief part of their diet. Awls, and doubtless some other implements, were made of bone, and straight-edged flakes* from flint; but, excepting maceheads, there was not found any weapon, either offensive or defensive or for the chase-neither celt, point of arrow or of spear, nor artificially formed slingstone. It would seem that such weapons as they had must have been of wood with firehardened points or points of bone, or unformed slingstones or bolos of naturally formed stones, or lastly lassos. Towards confirmation of this is the statement by Dr. Duerst that the bones he examined of the wild animals were of individuals of such ages as were easily killed.

In the lowest strata of this culture we find the practice of the peculiar mortuary custom of burying children, and only children, under the earthen floor of the dwelling. We were continually coming upon these little skeletons during our excavations. They lay generally on a fire-hardened bed of earth of about the size and shape of the hearths that occur everywhere in the floors of the dwellings, or in places on only a layer of ashes. Many of these burials contained beads or other burial gifts, and the intention was so evident that it seems probable that in those cases where no gifts were found, objects of perishable materials had disappeared, for no trace of animal or vegetable substance, excepting bones and charcoal, has been able to survive through eighty to one hundred centuries of Time's destroying agents. The remarkable preservation of the bones seems to be due to the niter with which they are saturated. This burial custom was followed so generally throughout the life of the kurgan that it would form the basis of a proximative estimate of the density of population of the kurgan and of its rate of growth, if we knew that all children dying under a given age were buried in this manner. Of this, however, we have no knowledge, and it is equally possible that they represent sacrifices. The existence of this custom through not only this earliest culture but through the two succeeding ones as well-through many thousand years-is a remarkable ethnological fact which, considered together with the associated custom of burial in a contracted position, may prove to be very useful in comparative ethnology when our knowledge of Eurasiatic and African burials shall have increased. At present there is little mention of the custom in ancient or modern literature. But this is perhaps due to a lack of observation during the process of excavating. The layers of débris that accumulate slowly during long periods of occupation are so full of bones of animals that these little skeletons might easily escape special notice, while in the deeper culture layers

* Such as were used in sickles in early Egypt and Susa. 
of Mesopotamia and on the Nile, the moisture of the earth would perhaps have caused complete decay.

In his concluding chapter Dr. Schmidt gives some instances of the custom. To these I may add that the Andamanese buried children under their houses, and the adults outside of the villages (Quatrefages, Les Pygmées). Mr. Jesse Benedict Carter has kindly given me the following notes from classical writers concerning the burial of children in Rome:

(I) Children who had not yet cut their teeth were buried, not burned (cf. Pliny, N. H., 7, 72, who says, "It is a custom in general practice that a human being who has not yet grown his teeth should not be cremated;" and Juvenal, 15, 140, who speaks of a child buried in the earth, being too young for the funeral pyre).

(2) The early practice of burying children in the houses rests on Fulgentius (De princip. rerum, 7, 560): "The bodies of children not yet 40 days old were buried under the eaves of the house."

There are three kinds of materials among the finds from this culture that point to external relations. They are beads of turquoise, objects of copper, and others of lead. Specimens of all of these were found among burial gifts. The turquoise could come only from Persia, where it has been mined from remote times at points to the south and southeast of Anau. The source of the copper is undetermined, but there can be little doubt that it too, as well as the lead, came from some part of Central Asia. Analyses made in the laboratory of Professor Gooch, of Yale University, show no trace of tin. The presence of galena together with the lead indicates a certain knowledge of metallurgy among the people who produced the objects found. While fragments of copper implements occurred at a low level in the side of the kurgan where some doubt attached to their age, others occurred in well-authenticated positions in the upper layers of this culture, beginning 6 feet or more-i. e., several centuries-below its upper limit.

This earliest culture occupied the kurgan until this had reached a height of 45 feet above its base. Its slowly accumulated strata are thin and closely compacted. And while there can be no doubt of the many centuries of the existence of this culture at this point, one can not help being impressed by its long persistence. One great mark of progress is recorded in its débris in the evidence of the domestication of animals accomplished by the inhabitants. The only other marked change that was noted is the absence, above the lowest 8 or ro feet, of a peculiar kind of excellently made and painted ware which Dr. Schmidt thought sufficient to characterize a separate culture, until he found that the lowest layers in North Kurgan west shaft I contained also the peculiar ware and decoration that characterizes the culture-strata from the base to 45 feet above it.

As far as we have read the record, this people, while themselves making new acquisitions of culture, retained those which they brought with them with the unchanging persistence that would seem to presuppose a background of long perspective, during which they had assumed a traditional sacredness. We have in this an evidence of the insufficiency of time acting alone in overcoming the conservatism of tradition. 
The most striking feature of this culture was, however, its part in the domestication of the useful animals. In Dr. Duerst's report which he has written with greater conservatism than he has used in conversation and correspondence, the reader can follow the chain of investigation of the comparative anatomist and see the proof of the domestication through the changes gradually wrought thereby in the different animals. He shows that during the earlier centuries, while the lower io feet of culture-strata were accumulating, these people knew only wild animals which they hunted for food. Then came a great change. The mighty Bos namadicus, the Asiatic urus, was tamed and converted to their use, then the horse, the pig, and successively two distinct breeds from the great-horned mountain sheep. I imagine that the taming of these animals may have been rendered relatively easy by the changing climatic conditions, which forced the remnants of once great herds of wild animals into close proximity to the people on the oasis.

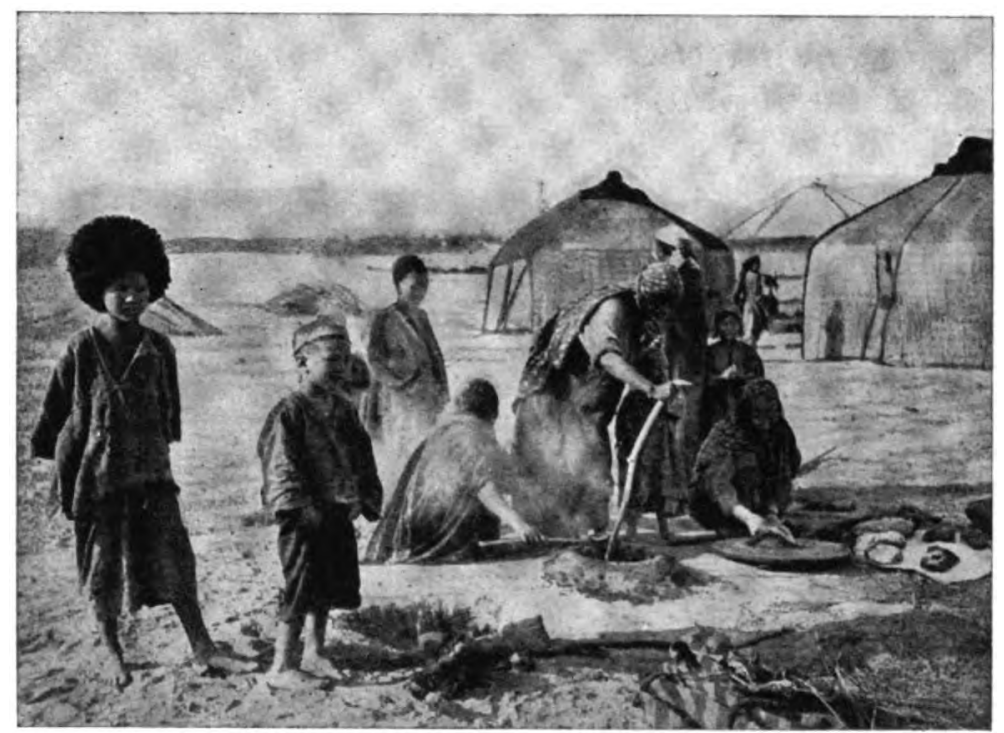

Fig. 19.-Turkoman Woman Baking Bread.

A horizontal red layer at about 35 feet above the base extends through the kurgan and undoubtedly records a conflagration. This would seem to show also that the houses of that time were thatched; and this would indicate a climate that favored a more abundant vegetation than now obtains. The same culture continues above this line until it ceases abruptly at 45 feet above the base, and is replaced, without transition, by an entirely new population bringing in culture II.

There is nothing to show whether the population abandoned the site voluntarily or were driven out or exterminated by an enemy. Some skeletons of adults, who seem not to have been formally buried, were found at this level, and these may be for us the record of a final tragedy. On the other hand, our physiographic analysis of the climatic changes shows a proximate coincidence between the ending of this culture and an extreme of aridity. 
Let us rest a moment and look back at this culture, whose top is marked by skeletons and whose beginning is buried in the depths of the earth. We look upon the ghost of a civilization that lasted through two millenniums of remote time, older than the known cultures of Babylon and Egypt. We see already in the beginning the busy village life, the women spinning, weaving, cultivating and grinding grain on mealing-stones and baking bread in the bottomless bake-oven pots. The potters are fashioning vessels, perhaps uttering incantations as they place ring after ring of moist clay in position, while others are preparing the ochers and deftly painting the long-inherited designs. Out on the plains men are cultivating the soil while others are hunting the wild cattle and horses with firehardened arrows, pits, or lassos, and tracking the sheep in the mountains.

But even while we look, the centuries have flown by, and lo! the village has grown high above the oasis. Far out on the plain men are herding cattle, horses, and flocks of sheep, or tending droves of swine in the woods of the mountain valleys. What we have seen in this view of a long-buried and long-forgotten people is a true picture of what has never been seen before-the actual transition of man from barbarism to civilization; we have seen the starting-point of our domestic animals and the beginning of that control of man over the horse which enabled him to revolutionize the ancient world.

\section{Culture II.-Anau Norti Kurgan, Upper Culture.}

No potters' wheel.

No handles to vessels.

No burnt bricks.

No glazed ware nor glazed beads.

No incrusted ware.

No tin-bronze.

No celts.

No arrow-points of stone or metal. No spear-points of stone or metal. No figures, human or animal.

No gold or silver found.
They had hand-made painted ware, both monochrome and geometric patterns.

bottomless bake-oven pots.

flint sickles and awls; mealing-stones. maces.

slingstones.

copper pins.

lead.

rectangular houses of air-dried bricks, with pivotal door-stones.

turquoise beads.

lapis-lazuli beads.

carnelian beads.

spindle-whorls.

contracted burials of children, in houses.

the domestic ox, both long and shorthorned, the pig and horse.

The domestic goat, camel, and dog appear, and a new -hornless-breed of sheep.

Standing in Komorof's trench one can see the beginning of this culture, marked by a well-defined horizontal line extending, at the level of 25 feet above the plain, along the side of the trench entirely across the kurgan. Above the level thus marked, the strata, while equally hard with those below, are, unlike these, honeycombed by wind-carving on their exposed edges, a condition that may be due to some difference in the manner of utilizing the clay in constructing the houses. Our excavations showed that this level marks everywhere the end of culture I and the base of culture II. 
This people had many points in common with their predecessors. They, too, buried children in the houses in the same contracted position; they continued the breeding of the same domestic animals; they used the same kinds of flint implements, including those resembling the elements of Egyptian sickles. They, too, made pottery by hand and painted it, but the workmanship and the whole grammar of ornament were entirely different, as Dr. Schmidt shows in his careful analysis, and as the reader may observe by comparing the figures on the respective plates. Dr. Schmidt shows also that -their pottery was not only wholly new in technique but was distinctly more highly developed in these directions. I think there can be little doubt that the points of resemblance indicate a culturally related people.

But in addition to a new pottery, they brought with them that which marks everywhere the overwhelming change from the stone age to the age of metalsthe greater knowledge of the use of copper, although the few small objects of copper in the upper layers of the lower culture show already a slight but prophetic acquaintance with the new metal. The analyses of these objects show no tin. Among the objects of copper found in the layers of the newer culture was a dagger which, if it belonged originally at the level at which it was found, was as prophetic in its way as was the metal of which it was made. It was taken, however, from the superficial earth and may have belonged to a period even later than that of the end of culture II. While in the earlier culture we found no weapons except mace-heads, the people of this second period used both the mace and well-formed slingstones.

To the animals that had been locally domesticated by the people of the earlier culture, they added the shepherd's dog and the goat; and, most important of all, the camel. If the horse was prophetic of raids and conquests, the camel was of even greater importance in that it rendered possible untrammeled intercourse with lands beyond the deserts. During this culture there appears a smaller domestic bovine, and to the second form of domesticated sheep, the "turbary" of the first period, there is added another-the hornless-variety which seems to supplant the older form. This culture period ended during a time of aridity.

\section{Culture III.-Anau South Kurgan.}

No incrusted ware.

No glazed or enameled ware.

No glazed beads.

Absence of characteristic western forms in pottery.

No celts of stone or metal.

No iron.

No burnt bricks.

No tin used to harden cutting implements of copper.
They had the potters' wheel.

the potters' furnace.

some incised ornament, on pottery and stone.

some inferior painting on pottery.

copper with sporadic appearance of low percentage of tin.

daggers, sickles, lance-heads, and arrowpoints of copper without tin.

intentional alloying with lead. arrow-points of stone and obsidian. houses of sun-dried bricks.

pivotal door-stones.

burial of children under floors, in contracted position lying on the side.

terra-cotta cult-figurines of goddess and of bull or cow. 
The third culture, beginning with the founding of the South Kurgan, belongs distinctly to the copper age of Central Asia, and enters upon the scene with a developed knowledge of the potters' wheel and furnace. With the introduction of the mechanical element in fabrication the artist in colors has disappeared, and, as Dr. Schmidt remarks, effects are sought rather in form than in painted ornament.

I have shown above that the settlement of the South Kurgan followed upon a climatic change to favorable conditions. This culture had an abundance of copper, to judge from the number of objects found, which, since they did not occur as burial gifts, had been lost and accidentally buried. This people brought with them the potters' wheel and furnace.

Tin now appears for the first time, but not in the way we should expect. It is an interesting fact that among the 20 objects examined for it by Professor Gooch only four contained it. A reference to the table of analyses will show that with the exception of a dagger near the top of the culture, in which the oxidized products showed 1.58 per cent of tin, all the cutting implements were wholly free from it. A ring and the crust on an awl contained each between 5 and 6 per cent, while the crust on another awl yielded 1.65 per cent. Tin exists in Khorasan, and on the border of Afghanistan, where it is also mentioned by Strabo.

Localities of copper ores in northern Persia are indicated on the geological map of Transcaspia by Muschketof, Andrusof, and Bogdanovitch, and since little is known of the mineral resources of Irania, there is no reason to suppose that the mountain system of northern Persia may not contain many other such localities. Copper was extensively mined during the real bronze age, and perhaps earlier, from Lake Balkash northward and eastward, according to Radloff (Aus Siberien) and to a letter from Mr. Fell, who is now mining copper there.

Further, the fact that the objects found in culture III are with so few exceptions wholly free from tin, and that where this does occur it is generally present in insignificant percentages and generally absent in cutting implements, shows that its use was not intentional. Its presence is in all probability due to the smelting of copper ores containing tin in irregular quantities. The general presence of arsenic and antimony in irregular quantities is doubtless due to the character of the ores. The metal would seem to be "blister copper" produced from oxidized ores.

On the other hand, the use of lead in the "stamp" (S.K. 363) and in the "ring" (S.K. 203) was probably intentional. That lead was known very early is shown by its occurrence near the end of the first culture. This is not surprising when we consider the striking appearance of galena and the ease with which it is converted to the metallic state.

While there is, therefore, little doubt that the copper was obtained from Central-Asian ores during the earlier cultures at Anau, the occurrence in culture III of figurines of Beltis, which indicate later communication with some region within the Chaldean sphere, makes it possible that objects were imported, or produced by remelting importations.

It would seem probable that in all of the earlier Asiatic and Mediterranean regions, the presence of tin was at first unintentional and due to its presence in 
some of the copper ores of each region. In time, before the knowledge of tin itself had been acquired, certain ores were found to make better edged implements, and the stage of bronze with low and irregular percentages of tin was inaugurated. Bronze proper, containing a definite percentage of 9 to 10 per cent of tin, presupposes a later-acquired knowledge of tin ores as such and of their treatment. Dr. Gooch's analyses of the copper objects of culture III show not only that the Anau-li of that period were ignorant of tin-bronze, but that the use of typical bronze with a high and relatively regular content of tin had probably not yet become general among the peoples with whom they stood in communication as late as the end of the III millennium B. c., since we should otherwise expect to find edged implements of that kind.

The amount of ground opened in the lowest strata of the South Kurgan by my exploratory shafts was not sufficiently large to throw much light on the question of external relations during the earliest and larger part of the life of this culturethrough the first two-thirds of its existence. A beautifully worked flint arrowpoint was found on the dump of shaft $\mathrm{C}$ in earth that probably came from between ro and 20 feet above the base of culture. This is the first evidence of any kind of relations with very distant peoples.

But in the deepest of our larger excavations, in terrace B, from the level of 40 feet above the base of culture upward, we found numerous witnesses of various kinds to western connections. Here was found at 48 feet above the base a threesided seal having on the different faces respectively a lion, a man, and a griffinin the form of a winged lion with the head of a bird. Photographs of it and of casts from it are shown on plate 45 , fig. 8 . In the concluding portion of his report Dr. Schmidt discusses at length the possible derivation of this object.

Still lower, at 40 feet above the base, there was extracted an arrow-point of obsidian, which most probably came from the Armenian Highlands. We have thus established a probable connection with a district on the great route of antiquity from the regions east of the Caspian through Armenia to the Mediterranean. The existence of such a line of communication is, I think, again shown by the sickle which was found at a higher level in the upper digging, between 45 and 49 feet above the base of culture (see plate 39, fig. 3). It is of copper with no trace of tin. The point of interest in it from the standpoint of comparative archeology is the bent-back tang, and its identity of form in this respect with several sickles found in the VI city of Troy, and figured in Dr. Schmidt's catalogue of the Schliemann Collection in Berlin. These, like our specimen, also contained no tin. Whether the idea underlying this form originated in Central Asia,* the primitive home of agriculture, or in the west, there can be little doubt that we have to do, not with a mere coincidence, but with evidence of an intercourse at that period, either direct or indirect, with the Mediterranean. There can, I think, be little doubt that the sickle, in its primitive form of a blade composed of flakes of flint or of rock-crystal, originated on the Central-Asiatic oases, whence it found its way in neolithic time

* In De Morgan's Collection from Susiana, in the Louvre, a case marked "Epogue Elamite" contains a copper sickle with bent-back tang, identical in character with that from Anau III. 
to Egypt. Flinders Petrie gives in "Illahun, Kahun, and Gurol" (plate vIr, fig. 27) a representation of such a sickle found at Kahun in which the cutting edge is formed by flakes of flint set in wood. And De Morgan found such flakes in abundance both in Egypt and in Susiana. Similar flakes abound in the earliest cultures at Anau; obviously the sickle would be one of the first implements to be made of copper after the introduction of that metal. It would not be surprising if future researches should show that the Anau and Trojan form with the bent-back tang was a survival from a much more ancient time.

The persistence of forms in objects of daily use through thousands of years is one of the most remarkable evidences of that conservatism that has till recently hindered the development of the inventive faculty of man in all directions. For nineteen centuries the Italian peasant has used agricultural implements identical in form with those in the Pompeian collection at Naples. This identity, as shown in Pompeii, covers the widest range of survivals still in use throughout the modern world, to mention only certain surgical and drafting implements, the sare forms in faucets and valves in plumbing, and in some kinds of bits for horses, and in the dice for gambling. Here, too, we find in the Pompeian astragali the same "knucklebones" which occur abundantly in the early culture-strata of Anau on the one hand, and were used in games by the Greeks, and are still in use by modern youth, marking perhaps a stage in a real sequence of tradition. The same method of yoking oxen has followed the ox from ancient Chaldea westward through the millenniums; and the American cowboy uses the lasso as it has come down to him with the horse from ancient Irania. The same form of spindle-whorls occurs in great quantities through eight thousand years of pre-Christian culture at Anau, and still later in the medieval city, where they differ only in being glazed. They had the same forms, too, though decorated, in Troy after the first city. It would seem that all of our stocks of forms and of ornament have their roots in many prehistoric centers, and that until the recent advance in mechanics and chemistry modification in forms was due almost wholly to the requirements in working newly discovered materials; and that the addition of new concepts was due to the comminglings of traditions from primitive centers of independent evolution.

I come now to what is, for several reasons, perhaps the most remarkable of the finds from this culture. Between 40 and 43 feet above the base of culture, there came to light numerous terra-cotta figurines of both human and animal forms. Of these the human figures all represent women, and those of animals are clearly meant for bulls or cows. They are shown on plates 46 and 47 . As a rule they are roughly formed, but in one instance (plate 46 , figs. 1oa and rob) the modeling is surprisingly artistic in so far as it was the evident intention of the maker.

These female figures belong undoubtedly in the class of images of the lifecreating and life-nourishing goddess.* As Beltis, Ishtar, Nana, Anat, Astarte,

* Hörnes has discussed, in his "Urgeschichte der Bildenden Kunst in Europa," the wide prehistoric distribution of this idea in various forms of representation. 
Astoret, this goddess was fundamentally connected with the cult of the ancient Semitic religions of Arabia, Elam, ${ }^{*}$ Chaldea, Assyria, and Asia Minor. These figures occur throughout these countries, and among Phenician colonies on the Mediterranean. She was worshiped also in Armenia and among the Hittites, whose racial affinities are still undetermined, and in II and III cities of Troy. Similar votives are found in the remains of neolithic and transitional cultures of southern Europe. Whether they all point back to a common Semitic origin or not, they are doubtless the expression of a very primitive idea of the All-mother, the giver of life and the nourisher, into whose care the dead are given. The expression of this fundamental character is common to the figurines wherever found; it is always shown in the realistically accentuated representation of the breasts, the navel, and the organs of generation. Beyond having these attributes in common, the treatment varies with different peoples. The next characteristic that is common to the greatest number of localities is that in which both hands are holding the breasts, as if to emphasize the nourishing function, or rest on the body below the breasts. Among the Phenicians the goddess, besides the characteristics just mentioned, is frequently accompanied by doves, or holds the lunar disk as an attribute of the Semitic moon-goddess, as in Chaldea she favors the crescent-shaped horn of the cow or bull. And these figurines are frequently accompanied by figures of the cow or bull, recalling the cow sacred to Hera. These representations are often reduced to the simplest form, as in Troy, where frequently only the eyes and nose with mere indications of the breasts and hands occur, made in the most rudimentary manner on vases. Again, in many of the neolithic sites of the Mediterranean a more or less developed steatopygous character is given, often comparable to the form of the "Hottentot Venus." Lastly, it is not unusual to find figures on which the arms are represented only as stumps, even associated with others in which the hands hold the breasts. This last-mentioned character attaches to our figurines of the South Kurgan. While the realistic treatment leaves no possible doubt of their cult affinities, the arms were not bent towards the breasts, but were merely indicated by stumps, which either projected outward or hung down.

While we can not speak positively in comparing or contrasting these figures with those found in different regions, we can say in general terms that in their general character, and especially in the delicate modeling of the one shown in plate 46 , figs. Io $a$ and $10 b$, they stand somewhat apart from those represented from other known localities. They seem distinct from the Chaldean and Phenician, and they are not accompanied by the "face-vases" of the II and III cities of Troy, on which the same cult idea is expressed. In looking for their derivation we must take into consideration the fact that they occur in the South Kurgan in intimate connection with the custom of burial of children under the house-floor. For this reason I think we must imagine this cult to have come from a point far enough to the

*In De Morgan's Susianan collection in the Louvre, a case marked "Epoque archaique," contains figurines of this goddess, from Tepe Moussian, some of which resemble those from the South Kurgan at Anau. Also in De Morgan, Délégation en Perse, Mémoires, t. viI, p. I I, M. Jequier gives a drawing of a very primitive form of Beltis found in the lower strata of Susa, apparently before the occurrence of copper and 25 feet or more below the first traces of writing. 
west to have been received from some people who possessed it, and yet not far enough away to have been beyond the sphere of the primitive peculiar burial custom that was conmon to this part of Asia; for I imagine that we must look upon the use of these votives as a custom engrafted on the older idea that underlay the practice of burying children in the contracted position, which sinulates that which they occupied before birth. Our slight knowledge of the lower 40 feet of strata of this culture leaves it an open question whether the cult of this goddess was brought to Anau by this people at the time of immigration or adopted by them later. Several of our finds from the later part of the copper culture (Anau III) of the South Kurgan point more directly to relations with Susa than elsewhere. Since Dr. Schmidt's report was written in 1904 I was able in 1906 to examine M. De Morgan's large collection of finds from Susa and the Moussian district of Susiana which has been exposed in the Louvre and described in volume virr of the Délégation en Perse. There is in these a general similarity in the forms of the tanged copper daggers, etc., to those from Anau and a copper sickle identical in shape with that from Anau III is shown among objects of the "Elamite period." In volume virr $M$. Jequier represents a winged and bird-headed lion differing but little from that on the three-faced seal from Anau III. It is from an impression on a tablet from the "Archaic" strata of Susa. Since these tablets are considered by Scheil to belong at least in the IV millennium (dating Sargon of Accad at 3800 B. c.) the conception may have belonged to the cult of the people then living in Susa. Susa had the cult of Ishtar (Winckler, 1905) and figurines of the goddess are found in culture-strata, from prearchaic time down, essentially like those from Anau III. Then, too, topographical conditions made Susa as directly and easily accessible as Babylonia.

The objects in question from Anau III belonged to the flourishing part of the copper culture and according to my chronology were about contemporaneous with the great expansion of the Elamite power when Susa was suzerain of Babylonia under Kutur Nahunte, 2280 B. C. (Winckler), and when she is supposed by Winckler to have extended her rule far to the north and east.

Dr. Duerst, Dr. Schmidt, and I have approached the chronological side of the question from wholly different sides and without any intercommunication as to this part of the investigation. In his concluding chapter Dr. Schmidt, bringing to the study the knowledge of a comparative archeologist with extensive experience in the field, discusses several of the few finds that appear to show western relations. Among these he lays, naturally, particular stress upon the three-edged arrowpoint found in the IV, or iron, culture, and the three-faced seal, and gives an exhaustive review of the literature relating to both classes of objects. As a result he is inclined to assign the arrow-point to the middle of the first millennium B. C., and the seal to a date not long after the middle of the second millennium B. $\mathbf{c}$. The end of the copper culture (III) of the South Kurgan he would place at about 1000 B. C., and the brilliant period of that culture in the second millennium.

When we come to consider the stages of culture preceding the iron period the finds are not available for western comparisons. Here Dr. Schmidt very naturally differs widely from me, without, however, intending to give any final 
opinion as to the age of cultures which have as yet yielded to us no equations that are solvable solely by archeology. Further on I shall attempt to show that this region of primitive civilizations had a very early and wholly independent evolution.

The copper culture of the South Kurgan (culture III) ends at 60 feet above the base. Its upper limit is well shown in Dr. Schmidt's sketches (fig. 37), where there seems to be evidence of a conflagration followed by a period during which the hill was not occupied and the ruined clay house-walls were dissolved and washed down to effect a rough leveling of the surface. Our geologico-physiographic observations show that the climatic oscillation was then near the arid extreme, and that a long period ensued during which the kurgan was not occupied.

\section{Culture IV.}

Overlying the remains of the copper culture (III) on the main part of the kurgan there are layers aggregating 12 feet in thickness which form the present capping of the South Kurgan. On the northern extension there is an aggregate of 20 feet of strata above the copper culture. In both places the lower 8 feet is represented by material of a different character from that both below and above. This material differs in character from the culture-strata. On the top of the kurgan much if not all of it seems to represent the products of wastage during abandonment. Upon this débris was built the later settlement of the iron culture. Since the final abandonment of the site the progress of wastage has covered the declivities of the kurgan with the products of wastage in which are represented material from the iron period, from the copper period, and from the intervening period of non-occupation. This 8 feet of intermediate débris contains some rough, hand-made pottery, which in places is associated with wheel-made pottery of the kind that is peculiarly characteristic of the overlying iron culture (IV). For this reason Dr. Schmidt has designated this lower member the "mixed layers." He adds that the relatively small amount of finds from this zone on the northern extension seems to indicate a period with little or no occupation. Overlying this "mixed" member there are on the summit of the kurgan 4 feet of pure iron culture still remaining, while on the low northern extension this is represented by 12 feet rich in artefacts. Iron was found in a considerable number of fragments, but, with perhaps two exceptions, they were too much wasted by oxidation to make their use evident. The exceptions were apparently parts of sickles, and on them we find the first evidence of the use of rivets for securing the tang to a haft. Among the few objects of copper or bronze that were found was the three-edged copper arrow-point that is fully discussed in Dr. Schmidt's concluding chapter. The lateness of the appearance of iron in the series of Anau cultures is due, I think, to a period of alternating abandonment and occupation by barbarians following upon the end of the copper culture. According to Herodotus the nomads of that region did not have iron in the fifth century B. c.

I have shown in the sketch of physiographic events that toward the end of the copper culture there existed a climatic change towards aridity, and that a reaction in the opposite direction was in progress before and during the period of pure 
iron culture. It will be seen by a reference to plate 5 that the latter part of the period following the copper culture and represented by the "mixed" strata includes the time during which history tells us that the "Scyths" overran the Persian Empire, and it may not be unduly stretching the imagination to see in this racial movement an armed migration set in motion by the increasing desiccation over the great Transcaspian plains.

It would seem that the city of Anau was founded by a new people. They made a different pottery and they used the system of irrigation that has continued down to the present time. Artificial irrigation was necessary to counteract arid climatic conditions. Our shafts at Ghiaur Kala show that artificial irrigation was used at about the same time on the oasis of Merv under the Sassanian rule.

\section{CHRONOLOGY.}

The greatest interest centers naturally in the problem of the age of these different cultures, and in their relation to the origin of Western civilization, if any such relations may be shown to exist. The wide geographical separation between Anau and the fields of western cultures, and the paucity of objects found by us that recall in a definite manner similarities to objects of external civilizations, surround the subject with the greatest obstacles.

A working hypothesis based on a different line of reasoning gradually formed itself in my mind and is developed in the following pages. To begin with I assume:

Ist. That distinctive pottery, peculiar to a culture throughout our successively superimposed earth layers, is evidence of corresponding continuity of that culture.

2d. That since it is a fact that throughout the lives of our sites at Anau the towns were built only of air-dried bricks, without stone foundations, the secular rate of growth of culture-strata can be taken as proximately uniform.

3d. That two separate sites, whose cultures are characterized by entirely different and peculiar potteries, can not exist contemporaneously for centuries in close proximity to each other without such an interchange of pottery as would come to light during the excavation.

This is applying to archeology simple rules of geological reasoning. We know the thickness of the strata of each of the cultures of the three neighboring sites, and we know the aggregate existing thickness of the cultures of all the sites. If we take the duration of each culture to be proportionate to the thickness of its accumulated strata, the duration of the entire series will be represented by the aggregate existing thickness of all the strata plus any culture-gaps between different cultures, and ininus any overlaps of the cultures of the neighboring sites. Having the standing thickness of the different cultures, two additional factors are needed to convert the stratigraphic record into a chronological one:

(a) The assignment of values to the observed four intervals that existed between the different cultures.

(b) The rate of accumulation of the culture-strata. 


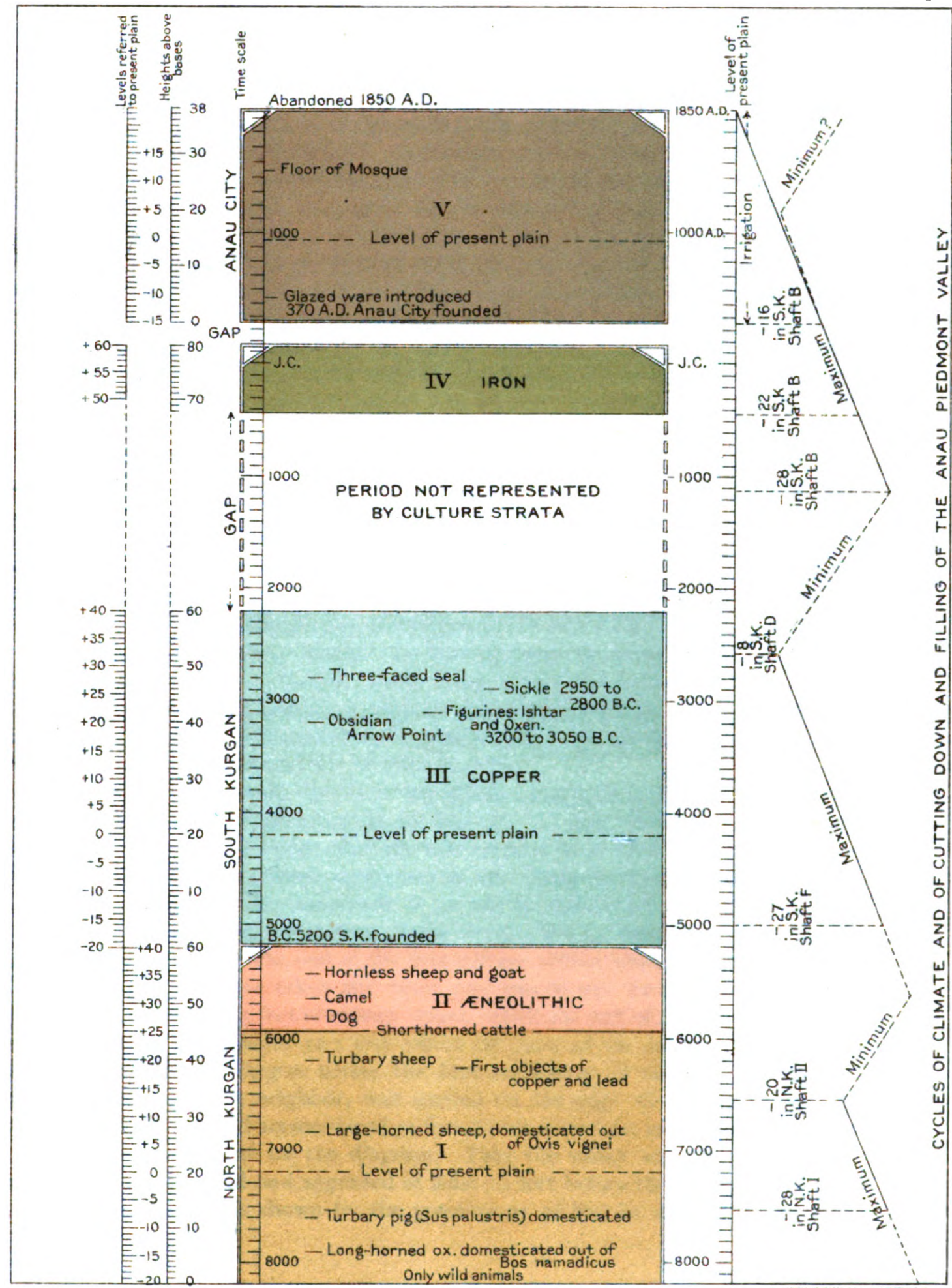

STRATIGRAPHIC CHRONOLOGY OF THE CULTURES 
Digitized by GoOgle 
On plate $5 \mathrm{I}$ have represented the three sites one above the other according to their order of succession, and have assigned values, in feet of strata, to the intervals that were due to periods of abandonment and wastage.

Into the method adopted in estimating the culture-gaps, there enter both geological and archeological factors. In chapter II it was shown that the observations made in our shafts proved that the delta lies on the piedmont belt of tilting, or rather of the reciprocal movement due to removal of load to the plainward side by the deposition there of alluvial silts. It was shown also that in the part of the delta upstream from the alluvial shore-line, the channel of the stream was, at repeated intervals, alternately cut down to a considerable depth, and again filled up with silts. We were able to determine definitely two such cuttings-down and three fillings-in or aggradings, all during the lives of the three sites. Now, these geological events ran parallel with the human history of the delta-oasis, and since they have an important bearing on this history in several directions, I have platted them on plate 5 parallel with the cultures.

The North Kurgan was founded on a previously dissected valley at a time when this valley was aggrading, and the valley continued to fill till towards the end of the oldest culture. The first settlement extended down the side of the valley to a level 28 feet below the present surface of the delta-plain, which latter we will use for a datum in this discussion. At this level we find in shaft I standing house construction, and at the same level in shaft II there occurred in alluvial sediments fragments of the pottery characteristic of this oldest culture. No pottery was found below this. From -28 feet upward the alluvium contains this oldest pottery as far as -20 feet, where there occurs the evidence of the filling having ceased; for the presence of pottery characteristic of the upper culture of the kurgan intimately associated with charcoal and animal bones indicates an occupation of a dry plain and not of a flood-plain.

The relative time during the life of the oldest occupation at which this aggrading ended is determined proximately as follows. It was shown in chapter II that we were able to determine that the rate of growth of the alluvial silts in the valley was to that of the culture-strata as $I$ to 2.5. Now the 8 feet of silts between -28 and -20 feet are the equivalent of 20 feet of culture-strata at the ratio of I to 2.5. But the oldest occupation of the kurgan has 45 feet of strata, leaving a range of 25 feet before the end of the first culture within which to place the end of the aggrading. I have taken the mean, and placed the time of ending of the aggrading at a point 12.5 feet of culture-strata before the end of the life of the first settlement, that is, opposite 32.5 feet above the base of the kurgan. The next aggrading had already begun before the first settlement of the South Kurgan, which, like its northern neighbor, was started on the edge of a valley; and it continued until there had accumulated 52 feet of culture-strata, as stated in chapter II, and is so represented on the diagram. That the valley was then cut down to at least -28 feet, and had aggraded at least 12 feet before the beginning of the upper or iron culture, is shown by the presence at 16 feet in shaft B of pottery 
peculiar to that culture. And this aggrading continued until the overlying irrigation sediments began to be deposited, which occurred at about the time of the founding of the city of Anau.

If we knew the rate of cutting-down as well as we know that of aggrading, and if we knew also the depth to which the cutting-down extended, we could assign very proximate values, expressed in equivalent feet of culture-strata, to the intervals between the different cultures, after which a determination of the rate of growth of these would give an absolute chronology expressed in centuries. I have no doubt that these missing factors could be determined by further work on the lines of the method we used. But as it now stands, while each of the first two aggradings falls wholly within the life of a culture, each cutting-down occurs partly during a culture-gap.

There is, however, one point at which the geological data are of the greatest use, in that they enable us to determine proximately the distance between the beginning of the upper or iron culture of the South Kurgan and the founding of the city of Anau.

We have seen that in shaft B there grew 7 feet of alluvial strata between the time of deposition of the pottery peculiar to the iron culture and the beginning of deposition of irrigation sediments which began at about the time of the founding of the city of Anau.

Using our ratio of $I$ to 2.5 we find that these 7 feet correspond to 17.5 feet of culture-strata. Now, on the low northern extension where they are thickest, there are only 12 or 13 feet of strata of the pure iron period, leaving about 4 or 5 feet unaccounted for. As there was no overlapping of the cultures of the kurgan and city, these 4 or 5 feet of interval may belong partly to a period of abandonment, or wholly to wastage. The top of the high kurgan itself has naturally undergone a greater amount of loss, and there we find only 4 feet of pure iron culture-strata.

\section{GAP BETWEEN COPPER AND IRON CULTURES.}

The conditions which are shown in Dr. Schmidt's sketch of the side of the "upper digging" (fig. 37) indicate that after the abandonment by the copper-using people, the kurgan remained for a long time unoccupied. The walls of the empty houses remained standing, and the rooms inclosed by them filled slowly with earth, drifted in from the slow wastage of the bricks. Eight feet of débris of wastage intervenes between the copper and iron occupation, and in this a few pieces of rough hand-made pottery and the absence of construction would seem to mark a temporary or occasional occupation by a nomadic people. There are no culture. strata properly speaking, and the gap itself gives no internal evidence of the duration of the interval. In bridging this gap we can use the geological method only as far as the observed amount of aggrading can help us. The observations in shaft B show that after the cutting-down that began towards the end of the copper culture there was an aggrading of at least 12 feet before the founding of Anau. This alone is the equivalent of 30 feet of culture-strata. To this must 
be added the unknown equivalent of the time consumed in the cutting-down that began towards the end of the copper culture and deepened the valley 20 feet. While we have no determination of the rate of this deepening of the valley, we may assume that, being dependent on the compensatory orographic process of loadshifting, it was neither spasmodic nor unduly rapid. Fven if we should assume what would seem an improbable rate of 2 feet per century, this 20 feet of cuttingdown would require ro centuries, the equivalent of 20 feet of culture-strata. Even this, added to the 30 feet equivalent of the aggrading, would insert the time-equivalent of 50 feet of culture-strata between the beginning of the cutting-down and the founding of Anau. A slower rate of cutting would lengthen the gap and time.

Of the 30 feet required as the minimum culture equivalent of the aggrading, I 4 feet belong before the iron culture, and represent that portion of the gap between copper and iron. Also, for the cutting-down of at least 20 feet, we have only the last 8 feet of copper culture-strata. From these geological considerations it is clear that the gap between the copper and iron is very considerably greater than the 14 feet determined by the aggrading.

Having explained the available geological factors, let us see what the copper culture itself offers. While the whole of this culture was characterized by an abundant use of copper for ornaments, domestic implements, and weapons of the earliest forms, not only was tin not used for hardening the metal, but, with the single exception of a ring, it did not occur in any of our finds until towards the end. Therefore these people lacked not only knowledge of full tin-bronze (9 to ro per cent tin), but they were not even in the transition stage in which smaller percentages of tin were used intentionally in cutting-inplements.

Now a large proportion of our copper finds in the South Kurgan, including cutting-implements, daggers, etc., were found in intimate association with objects belonging to civilizations in the Chaldean sphere of influence, especially the associated figurines of naked Ishtar and of the cow or bull. We do not know how early full tin-bronze or even the lower alloy was known in Babylonia, but this knowledge could not fail* to be nearly contemporaneous in Babylonia and Egypt. Montelius, after a careful survey of the whole field of existing knowledge of the subject, decides that the use of full tin-bronze ( 9 to ro per cent of tin) came into Egypt in the XI or XII dynasty, and that small amounts of tin are found in objects of the earlier dynasties. The probable Central-Asiatic origin of the lapis lazuli used in Egypt at least as early as the XII dynasty is, to the extent of that probability, evidence of commercial relations between Egypt and Babylonia. The most conservative chronology - that of the Berlin schools-places the beginning of the XII dynasty at 2000 to $2200 \mathrm{~B}$. C., and we are warranted in accepting this as about the date of the introduction of full tin-bronze in Mesopotamia. In view of these considerations I have felt justified in placing the end of the copper culture of the South Kurgan at 2200 B. C., as the latest probable date, and have left in the column a gap equal in feet to the requirements of this determination.

*According to Montelius, 1900, no tin has been found in any of the older objects of copper from Tello and other Babylonian localities. It has been found in objects from graves at Ur and Erech, which range from the second half of the III to the end of the II millennium. 


\section{GAP BETWEEN THE NORTH AND SOUTH KURGANS.}

We have no means of measuring the interval that existed between the time when the layers still in place at the top of the North Kurgan were formed, and the time of the founding of the South Kurgan. During the long lapse of millenniums, the northern hill has undergone a great amount of wastage on its sides, vastly reducing its circumference above its base. There can be no doubt that its height has been lowered also. Under absence of any kind of protection, the height would have diminished by many feet. But there is always the possibility that such an eminence would from time to time be protected by some kind of structure of which no traces remain, but which would retard its wastage. As the matter stands, we can only say that no evidence exists of overlap of the cultures of the two hills. My impression is that we have here a long period, perhaps of many centuries, not represented by culture-strata. I have therefore drawn the column without any gap, rather than insert one that would be only arbitrary.

To convert the stratigraphic column into a chronological expression requires a knowledge of the rate of growth of the culture-strata. At present the only means available is offered by the determination of the date of introduction of decorated glazed ware (faience) into Anau and Merv. The lowest strata of Anau city are characterized by a red, hard-baked, undecorated pottery, but at 5 feet above the base there appeared in all my shafts a greenish pottery and decorated glazed ware. This same ware we found in Ghiaur Kala (Merv) down to a depth of 20 feet and no deeper. It was there associated with Sassanian coins of the third century A. D. It is not likely that it was older than these coins. Since both Merv and Anau were under Persian rule, it seems probable that such a sudden cultural acquisition is referable to some important phase in the varying fortunes of the Persian monarchy in the early centuries of our era. The Mullahs of Anau told me that Anau was fortified by Anu-Shirvan (Chosroes I), the greatest of the Sassanian monarchs (531-579). Chosroes made his expedition in 559 against the white Huns in Trans-Oxiana, and fortified his northeastern and northern frontiers against the incursions of the nomads. This monarch extended his empire over Mesopotamia, the home of faience; and it is known that the Persians made this ware before the Arab conquest of Iran. This would point to the possibility, if not probability, of a contemporaneous introduction of glazed ware into Merv and Anau. If we take the middle of the sixth century A. D. as the date of introduction at Anau, the growth of the overlying 33 feet in thirteen centuries will give a rate of 2.54 feet per century.

Again, a Cufic inscription on the façade of the mosque at Anau tells that it was built in 1444. The floor of the mosque lies 9 feet below the general level of the top of culture-strata which have risen above the plaza and approaches. A growth of 9 feet in four centuries gives a rate of 2.25 per century. The 24 feet between the beginning of glazed ware and the floor of the mosque divided by nine centuries gives a rate of 2.66 feet. We have thus three rates-2.54, 2.25, 2.66. If we assume that the floor of the mosque was laid one foot above the street level, 
these three rates will come into quite close agreement, and stand 2.54, 2.50, 2.55 . I have therefore taken 2.5 feet per century as the rate of growth of culture-strata in Anau city.

The shafts sunk in Anau city found a very much looser earth than in the kurgans, so loose indeed that there was at times danger of caving. On the other hand, the kurgan strata are closely compacted and hard; they have evidently either grown at a considerably slower rate or have compressed in time by gravity. Perhaps both of these causes operated, but in any event, there is no doubt that the accumulation of a century is represented by fewer inches in the kurgans than in the city. The difference in texture and character is so very marked that I have taken a rate of 2 feet per century for all of the kurgan strata.

NoTE.-In the winter of 1906-7 I visited Egypt in order to get some information as to the rate of growth of culture-strata in Egyptian village mounds. The places examined were the mounds which have grown up around the temples, in some instances nearly burying them. The excavation of the temples during the past few decades has left good sections of these mounds. In these towns all constructions-houses, walls, etc.-were built wholly of unburnt bricks. According to their age these mounds now vary in height from 25 to 50 feet or more above the present level of the plain. Their upward growth has been caused by the fact that all material for construction and repairs, and practically all

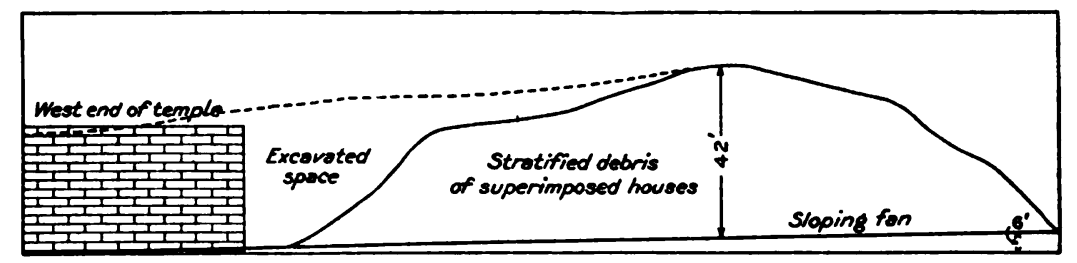

Fig. 20.-Explanatory Diagram of Village-mound Culture-atrata at Medinet-habu, Thebes, Egypt.

solid inorganic material that has been brought into the village from the beginning, has remained there. The bed of the Nile and the surface of the plain both rise at the rate of 39 inches in to centuries. The mounds (culture-strata) rise more rapidly. Thus, while the base of a mound is always being buried, the elevation of the streets and of the housefloors of the village at the top is always increasing. The mounds consist, from top to bottom, of the standing walls of houses and other constructions, and of earth which, in more or less regular and compacted layers, fills the spaces which have been rooms, courts, and streets. In this earth is contained practically all the organic matter that through the centuries was consumed by the population, and its high content of phosphates and nitrogenous salts gives it great value as a fertilizer. The mounds that have been bought in order to excavate the temples are for this reason being extensively exploited by the fellaheen for fertilizer. Fortunately for our purpose the fertilizing quality is largely confined to the earth instead of the walls; and the excavation of the former often leaves the walls standing, in places down to near the level of the plain. Observation shows that the growth of the mound is due to the combined rising of the level of the earthen floors, courts, and streets, through slow accumulation of earth and the mutual adjustment of all these factors to maintain a general level. The walls are continually becoming buried. When rooms become too low, additions are made to the top of the walls and a new roof is added. The products of wear and tear of the outer surfaces of the walls and of roofs by wind and occasional rains, go, together with abundant potsherds, to raise the surface of streets and 
courts. Such in general terms is necessarily the explanation of the growth of village mounds wherever crude bricks have been the materials used in construction.

The mounds examined in Egypt were those around the temples of Esneh, Edfu, Komombo, Medinet-habu, Luxor, and Karnak. The temple of Knum at Esneh stands buried to a height of 29 feet above the floor in the mound of a still important town. This temple was built in the Ptolemaic period and embellished with inscriptions by Roman emperors down to the time of Decius (249-25I A. D.). Since a part of it was added by Ptolemy VI Philometor ( $18 \mathrm{I}-146$ B. C.), at least $2 \mathrm{I}$ centuries have elapsed since the floor was laid. Obviously the temple was not built in a hole dug for that purpose into a then existing mound; it must have started on the then existing general level of the town which has since then grown up around it. If we assume that the floor was laid 2 feet above the general level, we have before us a growth of 31 feet in 21 centuries, a rate of 1.48 feet per century.

At Edfu the temple of Horus was built 2 I centuries ago. Adjoining it a mound rises to a height of 28 feet above the level of the floor. If we assume that the floor was built 2 feet above the general level, we have a growth of 30 feet in 21 centuries, or 1.43 feet per century.

At Kom-ombo the temple of Sobk and Haroëris was built by Philometor Euergetes II, ( $127-117$ B. C.). The temple was built on the edge of a preexisting mound, part of which seems to have been cut away to secure space for the site. Around part of the temple, and separated from the older mound by an outer wall, the newer growth has reached a height of 37 feet. Allowing 2 feet for the elevation of the floor, we have 39 feet of growth in 20.5 centuries, or 1.9 feet per century.

At Medinet-habu the temple (plate 6) was constructed by Thotmes III (about I 500 B. c.), and Ramses III (II98-1I67 B. C.) towards the foot of an alluvial fan sloping from the hills towards the flood-plain of the Nile. Near it, on one side, rises a mound, the growth of a village, occupied till recently, which, considering its distance from the cultivated lands and its situation near the temples of Medinet-habu and the Ramasseum, as well as to the important tombs, would seem to have originated in the labor needs of these constructions. The growth we have especially to do with, lies around the northwest or rear of the temple, where it rises to a maximum height of 45 feet. Assuming that the founding of the village was contemporary with that of the temple under Thotmes III, we have a growth of 45 feet in 34 centuries, or $\mathbf{r} .35$ feet per century.

At Luxor the village mound covers the northern end of the great temple and the Avenue of Sphinxes beyond. Over this avenue it attains a height of 29 feet above the floor of Ramses II, while it rises within the precincts of the temple itself to only 25 feet above the same datum. It is evident that this accumulation could not have begun before the decree of Theodosius I (379-395 A. D.). The difference in height of growth within and without the precincts is doubtless due to the fact that a Coptic church existed for some time in the sanctuary. The 29 feet that have accumulated outside the temple over the Avenue of Sphinxes in fifteen centuries give a rate of 1.9 feet per century.

At Karnak the village growth extended before the excavation across the Avenue of Sphinxes, leading from the great pylon on the west towards the Nile. It has attained a height of 21 to 25 feet above the Avenue. This growth could not begin till after the decree of Theodosius (379-395 A. D.) abolishing the Egyptian religion. This allows I 5 centuries for the growth, or 1.66 feet per century.

The average of these six instances is 1.6 feet per century, which can not be very far from the truth for the growth of villages constructed in the Egyptian climate of crude bricks made of the silt of the Nile.

The only manner in which the growth of the kurgans at Anau differed from that of Egyptian mounds would seem to be in a somewhat more rapid rate of wear of walls on the outside and of roofs in Anau, where some rain falls in the spring, and where the clay is a little less tenacious than that of the Nile. 
PLATE 6.

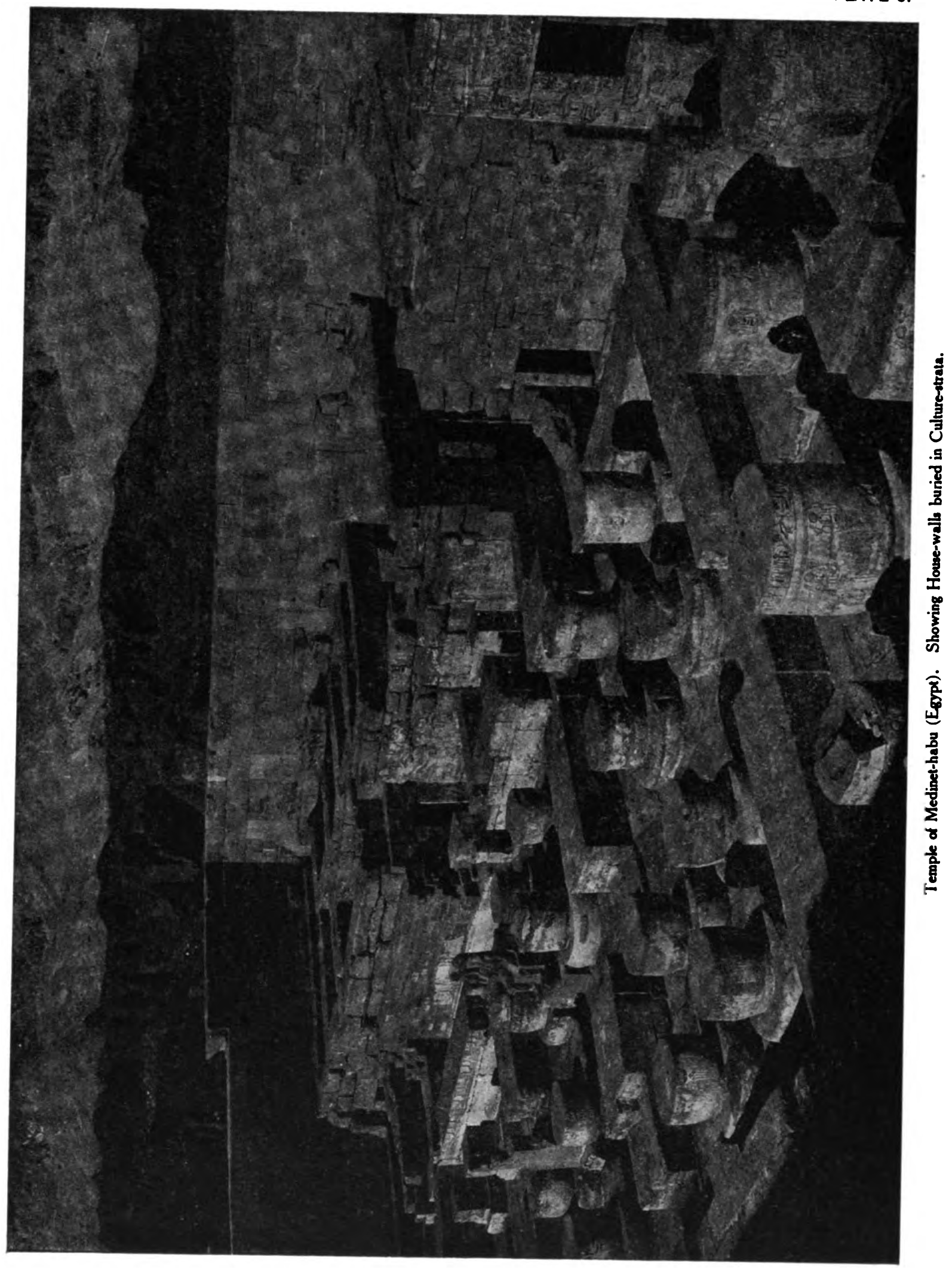

Digitized by Google 
Digitized by Google 

dates:

On the basis of the above-given reasoning we have the following proximate

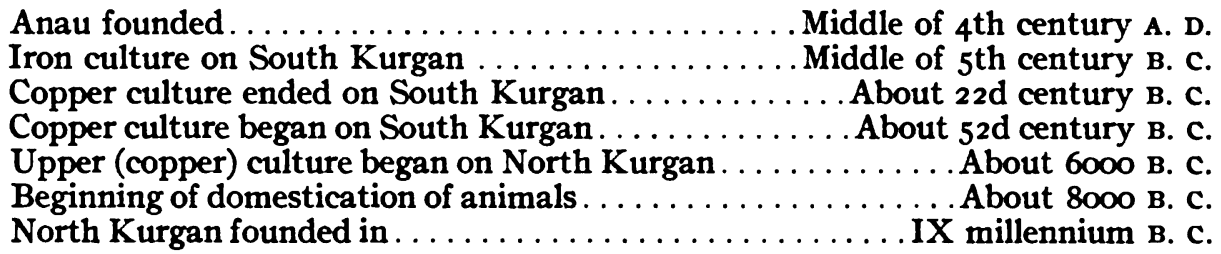

CYCLES.

The platting of the aggradings and cuttings-down of the delta-channel makes very clear an apparently cyclical character in these processes, and emphasizes their relation to the sequence of the civilizations of the region. How are these cycles to be interpreted? Are they due solely to movements of the crust in which the cutting-down may have been caused by change of base-level through a relatively sudden relief of strain after long accumulation of load? Or are the cuttingsdown the result of recurring climatic change, and if so, whether of change to increased or diminished precipitation in the mountains? We have in chapter II connected the deepening of the valley with periods of diminished water-supply; let us now see whether the historical portion of our series of cycles offers any means of testing the correctness of that hypothesis.

The evidence obtained from the observations in our shafts at Merv as given by R. W. Pumpelly in his report may be summed up as follows:

The ancient city of Ghiaur Kala, which is now surrounded by the present delta, was founded on a rolling loess-steppe with a relief of at least 25 feet, on which flying sands, after beginning to accumulate, were being buried by alluvial silts when the city was founded. The interpretation of these conditions is that the invasion of the sands indicates a climatic change to dryness sufficient to destroy the vegetation which, during the previous less arid period, had arrested the movement of the surrounding dunes, while the burying of the sands by alluviation points to a retreat of the delta, due to a diminished volume of water corresponding to the climatic change to dryness. Now we can determine the time proximately in which the founding of Ghiaur Kala falls. There are in the city 30 to 35 feet of culture-strata below the level at which glazed pottery begins to appear. I have given above reasons for placing the introduction of this ware in the sixth century A. D. As the city was abandoned in the twelfth century, the rate of growth of the strata would be about 3 feet per century. Applying this rate to the 30 to 35 feet below the glazed ware would date the founding of the city at least about the middle of the first millennium B. c., * that is, at about the same time as the founding of the iron-culture settlement on the top of the South Kurgan at Anau. We have thus

* The medieval Arab and Persian historians all agree that the citadel of Ghiaur Kala was founded by Tachmurez, a legendary ruler, and that later Alexander the Great founded the city itself; which probably means that he surrounded with walls the settlement that already existed adjoining the citadel. 
the evidence of a period of desiccation immediately preceding the founding of Ghiaur Kala and contemporaneous with that in which the cutting-down of the valley occurred at Anau between the copper and iron cultures.

Standing on the citadel of Ghiaur Kala and looking north, one can see nearly thirty high ruins of ancient sites scattered over the delta-oasis. And Mr. Huntington, as he shows in his report, found numerous others spreading out far beyond these. While the highly deformed and wasted shapes of some of these show that they belong doubtless in a previous cycle, many others belong clearly in the present cycle, and some of these seem from their state of preservation to have been abandoned less than a thousand years ago. One of these, Odontche tepe, which lies on the desert Io or 12 miles north of Ghiaur Kala, proved not only by its state of preservation, but also by pottery identical in character with that of the later layers of Ghiaur. Kala, to belong in the earlier centuries of our era. Of these sites the older, greatly wasted ones appear, as stated, to belong to the previous or copper cycle, when abundant water kept the delta and its apex farther north. Ghiaur Kala was founded in the next or iron cycle, after the reactions to dryness had caused the apex of the delta to retreat far enough upstream to spread the silts over the previously free loess surface. And the many better-preserved sites mark the later stage of recuperating climate which carried the delta again to the north, or at least extended its alluvions farther downstream. The wide distribution of these later sites indicates a period of prosperity and extent of population that seems to have required a much more abundant supply of water than could be derived now from the river Murg-ab. This view would seem to be fully confirmed by Mr. Huntington's observations on the Merv Oasis in this volume, where he gives the evidence towards showing a shrinkage of the water-supply within the last centuries. The era of prosperity preceding the present great decline coincided closely with the period of abundant water-supply in Persia, which Mr. Huntington, in our previous volume, after an analysis of the historical data in the light of his own extended physiographic investigations in Asia, states must include the time of both Alexander, 300 B. C., and Istakri, $900 \mathrm{~A}$. D.

Lastly, while observations show that the surface of landlocked seas, like the Aral and Balkash, are subject to negative and positive movements of short cyclical character, there is evidence, both historical and in the traditions of natives, that there has been during our era, a very considerable lowering of the surface of these waters. This is confirmed by a comparison of maps of the 18 th century with those of to-day, which show a shrinkage of thousands of square miles of area in the Aral and Balkash, and the total drying up of many smaller bodies of water.

Turning now to plate 5 , we find that the evidence offered in the parallel sequence of physical and human history is all in the direction of confirmation of the hypothesis of recurrent climatic changes, in which the deepenings of our valley in the zone of tilting were due to periods of diminished volume of water. The two kurgans were founded early during aggradings. The iron-culture settle- 
ment on the South Kurgan and the city of Anau were both founded during the last aggrading. The arid period between the two last aggradings coincides with the long abandonment of the South Kurgan between the copper and iron cultures, and the previous arid period coincides with the interval between the North and South Kurgans. Lastly, in addition to the agreement shown in the rise and decline of civilizations, we have confirmation from the biological side in the progressive stunting of the breeds of domesticated animals, as shown by Dr. Duerst, which, according to him and to Nehring, is due to insufficient food and to desert conditions.

We have no direct observations as to whether the valleys are now deepening on the zone of tilting in the present period of aridity, because under irrigation the silts are all held up, and alluviation is artificially maintained up to the apex of the deltas.

It would be of great interest to know whether these cycles were of proximately equal periodicity. Unfortunately, the two critical factors in the problem, depth and rate of valley-cutting, are wanting. Penck has shown that the last of his four ice-epochs of the glacial period was followed by a series of lesser though great oscillations of diminishing intensity; and it is thought that the oncoming and passing of each glacial epoch was marked by climatic oscillations of respectively increasing and decreasing intensity. Our cycles at Anau covered periods of between 3,000 and 4,000 years' duration. Oscillations of such magnitude would seem to belong in the order of phenomena of mundane extent and possibly of astronomic relations. The question may be risked, I think, whether they may not be fainter vibrations in a series, diminishing in intensity since the last of Penck's oscillations.

The argument contained in this chapter, and represented graphically on plate 5 , is based on observed facts and on the writer's inferences drawn from these facts. As facts of observation, we have in three neighboring sites an aggregate of 170 feet of culture-strata of uniform character belonging to the distinctly different cultures of five separate and successive occupations. That part of the argument which establishes the parallelism between the physical and human history of the region, rests upon observed parts of three periods of aggrading with two intervening periods of cutting-down of the valley. The aggradings are drawn in full lines in each case opposite that part of the culture-strata during the accumulations of which the aggrading took place. These full lines represent, therefore, the minimum depth of valley deepening, the observed amount and maximum height attained by aggrading, and its duration measured in feet of contemporaneously accumulating culture-strata. It will be observed that the essentials of this part of the argument consist in the observed aggradings, represented by full lines, and length of cycles. Plate 5 tells us the history of the oasis of Anau free from the writer's inferences, but it is desirable that some things previously stated be repeated at this point. 


\section{NORTH KURGAN.}

We see a town with houses of crude bricks being founded when the valley was filling with alluvium. The people are already cultivators of wheat and barley. They make without a wheel an interesting pottery with geometric designs, use mealing-stones for grinding, and spindle-whorls for spinning some vegetable or animal yarn. They make small implements of flint similar to the flint parts of the sickles of the prehistoric Egyptians and inhabitants of Susa. We see them beginning early the process of the domestication of animals, developing longhorned cattle out of the great wild Bos namadicus, a large horned sheep out of the wild bighorn, and a pig from the local wild hog. As the settlement rises slowly above the surrounding plain, the filling-in of the valley ceases, and cutting-down begins, and parallel with the progress of the conditions that deepen the valley goes the stunting of the sheep and cattle till there becomes established a breed of smallhorned sheep and one of short-horned cattle.

About this time this people disappears and is replaced by newcomers who bring a new culture, including a more advanced technique in the making and painting of hand-made pottery. While a few finds of ornaments of copper showed that their predecessors had a slight knowledge of this metal, this new people had more of it. They, too, made the same simple flaked-flint implements as their predecessors, but, like those, they had neither arrow-heads nor spear-points nor celts of stone. Their only weapons of stone were mace-heads and slingstones. Like them, too, they had the work of the lapidary, vessels of marble and alabaster and beads of stone, including carnelian and turquoise, to which they added beads of lapis lazuli. With these people came the shepherd-dog, camel, and goat; and it is noteworthy that towards the end of this culture, in the then advanced period of cutting down of the valley, the sheep became transformed into a hornless breed.

\section{SOUTH KURGAN COPPER CULTURE.}

After a greater or less interval after the end of the upper cuiture on its northern neighbor, an interval that does not appear on plate 5 , when the valley was again filling with silts, the South Kurgan was founded by a people who seem to have been ethnically related to the former from the fact that, like both of their predecessors on the oasis, they buried children under the floors of their dwellings in the same contracted position lying on one side. They made their pottery on the wheel without painted ornament and with an advanced potter's workmanship. They had a fully developed knowledge of copper, as shown in ornaments and various implements and weapons. As in the previous cultures, their copper contained, whether accidentally or intentionally, sufficient arsenic or antimony, or both, to give it hardness; though towards the end of the culture small amounts of tin appear sporadically and evidently as unintentional constituents. Relations with the Chaldean and Armenian spheres of influence appear now, as shown by the appearance of finely formed flint and obsidian arrow-points, and, towards the end, by terra-cotta figurines of Ishtar (Beltis) and by the winged and bird-headed lion.

This copper culture flourishes till the valley has again begun to be cut down, and then disappears, to be followed by a period of non-occupation, which is represented only by 8 feet of formless débris of wastage, in which occasional rough hand-made pottery seems to indicate occasional occupation by nomads. 


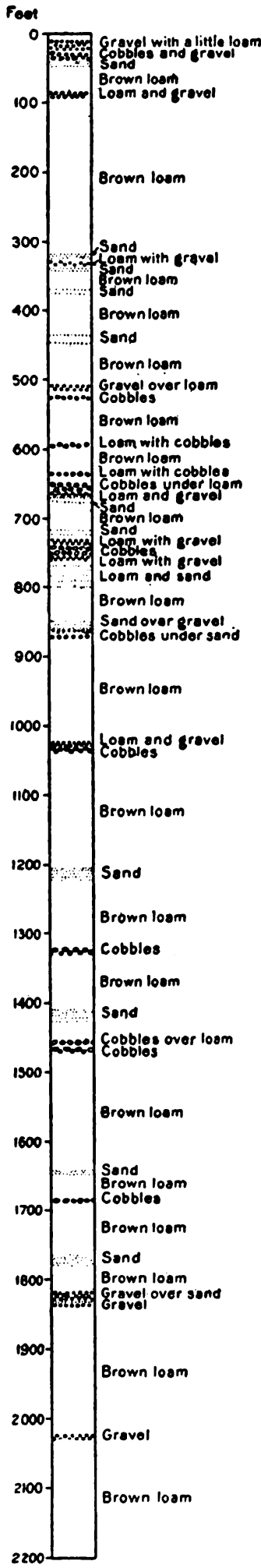

Fig. 21.-Geological Column, Ackbabad Well.
SOUTH KURGAN IRON CULTURE.

After an apparently long period of abandonment, the South Kurgan was again occupied, when a new cycle of aggrading was again filling the valley, by a people having an iron culture, during which at least 12 feet of culturestrata accumulated.

\section{ANAU CITY.}

After the abandonment of the South Kurgan, and at a time when the valley filling had progressed to a height at which the natural process of alluviation was superseded by the present system of artificial irrigation, the city of Anau was founded, early in our era, and, after accumulating 5 feet of culture-strata characterized by a red pottery, there appeared a greenish variety and a glazed and enameled and painted ware. In the middle of the fifteenth century, its large and beautiful mosque was founded, and in the middle of the nineteenth century the city was abandoned and became a ruin.

Such is the main outline of the most essential observed data on which the argument relating to the chronology of the assumedly interdependent physical and human history of the oasis of Anau is based, and which is assumed in its physical aspects and as regards the fundamental characteristics of the cultures to be regional in its applicability.

As regards uncertainties in the platting of the physical data, while the unbroken line representing the aggrading during the copper culture is drawn exactly.where it belongs, the point where the first aggrading ends and where the cutting-down begins may belong opposite a point 12 feet either way on the scale of feet on the culture scale. The gap between the copper and iron cultures is based partly on archeological and partly on geological requirements affecting the rate of cutting-down; it may be wider, but may not well be much smaller. There is little doubt that a gap should show on the plate between North and South Kurgans, but in the absence of any means of estimating it, even proximately, I have preferred to leave it unrepresented.

\section{THE ASKHABAD WELL.}

I can not leave this part of the discussion without referring again to the Askhabad Well. As stated above, this extends to a depth of 2,200 feet, and its bottom is still in delta sediments more than 1,400 feet below the level of the ocean. When we remember that the sinking of the zone of deposition is a geodynamic process due to the gravity of the secular accumulation of thin layers of alluvium, we realize 
that its progress must be very slow, and that the time during which these 2,200 fcet of sediments were laid down can be expressed only in terms of thousands of centuries. Since the uppermost of the sediments are of recent formation, it is evident that the column, as represented in the well, must extend into the glacial period, and probably include at least the last of the glacial epochs. We should therefore expect to find, in the character of the sediments, variations recording phases of the glacial period. The record of the boring shows uniformly brown loam with occasional layers of sand or of gravel, more rarely of cobbles, all of which are distinctly delta-oasis formations. An examination of the record on fig. 21 shows at once a great difference in the distribution of the coarser layers. Below 750 feet the layers of gravel range from 150 to 200 feet apart, and the lower 500 feet of the well has only a solitary and thin layer of any kind in the loam. On the other hand, between 500 and 750 feet, the coarse layers, and here largely cobble, recur with short intervals. And the percentage of coarse material, including sand, between 500 and 900 feet, is several times as great as in the rest of the column. This would seem to indicate a period when the stream had exceptionally great transporting power. Since there can be no doubt that at least the last iceepoch of the glacial period was contemporaneous with some part of this column, it would seem more probable that the conditions that caused the rapid recurrence of coarse beds are assignable to climatic rather than to orogenic causes. Looking at the column from this point of view, we might see the climax of the ice-epoch in the part between 600 and 800 feet. Without attempting to analyze closely the significance of all the details of the column, it may be worth while to carry this tentative speculation farther, and determine approximately the age of this part of the record. Since the beds coarser than loam clearly represent alluviation, they are evidence that the column has grown pari passu with the sinking of the zone of depression. The maximum rate of growth would be that of the maximum of alluviation on the sinking zone, and this rate is very nearly represented by that of the growth of irrigation sediments where practically all of the silts are held up artificially. For this we may take the rate of $I$ foot per century determined on the neighboring Anau delta. Applying this rate, the space between 500 and 900 feet would cover the period between 50,000 and 90,000 years ago; and the mean point at 700 feet would be 70,000 years ago. 


\section{CHAPTER IV.-THE HYPOTHESIS OF THE OASIS-WORLD.}

In considering the observed data of the earliest of the Anau cultures in their ethnographic relations, one must be struck by a singular fact: They had none of the usual weapons of stone for offense and defense; the cores from which they made the abundant flakes of flint, probably for sickles, arouse our wonderment at the absence of the arrow-points, spear-heads, and ceits found in almost all advanced stone-age and æneolithic settlements. Now axes, spear-points, and arrow-points of stone are, throughout the rest of the world, abundant where primitive man has existed; and in the iniprovement in the manner of their fashioning they serve to mark off the long stages in the slow development of primitive human culture. The evolution of these implements, from the almost natural shape to highly finished forms specialized for different uses, was exceedingly slow. This has been proved at several points in Europe, where they have been found in deposits of different epochs of the glacial period, and intimately associated with undoubtedly contemporaneous animals of those epochs; and the progress in time is paralleled by the improvement in workmanship. So true is this considered to be that in studying in Europe successive stages, glacial and interglacial, of the glacial period, the evolution of forms and of workmanship in the stone implements, when such are found, is only second in value to the bones of those animals with which the implements are associated, and which mark the long oscillations between subtropical and arctic climates. The early use of stone as a tool, and the slowly developing inventive faculty, at last rendered possible during interglacial time the manufacture of finely formed axes and spear- and arrow-points. These were acquisitions that stood causally and first in human development, in the same order with the discovery of the use of metals, powder, and steam. It is not conceivable that a people who had once possessed this acquisition, and had used axes and arrow-points and spear-points of stone, could have lost the advantage these offered. This would be still more remarkable in the case of our Anau-li, who, though settled in communities, still hunted wild animals, and who had quartzite close at hand, as well as access to the flint of which are found the flakes in such abundance, and the cores from which they were flaked. I see no way of accounting for the absence of these forms of implements and weapons except on the hypothesis that the ancestors of this people had become absolutely isolated from the rest of mankind at a period so remote as to be before the invention of these forms, and they must have remained without contact with peoples using these implements and weapons.

The next and necessary deduction under this hypothesis is that the whole of their culture is autochthonous in the sense that it received no impulses from outside the people, or circle of peoples, so isolated. It presupposes an early separation of a great inner-continental region from the rest of the inhabited world.

I imagine that the cause of this separation is to be sought in one of the stages of the glacial period, when the region, considered as a whole, became isolated, as far as human intercourse was concerned. Moreover, after this it probably took a long time for the reaction from the conditions induced by the ice-epoch to make 
much progress in breaking up the continuity of the loess steppes, and to widen the distance between habitable areas within the region thus isolated. The reaction did not begin until the inflow of water became insufficient to maintain the inland sea at its maximum of expansion. After this would come the change to segregation of communities, first into larger groups of loosely connected units, then the breaking up of these into smaller groups. Within the wider limits of the region more or less intercourse could exist between the delta-oases on some stretches along the piedmont belt, and often still more easily between those on opposite sides of relatively low mountain ranges. The essential condition was a sufficient frequency of springs or streams to permit travel on foot.

Under such conditions, continued through thousands of years, the related peoples, beconing isolated in oases or oasis groups, or in high mountain valleys, would differentiate, each evolving its own culture along lines influenced by inherited traditions, environment, and racial character. The development would, in general, on account of isolation, be peaceful, and, while alone and uninterrupted, would lack the benefit of acquisition of the new factors that come with intercourse with unrelated peoples. The growth of population on these restricted areas was necessarily accompanied by evolution in social organization. We find the people living in towns, where the long continuance of life under individual town government, practically without external relations, while developing individuality, must have given the many separate peoples thus situated certain fundamental political characteristics common to all. In the same way, in so far as the physical environment was similar, certain classes of customs, arts, and occupations must have evolved along similar lines. In so far as the peoples of larger or minor groups of oases differentiated from the same stock or from the same language stock, their languages would retain traces of the original generalized speech. All these are ethnographic data to be carefully searched for in sifting and analyzing the results of future investigations.

But several data among our finds from this earliest Anau culture show that more or less intercourse existed with other parts of the oasis-world. Turquoise beads, used as burial gifts with the skeleton of a child, must have come from Persia, where turquoise is known both to the south of Anau and farther eastward on the plateau; the same inference is to be drawn from the presence of copper.

We have at present no means of knowing how the earliest culture of the settlements at Anau stands in relation to the generalized cultures of Central Asia before the segregation into isolated communities, for there have been made no other systematic excavations anywhere to discover traces of the older civilizations, excepting in Susiana, southwest of the Iranian plateau, to which I shall refer farther on. The constituents of the earliest culture found at Anau presuppose a previous evolution during many thousand years. How slow it must have been is shown by the almost unvarying character of the pottery during the two millenniums at the North Kurgan.

When we compare this culture with that which succeeded it (No. II) on the same kurgan, we find both differences and points in common. Each has its own peculiar technique in pottery and scheme of ornamentation in painted decoration. The mace and artificially formed slingstones appear. But both cultures had in 
common agriculture, a rectangular construction of houses of air-dried bricks, the same spindle-whorls and mealing-stones and forms of flint implements, and exactly the same custom of burying children in a reclined contracted position under the house-floors. And since the peoples of culture II brought with them the domesticated dog, goat, and camel, which we may assume that they had themselves subjugated to their use, they had this achievement also in common with their predecessors, and they shared in a knowledge of copper.

- The differences are due to independent culture evolution on separate oases of one or two groups; but the points in common date from an earlier stage in the forming of groups, and they presuppose, beyond doubt, in the earlier stage, a long period of dwelling in houses, of knowledge of the potter's art and of spinning, and of agriculture. The peculiar burial custom probably dates from a still earlier and regionally more generalized culture.

When, now, we compare the succeeding culture (III) of the South Kurgan with its predecessors on this oasis, we find great changes. The skilfully made and painted pottery of the earlier peoples is supplanted by that made on the wheel; the mechanical production of variety in form has taken the place of the artist's brush and color-pot. Arrow-points of stone and copper appear, and objects that recall forms and cults of which we find traces in the remains of western antiquity. But underlying all these points of difference, there is throughout this culture the custom of burying children under the house-floor, which, I think, would alone class this people as belonging to the oasis-world. On the other hand, the points in which this culture differs from the preceding ones are probably due in part to progress through time, partly to independent development at a remote point before migrating to Anau, and partly again to intercourse with peoples who had been in contact with others who fashioned stone arrow-points; for intercommunication was now rendered relatively easy through the camel and horse. There is no evidence of Mediterranean influence. The celt is wholly wanting, and in the copper weapons the absence of Mediterranean forms of corresponding age is marked.

We are thus carried back two stages in the progress of differentiation of oasis groupings beyond the founding of our earliest culture at Anau; and I think most modern ethnologists will agree that this means periods of many thousands of years. But, however far back this may go, the time-interval must have been far greater that elapsed between the culture that built houses, had the art of spinning and a developed technique in pottery and design, and that remote and generalized stage of humanity in which the stone arrow-point and ax were invented. All this points to a regionally widespread autochthonous culture evolution, owing its generic character to its early regional isolation and its differentiations to the segregation into separated groups imposed upon it by the regional progress of desiccation. In this respect it is a unique ethnographic province, in strong contrast on the one hand with the west, where early man could move freely throughout Europe, Africa, and Asia Minor, and on the other with northern Asia and the Americas.

With the gradual shrinking in dimensions of habitable areas and the disappearance of herds of wild animals, man, concentrating on the oases and forced to conquer new means of support, began to utilize the native plants; and from among these he learned to use seeds of different grasses growing on the dry land and in marshes at the mouths of larger streams on the desert. With the increase of population 
and its necessities, he learned to plant the seeds, thus making, by conscious or unconscious selection, the first step in the evolution of the whole series of cereals.

For a long time the rainfall was doubtless sufficient to ripen grains, as it still is in some of the valleys of Fergana, and in some years even at Samarkand. Later, experience taught the need, and some simple method, of artificial watering, and with this acquisition began the broader development of agriculture and the conquest of the arid regions of the globe. In Asia it rendered possible the civilizations of Elam and Mesopotamia. All the really great prehistoric cultures were developed in arid regions-all of those of which we have knowledge, and perhaps others of which we have not yet found the remains-in Mongolia, Arabia, and the Sahara. The generous soil of the delta-oasis, responding to man's necessitated labor, was the foundation on which the independent cultures of village communities were built up. Only later, when the knowledge thus obtained could be applied to the utilization of great rivers in turning wide deserts into gardens, was it possible to render populous great countries, first under feudal conditions, and later under the centralized power that constituted empire. This later stage was never fully reached in Central Asia and northern Persia. The countless isolated oases, even under Chaldean, Persian, and Arab dominion, never advanced really much more than nominally beyond the stage of local independence.

If the hypothesis previously outlined be well-founded in its essentials, it follows that where we find among the acquisitions of the earliest of the cultures at Anau resemblance to those of neolithic cultures in the west, such similarity can not be due to importation from the western spheres. If they are not due to coincidence, these acquisitions must be considered as having originated in our oasis-world, and to have been transported beyond its limits after the domestication of the horse, or of the horse and camel, rendered extended intercourse possible. Among such native acquisitions we must include a knowledge of copper and lead and the art of spinning, the domestication of animals, agriculture, and probably the art of painting on pottery.

We have seen the birth of the great inner-continental region of the Eurasian Continent. We have seen that from the very condition of its birth it was predestined to a definite course of life-history peculiar to its kind; and treating it as an organic whole, we have seen this course towards ultimate desolation temporarily modified by the climate of the giacial period. What I wish particularly to emphasize is the conception that in the intervention of the glacial period and its reaction on the inner-continental conditions, we must see the initial-the motiving-factors in the evolution of the intellectual and social life of man. Shut off from the periphery of Asia and from the other continents, while still in a low stage of savagery, we see him gradually broken up into smaller groups which are forced into isolation on habitable oases, which are in the main continually diminishing; and we see on these the growth of differentiated, but fundamentally related, cultures. I,astly, and most important of all to us, we see here man under the spur of Necessity, the relentless goddess of evolution, building in village communities, in agriculture, and in the essential industries, the foundations of civilizations, to the reaction of which, upon each other, and upon cultures evolved later on the Nile, and in Mesopotamia, and on the Mediterranean, we owe the understructure of modern western civilization. 


\section{CHAPTER V.-MIGRATIONS.}

Some important inferences may be safely drawn from what has been said in the preceding pages; but, first, it is desirable to restate the following as premises:

The cultivation of cereals was discovered in Asia long before 8000 B. c.-before the founding of the oidest settlement at the North Kurgan. The domestication of cattle, pigs, and sheep, and probably of the horse, was accomplished at Anau between 8000 and 6800 B. C.; that is, after the founding of the North Kurgan settlement. Consequently, the agricultural stage preceded the nomadic shepherd stage in Asia.

It follows, therefore, that before domestication of animals was accomplished, mankind in Central Asia was divided sharply into two classes-settled agriculturists on the one hand, and hunters who wandered within a limited range on the other hand. When the nomadic hunters became shepherds, they necessarily wandered within ever-widening limits as the seasons and pasturage required for increasing herds. The establishment of the first domestic breeds of pigs, long-horned cattle, large sheep, and horses, was followed by a deteriorating climate which changed these to smaller breeds. This climatic deterioration, by diminishing the productivity of the fully peopled oases, caused unrest and migrations of agriculturists. Its effects were not so acutely felt till much later by the nomad shepherds, because, being dependent on the grasses of a semi-arid region, they would be able for a long time to maintain their herds by extending the range of pasturage.

This process of expansion, together with branchings off, would in time cover the plains of Central Asia from the Caspian eastwards with nomadic shepherds, until the principal races of peoples of Inner Asia had been raised to this stage of civilization. In considering the length of time needed to effect an overcrowding of the pasturage areas, we may not use the experience of the ranges of the Americas and Australia during the past half century; for these were suddenly fully stocked, and breeding was forced, to supply food for half the world. In Asia the problem was simply to feed and clothe the family group. It is, therefore, probable that the pasture ranges of Asia sufficed for expansion and maintenance of herds through the first succeeding dry extreme of climate. It was during the following favorable climatic oscillation, lasting till into the III millennium B. C., that the great expansion of population of shepherd nomads and their herds over all Inner Asia took place.

Dr. Duerst identifies the second breed of sheep with the turbary sheep (Torfschaf) and the pig with the turbary pig (Torfschwein), which appear towards the end of the neolithic period in the Swiss lake-dwellings, and other neolithic stations of Europe, already as domestic animals, and unaccompanied by any transitional forms that might indicate local origins. These animals must therefore have been descendants of those domesticated on the oases of the Anau district. The turbary 
breed was established not later than towards the end of the oldest settlement of the North Kurgan; that is, according to my chronology, about 6000 B. C. It was formed during the part of the climatic cycle in which prevailed those conditions, unfavorable to nutrition, to which the breed owed its stunted character. Its characteristic features became firmly fixed during the subsequent existence of many generations after transference to a nomadic life on the arid plains during the dry extreme of the cycle. And the firm establishment of the characteristics of the breed is proved by its persistence down to the present time, for it still exists at one point in the high Alps of the Grisons in Switzerland, and in Wales.

These domestic animals make their appearance in European neolithic stations apparently contemporaneously with an immigration of a people of a roundheaded Asiatic type which seems to have infiltrated gradually among the prevailing long-headed Europeans. The presumption is, therefore, that these animals were brought from Asia by this round-headed people, and that we have in this immigration one of the earliest, indeed probably the earliest, postglacial factor in the problem of Asiatic influence in European racial as well as cultural origins, for they brought with them both the art of cattle-breeding and some knowledge of agriculture.

While, however, the ultimate Transcaspian origin of these domesticated animals and of the wheat and barley, and probably of the accompanying roundheaded people as well, may be considered as practically assured, it is a noteworthy fact that we look in vain among the finds from the Swiss lake-dwellings and other neolithic stations of Central Europe for objects that recall the industrial culture of the primitive Transcaspian oasis towns. It is possible that the spindle-whorl and the art of spinning may have been brought to Europe with the arts of breeding and of agriculture. But aside from these the industrial products present in the main no Central-Asiatic suggestions. Instead of these we find only the evidences of the most-developed European neolithic culture with its store of finely wrought stone implements and characteristic primitive European pottery. This remarkable absence of traditions of the advanced industrial arts of the Transcaspian oasis towns seemed difficult to explain, if we should assume that the domestic animals and cereals were brought to Europe by the descendants of the oasis people who originated them, for we should not expect such acquirements to be lost, but rather to find them added to those of the local cultures.

It was not until May, 1907, that the basis of an explanation was discovered, when Professor Sergi of Rome kindly examined a series of skulls which I had submitted to him at his suggestion, including two of adults who had not been formally buried. These skulls had been sent to America by Mr. Langdon Warner, who had been intrusted by Dr. Schmidt with the uncovering and recording of the skeletons of children encountered during our excavations. They were all inscribed at the time of discovery with the exact vertical and horizontal position in the kurgan strata, and they ranged from the oldest layers of the North Kurgan through the first and second cultures to the top of the kurgan. As the reader will observe by referring to Professor Sergi's report, they are all dolichocephalic or mesocephalic, 
with a total absence of the round-headed element.* No skulls were kept from the South Kurgan, but Mr. Warner photographed in norma lateralis one obtained from the later part of the copper culture, the only formally buried adult found by us. From this photograph Professor Sergi pronounced the skull to be very dolichocephalic. We are therefore justified in assuming that domestication and the forming of the several breeds of domestic animals at Anau, as determined by Dr. Duerst, were effected by a long-headed people. And since the people of the two successive cultures were settled oasis agriculturists and breeders, we may assume as probable that agriculture and settled life in towns on the oases originated among people of a dolichocephalic type. Since Dr. Duerst identifies the second breed of sheep established during the first culture at Anau, with the "turbary" sheep which appears without transition from local forms, in neolithic stations in Europe, contemporaneously with skulls of the broad-headed Galcha type, it should follow that the domestic animals of the European neolithic stations were brought thither, together with wheat and barley, by round-headed immigrants (of an Asiatic type).

We have at present no means of knowing how many links there may have been in the chain of transference between the oases and Europe. But since the original agriculturists and breeders were long-heads, it seems probable that the immigrants were broad-headed nomads, who, having acquired domestic animals and rudimentary agriculture of the kind still practised by the shepherd nomads of Central Asia from the oasis people, infiltrated among the neolithic settlements of Eastern and Central Europe, and adopted the stone-implement culture of the hunting and fishing peoples among whom they came. It is the province of the anthropologist to discuss the bearings of Professor Sergi's determinations of skulls from the lowest, highest, and intermediate culture-strata of the North Kurgan at Anau; I will merely venture to recall Ujfalvy's insistence that in the forming of the Aryan-speaking broad-headed Galchas and Tadjiks there was a crossing of a dolichocephalic people on a broad-headed, presumably Asiatic stock. The Galchas and Tadjiks inhabit the valleys of the Hindu-Kush, where eastern Irania meets High Asia and Eastern Central Asia, the home of the broad-headed mongoloids. And in this connection it is surely not without significance that throughout the whole historical period, the combination of settled town life and agriculture has been the fundamental characteristic of the Aryan-speaking Galchas, and of the Iranians inhabiting western Central Asia and the Persian plateau, while the peoples of pure Asiatic mongoloid type have been essentially shepherd nomads, who, as I have shown, could have become shepherds only after the settled agriculturists of the oases had established domesticated breeds of cattle. The temptation is strong to carry this line of argument into the ficld of Aryan problems; but it would be beyond my province, and premature in our present state of ignorance of the great and successive ethnic changes that have doubtless occurred over this vast area during so many millenniums. But, however great these changes may

* Professor Sergi tells me that dolichocephaly in the skull of an infant is assurance of the same condition in the adult. 
have been, there can be little doubt that the long-headed people were located there in isolation from the rest of the world since preglacial, or at least since early interglacial, time.

As I have stated in chapter III, this conclusion follows necessarily from the total absence, during the first two cultures at Anau, of all traces of stone arrowpoints and spear-heads and celts, although they made from flint well-formed flakes, apparently for the cutting edge of sickles, and fashioned from stone maceheads and slingstones and vessels of alabaster. Arrow-points, spear-heads, and axes of stone abounded during the last interglacial epoch from the Dnieper to the Atlantic and throughout Northern Africa; and it is not conceivable that, if the ancestors of the Anau long-heads had ever possessed this important acquirement, they would have lost or abandoned it before they were able to replace it with metals. This isolation, as already stated, was caused by the glacial period, during which a large inland sea, formed by the waters from the ice-cap that covered Russia and from the glaciers of the Caucasus, Hindu-Kush, Tian Shan and Altai Mountains, cut off communication with Europe. At the same time the glacier-covered mountains of Armenia, of the Elburz, and of the lofty Zagros ranges, second in height only to the Hindu-Kush, intercepted intercourse with Asia Minor. I would therefore consider the area of isolation to have included the Iranian Plateau from the Zagros ranges on the west to the then impassable glaciercovered Hindu-Kush on the east; and the Transcaspian plains from the Inland Sea on the west to the then also impassable Tian Shan on the east. The Inland Sea, according to the observations of Konshin, Muschketoff, and other Russian geologists, extended eastward beyond the Aral, leaving a strip of lowland plains on the south, which, bordering on the Kopet Dagh range, widened out on the east, to connect with the Siberian steppes, then probably tundra-covered.

Excepting the connection with the Siberian steppes, there were only three points by which this area of isolation could be entered by land. In the east the so-called Djungarian Gate may have then as now been open to the plains of Eastern Turkestan and Mongolia. In the extreme southeast communication with India may have been possible along the seacoast. And in the southwest it is possible that the way was open through Susiana to Chaldea and Arabia.

Somewhere within this broad region our long-headed people became isolated while still in that very primitive stage of culture in which the making and use of stone arrow-points and spear-points were still unknown, and here under the spur of necessity they gradually evolved the organized settled life and agriculture of which we find them possessed when they founded the North Kurgan at Anau.

The area thus outlined is both vast and varied in topographic and climatic character, and the isolation might well have been shared by peoples of different primitive stocks. The Iranian Plateau is traversed in the west by very high mountain ranges inclosing extensive high and well-watered valleys, difficult of intercommunication and 3,000 to 7,000 feet above the sea. The central portion consists of great open areas, which, though now extremely desert wastes, must during the glacial period, and for a long time after, have been bordered by grassy plains traversed by large streams. And the northern part-the modern Khor- 
asan-which is still the most fertile part of Persia, must have been formerly still more favorable to habitation. To the north of the plateau the lowland strip lying between the Kopet Dagh and the Inland Sea and extending eastward to lose itself in the valleys of the Murg-ab, Oxus, Zerafshan, and Syr-darya, has ever since the glacier time been occupied by a chain of gradually shrinking oases. There were, therefore, many provinces potentially capable of supporting and differentiating populations.

The field is great, and only awaits scientific exploration to throw a strong light into the anthropological and cultural beginnings of the ancient world. As far as our present knowledge goes, the earliest occurrence of organized town life with agriculture and breeding of animals is confined to long-headed people on the oases, with a strong presumption that all these cultural characteristics were originated by them. Although many millenniums have passed since the disappearances of the successive cultures of the North Kurgan, it should be difficult to suppose that the descendants of this oasis stock are not still represented among the settled peoples of Persia and India, modified in various degrees by fusions with Semites from the west and Turanians from the east, and perhaps with other stocks which may have shared the long isolation.

As has been already stated in the foregoing pages and on plate 5 , there was a remarkable parallelism between the growth and disappearance of the successive cultures on the Anau oasis on the one hand and the favorable and unfavorable phases of the climatic cycles on the other hand, respectively.

The people of the second culture, who in the North Kurgan succeeded those of the first culture, being long-headed, were racially related to their predecessors, and their civilization, as shown in the burial of children in the houses and in their possession of agriculture, was of the same order. But the fact that they made an entirely different and more advanced pottery with a different scheme of painted ornamentation, and that they had a fuller knowledge of copper and new domestic animals, shows that they came from an oasis sufficiently distant to account for the differences in culture and in the varieties of domestic animals, for no remains of the dog nor of the goat nor of the camel were found by Dr. Duerst among the bones from the first culture. We have in this the evidence that the reaction of a deteriorating climate upon overcrowded populations had already set in motion migrations that were to result in the displacement or extermination of the weaker occupants of other oases.

The fact that these immigrants of the second culture brought with them both lapis lazuli and the camel makes it probable that the movement was from east to west, and the occurrence of bones of the turbary sheep at stations in Asia Minor is very possibly an indication that migrations of people of the oasis stock extended at least as far as the Mediterranean. The migrations of this period of unrest, in the first climatic cycle platted on plate 5, began, according to my chronology, at least about 6000 B. C. The founding of the South Kurgan and the continuance of its flourishing copper culture during thirty centuries shows that the climatic conditions of the favorable phase of the cycle may well have checked this early migratory movement. 
It does not seem probable that in the unfavorable part of the first climatic cycle indicated on plate 5 , so soon after the establishment of the turbary breed of sheep, the development and expansion of shepherd-nomad populations had obtained to such an extent as to be sufficiently affected by the climatic conditions to cause migrations beyond the steppes of Asia.

We may perhaps assume, as a working hypothesis, that peoples of the hunter stage of life received during this period from the oases domestic animals and the elements of agriculture, and that it was not until within the fourth millennium B. c. that the renewed trend toward the arid extreme set in motion those movements of nomadic peoples which, during prehistoric and later times, were destined to sweep in successive waves as far as the Atlantic, and to profoundly affect the physical and social characteristics of the modern world.

In these outward driftings of peoples, the lines followed by the nomad migrants would necessarily be over the Eurasian steppes and to the north of the Black Sea.

The agriculturists of the oases would, under an equal necessity, move from oasis to oasis, conquering or going under. The routes thus affected were those that ended in Mesopotamia and in Asia Minor.

\section{RELATION OF ANAU CULTURES I AND II TO EARLY BABYLONIA AND SUSIANA.}

Dr. Duerst identifies the long-horned ox of Babylonia with that of Anau. Therefore, unless we are prepared to assume both that the domestication of the ox was accomplished independently in different places, and also that at these different centers there existed the same wild form-Bos namadicus-it follows that the domestication of this animal at Anau antedates its appearance in Babylonia, and that the first civilization of Anau is older than that stage of Babylonian culture in which the domesticated ox makes its appearance. And since the archaic linear form of script, which preceded the wedge-shaped cuneiform, had characters derived from an earlier pictographic stage, both for a wild bovine and for the domestic ox $\forall$, this domestic animal must have been already known during the pre-Semitic Sumerian civilization, that is, before the time of Sargon of Accad, who is usually dated at about 3800 B. C., or about 2800 B. C., according to Winckler and Meyer.

Thus in that remote time, long before Sargon of Accad, when the protocuneiform script was still in the pictographic stage, far away beyond the Iranian plateau, and about 500 miles north and 600 east of Babylonia, the people of Anau lived in cities, cultivated the principal cereals that were raised later on the Euphrates and on the Nile,* and bred cattle which they had domesticated out of the local wild forms, and which they had, directly or indirectly, transmitted to Chaldea. This settled agricultural civilization was, excepting cattle-breeding,

* No traces of cereal grains were found in tombs of the older, indigenous Egyptians. De Morgan, "Les Origines de l'Egypte." 
already fully developed before the founding of the first settlement known to us at Anau.

In which part of the world did its traditions-its chain of cultural evolution originate? From what we know of prehistoric Europe we can now say without much fear of contradiction, that while Transcaspia contributed wheat and barley and the "turbary" domestic animals to neolithic Europe, it received nothing in return until a very much later time. We may, I think, safely say that Africa contributed none of those cultural elements that find their expression in the works of man found in the earlier cultures at Anau.

While it is possible that the ancestors of these Anau-li came from Africa, any such immigration must have entered Asia either before the glacial period, or during one of the earlier interglacial epochs; that is, before the development of the paleolithic flint-implement civilization, which has left the now desert wastes of northern Africa, as well as Europe, covered with stone weapons of war and the chase.

We have, then, to do with cultural traditions native to Asia. If now we search Asia for similarities of primitive cultures, we find only one point at which archeological research has been pursued with sufficient system and purpose to throw much light on the collective and comparative elements of civilizations. $M$. De Morgan at Susa, and his assistants, Messieurs Gautier and Lampre, in the neighboring Moussian district, have exposed several superimposed stages of cultures antedating the time of Sargon of Accad. At Tepe Mohamed Djaffar-a slight elevation in the Moussian district-they found an extensive flint-implement workshop which had not been occupied since the stone age. In this they found neither celts nor points of arrows or of lances, but immense quantities of flakes in the forms of scrapers (racloirs) and elements of sickles. Nor did they, in all their excavations in the Moussian district, find any points of arrows or of lances of stone. Awls and drills were rare; percuteurs, saws, scrapers, and the little blades to form the elements of sickles, like those of early Egypt, were everywhere in great abundance. At Mohamed Djaffar these were associated with a thick, hand-made, red, and often burnished pottery, some of which was decorated with simple designs, either scratched in with a point or painted in lines of dark red. The stage of transition from the stone age to the copper age is characterized by thin, wheel-made, yellow or light-green pottery, ornamented with designs in brilliant black with representations of human, animal, and vegetable forms. The pottery of the copper age was wheel-made and decorated also with representations of animals, painted in red and black. This successive order of similar cultures is repeated in the lower culture-strata of the citadel of Susa. According to De Morgan, all of these culture stages in Susiana preceded the "archaic" culture which ended about 4000 B. c. (dating Sargon of Accad at 3800 B.c.), and during which an Elamitic proto-cuneiform script appears for the first time in Susa.*

* According to Scheil, one of these inscriptions is of the time of the Patesi, Karabu-sa-in-Susinak, who governed in Susa in the middle, or in the end, of the IV millennium B. C., according to the earlier or the later dating of Sargon of Accad; the others may be older and not younger. 
If we may apply here the law which I have stated as controlling the growth of primitive cities built of air-dried bricks in dry climates, the thickness of the culture-strata exposed by De Morgan's excavations would give an interval of about 1,000 years (at the rate of 2 feet per century) between the end of the stone age and the end of the "archaic" period. Since the stone age and transition strata occur up to 60 feet above the plain, and remains of occupation extend several meters below the level of the plain, it is not improbable that there are not less than 2,000 or 3,000 years of prearchaic culture represented here.

Thus the exposed earliest civilizations of Anau and Susiana, separated by the broad expanse of the Iranian plateau, had several most fundamental traits in common, although the possession of the potters' wheel at Susa and a wider range of motives of decoration of pottery point to a civilization probably more advanced in development and of later date than that of Anau II. In both regions the people were settled in towns built of air-dried bricks; both peoples had agriculture, both peoples used the pivotal door-stone, and both had well-developed potters' arts and painted ornamentation. And in both places excavations, while showing extensive use of flint for sickles and other domestic purposes, have failed to bring to light any traces of its use, in the earliest cultures, for arrows and lances or celts. We may therefore consider both of these earliest civilizations to have been native to Asia. The total absence of stone arrow-points and stone lancepoints in the earliest cultures in Susiana corroborates the inference drawn from their absence in early Anau, that these civilizations were evolved during a period of isolation at least from Africa and Europe, dating from preglacial or early interglacial time. I have, in chapters I and IV, traced the cause of this isolation to the influence of the glacial period, and have given reasons for including within its sphere the whole region between the Caspian Sea and Mesopotamia on the west, and the Hindu-Kush and Tian Shan mountains on the east, with an additional but detached and perhaps independently isolated area to the east of these mountain barriers, including the whole of the Gobi region.

It would seem, then, that the widely separated civilizations of Anau and Susiana must have been genetically related, and that the region of isolation must have included not only Transcaspia but also Susiana, at least down to the time when the earliest culture of Susa, using sickle-flints and the contemporary variety of painted pottery, ceased to exist. A genetic relationship between these two civilizations presupposes a region in which they were in intimate contact, living in an agricultural stage of culture on oases somewhere, either on the Iranian plateau or on the lower lands along its northern edge.

We have at present no data for closely defining the region where this nextunderlying stage of culture existed. It could not have been on the Babylonian plain, for as Professor Sayce remarks, this was in its natural condition a pestiferous marsh, which could be conquered for agriculture "only by a people armed with a civilization which enabled them to dig canals, to mold bricks, and pile their houses and temples on artificial foundations."* This is due to the long-continued annual inundation of the plain common to the two great rivers, the flood of one

* Sayce, Archeology of the Cuneiform Inscriptions, p. 76. 
of which follows upon that of the other and lasts till September.* Further, at the time of the earliest culture at Anau, the Babylonian plain was still under the waters of the Persian Gulf.

There can be no doubt that the people who first subjected these rivers to their use had lived for generations on oases where the conditions, while less difficult, were still such as forced the development of the considerable engineering skill required in attacking this greater problem. This presupposes a long perspective of time, with perhaps several stages of migration in which Susiana may have been the last station on the way to the Euphrates, where the beginning of Babylonian culture may have been contemporaneous with the early life of the South Kurgan copper culture of Anau III. The relation of these cultures to the period and region of isolation from the outside world determines for them an origin eastward from Mesopotamia. The vast central region of the Iranian plateau is eliminated. There remain the long longitudinal depressions on the west, Sistan in the eastern half and northern Khorasan and the Transcaspian oases extending along the Kopet Dagh and into the embayments of the Oxus, Zerafshan, and Fergana on the north. It would seem that the region from which the culture possessing the characteristics common to early Anau and early Susiana radiated must have been in one of these directions.

We know that in the second culture of the North Kurgan the camel and lapis lazuli appeared, together with the dog and goat, and with new varieties of painted pottery. The lack of mention of one-humped camels in Babylonia or Assyria before Salmanesar II, in the ninth century B. C., strengthens the probability that our Anau camel came from the East; and since the great source of lapis lazuli is in the Hindu-Kush mountains, its presence in Anau would seem to point to a westward drift of migration of a people whose culture was related to that of their predecessors of Anau, and to eastern Irania or Bactriana as the point we are seeking. So also should the fact that the Sumerians knew the lion only after their arrival on the Chaldean plains. $\dagger$ But even if this drift were from the east its starting-points may have been, like Anau and Susiana, points to which an earlier radiation had taken place after the beginning of agriculture and of settled life. For, there can be no doubt that the conditions which we find already existing at the very beginning of the first culture at Anau-settled town life, cultivation of the soil, and a developed potters' art and painted designs-required for their evolution a time-perspective which vanishes in as yet unpenetrated darkness.

As at a later period the natural economic possibilities of the Chaldean plains invited irresistibly the fusion of the surrounding peoples of different ethnic and linguistic stocks into the mold of Sumerian culture, so also it may not be improbable that at an earlier period and in eastern Irania, similar conditions had produced similar fusions from which the Sumerians branched off to the westward.

\footnotetext{
* Hommel, Geschichte Babyloniens u. Assyriens, p. 186.

tThis is shown by the absence of a Sumerian word for lion (Hommel). Now, while the lion exists in Mesopotamia and in southern Susiana on the one hand, and in India on the other, contrary to current statements it does not exist on the Persian plateau, nor in either Afghanistan, Baluchistan, or Turkestan (Blanford and O. St. John). Oppert (quoted by Elisée Reclus, in L'Homme et la Terre, p. 492) states that "the primitive pictographic signs recall objects belonging in a climate different from that of Chaldea-no lions or leopards; no one-humped camel, but the two-humped Bactrian; no vines or palms, but conifers." The fact that the one-humped camel first appears in the gth century B. C., on the black obelisk of Salmanesar II, would seem to indicate a late domestication of the Arabian camel.
} 


\section{LIST OF WORKS CONSULTED IN PREPARING PART I}

ABEL, O. Ueber einen Fund von Sivatherium giganteum bei Adrianopel. Wien, I904 (Sitzungsb. d. K. Akad. d. Wiss.)

Adaxs, B. The new empire. N. Y., 1902.

ADLER, C. Ancient Eastern politics; abstr. of lecture. (From Johns Hopkins Univ. Circ., no. 114,1894 )

ANDREE, R: Ethnographische Parallelen und Vergleiche. Lpz., 1889.

Andrian, F. Freiherr von. Prähistorische Studien aus Sicilien. Berlin, 1878.

Andrussov, N. I. (Der Adschi-darja oder Karabugas-Busen. (Petermann's Mitteil., 43. Bd., 1897.)

Геологическіе изсльдованія въ Закаспіискои Области, 1887. [Geоlogical researches in the Transcaspian regions, $i$. $e$. east of the Caspian Sea.] S. Peterb., 1889.

— Керченскін иввестнякъ и его фауна. [Kertsch limestone and fauna.] S. Peterb., 1890. (Imperial Mineral. Soc. of Russia, Mem., v. 26.)

— Матеріалы къ познанію Шрикасniflckaro Heoreнa. [The Caspian Neogen.] S. Peterb., 1902.

Anthropologie, v. 1-17. Paris, 1890-1906. 17 v.

Arrian. Anabasis of Alexander, and Indica; tr. by E. J. Chinnock. Lond., Bohn, 1893.

BAEDEKER, K: Egypt. 5th ed. Lpz., 1902.

BALL, C. J. Light from the East. Lond., 1899.

Barbot DE MarNy, N. P. Tруды ApajoКаспінскои өкспедиціи. [Travaux de l'expédition Aralo-caspienne, livr. 6.]

BAYER, F : Untersuchungen über die ältesten Gräber- und Schatzfunde in Kaukasien ; hrsg. mit Vorwort von R. Virchow. Berlin, 1885. (Zeitschr. f. Ethnol., 17. Jahrg.)

BECK, G. Der Urmensch. Basel, 1899

BECK, L. Geschichte des Eisens in technischer u. kulturgeschichtlicher Beziehung. 2e Aufl. Braunschw., 1891 .

Berrin. Internat. Geog. Kongress, 1899. Verhandlungen. 2. Th. Berlin, 190r.

BerLloux, E. F. Les premiers voyages des Européens dans l'Asie Centrale et au pays des Sères, la Chine du nord; with map after Ptolemy. Lyon, 1898 . (Soc. de Gćog. de Lyon, Bull., 1808.)

Bertrand, A. Archéologie celtique et gauloise. Paris, 1889.

La Gaule avant les gaulois. ze éd. Paris, 1891.

Bewerth, F. Die Nephrit-Jadeit Frage. (In Anthrop. Gescllsch. in Wicn, Mittheil., v. 22, 1890.)

Blasio, A. DE. Crania agyptiaca vetera et hodierna. Siena, I893-94. 2 pts. (Revista ital. d. sci. nat., v. 13, I4.)

Bonvelt, E. Einige Nachrichten d. alten griechischen $u$. römischen Schriftsteller über die Skythen, u. s. w. [St. Petersb., 1878.]
BorchardT, L: Bericht über die Corrosion d. Sandsteinmaterials der Tempelbauten auf Philx. (Sitzungsb. d. K. Preuss. Akad. d. Wiss. zu Berlin, 1896 .)

— Nilmesser u. Nilslandsmarken. Berlin, 1906.

Boulitchov, N. DE. Antiquités de la Russie orientale. (MоскBa, 1902.

- Fouilles de la Russie centrale, Kourgans et Gorodietz; recherches archéol. sur la ligne de partage des eaux de la Volga et du Dnieper. (Москва, ) 1900.

Bourdoukov, N. Гонтарныя пздылія среднен̆ Авік. [Ceramic art of Central Asia.] S. Peterb. [1904].

Boyd, H. A. Gournia; rept. of American Explor. Soc.'s excavations at Gournia, Crete, I90I-03. Repr. from Univ. of Pcnn. Dept. Archaol., Trans., v. I, no. I, 1904.

British Association. Archæological papers. 66th report, 1896

BRUN NhOFER, H. Vom Aral bis zur Gangâ. Lpz., 1892. BUDGE, E. A. W. Egyptian magic. Lond., r 899 . antiquities. [Lond.], I000.

- The Nile. 3d ed. Lond., 1893.

Bullettino di palet Nologia italiana, v. 1-33. Parma, 1875.1907. 33 v.

Burves, Lieut. A. Travels into Bokhara, 1831 33. Lond., 1834. $3 \mathrm{v}$.

Burrows, R. M. Discoveries in Crete. Lond. 1907.

Chalfant, F. H. Early Chinese writing. Pittsb. 1906. (Carncgie Mus., Pub., v. 4 no. 1.$)$

Colini, G. A. Rapporti fra l'Italia, e.c.c., durante l' età neolitica. [1003?]

Collignon, M., and Couve, L: Catalogue des vases peints du Musée National d'Athènes. Paris, 1902-04. 2 v.

Delitzsch, F: Babel und Bibel. Lpz., 1903.

DE Morgan, j. La délégation en Perse du Ministère de l'Instruction Publique, 18971902. Paris, 1902.

- L'histoire de l'Elam d'après les matériaux fournis par les fouilles à Suse, 18971902. Paris, 1902.

- Mission scientifique au Caucase; études archéol., etc. Paris, 1889.

Mission scientifique en Perse. T. 4, Ie $2^{e}$ pte. Paris, 1896-97. $2 \mathrm{v}$. and cartes.

Recherches sur les origines de l'Égypte; l'áge de la pierre et des métaux. Paris, 1896.

and others. Recherches archéologiques. v. I, 7, 8. Paris, 1900-05. 3 v. (France, Ministère dc l'Instr. Pub. Délégation en Perse, Miém., v. I, 7, 8.)

- and others. Recherches archéol.; ethno graphie préhistorique et tombeau roya de Négadah. Paris, I897.

DeNiker, J. Les races de l'Europe; l'indice céphalique en Europe. Paris, I899.

Dmitriev-Mamonov, A., $c d$. Путеводите.1b по Туркестани. [Guide to Turkestan.] S. Peterb., 1903. 
DörPFELd, $\mathrm{W}$ :, and others. Troja und Ilion; Ergebnisse d. Ausgrabungen, 1870-94 Athen, 1902. $2 \mathrm{v}$. Continuous pagina-

Duerst, Jion. U. Experimentelle Studien über die Morphogenie des Schädels der Cavicornia. n.t.p. [Zürich, 1903.]

Die Rinder von Babylonien, Assyrien u Aegypten $u$. ihr Zusammenhang mit den Rindern der alten Welt. Berlin, 1899.

- Die Tierwelt der Ansiedelungen am Schlossberge zu Burg an der Spree. Zürich, 1903 .

Dumont, A. Terres cuites, orientales et grécoorientales. Paris, 1884.

Evans, A. J. Further discoveries of Cretan and Egian script, with Libyan and protoEgyptian comparisons. Lond., 1898. (From Journal of Hellenic studies, v. 17.)

Evans, Sir J. Ancient stone implements, weapons, and ornaments of Great Britain N. Y., 1872 .

- Same. $2 \mathrm{~d}$ ed., rev. Lond., 1897.

Fedtschenko, В. А. Matepiaлъ для флоры Шугнана. [Material for the flora of Shugnan.] S. Peterb., 1902.

- Ueber die Elemente der Flora des WestTian-Schan. Berlin, 1903

FitzNer, R. Forschungen auf der bithynischen Halbinsel. Rostock, 1903.

Forsyth, Sir T. D. Ost-Turkestan u. das Pamir-Plateau nach den Forschungen d. Brit. Gesandtschaft, 1873-74. Gotha, 1877. (Ergänzungsheft, no. 52, zu Petermann's "Geogr. Mittheil.")

Fovquer, D. Contribution à l'étude de la céramique orientale. Caire, 1900. (Instit. Egyptien. Mem.)

Fourdrignier, E: L'àge du fer; Hallstatt, le Marnien, la Tene. (Extr. de la Soc. Préhist. de France, Bull., 1904.)

Frech, F., and Geinitz, E. Die Flora u. Fauna des Quartärs. [Stuttg., 1902.]

Funlrotr, C. Der fossile Mensch aus dem Neanderthal. Duisb., 1865.

Geiger, W: and KunN, E. Grundriss der iranischen Philologie. Strassb., 18961904

Gexish, K. Каталогъ высотъ Авіатскон Россіи. [Catalogue of elevations in Asiatic Russia.] S. Peterb., 190I.

GinzEL, F. K. Handbuch der mathematischen u. technischen Chronologie. I. Bd. Lpz., 1906 .

Gladstone, J. H. On metallic copper, tin and antimony from ancient Egypt. (Soc. of Biblical Archaol. Proc. 1892.)

Golds MID, Sir F: J :, ed. Eastern Persia ; journeys of the Persian Boundary Commission, 1870-72. Lond. 1876. $2 \mathrm{v}$.

Guignes, J. DE. Mémoires dans lequel on entreprend de fixer la situation de quelques peuples scythes dont il est parlé dans Hérodote, etc. (Méms. de littérature, pp. 539-572.)

Hall. Earliest civilizations in Greece.

HEH N, V. Cultivated plants and domestic animals in migration from Asia to Europe; [tr.] by J. S. Stallybrass. Lond. 1901 .
HeIERLI Urgeschichte der Schweiz. Zürich, .901.

HeLbig, W. Führer durch die öffentlichen Sammlungen klassischer Altertümer in Rome. 2e Aufl. Lpz., 1899.2 v.
Die Italiker in der Poebene. Lpz., 1879.

Hed WALd, $F$ : voN. Russians in Central Asia ; tr. by Lt. Col. T. Wirgman. Lond., 1874

; ERODOTUS. History; new Eng. version, with notes, etc., by G: Rawlinson [and others]. N. Y., $1880.4 \mathrm{v}$.

Heuzy, L. Musée Nat. du Louvre; catalogue des antiquités chaldéennes; sculpture et gravure à la pointe. Paris, 1902 .

HILPRECHT, H. V. Explorations in Bible lands during the 19th century. Phila., 1903.

Hirth, F: Aus der Ethnographic d. Tschau Ju-kua. München, I898.

Die chinesische Sprache in Wort $u$. Schrift. Lpz., $1902 . \quad$ (Allgem. Zeitung. Beilage, no. 120, 121.)

Hunnenforschungen. Budapest [1000?]

Neue Forschungen über das Geschlecht Atilla's. München, 1900.

Ueber Entstehung u. Ursprungslegenden der Malerei in China. Lpz., 1900.

Ueber Wolga-Hunnen und Hiung-nu, I890. München, 1900.

Hoernes, M. Der diluviale Mensch in Europa. Braunschw., 1903.

- Die Urgeschichte des Menschen. Wien, 1892.

- Urgeschichte $\mathrm{d}$. bildenden Kunst in $\mathrm{Eu}$. ropa (-500 B. c.]. Wien, 1898.

Ном мег, F. Geschichte Babyloniens u. Assyriens. Berlin, 1885 .

Alt-Babylonischer Ursprung der egyptischen Kultur. München.

Houtum-SCHINDLER, Gen. A Eastern Persian Irak. Lond., 1897.

Ihering, R. von. Evolution of the Aryan; tr. by A. Drucker. N. Y.. 1897

Institut Francais d'Arch Gologie Orientale. Service des Antiq. de l'Égypte. Annales. v. 4 Caire, 1903.

International Geological Congress. Guide des excursions du $7^{e}$ Congrès Géolo. gique International. St. Petersb., 1897

Jivanji JamsuedjI Modi. The religious sys. tem of the Parsis. Bombay, 1893 .

Jost, W. Die Entwicklungsphasen der geometrisch-ornamentalen Urtypen im Vergleich mit d. jetzigen Verzierungskunst d. Bewohner d. Sudseearchipels. Düsseldorf, 1893.

Journal of Hellenic Studies, v. 11 , no. I. Lond., 1890.

Justr, F. Geschichte des alten Persiens. Berlin, 1879.

KaUlbars, A. V. AT.1act, Iportpc Bт вЪ низовьяХъ р. Аму-Дарьи. [Atlas of measurements of the lower Oxus.] n. p. $[1888]$.

Древнthluie pyc.1a Aмy-Дарьн. (Ancient course of the Oxus.) S. Peterb., 1887.

Низовья Аму-Дарьк. [Countries of the lower Oxus.] S. Peterb., 188I.

KAYSER, E. Lehrbuch d. geologischen Forma. tionskunde. 2e Aufl. Stuttg., 1902.

Keane, A. H. Ethnology. Camb., 1901.

- Man, past and present. Camb., 1899. 
Keidet, H., and St. Richarz, P. Ein Profil durch den nördlichen Teil d. zentralen Tian-Schan. Münch., 1906. (K. Bayer. Akad. d. Wiss. Abhandl., 23. Bd.)

Kelder, F. Die keltischen Pfahlbauten in den Schweizerseen. 2e Auf. Zürich, 1865

KIEPERT, H. Lehrbuch der alten Geographie. Berlin, 1878

KING, L. W. Babylonian religion and mythology. $2 \mathrm{~d}$ impress. Lond., 1903.

Konnakof, N., Tolstor, J., and S Reinach. Antiquités de la Russie Méridionale. $4^{\circ}$. Paris, $189 \mathrm{I}$

Konshin, A. M. Разъясненіе вотроса 0 древнемъ теченіи Аму-Дарьи. [Settlement of the question concerning the ancient course of the Oxus.] $S$. Peterb., 1897.

Kossinna, G. Die indogermanische Frage ar chæologisch beantwortet. (Zcitschrift f. Ethinol., Jahrg. 1902.)

KRAEMER, H., and others. Weltall und Menschheit. v. 2. Berlin [I89o].

KrAMER, - Russland in Mittel-Asien. Lpz. 1898. (Bd. 2 of Russland in Asien.)

LAPPARENT, A. DE. Leçons de géographie physique. $2^{e}$ éd. Paris, I 898 .

— Traité de géologie. $4^{\mathrm{e}}$ éd. Paris, 1900. 3 v.

Larousse illustre, Nouveau. Paris [1897].

7 v. and Suppl.

Legis, G. T. Fundgruben des alten Nordens. Lpz., 1829. 2 v.

LENORMANT, F. Chaldean magic; its origin and development, tr., with adds. and notes. Lond. [ 1877$]$.

- Incantation magique chaldéenne bilingue ; texte primitif accadien, avec version assyrienne, $t r$. et commentée par $\mathrm{L}$ (Journal asiatique, 1878.)

- Les principes de comparaison de l'accadien et des langues touraniennes. Paris, 1875 .

Lissauer, A. Zweiter Bericht über die Tätig keit der von der Deutsch. Anthrop. Gesellschaft gewählten Kommission für prähistorische Typenkarten. Berlin, 1905.

Lyall, Sir A. C. Asiatic studies, religious and social. Lond., 1882

Maefski, F. Полезнье ископаемья Закаспійской области. [Minerals of Transcaspian provinces.] S. Peterb., 1897.

Maraghiannis, G. Antiquités crétoises. ie sér. 50 plates by $M$., texte de $L$. Pernier et G. Karo. [19-]

Margerie, E. DE, and Heim, A. Dislocations de l'écorce terrestre. Texte fr. et allem. Zürich, 1888

Martex, E. A., and othcrs. Les abimes, les eaux souterraines, etc.; explorations, 1888-93, en France, Belgique, Autriche et Grèce. Paris, 1894

Maspero, G. Dawn of civilization; Egypt and Chaldæa; tr. by M. L. McClure. 4th ed. Lond., igor.

- Manual of Egyptian archæology; tr. by A. B. Edwards. 5th ed. enl. Lond. 1902.

Mettzen, A. Abbildungen zu dem Vorträge: Die verschiedene Weise des Ueberganges aus dem Nomadleben zur festen Siedelung bei den Kelten, u.s. $a$. Breslau, 1863.
Mestorf, J. Vorgeschichtliche Alterthümer aus Schleswig-Holstein. Hamb., 1885.

Meyer, A. B. Die Nephritfrage kein ethnologisches Problem. Berlin, 1883.

Meyer, E. Aegyptische Chronologie. Berlin, 1904. (K. Preuss. Akad. d. Wiss. Abhandl., 1904.)

Sumerier u. Semiten in Babylonien. Berlin, 1906.

Minaev, I. Свђдђнія 0 странахъ по верховьлхт Аху-Дарьи. [Countries on the upper Oxus.] S. Peterb., 1879.

Mirza MUhammad Haidar The Tarikh-iRashide; history of the Moghuls of Central Asia; ed. with notes by N. Elias; tr. by E. D. Ross. Lond., 1895 .

Montelius, $O$. Die älteren Kulturperioden im Orient $u$. in Europa. vol. 1. Stockholm, 1903.

La civilisation primitive en Italie, depuis l'introd. des métaux. Stockholm, 1895. 4 v. v. I, text; v. 2-4, plates. Die Chronologie d. ältesten Bronzezeit in Nord-Deutschland $u$. Skandinavien. Braunschw., 1900.

Die Kultur Schwedens in vorchristlicher Zeit ; übersetzt von C. Appel. Berlin, I885.

- Der Orient u. Europa, übersetzt von J. Mestorf. Stockholm, I899.

Morgan, E. D. Recent geography of Central Asia from Russian sources. n.t.p. [1886].

Much, M. Die Heimat der Indogermanen. Berlin, I902.

Die Kupferzeit in Europa u. ihr Verhältniss zur Kultur der Indogermanen. Wien, 1886.

- Samc. 2e verm. Aufl. Jena, 1893

Musн ketov, I. V. Tуркестанъ. [Turkestan; geol. and geogr. descr., 1874-80.] T. I. S. Peterb., 1886

- Краткін̆ очеркт геолог. строенія Закасп. области. [Brief sketch of the geological structure of the Transcaspian provinces.] S. Peterb., 1891.

Mrres, J: L. Early pot-fabrics of Asia Minor. (Anthrop. Institute, Journal, v. 33, I903.)

- Polychrome pottery from Kamárais in Crete. (From Soc. of Antiquarics, Proc., 1895.)

- and OH NEFAlSCH-RICHTER, M. Catalogue of the Cyprus Museum. Oxford, 1899.

Ialivin, V. P. Краткая исторія Кокандcharo ханства. [Short history of Kokand.] Kazan, I886.

Nicoluccı, G. . . Gl' Indo-Aryi ; memoria letta all' Accad. Pontaniana. Napoli, I902.

Nikitis, S., and Ossoskov, P. Зав0.1æъе. [La région transvolgienne de la carte géol. gén. de la Russie.] $n$. p., I 888. (Vol. 7, no. 2, of the Mémoires du Comité Gíol.)

Nürsce, J., and others. Das Schweizersb.ld; eine Niederlassung aus palæolith. u neolith. Zeit. 2e verm. Aufl. Zürich [1902].

Oh nefalsch-Richter, M. Ausgrabungen auf Cypern. (Verhandl. d. Berlin. Anthron. Gesellsch., I 899 .)

- Kypros; die Bibel und Homer. Berlin, I893. 2 v. 
Ostroymov, N. P., and Anitchioo, I. V. Описаніе археолог., еtс., коллекцін. [Descr. of the archeol. and numismat. collections of the Tashkent Museum and Turkestan Archæological Circle.] Tashkent, 1900.

Pantusov, N., and others. Various kurgans and the Samarkand ossuaries. n.t.p. [1899?]. Text in Russian.

Penck, A. Die alpinen Eiszeitbildungen u. der prähistorische Mensch. Braunschw., 1903.

- and Brǘckner, E: Die Alpen im Eiszeitalter. n.t. p. [19-?]

- and Richter, E. Glazialexkursion in die Ostalpen. n. p. [1903].

Penka, K: Die Herkunft der Arier. Wien, 1886.

Perrot, G., and Chipiez, C: Histoire de l'art dans l'antiquité. Paris, 1882-1903. $8 \mathrm{v}$.

Petersen E. Funde u. Forschung. (K. $D$. Archaeol. Inst. Rom. Mittheil., Bd.

Petrie, W. M. M. F. Abydos. Pt. II. Lond., 1903. (Egypt Explor. Fd., 24th Mem.)

Methods and aims in archæology. Lond., 1904.

Researches in Sinai. Lond, 1006

PIEtTE, E: L'époque éburnéenne et les races humaines de la période glyptique. SaintQuentin, 1894 .

Etudes d'ethnographie préhistorique; les plantes cultivées de la période de transition au Mas-d'Azil. Extr. de " $L$ 'Anthropologie," vol. 7 no. I.

Pigorini, L: Materiali paletnologici dell' isola di Capri. Parma, 1906.

- Stoviglie votive italichi dell' età del bronzo, e.c.c. Roma, 1897. ( $R$. Accad. dei Lincei, Rendiconti, v. 5, 1896 .)

Potanin, G. N. 0черки сьверо-западной Монголів. [Sketch of northwestern Mongolia.] S. Peterb. 188r.

Pulszky, F. von. Die Kupfer-Zeit in Ungarn. Deutsch. Ausg. Budapest, 1884.

Pum perly, R. Across America and Asia. 4th ed. N. Y., 1870.

- Geol. Researches in China, Mongolia and Japan. Smithsonian Inst., 1867.

ecular Disintegration, Loess, etc. Amer. Journ. Science, 1879.

- and others. Explorations in Turkestan; expedition of 1903. Wash., Carnegie Instit., 1905. (Pub., no. 26.)

RADDE, G. Die Sammlungen des kaukasischen Museums. Bd. V. Archæologie, bearb. von Gräfin P. S. Ouvarov. Tiflis,

RAdlofr, W: Aus Sibirien. 2e Ausg. Lpz., 1893. $2 \mathrm{v}$.

RAWLINSON. The five great monarchies of the Eastern World. New York, 188I.

REAd, C. H. British Museum; guide to the antiquities of the bronze age. Lond. 1904.

British Museum; guide to the antiquities of the stone age. [Lond.], 1902.

Reinach, S. Antiquités nationales; descr. du Musce de Saint-Germain-en-Laye. Paris [1889].

Catalogue sommaire du Musée de SaintGermain-en-Laye. $3^{e}$ éd. Paris [ 1898 ].

Cultes, mythes et religions. Paris, 1905 . 06. 2 v.
Reinecke, P. Neolithische Streitfragen. (Zeitschrift f. Ethnol., Jahrg. 1902.)

Reisner, G. A. The early dynastic cemeteries of Naga-ed-der. Leipzig, 1908.

Revue d'Assyriologie et ARCHEOLOGIE ORIENTALE, vol. 6. Paris, 1907.

Richthofen, F., Freiherr von. China; Ergeb. nisse eigener Reisen, u. s. w. Berlin, 1877-82. v. I and II.

- Führer für Forschungsreisende. Hannov., 1901 .

- Geomorphologische Studien aus Ostasien. Berlin, 1903

— Tagebücher aus China; ausgewählt u. hrsg. von E. Tiessen. Berlin, 1907. $2 \mathrm{v}$.

RipLEY, W : Z. Races of Europe. N. Y., I899. and suppl.

Riston, - Deux oasis asiatiques; Merv et Boukara. 1898

RockнILL, W. W. Diary of a journey through Mongolia and Tibet, 1891-92. Wash. Smithson. Instit., 1804

RoLLER, E Das Transkaspi-Gebiet in archäologischer Beziehung. (Petermann's Mitteil., 35. Bd., 1889.)

Romer, F. F. Résultats généraux du mouve ment archéologique en Hongrie. Budapest, 1878 .

Sarzec, E. DE Découvertes en Chaldée. Paris [1882]. $2 \mathrm{v}$.

SAyce, A. H. Archroology of the cuneiform inscriptions. Lond., 1907.

ScheIL, V. Textes élamites-sémitiques. Paris, 1905. (Délígation en Perse. Mém. v. $6,3^{e}$ sér.)

Schlagintweit $R$ von. Les routes du com merce dans la haute Asie; [tr. de Th L.]. (From Revue Britannique, 1869.)

Schlexм. J. Wörterbuch zur Vorgeschichte. Berlin, 1908.

SchliemanN, H : Ilios; results of researches and discoveries, $1871-79$. Lond., 1888.

- Mycenæ. Lond., 1878.

Schмidr, $H$. Bemerkungen zu der Abhandlung von Köhl über die Bandkeramik d. steinzeitlichen Gräberfelder und Wohnplätze in der Umgebung von Worms. (Zeitschrift f. Ethnol., 1903.)

- Der Bronzesichelfund von Oberthau. (Zeitschr. f. Ethnol., 1904)

Heinrich Schliemann's Sammlung trojanischer Altertümer. Berlin, 1902.

- Die Keramik der makedonischen Tumili. (Zeitschr. f. Ethnol., 1905.)

Troja-Mykène-Ungarn. (Zeitschr. f. Ethnol., 1904.)

Schrader, O. Prehistoric antiquities of the Aryan peoples; tr. by F. B. Jevons. Lond., 1890 .

- Reallexikon d. indogermanischen Altertumskunde. Strassb., 1901.

Schuch HARDT, C: Schliemanns Ausgrabungen in Troja, u.s.w., im Lichte der heutigen Wissenschaft. Lpz., $189 \mathrm{I}$.

Schwalbe, G. Die Vorgeschichte des Menschen. Braunschw., 1904

SCHWARZ, F. v. Alexander des Grossen Feldzüge in Turkestan. Münch., 1893.

- Turkestan die Wiege der indogermanischen Völker. Freib. im Breisgau, 1900.

Seemann, T. Die Kunst der Etrusker. Dresden, 1890 . 
Semenov, A. A. Этнографическіе очерки Зарафшанскихъ горъ Каратегина и Дарва3а. [Ethnographic sketches of Karategin and Darvaz.] [Moscow],

SERGI, G: Dalle esplorazioni del Turkestan. Roma, 1907.

Arii e Italici. Torino.

- The Mediterranean race. Lond., 1901. Gli Arii in Asia ed Europa.

- Qualche determinazione sulla cronologia dell' uomo quaternario in Europa. Roma, 1906.

- Die Variationen des menschlichen Schädels und die Klassifikation der Rassen; [übers. von M. Seiler]. Braunschw. 1904.

Eevertzov, $\mathrm{N}$. Les anciens itinéraires à travers le Pamir. (Socićté de Géogr., $3^{e}$ trimestre, 1890.)

Shuxovskr, V. A. Развалины craparo Mepвa. [Ruins of ancient Merv.] S. Peterb., 1894.

Strabo. Geography; tr., with notes, by $H$. C Hamilton and W. Falconer. Lond., 1889-1903. $3 \mathrm{v}$.

Strobl, J: Von der diluvialen Fundstelle auf dem "Hundssteig" in Krems. (Anthrop. Gesellsch. in Wien. Mittheil., Bd. 31, 1901.)

Studer, T. Die Thierwelt in den Pfahlbauten des Bielersees. [Berne, 1883.]

Suвотісн, D. I. Матеріалы по земле-водопользованію въ Закаспійской области. [Materials concerning land irrigation in the Transcaspian provinces.] Ashkabad, 1903.

Syres, Maj. P. M. Ten thousand miles in Persia. N. Y., 1902.

TerRIEN DE LACOUPERIE, A. Beginnings of writing in Central and Eastern Asia. Lond., 1894.

- Fabulous fishmen of early Babylonia in Chinese legends, Lond., 1888.

- Les langues de la Chine avant les chinois. Paris, 1888

- Le non-monosyllabisme du chinois antique. Paris, 1889.

- Old Babylonian characters and their Chinese derivates. Lond., 1888

On a Lolo ms. written on satin. Lond., 1882.

Thoмs, P. P. . . . Ancient Chinese vases of the Shang dynasty, 1743-96 B. C. Lond. 1851 .

Thurenu-Dingin, F. Recherches sur l'origine de l'écriture cunéiforme, lavec supplém.]. Paris, 1898-99. 2 v. (bd. in $\mathrm{I}$.)

- Die sumerischen u. akkadischen Königsinschriften. Lpz., 1907.

Tofteen, O. A. Ancient chronology. Pt. I. Chicago, 1907.

Tom:Aschex, W: Centralasiatische Studien. (K. K. Akad. d. Wiss. Sitzungsb., v. 87.1877 .)

TSChERNYSCHEv, T., and Loutouguin, L. Le bassin du Donetz. n. p., n.d., 1894 ?

Turkestan Circle of Archerological AmaTEURS. Протоколь. [Records of the sessions and contributions, 5th-7th year.] Tashkent, 1899-1902. 6 pts.
TrLor, E. B. Primitive culture. N. Y., 1874 2 v.

Ujfalvi DE Mezö-Kövesd, C: E. DE Les Aryens au nord et au sud de l'HindouKouch. Paris, 1896.

- Atlas des étoffes, bijoux, etc., de l'Asie Centrale. Paris, I880. (Expédition Sci. Française en Russie, etc., v. 4)

- Le Kohistan, le Ferghanah et Kouldja, etc. Paris, 1878 .

Le Syr-Daria, le Zérafchâne. v. 2. Paris, 1879.

UnDSET, I. Das erste Auftreten des Eisens in Nord-Europa. Deutsch. Ausg. von J. Mestorf. Hamb., 1882.

University of Pennsylvania. Free Mus. Sci. and Art. Dept. Archeol. Transactions, v. 1, pt. 3. [Phila.], 1905.

VAMBERY, A. History of Bokhara. 2d ed. Lond., I873.

- Sketches of Central Asia. Lond., I868.

Travels in Central Asia, I863. Lond., 1864

Veryatkin, V. Matepiaju къ исторнческоН̆ географіи Сахаркандскаго Вилаета. [Historical geography of Samarkand, 1459-1868.] Samarkand, 1900.

VILLENOISY, F. DE. Observation sur la chronologie préhistorique. Mons, 1895. ( $F s^{-}$ dération Archéol. et Hist. de Belgique. $9^{e}$ sess.)

VIRCHow, R. Das Gräberfeld von Koban im Lande der Osseten, Kaukasus, mit einem Atlas. Berlin, 1883 .

Wahnschaffe, F. Die Ursachen der Oberflächengestaltungen des norddeutschen Flachlandes. 2e Aufl. Stuttg., Ig0I.

Wallis, H. Persian lustre vases. Paris, 1899.

Walther, J: Das Gesetz der Wüstenbildung in Gegenwart und Vorzeit. Berlin, 1900.

Wilcken, M. Grundzüge der Naturgeschichte der Haustiere; neubearb. von J. U. Duerst. 2e Auf. Lpz., 1905.

WILLIAM OP RUBRUCK. Journey to eastern parts of the world, 1253-55; with two accounts of the earlier journey of Pian de Carpine, tr. by W. W. Rockhill. Lond., Hakluyt Soc., 1900.

Wilson, T. Prehistoric art. (Smithson. Inst., Ann. rept., 1896.)

WinckLer, H. Auszug aus der vorderasiatischen Geschichte. Lpz., 1905.

- History of Babylonia and Assyria; tr. and ed. by J. A. Craig. N. Y., 1907.

Wood, $\mathrm{H}$. Shores of Lake Aral. Lond., 1876.

Wood, Capt. J: Journey to the source of the Oxus. New ed., by his son, with Essay on the geography of the valley of the Oxus, by Col. H: Yule. Lond., 1872 .

Wosinski, M. Die inkrustierte Keramik der Stein- und Bronzezeit. Berlin, 1904.

ZeITSCHRIFT Für ETHNOLOGIE. I.-38. Jahrg. Berlin, 1859-1906. $38 \mathrm{v}$.

"Вемлевьдыніе", 1901. [Sources of the Oxus.] Moscow, 1901.

Zimmer, H: Altindisches Leben; die Cultur der vedischen Arier nach den Samhitâ dargestellt. Berlin, 1879. 


\section{PART II.}

ARCHEOLOGICAL EXCAVATIONS IN ANAU AND OLD MERV.

BY HUBERT SCHMIDT.

[Chapters vi-X. Plates 7-56.] 
Digitized by $\mathrm{OOg}$ Ie 


\section{CHAPTER VI.-THE ARCHEOLOGICAL EXCAVATIONS IN ANAU.}

Before the beginning of the excavations at Anau which are here treated, traces of former work were observed at several points on both kurgans. Twenty years or more carlier, the Russian General Komorof had dug through the North Kurgan a trench running from ENE. to WSW. (Compare Report of Roller in Petermanns Mitteilungen, 1889, p. 162.) General Komorof assumed that this kurgan was an artificial hill raised over a grave. Before the beginning of our work in 1904 the trench had a width of 3.6 to 5.8 meters and descended apparently to a depth of about 8 feet above the datum adopted in the 1904 survey of the kurgan, this datum being established at a point on the surface of the plain west of the kurgan.

At the South Kurgan, both near the summit and on the side, several small holes were observed, possibly also due to Komorof, as similar holes were found on the North Kurgan. A superficial examination showed that the North Kurgan seemed more promising than the southern one, for the surface of the former was strewn with fragments of very ancient hand-made pottery, while the pottery strewn over the surface of the latter gave evidence of belonging to a much younger and more developed ceramic art.

A preliminary examination made on our arrival in 1904 showed the importance of first determining the significance of the northern kurgan.

\section{THE EXCAVATIONS AT THE NORTH KURGAN.}

On March 23, 1904, a careful study was made of both walls of the Komorof trench. This examination fully convinced the writer that the great hill had been an inhabited site and consisted of horizontal layers of superimposed settlementsa view which had already been advanced by Pumpelly* as a result of his visit in 1903.

In the western half of the southern wall, at the bottom of the trench, there were two walls of unburnt bricks standing 2.7 meters apart, and a third one in the eastern half 18.7 meters distant from the others. Opposite these, on the eastern half of the northern wall, the writer observed two walls 6.4 meters apart, and in the western half a third, 14 meters distant from the others. Between and above these portions of vertical walls there were horizontal layers of débris, consisting of unburnt bricks, stones, ashes, bones, fragments of pottery, etc. Some of these layers sank away from the walls toward the intervening region, while others rose to the top of the walls and passed over them. Similar walls occurred in the higher layers of the hill. There was, therefore, only one explanation of the origin of the hill; namely, that it had gradually risen as the result of several settlements superimposed one upon the other.

*R. Pumpelly, in Year Book of Carnegie Institution of Washington, No. 2, 1903, p. 278. 
This view was fully confirmed by investigation with the spade; and having established the fact of the slow growth of the hill, the stage of culture development of the builders remained to be determined chiefly through the character of the pottery. It therefore appeared desirable to open all the layers of the hill with the spade.

GENERAL SUMMARY.

The excavations began March 24, 1904, with the cleaning out of the Komorof trench and the deepening of its ends, which were somewhat higher than the middle. Starting from the bottom of the trench, two "galleries" were driven a short distance into each wall, opening to this extent the heart of the hill. In the eastern half of the northern wall the east galleries, 5 and 6 feet wide, were opened and in the western half of the southern wall the west galleries, 5 and 8 feet wide. In this way the middle layers of the hill could be examined between +18 and +8 feet.*

At the same time the upper layers on the north half of the hill were attacked by two trenches running nearly parallel to each other. The larger one of these extended from the summit northward down the northern declivity of the hill and was divided into three sections by leaving narrow partitions, portions of the original earth, standing between them (terrace $\mathrm{I} a, b$, terrace II, and terrace III). This division was important, both because it facilitated the excavation in horizontal layers and because the observations could be sharply defined for each terrace. These terraces have a width of 7.5 to I I feet and are sunk in the heart of the hill to $+22,+18.1$, and +15 feet, respectively. The other and much shorter trench was dug with a width of 6 to 7.5 feet on the western declivity of the northern half of the hill (west digging) and opened the middle layers from +25 and +20 to +8.6 feet. In this way a certain relation was established through the west digging between the terraces and the galleries. The separate observations made at each locality would tend to supplement and corroborate each other.

For the purpose of studying the deeper layers, two pits were dug in the bottom of the Komorof trench, immediately adjoining the galleries, these pits having $a$ width of 6 feet and a length of 15 and 16 feet respectively (trench, eastern and western pits). Work was stopped on them, however, as soon as it was discovered that they were being sunk in the débris which General Komorof had dumped into his trench; and instead, two shafts were sunk in the "galleries." In both these shafts the culture-strata were opened to a depth of -21.5 feet (fig. 22 and plate 7).

The finds which were made in the above-mentioned localities gained in importance through the simultaneous discovery of burials (cf. special report of Warner). On March 26, several skeletons were exposed in terrace $1 a$, to the south of a wall of unburnt bricks. They were, however, destroyed by the picks of the workmen. During the following days more skeletons came to light in all three of the terraces. Their significance in connection with the finds that were being made became clear after the discovery that a skeleton grave found on March 30 in terrace I was that of a child buried in contracted position (Liegender Hocker),

*The datum is the level of the plain on the west side of the kurgan.-R. P. 


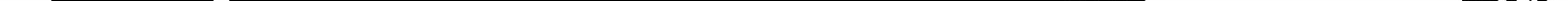


and that a skeleton unearthed on March $3 \mathrm{I}$ in terrace III was also, in all probability, buried in contracted position. Since similar skeletons appeared in terrace II and in deeper layers (cf. special report of Warner), it was impossible to consider these as later burials, and the find in terrace $I$ left no question that the skeleton graves belonged to the dwellings represented in the horizontal strata.

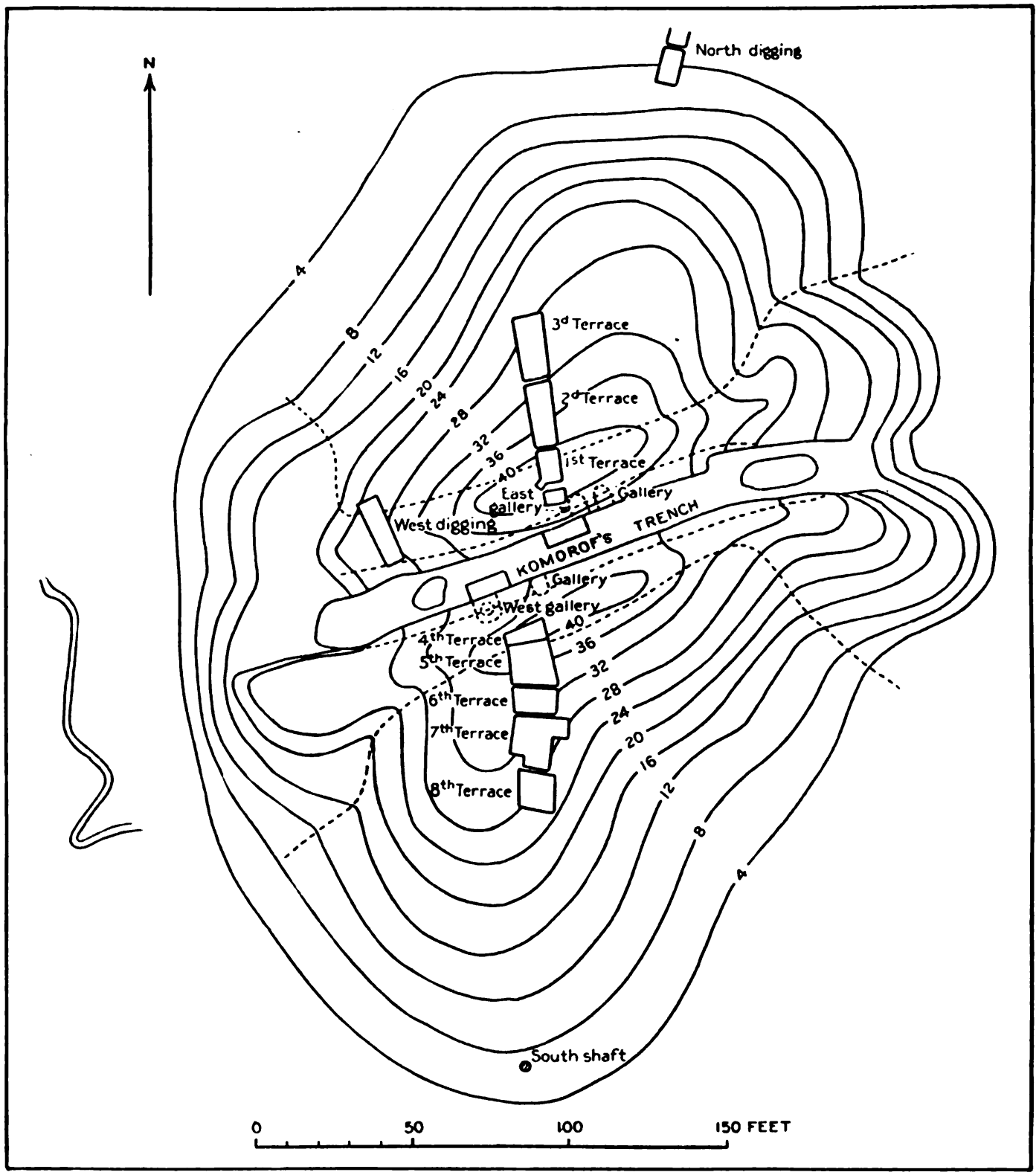

Fig. 22.-Plan of Excavations at North Kurgan, Anau.

Nevertheless, to test still further the correctness of these conclusions, the southern half of the hill was attacked on April $I$ in the same manner as the northern one. Here a trench 14 to 16 feet wide was dug, extending in a north-south direction; this trench being cut down in four terraces-rv, v, vI, vII- 
and later lengthened by an additional one, terrace virr. This excavation fully confirmed the observations made in terraces I to III. Here too, burials alternate in horizontal layers with the débris of the clay walls of houses.

There were also important finds during the examinations in depth that were made for physiographic purposes. The layers on the periphery of the hill were examined on the south side by means of a shaft (south shaft) sunk to a depth of -7 feet. On the northeast side of the hill three successive trenches were laid

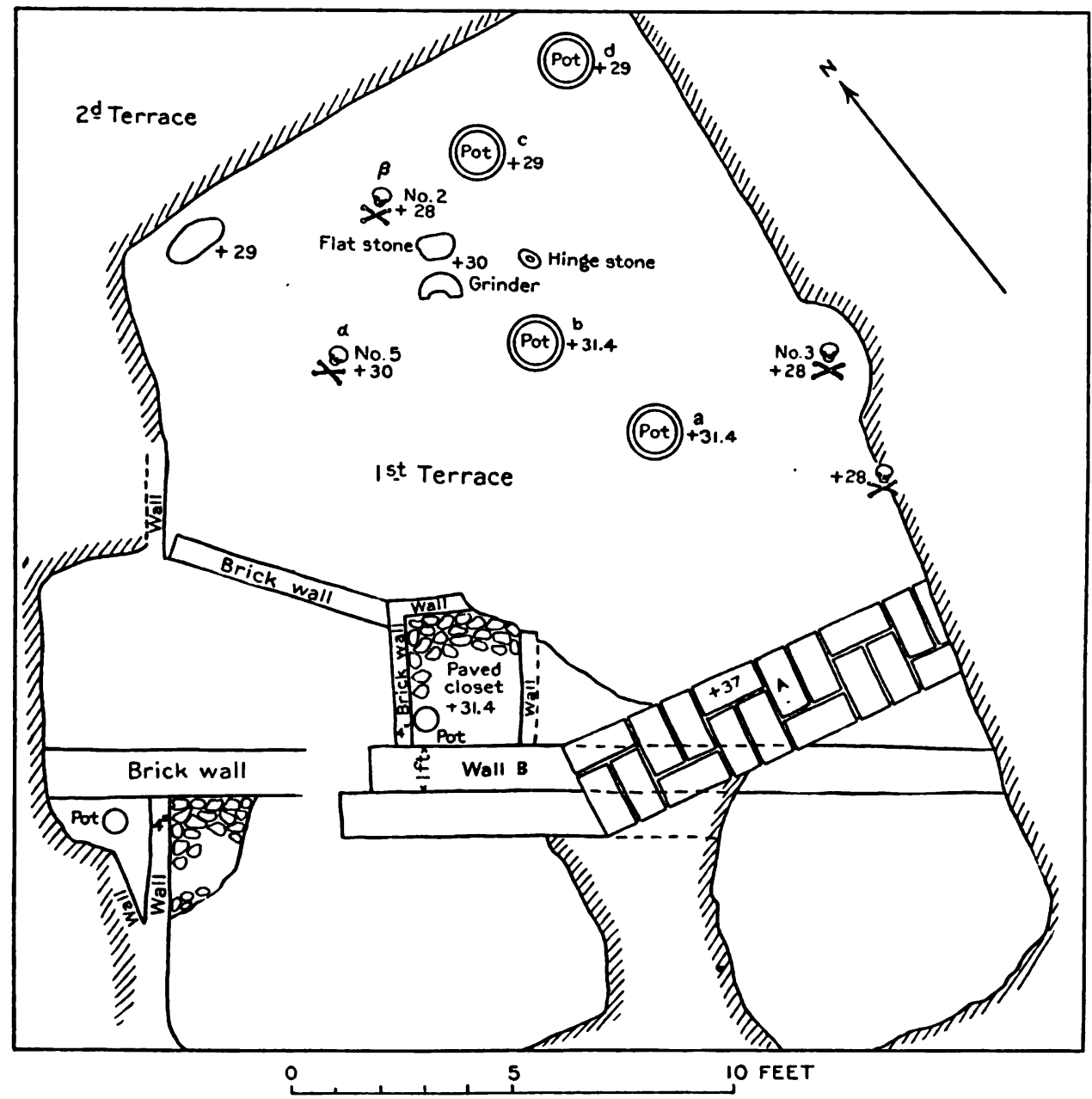

Fig. 23.-Plan of Terrace I.

out in the direction of the longitudinal axis of the shaft (north diggings, I to III). Of these the first two are of importance in connection with the culture problems. In north digging $I$ the work was stopped for practical reasons at a depth of -13 feet. In north ditch II, on the other hand, a depth of -24.5 feet was reached; and here, as in the galleries, the undisturbed natural surface of the plain was reached. North digging IV and the west shafts are also important in checking the observations made elsewhere ( $c f$. Pumpelly's report). 
THE WORK AND FINDS AT THE SEPARATE LOCALITIES.

THE EXCAVATIONS AT THE TERRACES.

Terrace $I a, b$ (see figs. 23 and 24). - Soon after the débris of Komorof's trench had been removed from the top of the hill, the excavation in the undisturbed layers exposed a wall of unburnt bricks $(A)$, which extended across the trench with a thickness of about 2.5 feet. The top of this wall lay at +37 feet and on its northern side, at the height of $3 \mathbf{I} .5$ feet, was a floor marked by two firereddened places. Each place surrounds the top of an earthenware pot sunk to the lip in the floor, the top diameters of the pots being 9 and 8.8 inches, respectively. The assumption that this floor and its clay vessels were contemporaneous with the wall just mentioned proved to be wrong; the wall proved to be younger.

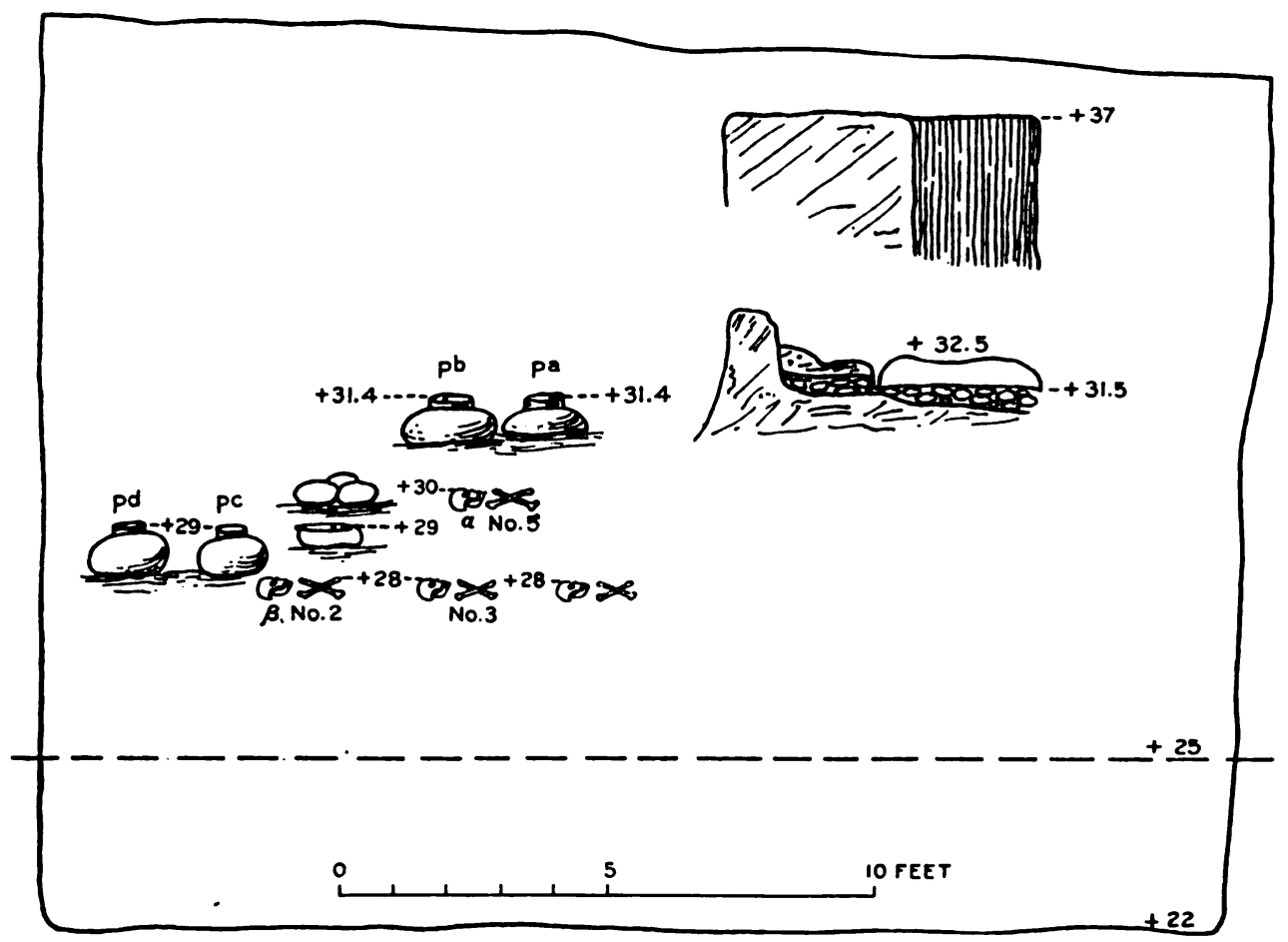

Fig. 24.-Vertical Section and Projection of Finds, Terrace $I$.

Under it were found older and narrower walls $(B)$, running in a different direction; and adjoining it on the north there was exposed a peculiar quadrangle of irregular form (2.8 and 2.6 feet), of which one corner was destroyed. The floor of this quadrangle was paved with small flat pebbles and the inner walls of its lower part were incrusted with fragments of pottery. The quadrangle, with thin walls running towards the west, is shown in fig. 25. In following the walls towards the west a similar small room was found, also incrusted with small fragments of pottery. Further examination of these rooms was not practicable under our general scheme of work, on account of the overlying mass of earth. However, since the floor of the quadrangle stood at the same level with the fireplaces and 
the tops of the pots $(+31.5$ feet), and the bottom of the narrow walls had the same elevation, they must all have belonged to the same establishment. The wide wall $(A)$ which was found first is, therefore, to be referred to a younger period.

Further to the north and at +30 feet-that is, 1.5 feet deeper than the hearths and the tops of the pithoi-there occurred several stones. Among these were an elongated stone with a round depression, evidently a door-stone-that is, a stone with a hole polished and scratched by the rotary motion of the pivot on which the door swung - and an elongated stone standing on its broken end, with a deep longitudinal groove, presumably a whetstone. The positions of the stones and the pithoi are shown in figs. 26 and 27 and in the vertical section in fig. 24.

The greatest interest attached naturally to the examination of the earthenware vessels standing in the floor. Pot $a$, standing nearest the wall of the terrace, had a cavity of 6.6 inches depth, filled with loose earth, mixed with ashes and

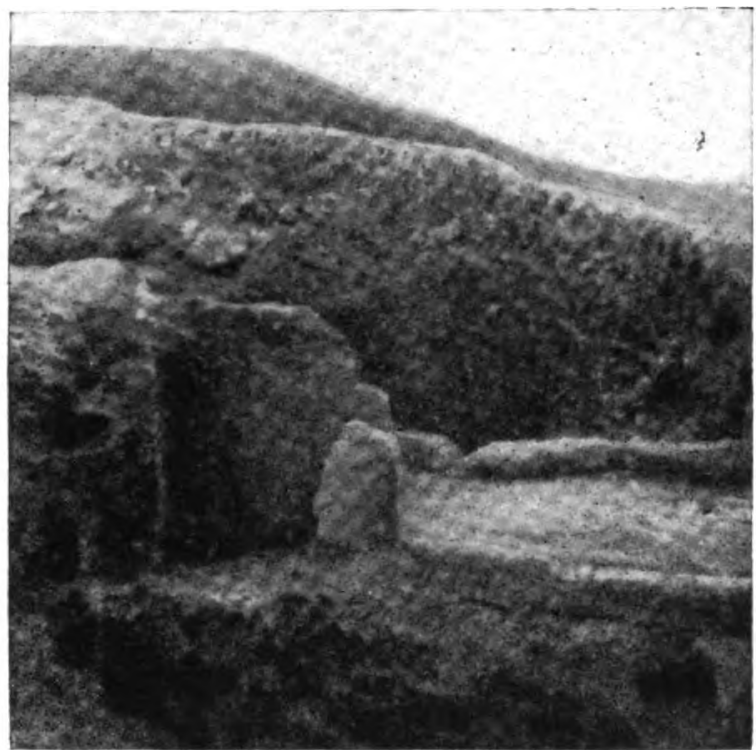

Fig. 25.-Incrufed Cabinet in Terrace I.

charcoal. Pot $b$, standing nearer the center of the excavation, contained unburnt earth in the upper part; under this a whitish, fine mass; still deeper, reddish-yellow burnt earth mixed with charcoal; and below this a quantity of the same white substance that was observed near the top. Further examination, after exposing the outside of the pots, showed that they had no bottoms, but had been placed in the earth as if without the lower half, their shape representing practically a hemisphere; and that their surface, originally red, was much blackened by fire. The interior was largely plastered over with clay, which was also burnt red; even the base on which the half-pots rested showed, to a considerable depth, red color due to burning. The long-continued and repeated use of these hearths is shown by the remains of an older pot under pot $b$. When this pot became useless, it was evidently replaced by pot $b$.

What is the significance of these pots surrounded with traces of fire? The hard-burnt earth surrounding the outside of the pots and filling the interior, and the charcoal and ash-like white mass found in the interior, allow only one interpretation. The pots must have been bake-ovens heated from the interior. Similar pot-like forms are still used as ovens in Turkestan, where I myself have seen them, and Mr. Huntington assures me that they are used also in Persia.

South of wall $A$, in terrace $1 a$, workmen had exposed on March 26 several skeletons at a depth of about 4.25 feet under the original surface of the hill, but 
they had so completely destroyed them with their picks that an examination of their position and of other conditions was impossible. That these were burials seemed probable because beads were found with them and a feeding-cup was found near the remains of a child's skull; we are in all probability justified in considering these as having belonged to the burials (see plate 9, fig. I). The feeding-cup is of the same red monochrome ware already found in the terrace. It was proper, therefore, to assume that the burials belonged to the same people whose culture remains have already been discovered in the highest layers of the hills. This assumption was soon to be further confirmed.

When the terrace was lowered for the examination of pots $a$ and $b$, a skeleton (a) was exposed on the west side of the terrace, at about the same level as the three stones mentioned above-that is, +30 feet. It was exposed by Mr. Warner and proved to be the skeleton of a child lying in the regular contracted position (Hocker position)* on the right side. The burial gifts-beads of lapis lazuliagree with the beads found in terrace $1 a$ (cf. the systematic presentation below). When the skeleton, stones, and pots had been removed, there were exposed in the north end of the terrace, at +29 feet, two more pots, $c$ and $d$, in position; near these, in the northwest corner of the terrace, the half of a mealing-stone; and finally, between this and the pots, but a little deeper, at +28 feet, another skeleton of a child $(3$, No. 2). The position of this skeleton is shown in fig. 27 by a small board (cf. the vertical

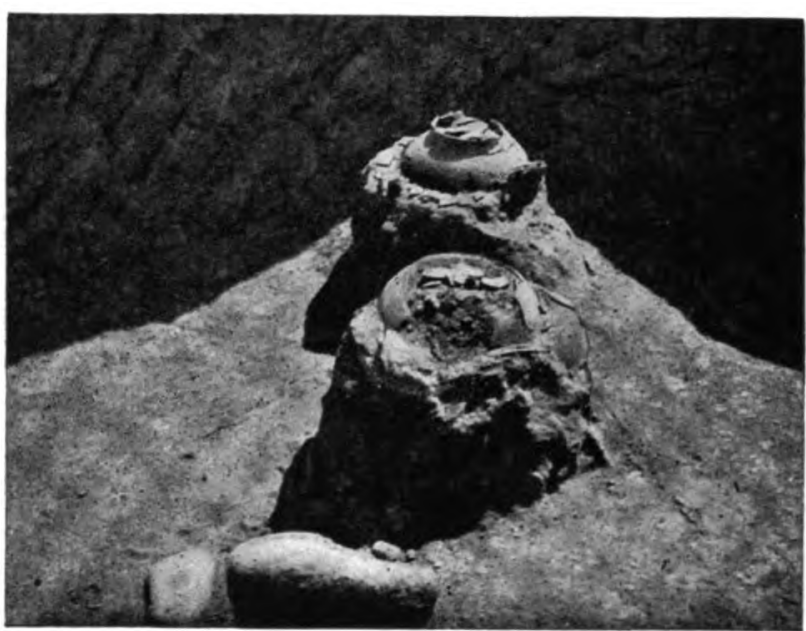

Fig. 26.-Pithoi $a, b$. Pivotal Door-stones and Grindstones, Terrace I. section). Of the two newly-found pots, only one (the western one, $c$ ) resembles the bake-ovens already described. Here again only the upper part of a pot was found, the diameter being $\mathbf{1} 2.4$ inches. Its contents are earth mixed with charcoal and a white ash-like substance, and the earth below it is burnt red; while, on the other hand, the earth surrounding the pot above is scarcely reddened. The eastern pot, $d$, stands full formed in the earth and is much blackened on the outside. The contents differ from those of the bake-ovens. They also consist, indeed, of much charcoal and earth, but this is so loose that one must assume it to have fallen in from above, while the earth in the bake-ovens is smeared on the walls and burnt hard. We may, therefore, consider pot $d$ to have served

*The skeletons are shown in the horizontal plan by skull and cross-bones. In the vertical sections they are indicated also by skull and bones in a different arrangement. In both cases, the corresponding skeleton is tangent to the bottom of these symbols. 
for cooking; its bottom must have stood in the earth, so that fire could be built around it.

However, the combination of bake-oven, kettle, mealing-stone, and child's skeleton corresponds wholly with the overlying layer, its pots, and its skeleton; so that we have here two successive periods of culture. The pots $c$ and $d$ must already have been out of use and buried when pots $a$ and $b$ were put in position; but they must also have been older than the child's skeleton $\alpha$, No. 5 , which lies in the layer between pots $a, b$ and $c, d$. Skeleton $\alpha$, therefore, must be referred to those inhabitants of the hill who used bake-ovens $a, b$, while the lower skeleton $j$ belongs to the older period. The highest layer-that is, the youngest period-is, however, represented by the skeletons destroyed in terrace $I a$, and by the thicker diagonal wall $A$. Therefore, at least three successive periods have left their remains between the surface of the hill $(+40$ feet) and the level of +27 feet.

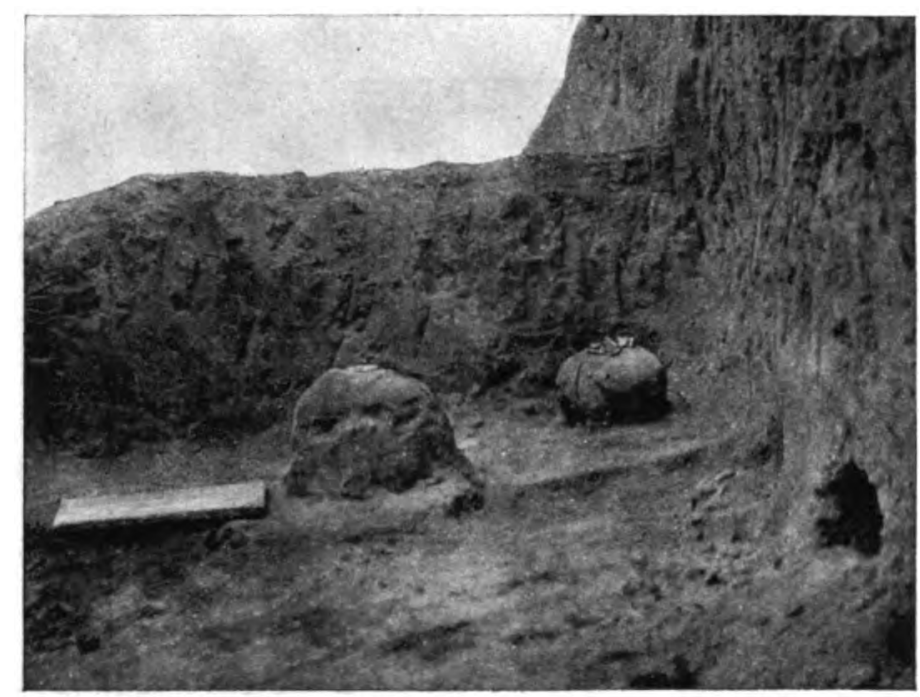

Fig. 27. - Pithoi $c$ and $d$ in Position and Steleton is.

In the east wall of terrace I still another skeleton (No. 3) was excavated at the level +28 feet, besides another left in the earth.

The question then arises whether these periods differed in their culture characteristics. In all probability they did not, for the beads in terrace i $a$ resemble those found with the child's skeleton in $1 b$, and the pots $a$ to $d$, as regards form and technique, are in all respects similar. The similarity in culture will be more evident when we consider the pottery that is characteristic of these layers.

When the upper terrace was begun on March 25, it yielded within three hours a great quantity of fragments of different kinds of pottery, the greater part belonging to a gray or red monochrome ware. The red was especially characterized by a good polish, while in the gray fragments one was struck by the excellent quality of the clay and of the technique. I will designate this monochrome variety for the present as group $x$. Besides this group $x$, there occurred painted ware of an entirely different technique-both finer and coarser vessels-which we were obtaining at the same time from the galleries; that is, from the middle layers of the hill. These fragments may for the present be called group $y$, in contradistinction to the others, or group $x$. The relation of these two groups, however, on their appearance in terrace $I$, was such that the monochrome was predominant at the top, but diminished in favor of group $y$ the deeper we dug. 
Thus on March $3 \mathrm{I}$, after the removal of bake-ovens $a$ and $b$ and the accompanying child's grave, the red polished ware was still predominant among the "mixed" pottery; but on the following day, when the excavation entered the layer of the older pots, $c$ and $d$, and the still deeper level of the second skeleton, the "mixed" ware consisted principally of the painted group $y$, while there was a rare occurrence of the monochrome $x$. Very different, however, appeared the character of the finds on April 5, when the layer of the older pots $c$ and $b$ had been removed and the terrace had been sunk to between +27 and +25 feet. The monochrome variety $x$ was entirely lacking; there appeared only the group $y$. This corresponded with the finds in the "galleries," where to a depth of +22 feet the only fragments found were those of the pottery of group $y$.

It was already possible to draw the conclusion that the monochrome variety $x$ was the younger. Considering the manner of its occurrence, it was also probable that it belonged to the same culture as that to which the walls, bake-ovens, kettles, and skeleton of terrace $I$ belonged, for the feeding-cup which was buried in the child's grave is of the same kind as the great mass of monochrome pottery of the upper layers. The question, to which period of house-construction the red monochrome ware was to be referred, was completely solved by the discovery of the quadrangles (see p. 87), for the pottery fragments with which the walls of these cabinets were incrusted were of this characteristic ware. The only doubt possible was in regard to the gray ware, which technically is far superior to the red. The occurrence of the older varieties of vessels of group $y$ in the upper layers is, however, sufficiently explained when we consider that the inhabitants of these layers must have materially disturbed the older layers, including their pottery, in establishing their own dwellings. As a matter of fact, no pure layer of either group was found in this transitional level of unmixed and monochrome ware, and such a pure layer appears not to have existed.

Terraces $I V$ and $V$ (see figs. 28 and 29, plan and vertical sections of terraces IV to VIII). - The finds in terraces IV and $\mathrm{V}$ correspond to the finds in terrace $\mathrm{I}$. Soon after the débris of the older excavations was removed and the undisturbed earth of the hill was attacked, a child's skeleton $(\gamma)$ was found in contracted or Hocker position, and lying on its right side (cf. special report of Warner, No. o). Its position is designated as in terrace IV. The horizontal layer of terrace $v$, corresponding to the location of the exposed skeleton $\gamma$, has almost wholly disappeared, as the original surface of the hill there falls off abruptly to the south. In terrace $\mathrm{v}$ there occurred first in situ a pot $(e)$ of the kind found on the northern half of the hill. To the east of this pot, and a little below the level on which it stands, several skeletons were found lying in a heap $\left(\delta\right.$, No. $o^{1} ; c f$. special report of Warner); and farther east, rear these, were the remains of a deeper-lying pot $(f)$ in situ, of which the lip was destroyed (see fig. 30).

This stratiform succession of pots and skeletons resembles closely the finds in terrace I. The levels are as follows: Skeleton, terrace IV +36 feet; lip of the upper pot $(e)$, terrace $\mathrm{v},+34.5$ feet; skeleton heap $\delta$ (cf. Mr. Warner's special report No. $\left.o^{1}\right),+34$ feet, near pot $e$; preserved edge of lower pot $(f),+33$ feet. 
THE ARCHEOLOGICAL EXCAVATIONS IN ANAU.
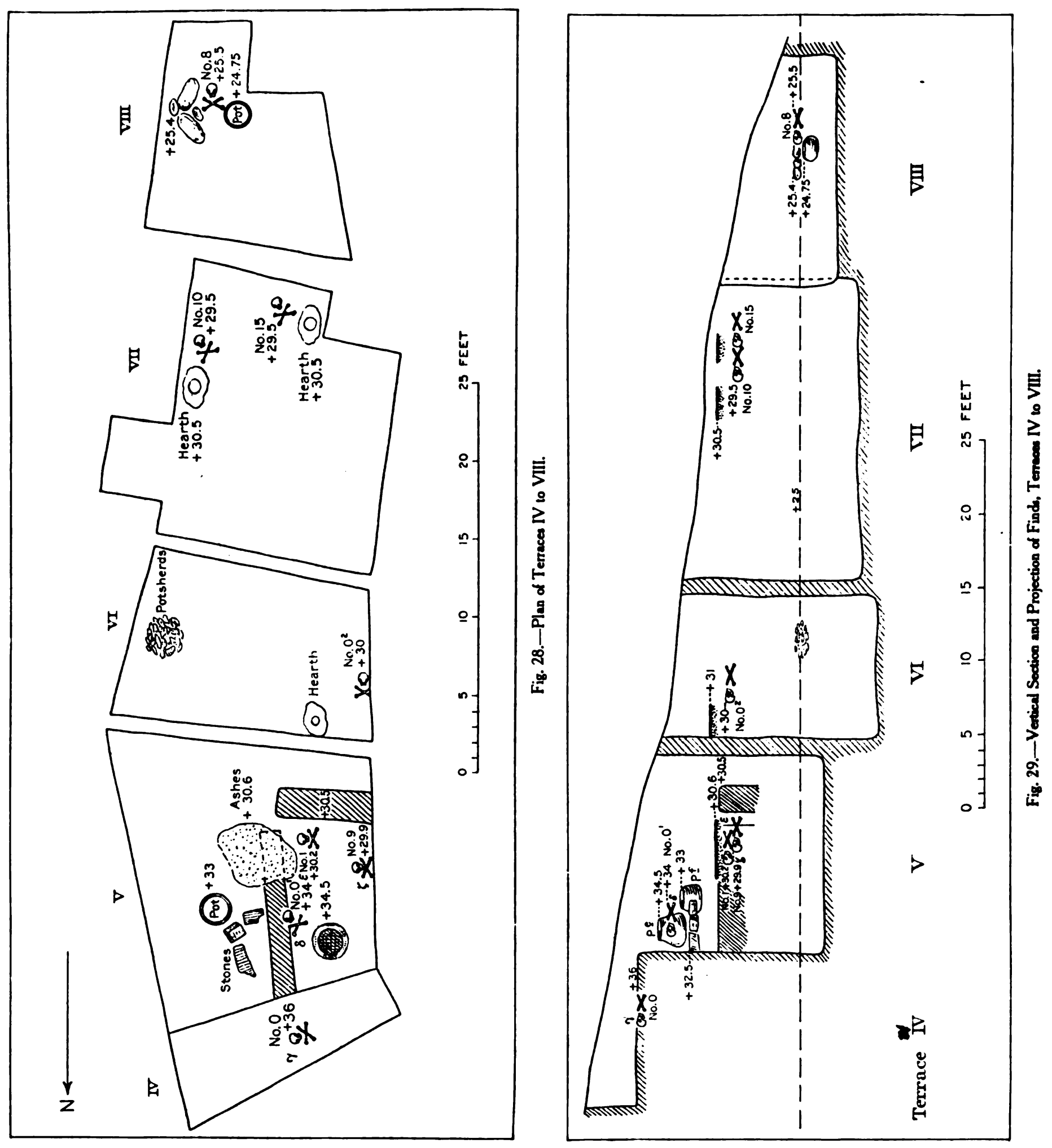
Many small stones and fragments of stones occurred in the layer between the pots and around the older pots, and even somewhat deeper. Presumably the earth had been disturbed here. After removing the skeleton there were found several flat stones and the fragments of a mealing-stone near the lower pot $(f)$, I.5 feet below its preserved lip, these representing the floor belonging to the lower pot. These stones, as well as the pots, were left temporarily in situ, while the remainder of the terrace was explored. About 2 feet deeper, signs of an older layer appeared in the form of remains of clay walls, the direction of two of which could be determined; and in the middle of the terrace, about on a level with the preserved top of the wall, there appeared a place with a whitish mass (ashes?). At the same time the skeletons of two children appeared, one $(\varepsilon$, No. I) to the north, near the top of the wall in the western side of the terrace, and the other $(\zeta$, No. 9$)$ southwest of the ash layer already mentioned, about 8 inches below its level. Ashes and the hard-burnt débris of walls were raised from this layer, which lay about 4 feet deeper than the lip of the upper pot (cf. figs. 29 and 30). Following are the levels: Flat stones in situ, +32.5 feet; ash layer, +30

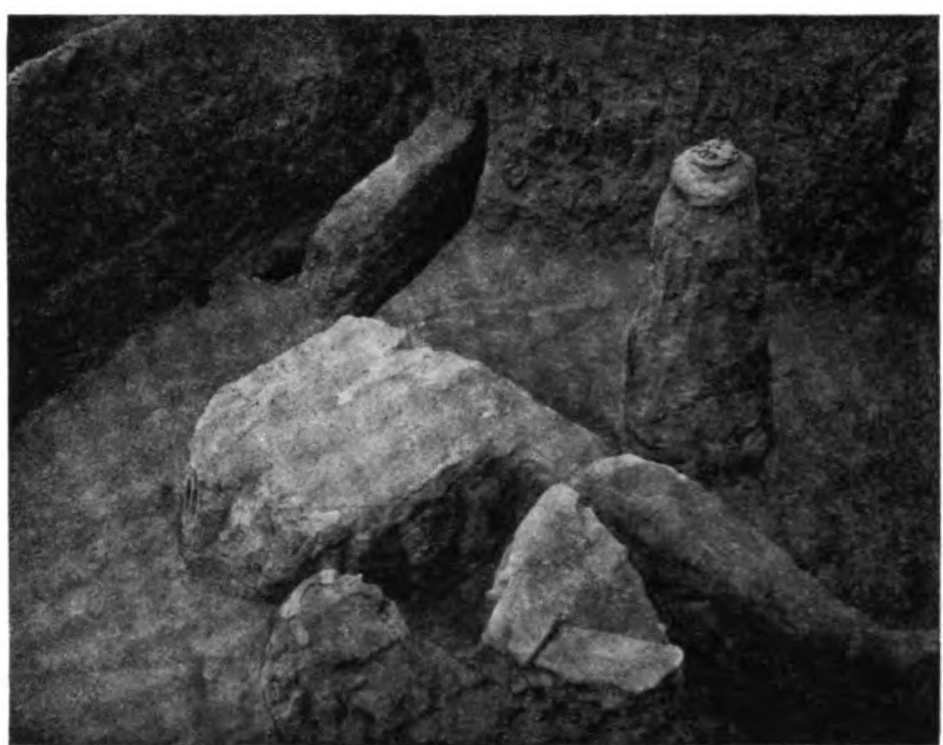

Fiq. 30.-Pithoi, Hearth, and Walls, etc., in Terrace V. feet 7 inches; upper edge of wall, +30.5 feet; child's skeleton $\varepsilon,+30$ feet 2 inches; child's skeleton $\zeta,+29$ feet $I I$ inches; visible lower edge of wall, +28 feet $I$ inch.

Stratigraphic Succession, North Kurgan, Terraces IV and V.

If, now, we wish to make clear the relative ages of the enumerated finds and their stratigraphic succession, we must treat separately the utensils found in place, $i$. e., the remains of occupation, and the skeletons that occur among them. For this purpose we may bring the finds into two parallel columns:

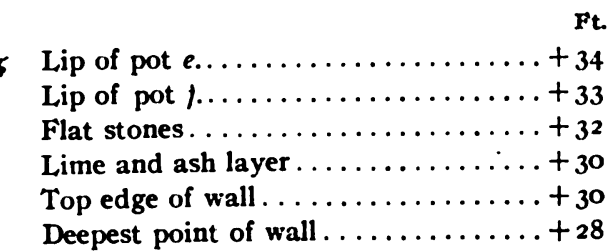

II.

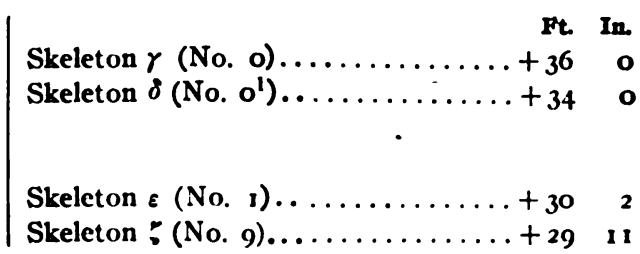


The distribution of the skeleton graves in the successive strata would be determined if we could establish the floors to which they correspond. Concerning this, however, we can form only conjectures. The height of the last-named wall is not known, while the corresponding floor presumably lies still deeper than the deepest point observed in the wall, the clay walls having had no special foundation of which we can take notice. In any case this clay wall marks the oldest of the periods with which we are concerned. The lime or ash layer lies above its floor and must, therefore, belong to the next later period. The flat stones, if they lie in situ, as seems to be the case, can have been laid in position only when none of the ash layer was still visible, and they presumably correspond to the floor of a third period. To this third period may be referred pot $f$. Its lip is, indeed, not well preserved, but it can not possibly have been much higher than level +33 feet. On the other hand, both the stones and pot $f$ must already have been buried when pot $e$, of which the lip is well preserved, was placed in position. Pot $e$, therefore, belongs to a fourth period.

The question now arises: how are the skeletons to be distributed among these layers? The highest one $(\gamma)$, determines the youngest layer. When the burial took place pot $e$ must already have been buried in the floor and out of use; therefore skeleton $\gamma$ belongs to a fifth period, of which we have found no other remains. The skeleton heap $\delta$ lies in the plan between the two pots $e$ and $f$ and also in a vertical plan between the levels determined by these pots. Therefore, the bodies can have been buried only after pot $f$ was already out of use. We must, therefore, ascribe this burial to the same people by whom pot $e$ was used; that is, skeleton $\delta$ belongs in the fourth period. The burial was very shallow, being immediately under the floor, which perhaps explains the very bad condition in which the skeleton was found. The child skeleton $\varepsilon$ at +30 feet 2 inches may have been buried by the people who had pot $f$ in use and who placed the flat stones at +32.5 feet; but this, of course, is uncertain. Skeleton $\varepsilon$ might, however, be brought into connection with the lime or ash layer near by if we suppose that the body, as in the case of skeleton $\delta$, was laid immediately under the floor. It must, therefore, remain uncertain whether skeleton $\varepsilon$ is to be referred to the third or the second period. This must also be the case with skeleton 5. This only is certain: both skeletons must be younger than the deeper-reaching wall. We have to assume, therefore, on the basis of the finds in question, five periods for terraces IV and $v$, for three or four periods of which we have established skeleton graves.

Not only is the succession of the layers in terraces IV and $\mathrm{v}$ analogous to those of terrace $I$, but there is also a correspondence in the character of the finds. In the upper layers the greater part of the pottery fragments brought to light were of the well-polished vessels of red monochrome. With these occurred relatively few of the gray variety. On the other hand, there appeared in the upper layers only isolated fragments of group $y$. But with these occurred also fragments of painted pottery of a kind not observed in terrace $I$, and entirely lacking in the deeper layers of the hill, which, from its technique, appeared to belong to a later age than the lower layers. We may call it group $z$. 
Generally speaking, however, there was no change in terrace $v$ as regards the pottery above the level of +32.2 feet, excepting that between +36 feet and +32 feet 2 inches fragments of polychrome ware occurred, painted black and red. These may be introduced here as group $v$.

The "mixed" pottery-i. e., about equal quantities of fragments of groups $x$ and $y$-was found only below the level of the flat stones which belong at +32.5 feet, the level of the floor which must have borne the older pot $(f)$; but here also it was evident that the deeper we dug the more the fragments of the group $x$ decreased, while those of group $y$ gained in numerical proportion. Between +28 feet 5 inches and +25 feet we found group $y$ almost exclusively represented. Still lower this group ruled alone; therefore it is only below pots $e$ and $f$, found in situ, that the real "mixed" layer begins.

The skelotons lying in this "mixed" layer are referable to the epoch in which the older pot $(f)$ was in use. It is not certain whether the deeper standing walls were built during the use of the ceramic group $y$.

For the relative age of the gray monochrome ware, the observations in terraces IV and v yield definite data. It occurs in the "mixed" layers, together with the red monochrome, as far as the level +28 fect 5 inches; but, like the red monochrome ware, it is wholly absent below the level of +25 feet. It must, therefore, have been contemporaneous with the red monochrome ware. Only the later analysis of forms and technique can show whether it went through the same evolution.

Now, since the pots found in situ in terrace $\mathrm{v}$ agree throughout in form, technique, and position with those of terrace $I$, we may assign them both to the same period of house-building as the upper settlements of the hill. On the basis of the pottery we can assert that this building period had its beginning above the level of +25 feet. Its end is marked, in so far as the layers are still preserved, by the thick wall $A$ in terrace I and by the skeleton of terrace Iv.

Below the level of +25 feet lie the strata of an older culture. Regarding these, we can say, at the present stage, only that their peculiar pottery is represented in the group $y$.

To what extent do the remaining terraces complete this picture? What do they teach us concerning the deeper layers of the older culture?

Terrace II (see fig. 31).- In the special report of Warner it will be seen that in terrace II, also, several layers have grown one above the other. It is true that in the upper layers of this terrace bake-ovens and pots of the same kind as those found in terraces I IV, and v, are lacking. On the other hand we have here, as there, similar places with depressions, which are filled with white ashes, one at the level of +26 feet 5 inches, and the other immediately under the first at +25 feet $-i$. $e$, two different superimposed layers. Considering the smallness of these depressions, it is not probable that they served the same purposes as the bake-ovens in terraces I and IV. Rather must we assume that these holes served for the protection of the smoldering charcoal and for the collection of ashes-i.e., that they were open fireplaces or hearths.

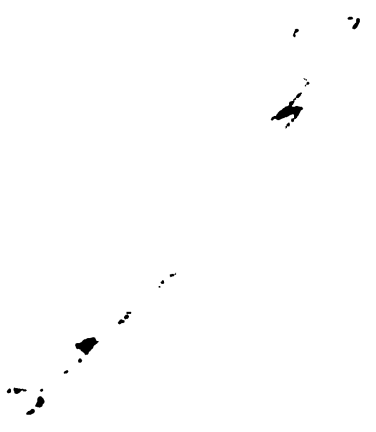


The two skeletons lying at +26 feet (Nos. 6 and 7) must certainly be younger than the deeper-lying fireplace at +25 feet; but they can scarcely be considered in connection with the upper fireplace, since the difference of level is too slight. They probably belong, therefore, to a higher and now vanished younger layer. Since

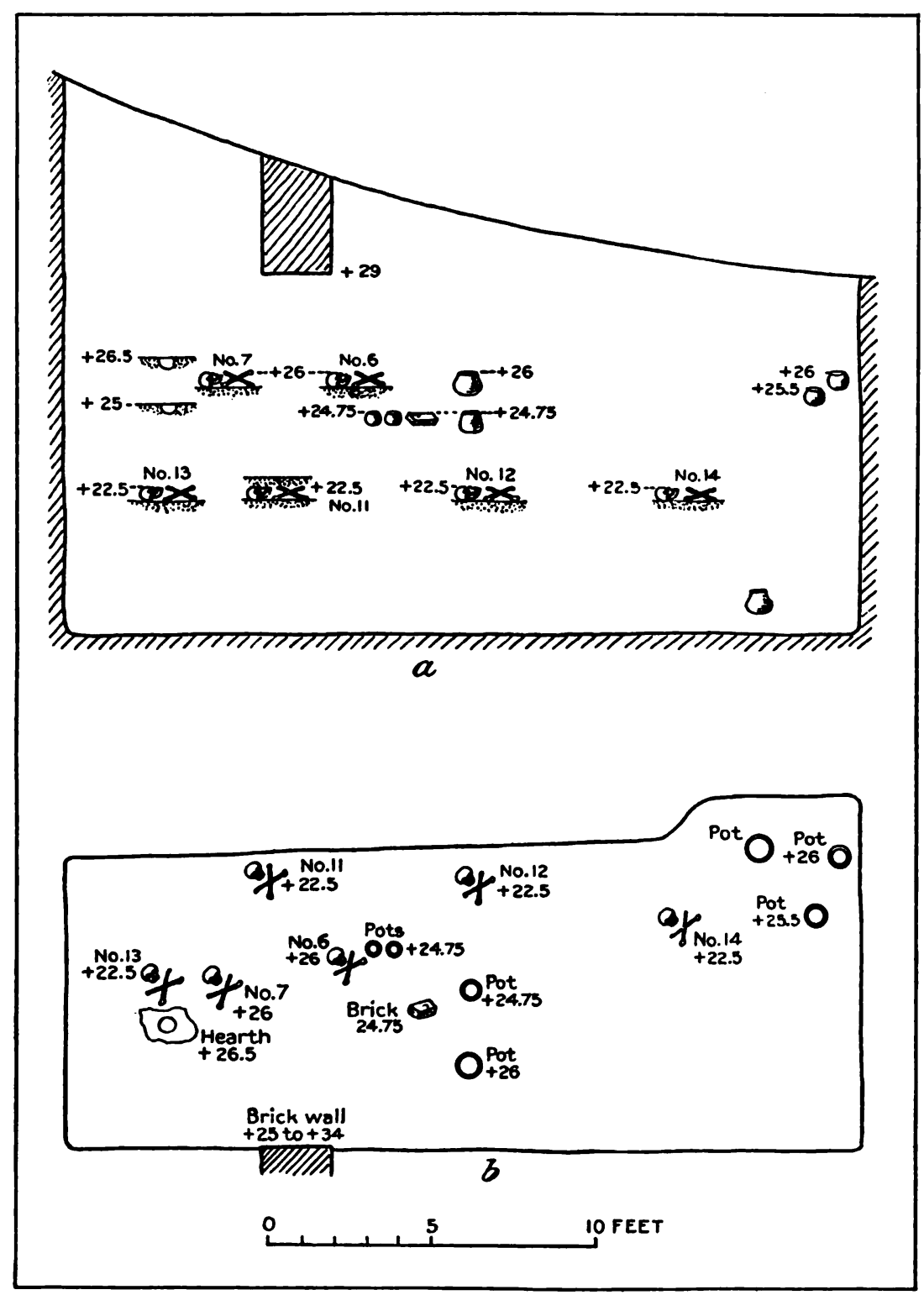

Fig. 31.-Vertical Section and Projection of Finds (a) and Horizontal Projection (b); Terrace II.

in terrace I the lowest skeleton belonging to pots $c$ and $d$ lies at +28 feet, we would have to assume still another intermediate layer of which no trace was found in either terrace $I$ or terrace II.

The second terrace has particular importance because it contains noteworthy remains of the older culture. The two pithoi standing at +24.75 feet belong in 
technique and form to the older ceramic group $y$, and are particularly valuable on account of the remains of painting which they bear. To the same layer $(+24.75$ feet) is to be referred the broken pot of ordinary technique and probably also the erect stone mortar whose lip stood at +25 feet 10 inches. Whatever occurs below this must equally belong to the older culture; therefore the four skeleton graves, together with their burial gifts of copper and bead ornaments, are of especial value as being the first burials of the older culture to be found.

The only question that could arise is whether the pottery fragments found in the succession of layers may not invalidate their evidence. In terrace II, as well as in terraces $\mathrm{I}, \mathrm{IV}$, and $v$, the upper layer abounded in fragments of the red and gray monochrome ware of group $x$, and fragments of the $y$ group were relatively rare. As we dug deeper the relation between these two varieties changed, until at last they were reversed. The red monochrome ware occurred only in isolated cases below +26 feet. Still, it is remarkable that in terrace II this isolated occurrence of the group $x$ reaches somewhat deeper than in terraces I and IV, and

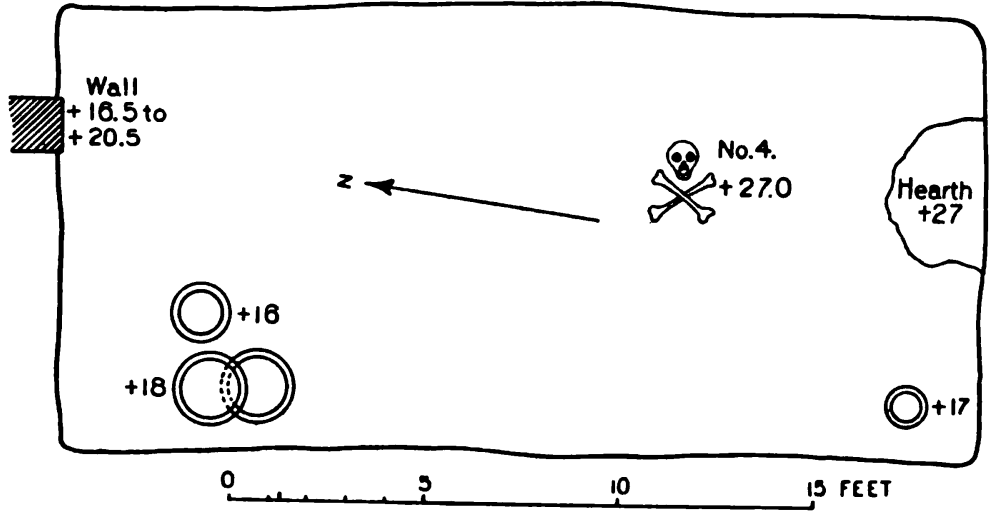

Fig. 32. - Plan of Terrace III.

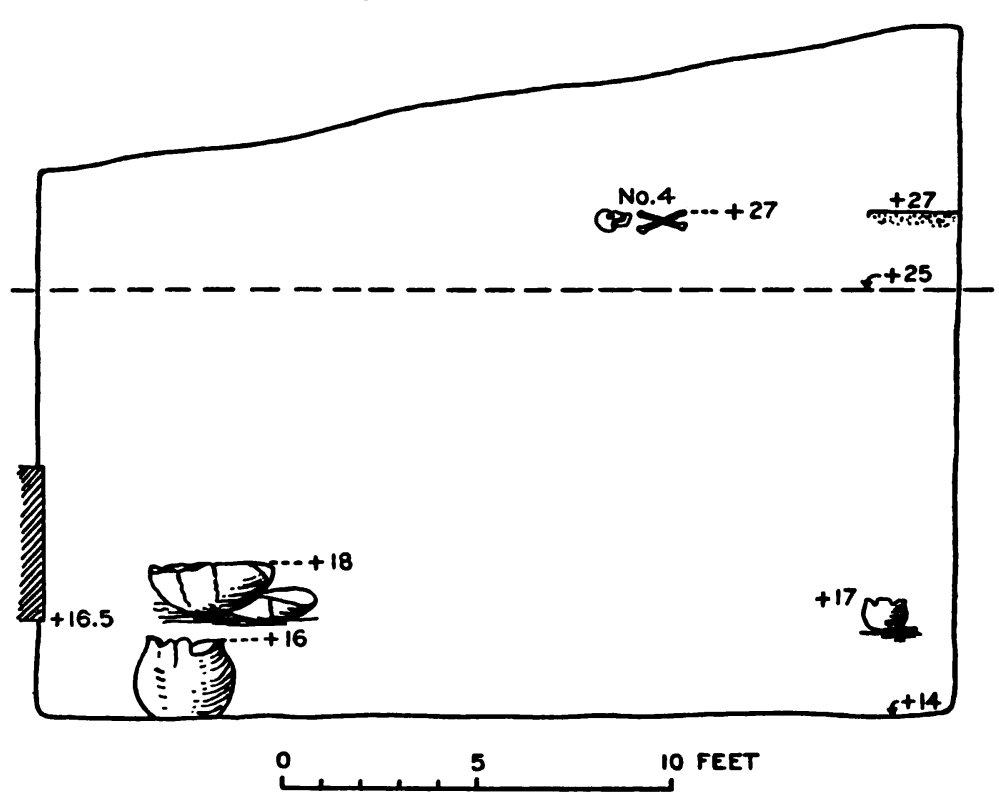

Fig. 33. - Vertical Section and Projection of Finda, Terrace III.

the group disappears wholly only below +22 feet 5 inches. This circumstance might be explained by the accidental falling of fragments during the excavation; but it is also possible that in ancient times they by chance became buried deeper here than elsewhere. A third explanation would be that the skeletons at +22 feet 5 inches were younger than the pithoi in situ. In this case the skeleton graves with their burial gifts would have to be assigned to the younger 
culture, and the deeper-lying pottery fragments of group $x$ would have to be explained as belonging with the burial. This, however, I consider improbable; for the number of the younger pottery fragments is too small, only one or two having been found daily in these lower layers. We shall be much more correct in assuming that the four bodies were buried by the same people who used the painted pithoi. In any case, these pithoi are an infallible proof that at the level of +25 feet we are already in the strata of the older culture. Henceforth we may assign to the older culture all layers in which similar pithoi are found in situ.

Terrace III (see figs. 32 and 33).-Terrace III, excavation of which began on March $3 \mathrm{I}$, lies with its upper edges lower than terrace II, much lower than terrace $I$ (see plan, fig. 22). Below the surface we soon came, at the south wall, upon pottery fragments, upright and close together, resembling the incrustation on the earth walls in the quadrangle of terrace $I$. It was not possible, however, to determine either the thickness or the trend of the earth walls or the character of the potsherds,

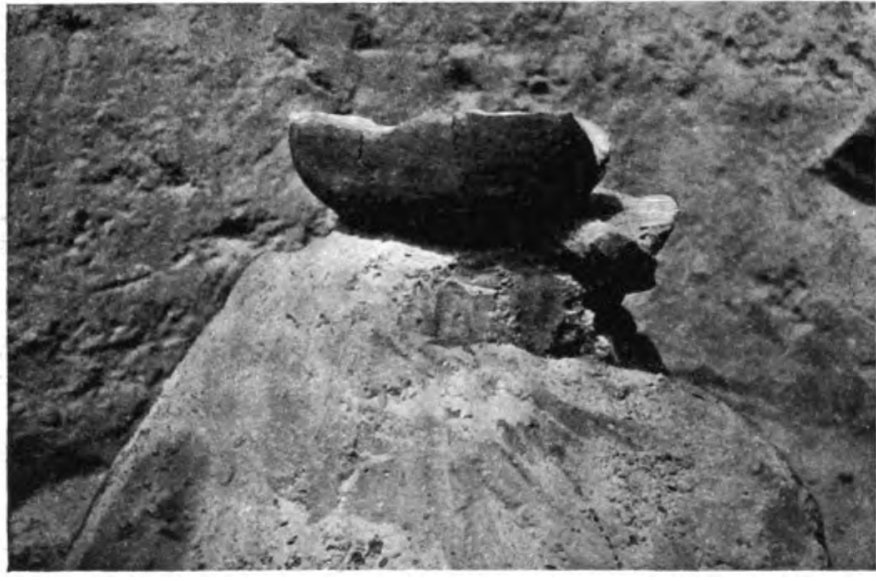

Fig. 34.-Pithos in Terrace III. which were light-colored and very poorly preserved. Near by, in the middle of the digging, a skeleton was discovered at +27 feet and uncovered by Mr. Warner. It was probably contracted in Hocker position, but this is not certain, because the skull and leg bones were almost destroyed by the workmen.

Lower down, at +18 feet, in the southwest corner of the digging, there were found in situ the bottoms of two painted pithoi, their positions warranting the conclusion that one of them had become useless and the other had been placed upon its remains (see fig. 34). They are, therefore, as in terrace II, evidences of settlements of the older culture. After removing these, there came to light, in situ, at the still deeper level of +16 feet, in about the same part of the terrace, a coarse domestic vessel with a diameter at top of 11.5 inches, and a height of 24 inches. It is of a different technique from that of the painted pithoi, and as the exterior is heavily incrusted with soot and the earth in the interior and around the external surface is much mixed with charcoal, the vessel would appear to be in situ and to have been employed as a kettle for cooking (see fig. 35). Here also, then, is evidence of a succession of superimposed settlements belonging to the older culture.

The skeleton uncovered above, however, must belong to the younger culture. It can not have been an inserted burial of later times, as its position immediately under the surface of the hill might at first sight indicate, because the finds accom- 
panying it and surrounding it do not differ in specific character from those of the terraces. Here, too, the fragments of pottery found on the surface and immediately under it were chiefly of the red and gray monochrome group, with very little of the painted variety of group $y$. At the level of the skeleton, on the other hand, there occurred almost exclusively the last-named variety, and under this only the "unmixed" culture layers containing pottery of group $y$.

Terrace VI (see figs. 28 and 29).-Near terrace $\mathrm{v}$ the trench, descending the southern half of the hill, bends a little toward the southwest, on account of the irregular form of the surface. Just here a shallow basin-shaped depression was observed on the surface, the explanation of which appeared in the deeper layers. In the northern wall of the trench there came to light at the level of +3 I feet a broad and extended hearth filled with ashes. Near it, but below its level, there was extracted a modern and but slightly rusted iron nail; and the digging soon exposed a great hole which, in the form of a roomy passage, extended into terrace $\mathrm{v}$ and could be followed underneath a wall which was discovered there at the level of +28 feet. Presumably this passage was the work of some animal, and belongs with other tunnel-like passages which appear in the walls of Komorof's trench and which need especial attention during excavation. This passage had at one time had an opening on the surface, and the basin-like depression was

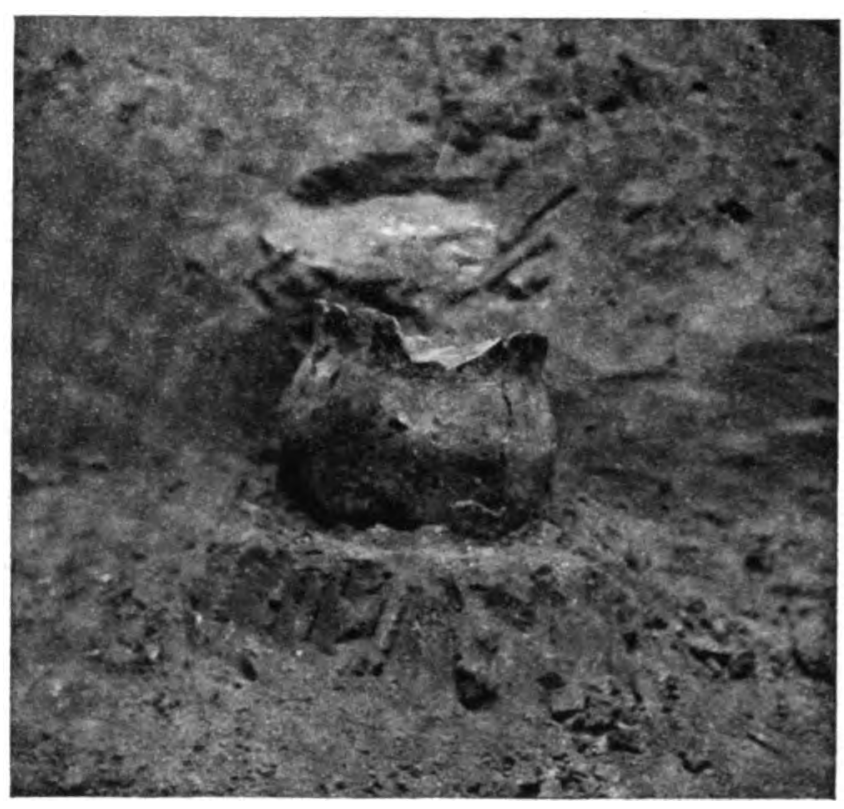

Fig. 35.-Pithos in Terrace III.

caused by its caving in. Where such occurrences have taken place, the layers must necessarily have become mixed and afford no basis for trustworthy inferences.

About I foot below the level of the hearth a child's skeleton was exposed in the western wall of the excavation (see special report of Warner); and on the opposite side of the terrace, at +25 feet, an accumulation of potsherds was found, together with fragments of different large pithoi. Here, therefore, begin the older culture layers of group $y$. The upper mixed layers also contained a predominating quantity of the older pottery. Nevertheless, if we follow the order of succession observed in the layers elsewhere in the hill, we must assign both the hearth and the child's skeleton found in this terrace to the younger culture and recognize a causative relation between them. They correspond to the flat stones $(+32.5$ feet $)$, or the somewhat lower-lying ash layer $(+30$ feet 7 inches $)$, in terrace $v$. The excavation of the deeper layers in terrace vi was rendered difficult and even 
dangerous through the undermining already referred to, and nothing new was discovered above the level of +19 feet 5 inches.

Terrace VII (see figs. 28 and 29).-In the southern extension of the upper trench, a little below the surface, we came upon two hearths at the level of +30.5 feet, one of which had a hole filled with an ashy earth, as in terrace II. Immediately adjoining each of these, but lying 10 or 12 inches deeper, there occurred skeletons (Nos. Io and 15 in the special report of Warner). No further finds in situ were found, although the terrace was sunk to $+2 \mathrm{I}$ feet.

The pottery found in the upper layers belonged chiefly to group $y, i . e .$, to the older culture; there was much less of the red and gray ware. Isolated fragments of red monochrome were observed as deep as +24 feet 2 inches, but below this they disappeared entirely. The conclusions expressed above also apply here: the hearths and the skeletons must be assigned to the younger culture, since they stand at the same level with the ash layer, +30 feet 7 inches, and the upper edge of the wall, +30.5 feet, in terrace $v$.

Terrace VIII (see figs. 28 and 29). -The predominant monochrome pottery disappears in the somewhat lower-lying parts of the southern declivity and the surface contains only isolated fragments of the red polished ware. The great mass of the fragments belong to group $y$. On the south edge of the trench, just under the surface, at +25 feet 5 inches, there occurred the remains of skeletons and four mealing-stones. Immediately adjoining these to the west, and but 7 inches deeper, there appeared the lip of a painted pithos (top diameter 19 inches, height 13 inches). With its broad vertical bands painted in chess-board pattern, it is an excellent specimen of this kind of vessel produced by the older culture, of which we found indications to the depth of +22 feet 5 inches in this terrace.

\section{EXCAVATIONS AT OTHER POINTS ON THE KURGAN.}

$$
\text { (Sce Fig. } 22 \text { and Plate 7.) }
$$

West digging.-No new facts were contributed to the history of the kurgan by the finds in the west digging. An earth wall trending in an easterly and westerly direction had been cut through between the levels of +18 feet and +10.5 feet. From its height and the finds accompanying it, this wall must belong to a building of the older culture. The only significance of the west digging in connection with the history of the kurgan consists in the finds of pottery made there, which connect the layers exposed in the terraces with those of the "galleries" in the Komorof trench. The digging yielded almost exclusively fragments of group $y$. Even on the surface no fragments were found of the younger pottery which represents the later civilization of the kurgan. This fact agrees with the observations made in the lower-lying terraces; in terraces III and viII the older culture was met with directly under the surface. The traces of the younger culture must also have disapfeared at the west digging, the highest edges of which stand at the level of +25 and +20 feet. Upon the surface here there was found the bottom of a coarse, light-colored vessel made on the wheel; but this stands entirely apart from all the rest of the pottery as a piece lying accidentally on the surface and in no wise connected with the development of the cultures of the kurgan. 
North diggings.- Similar specimens of a probably recent pottery were found, together with flat, square, burnt bricks, near the foot of the hill, 2 and 3 feet below the surface in north digging $I$, which at that point is almost on the level of the plain. The other finds at this level, consisting of older and younger pottery, show that the soil here consists of surface wash. Unmixed deposits of the older culture begin only in deeper layers at about the level of -4 feet; the greater part being derived from the older culture, though now and then a younger monochrome fragment turns up. Consequently one can, without hesitation, refer to the older culture the traces of earth walls which were discovered in north diggings I and II, between - I I and - I 2 feet, as well as a mass of ashes that occurred at the northwest corner near these walls, at about 6 feet 5 inches under the lowest edge of digging Ir. The circumstances of the finds are important in connection with the discovery of a skeleton grave near this ash layer in north digging $\mathrm{I}$, at $-\mathrm{I}$ I feet. The skeleton was exceedingly well preserved and is one of the best specimens of the contracted or Liegender Hocker position, which throws such an interesting light upon the burial customs of the ancient inhabitants of the kurgan. The skeleton belongs to the older culture period, although its relation in time to the neighboring wall and ash layer can not be absolutely determined, since layers belonging to the younger period of the hill can not be found in these depths. Still deeper, between -13 feet and - 19 feet, there occurred numerous fragments of a pottery not found in the higher layers, which we will call group $m$. They are fragments of deep cups made from well-washed light-brown clay, burnt very hard, the clay being covered with a fine light-brown coating and this in turn with matblack painting. The occurrence of pottery of such excellent technique at such a depth seemed strange at first, and claimed our special attention; but in connection therewith it was even more important to find painted fragments of the group $y$ still deeper, between -20 feet and -24 feet 5 inches, as this group has come to stand as a witness of the older culture of the kurgan in the deeper layers of the terraces and of the west digging. At -24 feet 5 inches in north digging in the natural surface of the plain was reached.

South shaft.-Excepting one fragment of the red polished ware, which was found between $-I$ and -5 feet and which had evidently fallen from above, fragments of only the coarse and fine-painted older ware of group $y$ were found in the south shaft in the layers between +5 feet and -7 feet. It is remarkable that here, in contrast with the conditions at the north diggings, the layer of surface wash and mixed pottery is missing. This difference is explained by the fact that the southern declivity is more exposed to the influences of weather, wind, rain, and sun than is the northern. The deformation of the hill must, therefore, have been more rapid and extensive here.

West shaft.-The shafts sunk at a distance of about 200 paces on the west of the hill show that the deeper culture-strata of the settlement had a wide extent, for here, at the level of -15 feet, a wall of air-dried brick was passed through. The pottery that was raised corresponded to that of the middle and lower layers of the kurgan and assigned the construction to the lower culture period. 


\section{THE EXCAVATIONS IN KOMOROF'S TRENCH.}

(See Fig. 22 and Plate 7.)

East and West Galleries; East and West Pits, in Botrom of Komorof's Trench.

The excavation of Komorof's trench promised to expose the undisturbed strata of the center of the kurgan, but in the course of the examination it soon became clear that the finds made here could not be accepted without question and could merely serve the purpose of checking in part the observations made on the surface.

As has been said, on March 25 and 26, the galleries were driven in the sides of Komorof's trench to examine the layers of débris occurring between the visible vertical walls. These galleries, whose floors stood at +8 feet, penetrated 7 to 9 feet into the sides of the trench, with a height of about io feet. On both days the layers yielded a mass of broken stones and a great quantity of fragments of coarse, thick-walled pithoi, reddish or greenish light-yellow, in part painted; also some fragments of a finer painted ware and especially some lip-pieces of cups, without profiling, all these belonging to group $y$. On the first day, however, there occurred specimens of the other variety, the red monochrome technique with a polish and the lip-piece of fine gray ware-i. e., fragments of group $x$-which occurred in great quantities on the surface of terraces I, II, IV, and V.

In the eastern and western pits in the bottom of Komorof 's trench,into which we started on March 25 for examination of the lower layers, the finds were only partially of the same kind as those of the galleries, for there occurred very many red and gray monochrome fragments. Besides this, the stratification and texture of the earth was different from that in the galleries. The earth here was loose and easily removable, while in the galleries the workmen had to exert all their strength in order to make progress. There were lacking, also, the masses of fragments of large thick walls, painted pithoi, and broken stone, which were peculiar to the galleries. It became evident that we were digging in a different kind of débris from that in the galleries-in an earth-mass, the origin of which requires a different explanation.

In order to verify the observations made in these pits in the bottom of Komorof's trench, we began on March 29 to sink shafts from the bottoms of the two galleries which adjoined the pits. A partition wall of the original undisturbed earth was left standing to separate the pits in the trench from the shafts, which were sunk in obviously undisturbed culture-strata. To a depth of +1 foot, the observations here corresponded throughout with the finds in the gallery layers above, with the single exception that an isolated piece of monochrome ware was observed. But when the partition wall fell in after about two days' work, and the digging proceeded without separation in the pits and the shafts, there came, in the west gallery at the datum-level, not only larger numbers of fragments of the suspicious monochrome ware, but even a piece of a modern iron band.

The paradox presented by these contradictory facts was explained on March 3I by R. W. Pumpelly, who demonstrated the existence in the west pit of a line 
or plane separating the different kinds of earth and coinciding with the plane that would represent the downward continuation of the wall of Komorof's trench. It was thus found that Komorof's trench continued in depth and extended much deeper into the middle of the hill than the level at the time of our arrival gave us reason to expect. This central and deepest part of the trench had been filled in by General Komorof, thus bringing into these depths earth from different ages of the kurgan, together with modern iron articles. This discovery compelled us to abandon all excavation in the trench bottom, confining ourselves to the shafts sunk from the galleries. In spite of this precaution there appeared from time to time pieces of pottery such as we had been accustomed to find only in the upper layers of the kurgan. Thus, in the shaft between -1 foot and -14 feet 8 inches, we came upon three fragments of gray ware, among them being a lip-piece, a hollow foot, and between -24 feet 7 inches and -29 feet, as represented by the workmen, another piece of gray ware. Farther on, in the east gallery shaft, as represented by the workmen, there occurred between -6 feet and -8 feet some fragments of red and gray monochrome ware; but these were in all cases accompanied by the ordinary painted ware of the middle layers, which occurred throughout in the lowest culture-strata of the kurgan. Only in the shaft of the west gallery, between -14 feet 8 inches and -24 feet 7 inches, did we find the fine painted ware of group $m$, such as was found in the north digging between - 13 feet and - 19 feet. It must, therefore, have only a relatively small and transitory importance in connection with the culture of the lower layers. The mixing of these old finds with the red and gray monochrome ware, in these deeper layers of the east and west gallery shafts, can, as stated, be of only secondary origin; for in the terraces mixed layers were, as a rule, observed no deeper than +25 feet, at which level the strata of the older culture began. We must, therefore, explain the occurrence of younger pottery in the gallery shafts as being due to the contact of the earth raised from the shafts with the débris of which the bottom of Komorof's trench was composed.

There is still an important find to be mentioned. At the level of -8 feet, in the shaft of the east gallery, there occurred two skeletons, one with bead ornaments (plate 40, fig. 7) as burial gifts, and the other, according to Warner, with two flint knives and two spin-whorls (cf. Warner's special report). They are a sure proof that the inhabitants of the lower strata practised burials within their dwellings, and they thus supplement the data afforded by the skeleton graves of north digging II.

$$
\text { OTHER FINDS-CHARACTER OF CULTURE-RELATIVE CHRONOLOGY. }
$$

The pottery enables us to distinguish older and younger epochs in the history of the development of the kurgan, and its forms and decoration permit us to form an opinion as to the artistic powers of the inhabitants of the settlements; but it does not enlighten us concerning the quality of the civilizations nor the culture character of the finds. Our information on these points is obtained from the whole culture equipment, and from all the special finds of metal, clay, and 
stone which were collected daily from the strata as places of settlement were opened up. These finds will be systematically treated in a later chapter. Here we can only refer to such facts as serve to indicate the kind of civilization and the relative chronology of the finds. Now, flint objects were found in all the layers of the hill, the most numerous objects being so-called knives or long scrapers. That these objects were also made on the spot is proved by the many flakes of flint and several flint-nuclei which occurred with them.

Nevertheless, we must not think we have to do with the stone-age culture. Iron is indeed excluded, only modern iron being found in the debris of Komorof's trench, and the absence of iron in such large masses of earth as were removed during the excavations leads us confidently to conclude that this metal was unknown to inhabitants of the North Kurgan. However, objects and fragments of copper* occurred so frequently, not only in the upper layers with the deposits of the younger culture, but also in the middle strata, that we are justified in referring the hill to the metal age. The absence of objects or fragments of metal in the lowest strata would not warrant us in concluding that the metal was unknown in the oldest period of the kurgan, for the pottery of the middle strata was so regularly followed downward into the lowest level of the hill that, notwithstanding the appearance of a special kind of vessels in the lower strata, we can not speak of different cultures or of a change of cultures between the lowest and the middle strata. On the other hand, on account of the different ceramic groups $x$ and $y$, we must distinguish between the two different periods of early metal age in the evolution of the hill. The distribution of all other finds through these periods will be shown in a systematic treatment of the finds and of the conditions under which they occurred.

\section{THE EXCAVATIONS AT THE SOUTH KURGAN.}

GENERAL SUMMARY.

(See Plate 8.)

The discovery of such important facts and finds at the North Kurgan, the importance and derivation of which could no longer be doubted, necessarily stimulated us to attack the South Kurgan; particularly as its surface was covered with pottery fragments showing a developed wheel technique, and because its height was fully ro feet greater than that of the other. An examination of the southern hill was therefore begun even before work was wholly stopped at the northern one.

In order that the course of the investigation and the criticism of the finds may be followed, it is important to remark that from the base of the roughly elliptical hill there extends toward the north a lower, level, tongue-shaped elevation. The whole hill, therefore, has a form that might cause one to presuppose an irregular and different development.

* Since Dr. Schmidt's report was written, analyses of five out of eleven objects found in the upper and lower culture-strata of the North Kurgan, including the cutting and punching implements, have shown complete absence of tin. Cf. report of Professor Gooch, Part IV.-R. P. 
Plate 8.

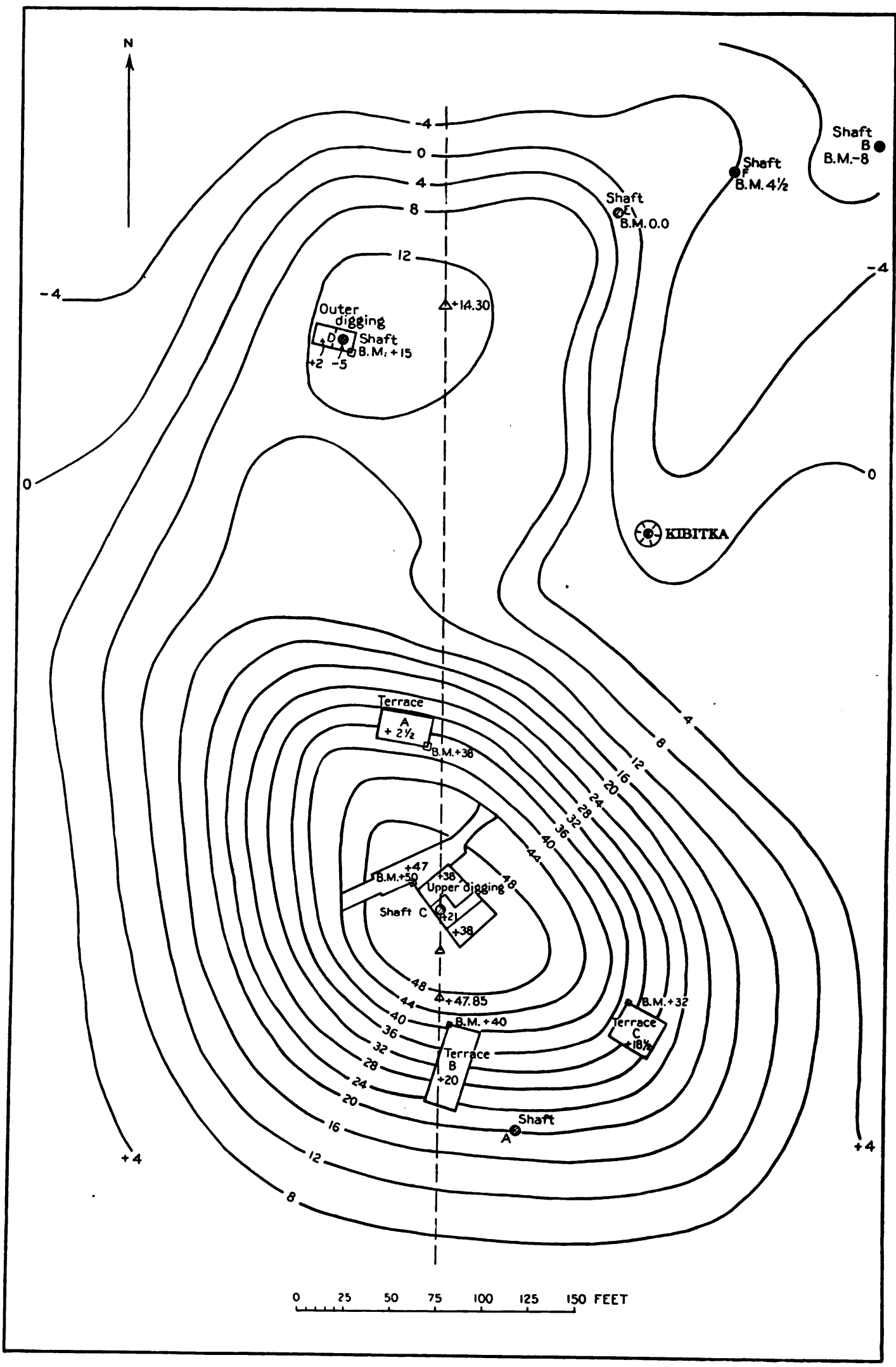

Plan of Excavations, South Kurgan, Anau. 


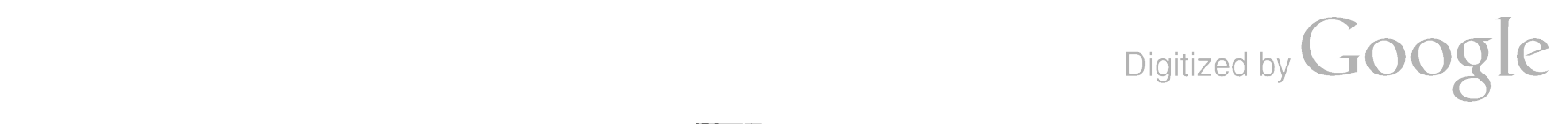


On April 8, 1904, the hill was attacked simultaneously at two points-on the plateau-shaped summit and on the northern declivity. At the height of +50 feet there was laid out, in the direction of the longitudinal axis, a large excavation 25 feet wide by 42 feet long, with two exits for the removal of the débris. By means of terracing this was sunk to the level of $+2 \mathrm{I}$ feet 2 inches, and was named the upper digging. By means of a shaft sunk from this level (shaft $\mathrm{C}$ ), it was possible to determine the culture-strata in the heart of the hill to the depth of -20 feet. On the northern declivity of the hill an excavation was made (terrace A), 15 feet wide by 30 feet long, and sunk to +21.25 feet; but here there appeared sloping layers, owing to the transition from the summit of the hill to the tongueshaped extension above mentioned, while the strata were horizontal in the upper digging. Therefore, in the course of our observations, terrace A was necessarily of importance in the problem of the relation existing between the tongue-shaped extension and the hill itself.

To settle this question, an excavation was laid out ro feet wide by 22 feet long in an east-west direction on the northwest edge of this extension and called the "outer digging." At a depth of - I foot a terrace was made and the excavation was continued to -4 feet. It was shown by this excavation that the plateau had been formed during the youngest period of the development of the hill and that it corresponds to the uppermost layers of the hill.

On the other hand, horizontal strata were more to be expected in those declivities which were steeper and where the hill had been subjected to greater deformation through the external influence of sun, rain, and wind than on the north side. Therefore, on April I I, a third excavation, i 9 feet wide, terrace $B$, was made on the southern declivity. The horizontal layers of the heart of the hill came to light immediately after the removal of the superficial loose earth. The exposure on April 15 of a threshold lying in situ at +27.5 feet, and on April 18 of a child's skeleton at a level of +25 feet, prompted an extension of the excavation. Terrace B was widened toward the outside and deepened. Simultaneously a third terrace (C), 22 feet wide, was started at another point to the southeast. Both places were destined to become the most productive points opened.

Terrace B yielded seven skeletons, vessels in situ, a peculiar quadrangle or chest of clay, and lastly, below these, at the level of +20 feet, more or less well-preserved walls of sun-dried bricks.

In terrace $\mathrm{C}$, between +26 feet 2 inches and +18 feet 5 inches there were found in several layers, lying one below the other, hearths and ashes, a skeleton grave, and the remains of a pithos in situ.

On the whole, the analogy of the finds in both terraces to the northern kurgan seems complete. Dwellings built one above the other contained skeleton graves; but the whole culture equipment pointed to a younger age than that of the northern kurgan.

The lowest culture-strata of the southern kurgan, like those of the northern one, could be examined only through shafts. This purpose was served by shaft $\mathrm{C}$ in the upper digging; by shaft A, which was begun on April 13 , on the southern 
declivity near terrace $B$, where the lowest culture-strata were found to the level of -22 feet; and lastly by shaft $D$, which began at -5 feet in the outer digging, and was sunk to a depth of $-3 \mathrm{I}$ feet, exposing culture-strata to a depth of -23 feet.

These shafts, as well as some others at the northeast corner of the kurgan, were intended chiefly for physiographic purposes; but the culture material which was raised from them was of archeological value, even though it furnished only a meager basis for understanding the character of the lowest culture-strata.

\section{EXCAVATIONS AND FINDS AT DIFFERENT LOCALITIES.}

Upper digging (figs. 36,37 , and 38 ). -The excavation laid out on the summit at +52 feet, datum being the level of the plain, was sufficiently extensive in area to permit the work to descend to a considerable depth. In this digging the succession of superimposed layers can be best seen on the western wall (see fig. 37).

In the upper layers, about 5 feet thick, there came to light a great quantity of fragments of a

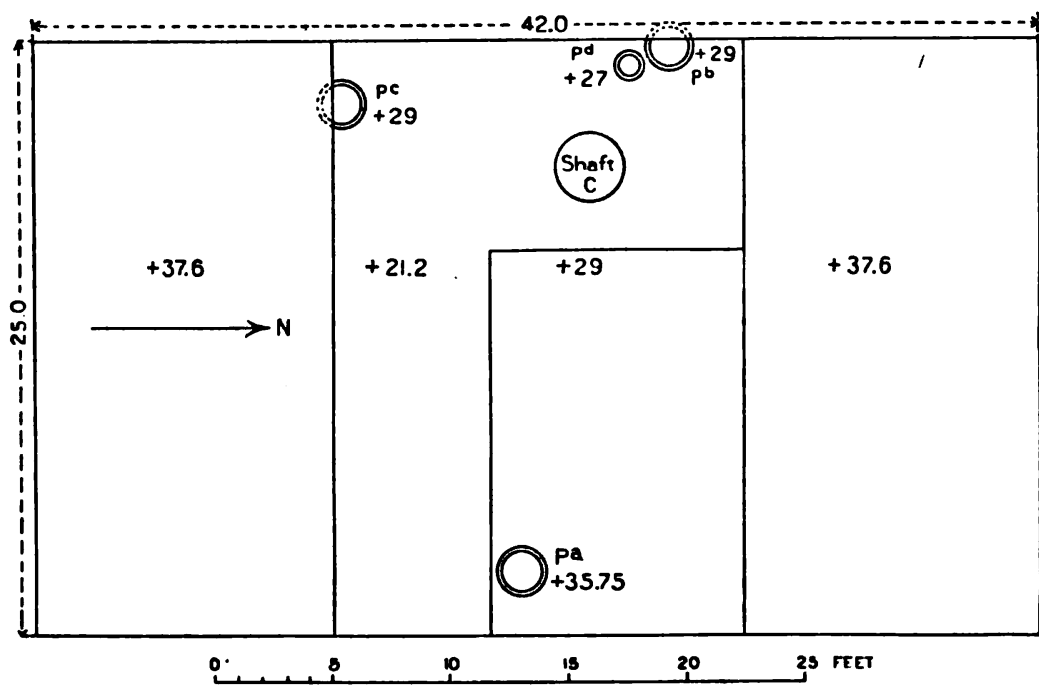

Fig. 36. - Plan of Upper Digging. common, wheelmade, light-colored pottery (group I). Among these there was found, a little below the surface, a single small gray pot $6.5 \mathrm{~cm}$. high (plate 9, fig. 5). At the same time there was observed a fragment of a heavily rusted iron knife (Special Finds Catalogue, South Kurgan, 2), and several small

unworked stones were found, but not in any position that would indicate an intentional arrangement. Above the level of +48 feet, which marks the upper limit of a stratum extending through the hill, there appeared in the southern end of the west wall several layers of débris, consisting of stones, ashes, charcoal, and earth. These lay between two earth cores, apparently the remains of walls of indeterminable length and thickness, and the whole recalling the stratification of the North Kurgan. The strata evidently mark the position of houses on the summit of the hill. Deeper, between +44 feet 8 inches and +43.5 feet, a reddish-brown layer, rising slightly toward the north, extended through the whole excavation-presumably a deposit of burnt earth brought together by the rains. Below this, again, the usual yellowish earth reached to about the mean level of $+4 \mathrm{I}$ feet. Here began a layer of débris mixed with considerable ashes and charcoal; but in the 
PLATE 9.

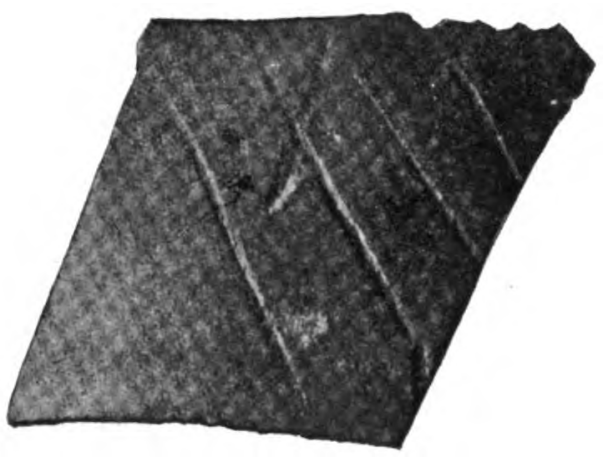

2

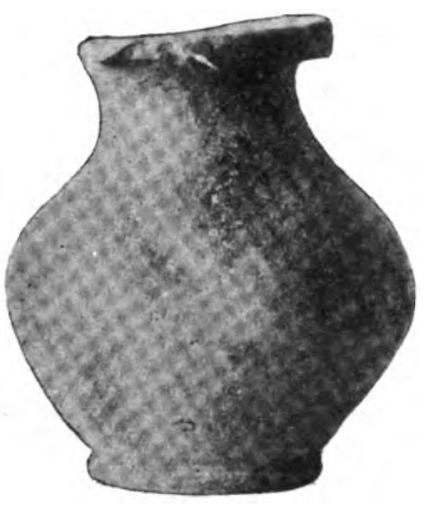

5

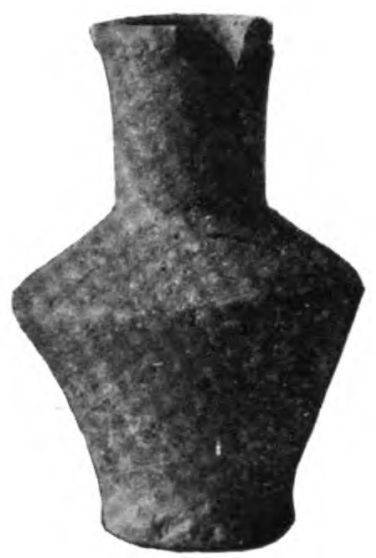

6

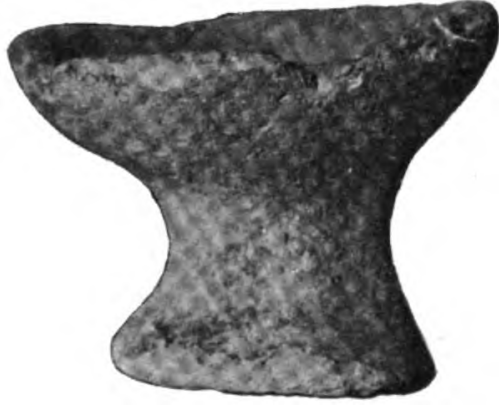

4

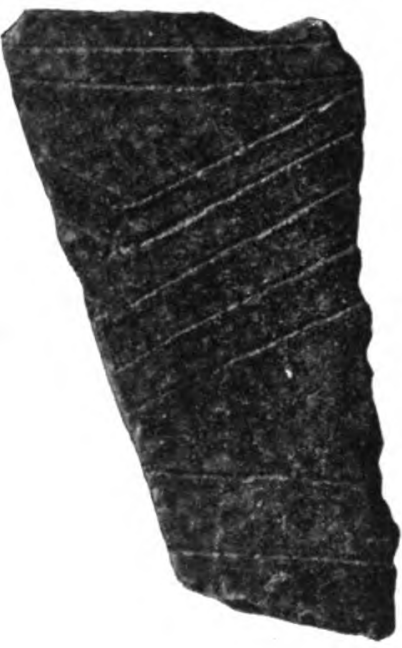

3

1

Pottery from North and South Kurgans, Cultures I, II, and IV.

Fio. I (N.K.). Feeding-cup (?). Terrace Ia, near Skeleton. about 4.25 feet below summit (about +36 to +38 feet). Height $6.5 \mathrm{~cm}$. 2 (N.K.). Smail Vessel (Cup, Height $5 \mathrm{~cm}$.; from mixed Cultures I and II, Terrace V.

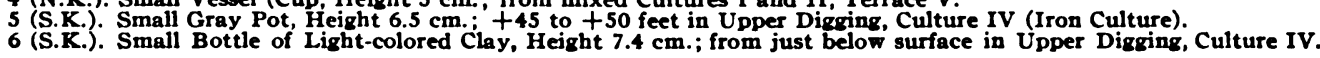

(Figs. 5 and 6 seem foreign to Culture IV.) 
$\because$

Digitized by $\mathrm{OOQ}$ C 

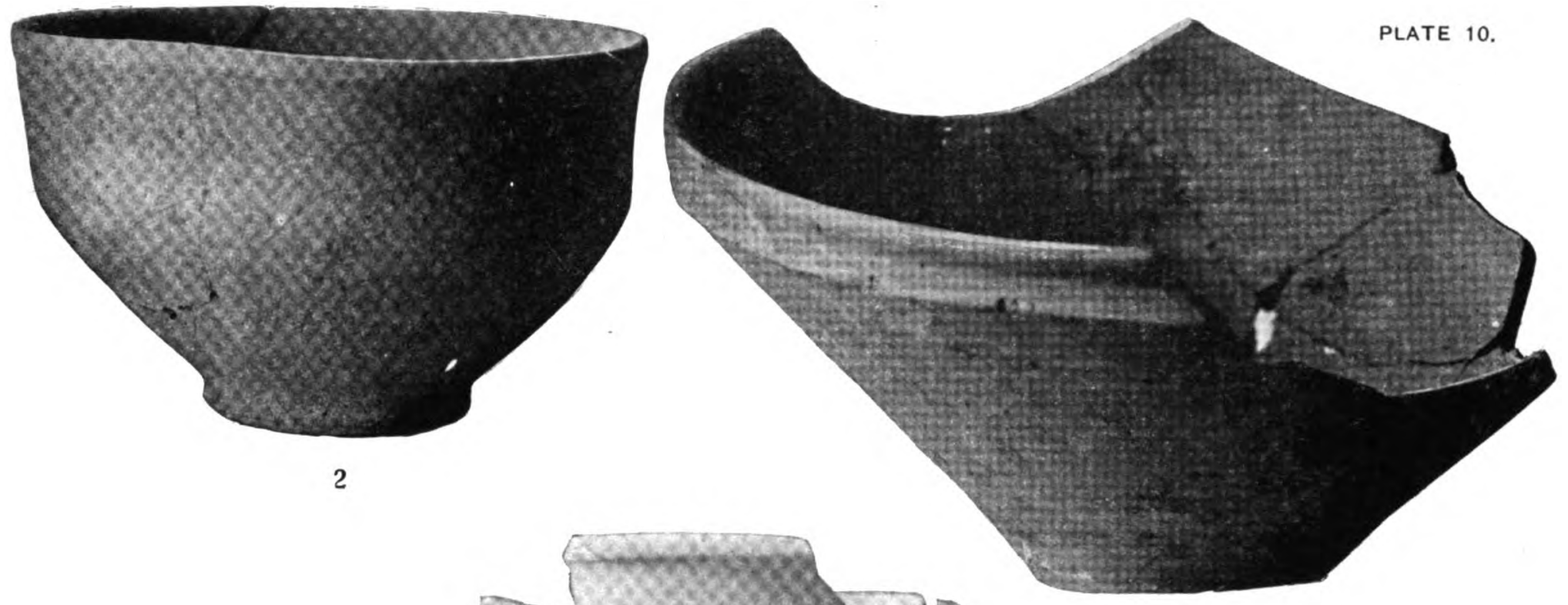

2

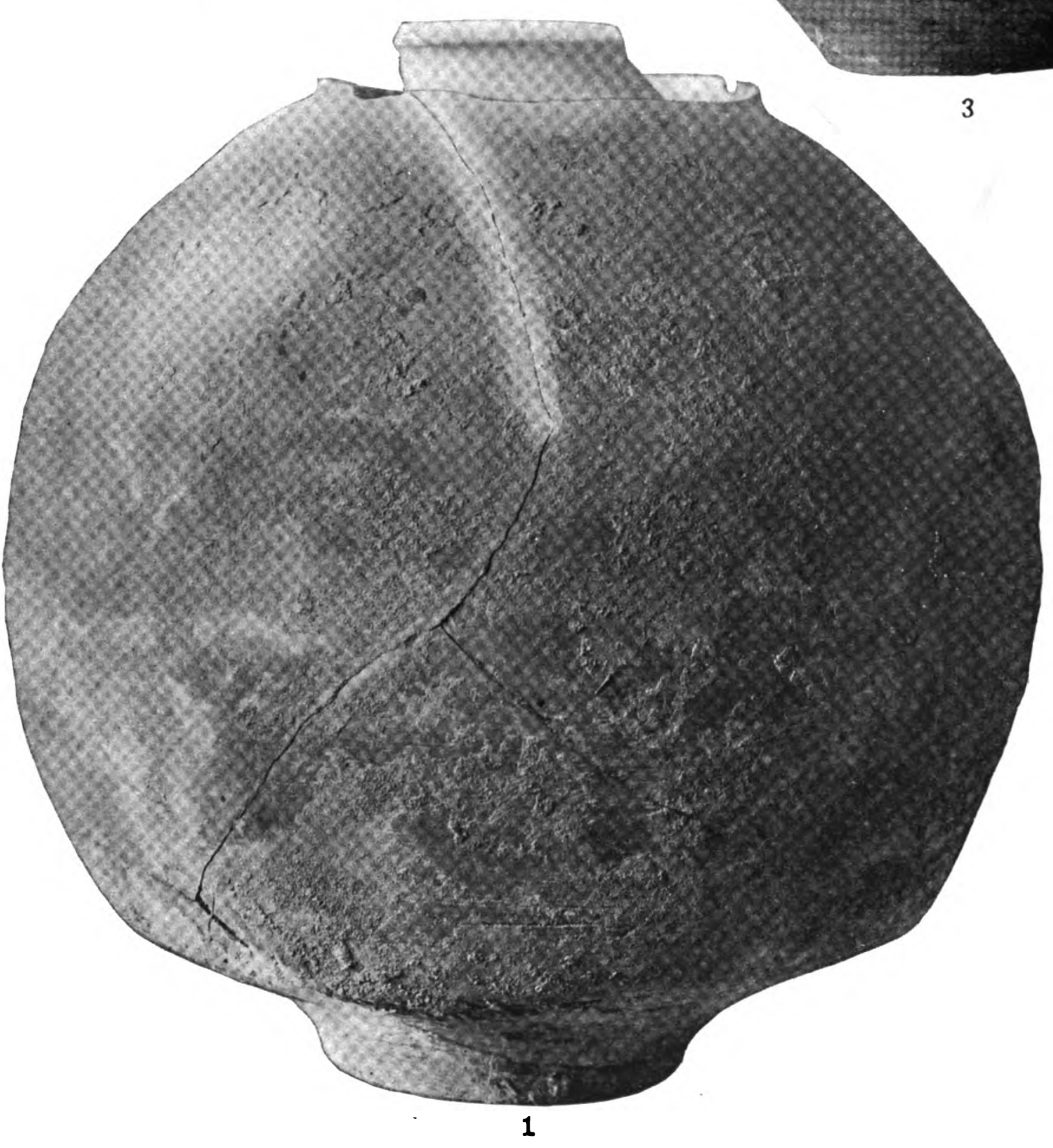

Pottery from Middle Strata, South Kurgan, Culture III.

Fio. 1. Spherical Vessel, Height $34 \mathrm{~cm}$. Fio. 2. Cup. Height $7.2 \mathrm{~cm}$. Fio. 3 . Bowl, Height $9.5 \mathrm{~cm}$. 
-

Digitized by Google 

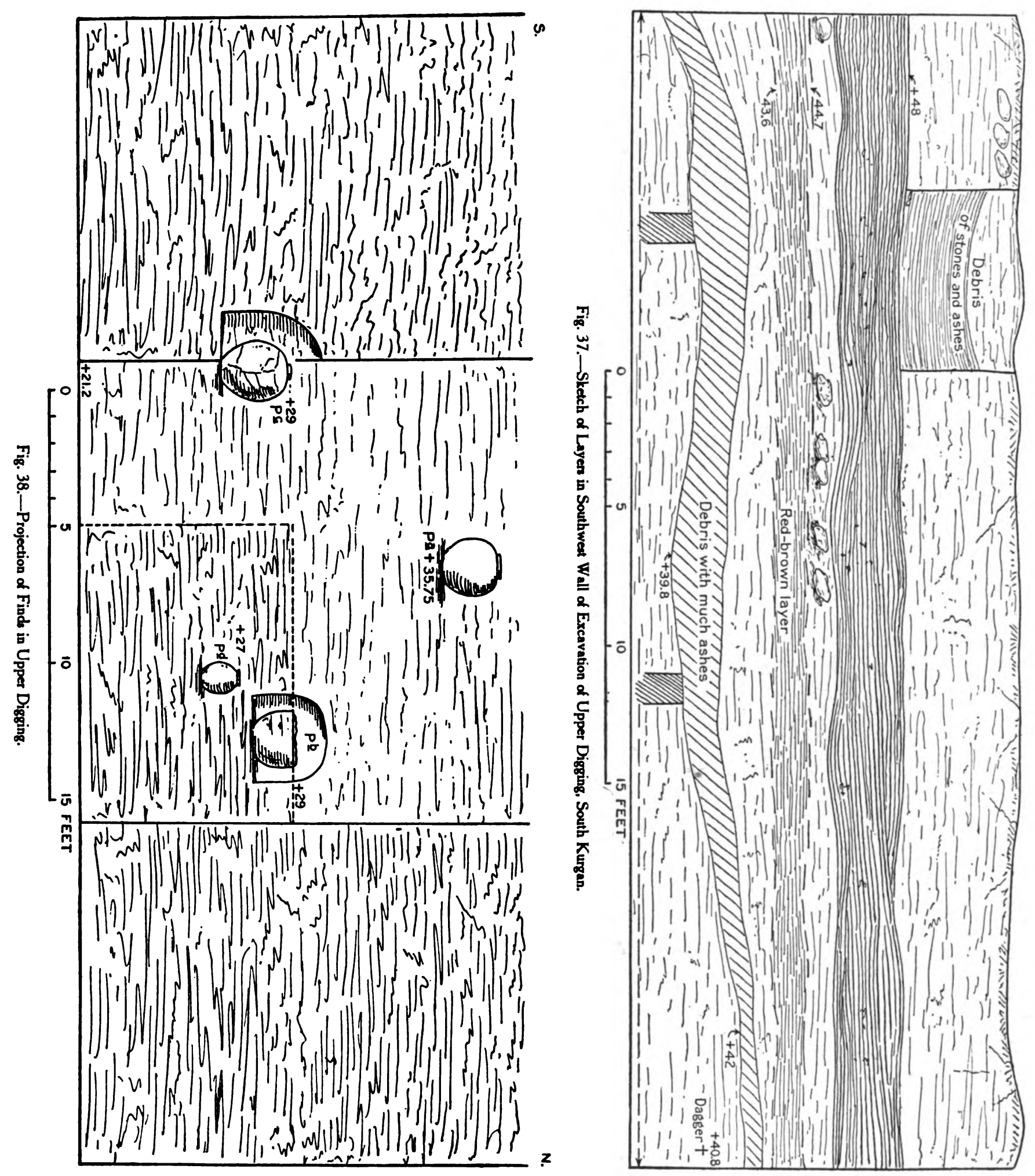
meantime a change occurred in the character of the objects removed between the levels of +48 and +43 feet.

While pottery of the kind characterizing the upper layers was still found,

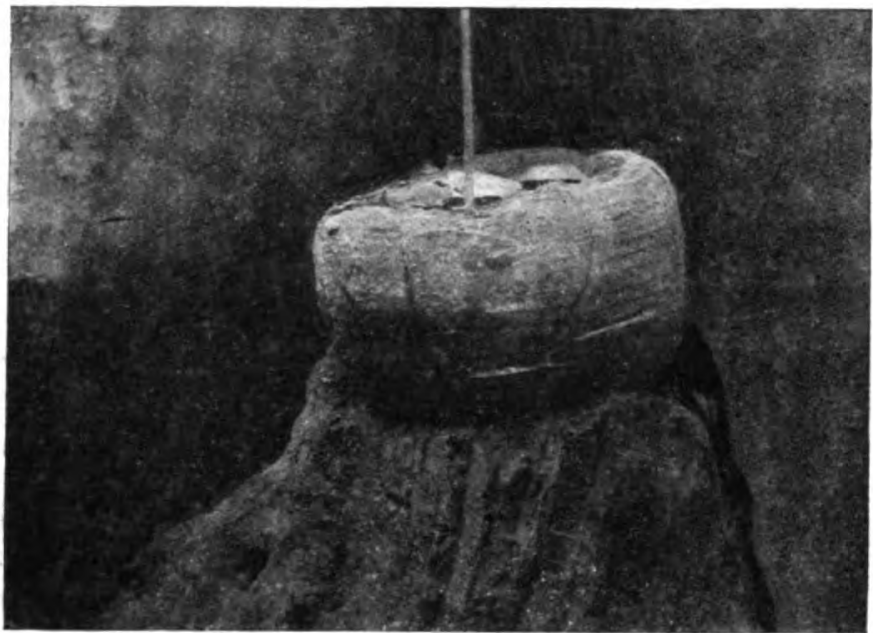

Fig. 39.-Pithos $b$ in Upper Digging. it was mixed with an inferior hand-made ware, some of which was colored red and roughly painted in geometric patterns, showing a very poor technique (group 2). The picture changed entirely as we progressed downward through the layer of débris mentioned above as lying below $+4 \mathrm{I}$ feet, in which we were digging on April 14 and 15, 1904. This layer, which is 2 feet thick, is clearly connected with the remains of two walls which came to light below it on the west side (cf.

the sketch, fig. 37). The pottery of the upper layers had here entirely disappeared. Now and then fragments of the hand-made group 2 turned up, but the rest had an entirely new appearance. It was soon possible to distinguish

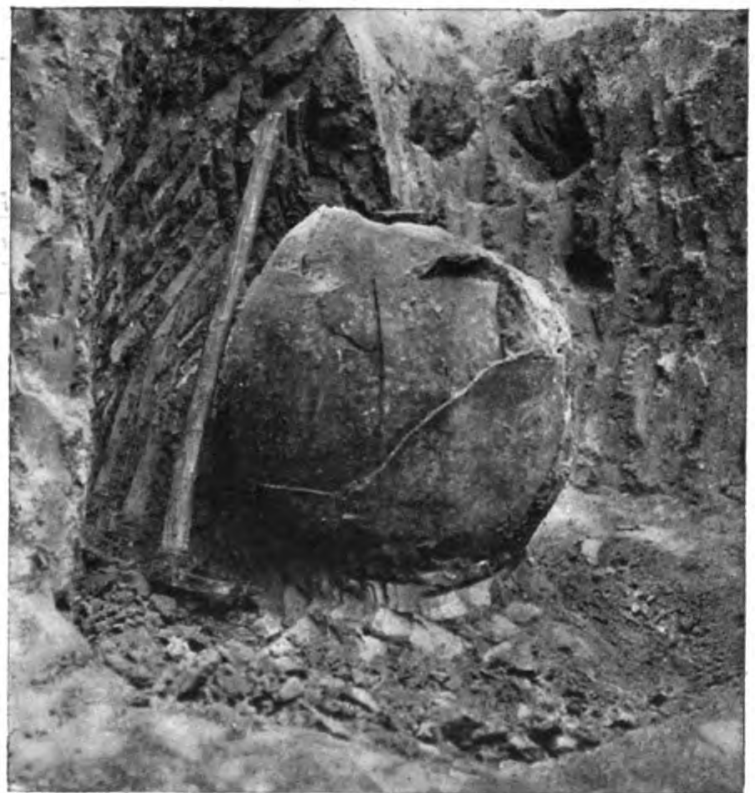

Fig. 40.-Pithos $c$ in Upper Digging. several groups-a red, a gray, and a light-colored, whitish-green ware (groups 3 to 5 ), all of which differed in technique and form from the pottery of the upper layers, but exhibited a developed wheel-work. We were already in the presence of an older culture-stratum. We can therefore say that the plane separating the older and newer cultures lies in the earth traversed by us on April 14 and $15, i$. e., between +40 feet and +37 feet 7 inches.

The new pottery accompanied the finds of the deeper-lying layers, the only change being that the red and gray ware became more rare, while ware made of a greenish clay (group 5), was found almost exclusively.

As regards the other finds, on April I 4 at +40 feet 8 inches in the northwest corner of the digging, we found a copper dagger, which we welcomed as a fore- 
runner of the newly discovered culture. In the meantime we had reached a depth requiring the formation of a terrace, thus restricting the work to the central portion of the excavation.

At the level of +35.75 feet, near the east wall of the excavation, we came upon the lip of a pithos $(a)$ standing in situ; and still deeper, between +32 feet and +29 feet, occurred several copper objects (a razor, a dagger-blade, and a needle-shaped implement). At the level of +29 feet another terrace was formed. At this depth, on the. west side of the excavation, there appeared the broken lips of two pithoi $(b, c)$ and somewhat deeper a well-preserved copper sickle, a glazed spinbob, and a pithos (b), also a smaller but well-preserved pithos $(d)$. After locating and removing these pithoi we reached the level of +2 I feet 2 inches, at which depth shaft $\mathrm{C}$ was started for study of the deeper layers (figs. 36 to 38 ).

The examination of the pithoi yielded the following results: As pithos $a$ had been crushed by the earth pressure, and preserved only as a pile of fragments, its original height was indeterminable.

Pithos $b$ was embedded in the western wall. It, too, had been separated into several fragments, but was sufficiently preserved to be photographed. Its lip had been broken off, but different pieces were found in the interior. The diameter was 20 to 24 inches (see fig. 39).

Pithos $c$ stood partly in the southern wall of

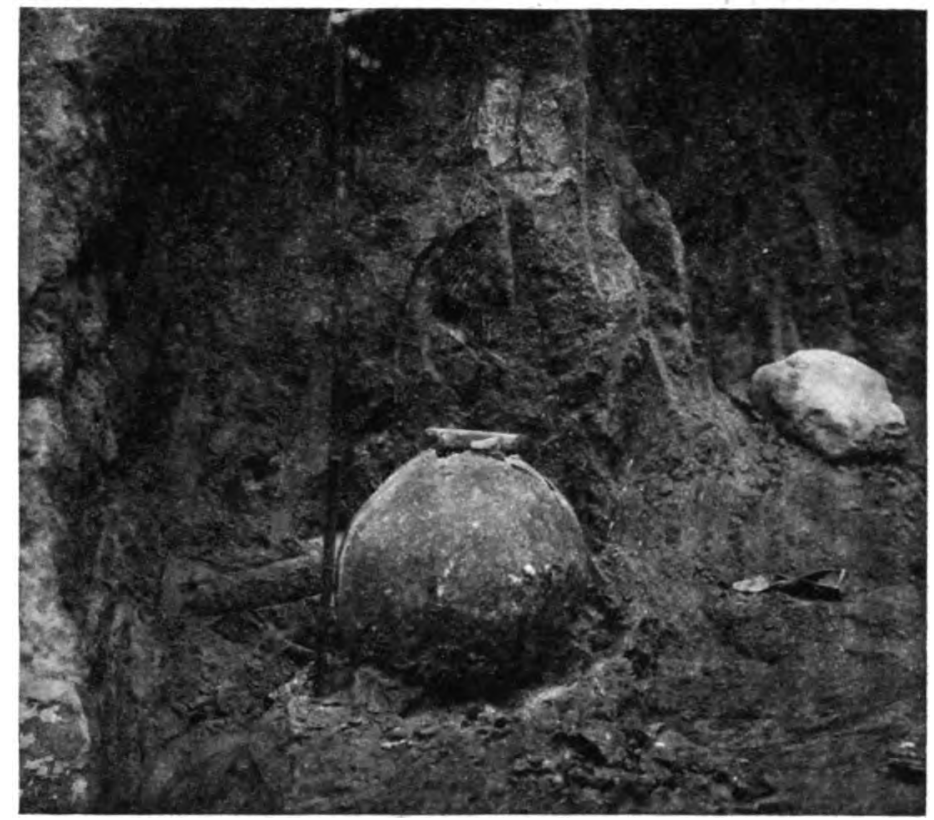

Fig. 41.-Pithos $d$ in Upper Digging.

the excavation. It, too, had lost its lip, but otherwise it was better preserved than pithos $b$. Diameter 25 inches; height 31.5 inches (see fig. 40).

Pithos $d$ stood a little lower and near pithos $b$, but it belongs to the same layer. It differs in form from the barrel-shaped $a$ to $c$, and has a narrow mouth, with a flaring lip, the opening being 4.5 inches, the circumference 39.5 inches, and the height 15 inches (see fig. 4I). In clay and technique all four pithoi belonged to the best ceramic product. They were made on the wheel; $a$ is redtoned; $b$ to $d$ are light greenish-white or dead yellow.

As regards the remaining ceramic finds, as the excavations progressed between +37 feet 7 inches and +21 feet 2 inches, uniform culture layers, with fragments of group 5, were disclosed. Only the different positions of the pithoi indicate the relative age. Since the lower edge of the wall mentioned above lies at +37 
feet 7 inches, pithos $a$, whose lip stood at +35.75 feet, must belong to an older period. Pithoi $b$ to $d$ must have been already buried when $a$ was put into position. Thus, in the upper digging three different periods are determinable in the older culture layers, from their upper limit, which is between +37 feet 7 inches and +40 feet, down to the bottom of the digging at +21 feet 2 inches.

We may assume that houses with earth walls belong to the pithoi in situ. Since we did not find traces of the floors the absolute levels are indeterminable, but from the position of the pithoi we can accept the figures +37 feet 7 inches, +35.75 feet, and +29 feet, respectively; also +27 feet (lip of pithos $d$ ).

Terrace $A$.-The northern terrace did not yield as important finds as did the upper digging, but was of importance in considering the connection between the northern plateau-like extension and the hill itself. In this terrace the sharp inclination of the layers showed that we were not in the strata of superimposed settlements, which the finds in the upper digging had naturally led us to expect. In reality, we were digging in the débris and wash which had descended from above, covering the outcropping edges of the horizontal layers. The finds are also to be judged in this light: that in each case it is not the absolute level of the terrace, but the relation of its position to the horizontal layers of the hill, that determines the layer to which a find belongs. Therefore, qualitatively speaking, the earth layers of terrace A are to be designated as "mixed." The masses of pottery fragments are to be distributed under the above-mentioned groups I to 5 , $I$ to 3 predominating among them with group 5 decidedly in the background. Therefore, the débris that has fallen from the upper layers is much thicker, the horizontal layers of the older culture periods being much less represented.

Among the special finds worthy of remark, there occurred a three-edged bronze arrow-point, fragments of an iron sickle, and some glazed pottery fragments, all of which will be discussed below.

Outer digging.-The conditions under which the layers and finds occurred in terrace $\mathrm{A}$ were explained through the observations made in the outer digging. Here the upper layers down to a level of +4 feet 2 inches yielded a pottery which was throughout identical with that of the upper layers of the upper digging. Indeed, a well-preserved pot found 24 inches under the surface and a pithos standing in situ, with a lip 5.25 feet below the surface, tend to complete the typematerial obtained above. From these finds it appears that this low, northwardprojecting plateau was formed during the youngest development of the hill.

In the deeper layers, between +4.2 feet and -4 feet, the pottery consists of fragments of both the older and younger periods, but they are so strikingly few in number that we may be warranted in supposing that a settlement had not yet been established at the corresponding level.

Other finds especially worthy of remark included a piece of glazed ware (of the kind found in terrace $\mathrm{A}$ ) between +6.5 feet and +4.2 feet, $i$. e., in the layer of younger pottery; and a bronze arrow-point found between +3 and +2 feet, $i . e .$, in the layer of mixed pottery. 


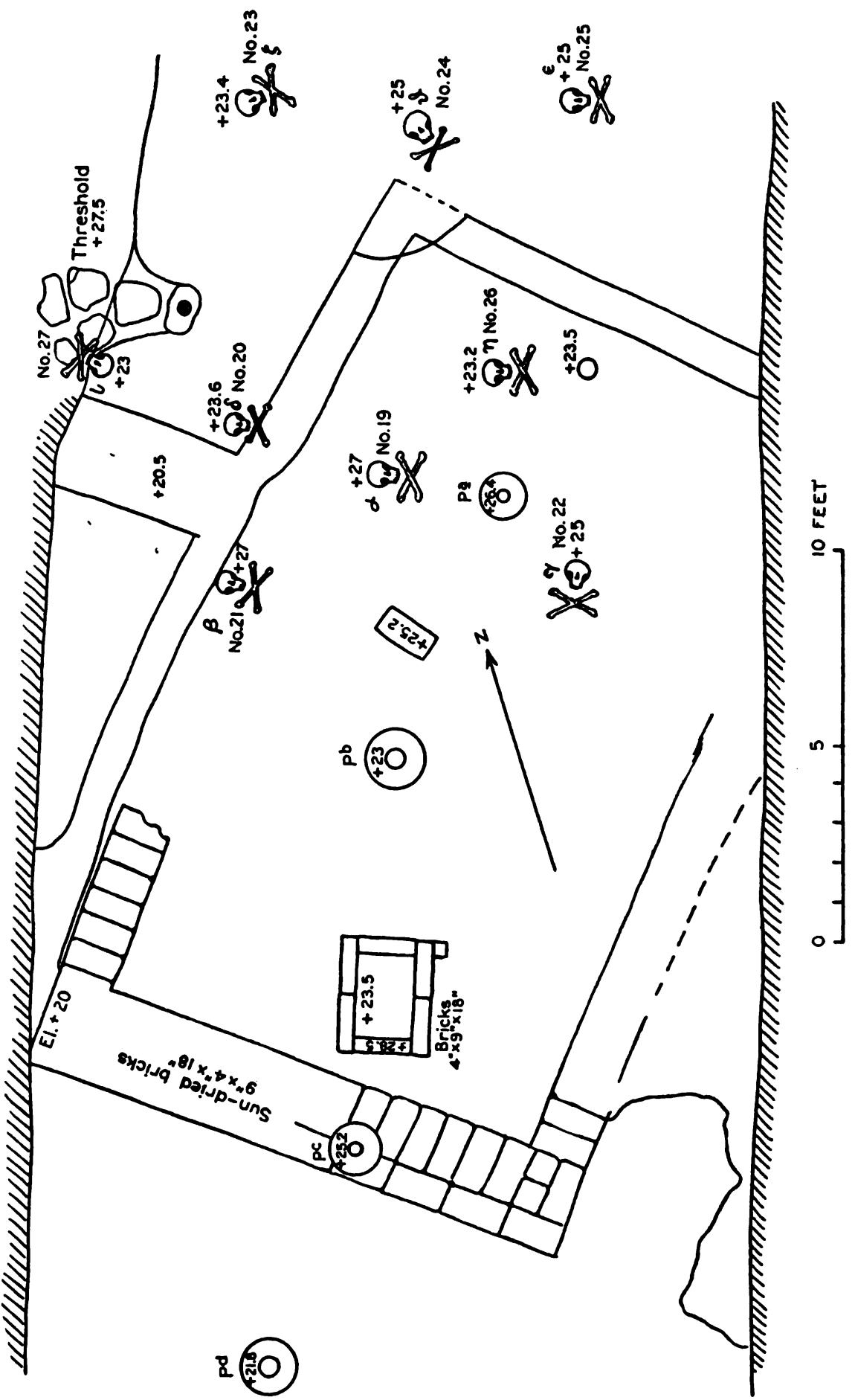

Fig. 42.-Plan of Terrace B.

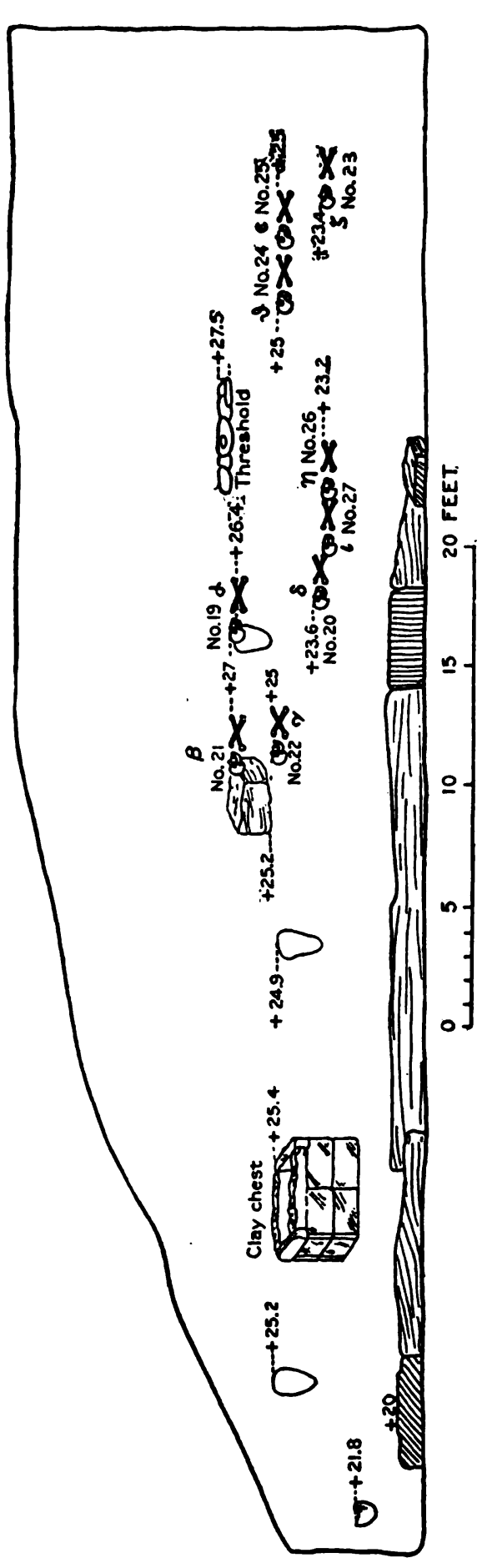

Fig. 43.-Vertical Section and Projection of Finds. Terrace B. 
Terrace $B$ (figs. 42 and 43 ).-After starting work in terrace $B$ and removing the superficial loose earth, horizontal layers were exposed in the edge of the hill,

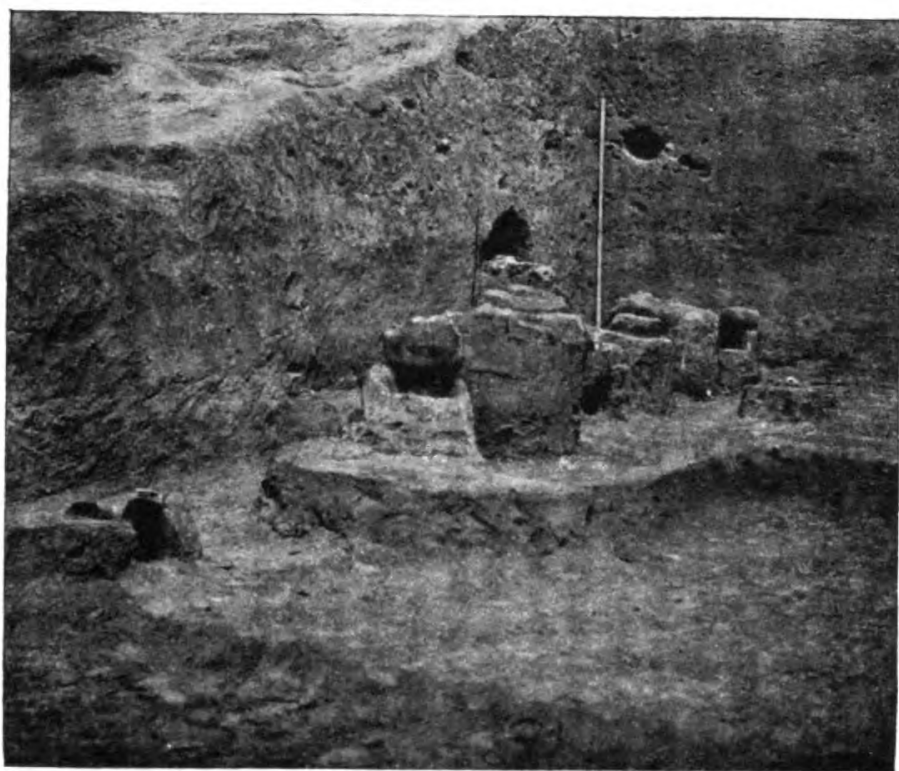

Fig. 44. - Objects in Position, Terrace B. which we had reason to expect contained unmixed finds of the older development periods of the hill. To the level of about +281 feet the pottery of the upper layers of this terrace corresponded to that of the upper digging between +40 feet and +37 feet 7 inches and belonged, therefore, in groups 3 to 5 . A three-sided seal of stone with figures (a griffin, a lion, and a man) which was found between +3 I feet and +28.25 feet naturally excited our expectations to the highest point. The next day (April 15) there came to light in the northwest wall of the digging, at +27.5 feet, a threshold in situ, composed of several irregular flat stones and a pivotal door-

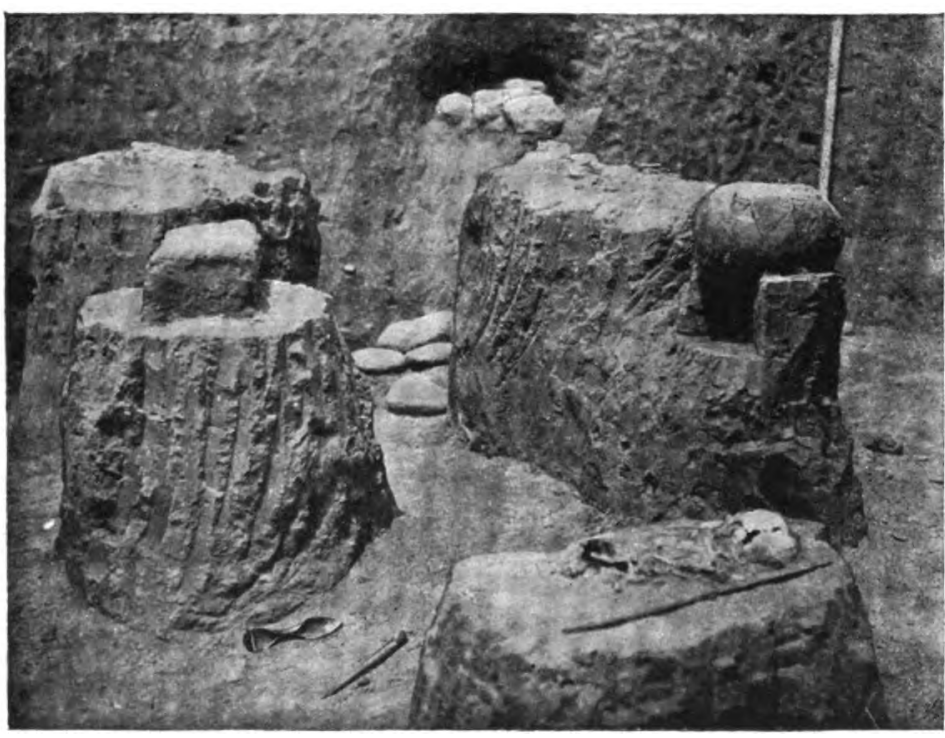

Fig. 45. - Objects in Position, Terrace B. stone; and (April 18 ) in the interior longitudinal wall, at +25 feet, a skeleton, apparently that of a child. We were now fully justified in assuming that we were working among the remains of a house, and in addition, the skeleton grave was analogous to those of the North Kurgan.

The deepening and enlarging of the terrace progressed several stages, and on April 20, at +27 feet, there occurred two skeletons $(\alpha$ and $\beta$, Nos. I9 and 21), $\alpha$ being a well-preserved "Hocker grave" (cf. special report by Warner). On the following day there came to light in the center of the terrace a peculiar quadrangle construc- 
tion of clay, with traces of fire in its interior. Besides this there were exposed at different levels five skeleton graves, some of them with vessels as burial gifts, $\gamma$ (No. 22) at +25 feet, $\delta$ (No. 20) at +23 feet 7 inches, $\zeta$ (No. 23) at +23 feet 5 inches, $\eta$ (No. 26) at +23 feet 2 inches, and $\vartheta$ (No. 24) at +25 feet (see fig. 42). The skeleton previously discovered at +25 feet was designated $\varepsilon$ (No. 25) in the series. Besides these, there lay in the middle of the terrace, at +25 feet 2 inches, the fragments of an air-dried brick, 17.5 inches long, 8.5 inches wide, and 4.5 inches thick. Lastly, there are to be mentioned four more or less well-preserved pithoi-pithos $a$ (46.5 inches in circumference, 12.5 inches high), between skeletons
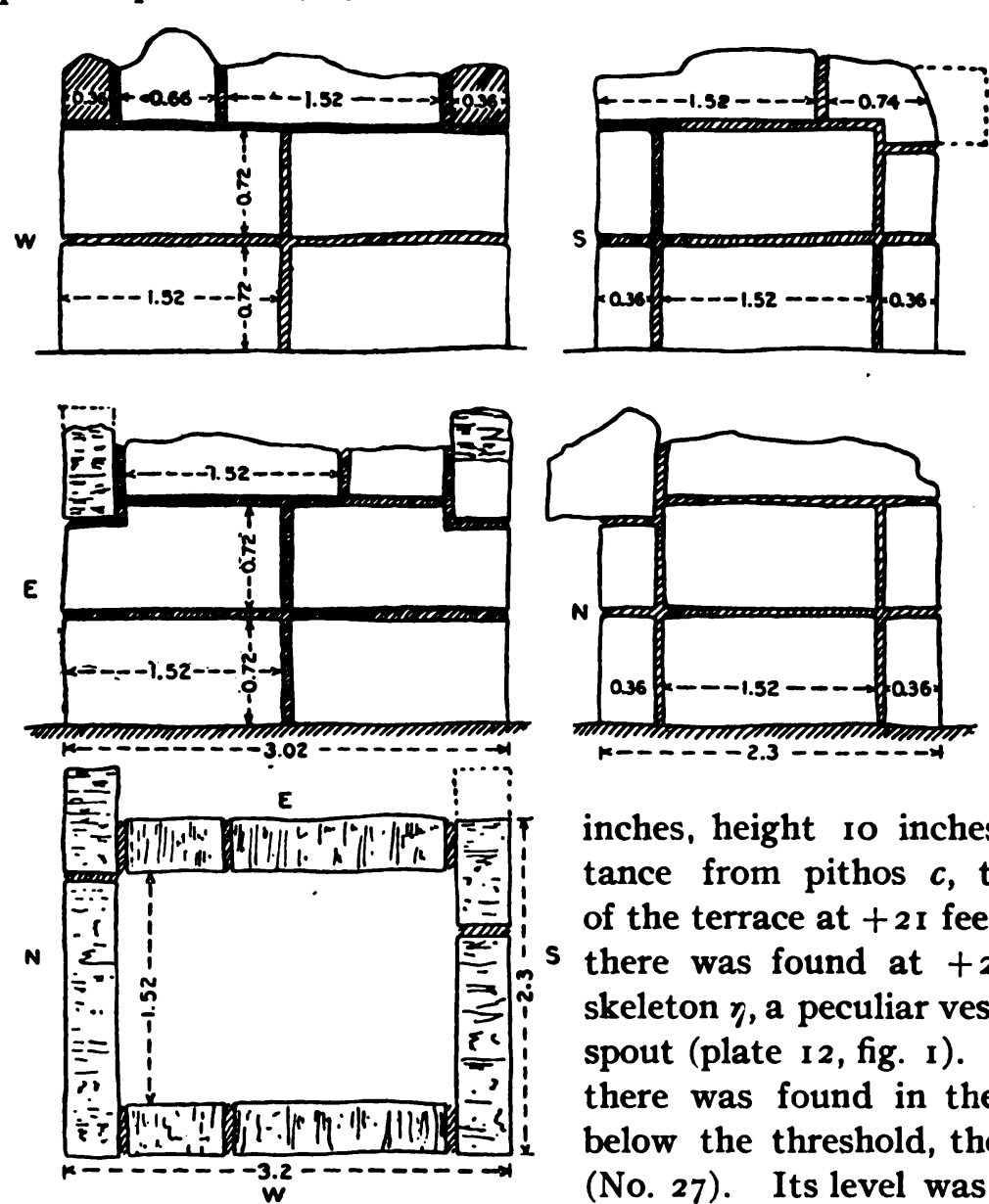

Fig. 46. - Clay Cheat in Terrace B. Details of Construction. Measurements in Feet.

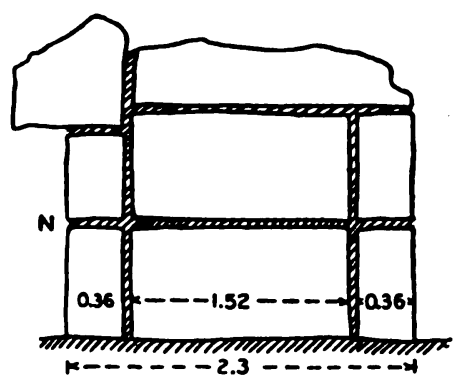
the threshold were removed. $\alpha$ and $r$ at +25 feet, the level of floor; pithos $b$ (circumference $6 \mathrm{I}$ inches, height 23.5 inches) at +23 feet, floor-level, between the isolated brick and the clay quadrangle; pithos $c$ (circumference 56.5 inches, height 20 inches) on the other side of the clay quadrangle, at +23 feet 7 inches, floor-level; and pithos $d$ (circumference of the preserved lowest part 57 inches, height to inches), situated some distance from pithos $c$, toward the outer side of the terrace at $+2 \mathrm{I}$ feet, floor-level. Further, there was found at +23 feet 5 inches, near skeleton $\eta$, a peculiar vessel with a beak-shaped spout (plate 12, fig. I). Upon further digging there was found in the wall of the terrace, below the threshold, the skull of a skeleton, c (No. 27). Its level was +23 feet, but it could not be wholly exposed until the stones forming

Of the pithoi already mentioned, $a$ is of coarse, gray-brown, badly burnt clay and contains fine earth mixed with ashes; the others ( $b$ to $d)$, on the other hand, are of excellent technique and of whitish-green clay. They were made on the wheel and belong to group 5. They are, however, in a worse state of preservation than $a$, the upper part, with the lip, being entirely gone; while of pithos $d$ only the lowest part with the bottom is well-preserved. This specimen contained 
some earth, but nothing else worthy of remark. The positions of these finds (threshold, pithoi, brick, clay quadrangle, and skeleton) are shown in figs. 44 and 45 , the pithoi separately in plate 19 .

Particular interest attaches to the clay quadrangle (fig. 46). It has the form of a box, square in ground-plan, and is built of air-dried bricks, 68 by $47 \mathrm{~cm}$. in the clear with an interior depth of $60 \mathrm{~cm}$. Externally it is $92 \mathrm{~cm}$. long by $70 \mathrm{~cm}$. wide and $68 \mathrm{~cm}$. high. Its lower edge can be determined all around, but the top is much broken. The inner surfaces are reddened and hardened by fire, while the exterior shows the rough, unburnt, air-dried bricks. This chest has a beam-like projection on the northeast corner, formed of a projecting air-dried brick, making a kind of handle. Similar projections probably existed at the other corners.

The earth in the interior of the chest was mixed with charcoal and with numerous animal bones. A remarkable number of fragments of pottery of group

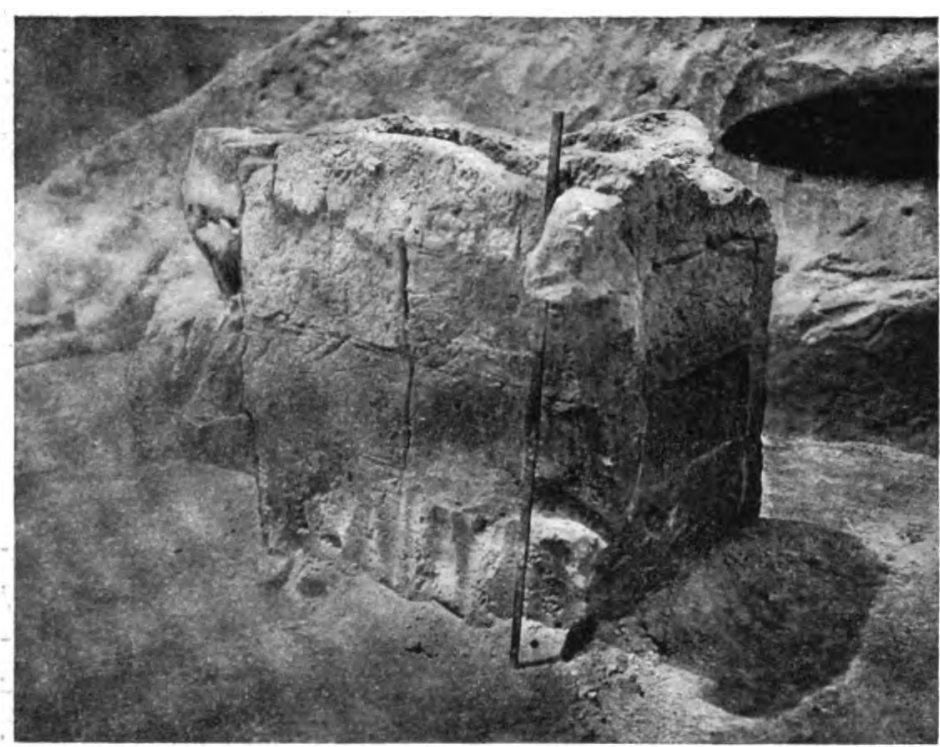

Fig. 47.-Clay Chest in Terrace B. 5 , a small clay figure of unburnt clay, and a decorated doubly-conical stone bead were also taken out. Fig. 47 presents the exterior of the chest. The idea of the whole can hardly have originated in a clay technique, for the beam-like projection suggests the imitation of a wooden chest. This explanation is to be considered in determining the significance of the construction. The clay figure might suggest

that it had to do with a religious rite, but quantities of such clay figures were found in the surroundings of the chest, both above and below it. The pithoi standing about point rather to practical significance. On account of the animal bones, I should call it a place for supplies and food; and the form and origin support this interpretation. The superficial burning of the interior would be explained as a protection of the clay walls against moisture.

After the finds thus far mentioned in terrace $B$ had been surveyed and platted by R. W. Pumpelly, and photographs had been taken of both the whole terrace and the separate finds, it was possible to remove the finds which had been left in situ, with the columns of earth that supported them. On April 26 traces of deeper-lying walls had been observed. These were now followed further as the terrace was deepened, exposing the remains of several notably thick walls, $i$. e., the constructions of an older period (see figs. 42 and 43 ). 


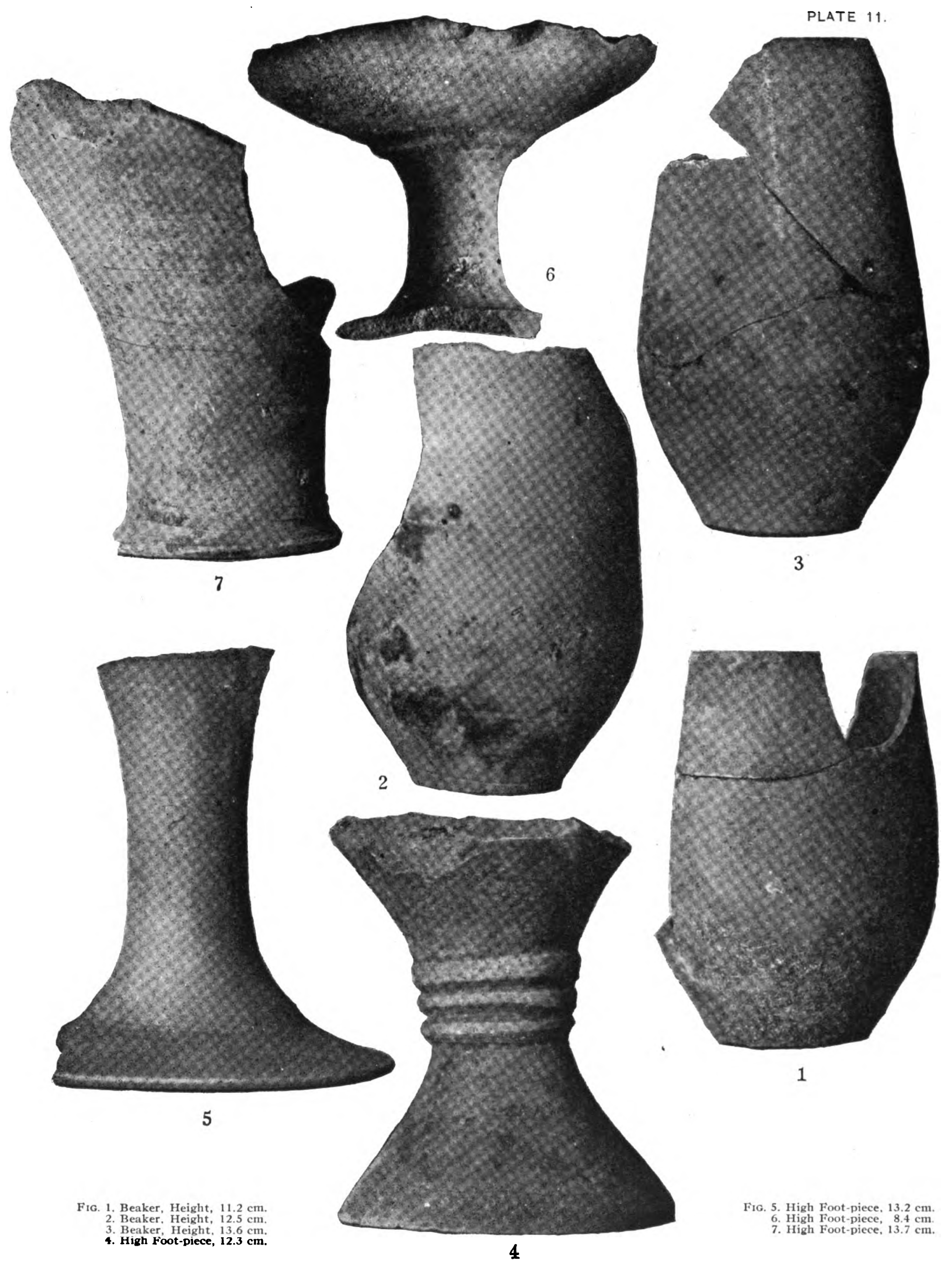

Pottery from Middle Strata, South Kurgan, Culture III. 


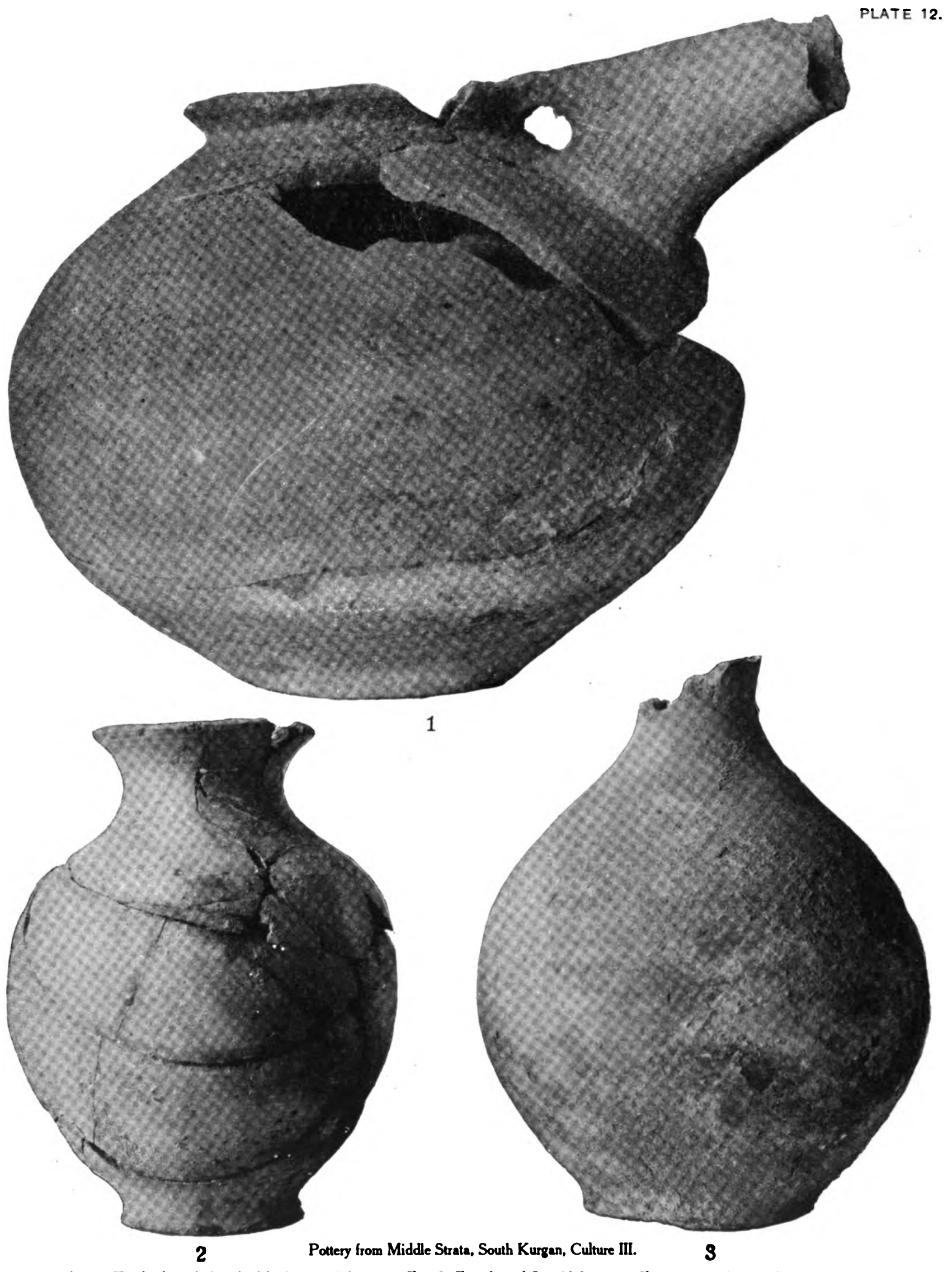

Fio. 1. Kettle-shaped Vessel with Spout, $14.6 \mathrm{~cm}$. Fio. 2. Egg-shaped Jar, $13.2 \mathrm{~cm}$. Fio. 3 . Pear-shaped Flask, $15.1 \mathrm{~cm}$. 

Two corners of a rectangular room or building were relatively well preserved. The outer cross wall is wider and stronger and better preserved than the longitudinal walls at right angles with it. Its upper edge lies at the level of +20 feet, and it was followed downwards to +18 feet. Indeed, it was possible from the survey of R. W. Pumpelly to determine, in part, the position of the walls and the size of the air-dried bricks used ( 9 by 4 by 18 inches). On the inner sides these thick walls still showed extensive remains of a white plastering of lime or mortar.

The extension of the longitudinal walls into the interior of the hill could not be followed. Less well preserved were some smaller walls adjoining this larger building; their upper edges stood at +20.5 feet and +19.5 feet. Judging from these walls, we have here extensive constructions, which must be merely part if a settlement covering the level of +20 feet throughout the hill. The question irises, therefore: What is the relation of this settlement to the finds discovered above in terrace $B$, and how do the layers rise one above the other? These buildings must already have been buried when the clay chest was built at +23 feet. Pithoi $b$ and $c$ must have been in use simultaneously with this chest. Pithos $d$ stood at a lower level than $b$ and $c$, but only its bottom is preserved; therefore it is older than $b$ and $c$, and possibly contemporaneous with the walls. Pithos $a$ stood 2 feet higher than $b$ and $c$, this difference being exactly the height of the latter, of which the upper part of the lip had disappeared. Pithos $a$, must, therefore, have been younger than $b$ and $c$; possibly these lost their lips when $a$ was put into place. The air-dried brick lies at about the same level on which pithos $a$ stands and was probably contemporaneous with it.

The threshold at +27.5 feet marks a higher layer. Since the preserved lip of pithos $a$ stood at +26 feet, it must already have been in the earth when the threshold was laid. We would thus have to distinguish the following periods from the top down:

Period IV, threshold.

Period III, pithos $a$ and the brick.

Period II, clay chest and pithoi $b$ and $c$.

Period I, large walls and pithos $d$.

The question still remains: How are the skeleton graves to be distributed? This depends on the levels of the different layers. For comparison we may arrange the finds in the following parallel columns:

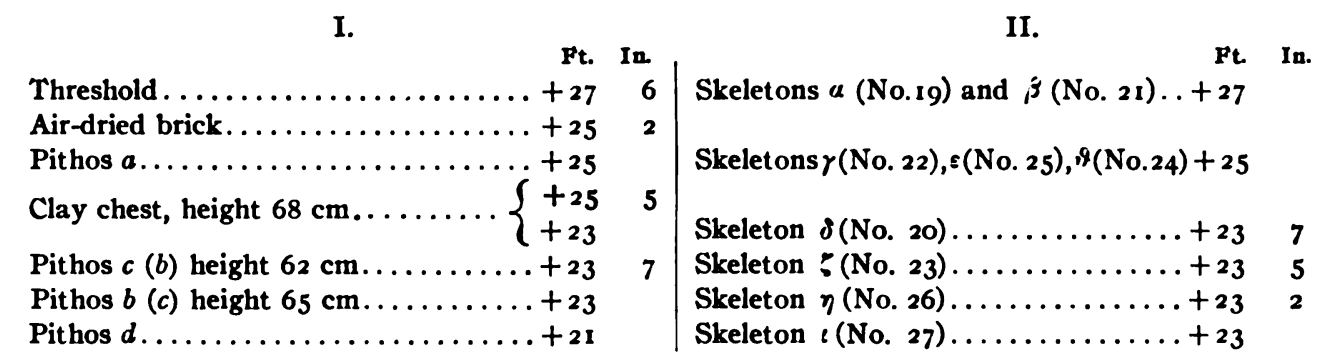

Only in the uppermost layer, period IV, is the height of the floor determined by the threshold. In all the other cases it is uncertain. A maximum height can be assumed from the lips of the pithoi and the dimensions of the clay chest. 
Pithos $a$ has, indeed, lost its lip, but the height of what remains is $33.3 \mathrm{~cm}$.; hence, the height of the floor of period III can be estimated at about +26 feet or a little higher. The position of the brick does not suffice to determine its height, since it may have fallen from above into débris. The clay chest suffices to determine the elevation of the floor of period II. As long as it was in use, together with its corresponding pithoi $b$ and $c$, the floor can not have been higher than the preserved edge, $i . e .,+25.5$ feet; indeed, it probably lay somewhat deeper, since pithos $b$ ( $+23 \mathrm{feet}$ ), after being put together, shows a height of $65 \mathrm{~cm}$. Pithos $c$ at 23.7 feet has only $62 \mathrm{~cm}$. height. The floor of the clay-wall layer is also undetermined. It probably lay deeper than its preserved upper edge $(+20$ feet $)$, since the inner sides of the thick walls were covered with a layer of white lime and must have been still visible. Therefore, the skeletons can not be brought into connection with the oldest period (I). They all lie above the presumable level of the floor and must, therefore, be younger.

If now we consider the skeletons from the bottom upwards, $\delta, \zeta, \eta$, and $\iota$ can be brought together, since they all lie between +23 and +24 feet. This position corresponds to period II. From this period are excluded skeletons $r$, $\varepsilon, \vartheta$, since they lie at +25 feet. We must, therefore, assign them to the following period (III), of which the level lies at +26 feet or a little higher. There remain, therefore, for period IV only the two skeletons $\alpha$ and $\beta$ at +27 feet. Here also it is to be assumed that the burials were very shallow-immediately under the floor-an assumption which is justified by our experience in the North Kurgan. If this were not so the skeleton groups would each have to be shoved upward by one period; that is, skeletons $\delta, \zeta, \eta$, and $\iota$ would have to be assigned to period III, $\gamma, \varepsilon, \vartheta$ to period IV, and $\alpha$ as well as $\beta$ to a still younger period, for which no determining finds have as yet been made in terrace $B$.

The buildings of period I seem to have been destroyed by fire, for the débris above it is much mixed with charcoal, and remains of burnt clay. It is possible that in the construction much wood was used. The layers of débris cover the remains of the walls and form the basis for the clay chest, pithoi, and skeletons. Skeleton c lies upon exactly such a burnt layer of the lower house-complex.

Figs. 48 and 49 will serve to show the relation of these layers. They represent the longitudinal sides of terrace $B$ at the close of the excavation. A still higher wall is standing in the upper part of the west side of the terrace, between +32 feet and +31 feet; it must, therefore, be younger than the threshold. At about the height of its lower edge there was found a well-preserved dagger-blade or lance-point of copper. At the same level, outside of the terrace and immediately below the surface of the hill, there was found a well-preserved and almost perfect vessel of group 5 (plate ro, fig. I). This find shows how the horizontal layers on the declivity come to the surface, through the gradually progressing deformation of the hill and there fall a prey to disintegrating forces.

Lastly, we must mention the principal finds.

As regards the pottery, it has already been remarked that groups 3 to 5 are represented until the level of $+\mathbf{2 8 . 2 5}$ feet is reached. Below this, the ware of greenish clay, group 5 , is conspicuously predominant. The red ware is really not 

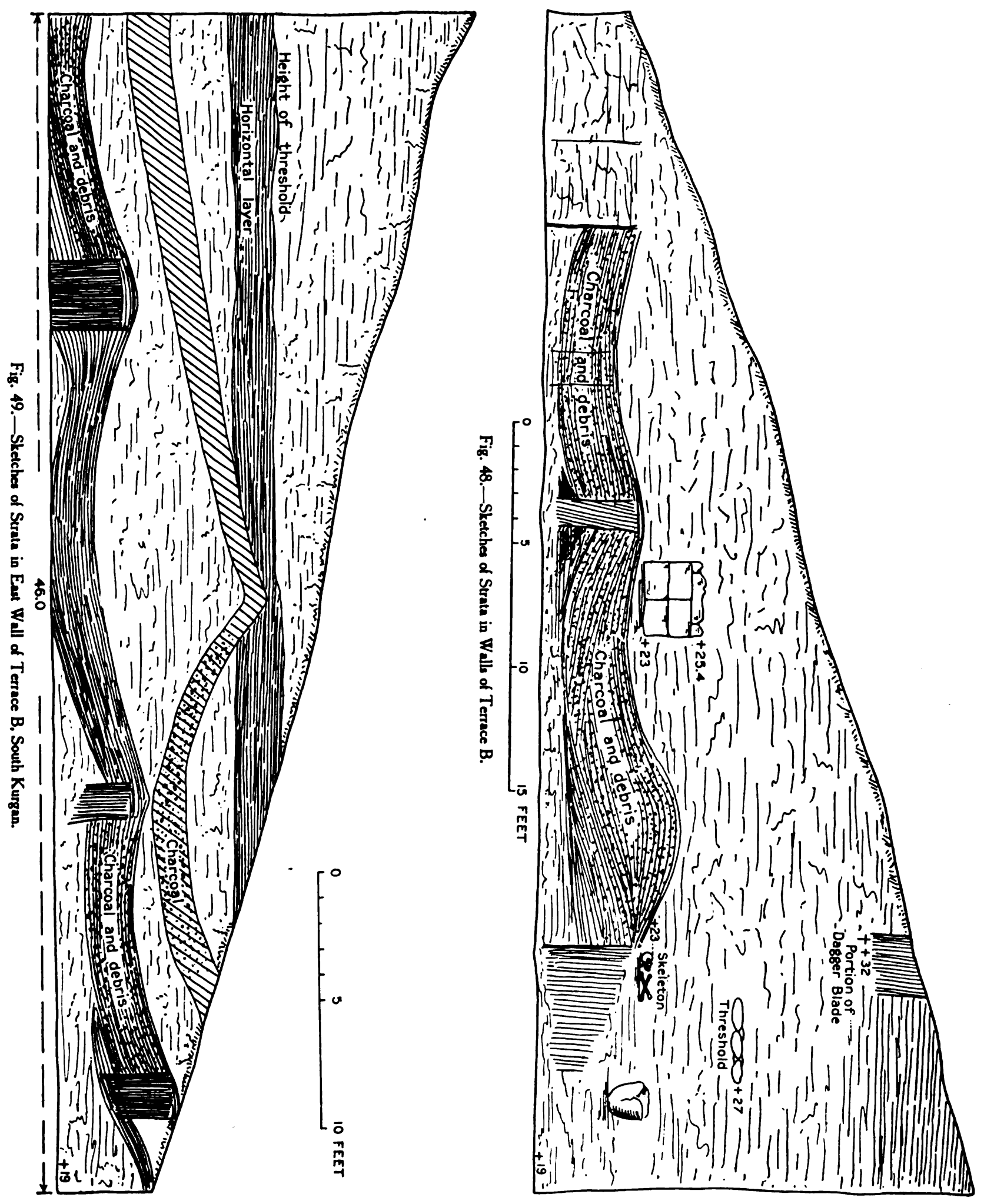
at all characteristic of terrace $B$, and the gray is rare. True, there occurred very fine gray fragments with incised decoration, even in the deeper layers of terrace B; but group 5 unites all the layers in a large, uniformly developed culture epoch.

Objects of copper are numerously represented among the finds. Altogether 25 were exposed. Besides various fragments, there are weapons like the dagger and lance-point mentioned above, utensils such as awls and chisels, and ornaments, pins, rings, pendants, and peculiar ornamental disks.

Among the finds of stone and clay is the three-sided seal with its representation of figures. Among the precious things are stone beads and pendants of different forms and sizes, some of these being of turquoise and of marble. There are also fragments of vessels of marble and alabaster. Human and animal figures made of clay were especially numerous, both in the skeleton layer and below it, to the lowest level of the excavation.

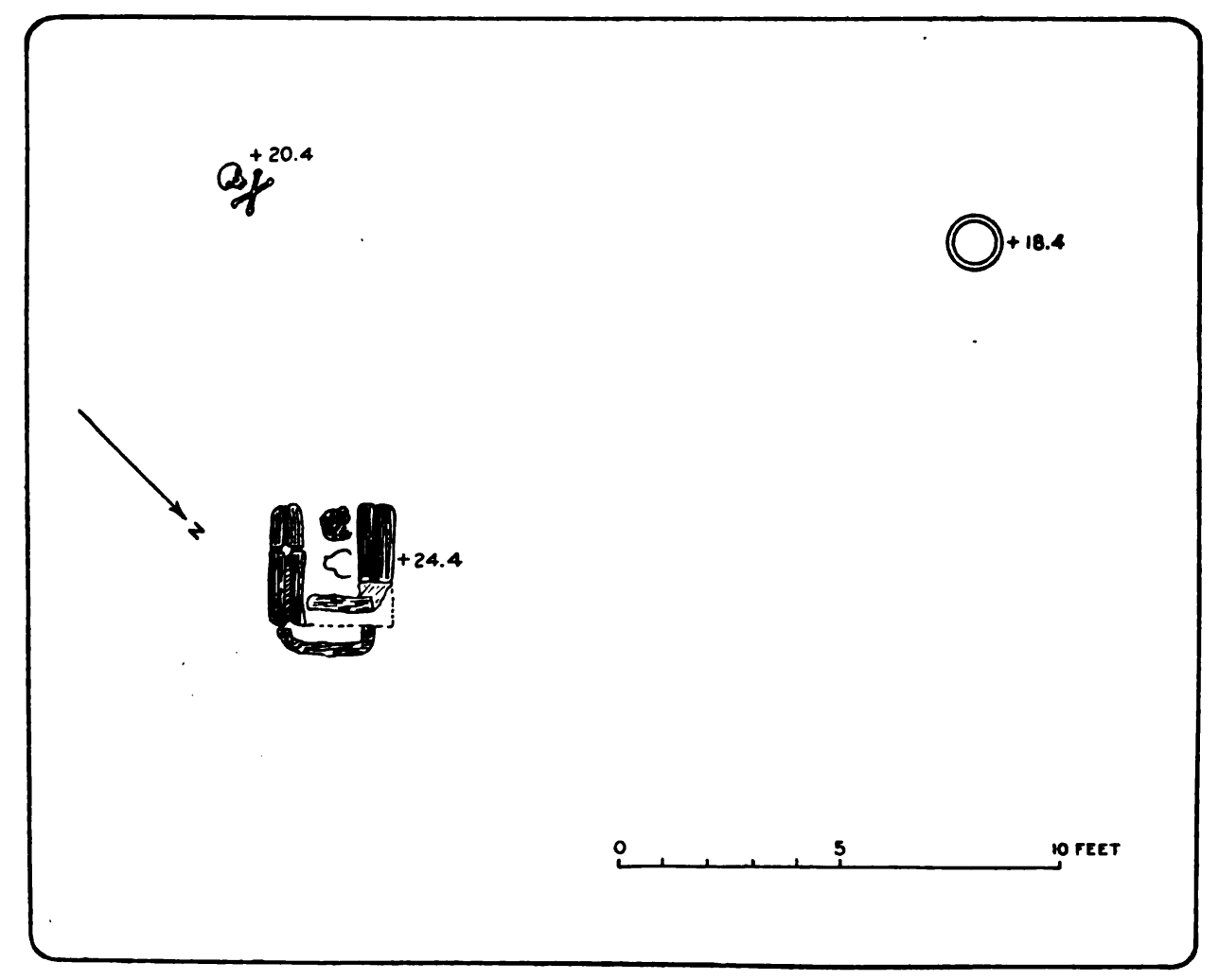

Fig. 50.-Plan of Terrace C.

Thus terrace $B$ may be considered as the principal source of finds of the expedition of 1904, whether we consider the architectural development of the hill or the important special finds themselves. Less productive but just as important in reaching a solution of the undetermined problems were the following localities.

Terrace $C$ (fig. 50).-The cut on the southeast declivity of the hill was begun on April 18, in order to arrive as soon as possible at the level of skeleton $\varepsilon$, which had been found on that day at +25 feet. On the evening of the following day, in the middle of the terrace, at the level of +26 feet, we came upon an apparently rectangular structure of burnt air-dried bricks. An examination showed this to 
be a hearth closed on three sides and built of air-dried bricks, which had been heavily subjected to fire (see fig. $5 \mathrm{I}$ ). The walls consisted of the air-dried bricks set in pairs on edge. Those on the northwest wall were the best preserved in the whole brick course, the opposite wall, consisting of whole and fragmentary bricks, being much broken, while in the last wall the rear brick is wholly wanting. On the north edge the backward-lying bricks did not suffice to complete the rectangle. Fragments were, therefore, used for this purpose, but they are only partially preserved. The fire and ash bed of the hearth consisted of an earth floor, paved with small stones. Of this pavement only a small part is preserved at the open side. Anciently it had been repaired during the period of its use - not with repaving, however, but by application of several thin earth layers, which are only preserved in places. The hearth is shown in different stages of the excavation and from different sides in figs. 52, 53, and 54. Fig. 52 was photographed before the examination; figs. 53 and 54 , after the examination.

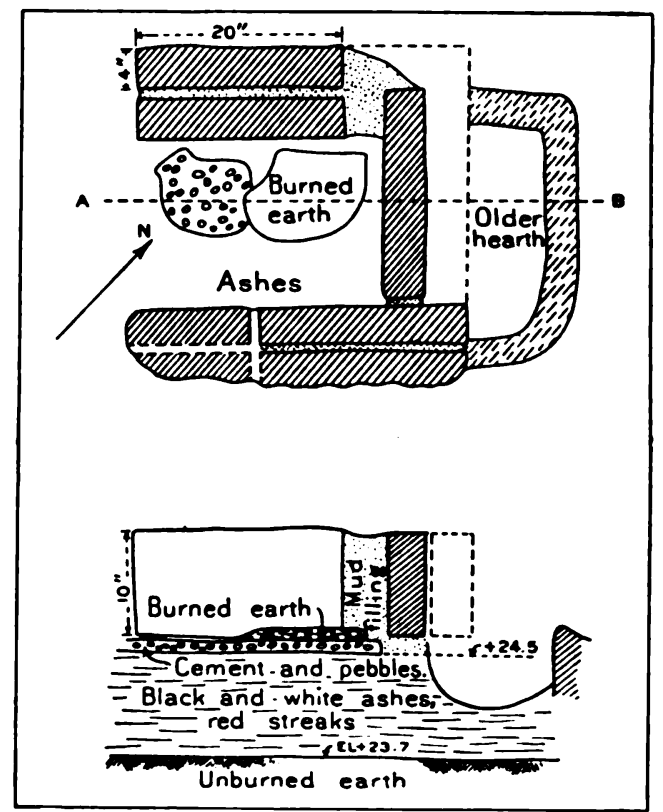

Fig. 51.-Sketch of Fireplace in Terrace C.

This hearth is simply the last member of a series of superimposed hearths and fireplaces. The remains of an older hearth of similar construction were found immediately underneath the one just described. It was shoved a little northeast, but, like the upper one, it opened on the opposite side. The preserved wall, consisting of simple rows of brick, had been completely slagged and glazed on the inside by the fire. Below this older hearth, ash layers can be observed to the level of +23 feet 7 inches. Where they stopped the earth floor is burnt and merges downward into the natural earth, which is the original floor of the room. This floor must have been gradually raised

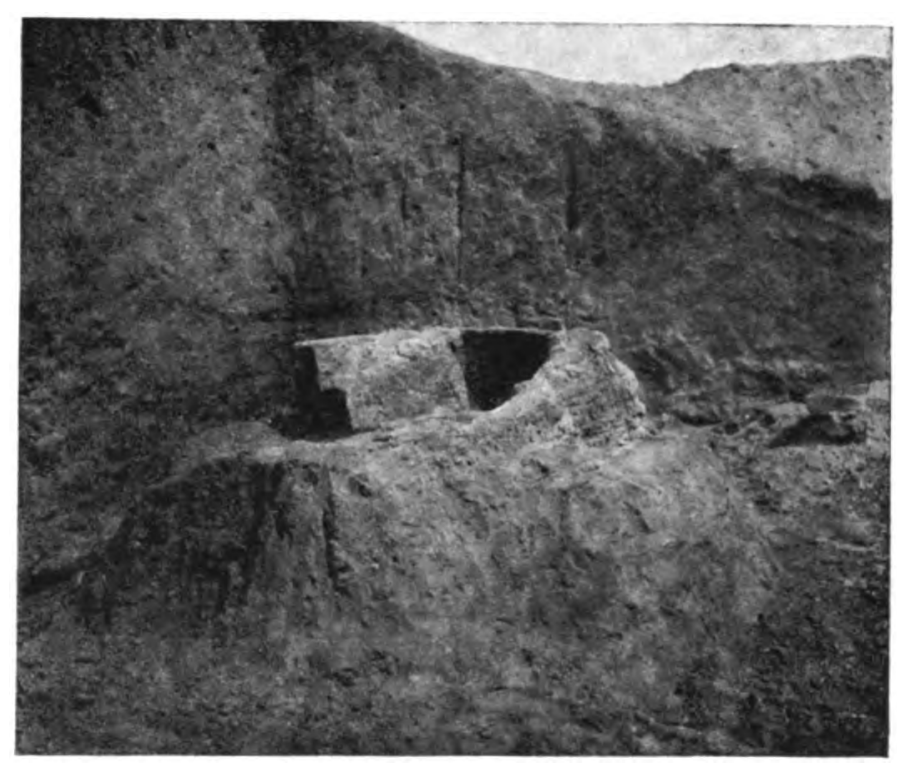

Fig. 52. - Fireplace in Stage of Excaration. to the level of +24.5 feet, for only in this way can we explain the upward succession of layers of ashes and hearths. 
Terrace $\mathrm{C}$ presents us with a skeleton grave, to confirm the rule that the dead were buried near the hearth. It lay in the southeast corner of the excava-

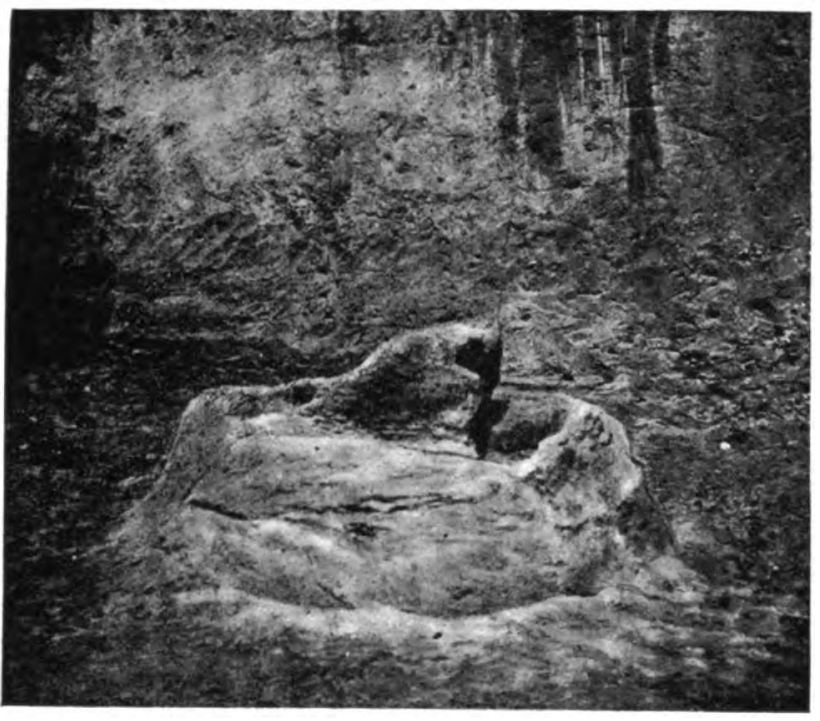

Fig. 53.-Fireplace in Stage of Excavation. tion at the level of +20 feet 5 inches (see special report of Warner)-i. e., about 3 feet below the original floor of the room. The position of the hearth and skeleton grave inside of terrace $\mathrm{C}$, together with the wall seen in the west side, is shown in fig. 54. Traces of a still older period were discovered in the southwest corner of the terrace after removing the hearth and in the general downward progress of the excavation. At +18 feet 5 inches stood the remains of a pithos (height 66 cm., circumference I meter 60 $\mathrm{cm}$.) of light greenish-yellow clay, made on the wheel.

The pottery found in terrace $\mathrm{C}$ was of considerably mixed older and younger groups. In enlarging the terrace the surface covering of the hill had repeatedly to

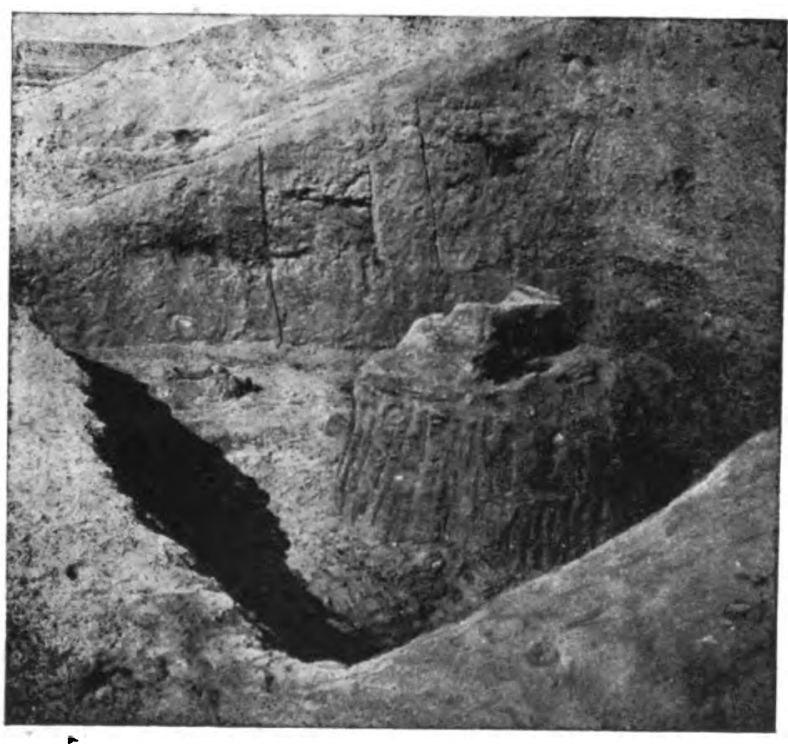

Fig. 54.-Fireplace in Stage of Excavation. (Skeleton in Pocition.) be removed. Owing to this and to the steepness of the declivity, remains of the upper younger culture must have fallen in; but, on the other hand, whenever the layers of the terrace were isolated from the surface, the pottery corresponded throughout to the finds of terrace $B$. There were 8 finds of copper, consisting of fragments of dagger-blades, pins, awls, and a ring. The smaller finds are also analogous to those in terrace $B$-beads of agate, turquoise, and stone, especially marble; fragments of stone vessels, etc.

The finds in the shafts mentioned above contributed materially to the collection of ceramic materials. The chief result in this respect was the discovery that the making of the ware of light-colored clay, in wheel-technique, dates from the earliest period of the kurgan. For the rest, I refer to the section concerning special finds. 


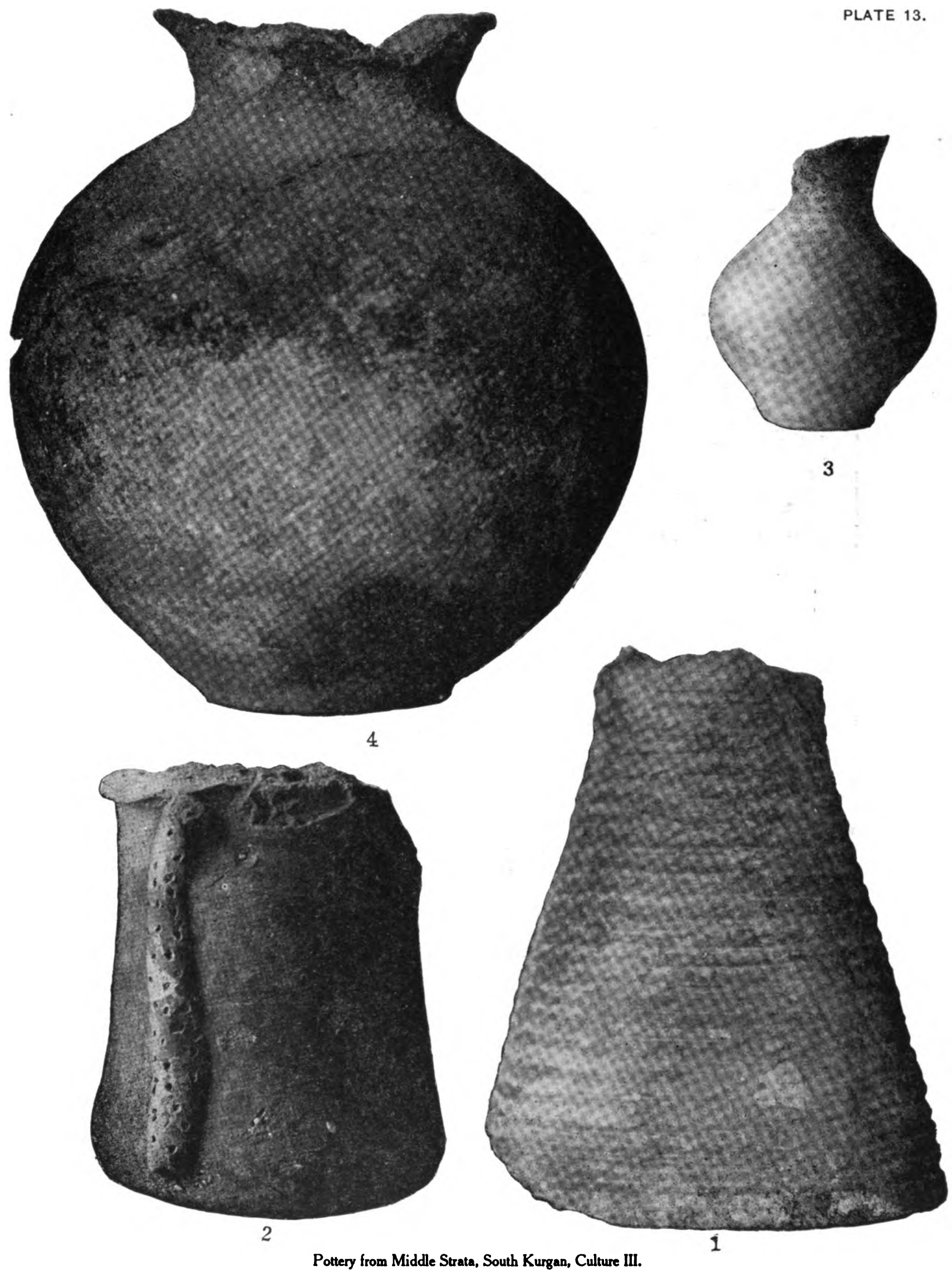

F10. 1. Conical Lower Part of Horizontally Grooved Vessel, Height $13.3 \mathrm{~cm}$. F1G. 3. Small Flask (numerous, Terrace B), Height $7.5 \mathrm{~cm}$. 2. Cylindrical Vessel with Snake-like Ornament, Height $12 \mathrm{~cm}$.

4. Spherical Vessel, Height $16.5 \mathrm{~cm}$. 

plate 14.
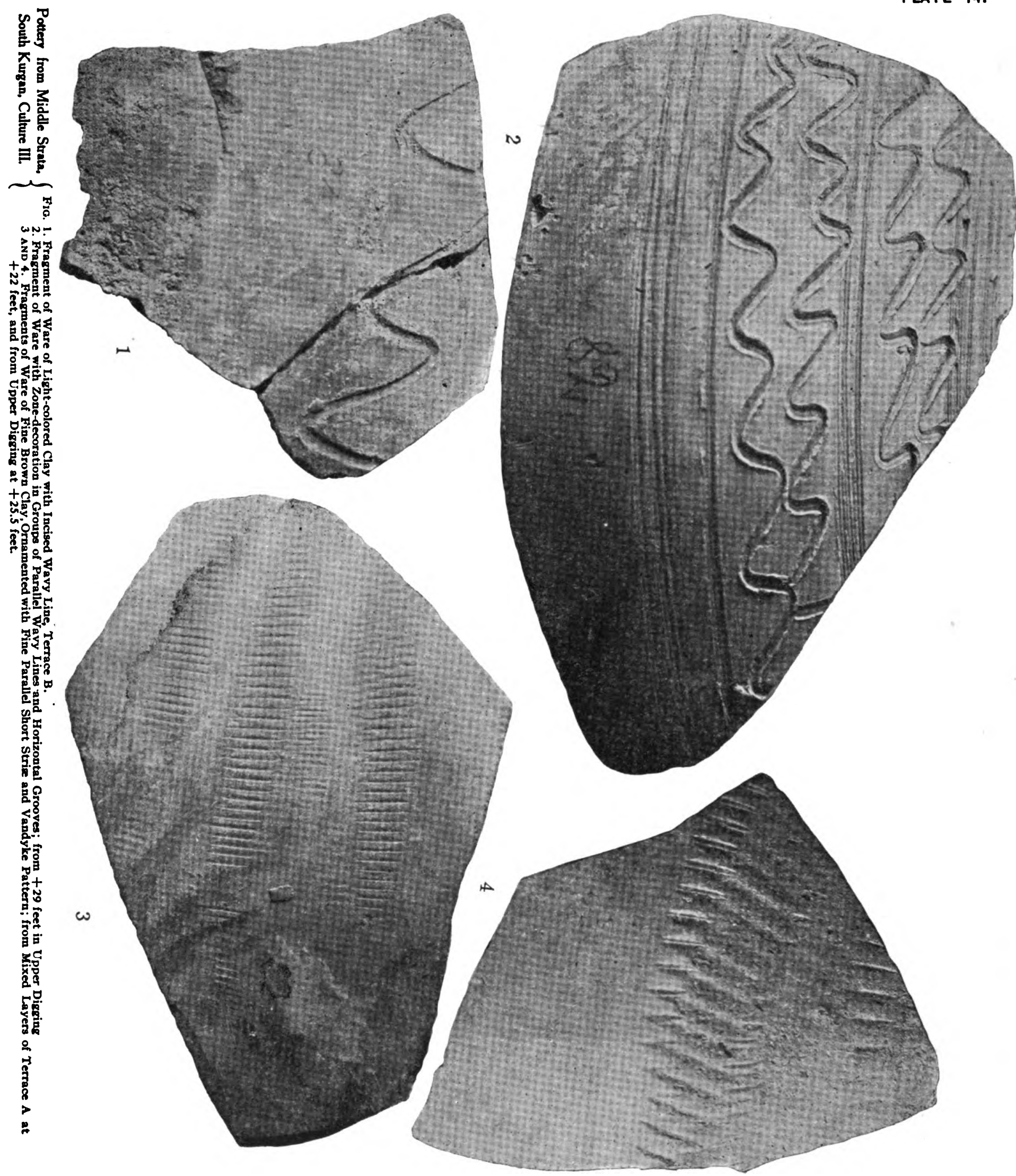

Digitized by $\mathrm{GOg} e$ 
Digitized by GoOgle 

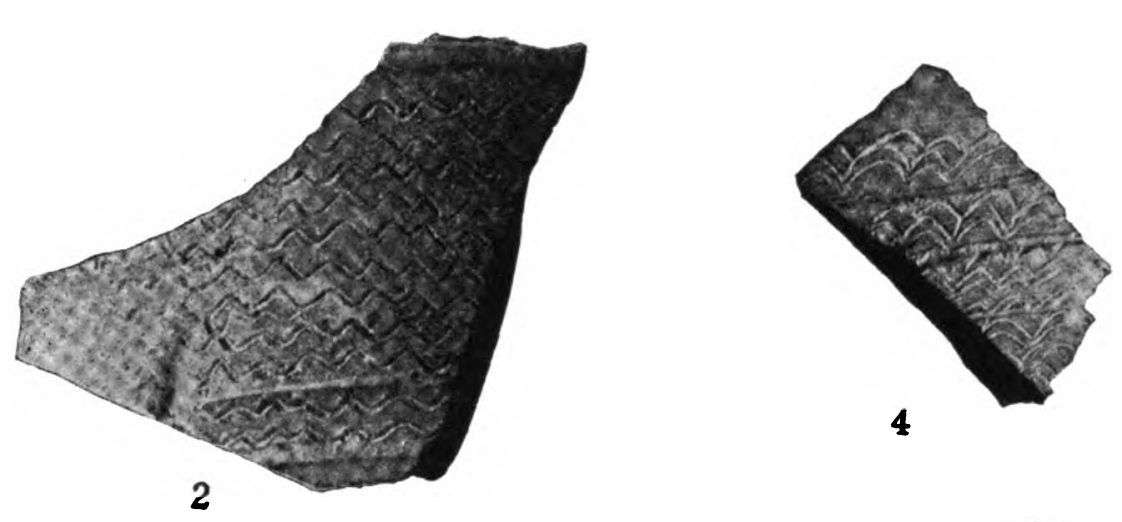

PLATE 15.

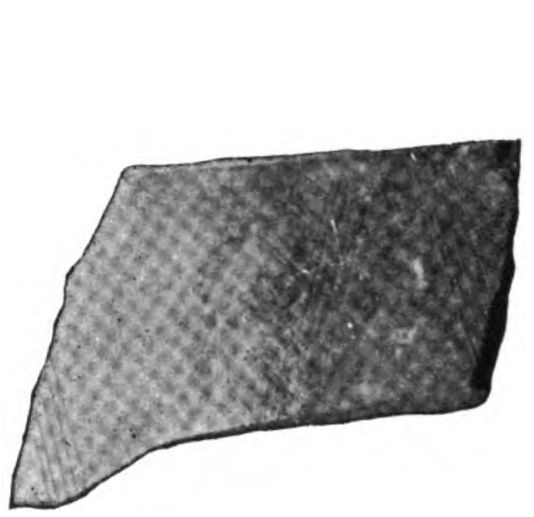

1
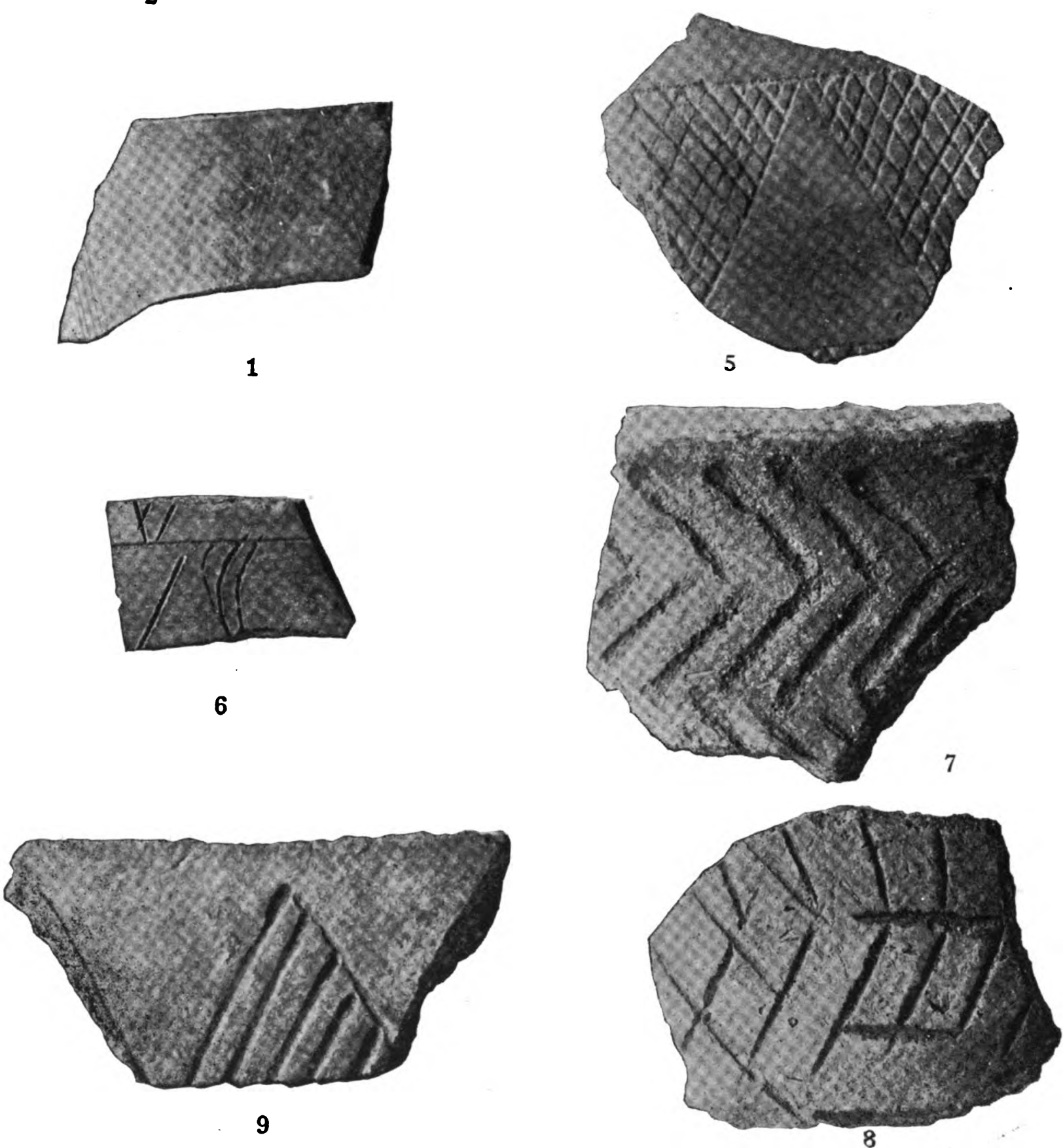

Pottery from Middle Strata, South Kurgan, Culture III.

Fragments of Gray Vessels, Fine and Coarse, with Incised Ornament; from Terraces B and C, between +19 and +26 feet 
Digitized by Google 


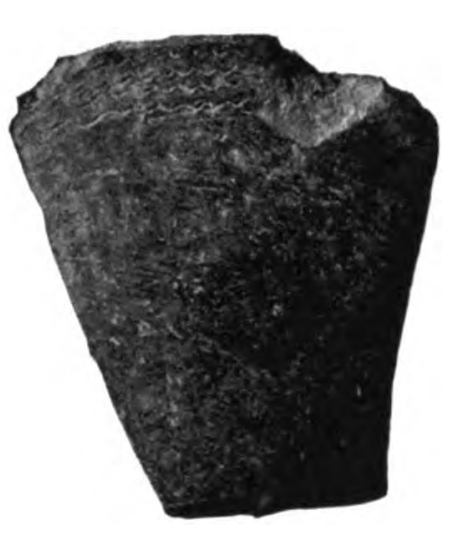

1

Plate 16.

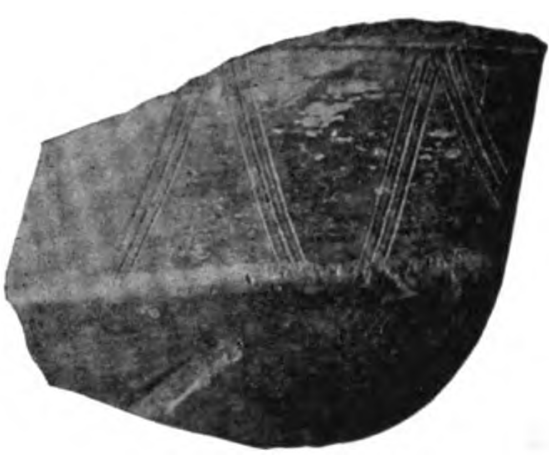

2

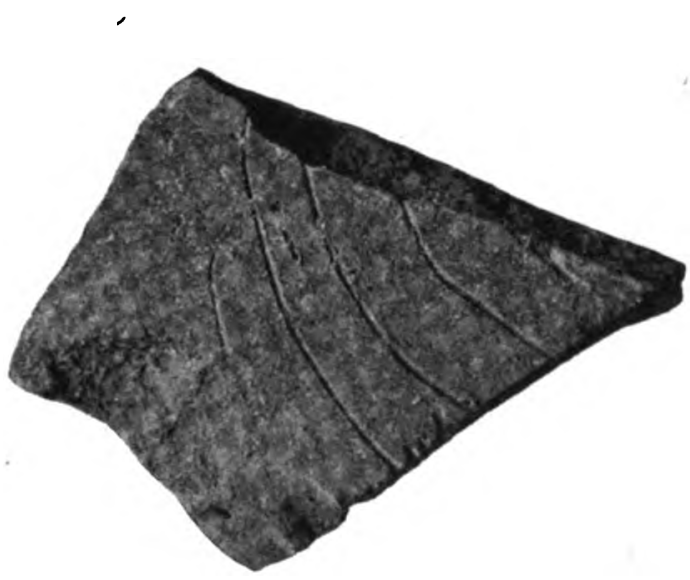

3

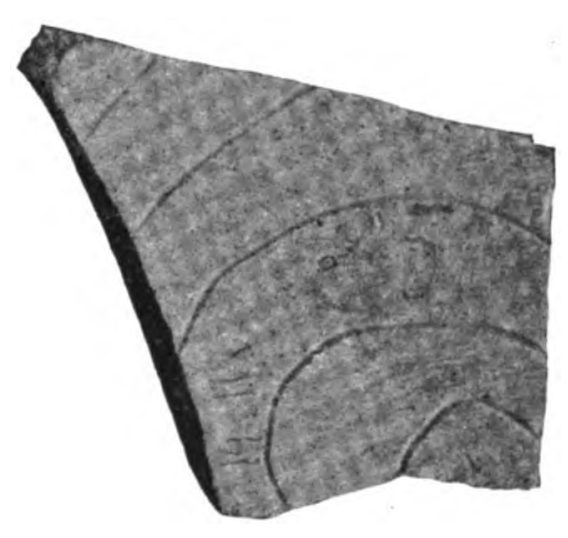

4

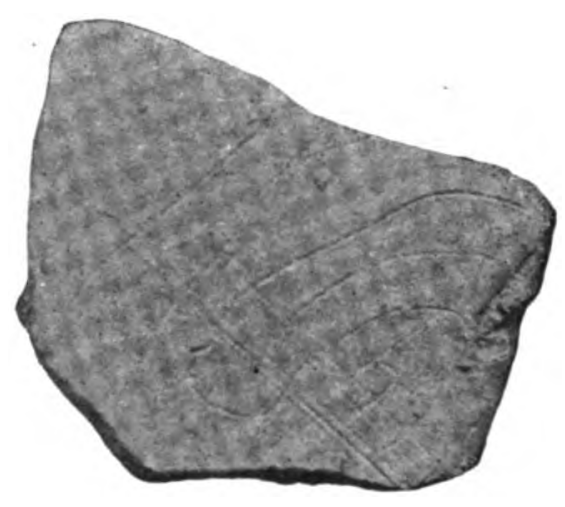

5

Pottery from Lower Strata, South Kurgen, Culture III.

Fias. 1 AND 2. Fragments of Gray Ware with Incised Ornament; from +1 foot. Shaft A.

1 AND 2. Fragments of Gray Ware with Incised Orament; from 



\section{CHAPTER VII.-RESULTS.}

\section{NORTH KURGAN.}

In both the observed finds and the conditions in which they occurred, as well as in the general course of investigation of the North Kurgan, we can distinguish two great epochs in its formation. Since the remains of their civilizations were deposited one above the other, it follows that one must have succeeded the other. Their relative age-relation is thus assured. In the terraces of the North Kurgan we have become acquainted principally with the younger of these cultures.

Culture II.-Three, relatively four, successive periods of this culture could be determined in the upper layers between +40 and +25 feet. At this time the inhabitants of the hill lived in huts or houses built of air-dried bricks. They used peculiar bake-ovens like the upper half of a pot, and large kettles on hearths, also fireplaces with a central hole; and they had the remarkable custom of burying their children inside of their dwellings, immediately adjoining the hearths. In these burials the body was generally placed in the so-called contracted or Hocker position. The pottery used at this time was the red and gray monochrome (group $x$ ). With this there were painted vessels, clearly a rarity (groups $z$ and $v$ ). The inhabitants of the hill built their houses on the deposits of an older culture and in this way caused a mixture of their own culture products with those of the older civilization.

Culture I.-The unmixed older culture layers do not occur, as a rule, except below the level of +25 feet. The infallible witnesses to this older culture are coarse and fine vessels, which are almost always painted in a peculiar style (group $y$ ). Wherever vessels of this kind are found in situ they are to be considered as the remains of the dwellings of the older culture. In terrace II the pithoi were found in two layers, one above the other, at the level of +22 feet 5 inches and +20 feet. In terrace III, also, at least two successive layers of the older culture are distinguishable, the upper at +18 feet, the lower at +15 feet. In terraces vi and virr traces of the older dwellings are found at still higher levels, i. e., +25 and +26 feet respectively. Traces of the remains of buildings of the older culture were observed both above and below the datum-plane-i.e., a wall in the west digging between +18 feet and +10 feet, one in north diggings $I$ and $I r$, between $-I_{1}$ feet and -12 feet; and one in the west shaft at the level of -15 feet at the top and -18 feet at the bottom edge.

In the deeper layers as well as in the upper and middle ones, there is an association of walls and pithoi and skeleton graves. Thus north digging II also yielded a wall, a pile of ashes, and at $-i \dot{2}$ feet to -13 feet an excellently preserved skeleton in contracted or inclined Hocker position, while in the shaft of the east gallery two skeleton graves were found at -8 feet. 


\section{SOUTH KURGAN.}

In the South Kurgan also we can distinguish two great culture epochs. In the development of the kurgan, these are topographically separated by a horizontal plane lying between +37 feet 7 inches and $+4 \mathrm{I}$ feet.

The younger culture (IV) claims the upper layers of the hill lying above the plane mentioned and essentially the whole of the plateau forming the northern extension. Real dwellings were not found, though traces of them were recognized in the southwest side of the upper digging above +48 feet, in the deposits of débris between two walls. On the lower plateau extension the pithos found in the outer digging points to a dwelling-place. Qualitatively, this younger culture is characterized by the pottery of groups $I$ and 2 , by the use of iron implements (knife and sickle), and by younger copper forms (three-edged arrow-point), all of these being finds from the upper digging and from terrace $A$.

The older culture (III) lies buried below the horizontal plane above mentioned and has the same significance in the development of the South Kurgan that culture I has in that of the North Kurgan. It was most comprehensively opened up in the middle strata of the hill. Here there were found, at different levels, considerable remains of buildings and dwellings built of sun-dried bricks, thresholds, hearths, and vessels. The people of culture III like the people of the cultures I and II in the North Kurgan, had the custom of burying children of different ages within their dwellings or precincts.

If we take into consideration the observations made in terraces $\mathrm{B}$ and $\mathrm{C}$ there can be recognized within the middle layers of the hill, six different periods (A to F), counting from below upward, as follows:

Period A.-The great clay constructions of terrace $\mathrm{B}$, between $+\mathrm{I} 8$ feet and +20 feet, with pithos $d$ of the same place. Pithos in terrace $\mathrm{C}$ at +18 feet 5 inches.

Period B. - Clay chest and pithoi $b$ and $c$ in terrace $B$, between +23 feet and +25 feet. Ash layers and two hearths of clay in terrace $C$ between +23 feet 7 inches and +26 feet, as well as the skeleton grave in the same terrace at +20 feet 5 inches.

Period C.-Pithos $a$, and the brick in terrace B between +25 feet and +27 feet, as well as skeletons $\delta, \zeta, \eta$, and $\iota$, between +23 feet and +24 feet.

Period D.-Pithoi $b$ to $d$ in the upper digging, between +26 feet and +29 feet; threshold in terrace $B$, at +27.5 feet, as well as skeletons $\alpha, \beta, \gamma$, and $\varepsilon$ in terrace $B$, between +25 feet and +27 feet.

Period E.-Pithos $a$ in the upper digging between +32 feet and +35.75 feet. Clay wall in the west side of terrace $B$, between +31 feet and +32 feet.

Period F. - Clay wall in the upper digging between +37 feet and +40 feet. Period F denotes the latest time of the older culture; above its deposits the younger epoch begins.

Qualitatively, the older culture is determined by the pottery of groups 3 to 5 . Essential ceramic differences are not observable within the development of the six periods. During period $\mathrm{F}$ the gray and red varieties must have assumed marked importance in comparison with the ware of light greenish-white or yellow clay, 
group 5. In the older periods ( $\mathrm{A}$ to $\mathrm{E}$ ) group 5 certainly predominates; and the now rarer gray vessels are distinguished by a very fine incised ornamentation. In connection with this highly developed, wholly wheel-made pottery, there occur characteristic types of copper weapons and implements. Iron is wholly wanting, and may, therefore, be supposed to be unknown.

The deeper layers of this older culture of the South Kurgan, like those of the North Kurgan, have been explored only to a limited extent. The systematic establishment of the succession of layers is here impossible. On the other hand, the ceramic finds point to an intimate connection between these deeper layers and the middle ones, so that here, as in the northern kurgan, they can all be combined into one great whole. To what extent the prototypes of the development of periods $\mathrm{A}$ to $\mathrm{F}$ are to be sought in the culture equipment of the deeper strata can be better determined by the results of future exploration than by the study of the finds now in hand.

In any event culture III represents a third copper age epoch, and in comparison with the two older ones of the northern kurgan it may pass for the brilliant epoch of the copper age of Transcaspia. The systematic treatment of the special finds may confirm this statement.

A word more in regard to the origin and mode of growth of the two hills. In both of them the strata accumulated with a continuous uniform development; in each kurgan by far the greater mass belongs to the earlier culture (I in the North Kurgan and culture III, in the South Kurgan). The thickness of the strata in each amounts to 60 feet and 72 feet, respectively.* This can only be explained as being due to a relatively rapid growth of the deposits. Such a rapid development was certainly favored by the method of construction, for the clay houses resolved themselves upon their destruction into compact masses, which are indistinguishable from the natural clay soil. In addition to this, the inhabitants themselves have contributed to this rapidity of growth by continued changes in their construction. This is shown in terrace $C$ in the South Kurgan.

The considerable height of the hill was produced not only by periodic destruction of the lower settlements, as we have seen in terrace B, but by the elevation of the settlements during each period through the continual renewal and raising of the earthen floors. We can, therefore, understand how similar finds can occur at considerable differences of level without being accompanied by changes in the character of the culture. The definite results of the observations made at the South Kurgan must also apply to the North Kurgan, and must be applicable generally, wherever the architecture is limited to unburnt bricks, without stone foundations and stone floors.

In the case of these hills, the inhabitants may, in consequence of the custom of making burials in the dwellings, have found a special reason for the continual changing and renewal of the floors. In connection with such an explanation, I can not neglect to meet two objections, or contradictory explanations. It might be suggested that the hills had been used alternately as dwelling and burial

*Counting from the base, which in each kurgan is buried about 20 feet deep in the plain.-R. P. 
places. Such a conception is refuted by the very close relation and connection between the skeleton layers and the dwellings, as was shown in terraces I, IV, and V in the North Kurgan, and in terraces B and C in the South Kurgan. Besides, the burial gifts of the skeletons belong unequivocally to the culture layers which were in each case exposed both above and below them. The only explanation is that the inhabitants buried the dead in their houses while they were occupying them.

Secondly, one might object to the term "dwelling" and look upon the constructions as burial or cult-houses and the hearths as former sacrificial places in connection with burial rites. But the special finds can be suitably explained only as objects of daily use. The culture equipment is throughout comparable in character to the finds brought to light in great quantities in other primeval settlements, which, like Troy, were occupied during many centuries. The great masses of animal bones, which were gathered in all layers of both hills, are only to be explained as the remains of the daily nourishment of the inhabitants. Moreover, food vessels, bake-ovens, and kettles are not easily associated with places consecrated to the honoring of the dead, even if one should throw burial feasts into the scale.

\section{THE FINDS FROM THE NORTH AND SOUTH KURGANS.}

After the excavations had enabled us to refer the finds from the two kurgans to three different epochs of the copper or bronze age and to one epoch of the iron age, the way was clear for a systematic presentation of the details.

The great mass of the special finds divides itself into separate groups, whether we consider their significance or group them according to material and form. These groups will be treated in the following pages in such a manner that the finds from the South Kurgan will, in each case, follow those from the North Kurgan.

First of all naturally comes the pottery, which was our guide in the separation of the superimposed strata and in a qualitative discrimination between the superimposed cultures themselves.

It would be natural to begin with the finds from the lower strata, but since our work with the spades exposed these to a limited extent only, it is desirable to begin with the middle layers. In this way we secure a firm foundation for the discussion of the finds from the upper as well as from the lower layers.

\section{POTTERY FROM THE NORTH KURGAN.}

MIDDLE STRATA, CULTURE I.

The material in hand consists almost exclusively of fragments of the pottery. Only a few vessels were found in situ and not one was whole. Nevertheless, the masses of fragments fall into two great groups-small vessels of finer technique and coarse vessels for common use and the storing of provisions.

(a) The Smaller Vessels of Fine Thchnique.

Forms.-There was practically but one form in use-a deep cup with a margin without profile, more or less drawn in, and having a low, flat foot, a little concaved beneath (figs. 55 and 56). The foot is sometimes lacking and the under-surface 


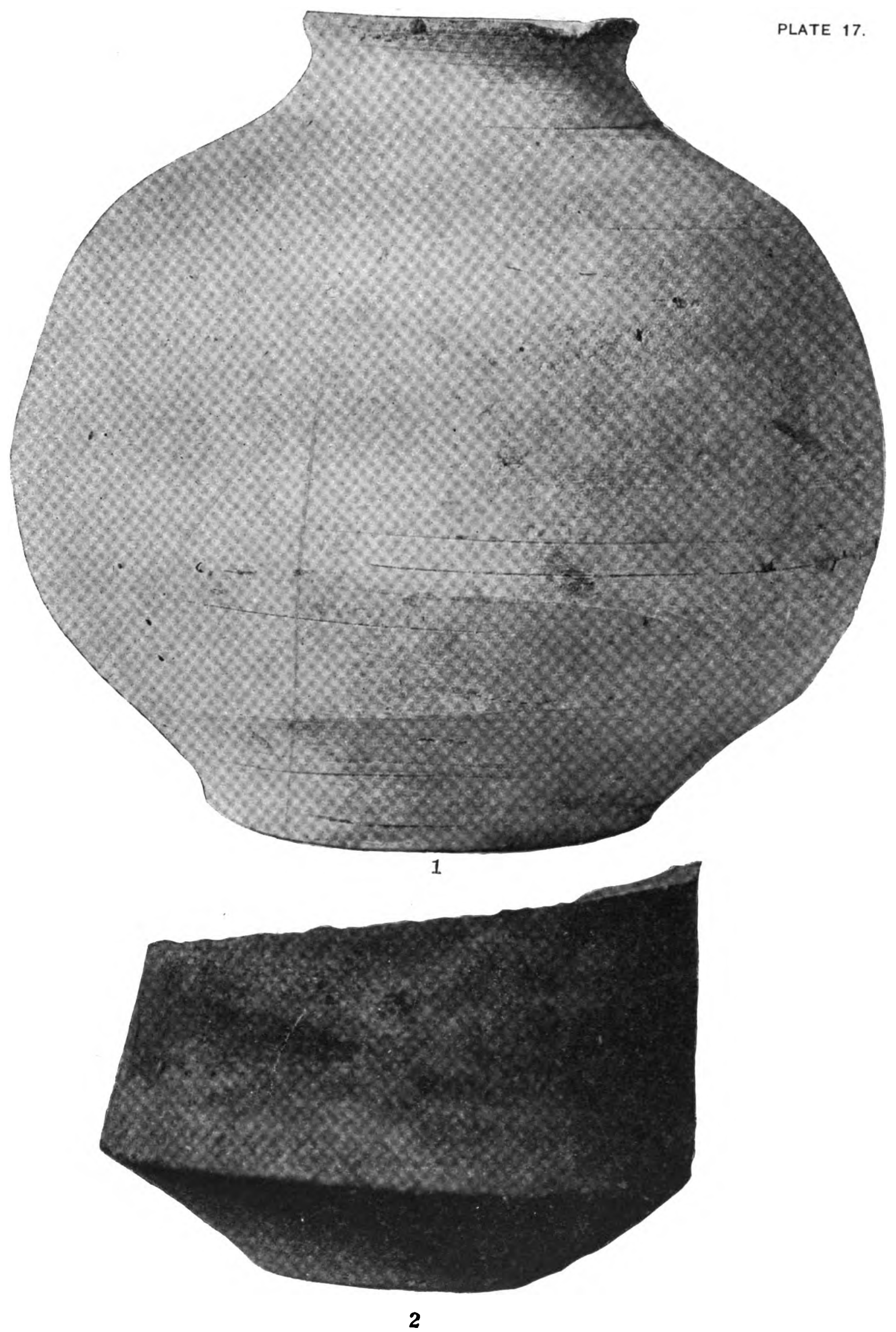

Pottery from Upper Strata, South Kurgan, Culture IV.

FiG. 1. Spherical Vase of Red Ware with Thin White Slip, Height $19.5 \mathrm{~cm}$. (Characteristic W. Lower Parte of Vulture IV) ( from 2 feet below Surface in Outer Digging.
2ame Ware. 
PLATE 18.

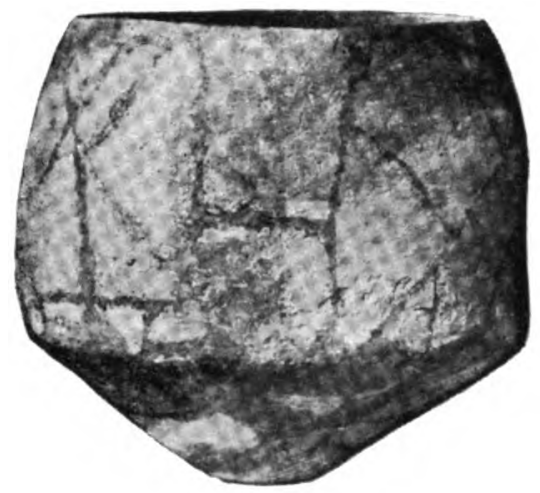

1

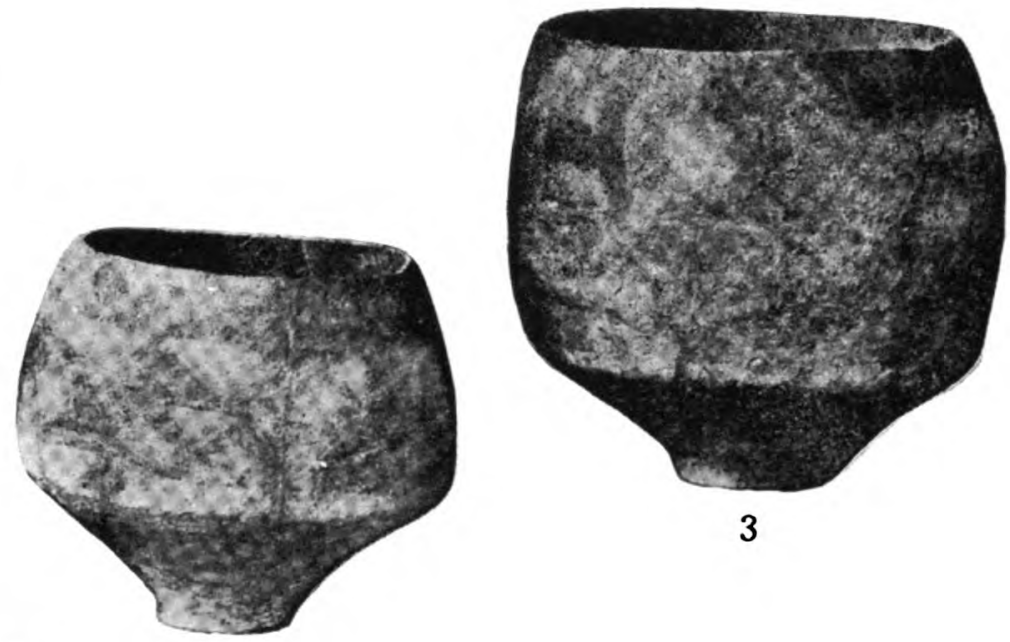

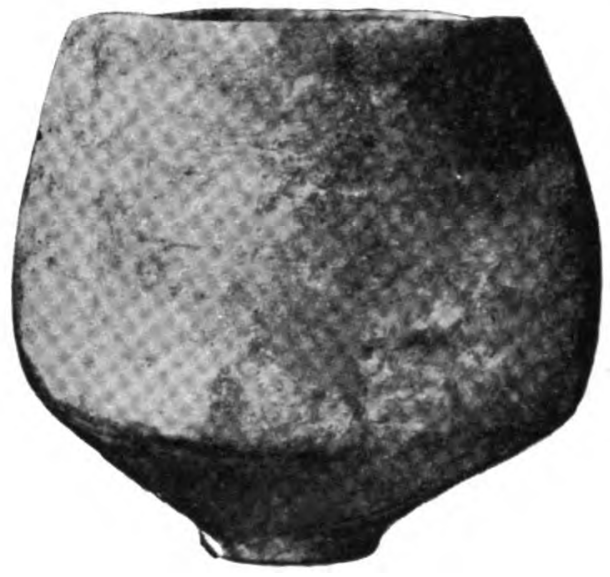

4

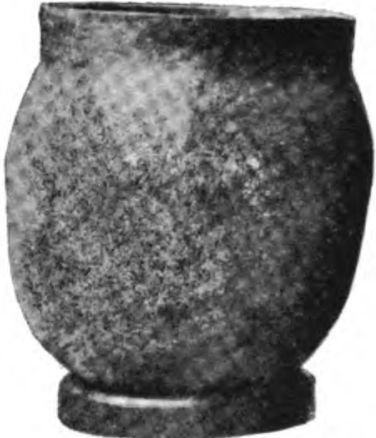

6

2

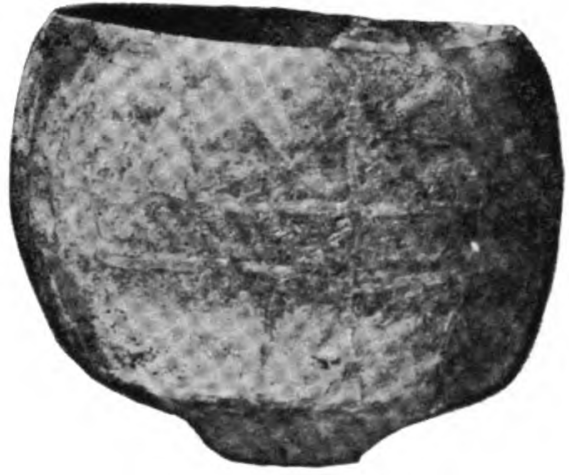

5

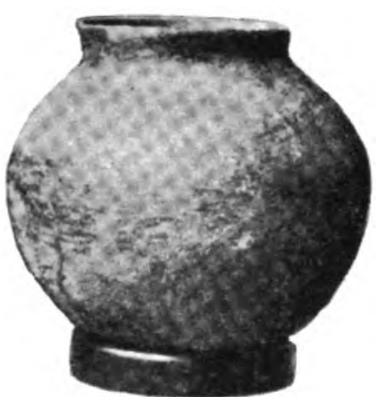

7

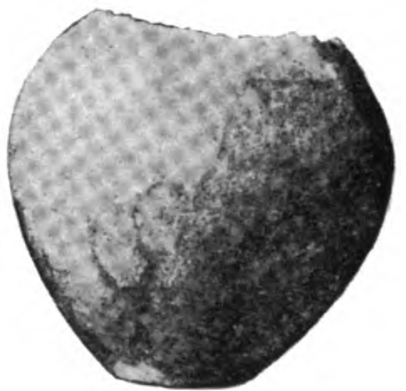

8

Delicate Hand-made Pithoi from North and South Kurgans.

F1o. 1 (N.K., Terrace VIII, Culture I). Height $44.7 \mathrm{~cm}$., Upper Diameter $40 \mathrm{~cm}$. Ornamented with vertical chessboard design. Cf. plate 21 , fig. 1. 2 (N.K., Terrace II, Culture I). Height $36 \mathrm{~cm}$., Upper Diameter $32.5 \mathrm{~cm}$. Ornamented with three rows of erect triangles. Cf. plate 20 , fig. 1 . 3 (N.K., Terrace II, Culture I). Height $43.6 \mathrm{~cm}$., pper Diameter $45 \mathrm{~cm}$.

. Yellow clay, strongly reddened; not painted.

5 (N.K., Terrace II, Culture I). Height $42.3 \mathrm{~cm}$., Upper Diameter $40 \mathrm{~cm}$. Ornamented with three rows of large ereet triangles. 6 N.K., Terrace III, Culture I). Height $38.5 \mathrm{~cm}$., Upper Diameter $30.5 \mathrm{~cm}$. Brown clay, in parts blackened and burnished. Cf. plate 21, fig. 2.
7 (N.K., Terrace I, Culture II). Height $31.5 \mathrm{~cm}$., Uper Diam. $20.5 \mathrm{~cm}$. Red monochrome, burnished and blackened in places. C $f$. pl. 20, fig. 2 .
8 (S.K., Terrace B, Culture III). Height $33.3 \mathrm{~cm}$. Pithos $a$, rough hand-made pot. Light pink-yellov clay. 
Digitized by Google 
PLATE 19.

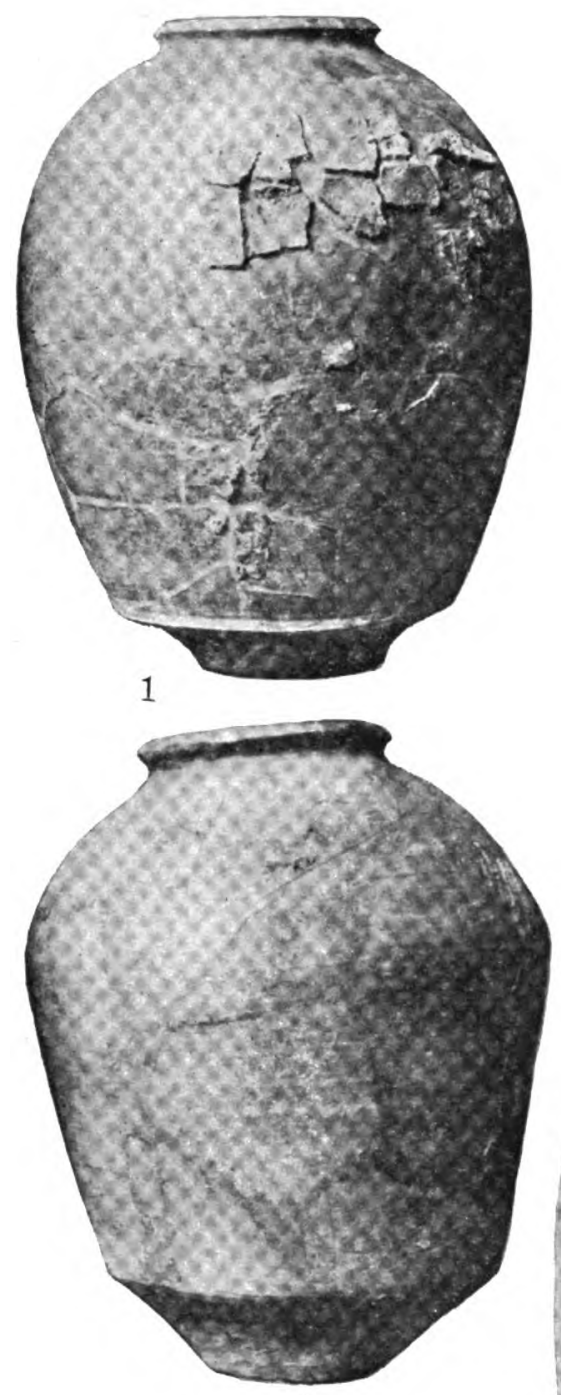

4

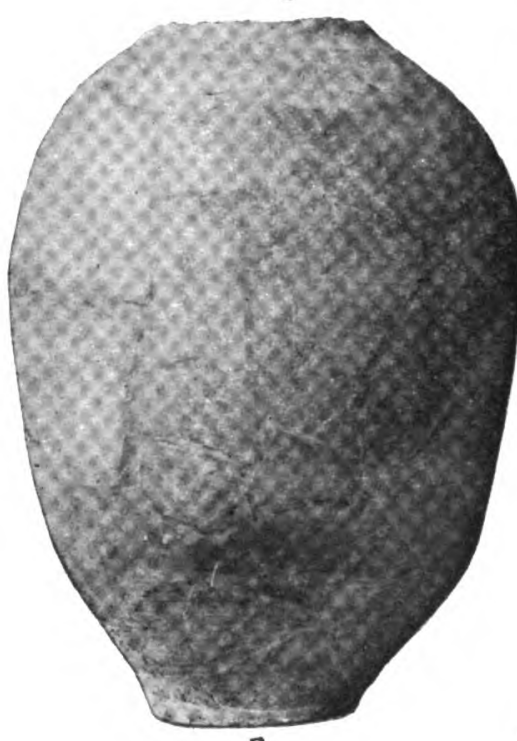

6

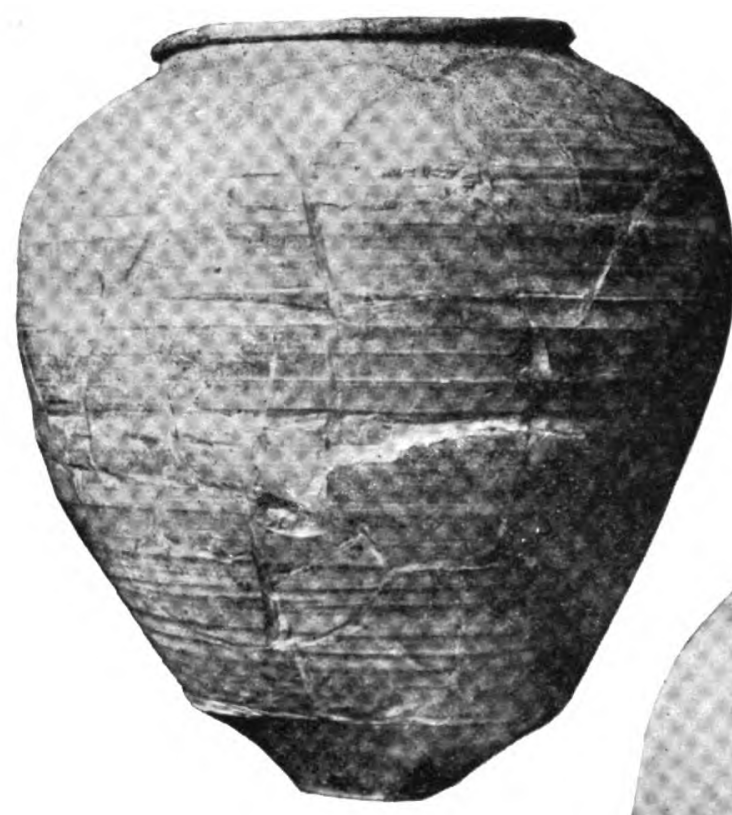

2

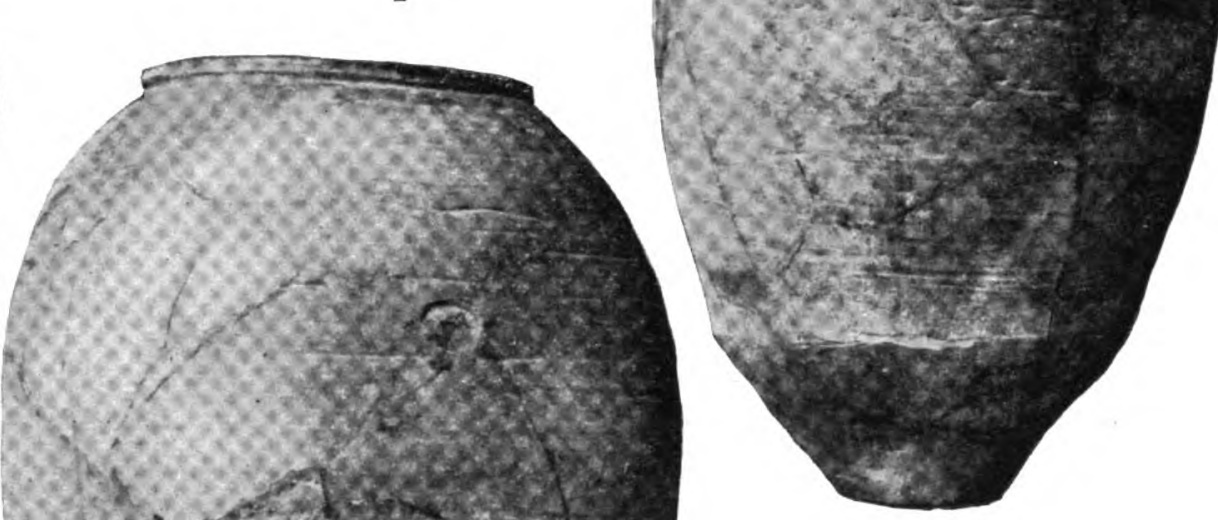

5
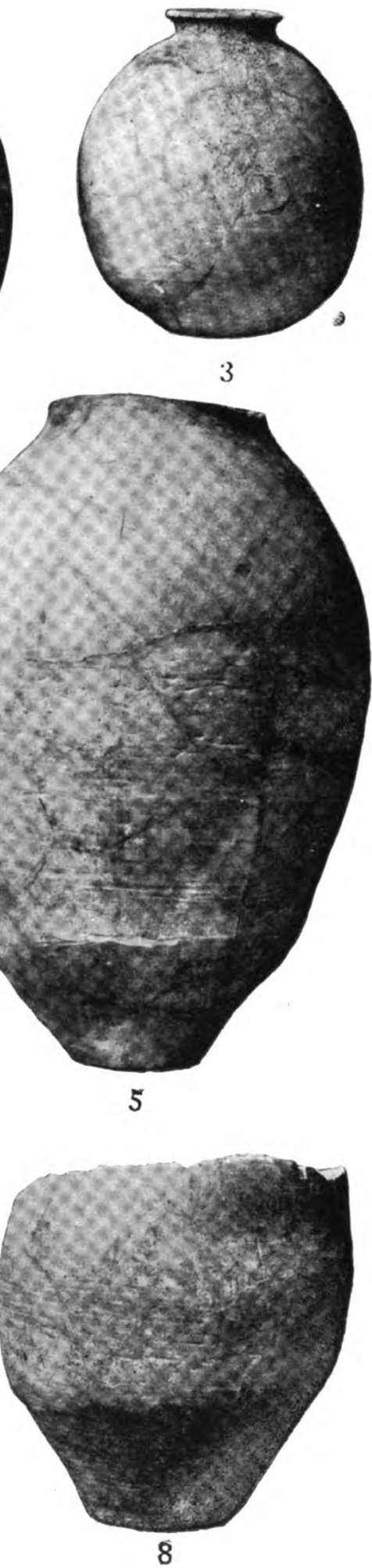

3

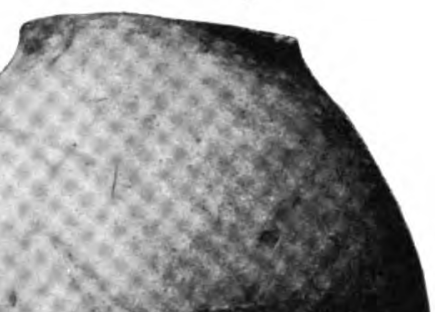

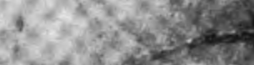

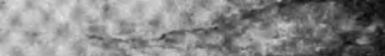

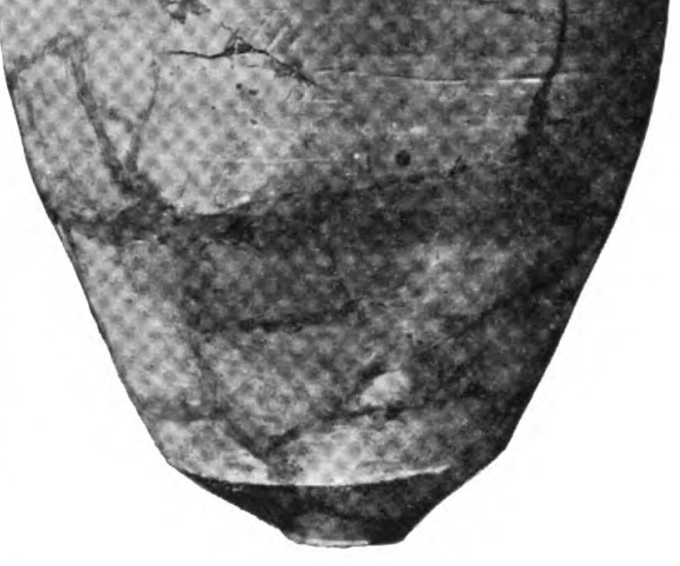

7

Pottery from Middle and Upper Strata, South Kurgan, Cultures III and IV. Fig. 5 from Culture IV; all others Culture III.

Fic. 1 (Terrace B). Pithos $c$ or $b$, Height $65.5 \mathrm{~cm}$., Upper Diameter $21 \mathrm{~cm}$. Heavily incrusted outside with lime, possibly to repair holes. Clay fine, greenish2 (Upper Digging); ; ithos b, Height $74 \mathrm{~cm}$., Upper Diameter $41.5 \mathrm{~cm}$. Clay fine, greenish-yellow, in places much reddened in burning.

3 (Middle Strata, Terrace B). Pithos $d$, Height $38.8 \mathrm{~cm}$., Upper Diameter $13.5 \mathrm{~cm}$. Clay finely levigated, greenish-yellow; good wheel workmanship. 5 (Upper Strata, Outer Digging). Height $83.5 \mathrm{~cm}$., Upper Diameter $27.5 \mathrm{~cm}$. Differs in clay and workmanship from pithoi of Culture III. Clay reddish; horizontal wheel-marks wanting on both outer and inner surfaces; vessel seeming to be hand-made.

6 (Terrace B). Pithos $b$ or $c$, Height $62 \mathrm{~cm}$., Upper Diameter $23 \mathrm{~cm}$. Well-levigated clay: wheel-made.

7 (Upper Digging). Pithos $c$. Largest Service Vessel Found; Height $95 \mathrm{~cm}$., Upper Diameter $38.5 \mathrm{~cm}$. Clay fine, yellow; wheel-made. Occasional oblique 8 (Middle Strata, Terrace C). Height $46.5 \mathrm{~cm}$., Upper Diameter $40.5 \mathrm{~cm}$. Clay light-greenish. About half of original vase. 
Digitized by GOOgle 
slightly concaved (fig. 57). Very rarely one finds a steep lip bent inward (fig. 58). This cup may also have an open spout on the lip. Very rarely there occurs a profile with a notched lip.

Technique.-The clay of these cups is, for the most part, washed fine and is a light or reddish-brown. It is almost always well-burnt, and to a great extent porous. The vessels were excellently well formed by hand; the potters' wheel was as yet unknown. The raw clay was covered with a very thin coat of color, which gave a surface for the painted decoration. Now and then this ground covering shows different tones-probably an effect of the burning. It is especially remarkable that in many cases the vessel was polished before being painted. According to the ground color, we can distinguish three groups:

(a) Vessels with different shades of brown or red ground covering (plate 23, figs. I, 2, and 3; plate 28, fig. I).

(3) Vessels with whitish-green or yellowish-green "slip." This also showed now and then a slightly red tone produced in the firing (plate 23, figs. 4,5 , and 6; plate 24, figs. I and 2).

(r) Vessels with carmine-red or violet slip. This was laid on thicker than in the other groups and often flakes off. In many cases one can observe a whitish intermediate ground under the colored slip. This probably served for the better fixation of the slip (plate 24, figs. 4 and 5 ; plate 25 , fig. I).

Technique of the painting. - The color used most frequently for the decoration of the more delicate vessels was black, but bluish-black, violet-black, violet, and black-brown werealso found. These colors were for the most part laid upon the very thin slip. Only in the case of the very common technique is this special ground lacking. In such cases the colors appear directly upon the plain surface. The ornaments themselves remain mat upon polished ground. The kind and execution of
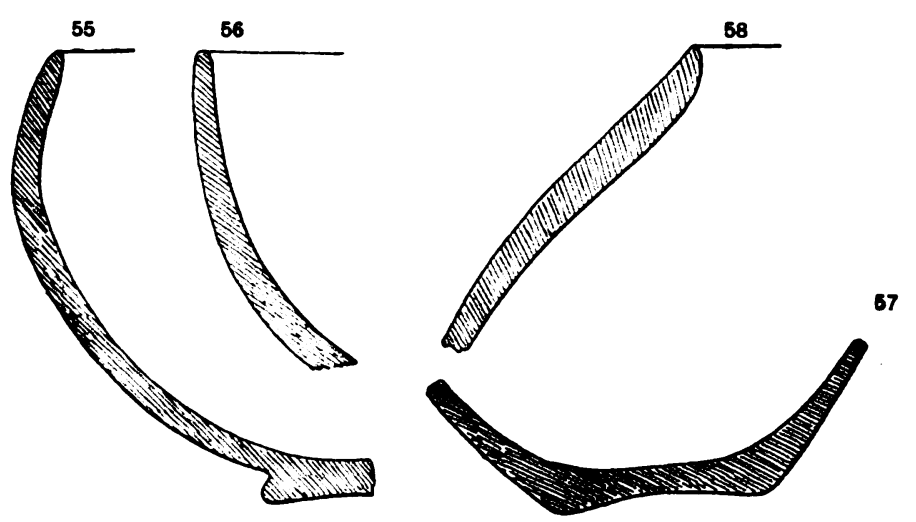
the decoration indicate a full mastery of brush technique, and the many shades appearing in the ground tones prove that the decorators of the vases were very expert in the mixture of colors.

The three groups of vases were also found numerously in the mixed layers. Fragments of groups $\beta$ and $\gamma$ were especially noticeable in terrace $v$ (April 4 ) above the level of +28 feet 5 inches, and fragments of $\beta$, exactly similar as regards technique and ornamentation, were found (April 6-7) between +20 feet and +18 feet in terrace II and March 28-3I between +18 feet and +10.5 feet in the west diggings, i. e., in pure and undisturbed layers of the older culture. Of the pottery occurring in the mixed upper layers we can refer to the younger culture only such as can not be found in the pure middle and lower layers. 
(b) Large and Sxall, Vessegls in Coarse Technigue.

Forms.-In this group, also, the number of forms is very limited. For the most part they are deep cups, or kettle-shaped pithoi, with flat bottoms (fig. 59). These last often have below the lip two or three short projecting horizontal ridges, lying parallel, one below the other, which presumably take the place of handles (fig. 60). More rare are the cups with indrawn margin and flaring mouth, $i$. e., with narrow throat. They occur only in hard-burnt red clay (fig. 6I). Cups with the 'margin thickened, as in fig. 62, are very rare. Very small cups, which are perhaps copies of larger vessels, are represented in figs. 63 and 64 .

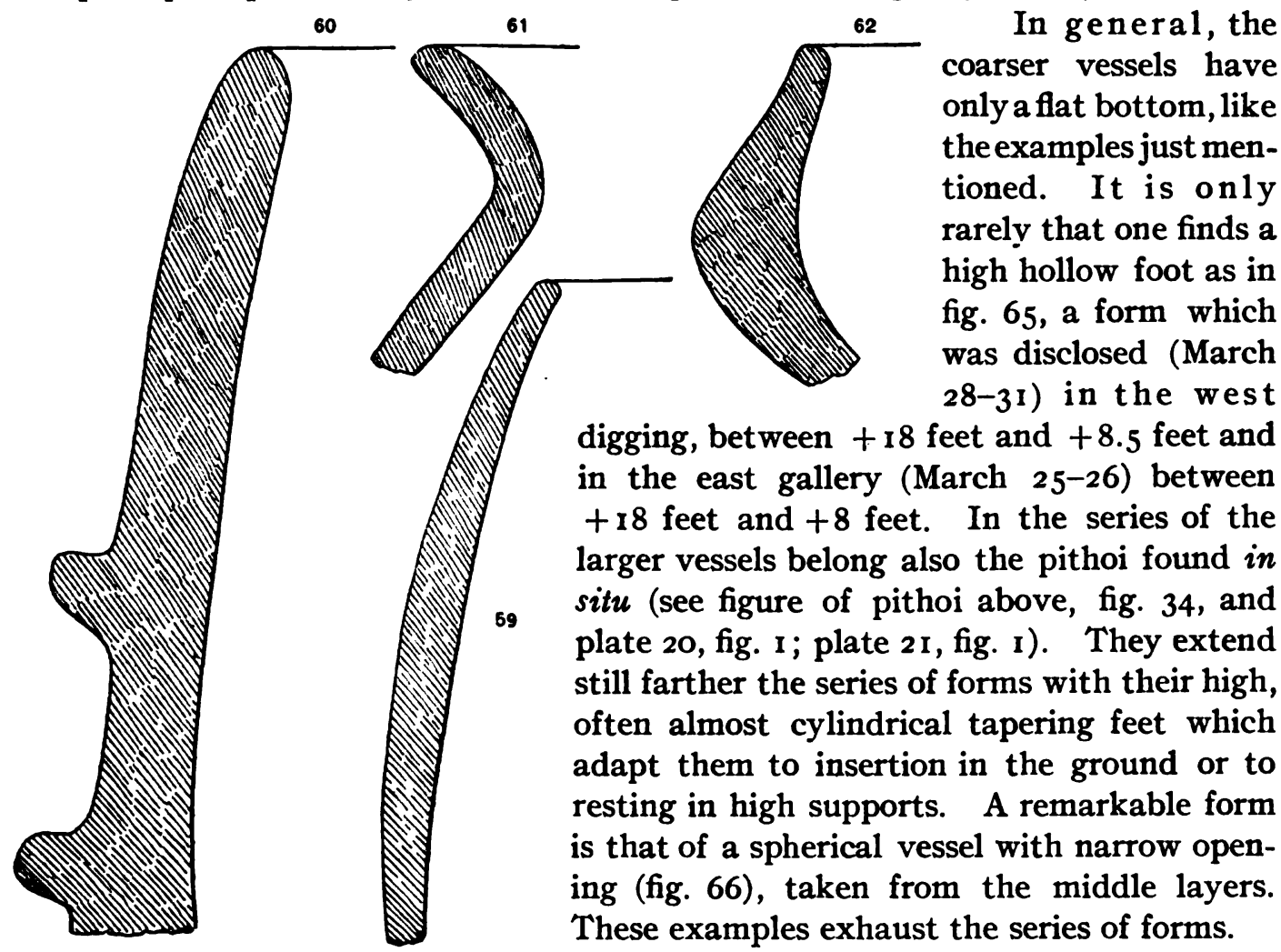

Technique.-The clay of the coarser vessels is, for the most part, very porous. It is often light-green, white or yellow with a greenish tone; grayish-white, lightbrown, or brown-red, and light-red also occur. In contrast with the small vessels of group $a$, their firing was very moderate, but they, too, show a thin color-slip, which, as a rule, corresponds to the color of the clay-light-green, whitish-green, yellowish, brownish, and reddish or light-red. In some cases we find the same violet-red that was seen on vessels in group $a$. On the surface of the coarser vessels there are often visible little elongated depressions, traces of pieces of straw which were originally baked in the clay, and, as a rule, the polishing is wanting. Still, there is a kind of red clay with a covering of red color which resembles the vessels of group $a$. In this group the vessel was polished before being painted (see plate 20 , fig. I; plate 2 I, fig. I; plate 24 , fig. 3 ; plate 25 , figs. $2-4$; plate 26 , figs. I 
and 2 ; plate 27 , figs. $1-3$; plate 28 , fig. 2 ; plate 29 , figs. $1-4$; plate 30 , figs. $1-3$; plate $3 \mathrm{I}$, figs. $I$ and 2 ).

Technique of the painting.-The colors were laid upon either a clay ground, more or less well-treated, or upon a thin color-slip. The coloring is, perhaps, still more varied than in group $a$. Here, too, black predominates, and with it occurs brown in different shades-light brown, black-brown, red-brown, and violet-brown. The manipulation of the brush was for the most part rapid, especially as large surfaces were often to be painted. Nevertheless, the lines are drawn appropriately and accurately.

The Decoration of Both Groups a and $b$.

The patterns used by the painters of the vessels may be divided into two classes, according to the arrangement on the surface of the vessels; horizontal, linearly arranged patterns (Reihenmuster), i.e., patterns of which the separate motives are arranged in rows, and in oblique bandpatterns (Bandmuster), patterns in which the parts become effective only when arranged in bands. Each starts from a ground formthe first from an erect triangle, with the point at the top, the other from a group of oblique parallel lines.

(I) The triangles are grouped in horizontal rows, either placed close together (fig. 67) or standing farther apart (fig. 68). A peculiar motif is formed when the top points are forked (fig. 69). This last variation recalls the com-
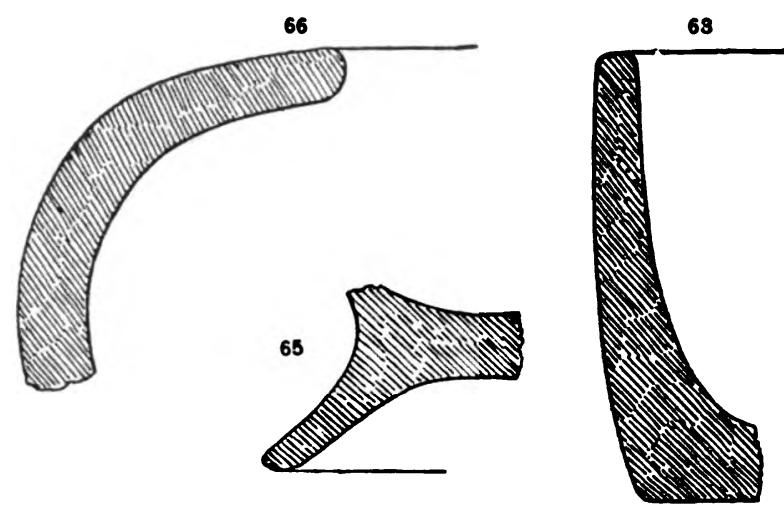
mon pole-tent, and the ground motif controls the whole decoration to such an extent that we may speak of a tent-ornamentation, merely for the purpose of identification, without any reference to the origin of the pattern.

The ground pattern occurs, however, in many variations. It is halved and placed obliquely, or directed upwards (figs. 70, 7I). The whole triangle or halftriangle is drawn only in contour (figs. $72,72 a$ ). Moreover, the triangular field is filled in in different ways-with a trellis pattern (fig. 73), or with parallel lines (fig. 74), or several lines may start simultaneously from the basal angles upwards, crossing each other at the apex (fig. 75). Again, the triangles are so shoved into each other that the sides cross each other at the bottom (fig. 76), or at the apex (fig. 77), as in the ground pattern (fig. 79). A pattern which is not infrequently used is shown in fig. 78 in which the somewhat curved apices of the triangles are ranged like the prows of ships (see plate 24, fig. 2). 
These and similar lineal patterns may be accompanied by spurs directed upwards, or by dots (figs. 79, 80). This peculiar motif is especially favored in group $a$ with the carmine slip $(\gamma)$, and it also occurs on similar vessels of group $b$ (see plate 27, fig. 2). It is also very interesting to note how the triangles may be grouped opposite each other to produce a rhombiform pattern (figs. 8I, 82). In this way an independent rhombus is formed and may be filled with the trellis pattern, as was the case with the triangle (fig. 83). These motifs have occurred thus far only in fragments of the group $r$.

Lastly, the triangles may be represented by oblique lines only, as in the cup (fig. 84). The same vessel also has an interior decoration, which is, however, not the rule for cups of this form, but has been observed in groups $a$ and $b$ (fig. 85). It consists of a sheaf or branch pattern on a long stem, and is spread crisscross over the whole interior surface, while large spots are placed in the angles on the bottom.

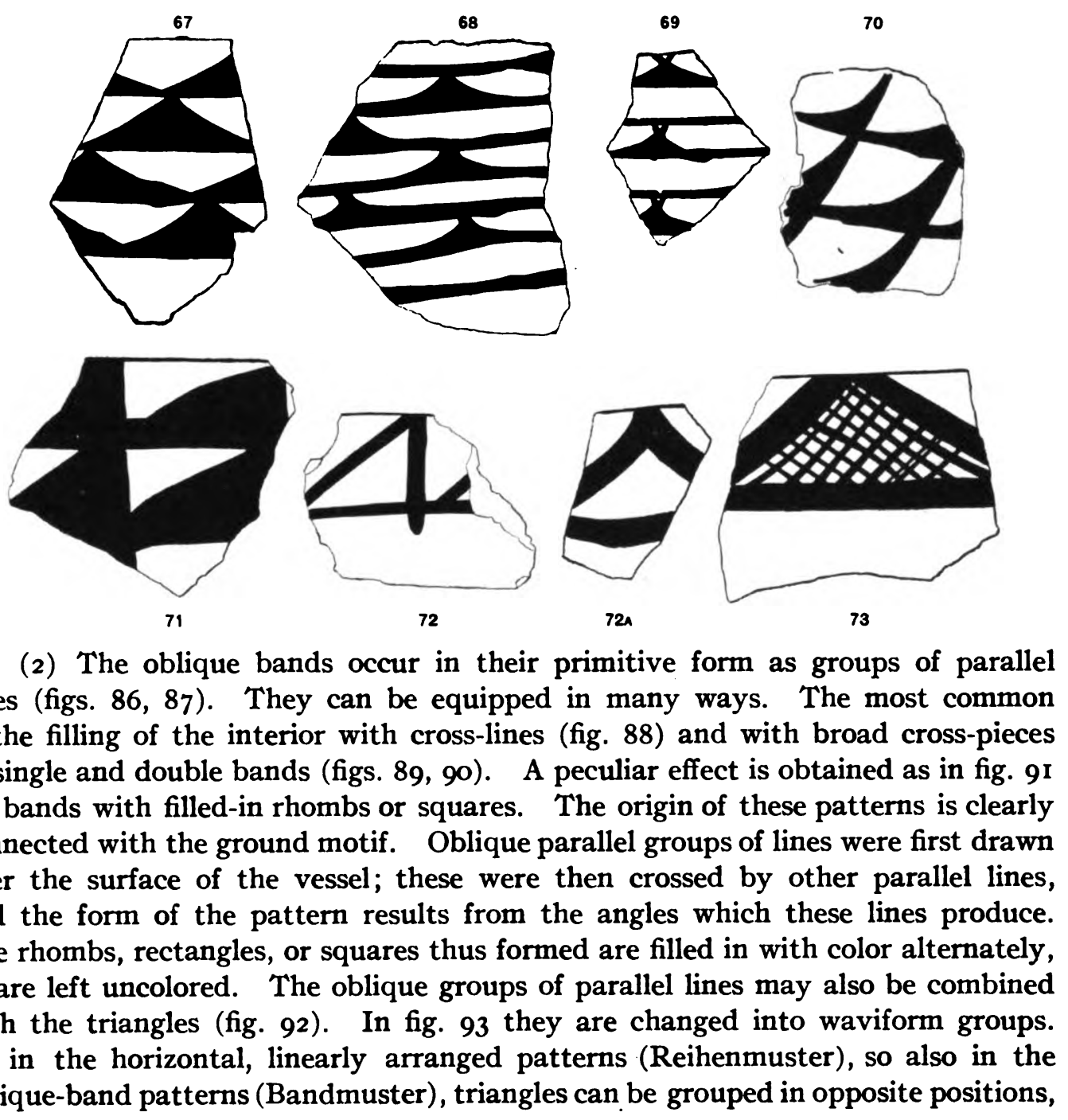
oblique-band patterns (Bandmuster), triangles can be grouped in opposite positions, 
as in fig. 94. A graceful effect is produced by parallel lines occupied with rows of spots, which may either stand alone, as in figs. 95 and 96 , or lie between two parallel lines, as in fig. 97. Larger fragments of service vessels show heavy crossbands which extend over the whole vessel (fig. 98) (cf. plate 26, fig. 2).

(3) Besides these two large and systematically connected groups of patterns, we find in both classes of vessels ornamental details which give evidence of the ability of the painters in the matter of design. Some examples, such as figs. 99-103, will show this. The groups of patterns referred to are distributed in such $a$ way that in both classes of vessels, $a$ and $b$, the horizontal linear-pattern (Reihenmuster) rules equally. The oblique-band pattern (Bandmuster) on the other hand, was preferred for the large vessel of group $b$, though there are
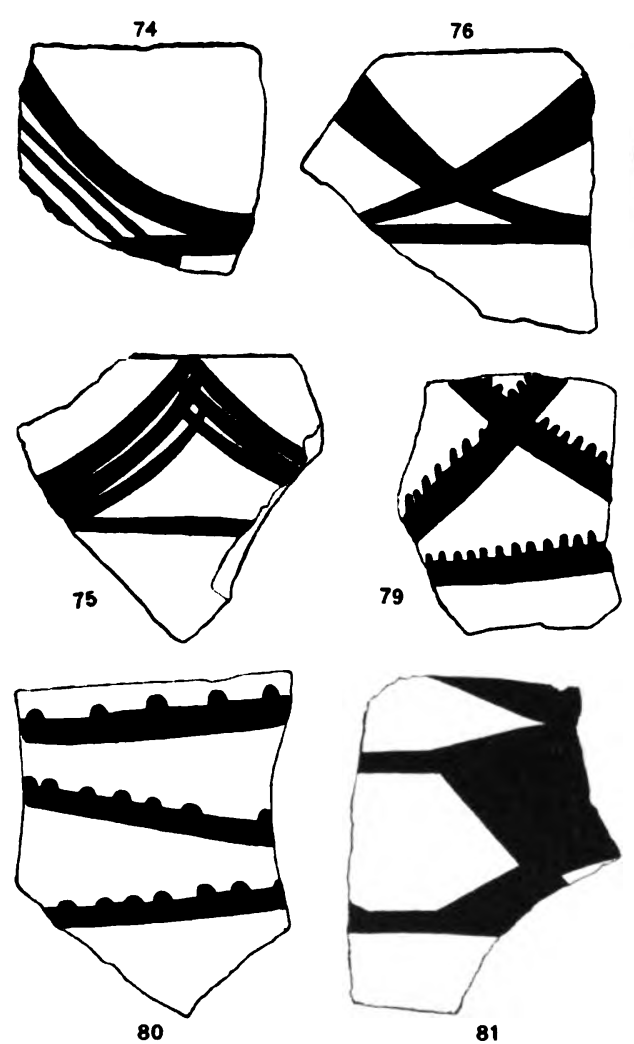

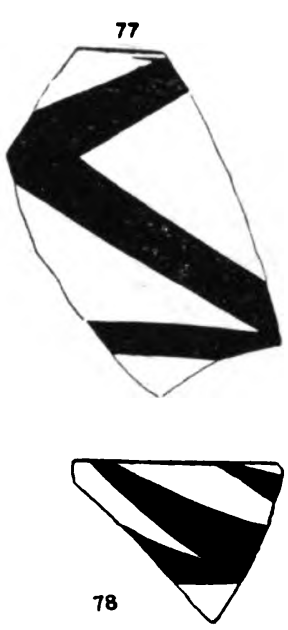

examples of more delicate vessels in group $a$, in which we find the band pattern.

LOWERSTRATA, CULTURE I.

In the detailed report of the excavation, reasons were given for referring the deposits of the lower strata to the same culture as that of the middle strata. We will now note some details.

In the north digging specimens of groups $a$ and $b$ occurred in all the strata lying below datum. Indeed, some painted fragments of the same variety as those of the middle layers were noted between -20 feet 5 inches and -24 feet 5 inches. Finds of the same significance were made in the west shaft. Here the culture-strata lying below datum are shown by the ceramic finds to be qualitatively similar to the middle strata of the

heart of the hill. In addition, there was observed between -23 feet 5 inches and -24 feet the lipped piece of a coarse vessel of whitish-green clay (group $b$ ), of the same form as that mentioned above from the west digging (fig. 66). Near it was the lip-piece of delicate whitish-green clay and a red-toned saucer with painting (group $a$ ). On the other hand, the finds from the lower galleries of Komorof's trench can not, as was remarked above, be considered without criticism on account of the isolated occurrence of the gray and red monochrome fragments. There is also to be remembered the painted pottery of the middle strata, with the tent-ornamentation, and the painted specimens of the groups $a$ 
and $\gamma$ which were found in the shaft of the west gallery at -20.75 feet. In the shaft of the east gallery, also, pottery of the groups $a$ and $b$ was found in all layers below datum.

For these reasons, we must look upon still another pottery, group $m$, which occurred within the lowest strata, only as an older and transitory occurrence in the evolution of culture $\mathrm{I}$. We will now call this group $c$, and examine more carefully into its technique, form, and ornamentation.

(c) Thin, Painted Cups of the Lower Strata.

(Plate 22.)

The significance of the thin, painted cups of the lower strata in connection with the topography of the hill may be shown by a list of the points at which they were found-west gallery shaft, between - 14 feet and - 24 feet (April 2-5,

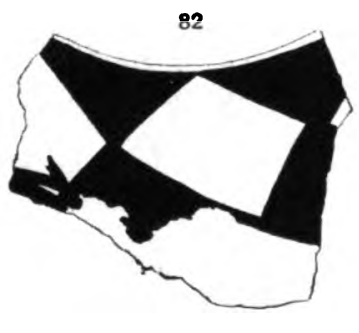

83

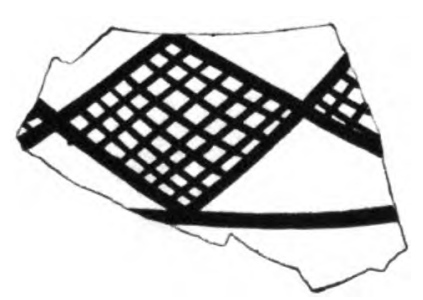

84
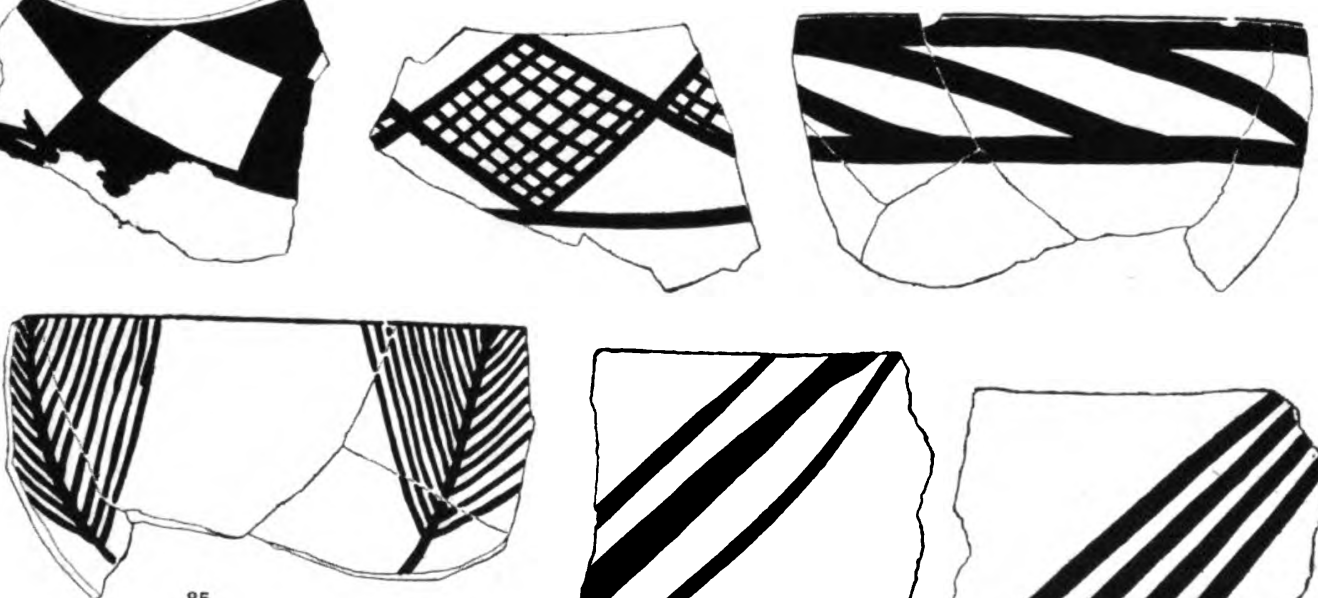

85

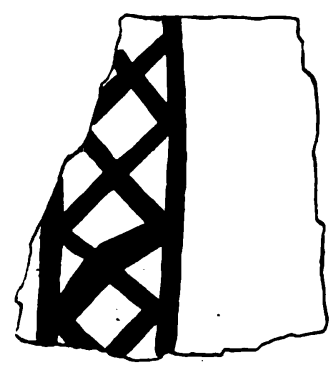

88
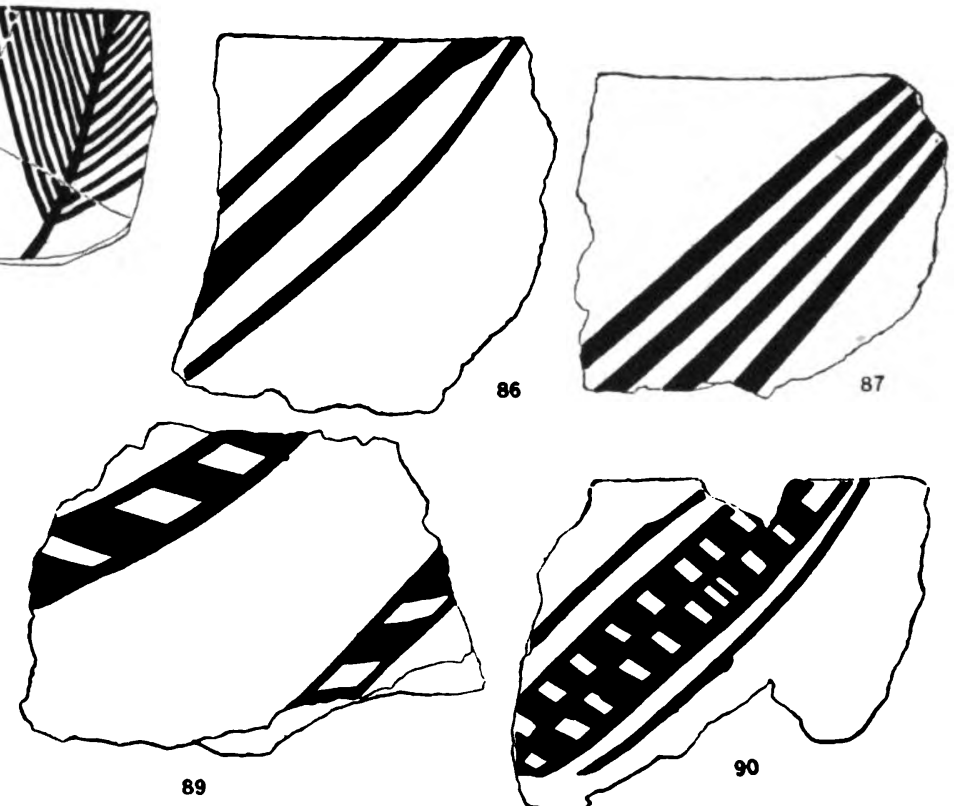

I904); north diggings ( 1 and 2), between -12 and -19 feet (April 4-5, 1904); terrace III, between +17 and +16 feet (April 6, I904).

The last-mentioned locality is surprising because it belongs to the middle strata. Still it concerns only a single lip-piece (fig. 59; plate 22, fig. 6) which 
might very easily have gotten by accident into the middle layers. Taken as a whole, group $c$ belongs decidedly to the lower and lowest strata of the northern kurgan.

Technique.-The fragments of group $c$ were so characteristic and deviated so widely in their technique from those of group $a$, that upon their first appearance they were at once regarded as something special. Their clay is especially well

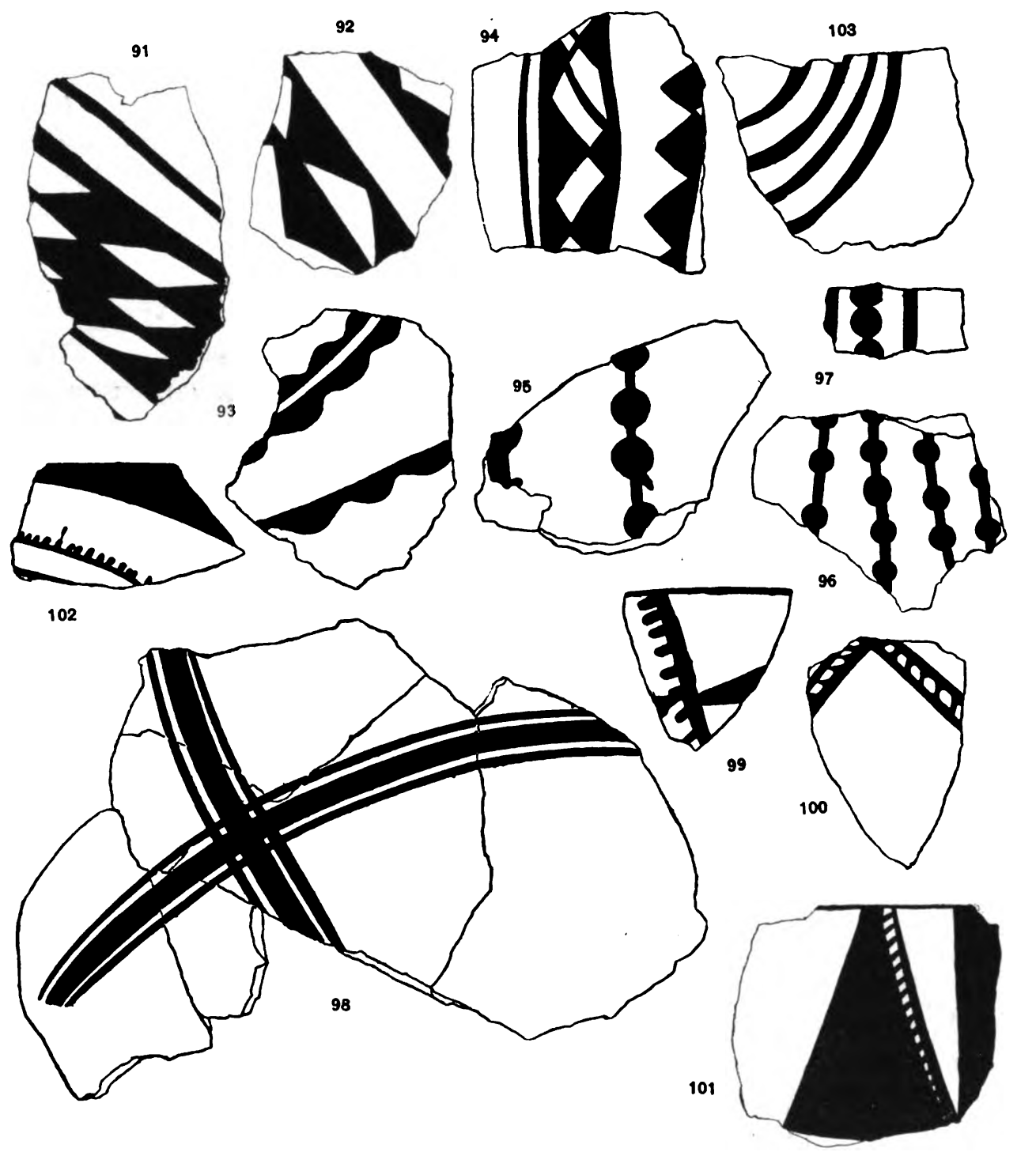

washed, almost always light-brown, having very rarely reddish shade, and very firm and hard-burnt. Traces of the potters' wheel were not observed, and as hand-work the vessels are excellent achievements. On the surface there is a very thin, fine, light-brown or light reddish-brown color-slip. A noticeable fact is the absence of all polish, the surface remaining dull and mat (see plate 22). 
Form.-The rather small collection of fragments exhibits only one forma deep cup with a lip gently drawn in and not profiled, and a concave bottom (figs. 104 and 105).

Ornamentation.-The patterns on the dull slip were mostly in a thin matblack or mat-brown color. The system of ornament has, in certain details, it is true, points of resemblance to the ornamentation of groups $a$ and $b$. As a whole, however, group $c$ differs so materially from groups $a$ and $b$ that it stands as a special group by itself. This group is shown in figs. 106-1 13 and in colors on plate 22, figs. $1-6$.

As the reader will see at the first glance, the characteristic motif of the decoration is a zigzag band filled with the trellis pattern, save in exceptional cases, as shown in fig. I I I. The lip pattern is very fine and effective-a band of simple or oppositely placed triangles, between which triangular or respectively rhombic areas remain in the ground-color. While the zigzag band does not occur in the pattern scheme of groups $a$ and $b$, the marginal pattern is related to it. The trellis-triangle as a filling pattern (fig. 106 and plate 22, fig. I) has also a resemblance to it; but its composition is original. The trellis-triangles can also be oppositely placed, and combine to form rhombic patterns (fig. I Io and plate 22, fig. 3). In this way they alternate pleasantly with the zigzag bands. Zigzag

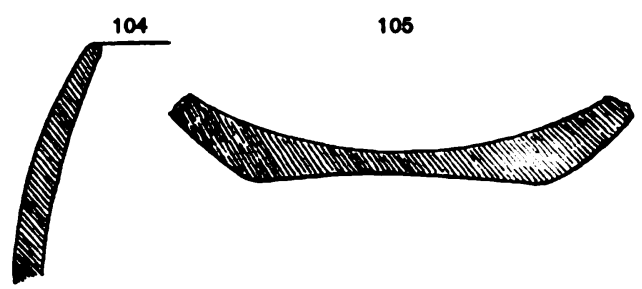
bands are themselves, at times, arranged to form rhomb patterns (fig. 109). An explanation is needed of the horizontal lines which are drawn through these patterns (figs. 106, 109, and 110, and plate 22, figs. $I$ and 3 ). They are doubtless aids for the regular execution of the composition and are a sign of the limitations of the technical ability of the decorators. They have without doubt, however, a significance in the evolutional history. One needs only to compare the examples from groups $a$ and $b$ in figs. 81 and 82. A special part is played in the decorations by broad lines filled with vertical zigzag lines (figs. 112 and 113 , and plate 22, figs. 5 and 6). They are distinguished from the band-pattern (Bandmuster), of groups $a$ and $b$ by their vertical position, and they have consequently a different significance.

In any event, the technical and decorative peculiarity of group $c$ points to another workshop than that of groups $a$ and $b$, the latter two certainly belonging to one and the same center of production. It can not, however, have been very far distant, for there are sufficient points of resemblance between group $c$ and groups $a$ and $b$ to prove their relationship.

\section{POTTERY OF THE UPPER STRATA, CULTURE II.}

While painting predominates in the pottery of the middle and lower strata, in the more delicate forms as well as in the coarser service vessels, it is much less present in the pottery of the upper strata. Here the common ware is to a much greater extent monochrome and the red and gray ware (entered above 


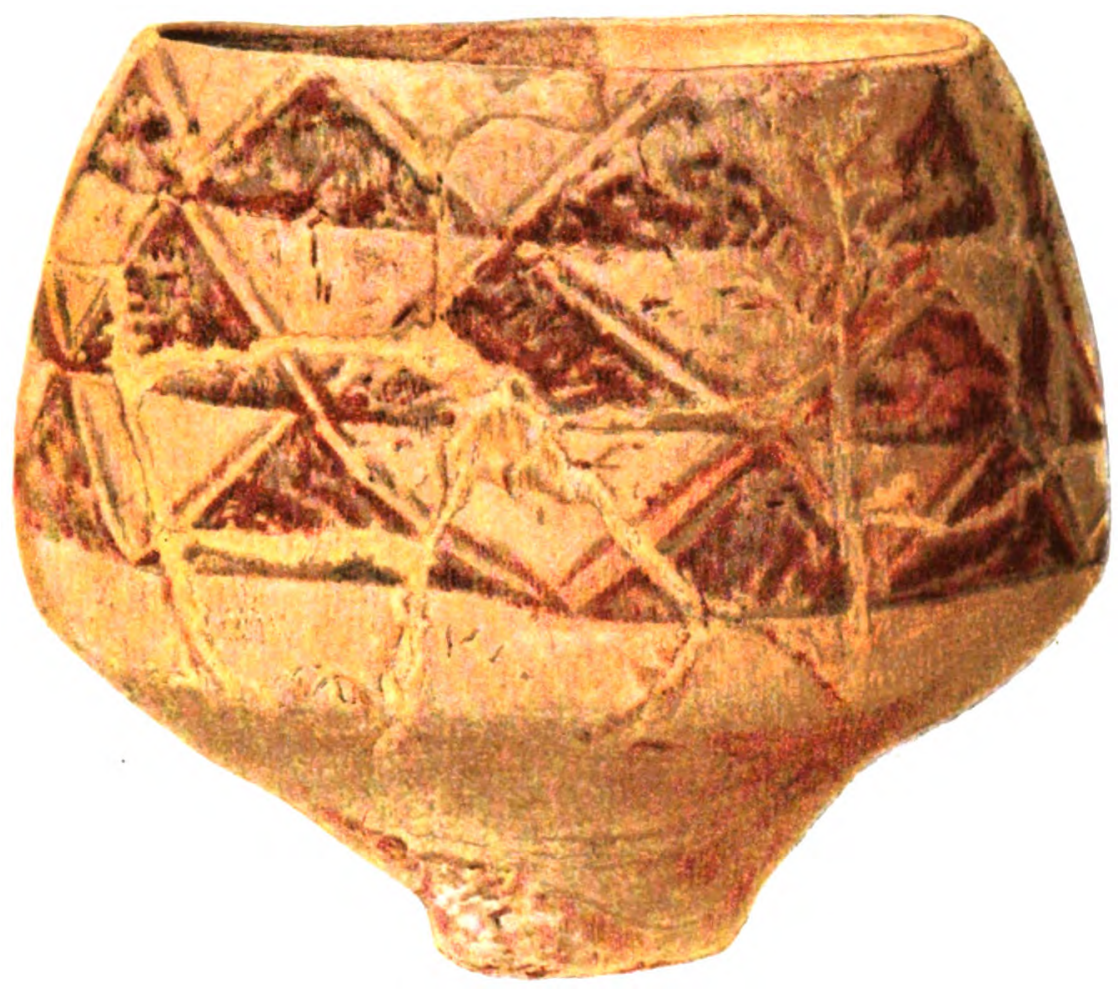

1.

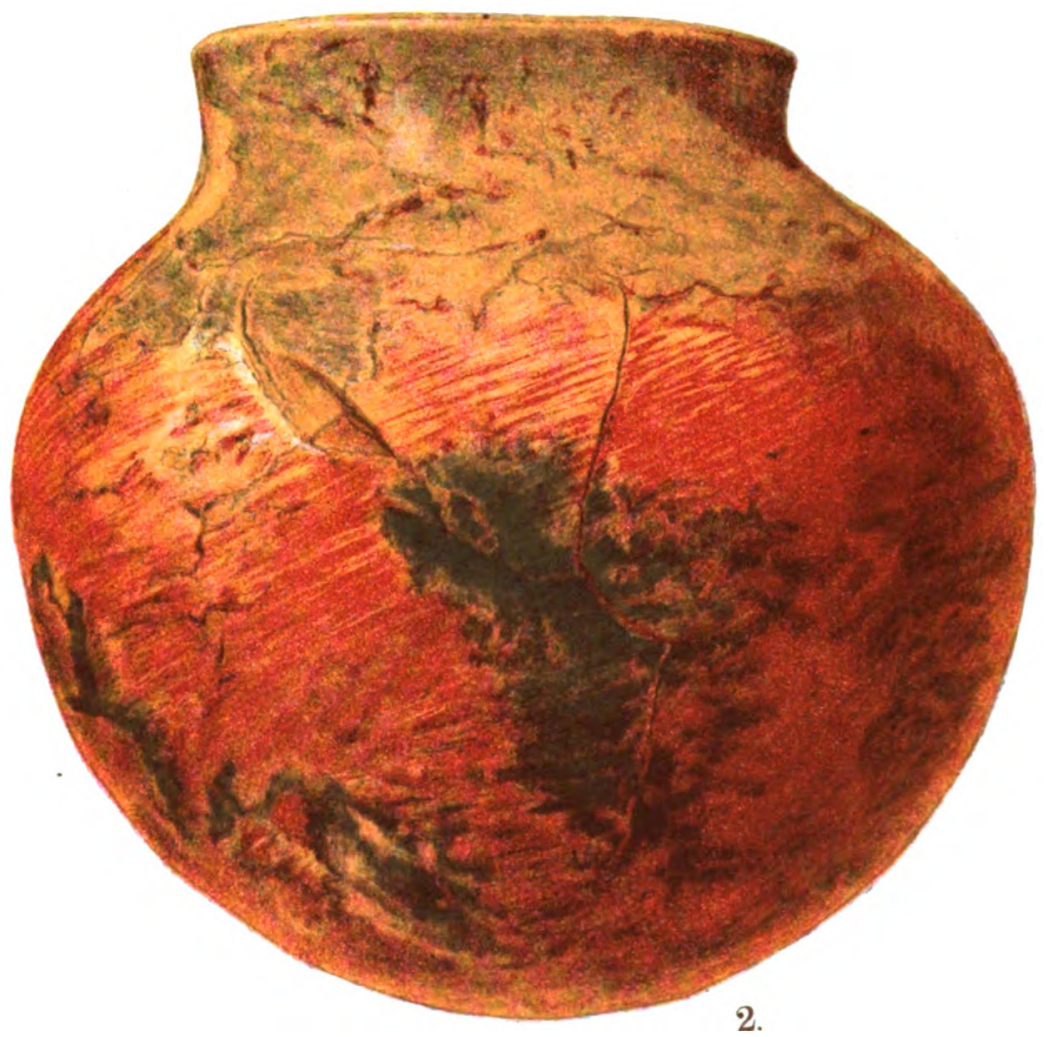

FIG. 1. Pithos characteristic of Middle and Lower Strata, North Kurgan, Culture I, Group 6. Height $36 \mathrm{~cm}$. Upper Diameter $32.5 \mathrm{~cm}$.

FIg. 2. Pithos of red Monochrome Ware, Polished with a Burnisher and Blackened in Blotches, North Kurgan, Culture II. Height $31.5 \mathrm{~cm}$. Upper Diameter $20.5 \mathrm{~cm}$. 


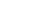



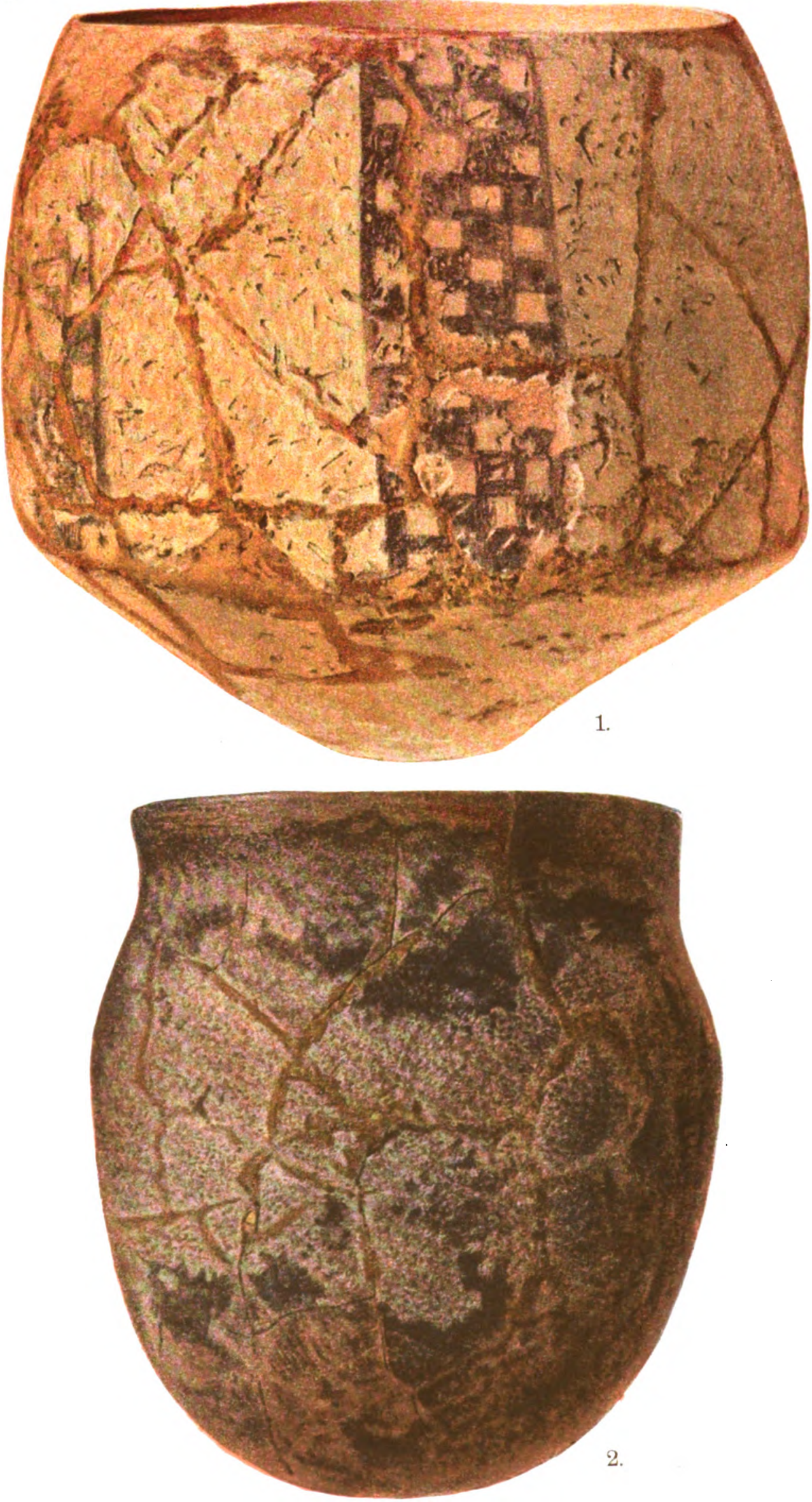

Fig. 1. Pithos characteristic of North Kurgan, Culture I, Group b. Height $44.7 \mathrm{~cm}$. Upper Diameter $40 \mathrm{~cm}$. Fig. 2. Pithos from Middle Strata of North Kurgan, Culture I. Height $38.5 \mathrm{~cm}$. Upper Diameter $30.5 \mathrm{~cm}$. 



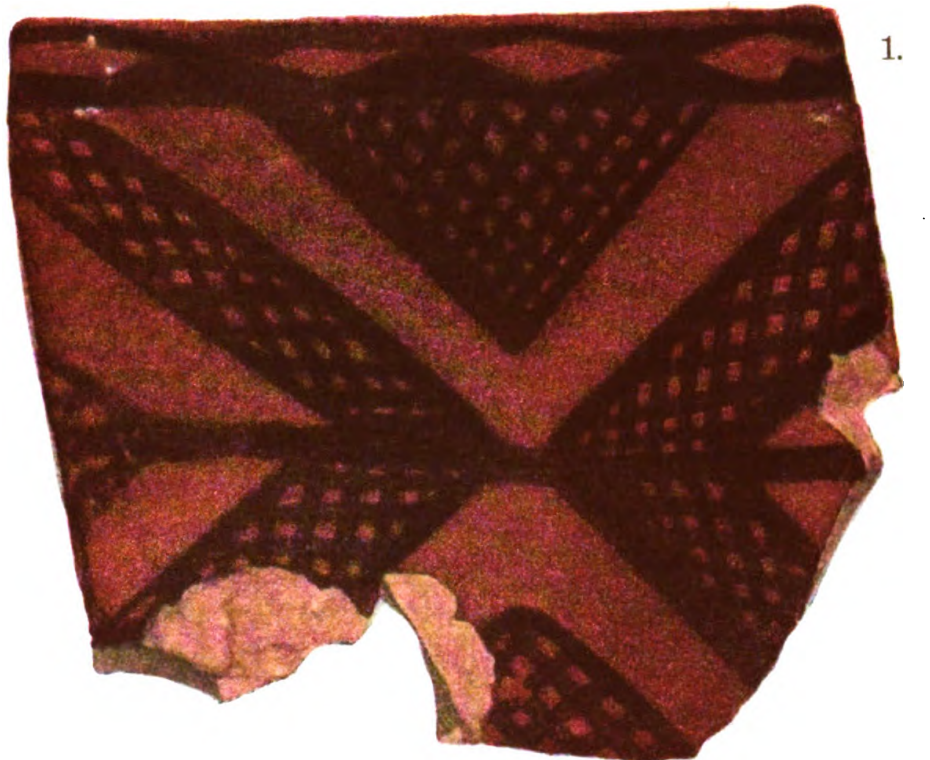

1.
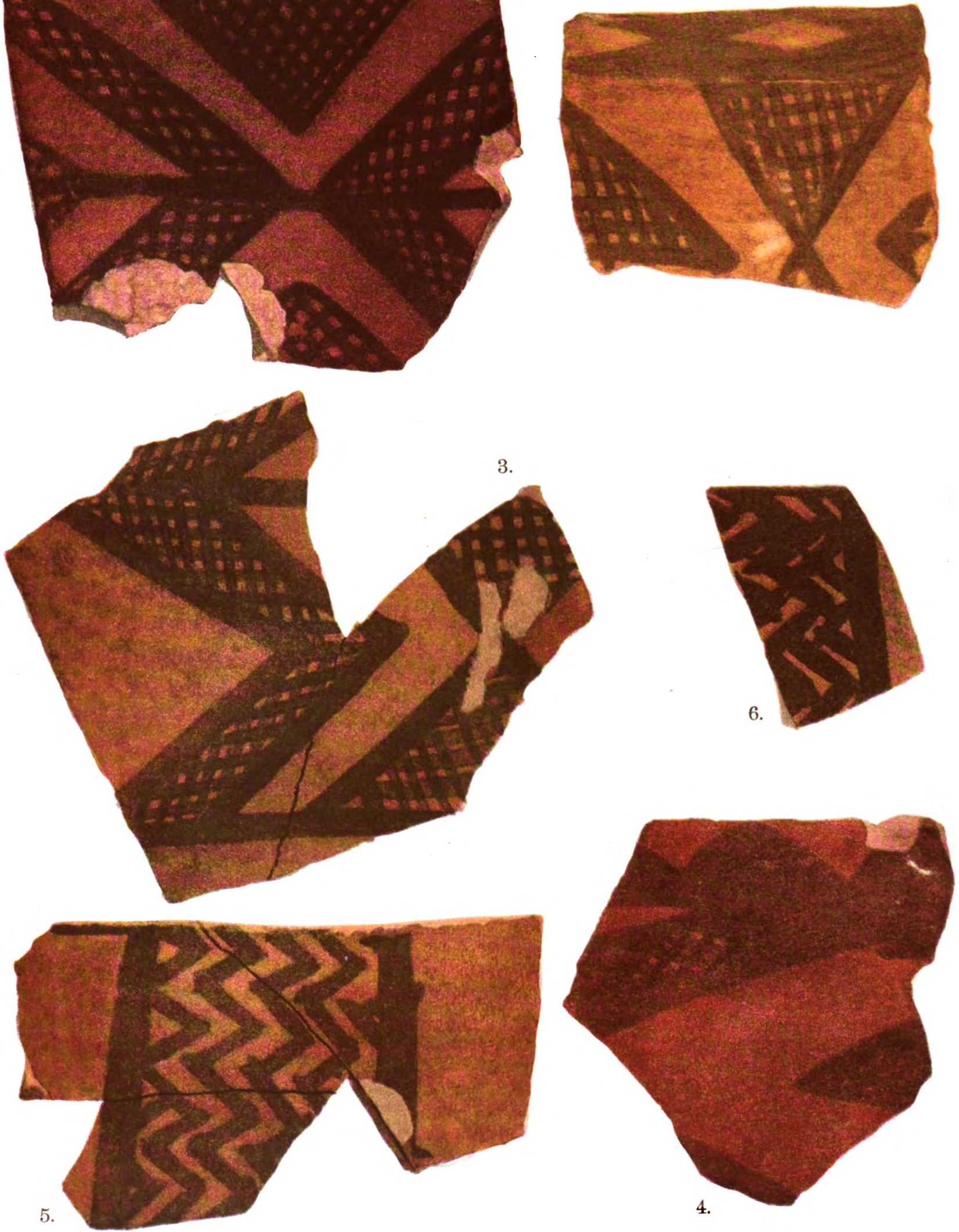

Dersigns on Painted Potrery from Lowest Strata of North Korgan, Culture I.

Figs. 2 AND 3. North Digging II, -13 to -16 feet.

Fig. 5. West Gallery, -14 to -20 feet.

Digitized by 7009 C 
Digitized by Google 


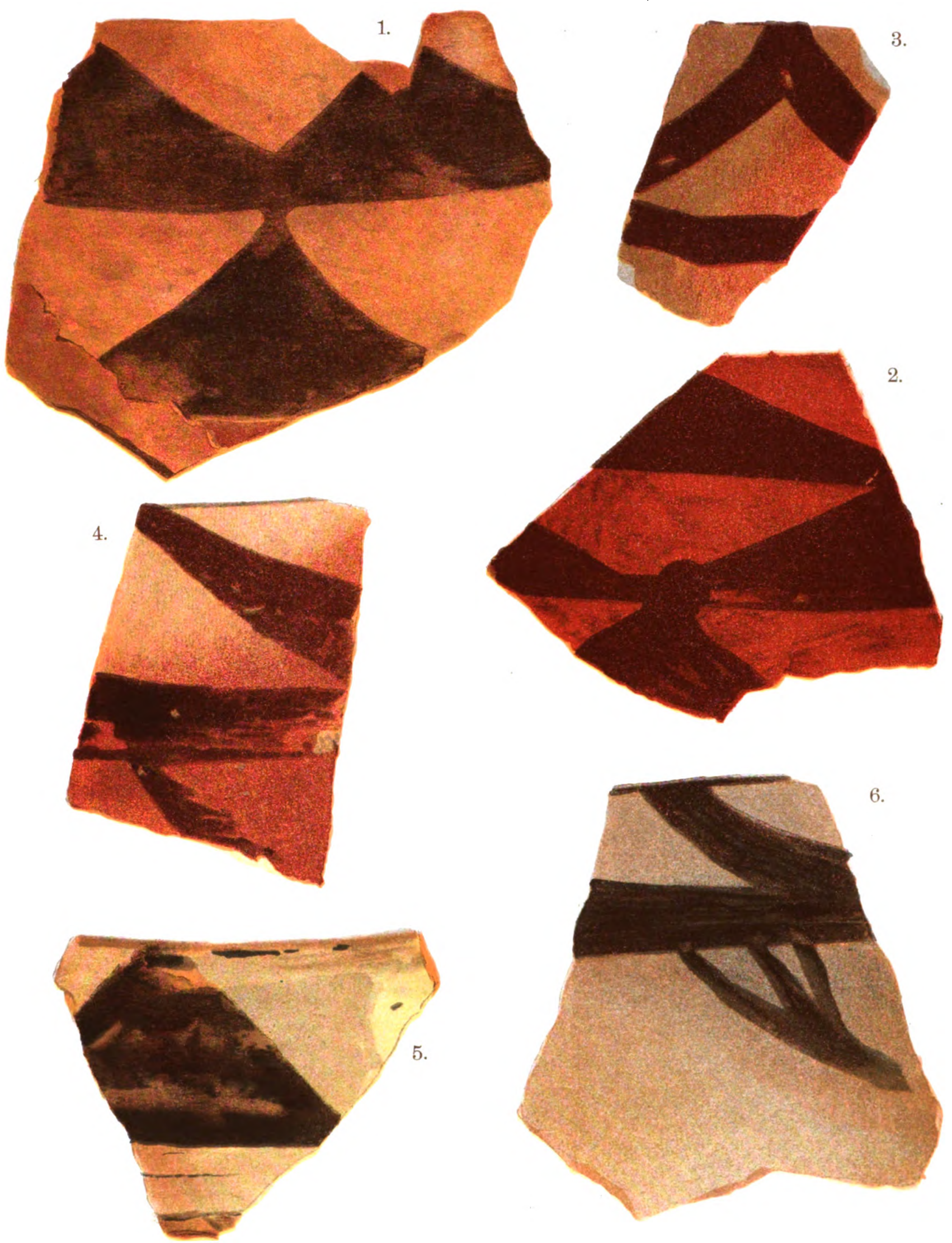

Dhigigs on Painthd Potthry from Mindi.f Strata, Norti kurgan, Cuiturh 1.

FIGs. 1-3. Group $a$, a. FiGs. 4-6. Group $a, \beta$. 
Digitized by GOOgle 
as group $x$ ) are to be distinguished. The remains of this pottery were found on the surface of the top of the hill in terraces I, II, IV, and V, as well as in the upper layers of terraces $I$ to virr, down to an average level of +25 feet.

TECHNIQUE.

Red monochrome vessels. - In the fracture the fragments show a clay which in the interior is gray or earth-colored, and towards the outside light-brown or reddish, or mixed gray and light-brown, according to the firing. Very thin vessels are burnt red throughout. In the washing the clay was strongly impregnated with mica and particles of quartz. The surface was covered with a thin-colored clay slip and polished after the firing. This slip became generally light-red in firing, but not uniform in tone. Brown vessels also occurred. The characteristic feature of the whole family, however, is the flame-blackening or flame-spotting

106
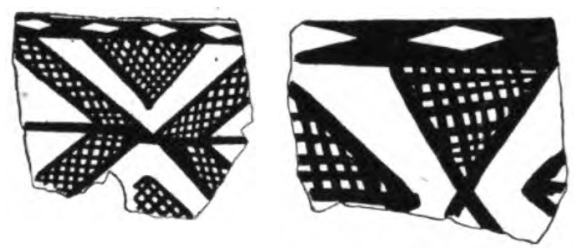

111

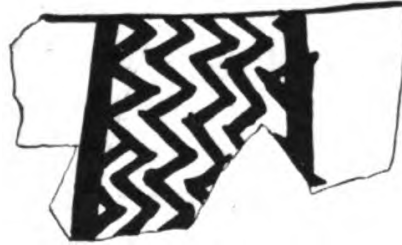

112
107

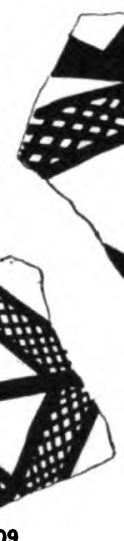

108
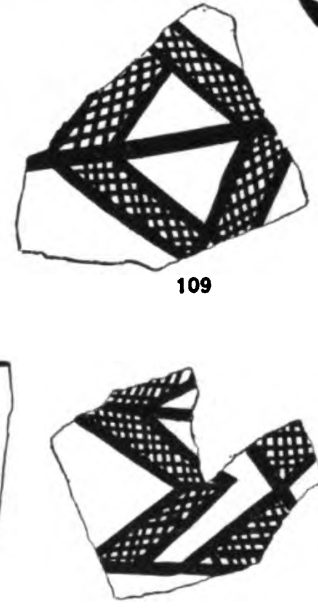

110

(Flaemmung) which shows itself in large black blotches on the surface. This flame-blackening may have had its origin in the method of firing and its imperfection, but it was clearly regarded as a decoration and may at last have been produced intentionally. The interior of the vessels is, as a rule, not flame-blackened (plate 20, fig. 2).

Gray monochrome ware.-The technique of the gray monochrome ware corresponds to the red, but is generally better. The clay is light or dark-gray, well washed for the most part, and much impregnated with white particles. The covering consists of a light or dark-

gray clay slip and is in many instances darker than the color of the clay.

Both groups of vessels were made by hand. In isolated examples of the gray ware with the very well-washed clay and hard burning, there is combined a semblance of wheel-work, but it is impossible to determine this with certainty.

\section{Forms.}

Red monochrome.-Small, delicate vessels, dishes, and deep cups are the predominating forms of the red ware, though larger, thick-walled forms are not lacking. From the lip profiles selected from the great mass of fragments the following series of forms has been compiled. 
(A) Dishes open wide, without marginal profiling (fig. I 14 ).

(B) Cups with different, more or less indrawn, margins, an essential feature being the polishing of the whole interior. Cups are distinguished from each other according to their profiling:

(1) With moderately indrawn lip (figs. 115 and 116 ). Here belongs the feeding-cup, height $6.5 \mathrm{~cm}$., mentioned above (pl. 9, fig. I).

(2) With broken-curved and strongly indrawn margin (fig. 117).

(3) With strongly indrawn lower part (figs. 118 and 119 ).

(C) Forms of vessels, the marginal upper half of which forms a more or less flat cone making at its base a sharp angle with the belly of the vessel; and reducing the size of the opening at the top. It is characteristic of this form that in the interior only the lip is slip-covered and polished (figs. 120-122).

(D) Bottoms and feet: The vessels mentioned under $\mathrm{A}$ to $\mathrm{C}$ show various kinds of bottom or foot-formation:

(1) Flat and somewhat concaved bottoms. Since the inner surface is always wholly covered and polished, this form probably belongs to groups A and B (fig. 123).

(2) High, conical, hollow feet, belonging to groups A, B, or C (fig. 1 24).

(3) High, cylindrical feet, hollow, with wide projecting edges; belonging to $A$ and $B$ (fig. 125).

(E) Larger-bellied vessels or kettles, with various kinds of lip form (figs. 126 and 127).

Gray monochrome. - The forms of the gray monochrome ware agree in almost all of these cases with those of the red. Thus we find in gray clay similar profiles to those shown in figs. $115,116,119,122$, and 125 . The high columnar feet, however, have occurred thus far only in the gray clay, and the technical characteristics, as well as certain peculiarities of form found in this gray pottery, point to a more

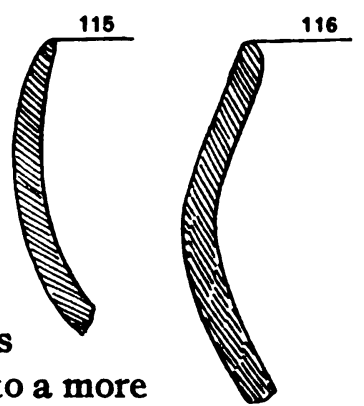
developed stage; as, for example, profiles of vessels in figs. 128 and 129, where fine horizontal ribs are combined with traces of wheel technique. It is possible, therefore, that the gray pottery reached a higher development than the red and remained longer in use. But their similarity in form, as well as in the circumstances under which they are found, point to the long-continued coexistence of the two families.

\section{Ornamentation.}

The greater part of the red and gray fragments are not ornamented. Only two pieces-lip-pieces of cups with similar profile, as fig. I1 5 -prove the existence of a very simple incised ornamentation, a form of technique which is wholly wanting in the pottery of culture I (see plate 9, figs. 2 and 3 ). Besides the better and more artistically made monochrome pottery, there were found also the remains of a coarse service ware of gray or brown clay. The forms, probably large kettles, are shown in figs. 130 and 131 .

The bake-ovens and kettles found in terraces $I$ and $\mathbf{v}$ are coarse examples of group a. It remains doubtful to which group the small vessel (height $5 \mathrm{~cm}$.) 
represented in plate 9 , fig. 4 , is to be referred. Its form would connect it with the cups with columnar feet, but the clay is light-brown and red without a slip. It was found among the "mixed" pottery in terrace $v$.

In contrast to the conditions in culture I, the painted pottery is very much less represented than the monochrome. Before we enter upon a more detailed treatment of the painted ware, however, we have to attempt an explanation of its presence, for it occurs, together with the monochrome pottery, in the mixed layers in which remains of the older pottery have also found a resting-place. On what grounds, therefore, can we associate the painted pottery with the monochrome in the upper strata? We are justified in so doing by the rule that those fragments belong to the younger culture which do not occur in the middle and lower strata of the hill, that is, in the pure deposits of the older culture I. This rule must apply to the monochrome as well as to the painted ware. As a matter of fact, painted fragments were found in the upper strata which are so very different in technique and ornamentation from those of groups $a$ and $b$ of the older pottery that their origin must be different also; and since they do not occur in the middle and lower strata, they must be younger.

The Younger Painted Potrery.

The younger painted pottery was found principally in terrace $v$, between +36 feet and +37 feet (April I to 4 , 1904). In the description of the excavations it is designated as $z$ and $v$. Some few fragments also lay on the surface of terrace I (March 25-26, 1904): These are to be classified as vessels decorated (I) in one color; (2) in several colors.

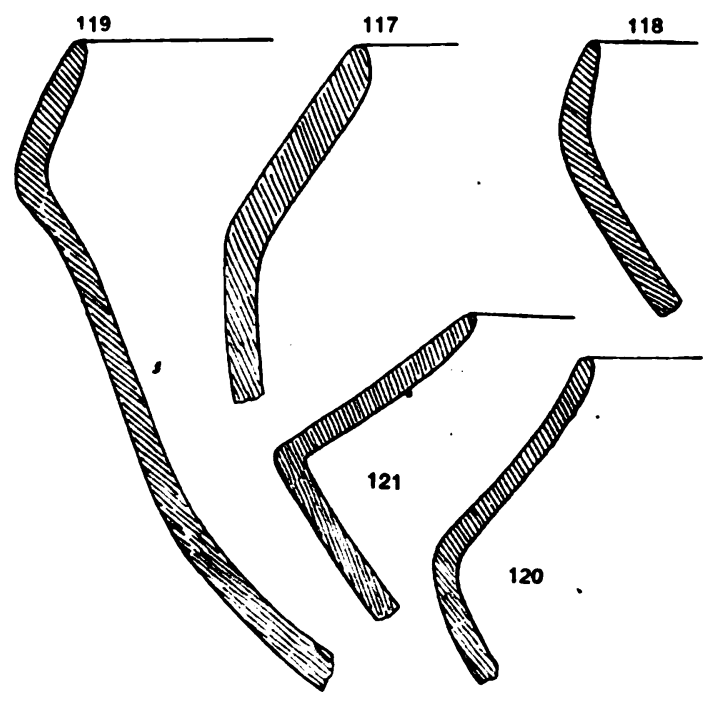

(I) Those painted in one color can be further divided into four groups:

( $\alpha$ ) Clay gray, brownish on the edges; painting dull-black on a red burnished slip (plate 32, fig. 3).

(३) Clay rose-yellow, porous; painting dull-black or blackish-brown on whitish-green slip, without burnishing (plate 31, fig. 3).

( $\gamma$ ) Clay reddish-brown, porous; painting dull-black on light-brown clay ground without slip or polish (plate 32 , fig. I, and plate 33 , fig. 5).

(b) Clay whitish-green, fine-washed; painting dull-black on a smooth clay ground without slip or polish. Transitional group to the pottery of the South Kurgan (plate 31, fig. 4, and plate 32, fig. 2).

Technically these groups are undoubtedly connected with the older painted pottery of culture I; group $\beta$ especially recalls, in clay and slip, the older variety made of light-colored clay. Group $a$ connects itself with the red monochrome vessels of the upper strata, while in group $\delta$, the quality of the clay and the technique show points of resemblance to the pottery of the younger South Kurgan. 
As regards ornamentation, however, we find evident progress when we compare the fragments of this pottery with specimens of the older pottery. In order to give a better idea of this development, I have brought together the characteristic patterns in black-and-white drawing (figs. 132-140). The ground motifthe erect triangle-shows the influence of the older pattern scheme, but the later composition is much richer and more varied. The triangles not only show more varied combinations in horizontal, oblique, and vertical arrangement, but they combine also with other horizontal, oblique, and vertical systems of lines. Fig. 135 exhibits a developed metope band, with a cruciform interior pattern. Equally new and peculiar is the ornamentation on the fragments, figs. 138-140.

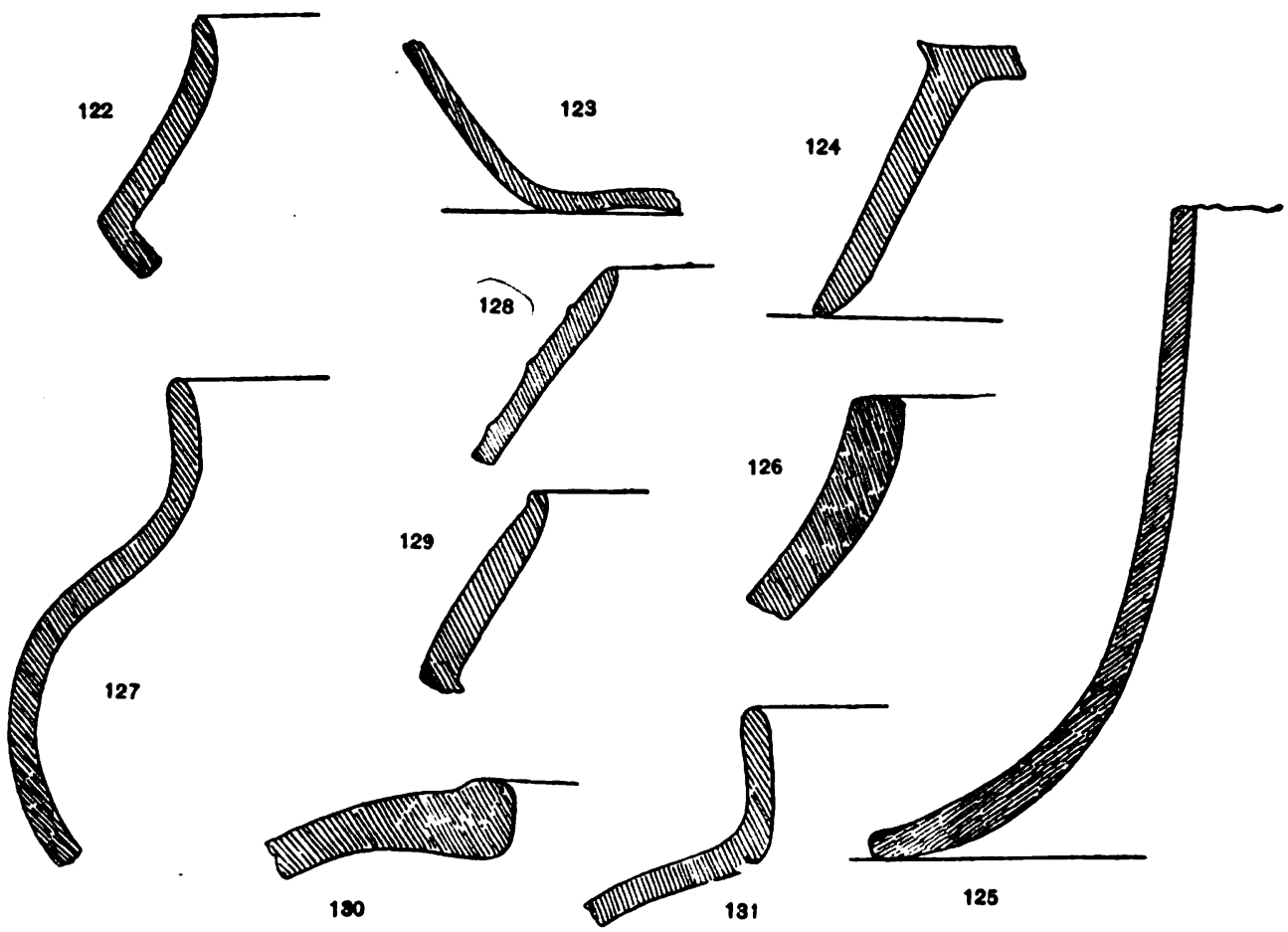

(2) The polychrome painted vessels lie completely outside of the ceramic development of cultures I and II and seem to have been imported from a more distant culture-center. They consist of marginal pieces of dishes without profiling and the fragment of a vessel with a high, steep lip. Some of them are made of gray-brown, porous clay with a yellow, finely-smoothed slip and dead black and dark-red ornamentation (plate 32 , fig. 4; plate 33, fig. 2). Similar to this is the fragment shown in plate 33 , fig. 3 , except that in this instance the ground clay is dull. The two remaining fragments (plate 33 , figs. I and 4) are of greenishwhite clay. In figure 4 the colors are violet, light-gray, and reddish-yellow, laid on very thin. In figure $I$ the white is not the result of painting, but is due to a deposit of salts, which often appears on the surface of antique vessels. The decorating colors are black and red on a ground of greenish-yellow clay. 
If, now, we compare the pottery of the upper strata with the older pottery from the middle and lower strata, we find a complete revolution in custom and taste. The sharper such contrasts appear the more the question arises: Was the evident revolution a sudden one, and is the contrast absolute? Were there lines of connection between the older and younger cultures? Was the revolution accomplished gradually, technique and forms changing with the change in taste? These questions are all the more important for the reason that on their solution depends another question: Does the appearance of a new pottery signify a new settlement? Was the new pottery brought by a new people who took possession of the place after the disappearance of the former inhabitants and their culture? It is not possible to answer these questions wholly satisfactorily from the
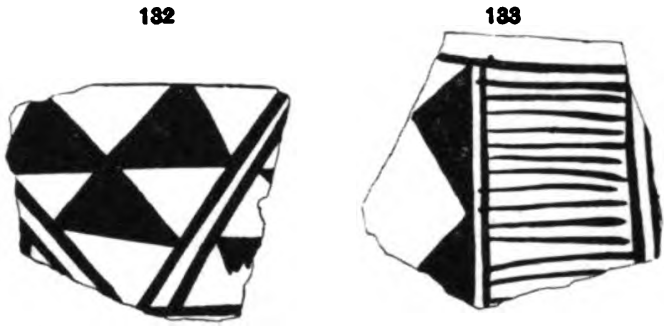

187 material thus far obtained, but I have already remarked that as regards technique and ornamentation it is possible to speak of points of contact and relations between the older and the younger pottery. More can be said when the strata of the North Kurgan, particularly the upper ones, shall have been opened up to a greater extent.
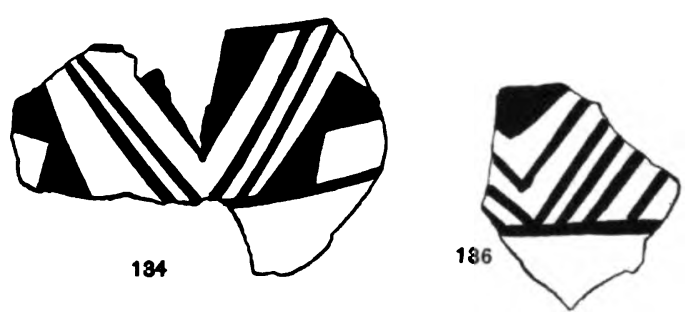

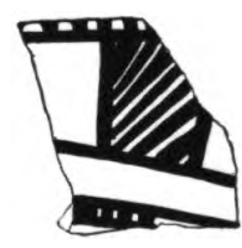

188

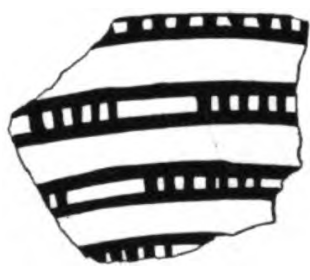

189
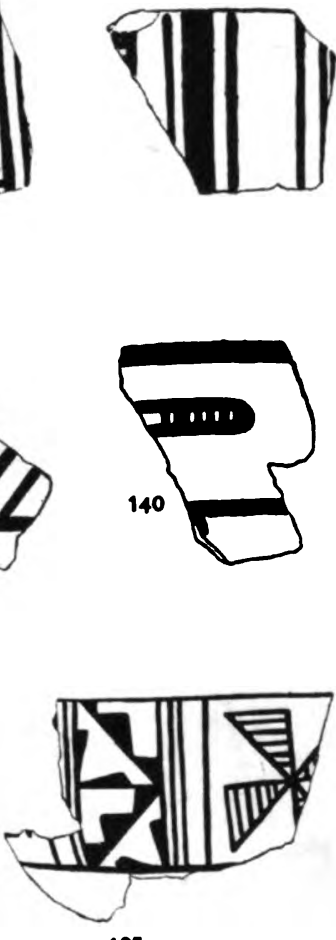

135

\section{POTTERY FROM THE SOUTH KURGAN.}

MIDDLE STRATA, CULTURE III.

The South Kurgan was investigated on a different plan from that pursued in the case of the North Kurgan, but with similar limitations as to area of excavation in the deeper strata. Here too, then, we obtain in the study of the middle strata a good point of view from which to judge the upper and the lower strata. The middle strata extends from a horizontal line drawn between +40 feet and +37 feet downward to the level of +18 feet, to which terraces $B$ and $C$ were sunk. As already remarked, in these deposits of not less than 20 feet thickness, similar objects were found; therefore they belong to one and the same culture epoch, 
which with the number III we will distinguish from that of the North Kurgan. The pottery (groups 3 to 5 mentioned above) falls into three groups of the finer technique, to which is added a fourth group, consisting of coarse service vessels.

(a) Light-COLORED CLAY.

Technique.-In most cases the clay has a gray-greenish or whitish-green color, always in a light tone; greenish-yellow or light-yellow clay also occurs. Now and then a fragment is yellow in the fracture and of a greenish shade on the surface; otherwise the surface corresponds to the fracture. I will remark here that the clay is seldom reddened through firing, in contrast with the pottery of the upper layers, where the vessels made of red clay have an entirely different character. The firing is never so firm and hard, even to brittleness, as that of the pottery of the upper strata. Otherwise, however, the technique stands at the

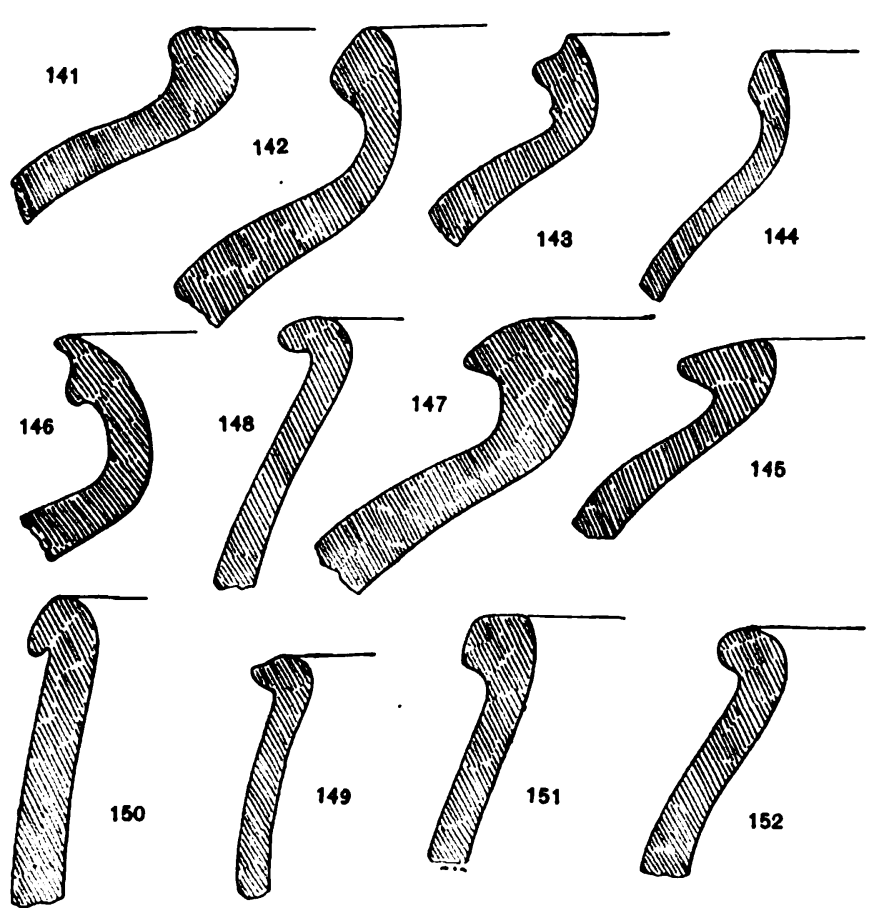
height of development-the very fine-washed clay is always turned on the wheel, hand-work in this material being an exception. Thinwalled cups of very fine quality show to what perfection the wheel technique was brought.

Forms.-The forms correspond in superior quality to the technique and are very rich. We have only a few whole vessels, but the great mass of the pottery fragments yields the following series:

(A) Large, kettle-shaped vessels with narrow mouths and simple profiles (figs. 14I-147). An entire vessel, height $34 \mathrm{~cm}$., is shown in plate Io, fig. I. Its lower part is sharply set off from the belly and drawn in with an arched form peculiar to the larger vessels of this pottery.

(B) Larger and smaller deep cups with wide mouth (figs. 148-152). A vessel, height $7.2 \mathrm{~cm}$. in contour, is shown in fig. 153, and plate 10, fig. 2 .

(C) Fine and, in part, very thin-walled bowls, with more or less sharp profiles (figs. 1 54-160). A broken piece, height $9.5 \mathrm{~cm}$., is shown in plate 10, fig. 3. These forms all show high feet (see below).

(D) Thick-walled dishes with various lip forms (figs. 161-165).

(E) Beakers, in part very fine; thin-walled, and in different forms, some delicately curved, others with walls bent back (figs. 166-168), or with fine horizontal grooves as in fig. I69. Broken specimens, height I1.2 to 13.6 cm., on plate $1 \mathrm{r}$, figs. $\mathrm{I}-3$. 
(F) High cylindrical feet, projecting far, in part with rich profiles; they belong to the fine bowls, C (figs. I 70-1 73). Broken specimens on plate I I, figs. 4-6.

(G) High, hollow feet, into which the walls of high vessels merge; very characteristic of the light-colored clay pottery of the middle strata (fig. 174). Broken specimen on plate 11 , fig. 7 .

(H) Vessels with spouts. This spout is either in the form of a depression on the lip of the vessel or a beak-form on a special tube; or is simply in the form of a nozzle, as in vessels intended for pouring (figs. 175-177). A whole vessel of this form, reproduced on plate 12, fig. 1, lay in terrace B at the level of +23 feet 5 inches.

(I) Service vessels or pithoi standing firmly embedded in the earth, with profiles like the large kettles (figs. 178-181). Of these there are fragments of pithos
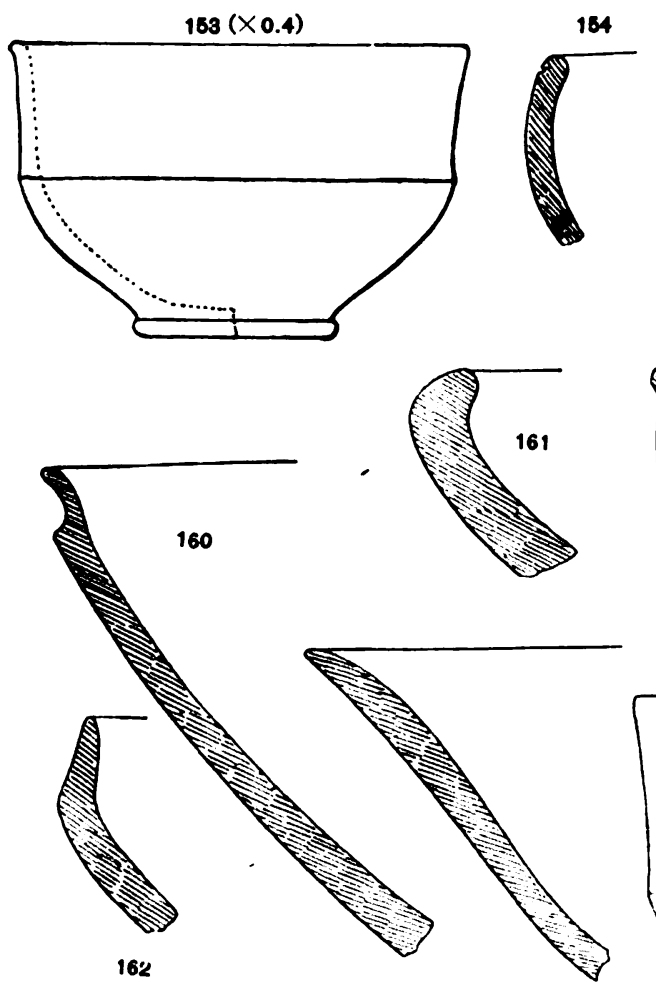

159

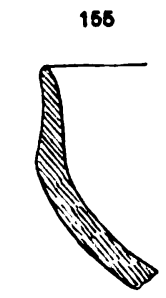

166
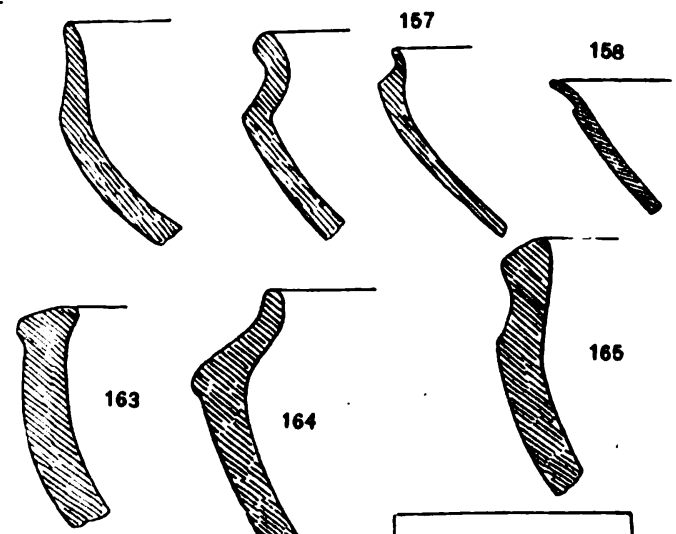

165

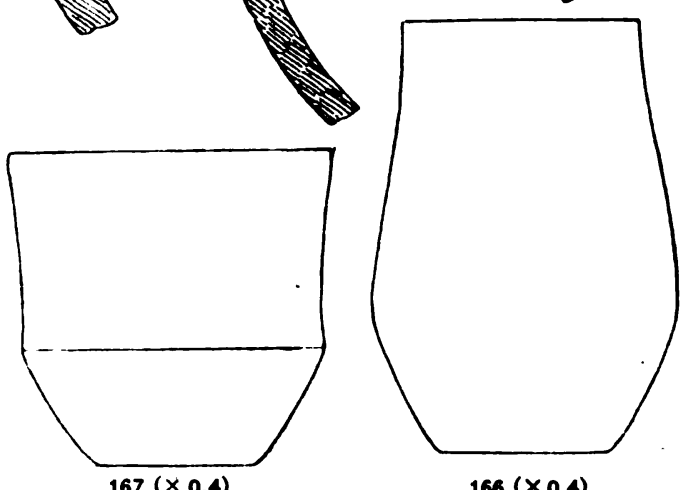

$a$, fig. 179; of pithos $b$, fig. 180; and of pithos $c$, fig. 181, all from the upper digging. The lip-piece of a tray-like.vessel is given in fig. 182 (see plate 19).

(K) Stands for larger vessels, open both above and below (figs. 183 and 184). The last-mentioned specimen has a cruciform pattern incised in the outer surface. The smaller stand comes from the upper digging between +25 and +33 feet; the larger one from terrace $B$, between +31 and +23 feet. No other examples of this form were found.

(L) Isolated forms. Among the burial gifts of skeleton No. 23 in terrace B, there was found, besides the above-mentioned cup (plate 10, fig. 2) an eggshaped vessel like a bottle, with a narrow neck (plate 12, fig. 2), height $13.2 \mathrm{~cm}$. A pear-shaped bottle, of which the neck was broken off, height $15.1 \mathrm{~cm}$. (plate 12,'fig. 3), was presumably also a burial gift, as it lay 
feet. In the same shaft, at a depth of - ro feet, there were found hollow footpieces like fig. 174; cylindrical pieces like fig. 170 between -4 and -5 feet; also lip-pieces of fine beakers and bowls, like figs. 159, 160, 166-168, from the same shaft between -9 and - I I feet.

Indeed, the finds of the deeper strata partly complete the scale of the pottery forms found in the middle strata. Here belongs the lip-piece of a steep-walled cup with sharp horizontal grooves, fig. 190, from shaft $A$ between +1 and +2 feet, and the lip-piece of a bowl with wide horizontal grooves (fig. 191) from the same shaft.

(b) GraY WARr.

In the lower layers there occurred also gray ware of the same technique as above. Thus, fragments of the fine group with incised ornaments were found in shaft $A$ between $+I$ and +2 feet, together with the marginal piece made from
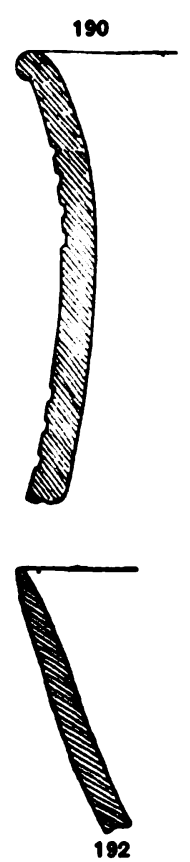
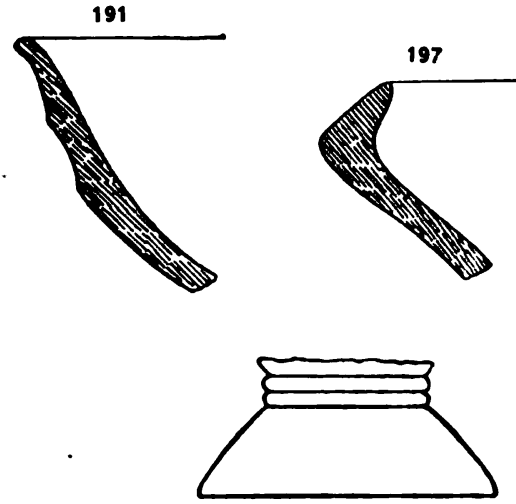

$194(\times 0.4)$
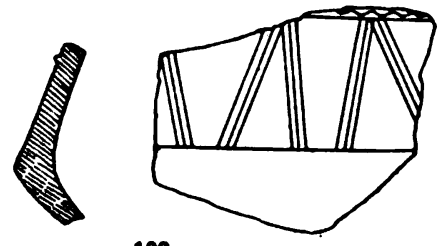
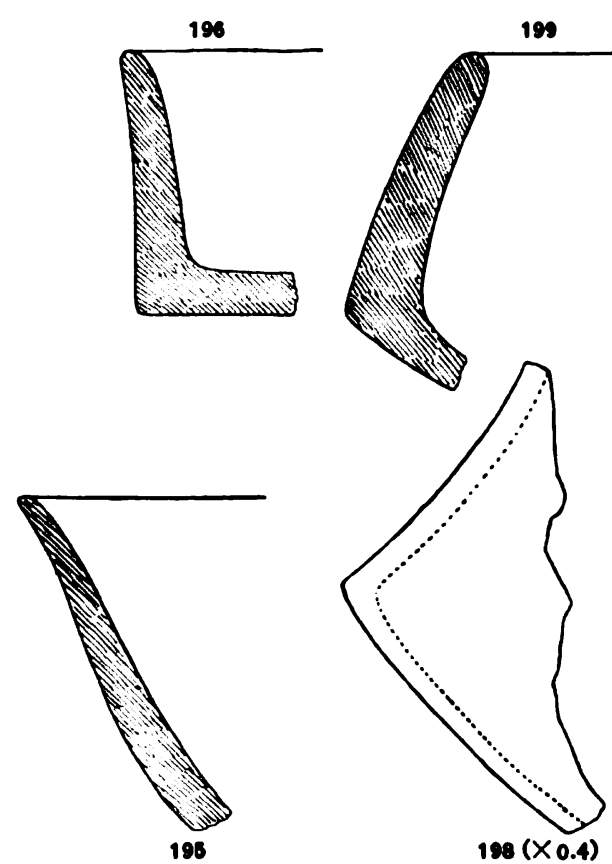

light-colored clay mentioned above (plate 16, figs. I and 2, with their profiles, figs. 192 and 193). From shaft $C$, at a depth of -16 feet to -17 feet 5 inches, came foot-pieces of beakers similar to those observed in terrace B (fig. 194). A lip-piece, like fig. 195 from -6 feet in shaft $\mathrm{C}$, corresponds to the simple dishes of the light-colored clay pottery.

Some new forms are shown in broad, steep-walled cups with flat bottoms, like fig. 196, from different levels of the same shaft $(-7$ and - I I feet to -12 feet 5 inches), perhaps imitations of stone vessels; and a dish with a low lip sharply bent back, like fig. 197, from -6 feet of the same shaft. Another new form is a vessel with sharply bent back wall, as in fig. 198, the profile of which resembles the red or gray monochrome pottery of the North Kurgan. 


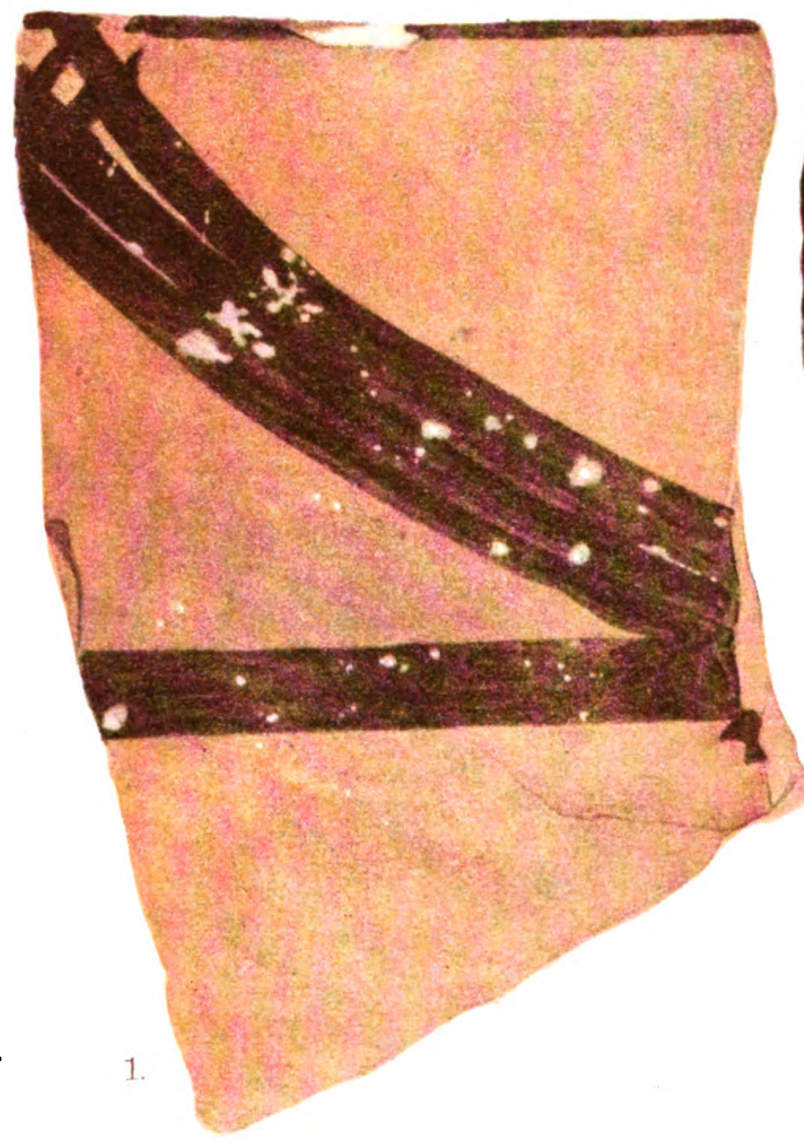

2.
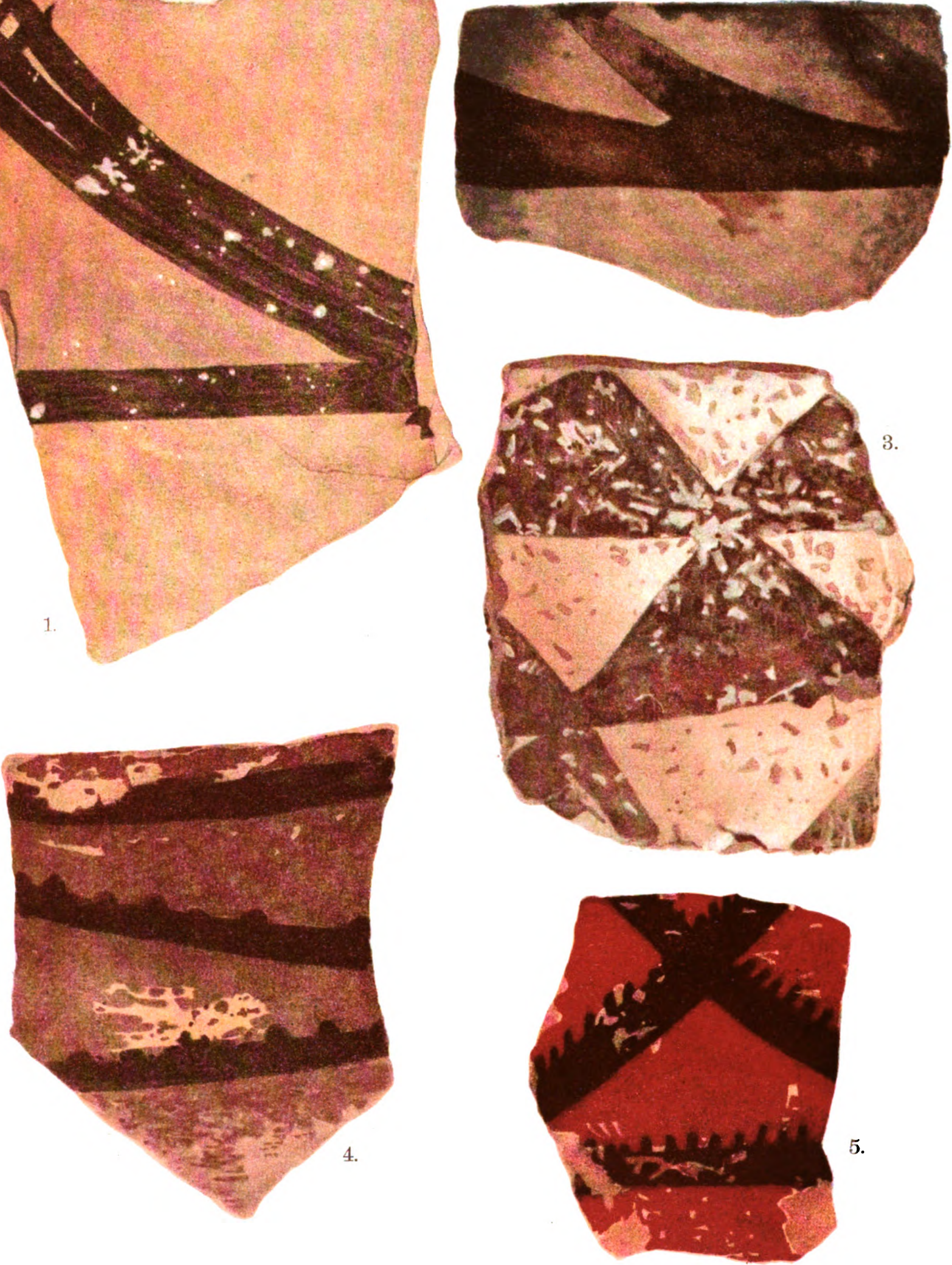

dfigigs on Painted Potrery from Middle Strata, North Kurgan, Culture i.

Figs. 1 AND 2. Group $a, \beta$. Fig. 3. Group $b$. Figs. 4 AND 5. Group $a, \gamma$. 
.

Digitized by Google 


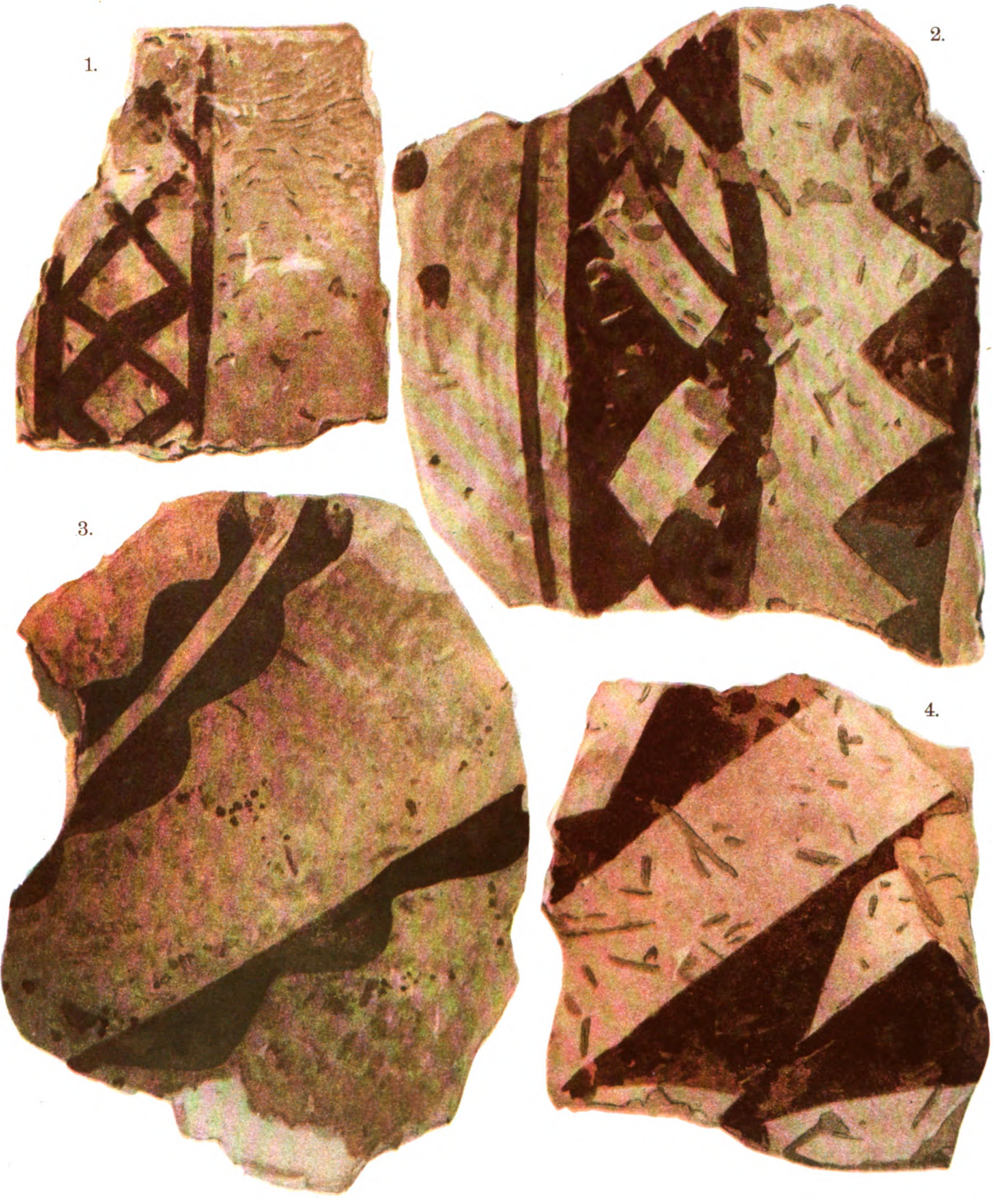

Designs on Painted Potthry from Middle Strata, North Kurgan, Cul,ture i, Grodp $b$.

FIG. 1. Terrace $I,+25$ feet. 
Digitized by Google 

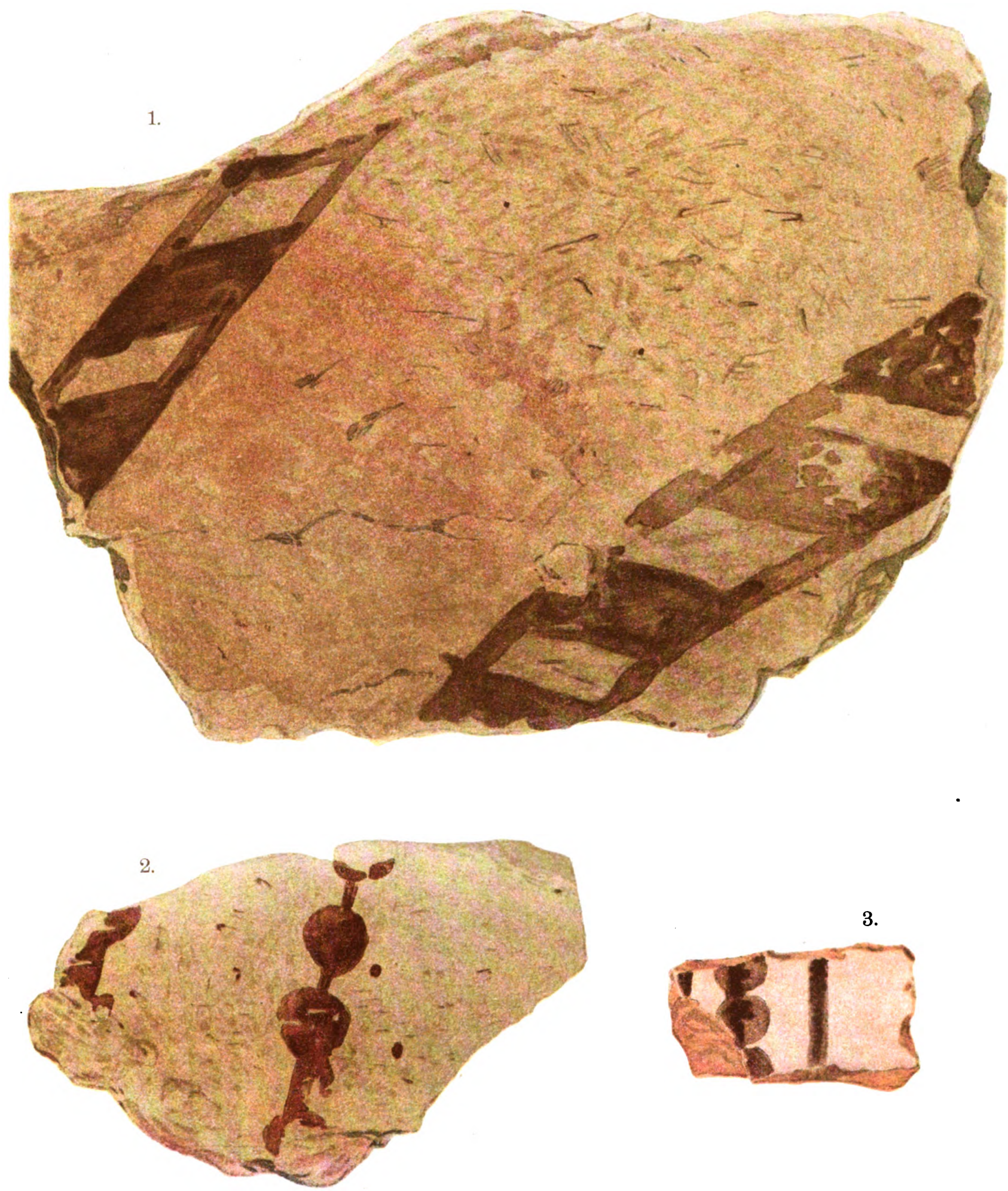

3.

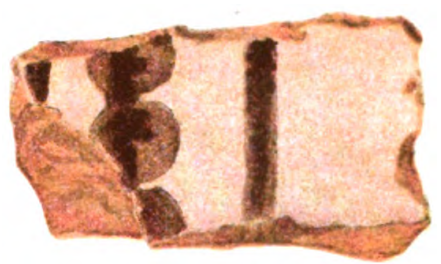

Designs on Painted Potthry from Midde Strata, North Kurgan, Culture I, Group $b$.

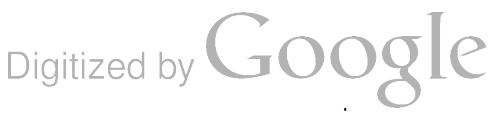




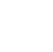




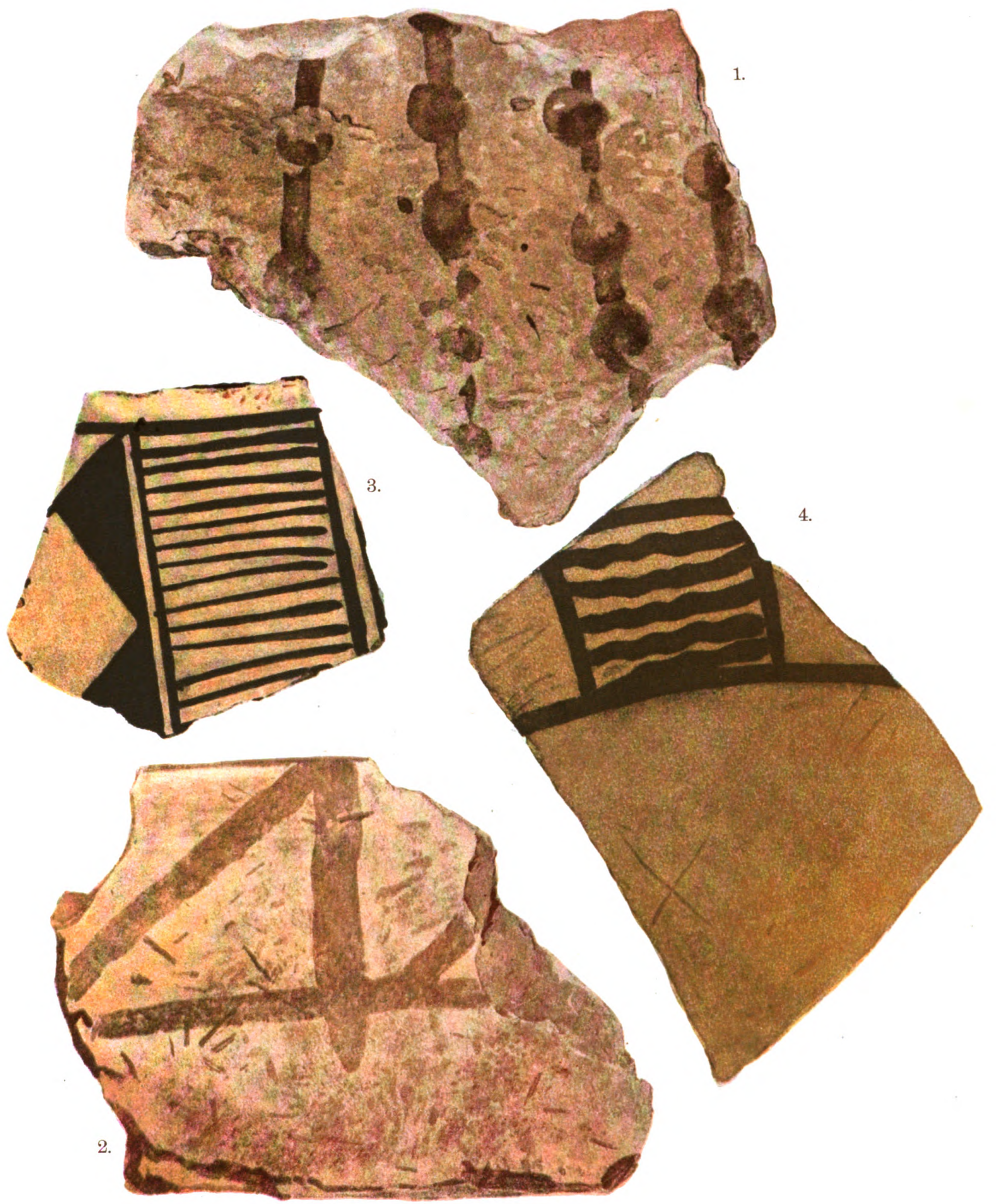

Dhsigns on Painted Potrery from North Kurgan. 

Whether these forms may be considered as prototypes of the more highly developed gray pottery can not be determined at the present stage of the investigation. In any event, the gray pottery of the lower layers must be connected with the gray ware described above, fragments of which were first found, in surprising quantities, at about +40 feet in the upper digging.

The classification of the red pottery is more difficult. We have thus far not encountered it in the lower strata of the South Kurgan, except that on April 20, 1904, in shaft A, good red pottery with a slip covering was found at - 44 feet 5 inches, together with gray pottery and ware of light-colored clay. Since it was wholly lacking in shaft $\mathrm{C}$ of the upper digging, however, it is desirable to leave open the question of its really belonging in the lower strata. On the other hand, very interesting specimens of painted pottery were also found in the lower strata.

(c) PanNtead Vesseils.

Here belongs a find from -14 feet 5 inches in shaft A, made on April 20, 1904. This consisted of numerous fragments of several (certainly two) painted vessels of fine brown clay, not very hard burnt, but quite characteristic. One part belongs to a thick-walled dish with high, sharply bent back lip (fig. 199). This form was found in similar technique in terrace $C$, between +19 feet 5 inches and +21 feet 2 inches, and also in terrace $A$, between +27 and +31 feet. The ornamentation, in broad vertical strokes, is placed upon the border as in plate 34, fig. 2. Other fragments of this find belong to the shoulder of a large pitchershaped vessel with a narrow mouth. The decoration has a peculiar naturalistic motif, a tree or branch pattern alternating with groups of vertical lines-a kind of metope decoration (see plate 34, fig. I). Other specimens of this painted pottery (plate 34, figs. 3-5) came from shaft $\mathrm{C}$, between -16 feet and -17 feet 5 inches.

(d) InCised ORnamgantation.

Gray ware with incised ornaments has already been mentioned as found in deep layers. Here I would call attention to a tendency to spiral ornamentation. There are indications of this on both sides of a fragment in fine brown clay from shaft $A$, between +2 feet 2 inches and + I I feet (plate 16, figs. 3-5) from mixed layers. Thus the painted as well as the incised ornamentation of the lower strata resembles, both in technique and form, the pottery of the middle strata. This close similarity increases the significance of the large walls, which were exposed in terrace $B$ at +20 feet. They point to an important establishment of which the floor-level is to be sought, as it probably lies still deeper than the level which we there reached.

POTTERY OF THE UPPER STRATA, CULTURE IV.

In the light of the investigation and its results, the upper strata of the South Kurgan extend downwards to a horizontal plane lying between +37 feet 7 inches and +40 feet, and parallel to this development runs that of the plateau forming the northern extension of the kurgan. The pottery here is distinguished both 
in form and technique from that of the middle and lower strata. We have, therefore, to refer it to a younger culture, which we will call IV to distinguish it from the three older cultures. Two different groups of pottery are distinguishableone turned on the wheel and the other made by hand.

\section{(a) WHEEL-WORK.}

Technique.-Judging from its technique this youngest pottery of the kurgan at Anau was intended for common use, but it meets all the requirements of a perfected wheel technique. Consequently its technical characteristics are to be
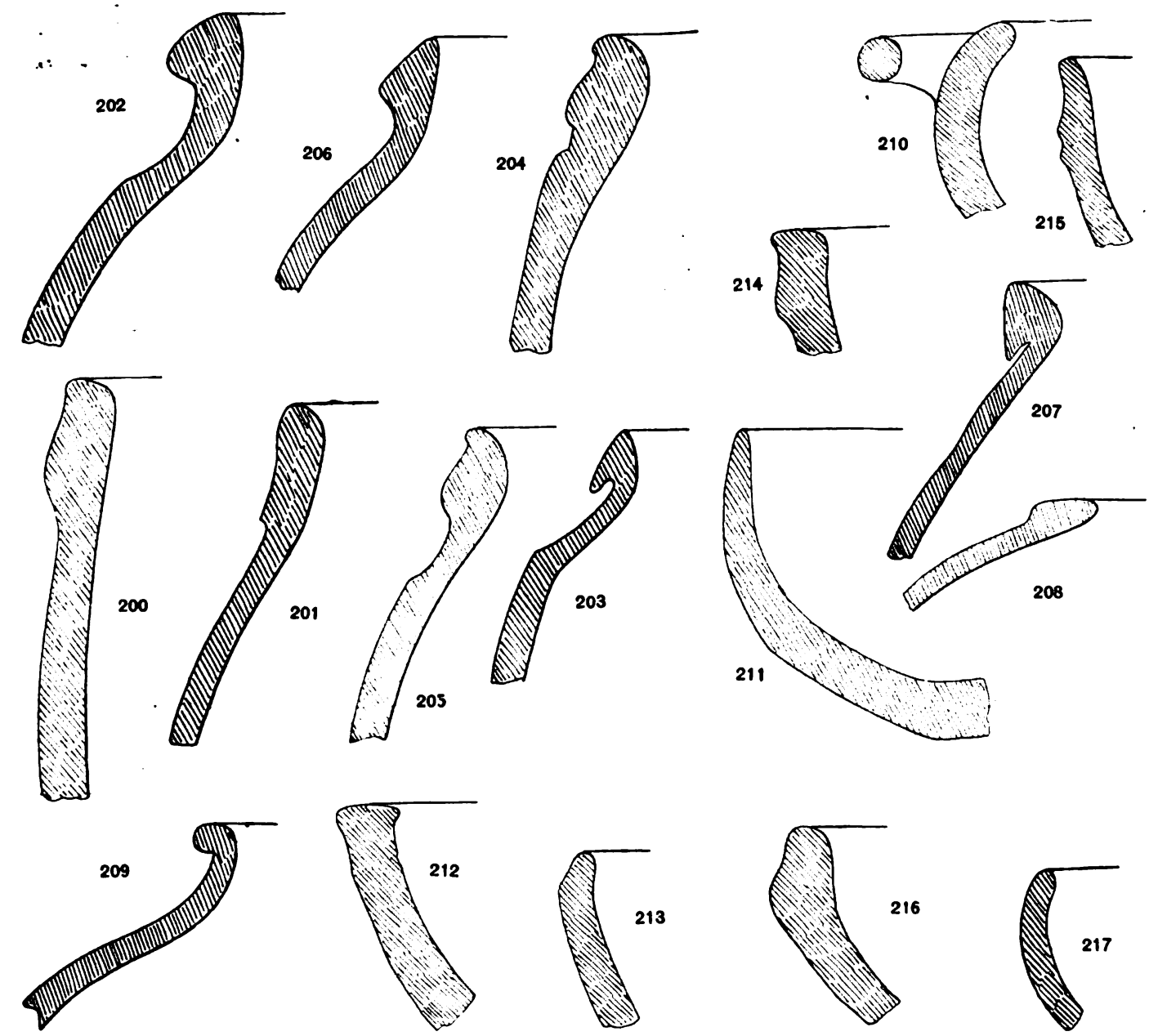

brought sharply into relief in comparison with the pottery of the middle strata; all the more so since the latter is the highest achievement in wheel technique. The clay is equally well prepared, but is burnt much harder and is more brittle than in the older ware. For the most part it is red, at times passing into a yellowish tone. It lacks, therefore, the numerous shades present in the older pottery. The exterior is generally covered with a very thin white or greenish-white slip. In bowls and cups we often find the interior covered with a thin red color. In 
some instances the white slip is present only as a band around the middle part of the belly of the vessel, as in the vase (height, $19.5 \mathrm{~cm}$.) represented in plate 17, fig. 1, which was found 24 inches below the surface at the outer digging.

Forms. - The series of forms of the youngest pottery is not inferior in diversity to that of the older. By means of the marginal pieces the following forms can be distinguished, and in each case they can be compared with the corresponding older form:

(A) Large, kettle-shaped vessels with sharply profiled lips (figs. 200-207).

(B) Smaller vessels of similar form, with both narrower and wider openings (figs. 208 and 209). A whole vessel of the kind from the outer digging has already been mentioned.
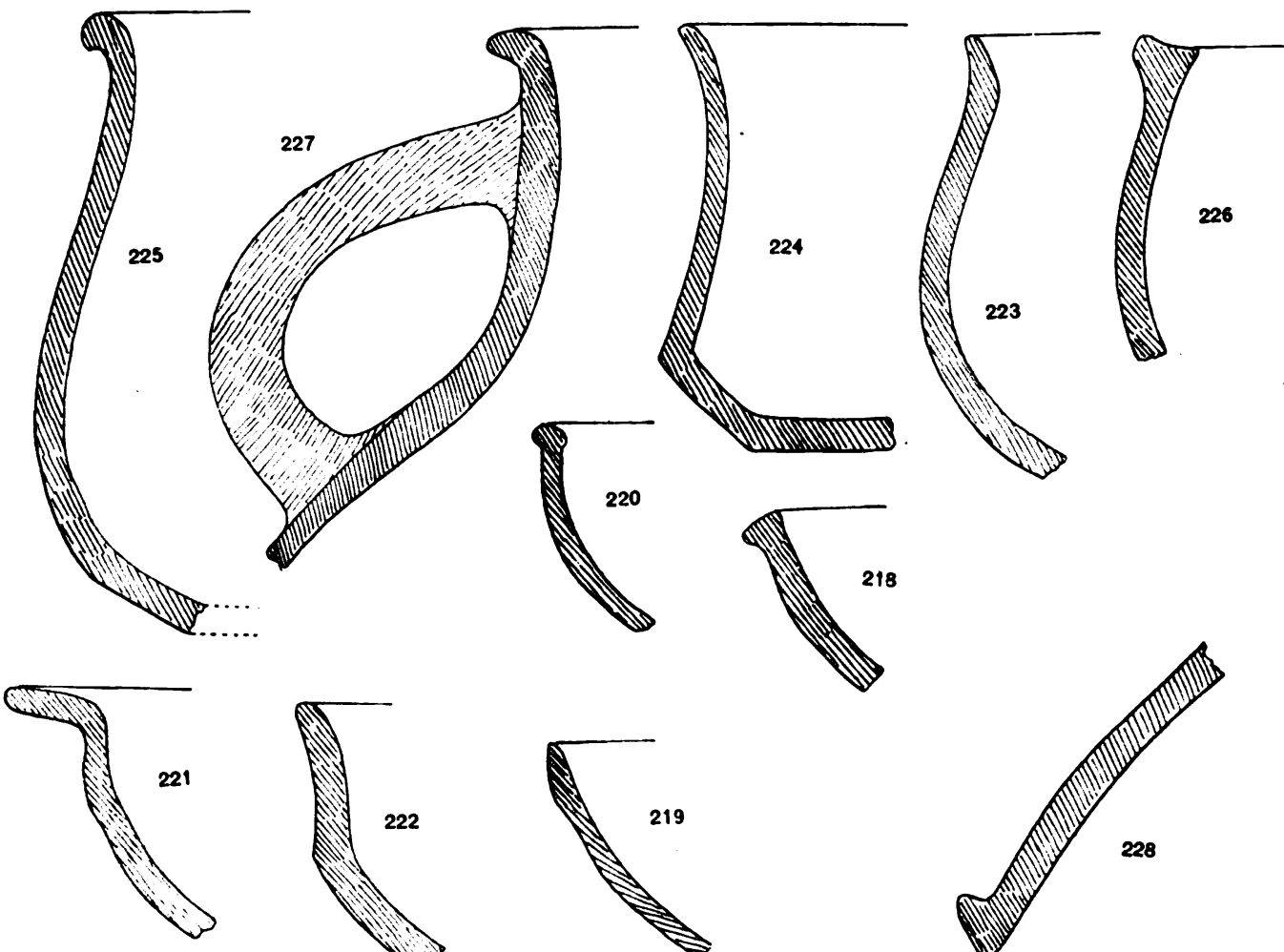

(C) Large, thick-walled dishes with different margin-profiles. Their bottoms are flat without feet. In some instances they have horizontal bow-shaped handles. The interiors are generally colored red (figs. 210-216). It is worthy of remark that handles are entirely foreign to the forms of the older pottery.

(D) Finer bowls with varied forms of margins. In these, too, the interior may be colored red (figs. 217-222).

(E) Deep cups, some with arched, and some with sharply bent backs and sides, and flat bottoms. They occur in various sizes, with either wide or narrow mouths (figs. 223-226). A broken piece of a cup with a sharply bent side is shown in plate 17 , fig. 2 . It is well in this connection to compare the corresponding forms of the older pottery, which may stand as prototypes. 
(F) Pitchers with handles (fig. 227). Hitherto this form has not been found at all in the older pottery.

(G) Stands 'or supports, with indrawn sides and projecting margins (figs. 228 and 229). Here, too, a comparison with the corresponding forms of the older pottery is very instructive.

(H) Thick-walled service vessels (pithoi), like figs. 230-232, and similar widemouthed kettles, as in fig. 233. In this category belongs the pithos found in situ in the outer digging (see plate 19, fig. 5).
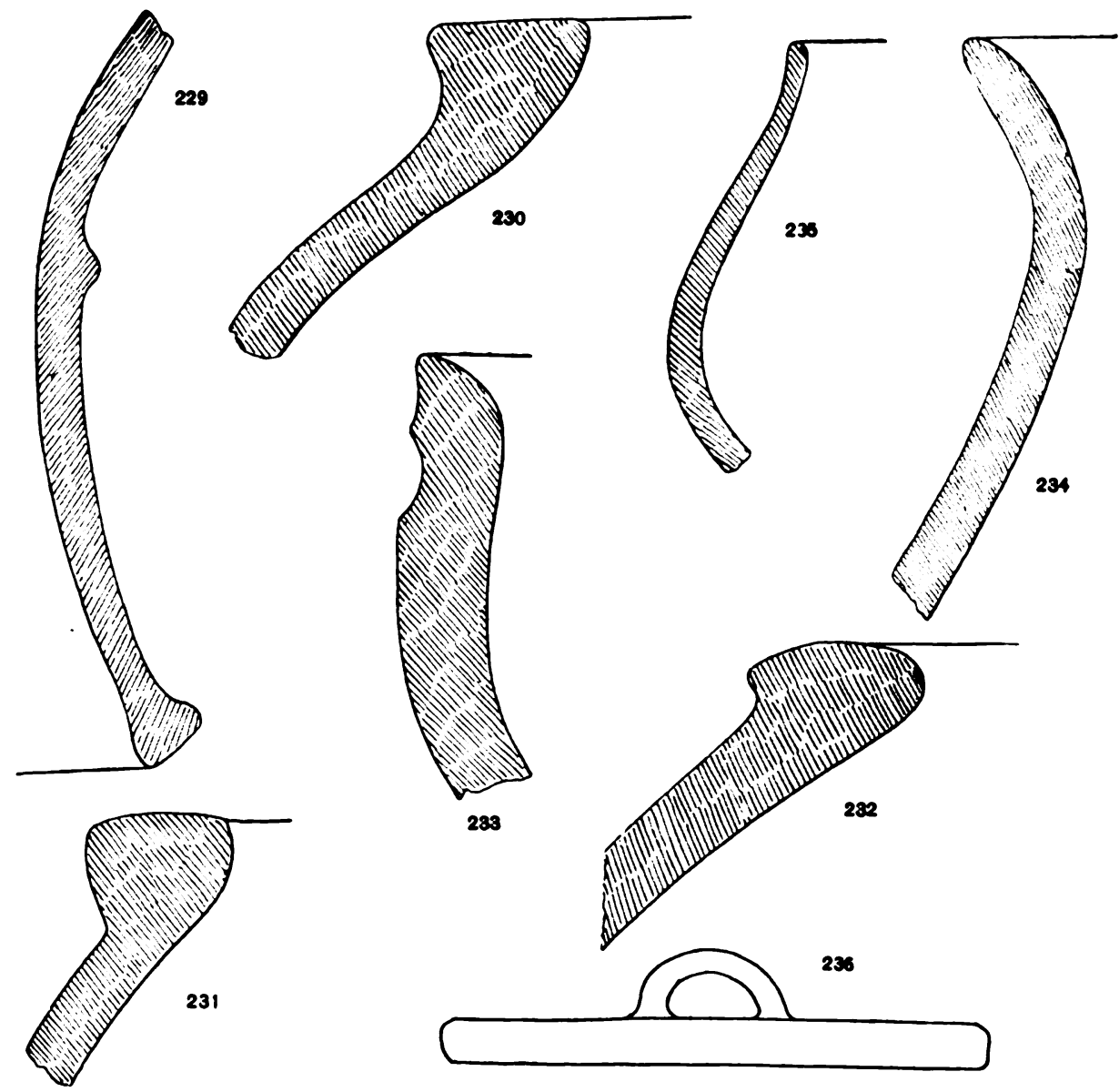

Certain forms that were found in the upper strata stand isolated and without analogies, owing to their peculiarity. First may be mentioned a small bottle of light-colored clay, height $7.4 \mathrm{~cm}$., with a narrow throat and a sharply set-off shoulder (see plate 9, fig. 6). Still more doubtful is a small jug of gray clay, height $6.5 \mathrm{~cm}$., which was found just under the surface in the upper digging (plate 9, fig. 5). Since ware of gray clay does not occur at all in the unmixed layers of culture IV, we must assign this little vessel to the older pottery and assume that it has come accidentally into the upper strata. A sure proof of the greater age of the gray ware is furnished by the finds in the outer digging. Here it is wholly wanting and consequently can not be brought into harmony with the youngest development of the hill. 
TURKESTAN.

PLATE 32.

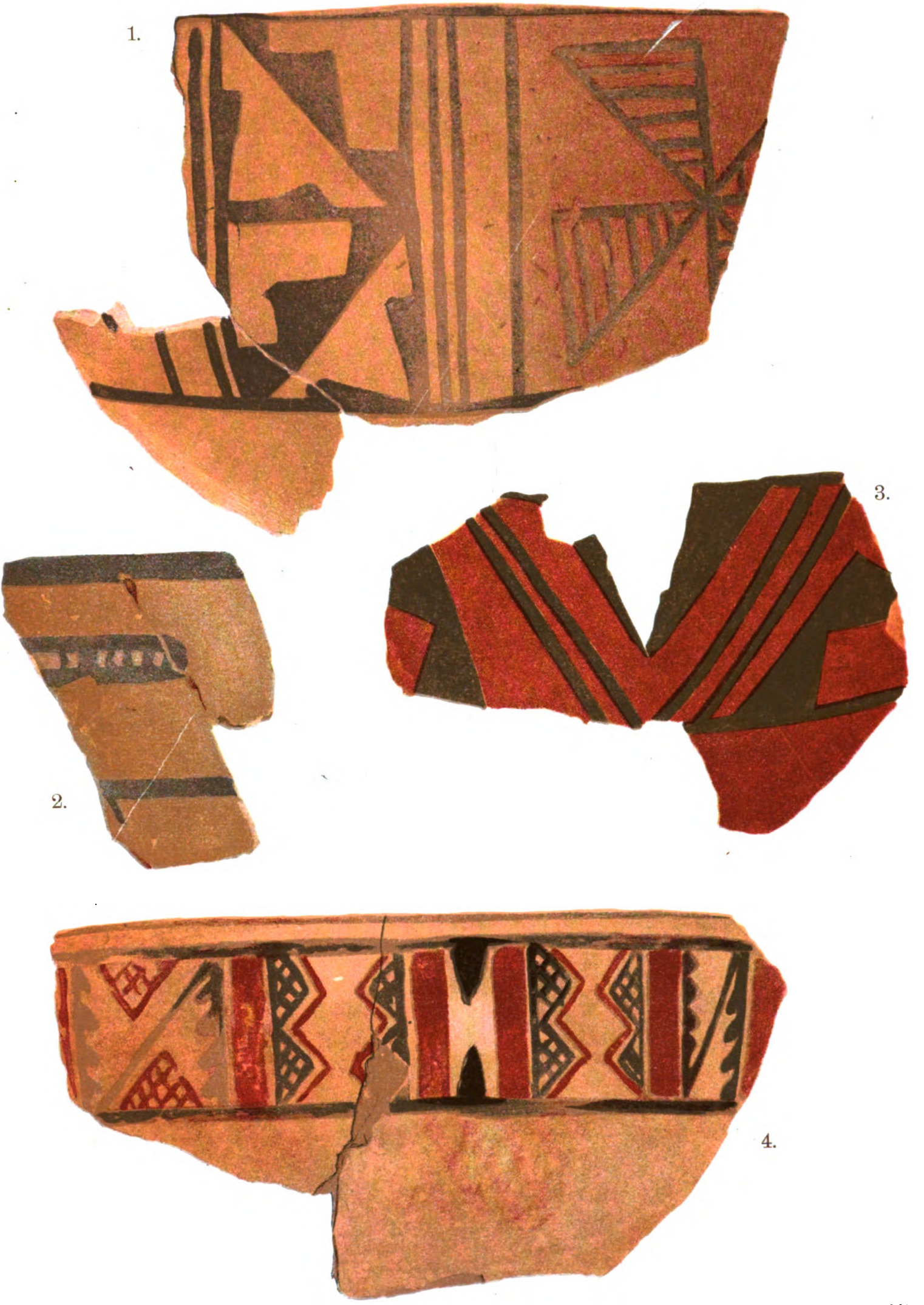

Dhigns on Painted Potthry from Upper Strata, Norty Kurgan, CUl,turh II, Group $c$.

Digitized by $\mathrm{OOg}$ le 


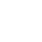



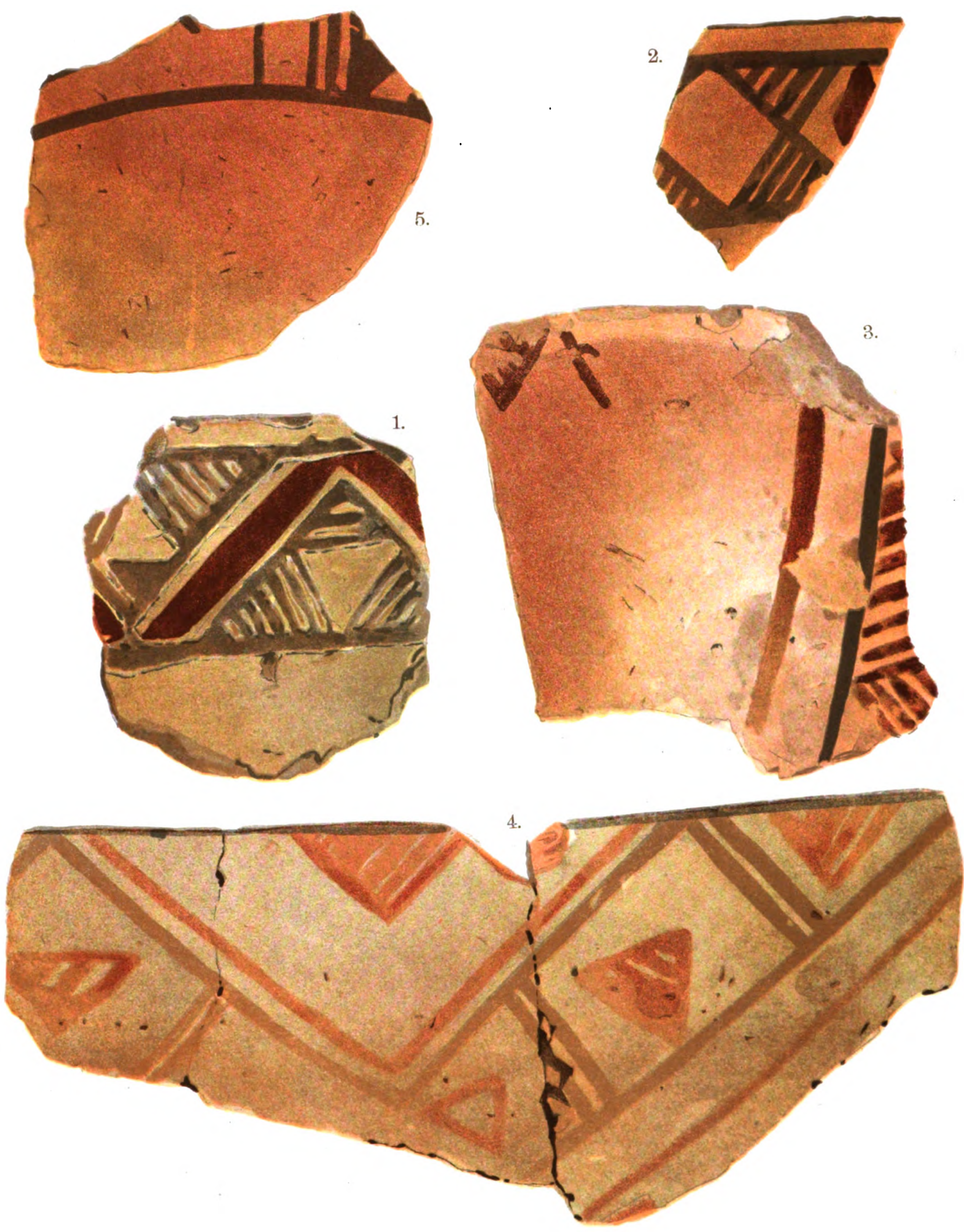

Designs on Painthd Pottery from Upper Strata, North Kurgan, Culture II, Groupc.

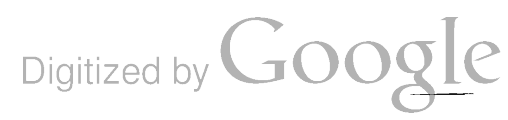




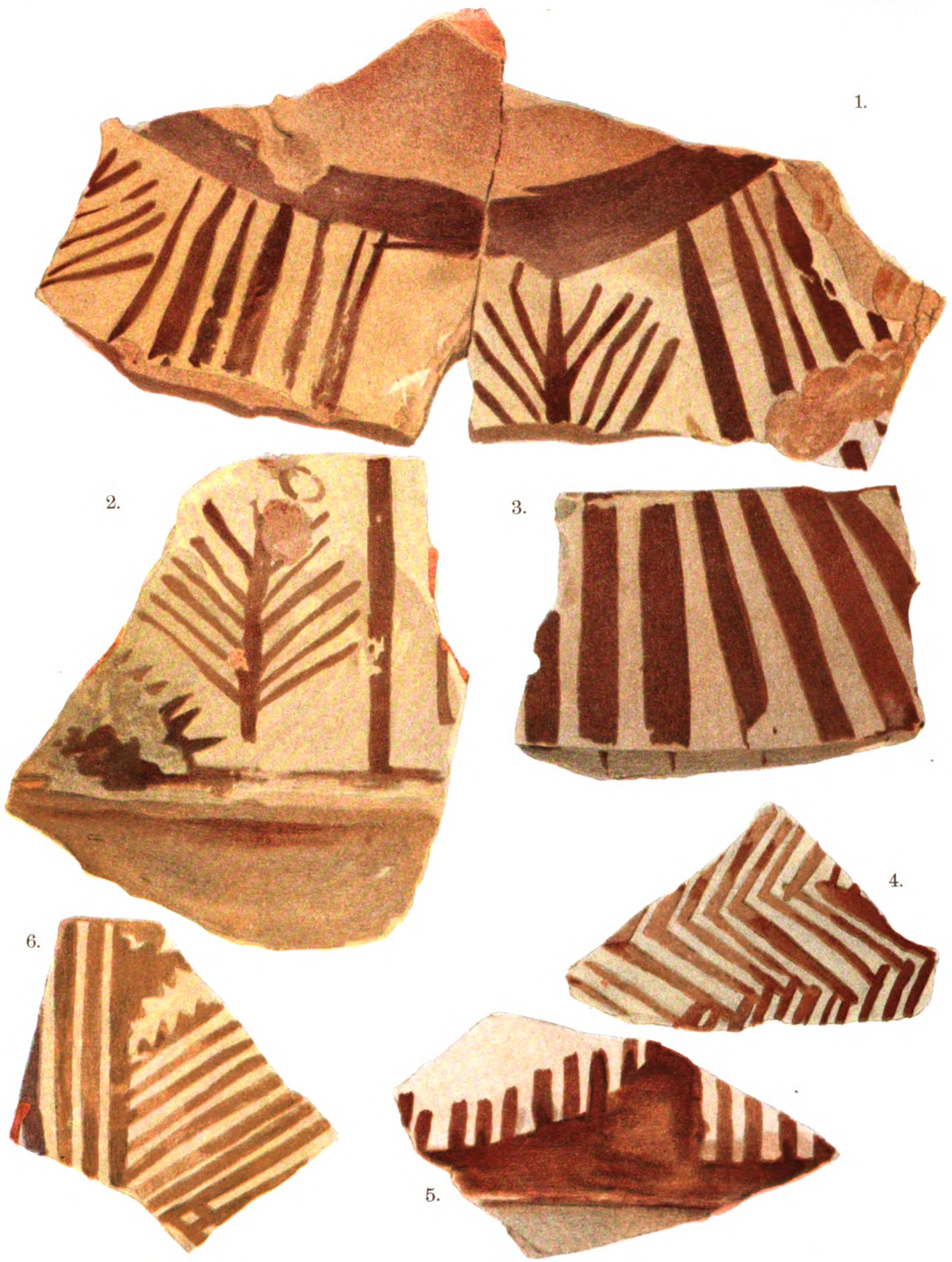

Degigns on Painted Potrery from Lowhr Strata, South kurgan, Culturf iII. 


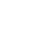

- . $\quad$ Digitized by GOOgle 

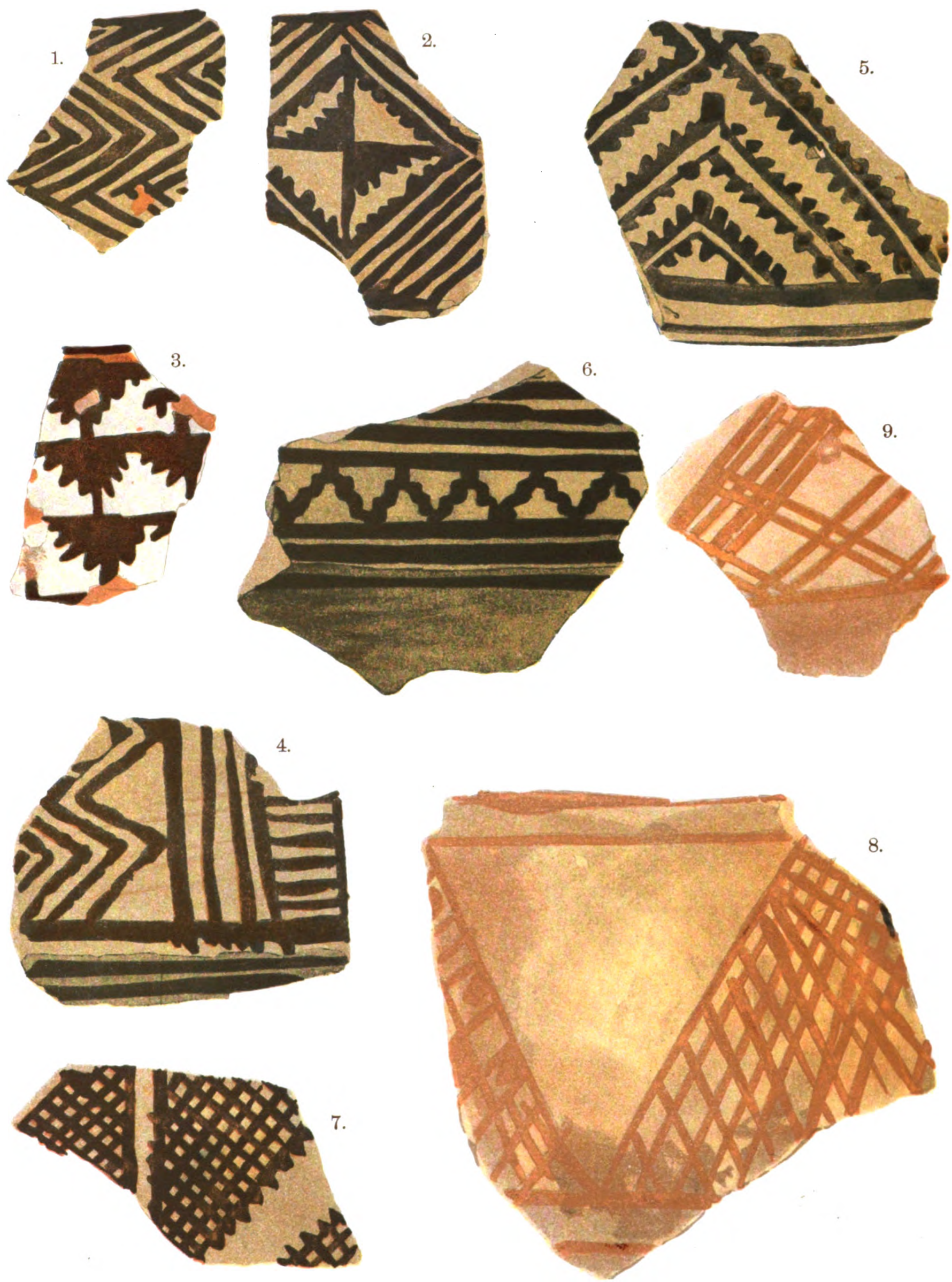

Dhsicins on Painthi Potrhey from South Kurgan, Culturks il and IV.

Figs. 1-7. Middle Strata. FIGs. 8 ANn 9. Intermerliate ()ccupation Y Rarbarian?) between Cultures III and IV. 
Digitized by Google 
Ornamentation is wholly lacking on these vessels of light-colored clay found in the highest strata. No fragments were found, either with painting or with incised patterns, which could be ranged according to their technique with pottery of the group $a$.

(b) HAND-WORK.

The hand-made pottery of the upper strata of the South Kurgan, referred to above as group 2, can not be associated with the wheel-made pottery, the conditions of occurrence and technical characteristics forbidding this. Fragments of this kind do not occur in all the upper layers of the upper digging, being confined to the lower portion of the same, between the levels of +47 and +43 feet. They also enter into deeper layers, between +43 feet and +37 feet 7 inches, mixing there with the deposits of the older culture, though they are not so numerous as higher up. Consequently, we must interpolate this pottery as an intermediate group between the end of the older culture III and the full development of culture IV. This isolation is also indicated by technical peculiarities.

Technique.-The clay is of a reddish-yellow or greenish tone, coarsely washed and not hard-burnt.

Forms.-The forms are very simple. From the material in hand we can recognize in the marginal pieces: (A) larger vessels (fig. 234); (B) smaller cups (fig. 235); (C) flat covers with bow-shaped handles (fig. 236).

Ornament.-The vessels are either entirely covered with a light-red or carminered color, or broad, horizontal, red stripes are painted on the margin over a dirty yellow slip. Again, we find larger geometric patterns, all showing rough and hasty execution. The patterns are trellis-filled triangles, or stripes forming angles which are filled in with parallel lines or trellis pattern. The triangles stand with their apices directed upwards, and are connected at the top by fine horizontal lines (plate 35, figs. 8 and 9). The whole group points to a decline of the better technique; for it is more comprehensible in connection with the older pottery than with the younger, as evidenced by the greenish-white clay, the painting, which recalls the motif of the older pottery, and lastly its occurrence in the same layers in which even better fragments of light-colored and gray clay were found. 
THE MINOR ANTIQUITIES OF METAL, BONE, CLAY, STONE, AND FAIENCE. (a) COPPER.

FROM MIDDLE AND LOWER STRATA OF NORTH KURGAN, CULTURE I.

Ornaments and implements of copper, or fragments of such, were found in different levels of the middle and lower layers, warranting the embracing of these in one culture epoch.

Copper ornaments. - The burials of terrace II at +22 feet 5 inches have yielded us, besides beads and flint implements, copper ornaments in the form of spiral

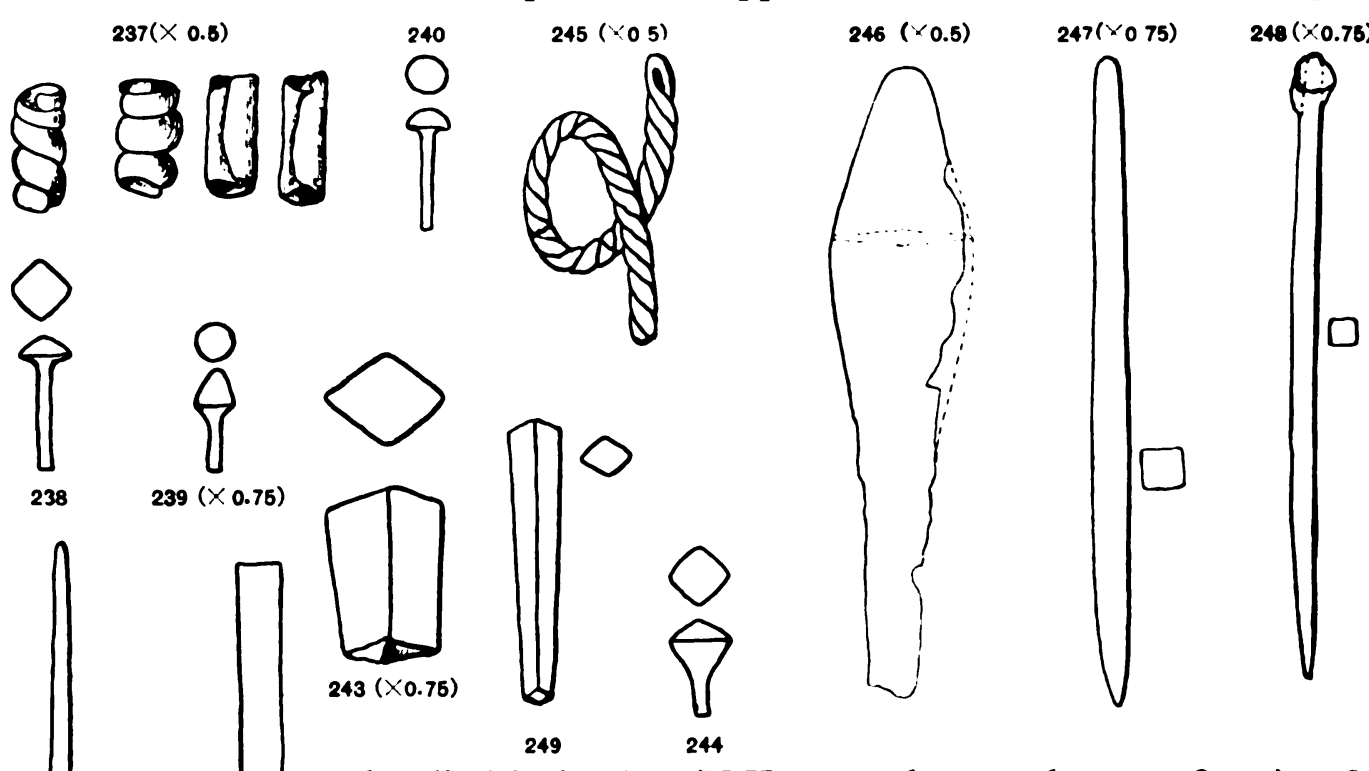

and cylindrical tubes (N.K. 81 and 185 ; plate 36 , fig. 1 ). Of these there are two spiral and two straight tubes, well preserved (fig. 237). The first have four and four and a half windings, respectively; the latter are made of thin sheet-metal in such manner that the edges overlap. Besides these, there are respectively five and three fragments which can not be joined. The

$241(\times 0.75) 242(\times 0.75)$ same burial yielded also lead tubes and a flint knife (cf. below).

Copper pins.-Pins were found with heads of various forms-pyramidal, as in fig. 238 , from terrace vII, between +24 feet and +22 feet 8 inches (N.K. 167; plate 36 , fig. 2), or hat-shaped with round cross-section, as in fig. 239 , from terrace viII, between +22 feet 8 inches and +24 feet (N.K. 187 ; plate 36 , fig. 4 ). Of doubtful connection with the older culture is a pin with a cap-shaped head (fig. 240), from the west pit of Komorof's trench (N.K. 20; plate 36, fig. 3).

Copper implements. - A simple punch with square cross-section (fig. 24I; N.K. 98, plate 36 , fig. 7) came from terrace III, between +18 and +20 feet.

The fragment N.K. I45 (fig. 242) belongs to a four-edged chisel from terrace vir, between +24 feet 2 inches and +26 feet.

Indeterminable is the piece of a four-edged bar with rhombic cross-sections (N.K. I88; fig. 243), from terrace II, between +20 feet and +20 feet 5 inches; and 
the same may be said of a knife-like fragment, N.K. I89, from terrace I, between +23 and +25 feet.

The deeper layers, lying below the datum-plane of the North Kurgan, have also yielded copper. These are, however, unfortunately only fragments, and owing to complete oxidation the form is no longer determinable. Such finds were made in north diggings $\mathrm{I}$ and $\mathrm{II}$, between -8 and $-\mathrm{I}_{3}$ feet (N.K. 48 and 87).

FROM UPPER STRATA OF NORTH KURGAN, CULTURE II.

Pins.-Fragment N.K. 75 (fig. 244; plate 36, fig. 5), from the surface of terrace vir, has a head in the form of a double pyramid. Pieces of a pin without a head (N.K. 82) were found in the uppermost layers of the same terrace.

Neck-ring or torque.-It is probable that the three fragments (N.K. 4; fig. 245 , plate 36 , fig. 6), from terrace $I$, between $+3 I$ feet 5 inches and +40 feet, belong to a copper collar made of braided double-wire.

Weapons.-The only fragment of a copper weapon was found on the surface of terrace vir. It is a lance-point or a dagger-blade, very broad, and with a rhombic cross-section and a flat, long tang (N.K. 83; fig. 246; plate 36, fig. 10).

Implements. - We have to thank Mr. R. W. Pumpelly for a well-preserved punch, square in cross-section (N.K. 248; fig. 247 ; plate 36 , fig. 8). He found it at a height of +34 feet in the undisturbed earth of the hill, while studying the walls of Komorof's trench.

A little copper rod with square cross-section (N.K. 93; fig. 248; plate 36, fig. 9), from terrace $I$, between $+3 \mathrm{I}$ feet 5 inches and +40 feet, should probably be regarded rather as a punch than as a pin. The thickening at one end, which might indicate a pin, is probably only the result of oxidation. The four-edged shaft is, however, common to punches and chisels.

There remains doubtful the explanation of a four-edged little copper rod with rhombic cross-section (N.K. 4 ; fig. 249), from terrace I, between +31 feet 5 inches and +40 feet. This may have been for the same use as fig. 243 of the middle strata.

Indeterminable are certain formless lumps found in Komorof's trench in the loose earth (N.K. 2), from the uppermost layers of terrace I (N.K. 3) and from terrace $1 a$, between +28 and +30 feet (N.K. 34 ).

FROM MIDDLE AND LOWER STRATA OF SOUTH KURGAN, CULTURE III.

The objects of copper found in the South Kurgan are much more numerous and varied than those of the northern kurgan, but they fall into the same categories-ornaments, implements, weapons, and different indeterminable objects.

Copper ornaments. - Of the pins, one with a cap-like head, found in terrace C between +19 feet 5 inches and +21 feet 2 inches (S.K. 249; fig. 250) connects itself with the types of the North Kurgan (cf. fig. 240). A new type is shown in S.K. 28I, 354 (figs. 25I and 252; plate 37, fig. 3). Both were found in terrace $B$-the better preserved one between +19 and +21 feet, the other under the pithos $d$; consequently both were in the débris deposits of the period $\mathrm{A}$, to which the large buildings belong. The round shaft of this pin splits above into two ribbon-like outward-rolled spirals. Another fragment worthy of notice has broad 
hammered ends (S.K. 140, fig. 253). It is from the upper digging at +29 feet. Besides these, only pins with shafts of round cross-sections were found, as S.K. 275 (fig. 254; plate 37 , fig. II), from terrace B between +19 and +21 feet, and S.K. 76 (fig. 255) from terrace $B$ at +26.25 feet.

Among the ornaments found were peculiar ornamental disks of differing forms with bow-shaped eyes on the reversed side. Some are wheel-shaped-with openwork, as in fragment S.K. 334 (fig. 256 ; plate 37 , fig. 16) from terrace B, + 2 I feet; others are star-shaped with scalloped edges, as S.K. 207 (fig. 257; plate 37, fig. 18 ) from terrace $B$, between +21 feet 5 inches and +23 feet 7 inches. One is flat, with plastic ridges as S.K. 353 (fig. 258 , and plate 37 , fig. 1 7 ), from terrace B at $+2 \mathrm{I}$ feet. All these objects belong, therefore, to the layers of period A (see also the fragment S.K. 202; plate 37 , fig. 6). More simple are the ornamental
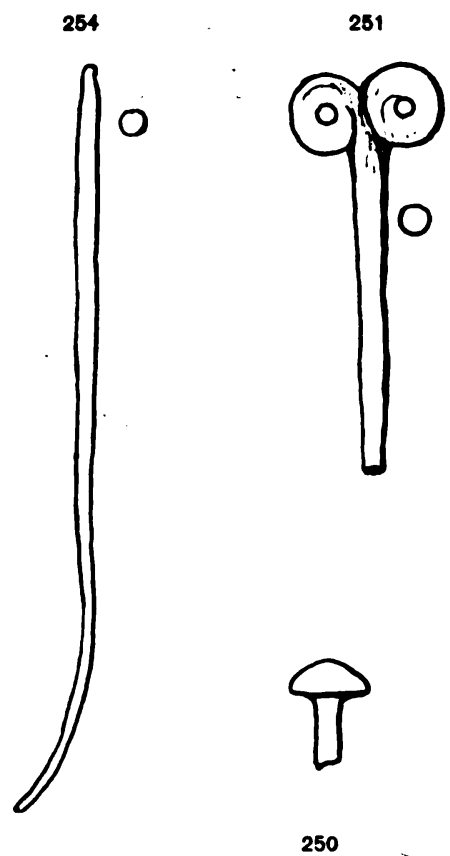

(1)

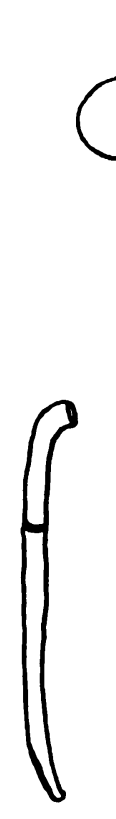

253 252
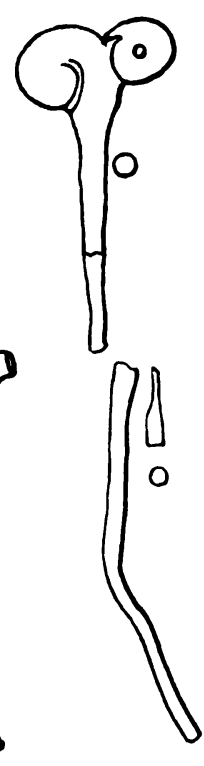

All Figures $x 0$

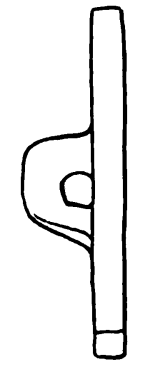

256
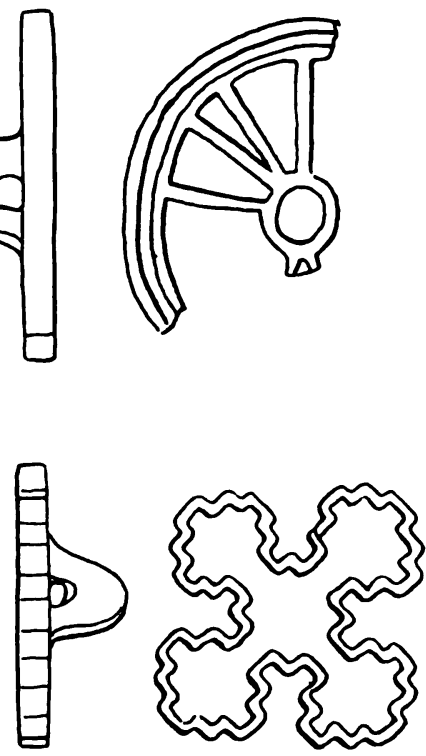

267

buttons, concave underneath; some with small ring-eyes S.K. 75; fig. 259), from the upper digging, between +37 feet 7 inches and +40 feet; others with two holes for sewing on the edge, as shown by the fragments S.K. I17 (fig. 260), from the upper digging, +32 feet. There is still to be mentioned a small open ring, with opposed ends (S.K. I 8 ; fig. 261), from the same locality as the former objects, and the fragment of a larger massive ring with circular cross-section (S.K. 203; fig. 262 ; plate 37 , fig. 14 ) from terrace $B$, between +21 feet 5 inches and +23 feet 7 inches. The material is probably not bronze, since it is surprisingly little oxidized; possibly it is antimony bronze.*

Copper implements.-Awls or punches and fragments of such were found in the South as well as in the North Kurgan. As a rule they are four-edged, with square cross-section like the large one (S.K. 274; plate 37, fig. 12) shown in fig. 263, from terrace B, at +19 feet, and a smaller one (S.K. 277; fig. 264 ; plate

* Since this was written, an analysis shows 70.42 per cent copper; 2 I.69 per cent lead; 0.41 per cent antimony; 0.49 per cent arsenic; 5.57 per cent tin.-R. P. 


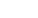

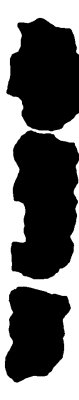

1

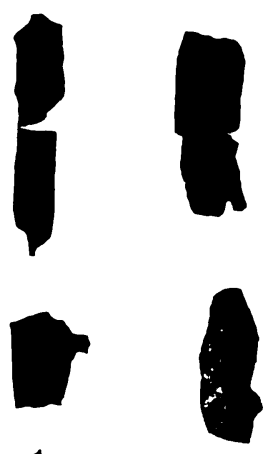

i

2

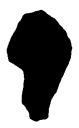

4

3

5
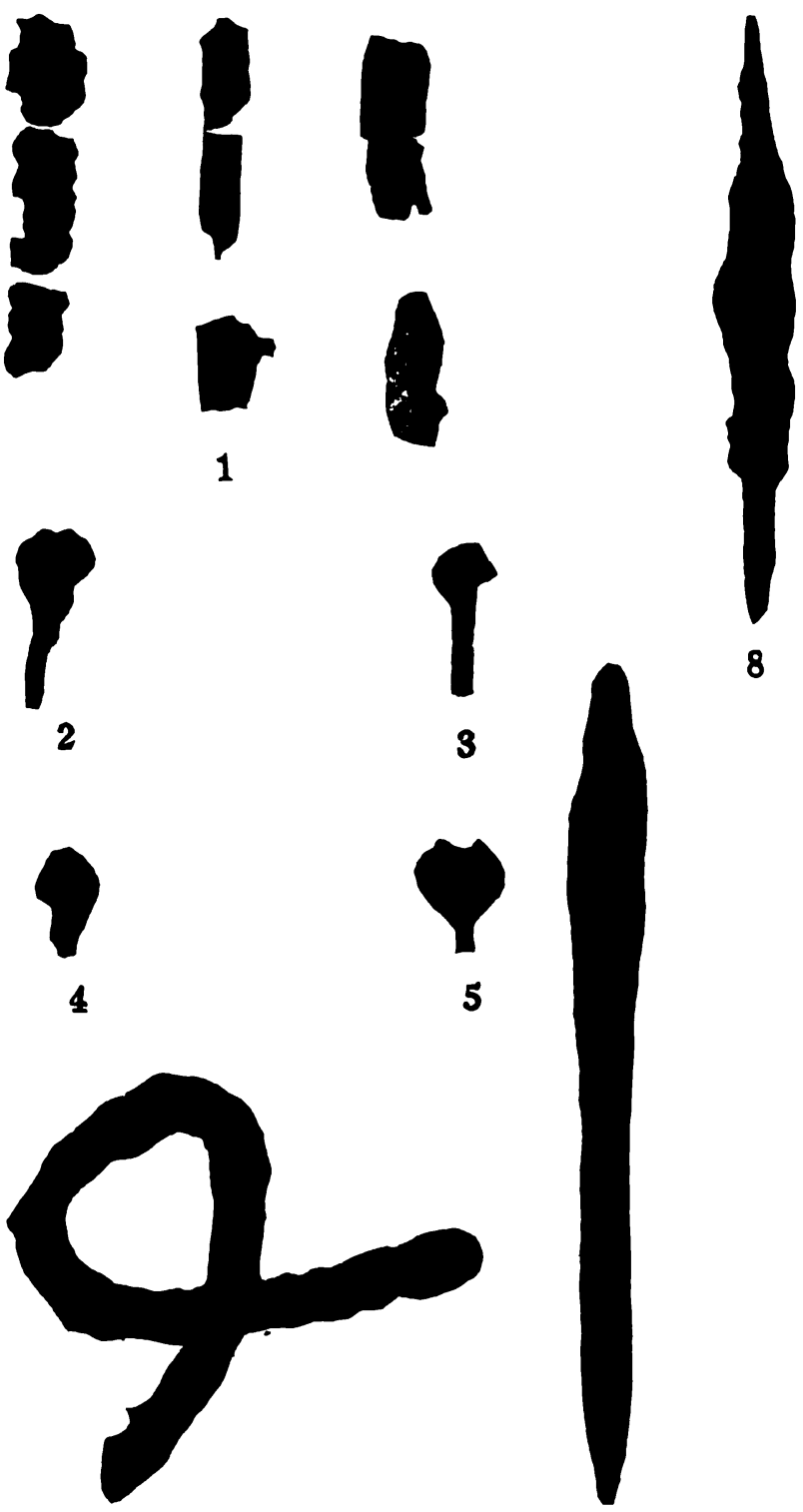

6

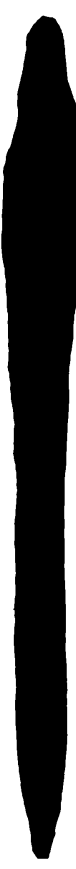

7

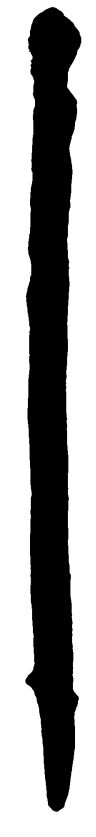

9

Plate 36.

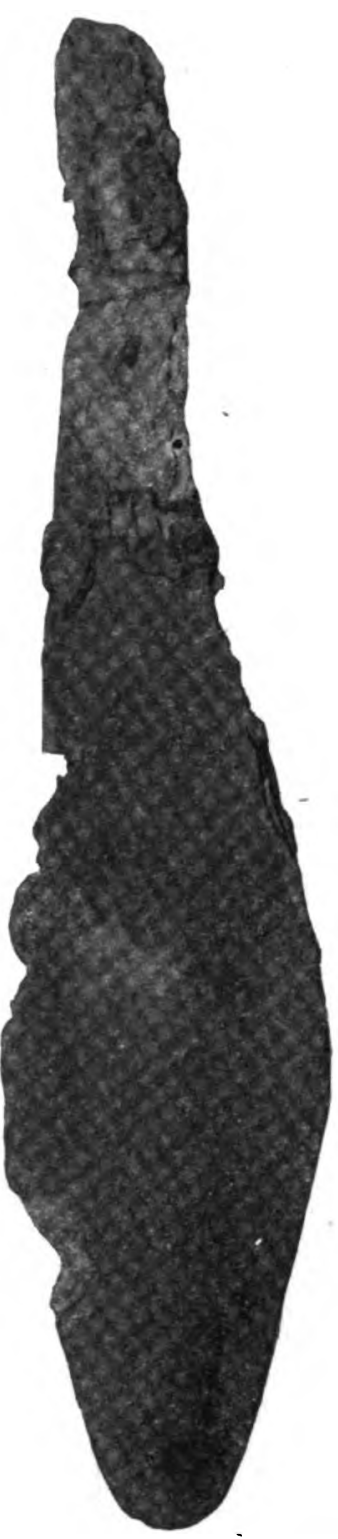

10

Objects of Copper from Cultures I and II, North Kurgan.

Fio. I (N.K. 81 and 185). Copper and Lead Tubes and Copper Spiral, Burial Gift, Terrace II, +22.5 feet, Culture I, text-figure 237

2 (N.K. 167). Copper Pin, Terrace VII, +23 to +24 feet, Culture I, text-figure 238.

3 (N.K. 20). Copper Pin, Bottom of Komorof's Trench, Culture I or II, text-figure 240

4 (N.K. 187). Copper Pin, Terrace VIII, +22.6 to +24 feet. Culture I, text-figure 239.

6 (N.K. 4). Torque of Braided Double Wire, Copper, Terrace I, +31 to 40 feet, Culture II, text-figure 24.5

7 (N.K. 98). Copper Punch, no Tin, Terrace III, +18 to +20 feet, Culture I, text-figure 241 .

8 N.K. 248). Copper Punch, no Tin, Wall of Trench, +34 feet, Culture II, text-figure 247.

10 (N.K. 83). Copper Dagger or Lance-Blade, Terrace vII on surface at +30.5 feet, Culture II (?), text figure 246. Analysis of corroded crust: Copper, 58.27; lead, 0.55; iron, trace; cobalt, none; nickel, none; antimony, 0.37 ; arsenic, 0.68 ; tin, none. 
Digitized by GoOgle 

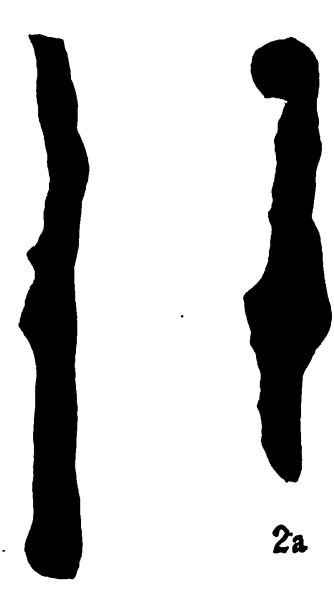

$2 a$

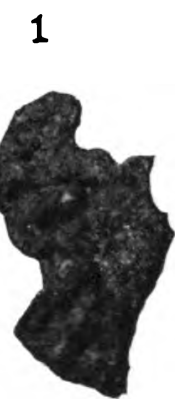

6

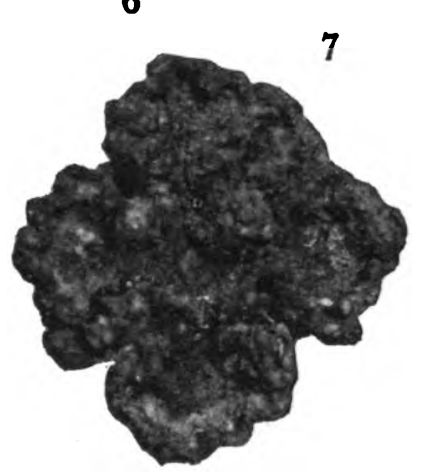

18

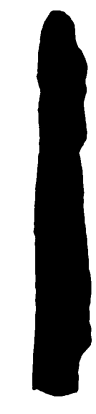

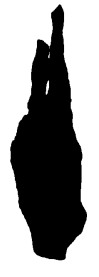

$2 \mathrm{~b}$

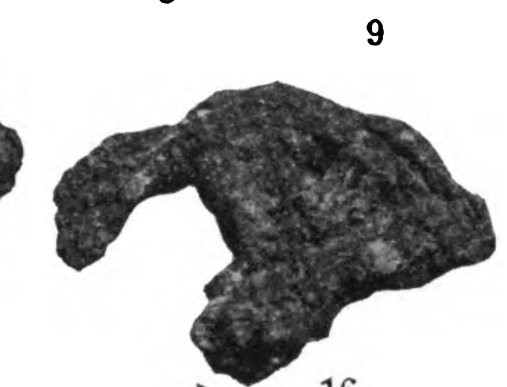

16
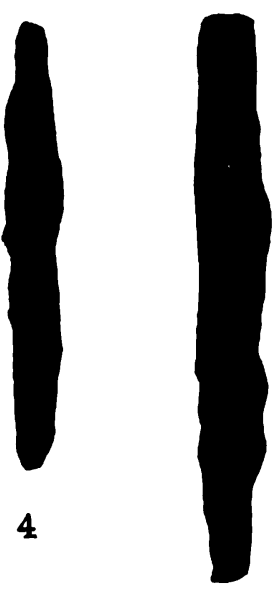

5
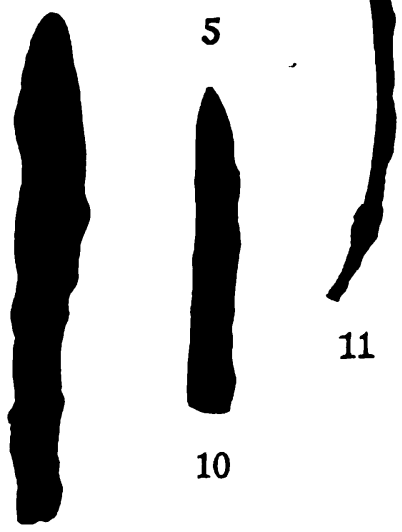

11

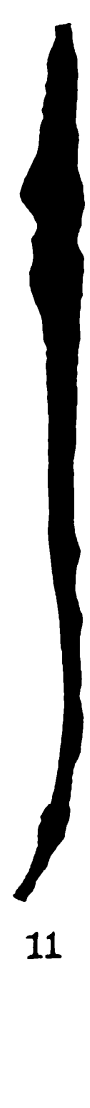

13

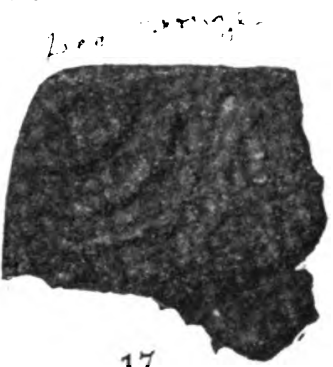

17

PLATE 37.

Objects of Copper from Culture III, South Kurgan.

Fio. 1 (S.K. 278). Copper Awl (?), Terrace B, +19 to +23 feet.

$2 a$ AND b (S.K. 280). Copper Tweezers, no Tin, Terrace B, +19 feet, text-figure 269

(251.

4 (S.K. 40). Copper Chisel, Terrace B. +33 feet, text-figure 265 . Analysis of corroded crust: Copper, 41.83 ; lead, 0.51 ; iron, trace; cobalt. none; nickel, 0.01 ; antimony, 0.10 ; arsenic, none; tin, 1.58

5 (S.K. 276). Piece of Copper Chisel, Terrace B, +19 feet.

7 (S.K. 166). Copper Punch, nearly Clean Metal.' Copper, 95.39; lead, 0.14; iron 0.76; cobalt, none; nickel, 0.02; antimony, 0.61; 8 arsenic, 2.04 ; tin, none; total, 98.96 . A separate analysis of the gerugo (crust) gave no tin.

8 (S.K. 277). Small Copper Punch, Terrace B, +19 feet, text-figure 264.

10 (S.K. 199). Copper Punch, Terrace B, +23 feet. Analysis of corroded crust: Copper, 55.58; lead, 0.37 ; iron, trace; cobalt none; nickel, 0.04 ; antimony, 0.16 ; arsenic, 0.64 ; tin, none.

11 (S.K. 275). Copper Pin, Terrace B, +19 to +21 feet, text-figure 254 . 1 . 0.06 ; cobalt, none; nickel. none; antimony, 0.15 ; arsenic, 4.88; tin, none; total, 98.63.

13 (S.K. 97). Copper Punch, no Tin, Terrace B, +21.5 to +23.5 feet.

14 (S.K. 203). Piece of Ring, Terrace B, +21.5 to +23.5 feet, text-figure 262 . Analysis of clean metal: Copper, 70.42; lead, 21.69;

15 (S.K. 144). Copper (?) Rod, Upper, Digging, +29 to +32 feet, text-figure 270 . Analysis of corroded crust: Copper, 50.63; lead, 16 (S.R. 334). Ornamental Dist, no Tin, Terrace B, + 21 feet, text-figure 256 .

18 (S.K. 207). Ornamental Button (?), Terrace B, +21.5 to +23.5 feet, text-figure 257. 
Digitized by GOOgle 


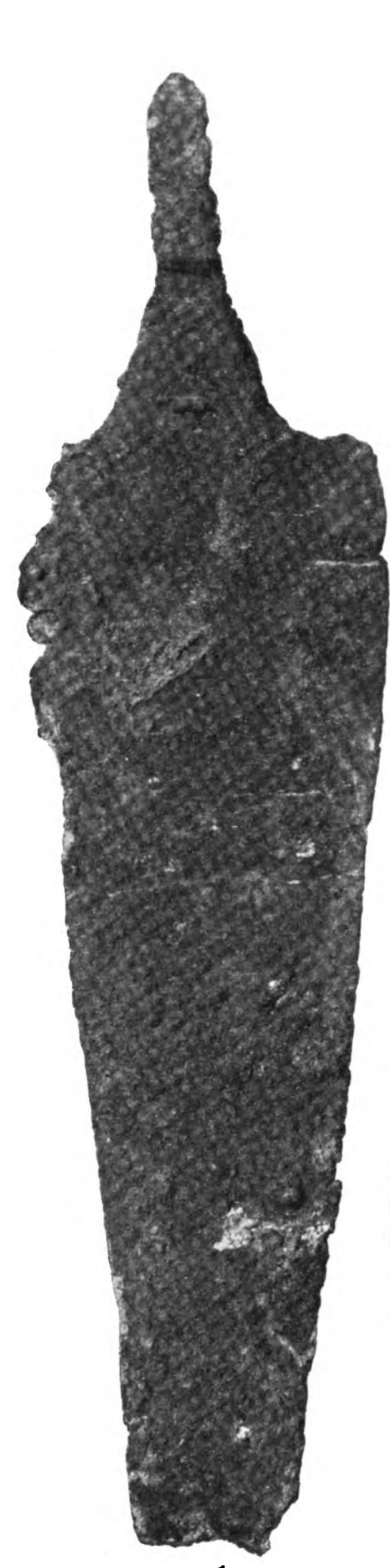

1

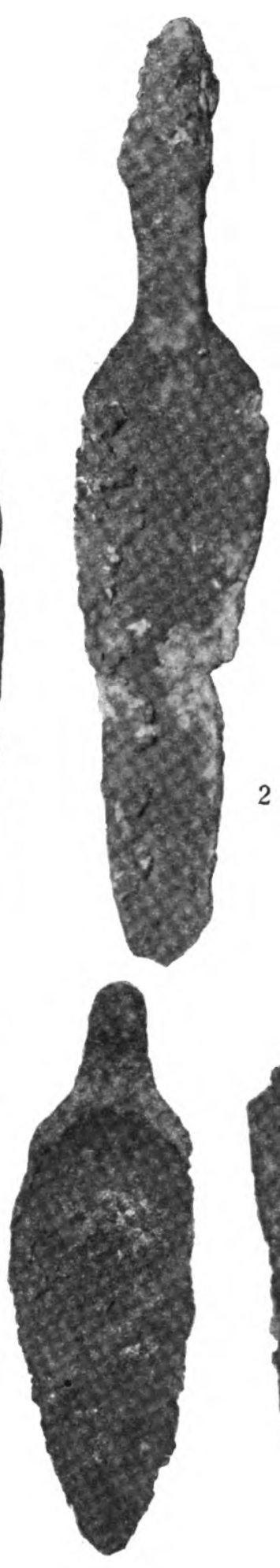

3

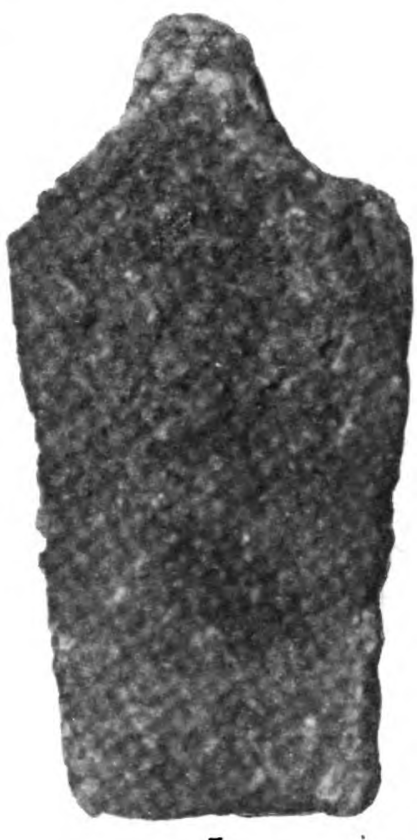

5

Objects of Copper from Culture III, South Kurgan.

PLATE 38.

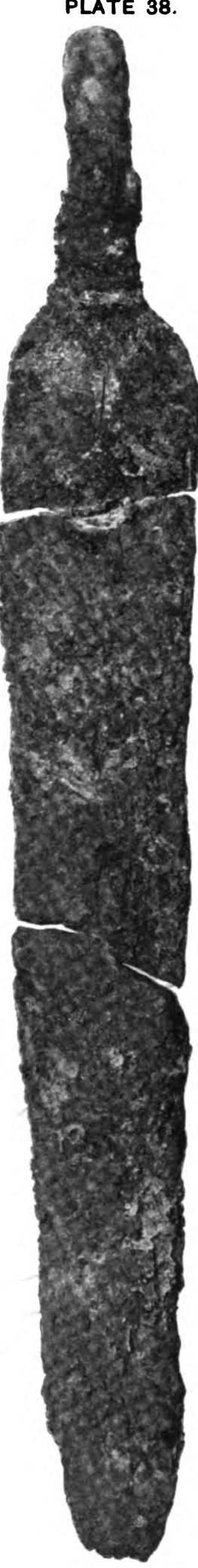

4

F10. 1 (S.K. 142), Copper Dagger, Upper Digging, +29 to +32 feet, text-figure 276. Analysis of nearly clean metal gave: Copper, 2 (S.K. 141). Blade of Dagger or Lance, Copper, in surface near Terrace B, text-figure 279 . Analysis of crust of corroded products 3 (S.K. 332 ). Copper Dagger or Lance-blade, Terrace B, +19.5 feet, text-fig. 280. Analysis of crust of corrosion products gave no tin. 4 (S.K. 61). Dagger, Copper (1.68 tin), Upper Digging, +40 feet, text-figure 275. Analysis of corroded crust gave: Copper, 41.83 5 (S.K. 247): Dagger, Copper (no tin), Terrace B, +21.5 feet, text-figure 277. 7 (S.K. 201). Arrow-head of Copper or Brone (not Analyzed). Outer Digging, +2 to +4 feet, Culture III or IV, text-figure 281 . 


\section{Digitized by Google}



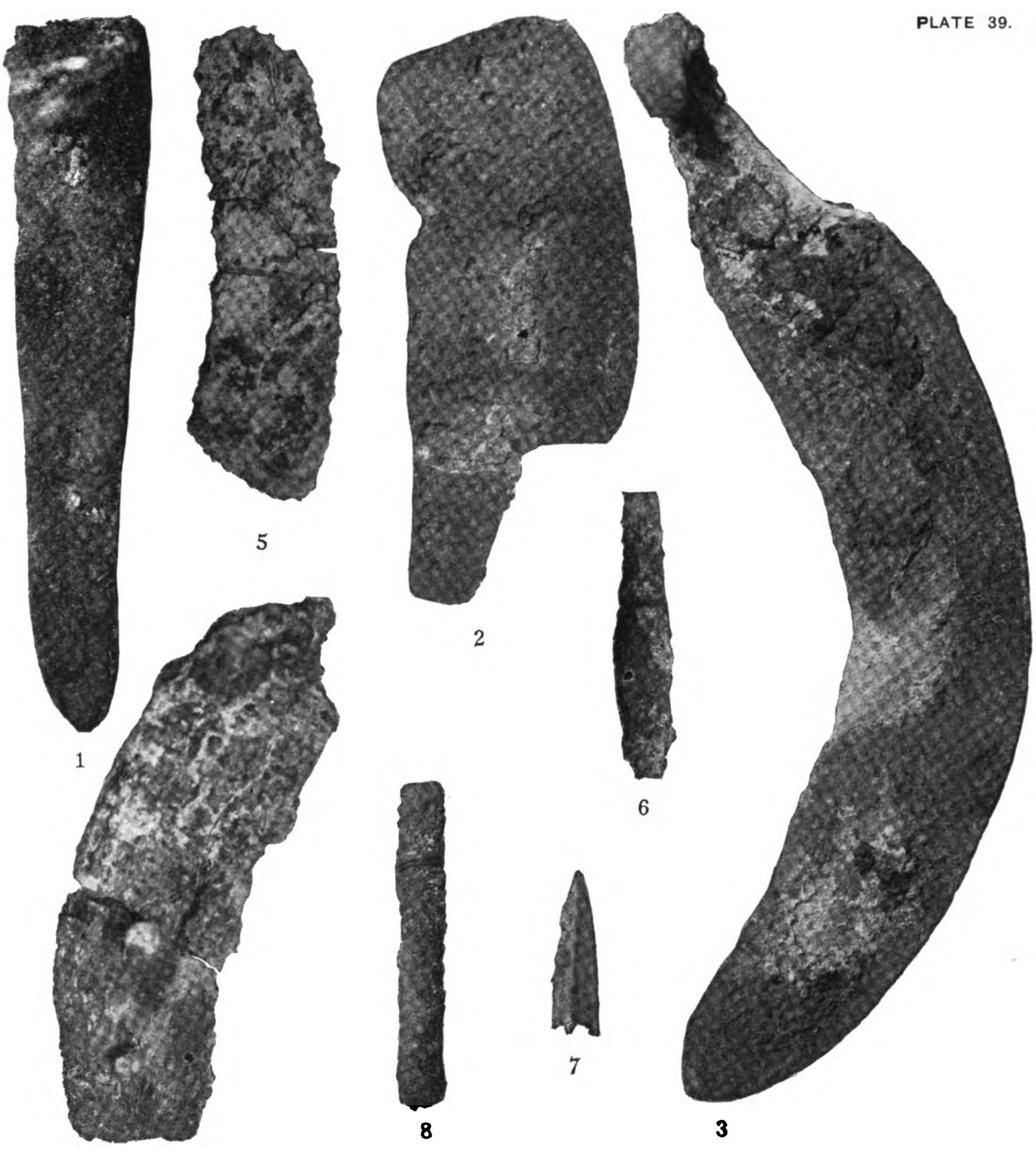

4

Objects of Metal from Cultures III and IV, South Kurgan.

Fio. 1 (S.R. 62). Knife-blade, Copper or Bronze (?), Upper Digging, +40 feet, Culture III (?), text-figure 271.

2 (S.K. 143). Razor-shaped Blade of Copper, Upper Digging, +29 to +32 feet, Culture III, text-figure 273 . Analysis of clean metal gave: 3 (S.K. 146). Copper Sickle, Upper Digging; cobalt, none; nickel, none; antimony, trace; arsenic, 4.43 ; tin, none; sulphur, 0.08 ; total, 99.69 . 3 (S.K 146): Copper Sickle, Upper Digging, +25 to +29 feet, Culture III, text-figure 274 . Analysis of clean

4 (S.K. 41). Iron Sickle, in Talus-débris of Terrace A, Culture IV, text-figure 289.

S.K 22. Piece of Iron Sickle, Terrace A, Culture IV, text-figure 290.

7 (S.K. 8). Three-edged Copper. Arrow-point, 5 feet deep in the Talus-debris of Terrace A, Culture IV, text-figure 288. Analysis of products 8 (S.K. 145). Copper Rod, Outer Digging, +6.5 to +10 feet, Culture IV, text-figure 287 . Analysis of crust of corrosive products gave: Cop-
per, 81.85; lead, none; iron, 1.13 ; cobalt, trace; nickel, 0.06; antimony, $0.10 ;$ arsenic, 0.38; tin, 0.59 . 
37, fig. 8) from the same point. Fragments of such implements were also found at other places: terrace $\mathrm{A}$, at +22 feet (S.K. 96); in the upper digging, at +33 feet 2 inches (S.K. 97 ; plate 37, fig. 13); at terrace B, between +21 feet 5 inches, and +23 feet 7 inches (S.K. 166; plate 37 , fig. 7), and from the same point at +19 feet (S.K. 276; plate 37 , fig. 5). Such fragments may also have belonged to chisels. They are distinguished from awls by a more or less formed cutting edge. There are two well-preserved small chisels, one from terrace $B$, at +31 feet (S.K. 40; fig. 265; plate 37, fig. 4), the other (S.K. 302), also from terrace B, at +19 feet (S.K. 302; fig. 266; plate 37, fig. 9). A fragment of a wider one with a more projecting cutting edge (S.K. 165a) is shown in fig. 267 from the upper digging, between +25 feet 5 inches and +29 feet.

It is impossible to say whether fragments of implements with a square crosssection and a needle-like point belong to awls and punches or to pins. Such a fragment (S.K. 200) from terrace C, between +21 feet 2 inches and +23 feet 2 inches, is shown in fig. 268.

A pair of tweezers of peculiar form (S.K. $280 a$ and $280 b$ ) is an isolated occurrence. It is from terrace $B$ at just +19 feet, and is shown in fig. 269, and plate 37 , figs. $2 a$ and $2 b$. It has a four-edged shaft with square cross-section and a spiral, inrolled end which has been hammered thin; the other end is forked in two parts. Equally remarkable is a little rod, round in cross-section, with a club-shaped, thickened end (S.K. 144) shown in fig. 270 and plate 37 , fig. 15. In its form it recalls a common surgical instrument of later times; it comes from the upper digging between +29 and +32 feet, $i$. e., from the layer of pithos $a$.

- Of knives, several finds are to be noted. One of simple band-shaped type (S.K. 62), with a square hole at the handle end, from the upper digging at +40 feet, is shown in fig. 271 and plate 39, fig. I. The handle end is bent over. A fragment of a copper knife-blade (S.K. 248; fig. 272) came from the lower layers of terrace $C$ between +19 feet 5 inches and +21 feet 2
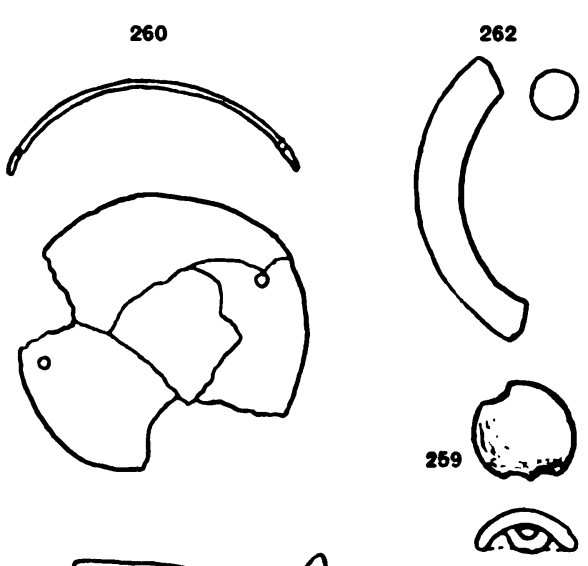
inches. Naturally one can not say whether or not its missing portion would prove it to be of the same type as the last-mentioned knife. A razor is probably represented in a short, broad blade, with an outwardly curved edge and a short tang or haft (S.K. 143; fig. 273; plate 39, fig. 2), from the upper digging, between +29 and +32 feet. On the other hand, a sickle served an agricultural purpose. It has a strikingly thin blade, probably abraded by frequent grinding, and a thick tang or haft, the end of which is bent over (S.K. 146; fig. 274; plate 39, fig. 3). It is from the upper digging between +25 feet 5 inches and +29 feet.

Special importance naturally attaches to the weapons-daggers, lance-heads, and arrow-points. A narrow blade somewhat thickened in the middle, with a 
short, tapering tang or haft, and broken in three pieces, doubtless represents a dagger (S.K. 6I; fig. 275; plate 38, fig. 4). It is from the upper digging, +40 feet, and contains 1.58 per cent of tin. Another dagger from the upper digging at between +29 and +32 feet, is lenticular in cross-section (S.K. 142; fig. 276; plate 38 , fig. 1 ). To the same type probably belong two fragments (S.K. 247; fig. 277; plate 38 , fig. 5). They are from terrace $B$ at +21 feet 5 inches. Probably to the same type belongs S.K. 74 (fig. 278) from the upper digging, between +37 feet 7 inches and +40 feet. In the case of two other specimens it is uncertain

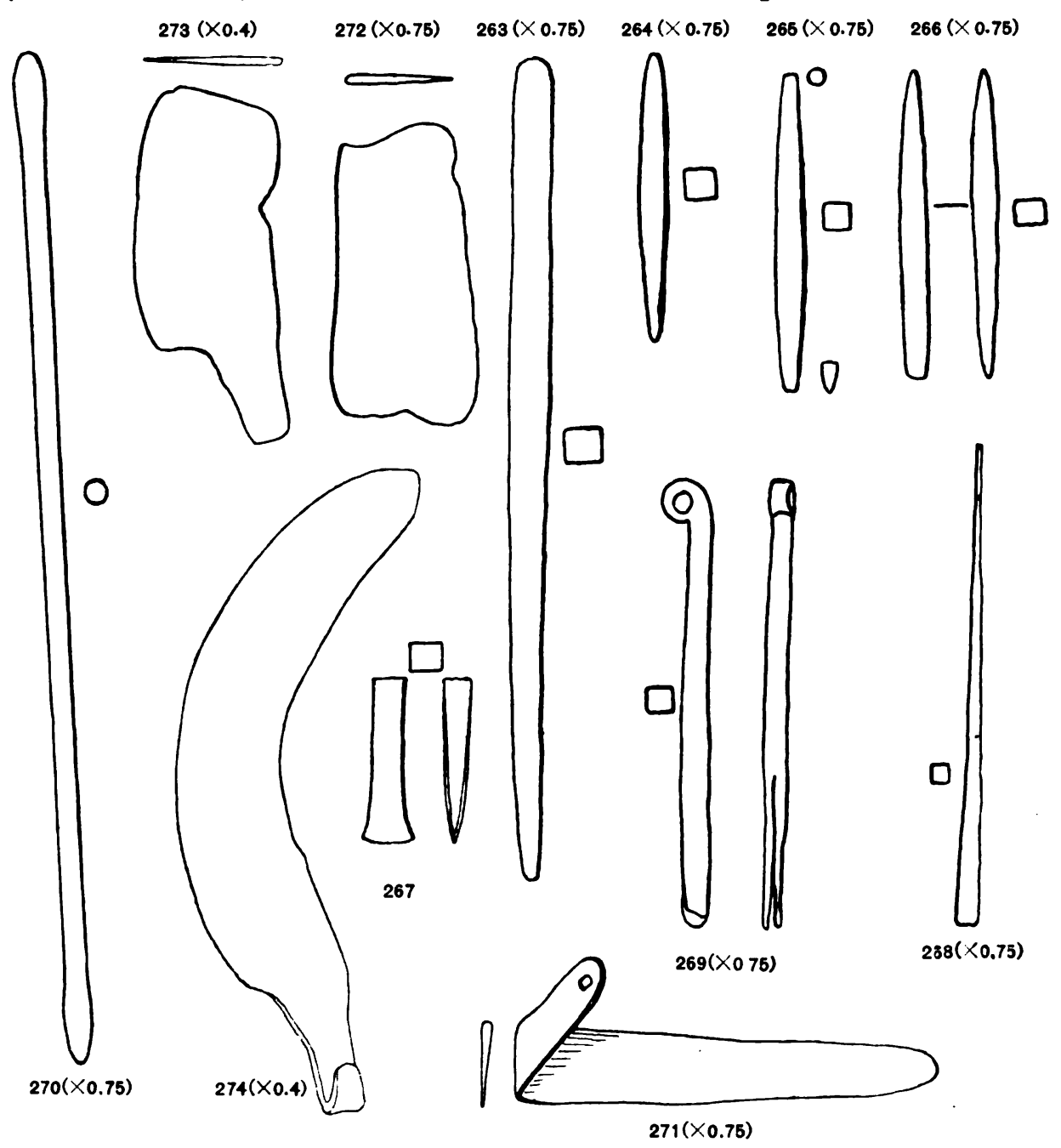

whether they should be called daggers or lance-blades. One has a thick fouredged tang, which continued along the blade as a strong central ridge (S.K. I4I ; fig. 279; plate 38 , fig. 2) from terrace $B$ at +32 feet; the other has a simple leaf shape and is flat (S.K. 332; fig. 280; plate 38 , fig. 3), from terrace B at +19 feet 5 inches. S.K. 205 (fig. 28I; plate 38 , fig. 6) is undoubtedly an arrow-head with a strongly raised central ridge, thin side-wings, and a shaft end with a circular crosssection; but it is uncertain whether this find, which comes from the outer digging, between +2 feet 2 inches and +4 feet 2 inches, is to be assigned to the older 
culture III or to the younger IV. The infrequently occurring pottery at this depth in the outer digging consists of mixed younger and older sorts.

Lastly, there are some miscellaneous objects, of which the use and significance can not be definitely determined from the form. A fragment of a double tube made from sheet copper (S.K. 165b, fig. 282), from the upper digging, between +25 feet 5 inches and +29 feet, is possibly an ornament. The fragments of a doubly bent band of copper seem to have been the binding of some round object (S.K. 306, fig. 283). They are from terrace $C$ between +18 feet 5 inches and + I 9 feet 5 inches. An object with elliptical cross-section (S.K. 201, fig. 284; plate 38, fig. 7), resembles a handle or hilt. It comes from terrace $B$, between +21 feet 5 inches and +23 feet 7 inches. A trough-shaped object (S.K. 98, fig. 285), made from sheet copper or low bronze, was found in the upper digging between +33 feet 2 inches and +37 feet 7 inches.

No objects of copper or bronze have hitherto been found in the lower strata
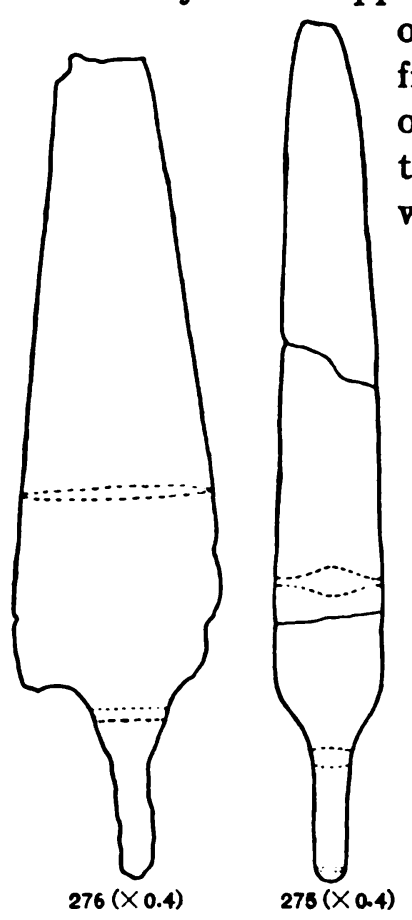
of the South Kurgan. It can not, however, be concluded from this that none are to be found there. The study of the ceramic finds shows that in degree and quality the culture of the lower layers stands on an equal footing with that of the middle strata.

\section{COPPER FROM UPPER STRATA, CULTURE IV.}

The localities to be considered in connec-

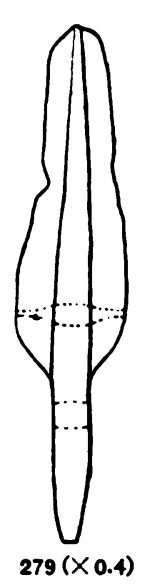
tion with the finds of the younger culture are the layers of the upper digging between +40

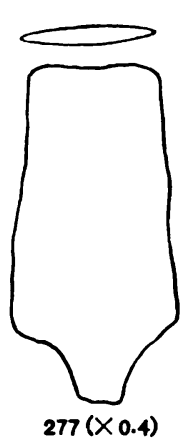
and +52 feet, terrace $A$, and the outer digging down to the level of +4 feet 2 inches. The number of copper finds brought to light there is very small. It is possible that a piece of wire (S.K. I I, fig. 286), belongs to a pin. It was found 3 feet below

the surface of the upper digging. The purpose of a little rod (S.K. 145; fig. 287; plate 39 , fig. 8 ) is indeterminable. The rod comes from the outer digging, between +6 feet 5 inches and + ro feet. The most important find, however, is a threeedged arrow-point of copper; that is, it has a triangular cross-section (S.K. 8; fig. 288; plate 39, fig. 7). The three edges are raised slightly above the deeperlying lateral faces and they are extended downward into blunt projecting points. It has no socket for the shaft-merely a hole bored into the heart of the copper. It was found April 8, 1904, 5.25 feet below the highest edge of terrace A, which practically corresponds to the absolute level +35 feet. But since the layers in terrace $A$ fall with the present surface of the hill toward the northern plateau extension, they are to be considered in relation to the horizontal strata of the 
upper digging. The pottery found with the arrow-point is identical with the younger pottery in the upper layers of the upper digging. There can, therefore, be no doubt that the finds of April 8 at this point belong to the younger culture IV. It is only in the deeper levels of terrace A that the older (mixed) layers occur. In considering the conditions connected with these finds, those connected with the finds of iron objects in terrace $A$ should be taken into account.

Fragments of awls or punches and pins (S.K. 96) occur in the "mixed" layers of terrace A, just as they do throughout the middle layers of the hill. Therefore these may be assigned to the older culture. It is uncertain to which culture we shall assign the arrow-point above mentioned, which came from the outer digging between +2 feet 2 inches and +4 feet 2 inches (fig. 28I).

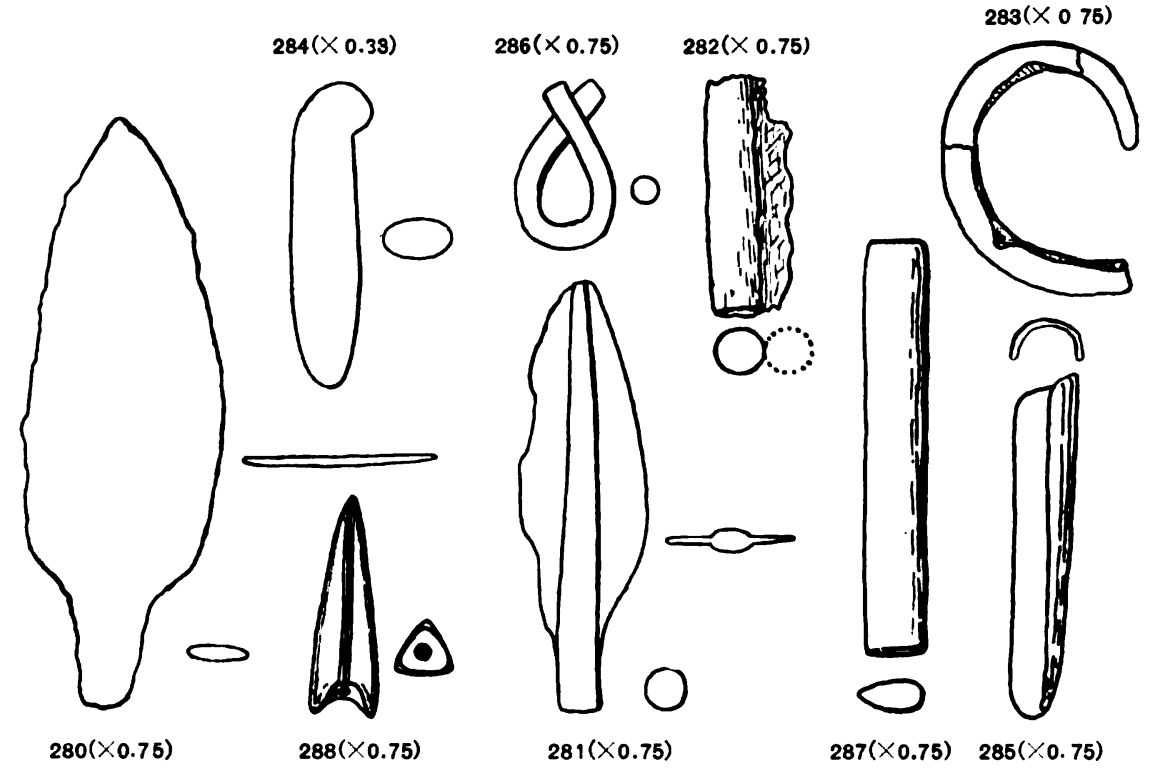

(b) IRON.

Excepting a piece of a modern iron band taken from the débris in Komorof's trench, and a modern iron nail from the surface of the terrace vi, iron was found only in the upper layers of the South Kurgan. Hence we can unhesitatingly draw the conclusion that iron was unknown to the inhabitants of both hills, during the life of the older epochs, these epochs being also sharply differentiated from the younger by their pottery. Iron was found in the upper digging just under the surface in terrace $A$ and in the outer digging; that is, at all those points whose pottery characterized the youngest culture.

There can be little doubt that we have a sickle in the two much-rusted fragments (S.K. 4I; fig. 289; plate 39, fig. 4). The fragments show a broad, short handle and two rivets. The point at which this sickle was found is of prime significance, it having been collected in terrace A on April 12, 1904, at the deepest level at which iron was found in this terrace. On that day the absolute level of +27 feet was reached here. This, according to the calculations of R. W. Pum- 
pelly, corresponded to the layers between +43 and +48 feet of the upper digging, and was therefore wholly in the region of the younger culture IV. In full accord with this is the fact that the pottery fragments found from April I I to I 4 in terrace A belonged for the greater part to the younger pottery of red clay, while only isolated specimens of that made of gray clay were observed. It was not till April I 5 that the gray ware appeared more often.

The three other finds of iron from terrace A came from still higher layers. Of these, the fragment of a sickle (S.K. 22; fig. 290; plate 39, fig. 5), was found on April 9; that is, deeper than the above three-edged copper arrow-point. A four-edged bar (S.K. 25; fig. 29I ; plate 39, fig. 6) was found on April I I between +27 and $+3 \mathrm{I}$ feet, and at the same time some indeterminable fragments (S.K. 35).

Two other finds were made-a piece of a knife (S.K. 2, fig. 292) in the upper digging I foot ro inches below the surface, and some fragments (S.K. 109) in the outer digging, about 2 feet deep, in the neighborhood of the pithos found there in situ. This closes the list of iron objects found in the Anau kurgans.

(c) LEAD.

Objects of lead were found only in the middle layers of the North Kurgan. They belong, therefore, to the oldest culture epoch, I. Indeed, lead was made into objects of ornament, and stands, therefore, on a par with copper. This is shown also in the forms. Such ornaments of lead are found among the burial gifts in the burials of terrace $\mathrm{II}$ at +22 feet 5 inches. Like the copper ornaments, they occur in the form of cylindrical spirals and cylindrical tubes (N.K. 143; fig. 293; plate 40, fig. 3 ; and N.K. 185; fig. 294; plate 36 , fig. I).

Of the lead spirals, which belong to the burial gifts with skeleton 13 , the largest has six windings, apparently fully preserved. Of the other one pictured, only 4.5 windings are preserved; a third one, not pictured here, is broken and much bent. The lead tubes from the burial gifts of skeleton 14 differ from the analogous copper tube found with them in that they are wholly closed on the sides (cf. the abovementioned spiral tube with fig. 237).
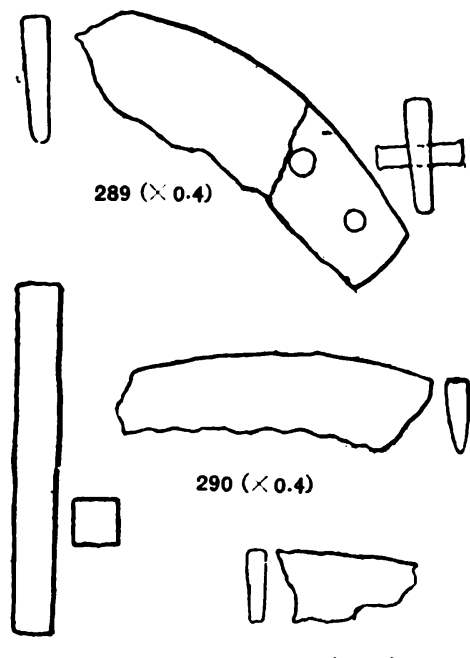

(d) ORNAMENTS OF STONE, CLAY, AND FAIENCE.

FROM LOWER AND MIDDLE STRATA OF NORTH KURGAN, CULTURE I.

Beads.- In the list of burial gifts of the lower and middle strata of the North Kurgan there were, besides copper and lead ornaments, numerous beads. Very peculiar and primitive are six turquoise beads which were found, with two small drilled snail shells, with skeleton 17 at -8 feet in the shaft of the east gallery (cf. N.K. I13; fig. 295; plate 40, fig. 7). They occur in two forms, are nearly beanshaped, and, like slides, are pierced transversely (fig. 295). Stone beads of 
different color and differently formed were found with the skeleton $I \mathrm{I}$ in terrace II at between +20.5 and +22.5 feet (N.K. 114; fig. 296; plate 40, fig. 2 ): One large one, elongated, with four rounded edges of unequal size, made out of a yellowwhite material; 58 small ones of similar stone, approximately double-conical, with truncated points; and I I made from blood-red stone, nearly ring-shaped, but unequally cut (cf. fig. 296).

With another skeleton (No. 13), in the same locality, +22 feet 5 inches, there occurred, besides the three lead spirals, two small white stone beads of about the

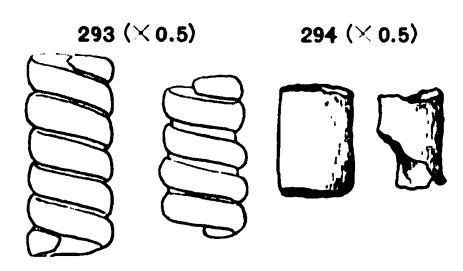
same form and kind as those just mentioned (N.K. 143; fig. 297; plate 40, fig. 3). The third skeleton, No. 12, found there had for a burial gift 67 small white stone beads (N.K. 144; fig. 298; plate 40, fig. 8), most of them of the same form as those just described-cylindrical with beveled edges. The other
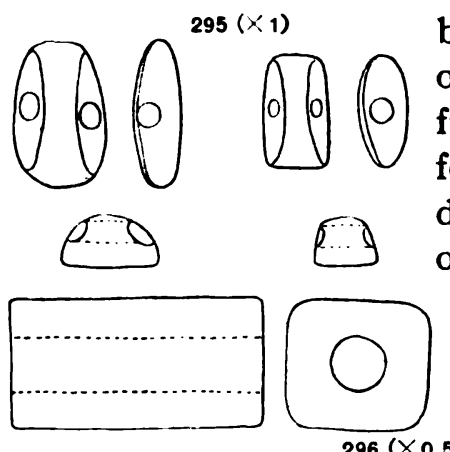
beads found are separate finds. One was barrel-shaped, of white stone (N.K. I40; fig. 299; plate 40, fig. I I) from terrace II, between +20 feet 5 inches and +22 feet 5 inches; another, a sniall whitish stone bead, cylindrical, with unequal sides; another, the half of a bead of polished marble in the form of an angular disk (N.K.
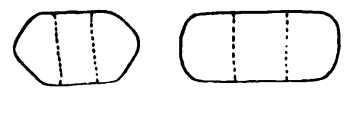
24I; fig. 300); both of the latter from the north digging II, between +20 feet 5 inches and +24 feet 5 inches; and lastly, an angular

bead of dead-white stone (N.K. 243; fig. 301) from north digging IV.

The clay beads are either double-conical, like N.K. 152 (fig. 302), from terrace vir at +23 feet, or spherical, like N.K. 219 (fig. 303), from north digging II, between -20 feet 5 inches and -24 feet 5 inches. Similar double-conical ones were found in the west digging between +13 feet 4 inches and +18 feet (N.K. 24); also in the shaft of the west gallery between $o$ and -1 foot.

Miscellaneous.-There is little else to be noted in the way of ornament. A clay knob, somewhat pear-shaped, with impressions in the upper edge (N.K. 57; fig. 304; plate 40, fig. 13), comes from the north digging II, between -12 and - I3 feet. A more simple clay knob (N.K. 25I) is shown in fig. 305 and plate 40, fig. 12. An object made of gypsum (N.K. 43; fig. 306; plate 40, fig. 4), also a knob, is from north digging $\mathrm{I}$, between - Io feet and - II feet 5 inches. An ornamental disk of gypsum with central hole (N.K. I1 2; fig. 307; plate 40, fig. 14), is of undetermined derivation.

\section{FROM UPPER STRATA OF NORTH KURGAN, CULTURE II.}

Beads.-The beads of the upper strata are all burial gifts of the skeletons found in the terraces. Those found in terrace $\mathrm{I} a$ (cf. above, page 89) are N.K. I, fig. 308; plate 40, fig. I); two carnelian beads, one light-colored and cylindrical, the other dark and ring-shaped; a bead of lapis lazuli, bluish-white 
with blue spots and cylindrical; and a pendant of lapis lazuli, blue with white spots. Of identically the same material as the last-named bead was an irregular cylindrical bead (N.K. 26; fig. 309; plate 40, fig. 10), found with skeleton 2 of terrace $\mathrm{I}$. The other skeleton, No. 5 , in terrace $\mathrm{I},+30$ feet, also had burial gifts, which in material and form class themselves with those just mentioned (N.K. 50; fig. 310; plate 40, fig. 6); four beads of lapis lazuli, of which two are angular, the others irregularly double-conical, with truncated points; two of them are bluish-white with blue spots, the third light-blue with white spots, the fourth uniformly light-blue. A large quantity of very small cylindrical beads of yellowishwhite stone were found with the skeleton Ig $_{9}$ in terrace $v,+29$ feet (N.K. 222; fig. 3 I I plate 40 , fig. 5).

FROM MIDDLE AND LOWER STRATA OF SOUTH KURGAN, CULTURE III.

Beads.-There is only a single bead to be noted from the skeleton graves of the South Kurgan-a small, cylindrical, yellowish-white stone bead (S.K. 244; fig. 312 ; plate 41 , fig. I6). It was found April 22 , 1904 , in terrace $B$, with skeleton $19,+27$ feet.

All the other beads were separate finds, which are described as follows: Two beads, one graystriped and barrel-shaped, the other gray-green with dark veins and annular (S.K. 104; fig. 313; plate 4I, fig. II). They were found in terrace $B$, between +25 and +26.25 feet. One bead (S.K. 287; fig. $3 \mathrm{I} 4$; plate $4 \mathrm{I}$, fig. 5 ) is very remarkable on account of its material and form. It comes from terrace $B$, between +19 and +20 feet. It is somewhat flat, the shape of a prune stone, elliptical in cross-section, and shows a peculiar pattern on both sides-darkgray on a light-gray ground. It is a polished pebble, containing a fossil. Another bead (S.K.I 57) of lenticular cross-section and cylindrical in longitudinal section, with indrawn sides and made of milk-white
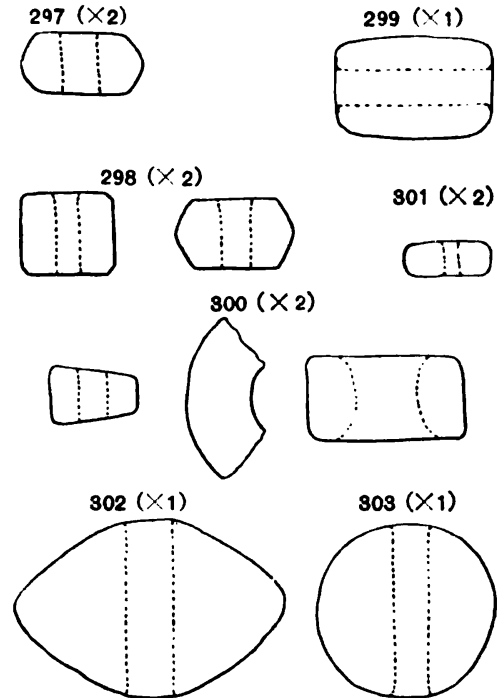
alabaster with water-gray stripes, is shown in fig. 315 , and plate 41 , fig. 12 . It comes from terrace $\mathrm{C}$, between +23 feet 2 inches and +26 feet 2 inches. At the same terrace, between +21 feet 2 inches and +23 feet 2 inches, there were found two beads (S.K. 218; fig. 316; plate 4I, fig. 4). One is made of carnelian, nearly spherical; the other of dark-brown lapis lazuli, in pyramidal form and pierced at the top like a pendant.

There were found numerous double-conical stone beads in the form of whorls, made from variegated materials and always well polished. They are either low and wide or high and narrow. A gray-green specimen (S.K. 193) is shown in fig. 317 and plate 42 , fig. 4 . It is from terrace $B$, between $+2 I$ feet 5 inches and +23 feet 7 inches. In terrace $C$, between +21 feet 2 inches and +23 feet 
2 inches, there was found a chocolate-colored bead and one light-yellow, both shaped as shown in fig. 318 and plate 42 , fig. 3 (S.K. 194). At the same place, between +18 feet 5 inches and +19 feet 5 inches, there was found a light-gray bead (S.K. 299) with light-brown stripes. A dark-gray specimen (S.K. I52; fig. 319), of less regular workmanship and bored with a large hole, was found in terrace $B$, between +21 feet 5 inches and +23 feet 7 inches. A similar one was observed also in the upper digging, between +25 feet 5 inches and +29 feet 5 inches. These beads are also often ornamented with small single or concentric circles with a central point, which must have been made with a compass. Two
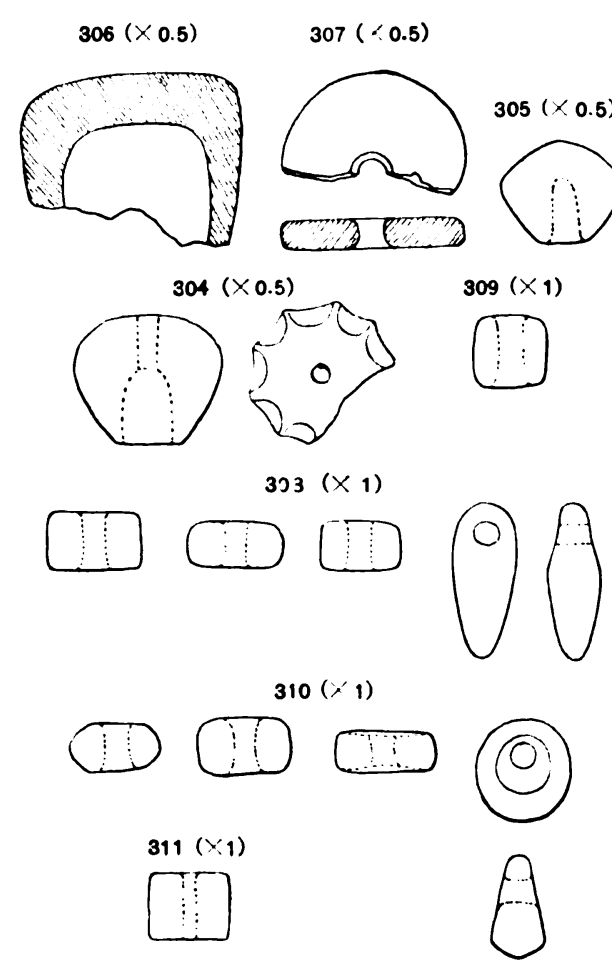
specimens made of greenish stone (S.K. I 24; fig. 320 and plate 42 , fig. I) were found in terrace $B$, between +23 feet 7 inches and +25 feet, and another at the same place but deeper, between $+2 \mathrm{I}$ feet 5 inches and +23 feet 7 inches (S.K. 253).

The clay beads are, like those of the North Kurgan, spherical or double-conical as in S.K. I50 (fig. 321), from the upper digging, between +25 feet 5 inches and +29 feet, and S.K. I5I (fig. 322), from terrace B, between +21 feet 5 inches and +23 feet 7 inches.

Especially worthy of remark is a doubleconical bead of blue-white faience (so-called Egyptian porcelain), with blue-white glaze (S.K. 154; fig. 323 and plate 42 , fig. 8). It was found in the upper digging in the layer of the pithoi between +25 feet 5 inches and +29 feet.

Miscellaneous.-A toggle-like object of quartz with a central groove (S.K. 82; fig. 324 and plate $4 \mathrm{I}$, fig. 22) was found in the

upper digging, between +37 and +40 feet. One can not say whether it was for ornament or use.

A clay disk of light-gray material, almost wholly blackened, was probably an ornament. It has a notched edge and two eccentric transverse holes (S.K. 318; fig. 325 and plate 4 I, fig. 21 ) from terrace B, between +18 and +21 feet.

FROM UPPER STRATA OF SOUTH KURGAN, CULTURE IV.

Beads.-A small cylindrical turquoise bead (S.K. 28; fig. 326) was found in terrace $A$, between +27 and +31 feet, among the fragments of the younger pottery of the upper digging. To the younger culture of the kurgan also there belongs a barrel-shaped bead of bluish-white glass, with fine black points (S.K. 65; fig. 327; plate $4 \mathrm{I}$, fig. I 4 ), from the upper digging, between +40 and +43 feet. A stone bead in the form of an egg with truncated point, of light-gray 
PLATE 40.

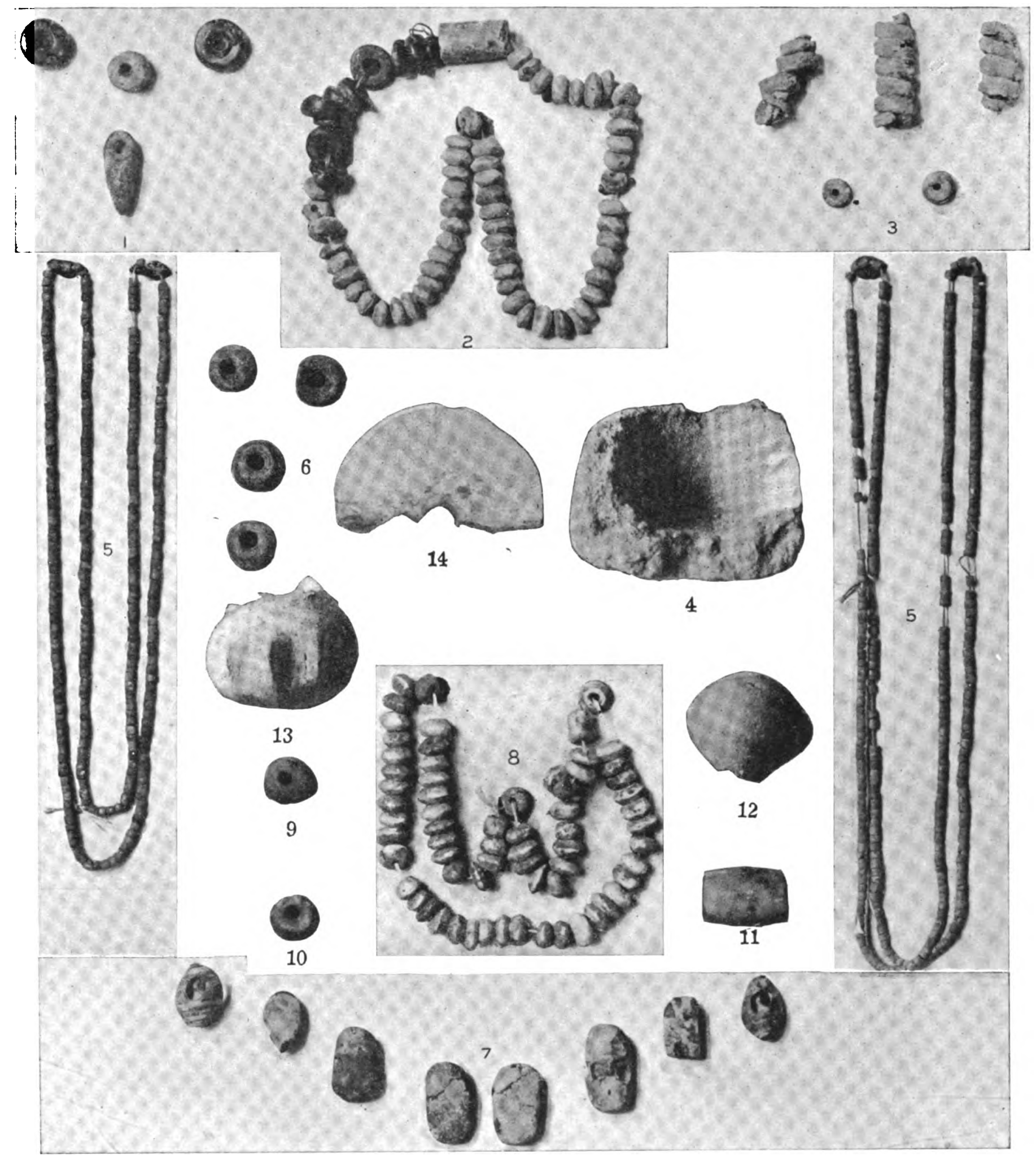

Beads and Ornaments, Cultures I and II, North Kurgan.

Fic. 1 (N.K. 1). Two Carnelian Beads, and a Bead and Pendant of Lapis Lazuli, Terrace Ia, Culture II, text-figure 308.

2 (N.K. 114). Beads of Yellowish-white Stone, 1 large, 58 small, and 11 of Blood-red Stone, Terrace II, between +20.5 and +22.5 feet, with Skeleton No. 11 3 (N.K. 143). Cylindrical Spirals of Lead, 2 White Stone Beads, Terrace II, +22.5 feet, with Skeleton No. 13, Culture I, text-figures 293 and 297. 4 (N.K. 43). Knob of Gypsum, North Digging $I,-10$ to -11.5 feet, Culture 1 , text-figure 306 .

5 (N.K. 222). 1,066 Small White Stone Beads, Terrace V, + 29 feet, with Skeleton No. 9. Culture II, text-figure 311.

6 (N.K. 50). Four Beads of Lapis Lazuli, Terrace I, +30 feet, with Skeleton No. 5, Culture II, text-figure 310.

7 (N.K. 113). Six Beads of Turquoise and two Pierced Shells, East Gallery, -8 feet, with Skeleton No. 17 , Culture I, text-figure 295.

8 (N.K. 144). 67 Small White Stone Beads, Terrace II, +22.5 feet, with Skeleton No. 12, Culture I, text-figure 298.

9 (N.K. 11). Clay Bead, North Digging. I, Burial Gift, Culture I.

11 (N.K. 140). Bead of White Stone, Terrace II, +20.5 feet, Culture I, text-figure 299.

12 (N.K. 251). Clay Knob, Culture I, text-figure 305.

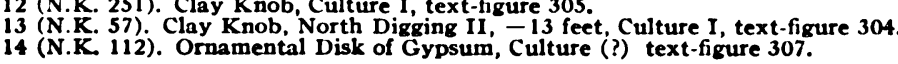


Digitized by Googie 

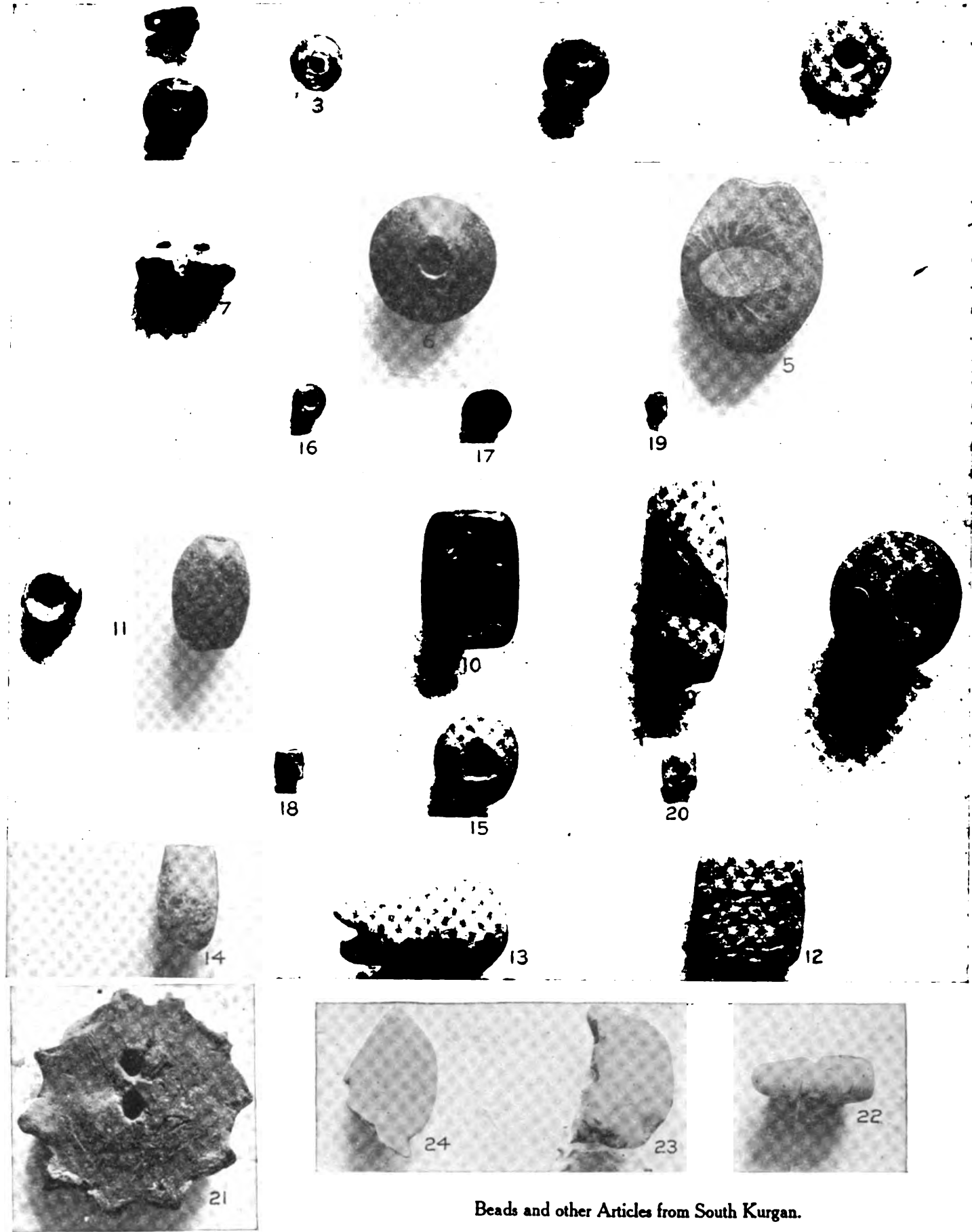

Beads and other Articles from South Kurgan.

Fio. I (S.K. 243). Flat Bead of Marble, Terrace II, +19 to +21.5 feet, Culture III, text-figure 335.

3 (S.K. 125). Light-blue Glass Bead, Dump from Terrace B; possibly from Wash Debris and of indeterminable age, 4 (S.K. 218). Two Beads: One Carnelian, One Pendant of Lapis Lazuli, Terrace C, +23 to +26 feet, Culture III, 5 (S.R. 287). Bead of Polished Limestone with Fossil Coral, Terrace $B_{,}+19$ to +21 feet, Culture III, text-figure 314. 6 (S.K. 1.53). Double-conical Bead, Upper Digging, +25 to +29 feet, Culture try

7 (S.K. 86). Three-sided Slide of Greenish-white Glass or Material Resembling Faience, from Mixed Talus-débris of 8 (S.K Terrace A (North Terrace); doubtrul age. Text-figure 333 .

8 (S. K.). Stone Bead with Concentric Circles, Culture III, text-figure 320.

10 (S. K. 73). Three-sided Stone Seal with Pigures in Intaglio of Lion, Griffin, and Man, Terrace B, 28 feet, Culture 11 (S.K. 104). Two Beads: One Striped Gray, One Gray-green with Dark Veins, Terrace B, +25 to +26 feet, Culture 12 (S K. 157). Bead of White Alabaster, Terrace $C .+23$ to +26 feet, Culture III, text-figure 315.

13 (S.K. 224): Pendant of Marble, Terrace B, +21.5 to +24 feet. Culture III, text-figure 339 .

14 (S.K. 65). Bead of Bluish-white Glass, Upper Digging, +40 to +43 feet, Culture IV, text-figure 327.

16 (S.K. 244). Cylindrical White Bead, Terrace B, +27 feet, with Skeleton No. 19, Culture III, text-figure 312.

17 (S.K. 24). Cylindrical Bead, Terrace B, 3 feet below surface at +38 feet, Culture IV (?), text-figure 336 .

18 (S.K. 89). Stone Bead. Terrace A, Mixed Talus. Culture (?), text-figure 332

19 (S K. 245). Turquoise Bead, Terrace C, possibly from Superficial Talus-débris, Culture IV (?).

20 (S K. 69). Turquoise Bead, Terrace A, Mixed Talus-débris, Culture (?), text-figure 331.

21 (S.K. 318). Ornamental Clay Disk, Terrace B, +18 to +21 feet, Culture III, text-figure 325.

22 (S.K. 82) Toggle-shaped Object of Quartz, Upper Digging, +37 to +40 feet, Culture III, text-figure 324.

23 (S.R. 15). Bead of Shell, Upper Digging, 47 to + 



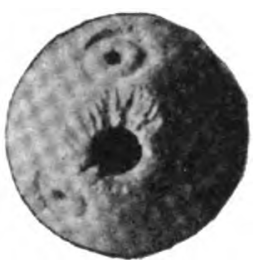

1

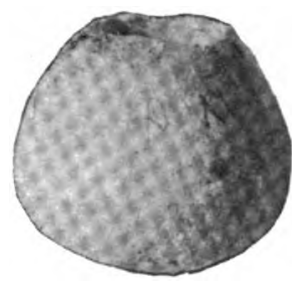

2

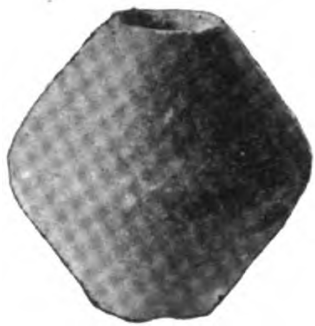

3

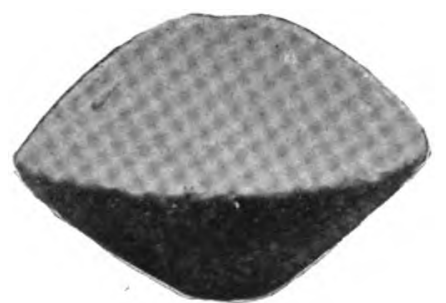

4

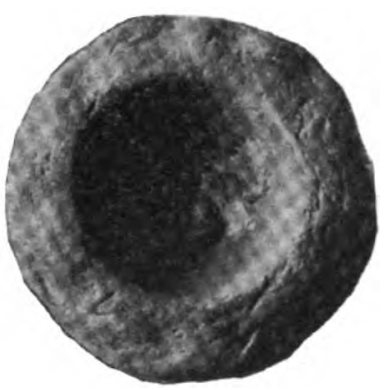

6

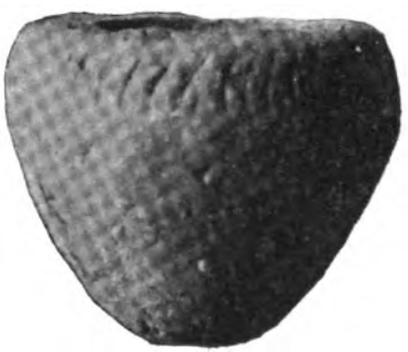

9

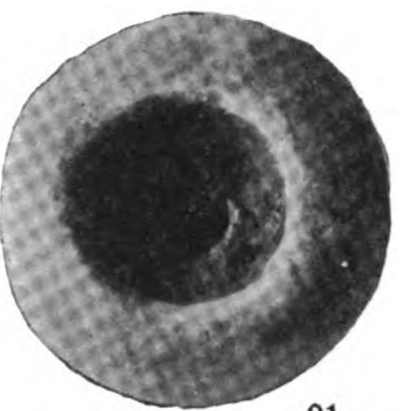

21

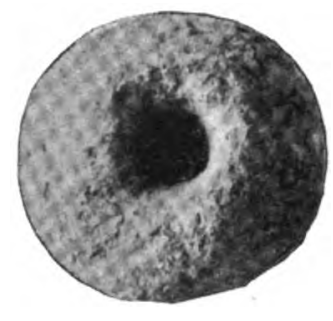

7

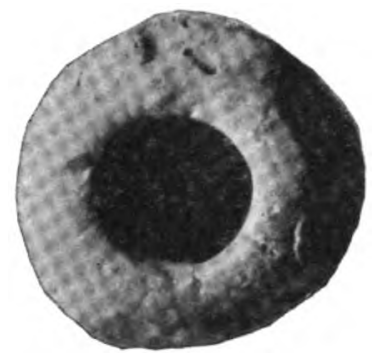

11
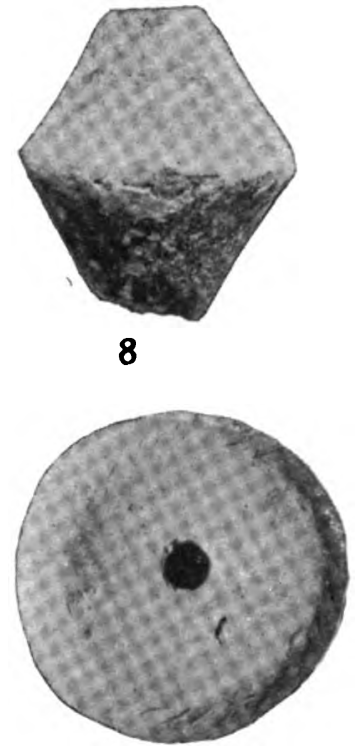

12

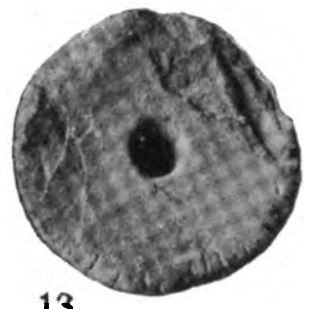

13

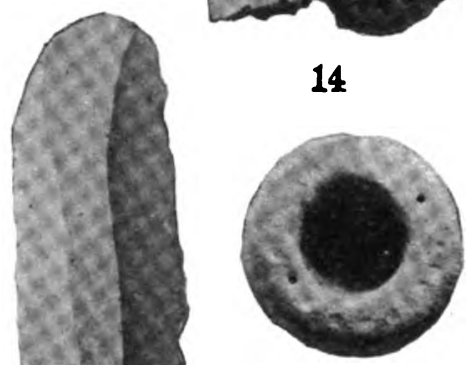

10

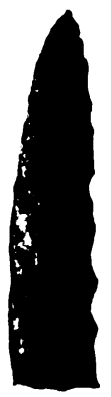

19
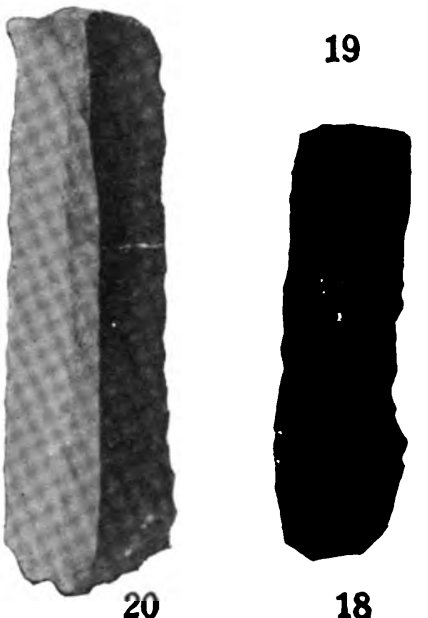

18

Beads from South Kurgan. Whorts and Flints from North Kurgan.

Fio. 1 (S. K. 124). Large Stone Bead. Terrace B, +23.6 to +25 feet, Culture III, text-figure 320.

2 (S.K. 32). Polished Stone Bead, Upper Digging, ++6 to +47 feet, Culture IV, text-figure 328.

3 (S.K. 194). Double-conical Bead of Polished Stone, Terrace C, +18.5 to +19.5 feet, Culture III, text-figure 318 .

4 (S.K. 193). Double-conical Bead, of Polished Stone, Terrace B, +21.5 to +23.5 feet, Culture III, text-figure 317 .

6 (N.K. 51). Clay Spindle-whorl, Middle Strata. North Kurgan, Culture I, text-figure 346.

7 (S.K. 84). Clay Knob, Terrace A, from Mixed Talus-débris, Culture (?), text-figure 340.

8 (S.K. 154). Double-conical Bead of Blue-white Faience (so-called Egyptian Porcelain), Upper Digging, +

9 (N.K. 192). Striated Whorl with Concave Top. Middle Strata, North Kurgan, Culture I, text-figure 348.

10 N.K. 191). Whorl with Combined Pierced and Striated Ornament, Middle Strata, North Kurgan, Culture 1.34.

11 (N.K. 196). Whorl with Impressions formed with Fingers, Lower Strata, North Kurgan, Culture I, text-figure 345.

12 (N.K. 60). Whorl with Concave Top and Striated Edge, Lower Strata, North Kurgan, Culture I, text-figure 347.

14 (N.K. 60). Whorl with Concave T 122 ). Belongs with No. 5 .

15 (N.K. 44). Polishing Stone (?), North Digging II. -8 to -11 feet; probably in wash from talus-débris; Culture (?), text-fig. 362.

16 (N.K. 101). Two-edged Flint Knife. Terrace V, +28 to +32 feet, Culture II, text-figure 356 .

17 (N.K. 7). Two-edged Flint Knife, West Pit. Komorof's Trench. Culture I or II, text-figure 357.

18 (N.K. 16). Two-edged Flint Knife, East Pit, Komorof's Trench, Culture I or II text-figure 355 .

19 (N.K. 162). One-edged Flint Knife, Terrace VII, +23 to +24 feet, Culture I, text-figure

20 (N.K. 249). Scraper or Knife, Low 
Digitized by Google 


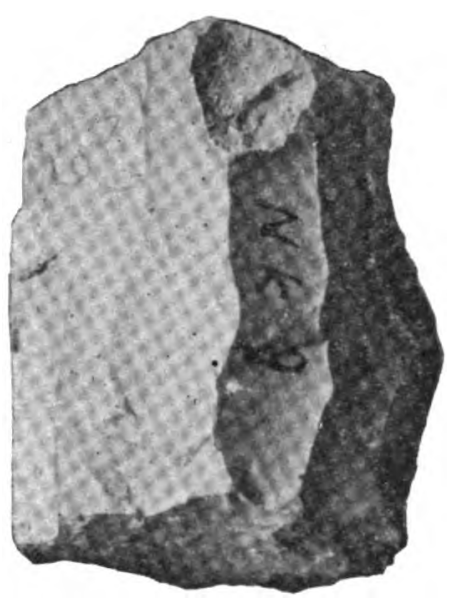

1

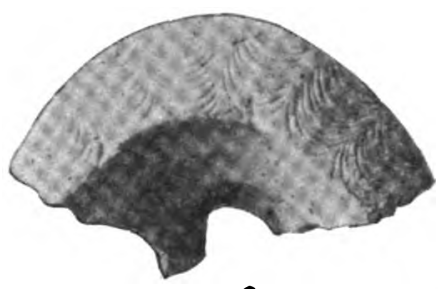

82

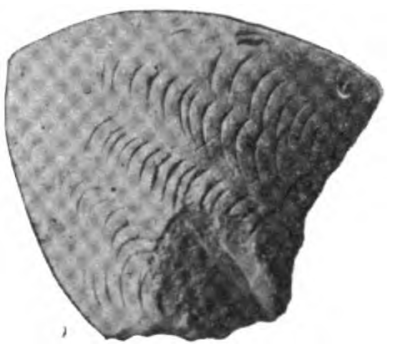

$8 b$

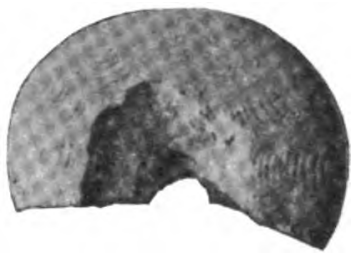

10

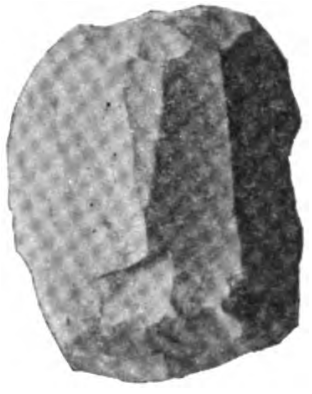

2

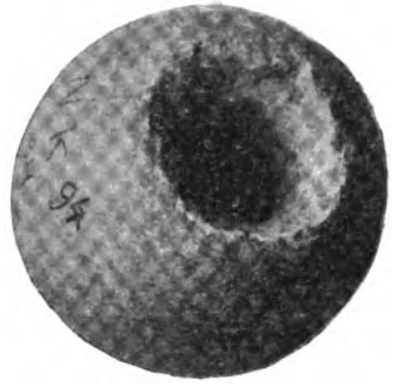

4

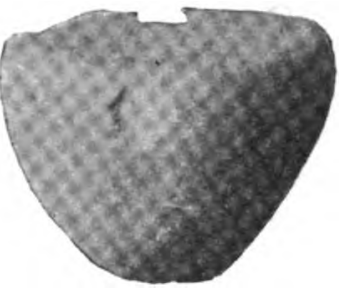

15

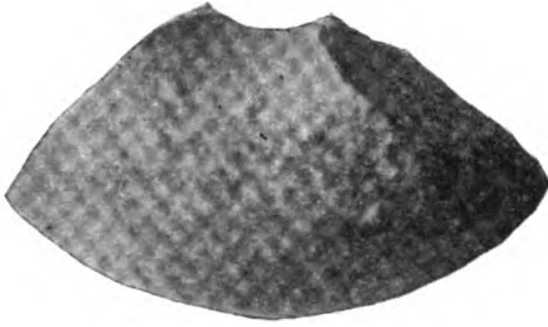

3

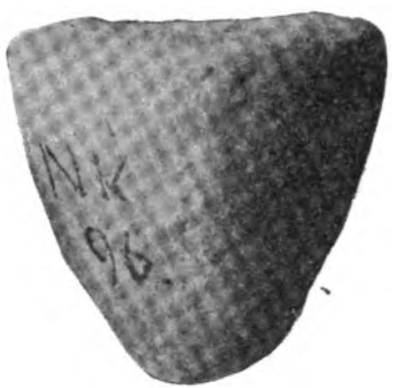

14

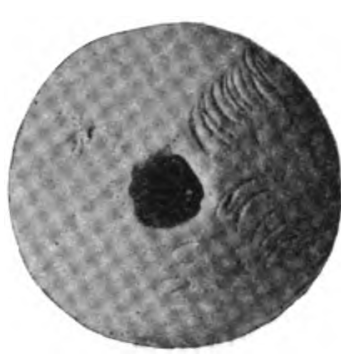

11

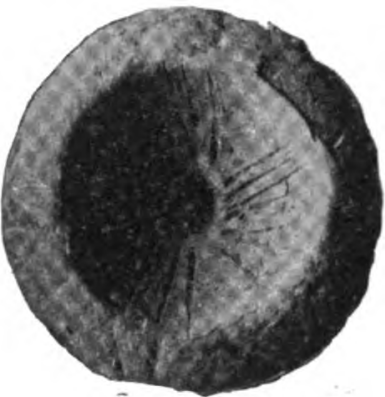

13

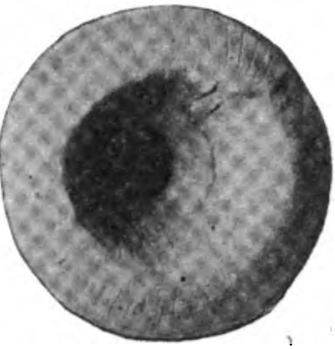

12

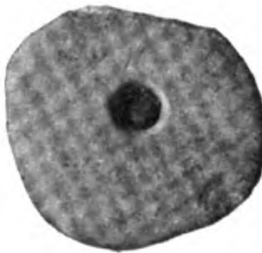

5

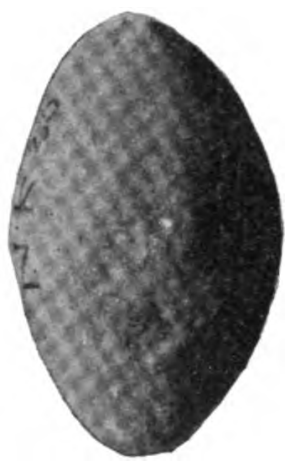

6

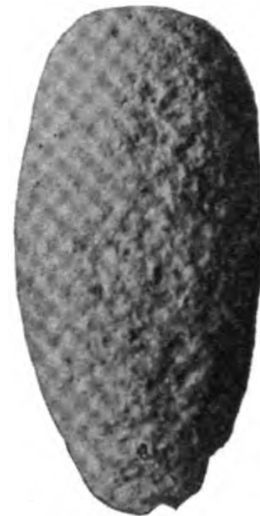

7

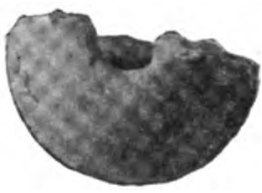

9

Objects of Stone from North Kurgan and Clay Spindle-whorts from South Kurgan.

Fic. 1 (N.K. 9). Flint Nucleus, Loose Bottom. Komorof's Trench, Culture I or II, text-figure 358.

3 (N.K. 31). Flint Nucleus, Middle Strata, North Kurgan, Culture I, text-figure 359. 4 (N.K. 94). Stone Mace-head, Terrace V, +28.5 to +32 feet, Culture II, text-figure 361.

5 (N.K. 181). Pierced Slate Disk, Terrace I, +23 to +25 feet, Culture I, text-figure 365 .

6 (N.K. 25). Clay Slingstone, Terrace I, +30 feet, with Skeleton No. 5, Culture II, text-figure 364. 7 (N.K. 240). Stone Slingstone, North Digging IV, wholly in irrigation sediments. The object was washed into position from Strata of Cultures I or II, or possibly at a later period. Culture (?), text-figure 363 .
$8 a$ AND $b$ (S. K. 113). Clay Whorl Showing Systematic Grouping of Crescent Curves in Contrast to Simpler Use of this Ornament in Oider Cultures of North Kurgan, Upper Digging, +32 to +33 feet, Culture III, text-figure 367

9 (N.K. 28). Half a Polished and Pierced Marble Ball, West Gallery, 0 to -7 feet, Culture 1 . text-figure 366.

10 (S.K. 366). Clay Whorl with Systematic Crescent-curve Decoration, Shaft C, tis feet, Cuiture III, text-figure 368.

I1-13 (S. K. 357, 51, 229). Whorls with Varied Systematic Ornamentation, Middle and Lower Strata, South Kurgan, Culture III.

14 (N.K. 96). Whorl, Terrace III, +18 to +20 feet, Culture I.

16 (N.K. 191) Whorl, Terrace II, +19 to +20 feet, Culture I. 
Digitized by GOOgle 
color and well polished (S.K. 32; fig. 328; plate 42, fig. 2), came from the upper digging, between +45 feet $I$ inches and +47 feet. It has a peculiar perforation, which tapers toward the interior.

Miscellaneous.-Ornamental disks with central perforation served the same purpose as the beads. S.K. 15, fig. 329 (plate 4I, fig. 23), shows half of one of lenticular shape, consisting of milk-white, finely polished material (shell?). It is from the upper digging, between +47 and +50 feet. The fragments of another lenticular disk of polished marble (S.K. 45 ; fig. 330; plate 4I, fig. 24) were found in the upper digging, somewhat deeper, between +43 and +45 feet.

\section{UNCERTAIN WHETHER FROM OLDER OR YOUNGER CULTURE, SOUTH KURGAN.}

In addition to the ornamental objects just enumerated there is a series of beads and similar ornaments, but the conditions of their occurrence do not permit us to say to which of the two culture epochs of the South Kurgan they belong.

First of all, delicate turquoise beads, in the same class with the one mentioned above, are shown in fig. 326. One of these, barrel-shaped in longitudinal section, lenticular in cross-section (S.K. 69; fig. 33I; plate $4 \mathrm{I}$, fig. 20), is from ter-
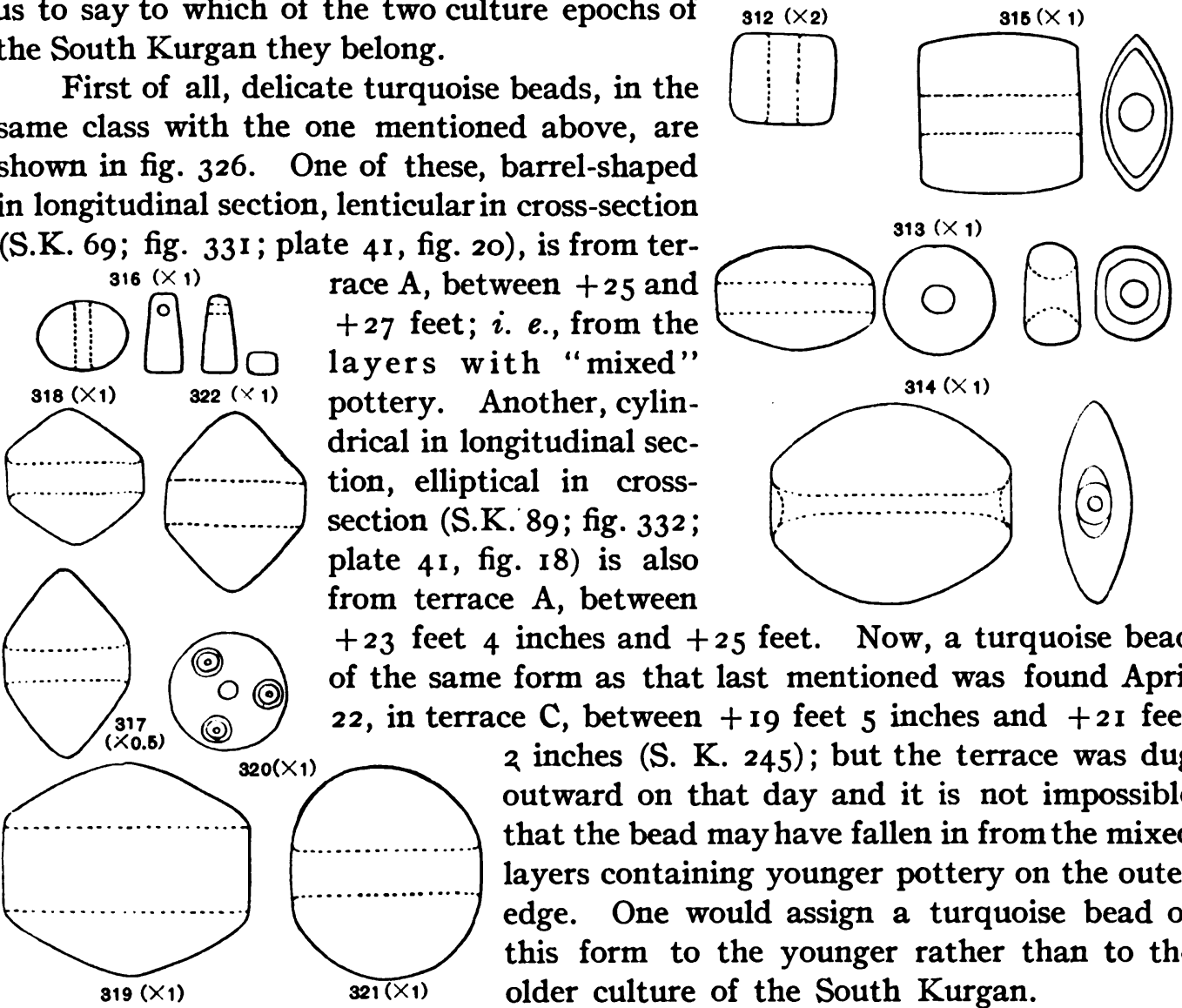
from terrace $A$, between +23 feet 4 inches and +25 feet. Now, a turquoise bead of the same form as that last mentioned was found April in terrace $\mathrm{C}$, between +19 feet 5 inches and $+2 \mathrm{I}$ feet 2 inches (S. K. 245); but the terrace was dug outward on that day and it is not impossible that the bead may have fallen in from the mixed layers containing younger pottery on the outer edge. One would assign a turquoise bead of this form to the younger rather than to the older culture of the South Kurgan.

The "mixed" layers of terrace A, between +23 feet 4 inches and +25 feet, furnished also a three-sided slide made of greenish-white glass of faience-like material, with two perforations and two notches on the edge (S.K. 86; fig. 333; plate $4 \mathrm{I}$, fig. 7). A very striking bead is shown in S.K. 246 (fig. 334; plate $4 \mathrm{I}$, fig. 9). It is large and barrel-shaped, made of milk-white agate, striped with 
light-gray. It came from terrace $\mathrm{C}$, between +9 feet 5 inches and $+2 \mathrm{I}$ feet 2 inches. At the same point there was found an angular disk of marble (S.K.
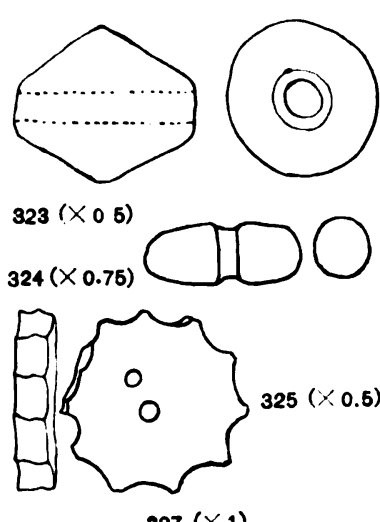

$327(\times 1)$

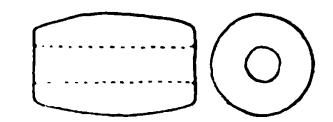

$326(\times 2)$
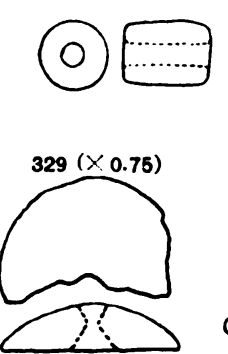

$328(\times 0.5)$
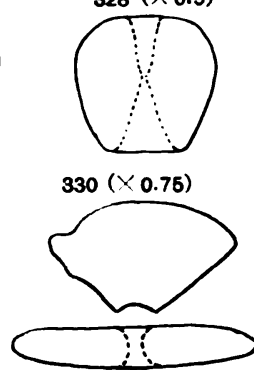

243; fig. 335 ; plate $4 \mathrm{I}$, fig. I). It remains to be determined of what material the bead (S.K. 24) shown in fig. 336 and plate 41 , fig. 17 , was made. It is cylindrical, with depressed upper and lower sides, consisting of soft brown material, and was found in terrace B, April II, I904. A nearly spherical light-blue glass bead (S.K. I25) is also striking on account of the material of which it is made. It is shown in fig. 337 and plate $4 \mathrm{I}$, fig. 3, and was found April 19, in the dump of terrace $B$, which had been enlarged; it may therefore have come from the surface of the hill.

A button of dark-brown lapis lazuli (S.K. 219; fig. 338 ; plate $4 \mathrm{I}$, fig. 2), belongs more in the class of the older lapis-

lazuli ornaments. It is remarkable for its notched perforation. It was found in the outer digging, between +2 feet 2 inches and +48 feet 2 inches, in a layer where very few fragments of pottery were found, although fragments showing the technique and forms of the older pottery occurred occasionally, together with those of the younger kind.

We can probably assign to the older culture a pendant of marble (S.K. 224; fig. 339; plate $4 \mathrm{I}$, fig. I3) found in terrace $B$, between +21 feet 5 inches and +23 feet

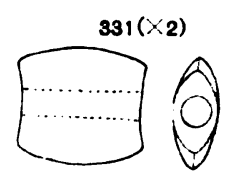

$332(\times 2)$
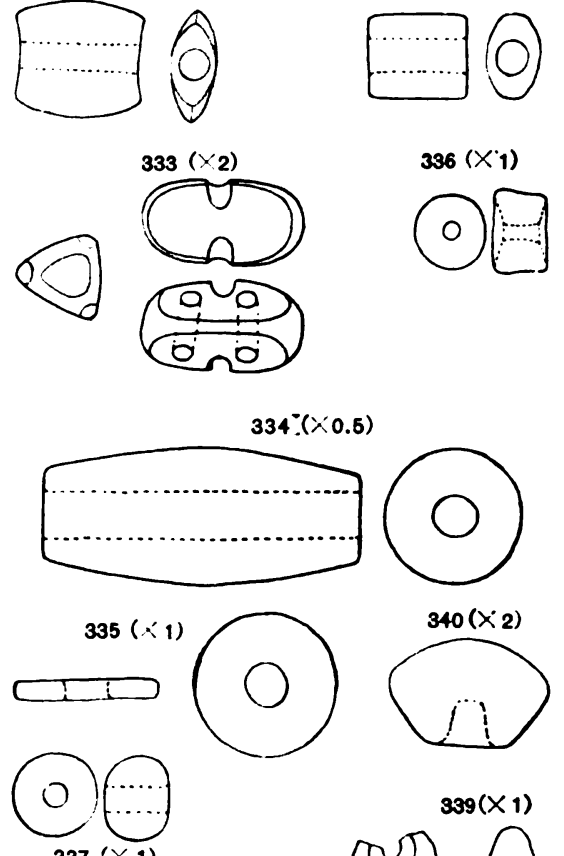

$337(\times 1)$

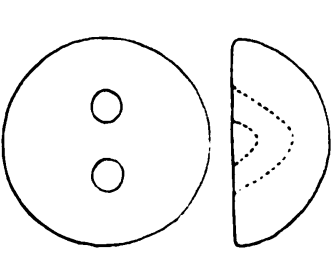

$338(\times 2)$

7 inches, but I mention it here because it was found on the day that the terrace was widened outward. Lastly may be mentioned a small clay knob (S.K. 84; fig. 340 ; plate 42 , fig. 7) from the mixed layers of terrace $A$, between +23 feet 4 inches and +25 feet. 
(e) USEFUL OBJECTS OF STONE, CLAY, AND BONE.

FROM MIDDLE, LOWER, AND UPPER STRATA, NORTH KURGAN, CULTURES I AND II.

Whorls of clay.-It is difficult to make any essential distinction between the whorls of the middle and lower strata in respect to form, technique, and ornamentation. For that reason I do not mention in detail the points at which they were found. The most favored form is the conical, with and without raised edges, and with a deep impression on the upper side of the whorl, as in N.K. 96 (fig. $34 \mathrm{I}$ ) and N.K. 67 (fig. 342). More rare is the conical form with convex top like N.K. IO2 (fig. 343); and other simpler forms are not lacking, as N.K. 191 (fig. 344).

The technique of decoration is restricted to impressions of the finger and finger-nails, as well as to pricked-in points. In so far as we can judge from the abundant material thus far obtained, the technical differences in the whorls of the middle strata were due to the instruments used to impress the patterns - a point to make the dots and a knife or a pinshaped instrument for fine short
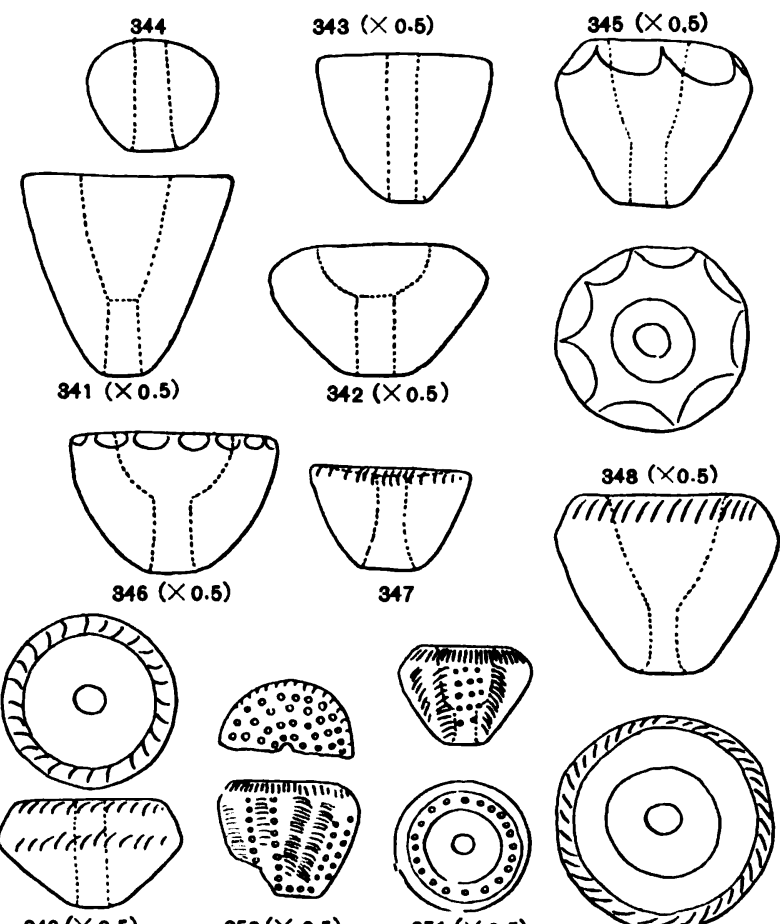

$350(\times 0.5)$
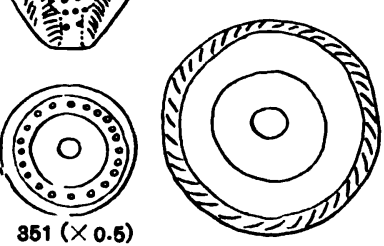

strokes. Whether these differences indicate a marked progress in the technique can not, of course, be determined from the material in hand. The line pattern is for the most part too fine and too closely compressed to have been made with
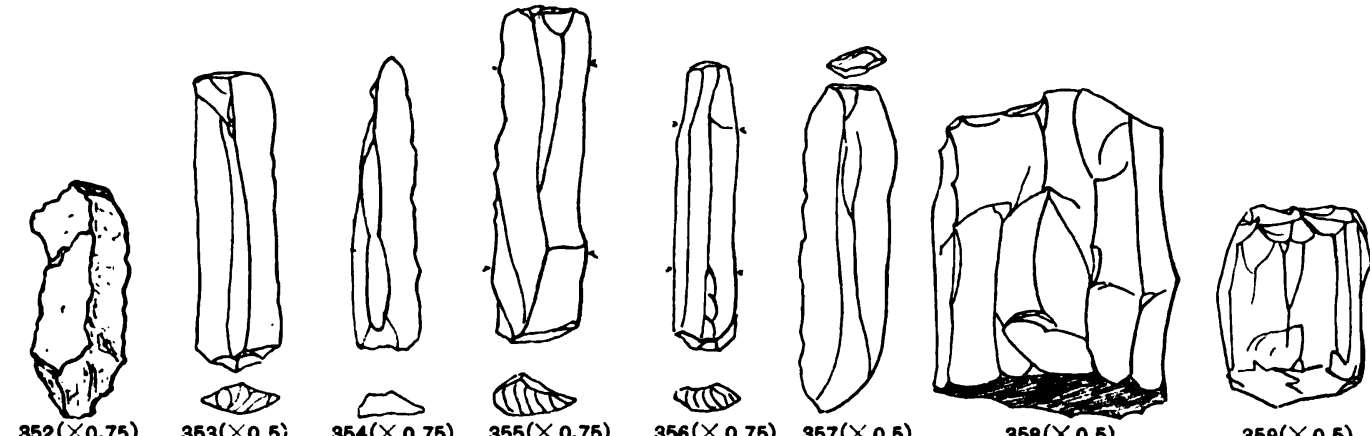

the finger-nail. In the whorl N.K. I 96 (fig. 345; plate 42, fig. I I), from the lower strata, the impressions on the edge are made with the finger; but in the betterformed ones of the middle strata (N.K. $5 \mathrm{I}$; fig. 346 ; plate 42 , fig. 6), they are 
made with a point or style. A whorl (N.K. 60), concave on the top, from the lower strata, is decorated on the edge with little lines (fig. 347; plate 42, fig. 13); so also are the whorls from the middle strata (N.K. 192; fig. 348; plate 42, fig. 9; and N.K. 225; fig. 349; plate 42, fig. I 2 ).

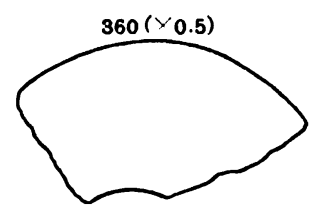

Combinations of pricked points and line patterns are found on two whorls from the middle strata (N.K. I22; fig. 350 ; plate 42 , figs. 5 and 14 ; and N.K. 191 ; fig. 351 ; plate 42 , fig. ro).

In isolated cases it was possible to determine with cer-

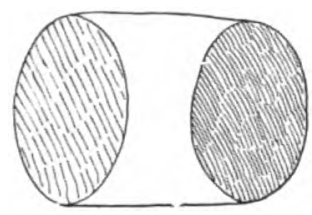
tainty a white incrustation of the incised ornamentation on whorls. But in no case was importance attached to a systematic grouping of the patterns. Interest in design or in the varying of the patterns does not yet make itself felt. The only essential differences are in technique. The clay whorls
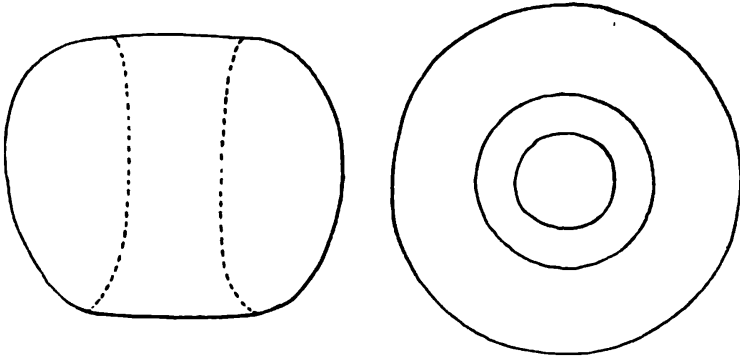

$361(\times 0.5)$ found in the upper strata add little to our knowledge. Besides, they come from mixed layers and may also belong to the remains of the older culture.

Flint implements.-Worked flint implements occur in all layers of the North Kurgan and are especially abundant in the middle and lower strata. For the most part they are flakes of flint which were worked and used as knives or long scrapers. A small flint implement (fig. 352) was found as a burial gift among the bronze and lead ornaments grouped under N.K. 185, with a skeleton in terrace II at +22 feet 5 inches. A beautifully worked long scraper (N.K. 249; fig. 353 ; plate 42 , fig. 20) comes from the lowest culture-strata. To the 'middle strata belongs a oneedged knife (N.K. I62; fig. 354; plate 42 , fig. I 9 ), from terrace vir between +23 and +24 feet. Two-edged knives with well-worked ends and traces of use on both edges are shown in N.K. 16 (fig. 355 ; plate 42 , fig. I 8 ), from the east pit in Komorof's trench, and N.K. IOI (fig. 356; plate 42, fig. I6), from terrace $\mathrm{v}$ between +28 and +32 feet. In the last one both ends are well
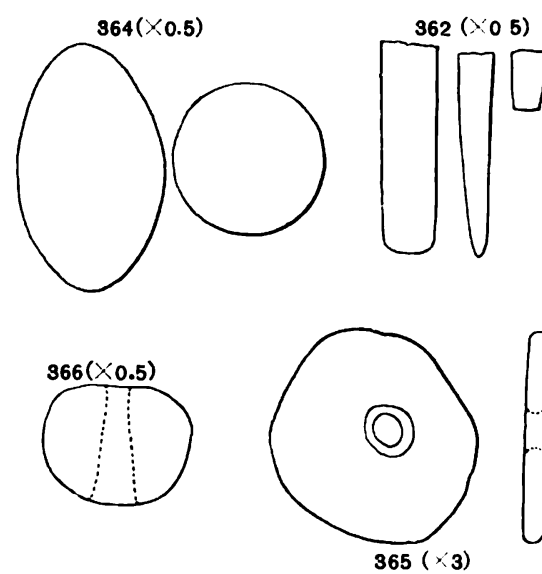

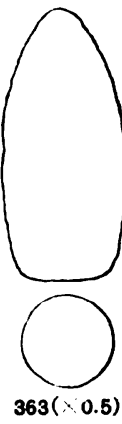
worked. N.K. 7 , on the other hand, is a two-edged knife with traces of use on one side (fig. 357 ; plate 42 , fig. I 7 ). It is from the west pit of Komorof's trench.

That these flint implements were not imported, but were made by hand on the spot, is shown by the abundant flakes of flint which occur as refuse of the 
workshops in all layers of the hill, and by two nuclei. One of these (N.K. 9; fig. 358; plate 43 , fig. I) is from the dump of Komorof's trench; the other (N.K. $3 \mathrm{I}$; fig. 359; plate 43 , fig. 2) is from the middle strata.

Perforated stone implements. - Only one form of perforated stone implements was recognized-a ring-shaped stone club-head. A fragment of one of these, made of light-gray stone, polished, and with polished perforation (N.K. 235; fig. 360 ; plate 43 , fig. 3 ) comes from the lowest culturestrata in the shaft of the east gallery. A well-preserved specimen, made of a pink stone with blue spots, is shown in N.K. 94 (fig. $36 \mathrm{I}$; plate 43 , fig. 4). It was found in terrace $v$ between +28 feet 5 inches and +32 feet, in the layer of the bake-ovens.

Miscellaneous.-A four-edged implement made of slate (N.K. 44 ; fig. 362 ; plate 42 , fig. ${ }^{\prime} 15$ ) was probably a chisel or polishing stone. It was found in the north digging between -8 and - I I feet.* Of isolated occur-

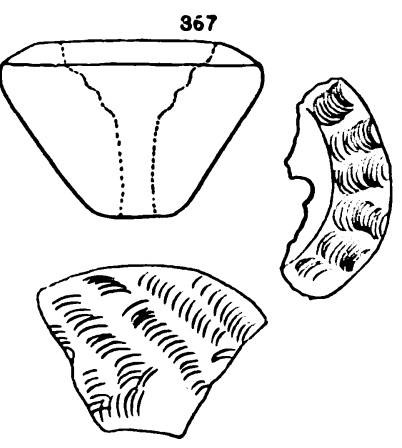
rence were so-called sling implements of stone and clay. One of skittle-shape, made of stone, with a much corroded surface (N.K. 240) is shown in fig. 363, plate 43, fig. 7. $\dagger$ It was found in the north digging IV, April 20, 1904. Another from +30 feet, terrace I, in the form of an egg, made of fine gray clay (N.K. 25), is reproduced in fig. 364 and plate 43 , fig. 6. An irregularly worked disk of slate

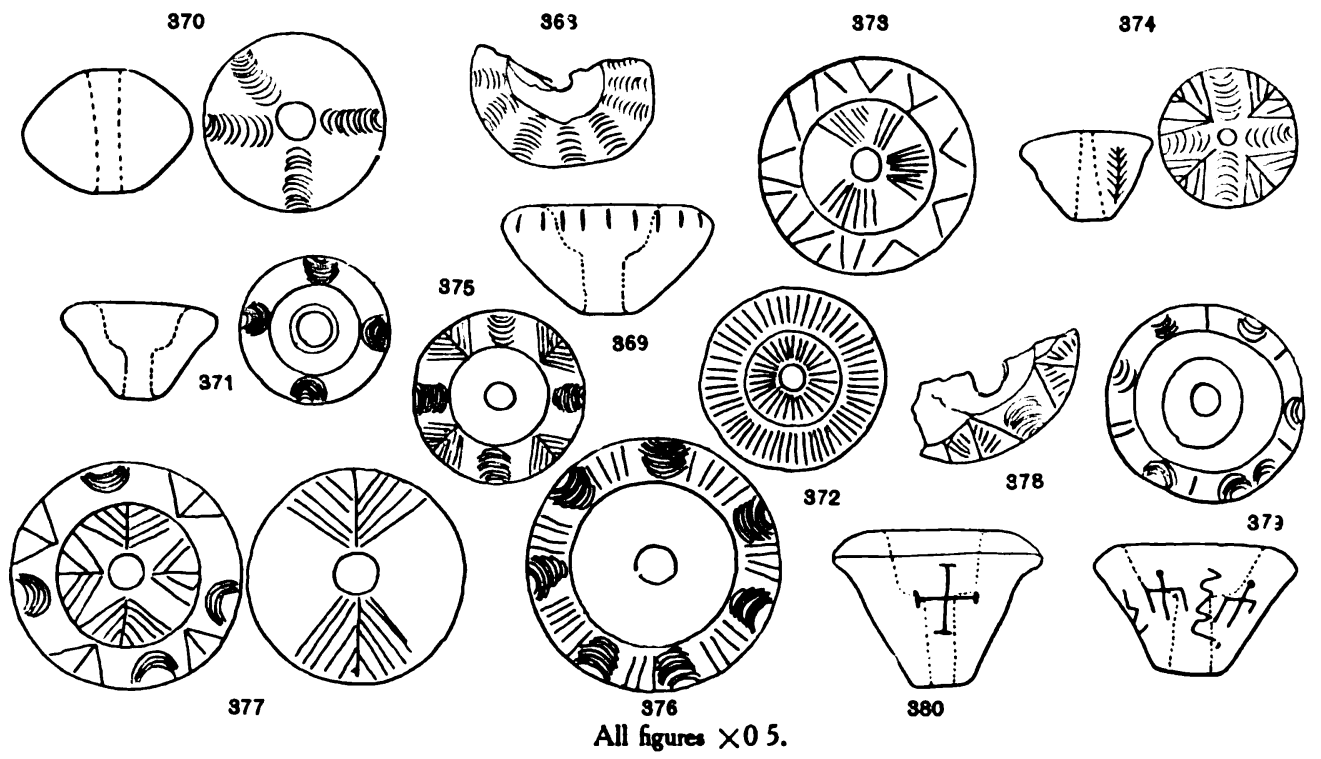

(N.K. I8I) with central perforation, from terrace I, between +23 and +25 feet and of undetermined use, is shown in fig. 365 and plate 43 , fig. 5 .

Implements of bone are also to be noticed from the North Kurgan. Fragments of two polished implements (N.K. I8), probably made from the ribs of an

* The finds at this point above - 12 feet, in north digging 11 , are of doubtful age, being near the contact between culture-strata in situ and "wash" from above.- $R$. P.

$\dagger$ North digging IV was wholly in irrigation sediments. This object is, therefore, younger than either of the kurgans. $-R$. P. 
animal, were found in the west gallery shaft between $o$ and +7 feet. The fragment of a common bone awl (N.K. I I8) was found in the east gallery shaft between -8 and - io feet.

The half of a polished white stone ball (N.K. 28) (of marble?) of undetermined usefulness, from the shaft of the west gallery between 0 and -7 feet, is shown in fig. 366 and plate 43 , fig. 9.

FROM MIDDLE AND LOWER STRATA OF SOUTH KURGAN, CULTURE III.

Whorls of clay. - The clay of the whorls corresponds to that of the pottery. It is for the most part light-colored, with a greenish tone like the vessels; also delicate yellow, rarely red. In the middle strata isolated examples were found of a fine ware of gray clay without ornamentation (S.K. 106). As a rule, the surface of the whorls is simply finely smoothed. Only in isolated instances was a red color-slip to be clearly recognized (S.K. 149).

The most favored forms are the conical, with a margin and a strong depression, which are very frequent in the North Kurgan. It was attempted, however, as the illustrations show, to profile both the outside and the interior, and a profile

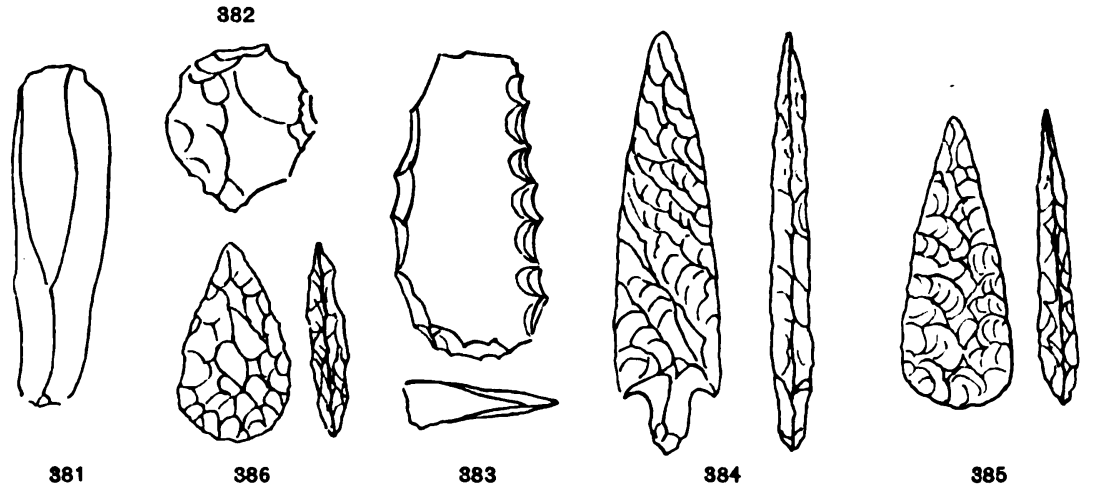

in calyx-form seemed to have been particularly liked. Conical whorls with convex and double-conical tops, occur more rarely. The ornamentation, in contrast with that of the North Kurgan, shows, in these whorls, a decided progress. The curved lines, which were probably always made with an instrument, stand on the same footing with the parallel line and angle group; but the principal progress consists in the systematic grouping of the ground motif that had come to be usual. This is not always to be observed, as, for instance, S.K. I 13 (fig. 367), and S.K. 366 (fig. 368 and plate 43 , figs. $8 a, 8 b$, and Io). The first is from the upper digging between +32 and +33 feet; the last was found in the shaft of the upper digging at $-\mathrm{I}_{4}$ feet.

The following examples (figs. $369-378$ and their equivalents in the plates as given below) show how the ground patterns are represented, sometimes independently, sometimes in combination, with a diversity such as one is accustomed to see in the rich series of whorls from Troy. In addition to these (S.K. 357, fig. 370 and plate 43 , fig. II; S.K. 51 , fig. 372 and plate 43 , fig. 12 ; S.K. 229, fig. 373 and plate 43 , fig. 13 ; S.K. 357 , fig. 375 and plate 44 , fig. I; S.K. 122, 
fig. 376 and plate 44 , fig. 2 ; S.K. 209, fig. 377 and plate 44 , fig. 3 ; S.K. 266 , fig. 378 and plate 44 , fig. 4) there are forms which are clearly to be traced backward to naturalistic prototypes, as on the side of S.K. I48 (fig. 379; plate 44, fig. 7). Here there are alternate snake-like forms and a figure which one is inclined to look upon as human. The cross pattern, on the other hand, on S.K. 272 (fig. 380) appears to be a stiff, decorative human figure. Both motifs find the strongest

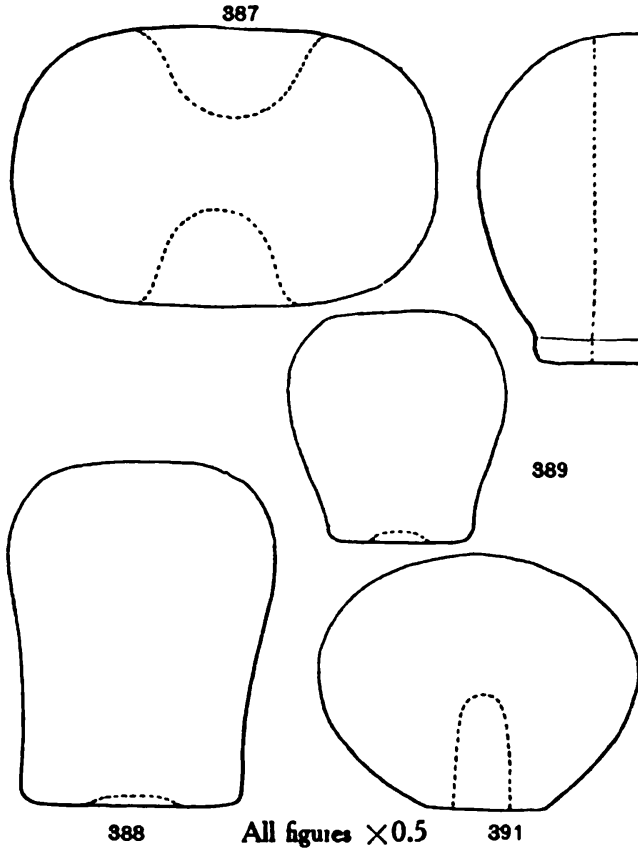
decorative parallels in the ornamentation on the whorls of Troy.

Implements of flint and obsidian.In the South Kurgan also, flint implements were often found in the middle strata. Simple flint knives were numerous, as in S.K. I62 (fig. 381 and plate 44 , fig. Io), from terrace $B$, between $+2 I$ feet 5 inches and +23 feet 7 inches; scrapers are more rare. S.K. 80 (fig. 382 and plate 44 , fig. 6 ) was found in the dump of the upper digging. One-edged saws were also found, like S.K. 79, fig. 383 and plate 44 , fig. 12, from the same layer. The most excellent workmanship in the working of stone implements is shown in the fine arrow-point (S.K. 120) which also attracts our attention by its form showing small barbs and tongue. It is shown in fig. 384 , and plate 44 , fig. 9, and was found in terrace B between +23 feet 7 inches and +25 feet. Of another form but of equally perfect workmanship is the arrow-point (S.K. 365 ; fig. 385 and plate 44 , fig. 8) taken from the fresh dump of shaft $\mathrm{C}$ of the upper digging on April 30, and derived from near the middle height of culture III; probably from between 0 and -14 feet. A smaller, more compact and broader arrow-point of obsidian (S.K. 35I)
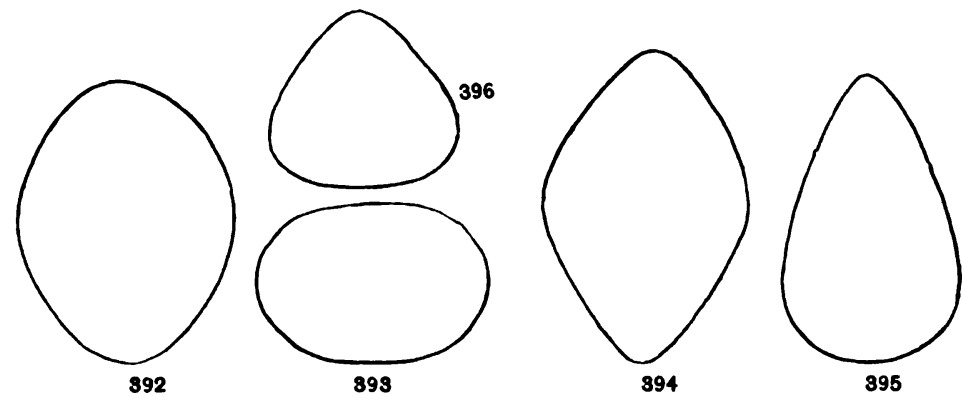

was found under skeleton $\gamma$ in terrace $B$ at +25 feet. It is shown in fig. 386, and plate 44, fig. 5. It was the only obsidian implement that it was our good fortune to find and in workmanship is equal to the last-mentioned flint implements.

Perforated stone implements.-An unfinished implement in the form of a flattened ball of gray stone (S.K. 70) is probably to be classed with the annular 
maces, or heads of clubs (fig. 387 and plate 44 , fig. II). It is from terrace $B$, between +28.25 feet and +31 feet. The drilling, which is unfinished on each side, has left no trace of drill cores. Among the maces I also class hat-shaped stone implements like S.K. 67 (fig. 388), and S.K. 91 (fig. 389), both found with the gray pottery in the upper digging between +37 and +40 feet. They also are unfinished, the drilling only having been begun. The smaller of the two maces shows also on the upper side the beginning of a perforation, which is really the reason for referring these forms to the maces instead of to the knobs. But both approach in form the only half-preserved mace of black-gray stone (S.K. 132; fig. 390 and plate 44 , fig. 13), which is distinguished from the others by a projecting shaft-collar at the bottom. For comparison, a similar, somewhat smaller, but perfectly preserved implement is worthy of remark (S.K. I 56). It is made of pink clay with a whitish-yellow slip, and was found in terrace B between +21 feet 5 inches and +23 feet 7 inches. The significance of an implement made of marble (S.K. 1 37; fig. 391) remains uncertain. It is from the upper digging between +29 and +32 feet, and is drilled only to the center. If it was finished, then it is to be classed with the knobs.

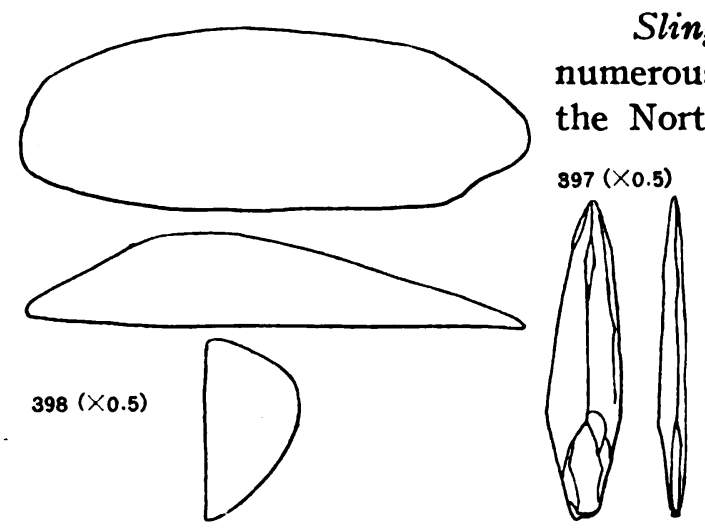

Slingstones.-So-called slingstones are very numerous in the middle strata, as they were in the North Kurgan. Those of the South Kurgan are more varied in form and for the most part excellently polished, even if not always regularly formed. There occur forms with elliptical longitudinal section, as in S.K. I I (fig. 392 and plate 44 , fig. 15 ), from the upper digging at +33 feet, and S.K. 195 (fig. 393 and plate 44 , fig. I4), from terrace $C$ between $+2 I$ and +23 feet; or double-conical as in S.K. II 5 (fig. 394 and plate 45 , fig. I) from upper digging between +32 and +33 feet; or egg-shaped like S.K. 242 (fig. 395 and plate 45, fig. 2), from terrace C between +19 and +21 feet; or conical as in S.K. 85 (fig. 396 and plate 44 , fig. I6) from the upper digging between +37 and +40 feet.

Implements of bone.-Here, as in the North Kurgan, objects made of bone were very rarely found, and even when found their significance remained somewhat uncertain. Two implements, of which S.K. 208 (fig. 397 and plate 45, fig. 3) shows the form, look like arrow-points. They were found in terrrace $B$, between +21 feet 5 inches and +23 feet 7 inches. The implement S. K. 182 (fig. 398 and plate 45, fig. 4) may have been used for polishing. It is from the upper digging, between +25 and +29 feet.

Unclassified.-A hoe-shaped implement (S.K. 352) deserves especial mention. It is made from micaceous schist with a shaft dowel, which is broken off (fig. 399 and plate 45 , fig. I3). It was found in terrace B, below the clay chest, and is made from a polished piece, the original form of which is rather roughly hewn and is 
PLATE 44.

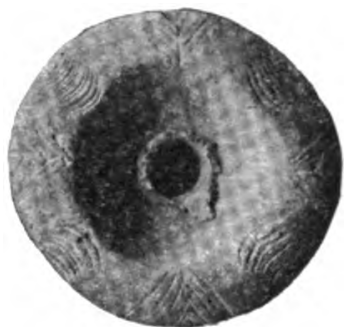

1

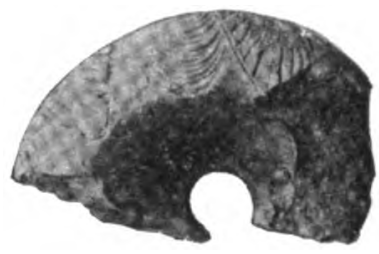

4

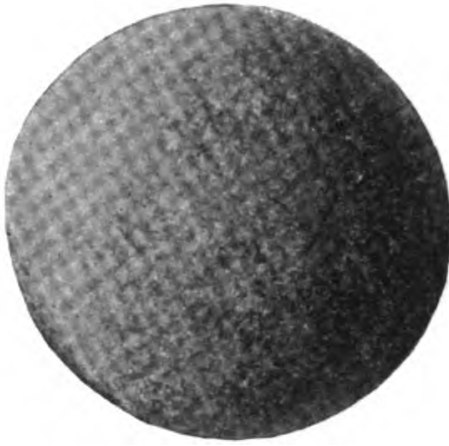

14

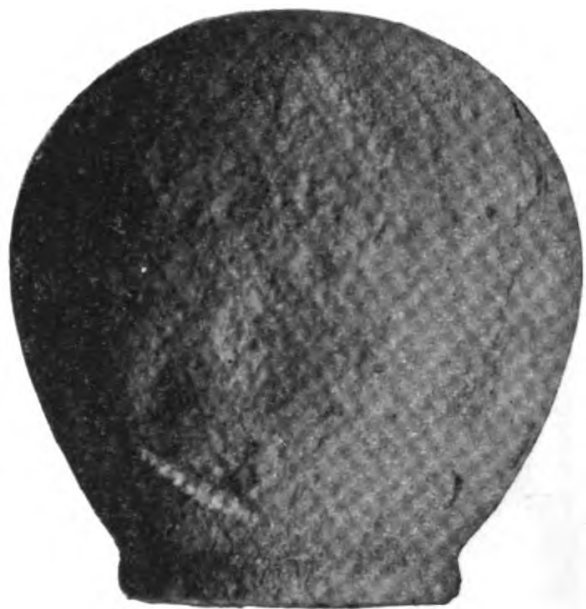

13

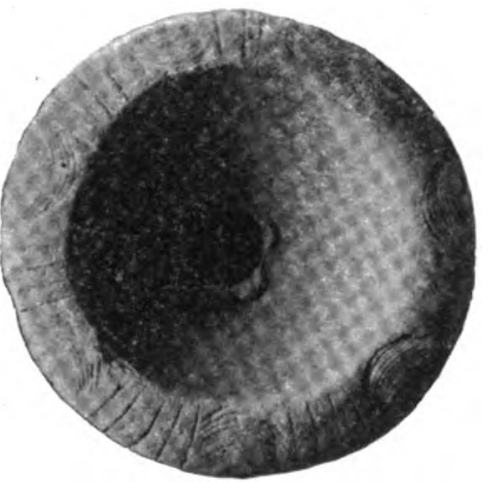

2

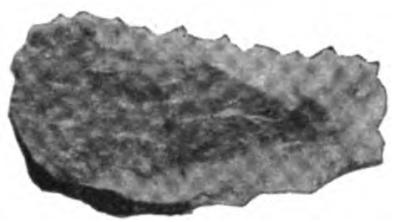

12

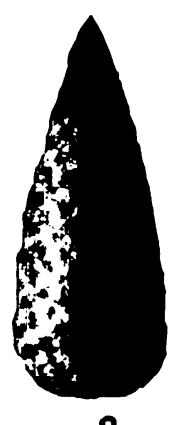

8

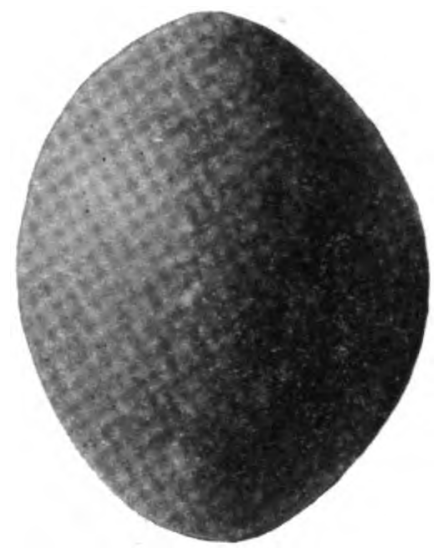

15

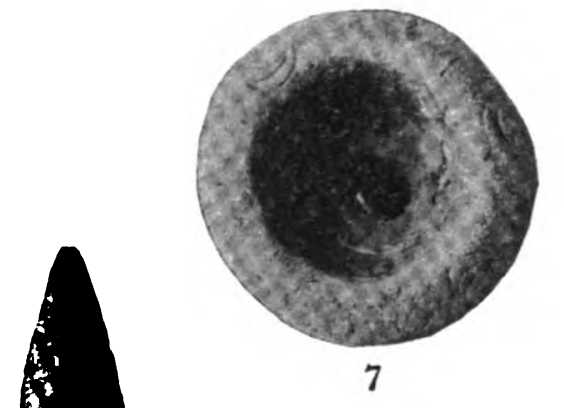

3

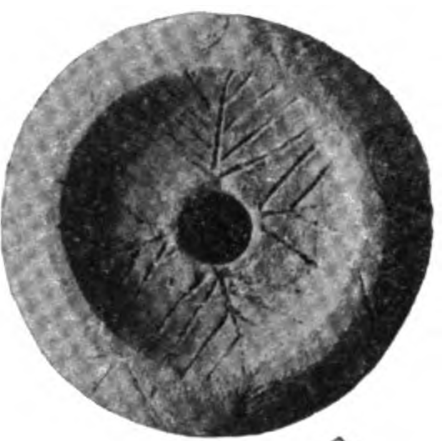

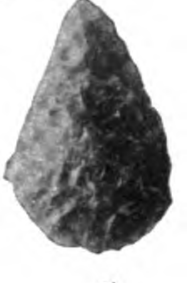

5
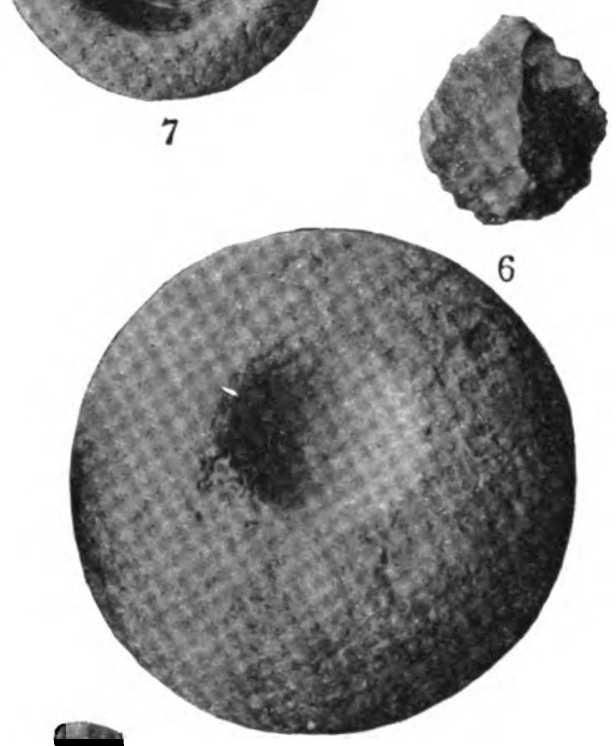

11

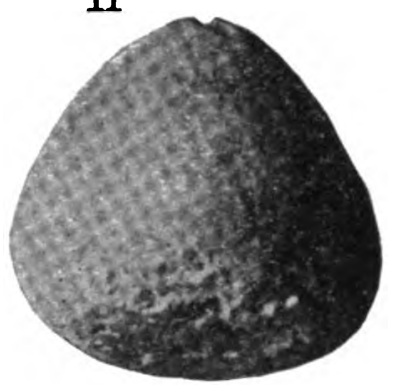

16

Whorls, Flints, and other Stone Implements from Lower and Middle Strata, Culture III, South Kurgan.

Figs. 1-4 (S.K. 357, S.K. 122, S.K. 209, S.K. 266). Whorls with Varied Sys- Fio. 10 (S.K. 162). Flint Knife, Terrace B, +21.5 to +27.5 feet, text-figure tematic Ornamentation, Middle and Lower Strata, South Kurgan.

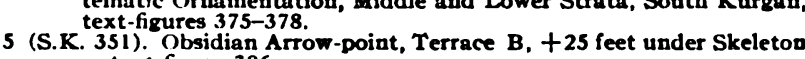
5 (S.K. $\gamma$. text-figure 386 . 6 (S.K. 80). Flint Seraper (?),

7 (S.K. 148). Whorl with Seemingly Conventionalized Representation of Man and Serpent, Terrace B, +23 to +25 feet, text-figure 379 8 (S.K. 365). Flint Arrow-point, Dump of Shaft C, probably from be-

9 (S.K. 120) Slightly Barbed Flint Arrow-head, Terrace B, + 23.6 to +25 feet. text-figure 384 .

11 (S.K. 70). Probably Unfinished Annular Gray Stone Mace-head. Ter12 (S.K. 79 ). Flint Saw (?), Upper Digging, +37.6 to +40 feet, text12 (S.K. 79). Flint Saw (?), Upper Digging, +37.6 to +40 feet, text14 (S.K. 195). Slingstone with Elliptical Section. Terrace C, +21 to +25 15 (S.K. 111 ). Slingstone with Elliptical Section, Upper Digging. + 33 feet, 16 (S. K. 85). Conical Slingstone, Upper Digging, +37 to +40 feet, textfigure 396 . 


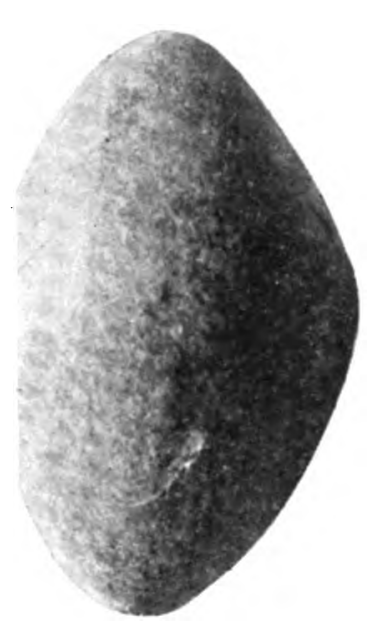

1

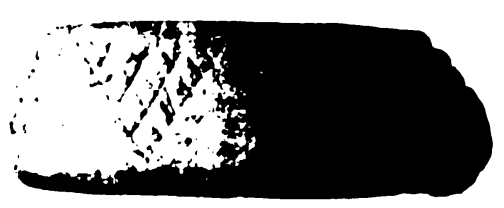

6

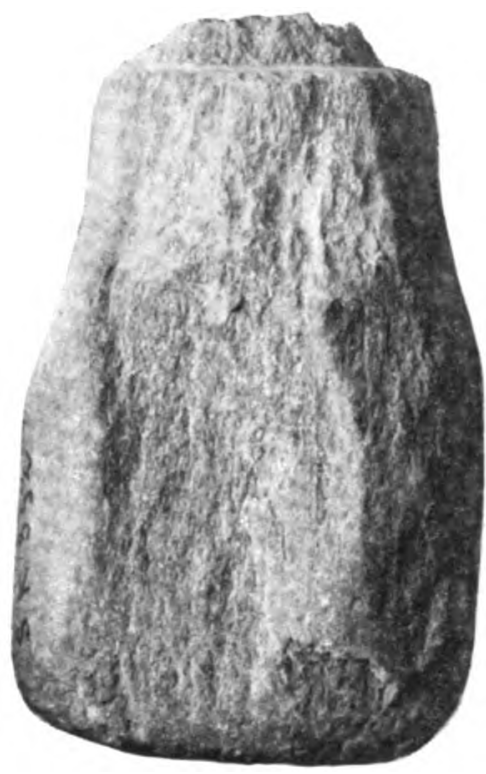

13

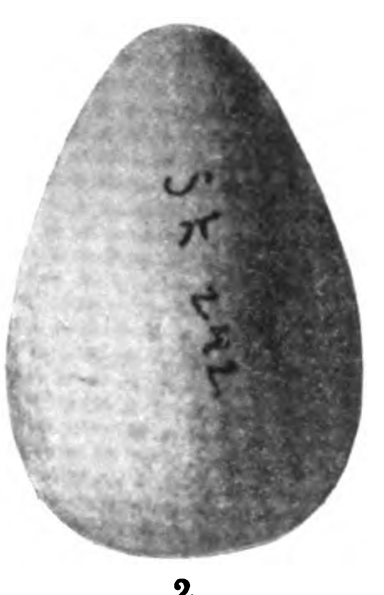

2
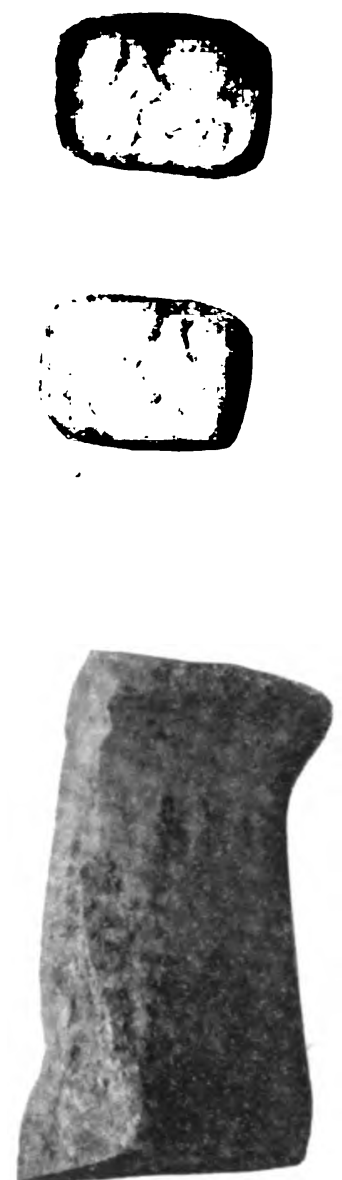

12

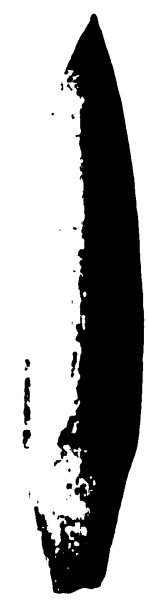

3

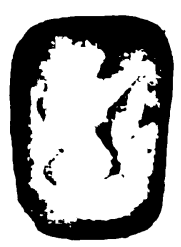

8
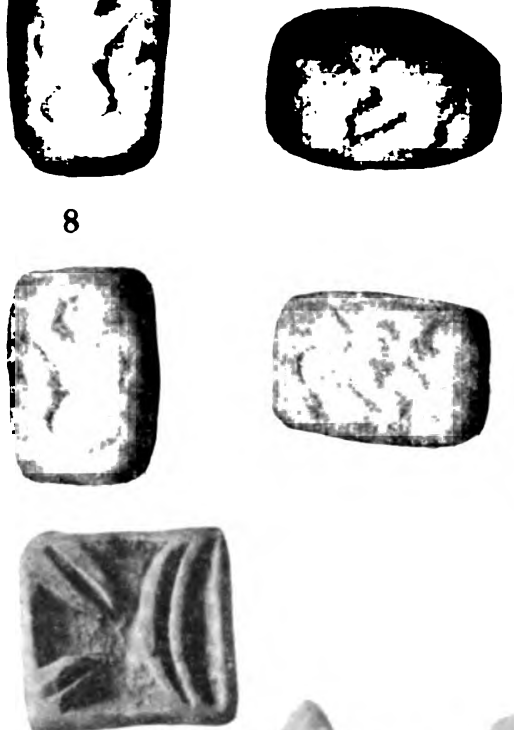

11

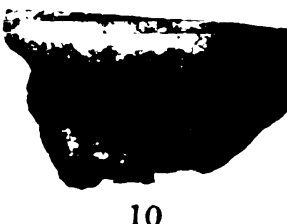

10

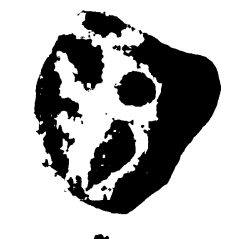

7

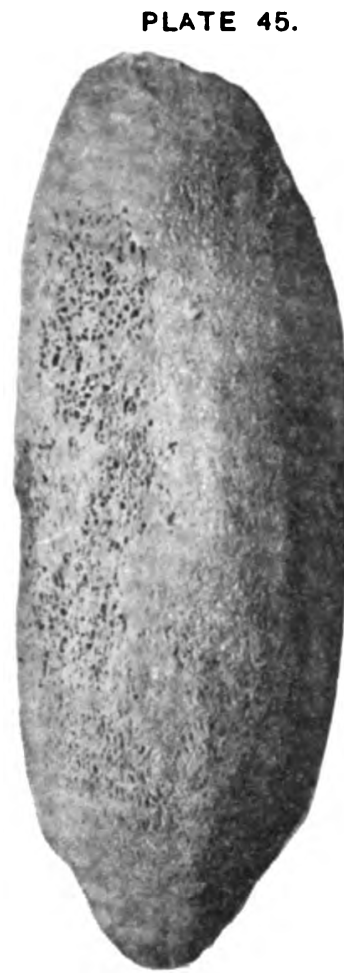

4
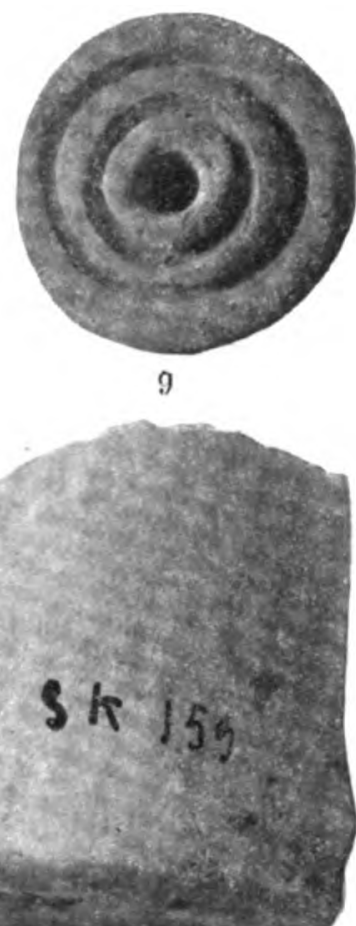

5

Objects in Stone, Clay, and Bone, from Middle and Lower Strata, Culture III, South Kurgan.

F1G. 1 (S.K. 115). Double-conical Slingstone. Upper Dizzing. +32 to +33 feet. text-figure 39 t

2 (S.K. 242). Egg-shaped Slingstone, Terrace C, +19 to +21 feet, text-figure 395 . 397

4 (S.K. 182). Smoothing Instrument (?) of Bone. Upper Diggin 3 . +25 to +29 feet, text-figure 398.

5 (S.K. 159). Stone Vessel, Terrace B, +21.5 to +23.5 feet, text-figure 407

6 (S.K. 169). Incised Fraginent of Stone Vessel, Upper Digginz. +25.5 to +29 feet. text-figure 408.

7 (S.K. 170). Stamp of Dark-gray Polished Stone, Upper Digring. +25.5 to +29 feet. text-figure 403 .

8 (S.K. 73). Impressions and Casts of Three-sided Stone Seal, with Figures of Lion, Grifin, and Man, Terrace B

9 (S.K. 341). Stamp of Greenish-white Clay with Concentric Circles, Shaft C, text-figure 401.

10 (S.K. 362). Piece of Margin of Stone Cup. Terrace B + +21.5 to +23.5 feet, text-figure 406.

11 (S.K. 105). Square Clay Stamp, Terrace B, +25 to +26.5 feet. text-figure 402

12 (S.K. 239). Part of Marble Cup, Terrace B. +20 to +23 feet, text-figure 404. (S.K. 352). Hoe-shaped Implement of Alica Schist, Terrace B under Clay Chest, text-figure 399. 
Digitized by GOOgle 
PLATE 46.
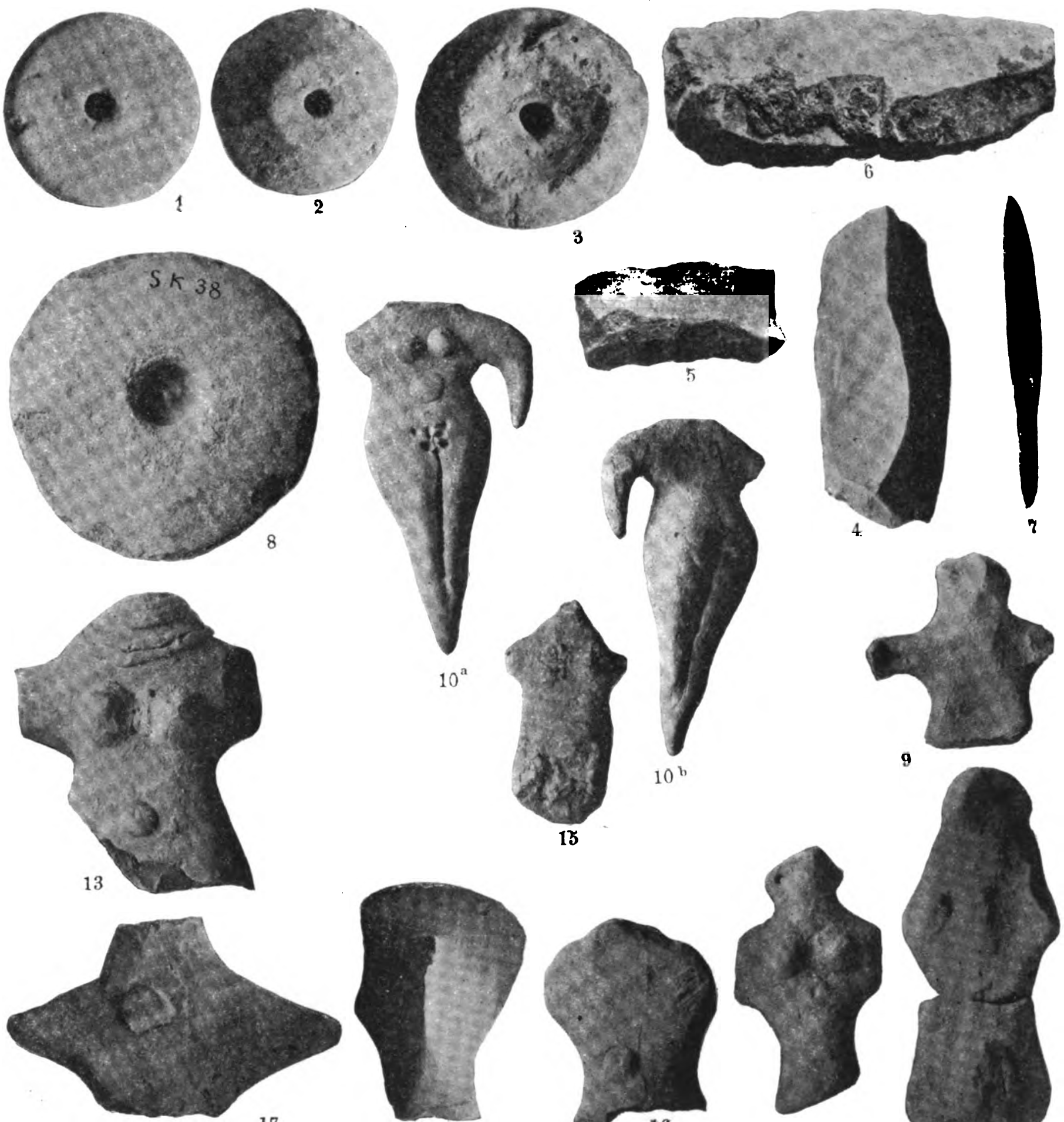

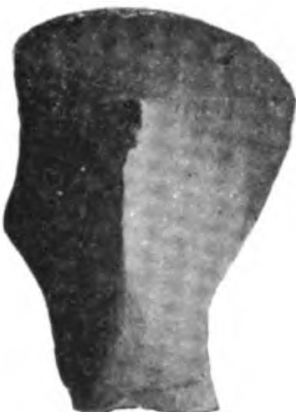

11

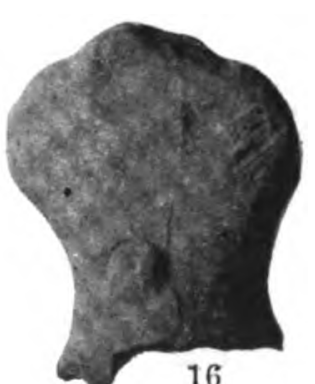

16

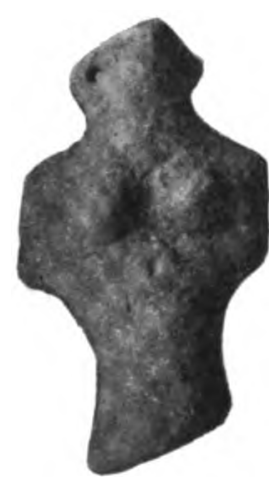

14

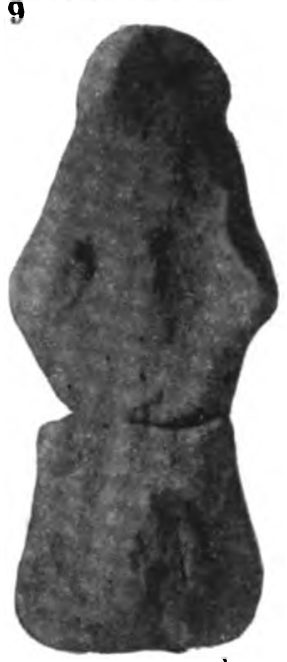

12

Whorls, Flints, Mace-head, and Bone Implement, chiefy from Upper Strata or Iron Culture, South Kurgan.

FIc. 1 (S.K. 121). Conical Whorl, Upper Digzing, + 29 feet, Culture III, text-figure 409. (S.K. 33). Double-conical Whorl, Dump3, South Kurgan, Cultuie (?), text-figure 3 (S.K. 3). Whorl with Usual Depression at Top. Upper Digging, +50 fezt, Culture 4 (S.K. 53). Flint Knife (?), Upper Digging. +40 feet. Culture III (?), text-figure 412. 4 (S.K. 53). Flint Knife (?), Upper Digging. +40 (?)et. Culture 111 (p). text-figure 412. 7 (S.K. 44). Awl-shaped Implement of Bone, Upper Digging, +43 to +46 feet, 8 (S.K. 3s). I.enticular M.cce-head of Polished Vinlet-gray Stone (Unfinished Drilling Shows Remains of Drill-core). Dump M.terial of Upper Digging between

Terra-Cotta Figures of Religious Significance. Culture III. South Kurgan.

Fic. 9 (S.K. 285). Possibly a Male Figure. TerFemile Figures, Generally Roughly Made of Clay:
$0 a$ AND $b$ (S.K. 339). Terrace B, +20 to +23 11 (S.K. 313 ). Terrace $B,+20$ to +23 feet.
12 (S.K. 252). Terrace B, +20 to +23 feet.

1.3 (S.K. 235) Terrace B. +20 to +23 feet.

it (S.K. 174). Terrace B. +23 feet.

15 (S.K. 57). Upper Digging, +40 feet.

16 (S.K. 361 ). Terrace $B$, +20 to +2.3 feet 
Digitized by GOOgle 

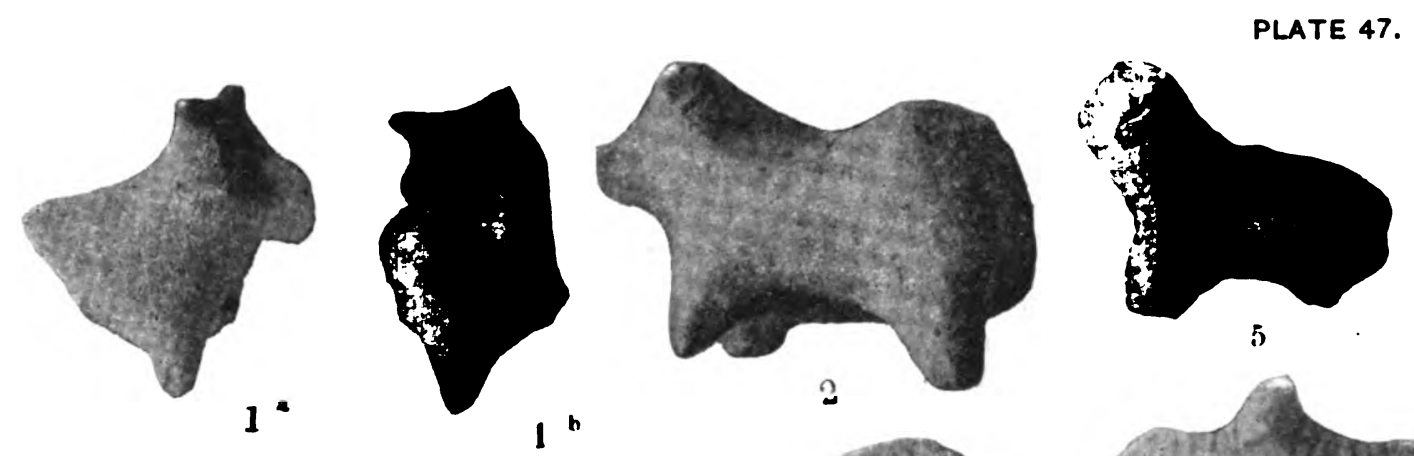

b
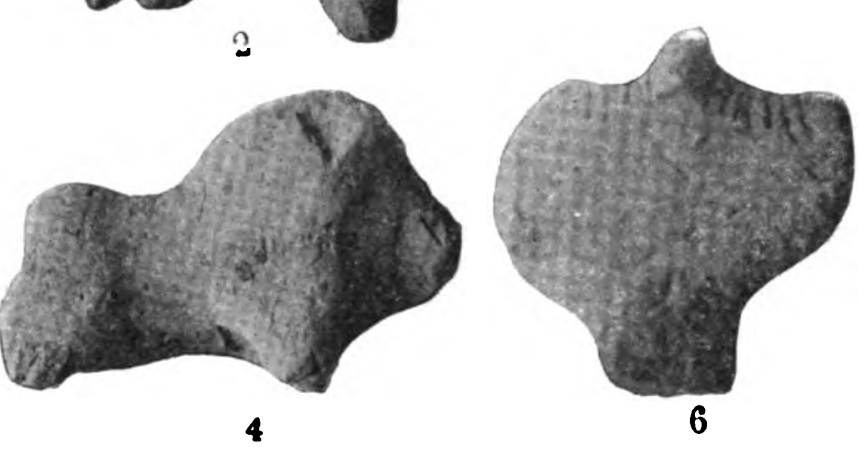

3

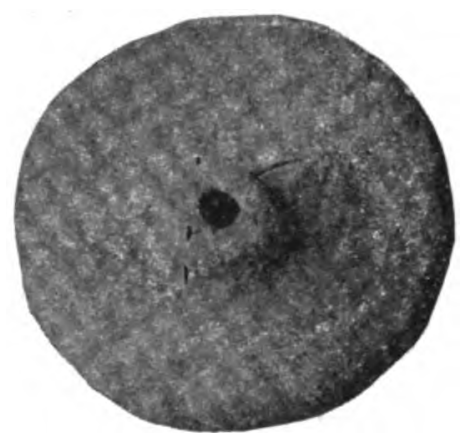

8

9
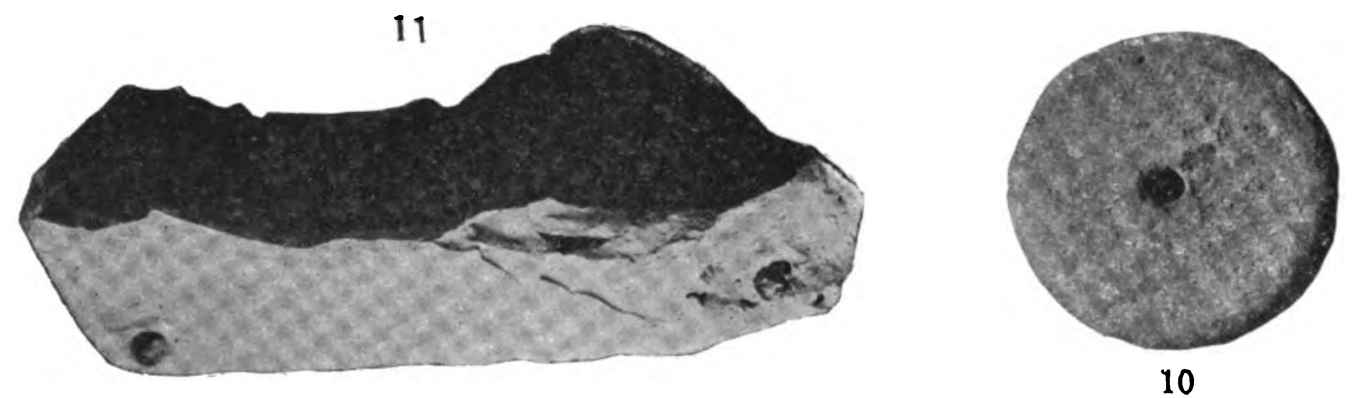

Objects of Terra-cotta, Culture III.

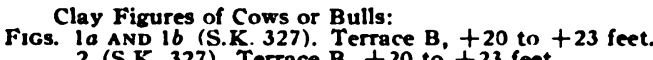
2 (S.K. 327 ). Terrace B. +20 to +23 feet. 3 (S.K. 344). Terrace B. +20 to +23 feet.
4 (S. K. 83). Upper Digging, +38 to +40 feet

Clay Figures of Indeterminable Animals:
Fir. 5 (S.K. 311 ). Terrace $B,+20$ to +23 feet. 6 (S.K. 356). Terrace B. +20 to +23 feet. 8 (S.K. 329). Terrace B, +20 to +23 feet.

Fio 9 (S.K. 134). Clay Wheel. Dump of Terrace B, text-figure 418 .

11 (S.K. 211 ). Clay Wagon-box, Terrace C. +21 to +23 feet text-figure 419 
not determinable. Traces of the polishing are visible on both sides. The shaft end was made by sawing around the bottom of the hoe.

The advanced culture of the South Kurgan also shows itself in implements and objects which were in a certain sense intended to serve as luxuries, and with them we will close the list of objects from the middle strata.

Seals and stamps.-In describing the excavations in terrace B, mention was made of the discovery of a three-faced stone seal of triangular cross-section, showing figures on all three sides (S.K. 73). The black stone shows some cracks and scratches. On it are represented a man, a lion, and a griffin; the stone is shown in fig. 400 and the negative and positive casts in plate 45 , fig. 8 . It was found in terrace $B$ at +28.25 feet. The workmanship is very imperfect, the cutting is shallow, and the representation of human and animal forms leaves much to be desired. The human figure is par-
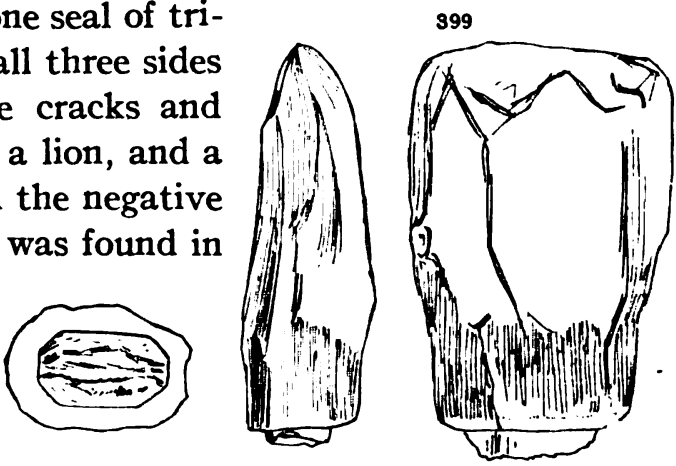
ticularly awkward, both as regards its attitude and the rendering of the form in detail. The animals are somewhat more successful; at least there is no doubt as to their identity. Very little care was taken, however, in representing the legs of the lion; and the characterization of the head is not sufficiently apt. The griffin is better, even though the wings are clumsily placed on the neck of the animal.

More simple ornaments are produced by the other stamps made of stone and

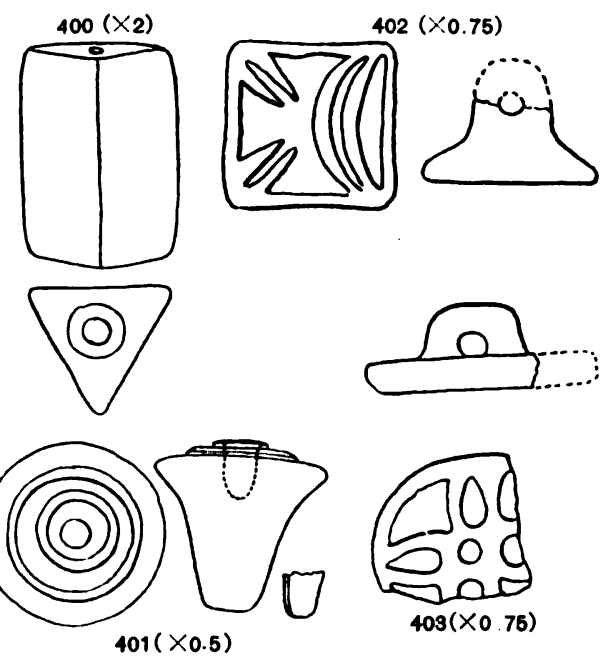
clay. Concentric rings with a high central boss were produced with a stamp made of greenish-white clay (S.K. 34I ; fig. 40I and plate 45, fig. 9), from shaft $C$ of the upper digging, April 26, 1904, in the middle layers of culture III. A cross form, with ridges projecting between the arms and showing crescent-shaped figures at the top, is shown in the square clay stamp with a perforated handle (S.K. 105; fig. 402 ; plate 45 , fig. 11 ), from terrace $B$, between +25 feet and +26.25 feet. A partially preserved stamp of dark-gray, polished stone, with perforated handle (S.K. 1 70; fig. 403 and plate 45 , fig. 7 ), from the upper digging, between +25 feet 5 inches and +29 feet, served to produce a star pattern.

Stone vessels.-We may also class vessels made of stone among the precious objects of luxury, of which only small fragments-lip and bottom pieces-remain. They are small, deep, steep-walled cups with variously lipped forms. In some the lip is only slightly thickened, as in S.K. 256 (fig. 404) from terrace B, between +21 feet 5 inches and +23 feet 7 inches. In some it widens outward horizontally 
as in S.K. 239 (fig. 405 and plate 45 , fig. 12) from the same point, and also in S.K. 362 (fig. 406; plate 45, fig. Io), from terrace $B$ between +18 feet and +30 feet. The bottoms are strikingly thick, as in S.K. I 59 (fig. 407 and plate 45, fig. 5) from terrace $B$, between +21 feet 5 inches and +23 feet 7 inches. The greater part of the fragments found are of marble, but two of alabaster were collected. The finds all come from the lowest layer of terrace B and are important in connection with the buildings found there. While the marble and alabaster vessels are smooth, two fragments with incised patterns (S.K. 169) belonging to a small shallow cup of dark gray-green stone, are shown in fig. 408 and plate 45 , fig. 6, from the upper digging between +25 feet 5 inches and +29 feet.

\section{FROM UPPER STRATA OF SOUTH KURGAN, CULTURE IV.}

Whorls.-The number of whorls found in the upper strata of the South Kurgan was strikingly small. They have no peculiarities of form. Some are conical, as S.K. I I (fig. 409 and plate 46, fig. I); some are double-conical, and truncated like S.K. 33 (fig. 4 Io and plate 46, fig. 2); some, as is more usual, are furnished with

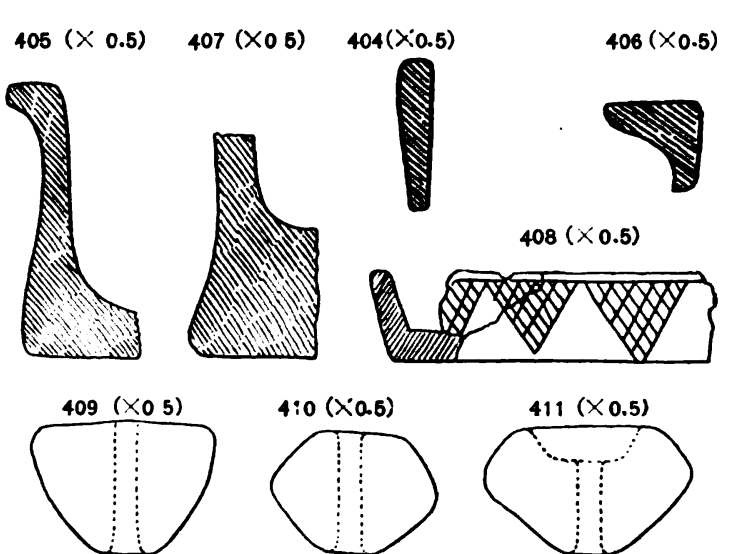

a depression as in S.K. 3 (fig. $4 \mathrm{I}$ I and plate 46 , fig. 3). Ornamented whorls occur also in these layers, the patterns consisting throughout of contiguous short curved lines-the favorite motif of ornamentation of the middle and lower strata.

Flint implements.-Flint implements are also rare in the upperstrata. A knife (S.K. 53; fig. 412 and plate 46, fig. 4) may serve as a specimen; also a two-edged saw (S.K. 13; fig. $4 \mathrm{I} 3$ and plate 46 , fig. 5 ), and a oneedged saw (S.K. Ioo; fig. 4I4 and plate 46, fig. 6). It is not determinable whether these belong to the culture of the upper strata or, as older artefacts, came accidentally into the deposit of that time.

Miscellaneous.-A lenticular mace (S.K. 38 ; fig. $4 \mathrm{I} 5$ and plate 46 , fig. 8) from the débris of the upper digging from between +45 feet II inches and +47 feet, stands by itself. It is made of violet-gray stone, is polished, and has an unfinished perforation. In the hole on one side there still remains a part of the drill-core. Among the miscellaneous objects there is an awl-shaped bone implement with a longitudinal channel (S.K. 44; fig. 416; plate 46, fig. 7), also found in the upper digging, between +43 feet and +45 feet 11 inches.

One is disposed to regard the greater part of the separate finds from the upper layers with more or less skepticism. They add nothing to our knowledge of the culture characterized by the finds of iron in these strata, and only future studies can determine whether they are to be referred to the older culture and have come accidentally into the younger layers. 


\section{(f) IMAGES OF TERRA-COTTA, CULTURE III.}

Besides numerous ornamental and useful objects of bronze, stone, clay, and bone, the middle strata of the South Kurgan have yielded numerous figures in terra-cotta-representations of men and animals-in burnt and unburnt clay. The greater part of the finds comes from terrace B, from the deeper layers of the terrace, among the skeleton graves; from the level of the clay chest; and from the layers of débris of the remains of buildings found there. In the upper digging only three such finds were made between +25 feet 5 inches and +40 feet-two clay idols and an animal figure (S.K. 57, 175, and 83).

Human figures.-Unfortunately, no perfectly preserved human figures were found, though the fragments certainly show a praiseworthy attempt to express the modeling of the human form. All the specimens in hand are in the round; and they are clearly naked, female forms. S.K. 285 (plate 46, fig. 9) represents a small miniature-like figure, without indication of sex, but certainly a shortened human form. Only the trunk is represented; the stump-shaped arms, of which the left one is broken off, being raised and extended. Of the face only the nose is represented by a projection and the eyes by small depressions. In all the other figures the female breasts, and in most of them also the navel, are clearly expressed through plastic forms. The position of the ears is bored in the fragment (S.K. 174; plate 46, fig. 14). A modeled neck ornament is shown on the torso (S.K. 286; plate 46 , fig. 13). S.K. 313 (plate 46 , fig. II) shows the head of a larger figure, in which the face is indicated only by a strong projection of the nose, while in S.K. 57 the head is shrunken to a stump (plate 46 , fig. 15). S.K. 252 (plate 46 , fig. 12) was roughly kneaded of unburnt clay and was found in the clay chest of terrace B. S.K. 339 (plate 46 , figs. Io $a$ and $10 b$ ) shows the greatest progress in the modeling
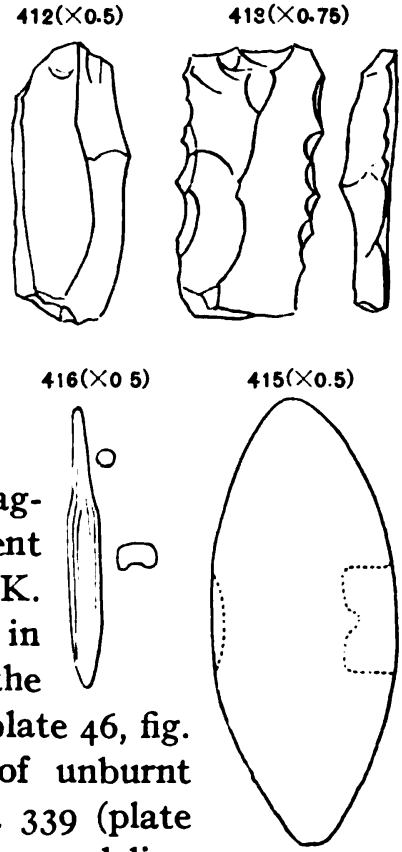
of forms and in the accentuation of detail. It is represented in front and rear. Particularly striking is the strong development of the hips, while the legs run together in a point. The private parts are brought out in a particularly realistic manner by punch-marks, and the type of the whole figure differs from the other examples in the pendant position of the arm.

Animal figures.-Figures of animals are much more numerous, even though preserved only in fragments, in the above-mentioned layers of terrace B. Unfortunately, however, the condition in which they reach us is so bad that their identification with different animals is only rarely certain. In isolated cases we can recognize horned animals, probably oxen, as in S.K. 327 (plate 47 , figs. $1 a$ and $1 b$ ). In other cases, other animals may also be meant (S.K. 344 ; plate 47 , fig. 3 , and 
S.K. 3 II ; plate 47 , fig. 5). I think I can recognize an ox in the large fragment of whitish-green clay in S.K. 83. It is shown on plate 47 , fig. 4 , and comes from the upper digging. The standing figure (S.K. 356 ; plate 47 , fig. 6) is unique in the collection. It is a flattened form, thickened and contracted on one side and having on the other side a small elevation. On both sides of the latter the edge is marked with fine lines. In this, perhaps, we may see the plastic representation of a flying bird. Two objects difficult of explanation may, perhaps, be abbreviated representations of horned animals (S.K. 345 ; plate 47 , fig. 7 ; and S.K. 329; plate 47 , fig. 8). Both are provided with a surface to stand upon and stand erect like skittles. On the upper edge of one there are two horns directed toward one side. The other has two points which turn to opposite sides.

In the North Kurgan also, two fragments of animal figures were found; one

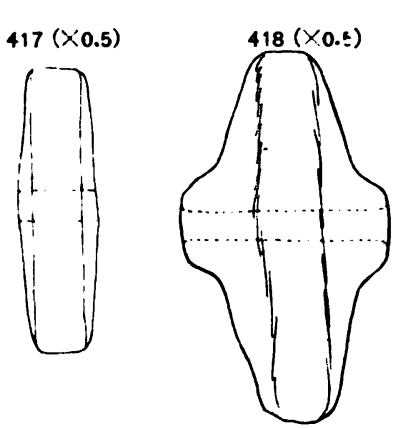

(N.K. 72) comes from the surface, the other (N.K. 239) from the north digging $\mathrm{IV}$, but in the heart of the hill they have not been observed. It must be left to the future to determine whether such figures had a significance in connection with the older cultures of Anau.

Children's playthings. - In both hills little balls of clay and stone often came to light, the first sometimes ornamented with incised markings. While only isolated finds of this kind were made in the North Kurgan (N.K. $90,127,166,184,230$ ), they occurred in surprisingly large

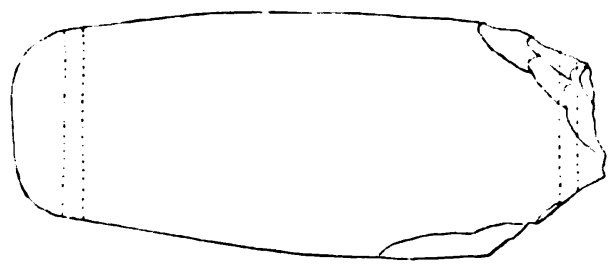
numbers in the South Kurgan, especially in the same layers of terrace $B$ with the animal and human figures we have just described. Besides these, the same layers of the South Kurgan yielded clay wheels of different forms. Some are flat and diskshaped, being but little thicker in the center

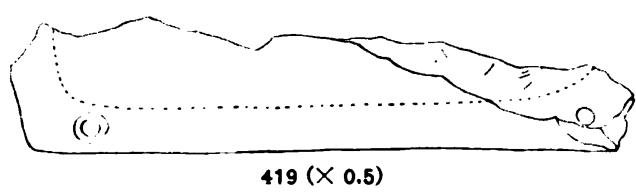
than on the edge, as in S.K. I6I (plate 47 , fig. 10) and in fig. 417 ; the others have a strongly developed hub as in S.K. I 34 (fig. 418 and plate 47 , fig. 9). From these clay wheels we inferred that they had also produced imitations of wagons. In one case we were really able to identify a wagon-box made of clay (S.K. 21I). The bottom and the side view of this are given in fig. 419 and plate 47 , fig. II. It was found in terrace $\mathrm{C}$, between $+2 \mathrm{I}$ feet 2 inches and +23 feet 2 inches. The upper edge and one of the narrow sides are broken off. The form is elongated with rounded-off sides. Its significance is clearly shown by the holes for axles which traverse the thick bottom, both in front and behind. They can scarcely have served for any other purpose than the attachment of the numerous wheels that were found. Whether in this connection the animal and human figures are also to be considered as children's playthings remains an open question. Nothing stands in the way of so considering the animal figures; but in the case of the 
human figures it will be preferable, on account of their nakedness, to retain the usual term of "idols," especially on account of the absence of any indication of clothing and the emphasizing of certain natural characters.

\section{(g) THE FINDS OF FRAGMENTS OF GLAZED POTTERY IN THE SOUTH KURGAN.}

Several times during the excavation in the South Kurgan, pieces of glazed pottery were handed in by the workmen. As regards technique, a dark blue-green or light-green glaze of considerable thickness covers both sides of the vessel. The body, however, does not consist of clay, but of a white sandy mass which may, perhaps, be compared with the so-called Egyptian porcelain. The vessels themselves are very thick-walled, but in the absence of marginal pieces their form is indeterminable. The localities are terrace $A$ between +27 and $+3 I$ feet; terrace $\mathrm{C}$, between +23 feet 2 inches and +29 feet; and the outer digging, between +4 feet 2 inches and +6 feet 5 inches; $i$. e., they occur in the South Kurgan, both in the "mixed" layers and with the pottery of the younger culture. Therefore, from their manner of occurrence, we gain no information as to where they really belong. In my opinion the thought that they are of modern or medieval origin is not to be entertained. One of the fragments has a metallic luster of the same kind that exists upon glass that has been long exposed to the influence of the soil. Besides, they are clearly distinguishable from a glazed fraginent of undoubtedly recent origin which belongs to a wheel-made bowl of yellow clay with a dark yellow-green glaze covering only the interior of the vessel. It must remain for future investigations to determine the age of this glazed ware. 


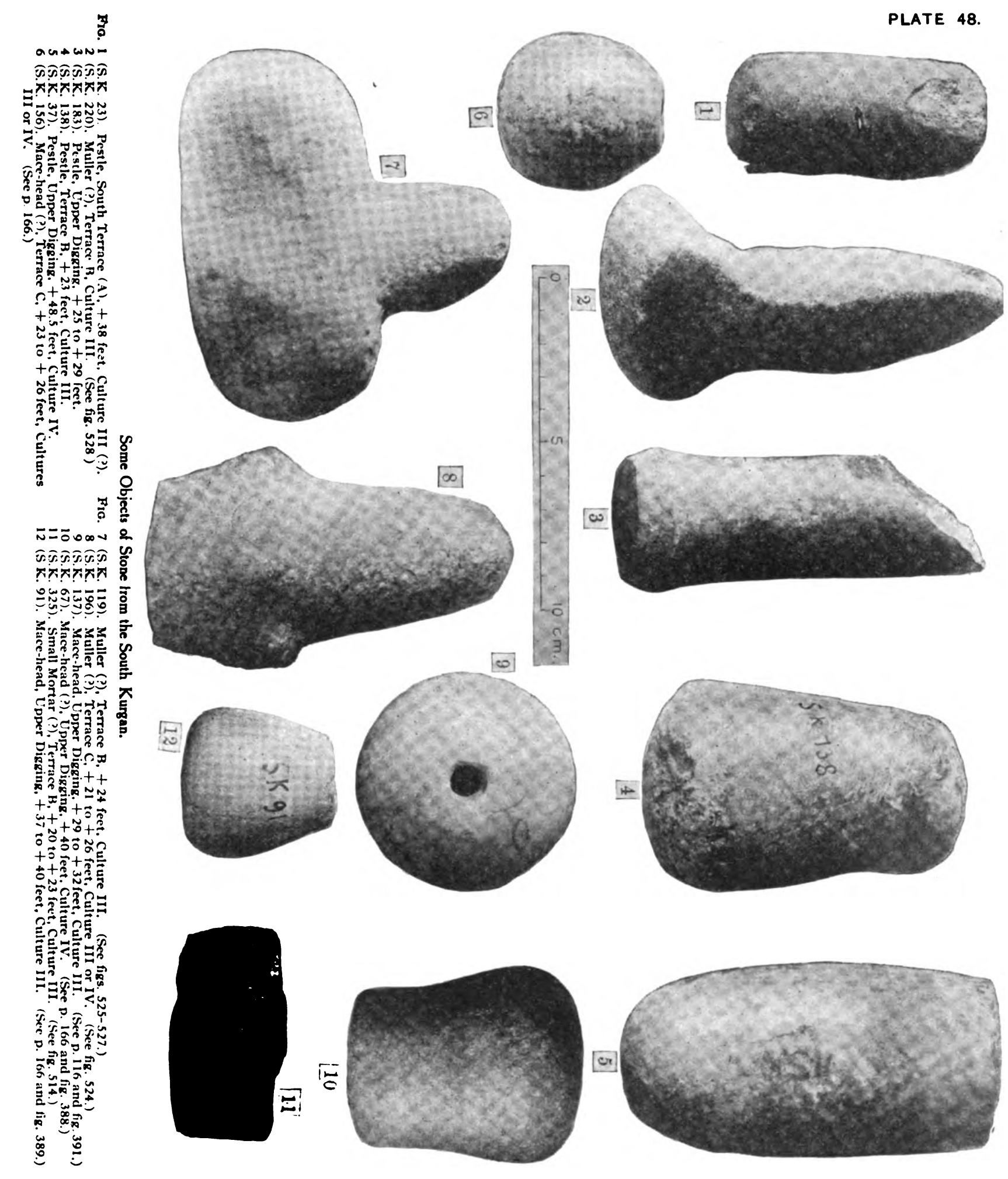

Digitued by Google 
Digitized by Google 


\section{CHAPTER VIII.-RESULTS.}

The systematic treatment of the special finds has brought before us not only each of the four culture epochs of Anau in its objects of daily use; but it has also shown us the gradual evolution from the more primitive to the more perfect stages of knowledge and taste among the people of Anau. The greatest value naturally lies in the recognition of a continuous progress within the three epochs of the copper or bronze (?) age, which is shown principally through the custom of child burial common to all three epochs. This progress of evolution is revealed most clearly by the pottery, in its three active factors-form, technique, and decoration. Although during the development of the northern kurgan the technique was restricted to hand-work, yet the vessels of both the older epochs I and II are excellent ceramic productions in regard to burning, preparation of clay, and modeling; and it is a striking fact that, in respect to technique among the different groups, it is the oldest one (plate 22) which stands preeminent. The fact that the need of decoration and the desire for color was greatest in the oldest epoch (I) may be looked upon as a sign of primitive taste. Nevertheless, the perfecting of a thoroughly uniform style of painting depended, as we have seen, on two very simple ground motifs-the erect triangle and the oblique band of parallel lines. In contrast with this, the fund of forms in the vessels is relatively insignificant. Both are changed in epoch II. Solid color gains the upper hand, monochrome technique in red and gray predominating. Painting, on the other hand, loses in importance; but its style, in so far as we can see, depends upon the traditional patterns handed down from the older time and advances a step forward in the grouping of them. At the same time, the polychrome painted bowls must pass for importation. On the other hand, the series of forms of the red and gray monochrome ware is richer than in the pottery of the older epoch.

The introduction of the wheel technique, an acquisition of the youngest copper period of culture III, produced a complete revolution in the making of pottery. It is true that in isolated cases very characteristic forms of vessels are retained, such as the bowls with high feet; but in general the new technique produced new forms and developed them further. This evolution of ceramic forms will appear much more clearly if future investigations produce the necessary material. The connecting link between cultures II and III, as regards form, technique, and ornamentation, seems to be the gray ware. In this the incised ornamentation, which occurred only in isolated instances on the gray monochrome ware of the older culture (plate 9, figs. 2 and 3 ), is continued, but forms in the newer culture a style of decoration in which the wavy line plays an important part.

However, the pottery of light-colored clay, which during the middle copper epoch occupied a subordinate position, now comes forward as the principal group. In it technique is uppermost, confirming the observation made upon the appear- 
ance of the potters' wheel in other culture regions-that the more the potter, through the mastery of the wheel technique, is enabled to satisfy his feeling for form, the less he feels the need of decorating the surface of vessels. Consequently the practice of painting decreases more and more.

The red ware now seems to be the rarest. Unfortunately, it must remain uncertain whether this ware is a continuation of the red monochrome ware of the North Kurgan or whether it is to be considered a new creation of the youngest copper epoch. If we compare the three epochs, therefore, according to their ceramic accomplishments, then culture III must be marked as the brilliant epoch of the copper age of Transcaspia.

This statement finds its confirmation in the other culture equipment of the three epochs. First of all comes the objects of copper. From the absence of certain forms in particular layers we are not justified in drawing conclusions concerning the supply of objects of copper of the corresponding epoch. Still, we must take into consideration the fact that considerable masses of earth were moved in both hills, and we are justified in comparing the mass of finds from both hills according to quantity and quality. The wealth of copper from the middle strata of the South Kurgan could certainly not be accidental. Culture III excels both of the older epochs very decidedly in abundance of copper objects. It is interesting also to compare the metal forms represented in the three epochs. Without any doubt the ornamental objects of culture I, such as spiral tubes and nozzles, which we have found among the burial gifts, have a primitive character; while the equal value which seems to have been placed upon copper and lead, which were both worked into jewelry, points to a relatively high age. Pins of a similar kind are found in all three epochs. Culture III brings a new form to these in the pin with double scrolls at the head end. The copper ornamental disks of the third epoch can also pass as enrichment of the ornamental equipment of the copper age. As regards tools, similar awls and chisels occur in all the epochs; but it may not be without significance that we find in the youngest copper epoch a small chisel with a broad, widened cutting-edge. We certainly can not produce much more evidence, the weapons found in the older epochs being too few in number to invite a comparison.

In general it can be further stated that in the third epoch the need of luxury finds its expression in the use of vessels of marble and alabaster, of stamps, and of stone seals. The ornamental beads also show a more artistic and varied use of precious stones. To those previously in use-turquoise, lapis lazuli, and carnelian-there were now added alabaster and marble. Lastly, we can observe this progress in the direction of taste in some of the implements of daily usein the ornamented whorls, for example. The whorls are all the more important on account of their rarity; and we are really justified in laying stress upon the difference between the respective groups of whorls of the two hills. Not only can one observe a finer modeling of form in the whorls of the South Kurgan, but the decoration also shows distinct progress in the systematic grouping of the patterns which in the older epochs were used as separate motifs. 
Thus we have a whole chain of details from which, according to the finds, we can deduce an evolution of culture within the three epochs of the copper age; and the conclusions regarding the relative chronology which we have drawn as dry facts from the location of the finds become justified and comprehensible through the formal examination we have made of the finds themselves.

There remains only the question whether the finds furnish data for an absolute chronology. Such data can be obtained only through the comparison of our finds with those of other regions and countries.

In connection with the decoration of the whorls, frequent mention has been made of Trojan parallels, but one must naturally avoid drawing conclusions from these as regards chronological and ethnological relations. On the other hand, other details are to be brought into consideration, since they concern the external culture and the form of life. 
Digitized by Google 


\section{CHAPTER IX.-CONCLUSION.}

The problem of the relation of Transcaspia in prehistoric times to other regions of Asia, and especially to Europe, is all the more important because the pottery of Anau and its ornamentation show throughout a non-European character. The painting of pottery begins to play a part in Europe in the younger periods of its older phases of culture. Moreover, the style of decoration of Old Anau differs entirely from the Old European systems. Indeed, with its rows of erect-standing triangles, which form the foundation of the "tent-ornamentation," it stands in direct opposition to the system of horizontal and vertical ornament, which we can follow as an Old European peculiarity through all the prehistoric epochs of Europe.

Now, if we seek in Asia parallels to the pottery of Anau, we are confronted, it is true, by wide gaps in the knowledge of the oldest culture epochs of the neighboring continent. Only in Persia, in the very old Tell of Susa, where De Morgan* has exposed several superimposed cultures, have discoveries been made which might be compared with the cultures of Transcaspia. In the deepest layers of the hill, 24.9 meters below its summit, there occurred a finely painted pottery which, according to De Morgan, was even wheel-made (De Morgan, plates XvII to $\mathbf{x x}$ ). The layers lying above this are characterized by a coarser pottery, which is also painted (plates XXI, XXII), and which marks the decay of the older group. $\dagger$ We have, therefore, to regard the painting of pottery as an essential characteristic of the oldest cultures in Persia as well as in Turkestan. More than this can not be said, for the decorative motifs and the style of painting have nothing in common. No opinion can be given as regards form, because, unfortunately, in De Morgan's publication importance is given only to the decoration. However, the oldest culture groups of Susa and Anau can not be widely separated in time, for in the Tell of Susa also, artefacts of flint were of constant occurrence in the lower and lowest layers. Generally speaking, as regards the occurrence of flint, the hills of Susa and Anau show much similarity, for De Morgan found it present in all the layers and concluded (p. 19i) that artefacts of silica were either used during the historical efochs in Susa or had found their way into younger layers through disturbance of the earth-masses. There is no way of determining which of these views is correct.

The prehistoric relation of Central Asia to Europe appears in an entirely different light when we examine further the elements of culture and the social peculi arities of Old Anau. Of these the first to attract our attention is the burial custom.

* Mémoires de la Délégation en Perse, I, I 83

$\dagger$ The succession of the layers can be seen in a smaller writing of the same author-Bulletin et Mémoires de la Société d'Anthropol. de Paris, 1902, p. $712 \mathrm{ff}$. 
But we shall attach less significance to the burial custom the less we are inclined to ascribe an ethnical origin to burial in the contracted position. In Europe we find the custom of burying the dead in the so-called contracted position practised principally in neolithic, but in widely separated regions into the early bronze age as well.* An enumeration of the localities of such finds is unnecessary. I refer to Colini's compilation (Bulletino di paletnol. ital., XXIV, pp. $240 \mathrm{ff}$., note 100). To this may be added the remarkable groups of finds in the sphere of Agean culture. Burials in contracted position, belonging to both the stone and early bronze ages, have been found, not only in the islands of the Agean Sea (Ephemeris Archaeologike, 1898, pp. 137 ff.; 1899, pp. 73 ff.) but also on the Grecian mainland (Orchomenos). Indeed, a burial in the contracted position (liegender Hocker) has been lately found even in the sphere of Mycenean culture in a tumulus of Orchomenos (Mitteilungen des kais. deutschen archaeologischen Instituts zu Athen, 1905, pp. I $30 \mathrm{ff}$.). Outside of Europe, burials in contracted position are known in Egypt in the necropoli of the oldest dynasties (cf. De Morgan, Rech. sur les origines de 1 'Égypte, 1897, pp. $132 \mathrm{ff}$.). It is perhaps worthy of especial remark that there is evidence of this custom in a relatively late epoch in the Caucasus. In the necropolis of Koban, on the north side of the range, burials in a contracted position were found in many of the graves, though not in all of them ( $R$. Virchow, $d$. Graeberfeld von Koban, p. I3; E. Chantre, Rech. anthrop. dans le Caucase, II, pp. 25 ff.). According to the objects found in the graves this necropolis belongs to the early iron age, therefore to the I millennium B. C. We have here, then, a region that in finds approaches nearest to Transcaspia. Nevertheless, one must beware of drawing important conclusions from this fact unless closer cultural connections can be deduced from other circumstances. At the present time we are only justified in saying that in three probably successive, prehistoric culture periods of remote antiquity in Transcaspia there was a burial custom which was widely practised in Europe, from east to west and from north to south, during the late neolithic and early bronze ages.

Now it is a very striking and remarkable fact that the burials found within the dwelling-places of Anau contain, as a rule, skeletons of children only. I know of nothing analogous in the history of European cultures. On the other hand, I find in Sellin's report on his excavations at Tell Ta'aneek in Palestine similar observations (Denkschrift d. Wien Akad. d. Wissensch. Phil. Hist., Bd. 50, I904, pp. $32 \mathrm{ff}$.). There were found at several points on the hill, "under or close to the houses and in or near pots, burials of children not over 2 years of age, half of them indeed newly born; in one instance the body was clearly that of an adult." Sellin places the beginning of this custom (pp. $96 \mathrm{ff}$.) at an early period of the settlement of the hill in the layer $1 b$ (about 1600 to 1300 B. c.). It lasted through layer $2 a$ and extends even into the layer $2 b$ (about 1000 to 800 B. C.). It ceased during the time of the Greek influence (in the eighth to the seventh century B. c.).

*In the Picentan necropoli of Italy (Novilara group), it extends till into the iron age, $i$ e., about into eighth to seventh centuries $B$. $c$. 
Sellin leaves it an open question whether or not we have here in Ta'aneek evidence of the sacrifice of children buried alive, such as was observed under the Canaanitic temple in Gezer (Palestine Exploration Fund, 1903, pp. 32 ff.).

Naturally we are still less able in the case of Transcaspia than in that of Ta'aneek to draw any conclusions as to whether such ideas underlie the method of child burials. The graves at Anau are certainly different, not only in the position of the skeletons, but also in the frequently greater age of the children buried in them. Here we certainly have no evidence of sacrifices. The future may throw more light on the burial custom of Anau.

In connection with the lapis-lazuli button drilled with an elbow-shaped hole (fig. 338) we may remark that similar buttons were widely distributed in Europe in the period of transition from stone to metal (cf. M. Much, die Kupferzeit in Europa, 2d edition, p. 95 ff.; Olshausen, Zeitschrift für Fthnologie, 1890, Verhandlungen, p. $287 \mathrm{ff}$.). What connection may have existed between these widely separated occurrences is uncertain.*

Mention has frequently been made of flint implements and flint flakes. Obsidian is a great rarity. It is represented in a single well-worked arrow-point (fig. 386 ) in culture III. There probably it was imported, either ready-made or in the raw material. The nearest source would probably be in the Caucasus.

Among the objects made from metal-copper or bronze-there occur few which invite comparison with other fields of discovery. The ornamental pins of culture I represent the simplest types that remained in use in Europe from the earliest metal times up to the iron age and they have a wide range of distribution (cf. figs. 238 and 240). In Anau, too, these types continue through culture II into culture III. As parallels I mention only those from Troja-Hissarlik, whose stock of types connects Asia Minor with Europe over the bridge of the Egean Sea. Thus the pin with a round cross-section and double pyramidal head (fig. 239) occurs also in the Schliemann collection under the catalogue number 6292 (Doerpfeld, Troja und Ilion, p. 355, fig. 290c); and the pins with four-edged cross-section (figs. 238 and 244) will be found in catalogue numbers 6336 and 6353 (= Troja und Ilion, figs. $219 a$ and 29Ic). Special remark attaches to the scroll pins (Rollennadeln). The type with a single scroll, so widely distributed in Europe (cf. R. Virchow, das Graeberfeld von Koban, pp. $32 \mathrm{ff}$.), is wanting among our finds. A corresponding form of head is seen on the tweezers from culture III (fig. 269). On the other hand, the pin with double scroll is represented by two specimens in culture III (figs. 25I and 252). In a general survey of the distribution of this type one would have to distinguish between those with wire spirals (Drahtspiralen) (e. g., in M. Much, Kunsthistor, Atlas, plate XXII, 5, and p. 62, fig. I8; or, Montelius, Civilisation primitive en Italie, I, plates 7, 5, 16, 20, from Italian pile-dwellings and terramara) and those with band-spirals (bandspiralen). The latter were found in Anau. Their nearest parallels would again be Trojan (Cat. No. 6401, 6402 $=$ Troja und Ilion, figs. $294 h$ and $294 i$ ).

* As this button came from +2 to +3 feet in the "mixed strata" of the outer digging of the South Kurgan it may have belonged to culture III.-R. $P$. 
Among the implements, the sickle from culture III (fig. 274) is worthy of remark. It differs in its form from all European types of sickles (cf. H. Schmidt, Die Bronzesichelfund von Oberthau Kr. Merseburg, in Zeitschrift f. Ethnologie, I904, pp. $416 \mathrm{ff}$.). The characteristics of the sickle of Anau are the smooth surface of the blade and the form of the tang or haft, the end of which is bent backward. The same peculiarities I find, in contrast to the European types of the bronze period, only on the sickles from Troja which belong to a hoard $(P)$ (Depotfunde) of the VI city (Cat. Nos. 6r 37-6r 39 of the Schliemann collection).

Striking, too, is the knife-blade with a square hole in the handle-end without any particular forming of the tang, found in culture III (fig. 27I). I find similar formless knives occurring only in the Altai-Ural bronze age, of which the stock of types has been brought together by Aspelin (Antiquités du Nord Finno-Ougrien, figs. 184-187, 214-217) and by Radlof (in the Materiali po arxeologie Roccii, Nos. $3,5,15,27$; cf. No. 3, plate I, 6).

Therefore, while we are able to show several instances of the relation of Turkestan with the western and southern discovery districts, the connections with the north seem to have been very slight and rare.

Of course, the established equations do not suffice for chronological determination, because we have here to do for the most part with types which were in use for a long time. Among the remaining finds from the four successively flourishing cultures of Anau there are only two objects which might be used for an absolute chronology, and these only with grave reservation. The engraved stone with representations of a man, a lion, and a griffin (fig. 400) is undoubtedly imported, and has been brought only from Western Asia to Central Asia. Possibly the route was the same as that of the connections with the Trojan sphere.

In forming an opinion concerning the stone, two points are to be consideredthe form and the representations. As regards form, three-sided stones, drilled longitudinally, have, as is well known, been found in Crete; they have picture writing on all three sides and belong in the beginning of the early Mycenean development.* With these stones ours has in common only form. The representations on ours differ wholly, not only from these stones inscribed with pictographs, but also generally from all Cretan seals and so-called island stones (Inselsteinen); and they point to another center of origin. The so-called Hittite stones are also of another kind, both as to technique and sphere of representations, and belong surely to a younger epoch of the Oriental art of engraving on stone. No other analogies are known to me. I can only surmise that the stone of Anau points to Asia Minor. With Assyro-Babylonian representations it has nothing to do. The griffin seems to me to point more to Syrian origin. As regards its age, of course nothing definite can be said; but the form and the very awkwardly formed representations indicate for it a place in the II millennium B. C. The analogy with the Cretan stone would bring into consideration the time of the XII Egyptian dynasty,

*A. J. Evans, Cretan pictographs and pre-Phœnician Script, p. 19, fig. 20, $a, b$, pp. 21 ff., 55 ff.; Journal of Hell. Stud., xIv, 1894, pp. 270 ff.: Further Discoveries, in Journal Hell. Stud., xvII, 1897, pp. $327 \mathrm{ff}$. Cf. Furtwaengler, Geschnittene Steine im Antiquarium, Nos. 57, 58, and Antike Gemmen, 1II, pp. $27 \mathrm{ff}$. 
which, according to the newest chronological determination, would indicate the nineteenth century B. c. It is, however, improbable that the stone arrived in so distant a locality at the same time that analogous types came into use. Its importation into Central Asia presupposes a flourishing epoch of culture III; on the other hand, it may have been in use a long time here before it became buried in the strata of this culture. Thus the possibilities vary and with them the chronological determination; but we need not seek much later than the middle of the II millennium B. c. to find the latest date of the continuance of its use.

In dating the youngest culture (IV) there is to be considered an implement which was certainly imported-the three-edged arrow-point of copper (fig. 288). Objections might be raised to the use of this in dating an entire culture, inasmuch as two bronze arrow-heads of the same type were also found on the acropolis of Ghiaur Kala (plate 5I, figs. 6 and 7). Here, however, the surroundings in which they were found are entirely different and contradict in themselves the possibility of the arrow-points being contemporaneous; otherwise one would be forced to the assumption that the three-edged bronze arrow-heads had remained in use in those distant regions until the middle of the first century A. D., which seems impossible. The circumstances are different in Anau. Here the bronze arrow-heads do not in any way fall outside of the framework of the youngest culture (IV).

A typological study of the three-edged arrow-points of bronze would be a useful and praiseworthy undertaking; but I must confine myself here to a determination of the principal points in regard to their form, distribution, and chronology. The three-edged arrow-points of bronze belong in the series of arrow types which were published by P. Reinecke as Scythian (Arch. Ertesito, XVII, I887, pp. I 8 ff., figs. 6 and II). They might be more properly termed Græco-Scythian, unless one preferred to call them Southeast European, from the region in which they originated. From there they spread in a westerly direction to Central Europe, eastward to Central Asia, and in northern and northeastern directions to Siberia. As regards their form, essentially two types can be distinguished. The first has a hole through the heart of the arrow-head to receive the end of the shaft; the second type has a shaft-socket. The variations in the two types arise from the varied conformation of the surfaces of the sides; of the edges, which change to more or less broad wings, and of the three lower corners, which are either truncated or drawn out to form shorter or longer spines. These last represent the dangerous barbs on arrow-points. In exceptional cases there is found on specimens of the second type a special spine or barb set upon the socket and directed downwards, such as occurs often on two-winged arrow-points. When a three-edged arrowpoint has a shaft spine, it has this barb in common with the two-winged type. Our arrow-point of Anau represents the first type, with truncated lower corners, and has the compact form of a bolt. This is probably the earliest.

The principal localities are the coastal regions of the Black Sea and the inland part of Southern Russia. Here the three-edged arrow-heads belong among the customary burial gifts in the so-called Scythian kurgan graves of the fourth century B. c. In the celebrated kurgan of Koul-Oba there were found more than 
200 arrow-points of different kinds. I was able to observe numerous examples of the three-edged forms in the museums of Kertch and Odessa. They all came from the old Panticapæum and from Olbia. I saw them also in the Ermitage at St. Petersburg among the finds from the kurgans of Nicopol and Alexandropol. The compilation of the types from the Crimea is given in S. Reinach, Antiquites du Bosphore Cimmerean (plate xxvir, figs. 11-19). In the atlas accompanying the papers of the First Archeological Congress in Moscow (1871, plate Xv, figs. 1-45), are represented those from the older finds of Alexandropol, Kertch, and Olbia. Especially important are the well-observed finds from the contemporary Scythian graves in the museum of Kieff. The types occurring here are represented synoptically in the Khanenko collection (Antiquités de la région du Dniépre, II, plate vI). The collection of Count Bobrinskoi contains also finds from the region of Smjela. (Compare his publication (Russian) on kurgans and occasional archeological finds in the neighborhood of the village of Smjela, plate IV, figs. 5, 7; vI, figs. 4, 5, 10, 14, 15, 20).

Further east we find, in the district of Kuban, in the steppe lying north of the Caucasus, the kurgan of Karagodeuachkh, with brilliant burial gifts of the fourth century B. C. (Matériaux pour l'archéologie russe, XIII, plate viII, figs. 5 to 8 ). These appear also in the Caucasus. Examples from Tsthetschma are published by R. Virchow (Das Graeberfeld von Koban, pp. 88 ff., figs. 32, 33, 34). Count Zichy also collected them in the valleys of Baksan and Tschegem (Voyages au Caucase, II, plate XII, figs. 6-10. Text by B. P6sta). As far as I know they have not been observed here in graves. In the older iron stage the two-winged type were here still in use and also in the necropolis of Samthawro near Tiflis (E. Chantre, Rech. anthropol, dans le Caucase, II, plate 47 , figs. 4 to 7 ). The threeedged types appear here to be younger than the hitherto known Caucasian necropoli of the post-Mycenean epoch.

These types may have come to Transcaspia from the South Russian point of origin, along the same route by which they finally advanced to Siberia, somewhere northward around the Caspian Sea. In any event, they were known earlier in Central Asia. I found in the historical museum at Moscow a collection with representatives of both the types above named, labeled "from Caspia and Transcaspia."

They have been collected also in the neighborhood of Bokhara. The Indian division of the Royal Museum für Völkerkunde in Berlin possesses all sorts of surface finds from that region, including small objects of the most varied form and significance from different epochs, and among them different types of arrowpoints of bronze and iron, showing representatives of both of the above-named principal types of the three-edged arrow-head. They may have come into that frontier region of the classic world with the Greek culture in the Hellenistic period. There is thus a third possible way in which the three-edged arrow-points may have come to Turkestan. They are known also from Persia (cf. Polak, Mitteilungen der Wiener anthropologischen Gesellschaft, XIV, 1884; Sitzungsberichte, p. 28, figs. 23-25). They are said to have been abundantly found on the champaign 
of Hamadan and Merdescht (Persepolis). They were certainly used in GræcoPersian wars by the Persians as well as by the Greeks.

Because of this Persian find we may assume also that they penetrated still further eastward and were known also in Bactria. The find from Bokhara tends to confirm this assumption. To Siberia the three-edged arrow-points of bronze or copper certainly penetrated from the South Russian locality. This is proved by the numerous other points of contact between the Siberian stock of types and the forms which have become known from the South Russian kurgan graves (cf. Aspelin, op. cit., p. 62, figs. 262 to 265 ; p. I 1o, figs. 438 to 440 , the last from the necropolis of Ananino, on the left bank of the Kama, in the Government of Wjatka, showing what singular routes the distribution followed. Radlof, op. cit., No. 15, plate XXI, figs. 20, $21,25,29,33,34)$.

Three-edged arrow-heads from the Græco-Agean sphere have long been known. Kemble mentioned them as coming from Kalymnos, an island on the Karian coast (Horæ feralis, plate vi, figs. 3, 4). Many have been found in the Altis of Olympia (Furtwaengler, Bronzen von Olympia, plate LXIV, Nos. 10831092). Friederichs (Kleinere Kunst $u$. Industrie im Altertum) enumerates some from Attica (III6). Helbig represents a specimen from Megalopolis in Arcadia (Das homerische Epos, 2 Aufl., fig. 134). From the Egean sphere they may also have spread to Egypt. Cairo is given as the source of several examples in the collection of Prince Hohenzollern in Sigmaringen (L. Lindenschmitt, die vaterlaendischen Altertuemer, plate $\mathrm{XL}$, figs. 13 to $\mathrm{I} 6$ ). On the western route of distribution the three-edged arrow-heads of bronze made a halt in a district which has preserved for us rich necropoli of the younger Hallstatt period. These finds are therefore of importance for the chronology.

In a grave of Hallstatt itself there was found a three-winged specimen without shaft-socket (v. Sacken, das Grabfeld von Hallstatt, plate vir, fig. 10). The necropoli in Krain have yielded them also-from Waatsch (Denksschriften der kais. Akad. d. Wissensch. zu Wien, Math.-Naturwiss. Cl., Bd. XLvII, plate XI, fig. 13) and from St. Margarethen (M. Much, Kunsthistor, Atlas, pl. 56, fig. I5). Other isolated localities are: Villach, in Carinthia (v. Luschan, Mitteilungen d. Wien. anthropol. Gesellschaft, viII, I879, pp. 89 ff.); Velem St. Veit, in Western Hungary (v. Miske, Archiv f. Anthropologie, N. F. II, 2, pp. 134 ff., figs. 48 to 50); Horodnica, in Galicia (Museum Dzieduszycki in Lemberg, from personal examination). Further west they appear to be of only rare occurrence. The most western locality is Châlons-sur-Saône, in France (Bonstetten, Antiquités de la Suisse, plate II, fig. 9).

On the strength of these statistics of finds we may assign the three-edged arrow-heads of bronze at least to the younger Hallstatt period, $i$. $e_{\text {., }}$ to the first half of the I millennium B. c. In the fifth century B. c. they must already have been generally distributed; they remained still in use during some centuries, for they connect with the Roman arrow-heads made of iron. In all probability, however, we must put back the time of their introduction into the beginning of the last millennium B. C., for these forms must have hovered before the eyes of 
the Homeric poets, one of them ( II. v, 393; XI, 507) having called the bronze arrow-

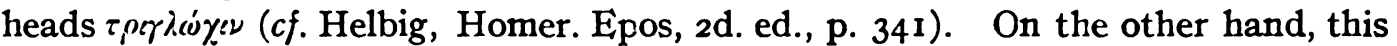
form is still unknown in the Mycenean sphere. For us, therefore, the three-edged arrow-point of Anau may indicate a post-Mycenean epoch. Here, too, iron appears for the first time. Among the other finds from the upper strata of the South Kurgan nothing is contradictory to the first half of the first millennium B. C. We may, therefore, date the culture IV approximately 1000 to 500 B. C. How far back we can go beyond the year 500 B. C. will doubtless appear when the next younger culture period in the city of Anau shall have been explored.

Naturally the upper limit is equally uncertain, for we do not know whether or not the occupation of the place continued uninterr uptedly. Since the burial of child skeletons is lacking in the upper culture-strata of the South Kurgan, we should perhaps assume certain disturbances in the continuity of development. In any event, the round date 1000 B. c. must be set as the terminus ante quem for culture III, and on account of its long continuance we must imagine its brilliant period to have been in at least the second half of the II millennium B. C. This practically corresponds to the flourishing period of the Mycenean culture. Indeed the engraved stone points to an earlier time. The agreements with the Egean sphere in this way find chronological support. How far back the beginning of the culture reaches we have naturally at present no means of determining.

The cultures of the North Kurgan must be still older. More exact determinations are not possible, since datable objects are wanting which might be compared with the finds of other spheres. For culture II, however, we obtain approximately the first half of the second millennium B. c.; and for the oldest culture (I) 2000 B. C. as a rough date will certainly not be too high. We will have to imagine the beginnings of the settlement of Anau as having taken place in the III millennium B. C.

Generally speaking, therefore, the absolute chronology of the four culture epochs of prehistoric Anau stands still on a very weak basis; but the finds hitherto made lead us to expect still better data for its further consideration.*

*In these conservatively suggested datings Dr. Schmidt is guided by the presence or absence of European and Mediterranean analogies among the finds, together perhaps with an unexpressed inclination to seek western origins for the cultures.

The reader who has examined the arguments stated in chapters III, IV, and $v$ will see that they are based-Ist, on evidence advanced to show that the early cultures of Transcaspia were not only of CentralAsian origin, but that they contributed to the cultures of neolithic Europe and of early Babylonia; 2d, on the determination of a law of proximate uniformity of stratigraphic growth of city mounds in dry climates in the absence of the use of stone and burnt brick in construction, and on the determination of the rate of this growth in Anau checked by that in Egyptian mounds; $3 \mathrm{~d}$, on the finds, both the artificial objects studied by Dr. Schmidt and the bones of animals which supplied the material for the brilliant discoveries of Dr. Duerst; 4th, on the confirmatory evidence of cyclical climatic changes, which in turn are found to agree with Dr. Duerst's independent conclusions, based on the progressive changes in size, etc., of the domesticated animals.

But most of these elements of the argument could not have been established without the fundamental and scientifically planned work of Dr. Schmidt. It is to this that we owe the knowledge of the exact stratigraphic position of every artificial object and every bone, while to his knowledge of ceramics we owe the ability to use the fragments of pottery, as the geologist uses fossils, in determining the culture periods of the successive alluviations which mark the favorable parts of the climatic cycles. $-R$. P. 


\section{CHAPTER X.-THE EXCAVATIONS IN GHIAUR KALA (OLD MERV).}

\section{GENERAL SUMMARY.}

Among the extensive ruins of Old Merv, those that lie farthest to the east are called by the people of to-day "Ghiaur Kala." They consist of a broad plateaulike elevation with a rolling surface, surrounded by a chain of closely contiguous, conical hills, the present representatives of the former walls of the city. Within this large and nearly square inclosing wall there is a smaller, nearly circular inclosure which attaches itself on its north side to the general wall of the larger city. It incloses a small, topographically independent part of the city; and its wall, rising to a great height, dominates the surrounding area. In the middle of this small inclosure there rises a tumulus-like elevation. On the southeast and west it is connected, through a low plateau, with the encircling wall, from which it is separated on the north by a deep valley or plain. In this depression there rises an independent, smaller plateau, adjoining the northern portion of the wall. Of the walls there remain only insignificant ruins, which give the impression of having been built upon the remains of older ones.

The excavations in Ghiaur Kala were undertaken on a much smaller scale than in the kurgans of Anau and served merely for preliminary examination. The city was attacked at four points-at two points each within and without the circular inner wall (see figs. 420 and 421 ).

On the top of the hill, 82 feet high, which has the significance of an acropolis, a large cut was made toward the northern declivity. It had a breadth of 25 feet and was about 50 feet in length (upper digging), and it was sunk by means of four terraces, to a depth of 40 feet 4 inches. (The figures referring to levels will here be reckoned from the top of the hill downward.) At the foot of the hill, in the depression to the north, there was started a pit (lower digging) 33 feet long and 20 feet wide, which was sunk by means of a terrace to a depth of 16 feet.

On the plateau of the larger city, 200 paces to the south of the wall encircling the acropolis, there was laid out the outer digging I, 45 feet long and ro feet wide. Here, by means of two terraces, a depth of 27 feet was reached. Outer digging II was the place at which were found seven large supply vessels standing in situ, which were discovered at first in sinking a shaft. This was on the plateau of the larger city. The uncovering of these vessels was undertaken by Mr. Homer Kidder, who describes the find. Besides these excavations, three galleries were driven horizontally into the heart of the acropolis hill from its west side.

Lastly, here too, as at Anau, several shafts were sunk for physiographic study which have contributed little to the archeological problem. 


\section{THE SEPARATE EXCAVATIONS.}

UPPER DIGGING.

A little below the surface, at a depth of I foot Io inches, there was uncovered the remains of a brick pavement $(a)$ in the middle of the excavation. The flat, square, burnt bricks-all $\mathrm{I} 5$ by $\mathrm{I} 5$ by 3 inches-were set with mortar and formed

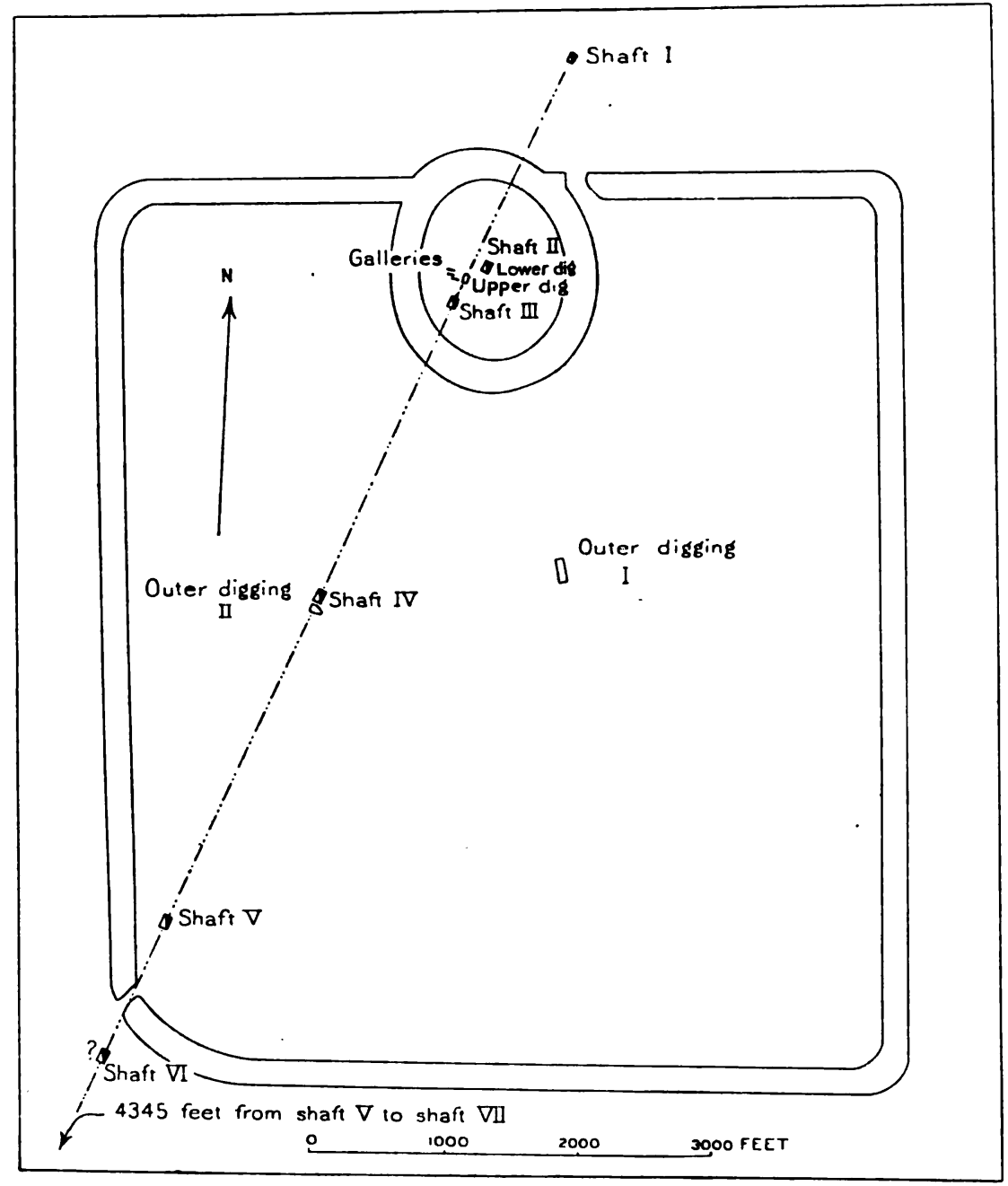

Fig. 420.-Plan of Ghiaur Kala.

only a single layer. At the same level very important finds were made-two marginal pieces of a large, thick-walled supply vessel, a small piece of a thin-walled vessel, and some pieces of animal bones, all inscribed with cursive letters in black color. Copper coins were also found in the same layer. I will precede the following description with the remark that copper coins occurred in the upper digging in the deeper layers down to 32 feet 7 inches. They will be considered further on in connection with the coins from the other point (see fig. 422). 
Plate 49.

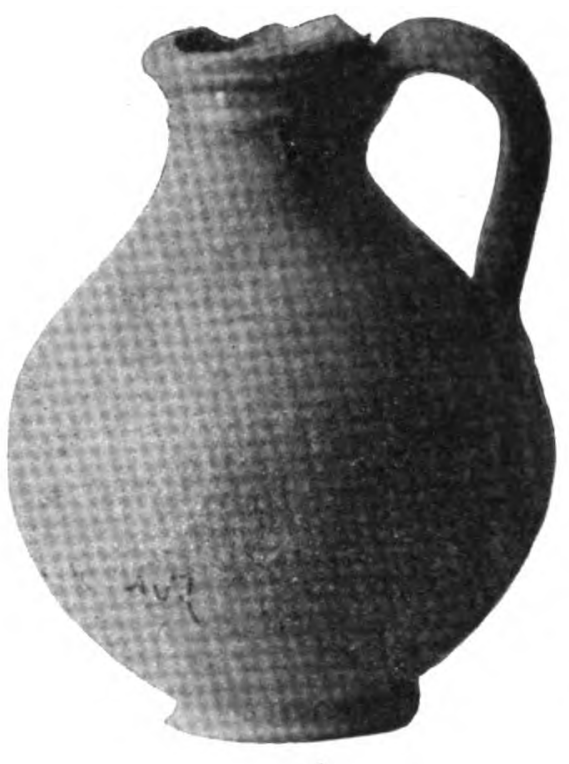

1

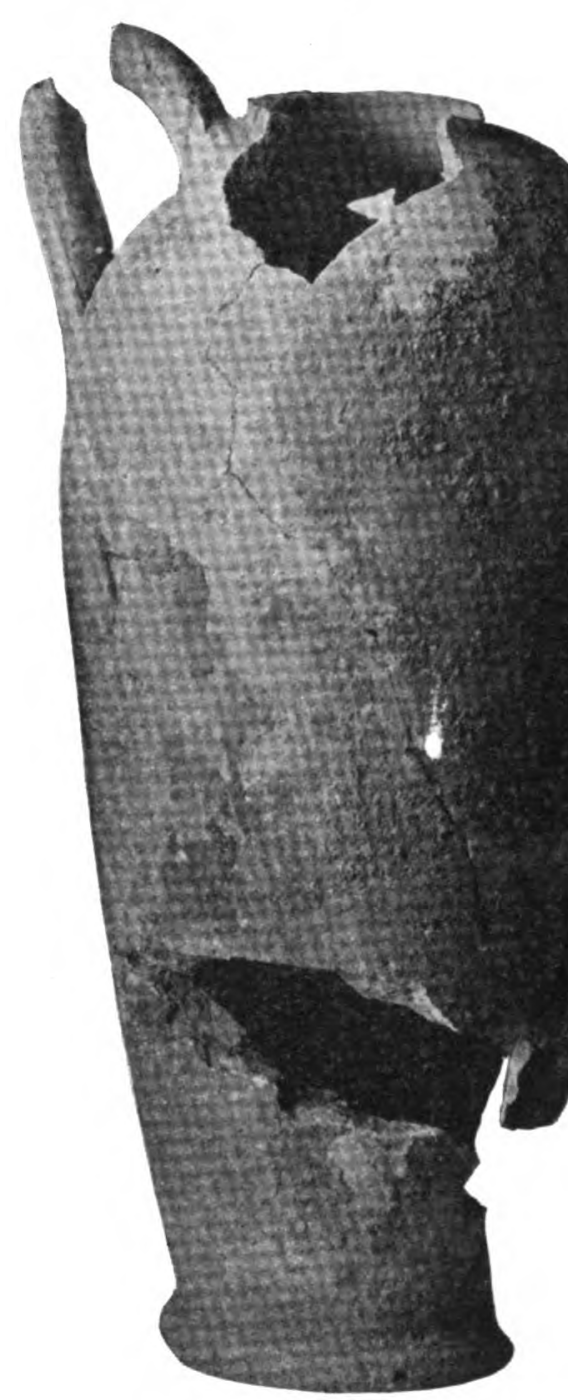

2
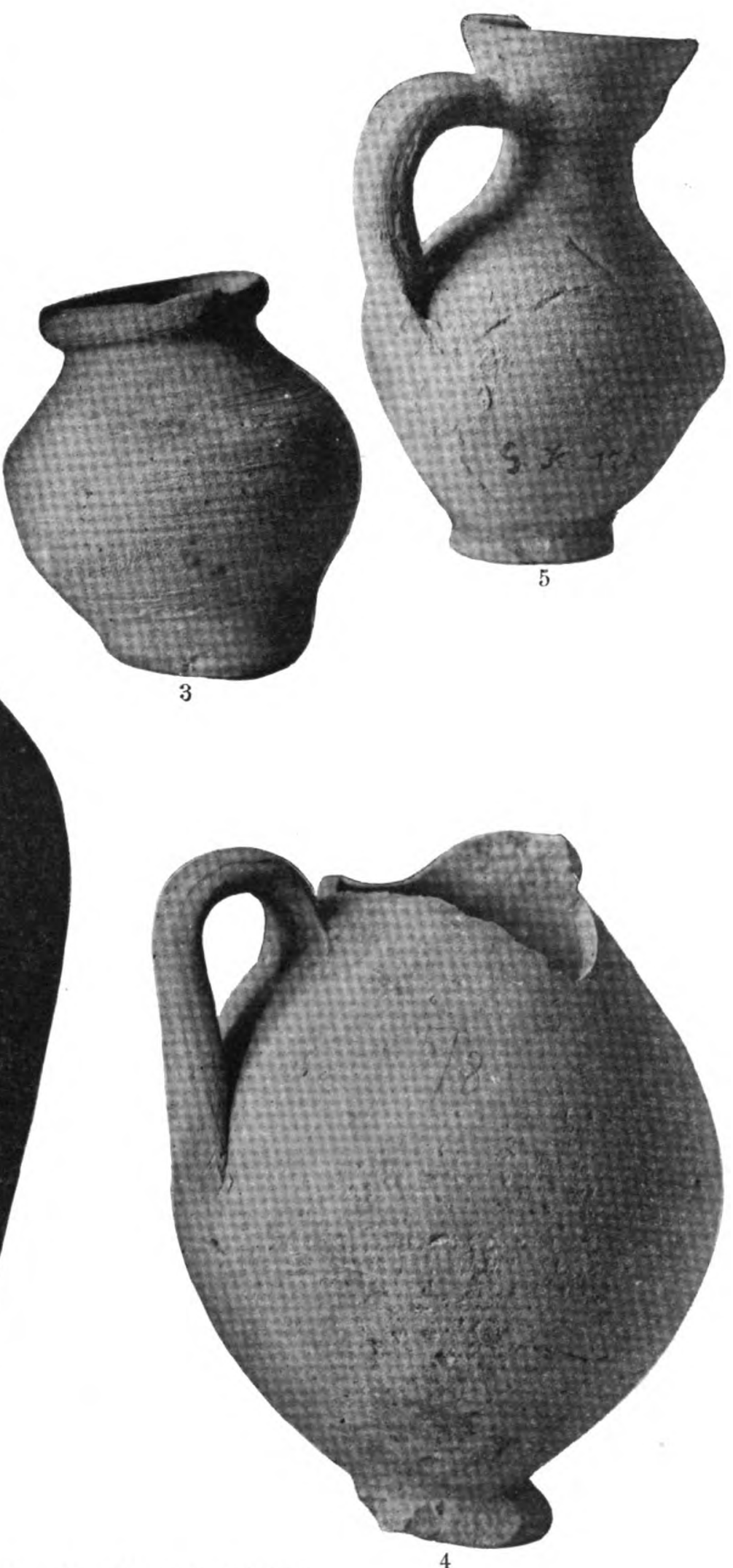

Pottery from Ghiaur Kala (Old Merv).

F10. 1 (G.K. 107). Outer Digging I, at 4 to 9 feet, Height $10 \mathrm{~cm}$.

2. Upper Digging at depth between 9 and 10 feet, Height $23.5 \mathrm{~cm}$. $7.4 \mathrm{~cm}$. 4 (G.K. 164). Outer Digging I', between 14.5 and 17 feet, Height $13.5 \mathrm{~cm}$. 
plate 50.

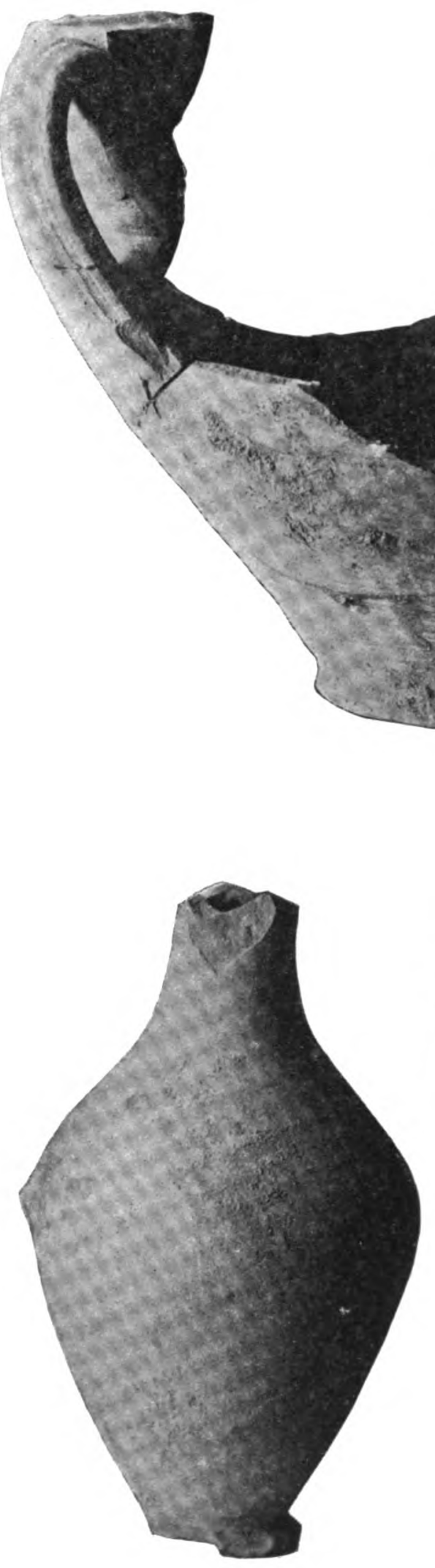

1

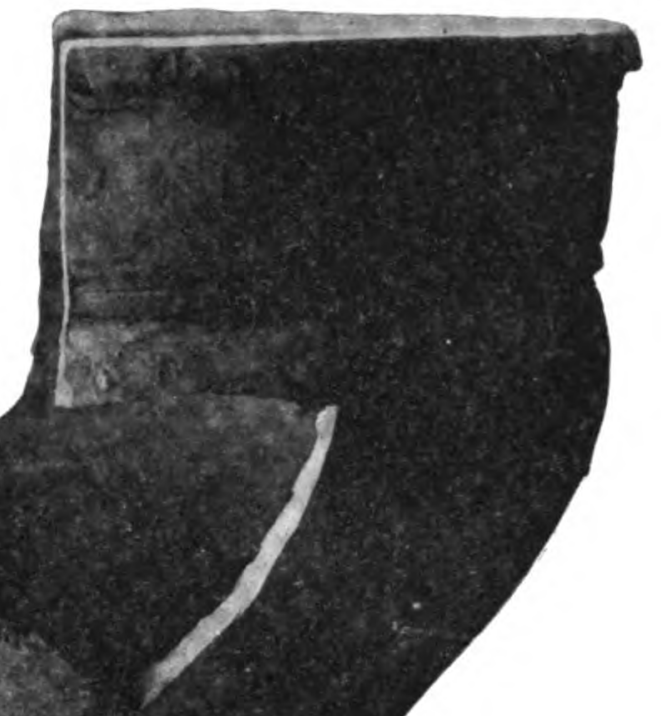

3 
Digitized by GOOgle 
PLATE 51.
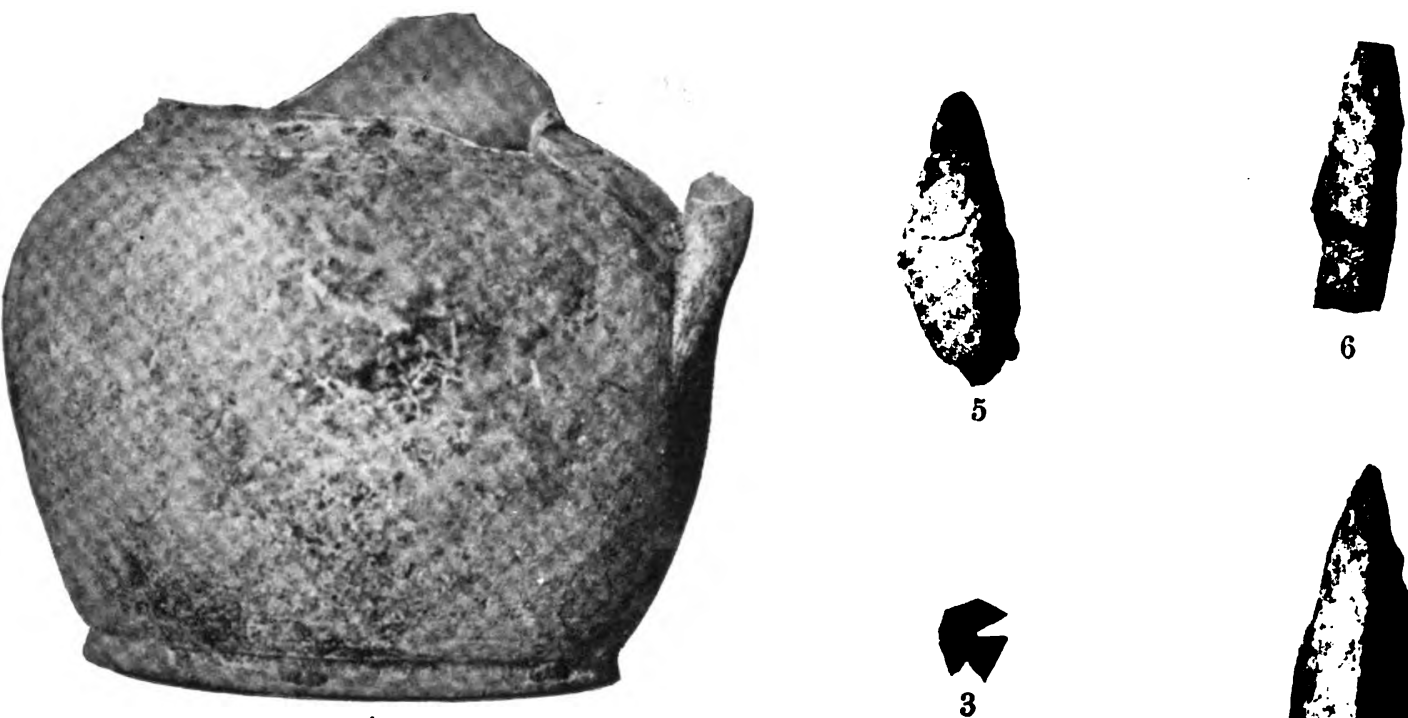

6
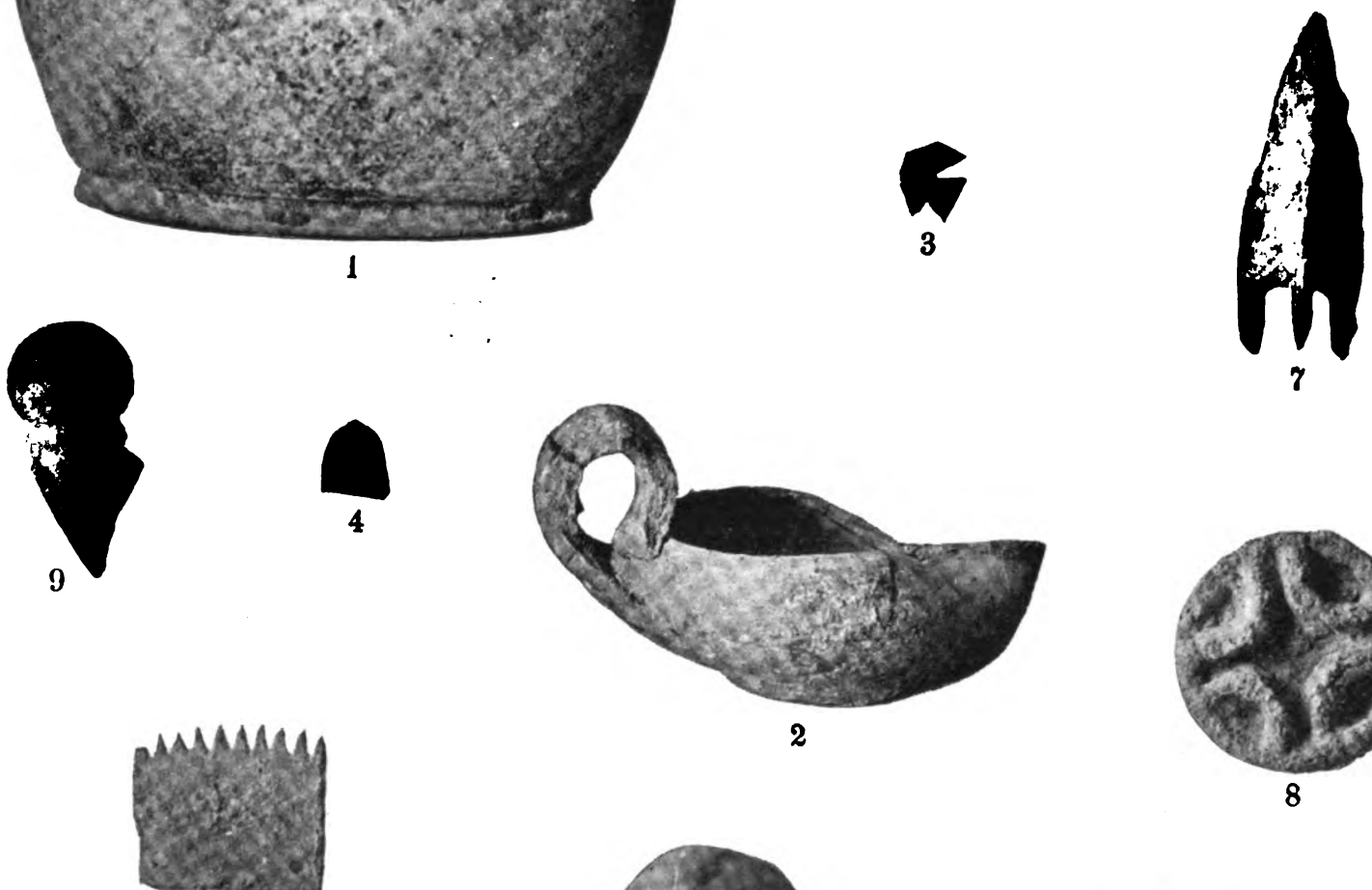

10

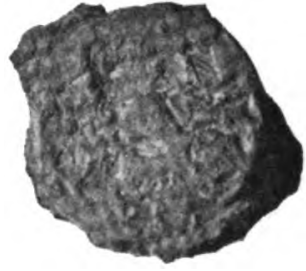

11

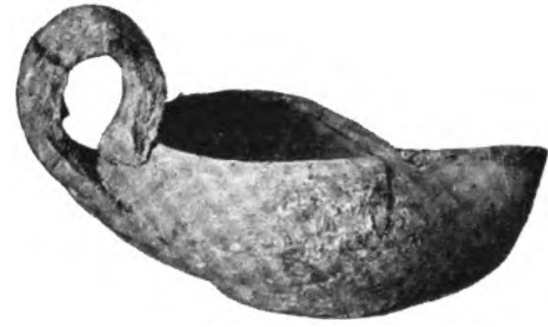

2
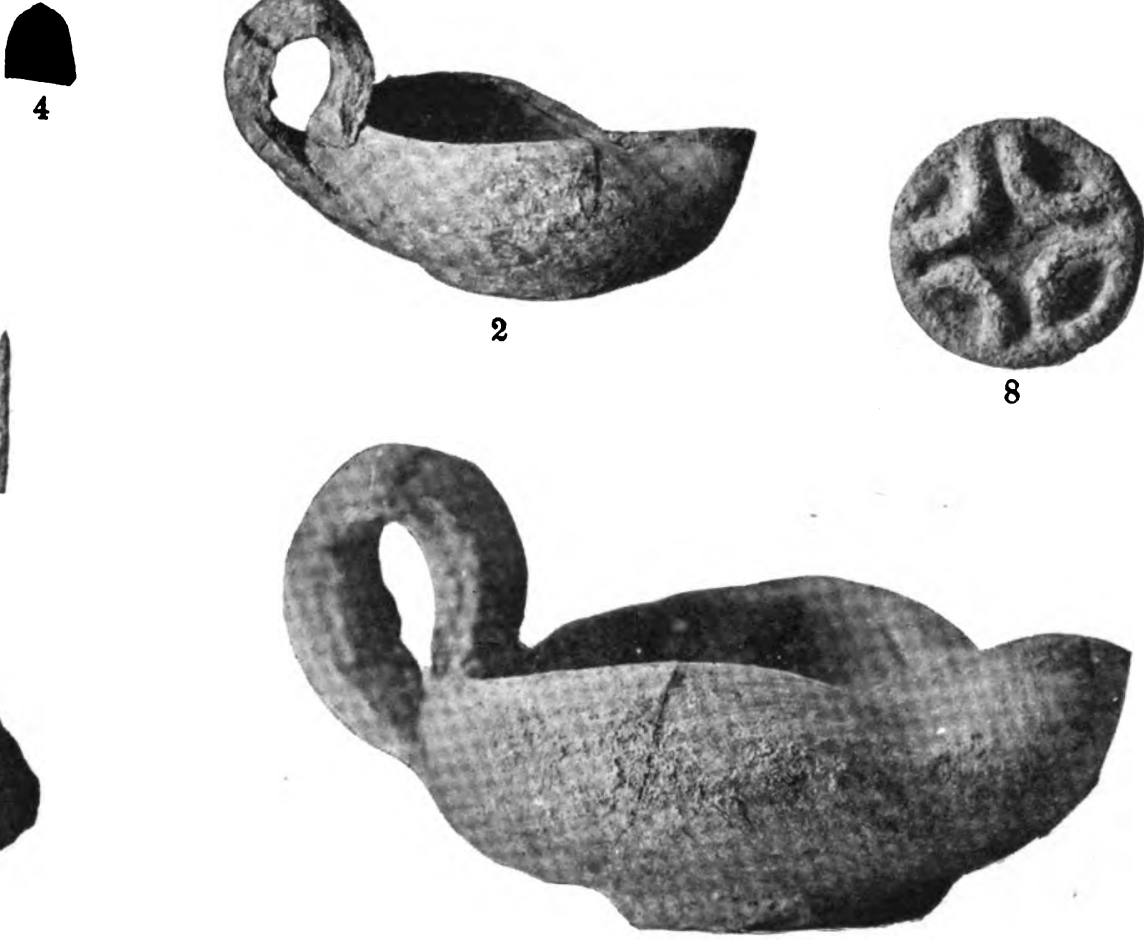

$2^{a}$

Pottery and Objects of Metal from Ghiaur Kala (Old Merv).

Fio. 1 (G.K. 207). Ornamented Pitcher, from Depth of 12 feet in Shaft near Outer Digging II.

2 AND 2a (G.K. 77). Two Lamps of Glazed Ware, from Outer Digging II,

5 (G.K. 138). Leaf-shaped Arrow-point of Bronze or Copper (not Analyzed), highly Corroded. From Talus-débris on Slope of Citadel.

6 (G.K. 110). Bronze (not Analyzed) Three-edged Arrow-point and Short Shaft Hole; found with No. 5.

7 (G.K. 109). Bronze (not Analyzed) Three-edged Arrow-point, the Edges Projecting Downward to Form Barbs.

8 (G.K. 4). Bronze Stamp (not Analyzed), with a Ring Eyelet on Back. Upper Digging, within 2.5 feet of surface

9 (G.K. 178). Bronze Object (not Analyzed), Outer Digging II, within 4 feet of surface.

10 (G K. 59). Bronze Object (not Analyzed), Outer Digging II.

11 (G.K. 87). Iron Seal-ring. Two figures seem to be represented, one sitting and one standing. From Surface of Outer City. 
Digitized by GOOgle 
The brick pavement (a) lay above a round, kettle-shaped fireplace $2 \mathrm{I}$ inches in diameter and 12 inches deep. At the same level as that of the fireplace, i. e., at 3 feet 8 inches, a second brick pavement $(b)$ came to light, the bricks and construction being similar in every way to the higher pavement. Only one complete

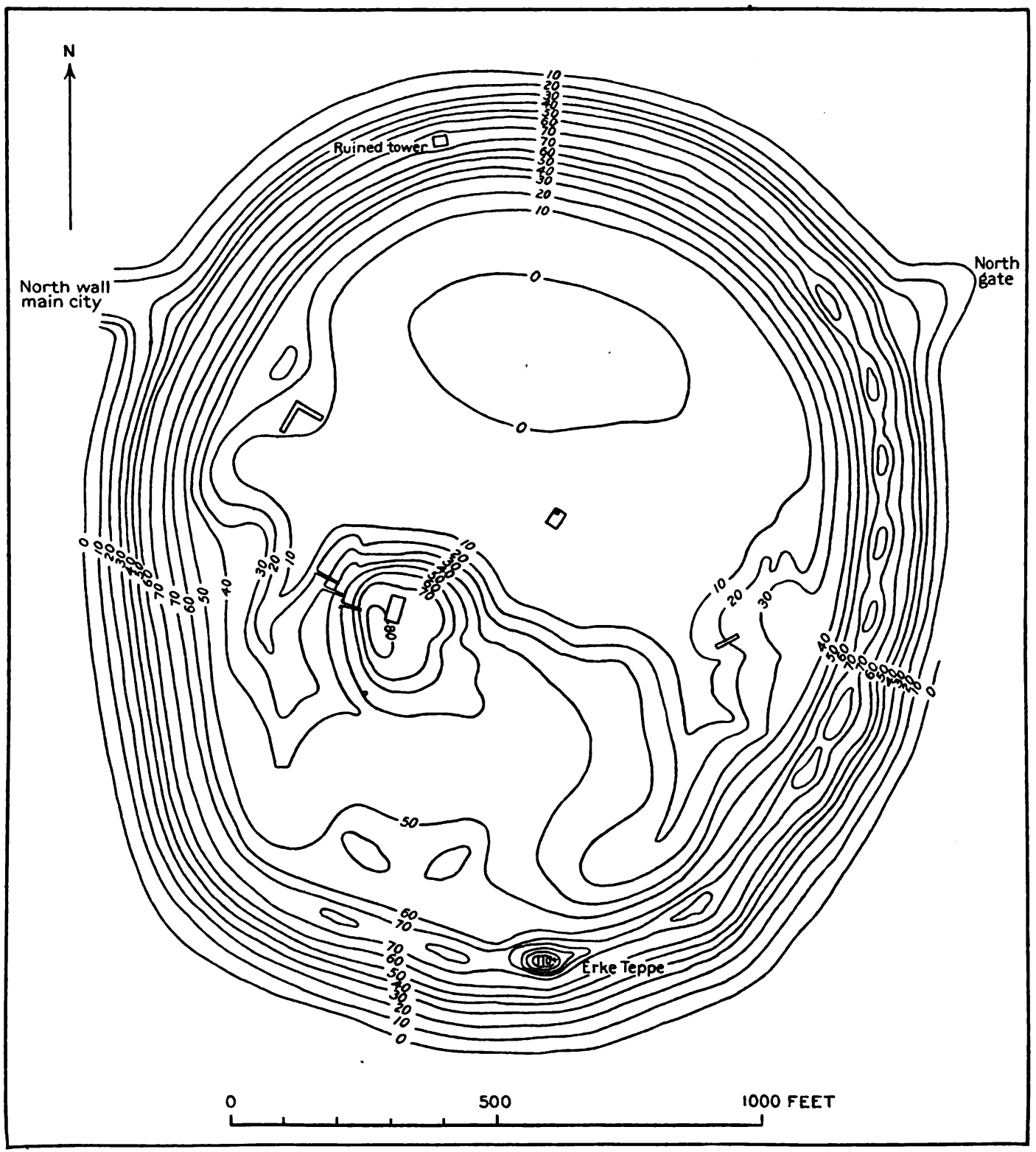

Fig. 421.-Map of the Inner City of Chiaur Kala.

brick and three adjoining fragments are preserved. At the northern end of the digging, at a depth of 5 feet and deeper, there occurred the traces of a thick wall built of air-dried bricks; but its trend could not be determined, because at the depth of 6.25 feet it was necessary to establish a terrace 9 feet wide to receive 
the earth shoveled up from the deeper part of the excavation. A third, deeperlying floor was discovered at a depth of 8.25 feet with much lime and ashes, as well as with the remains of a third brick pavement $(c)$ similar to the former.

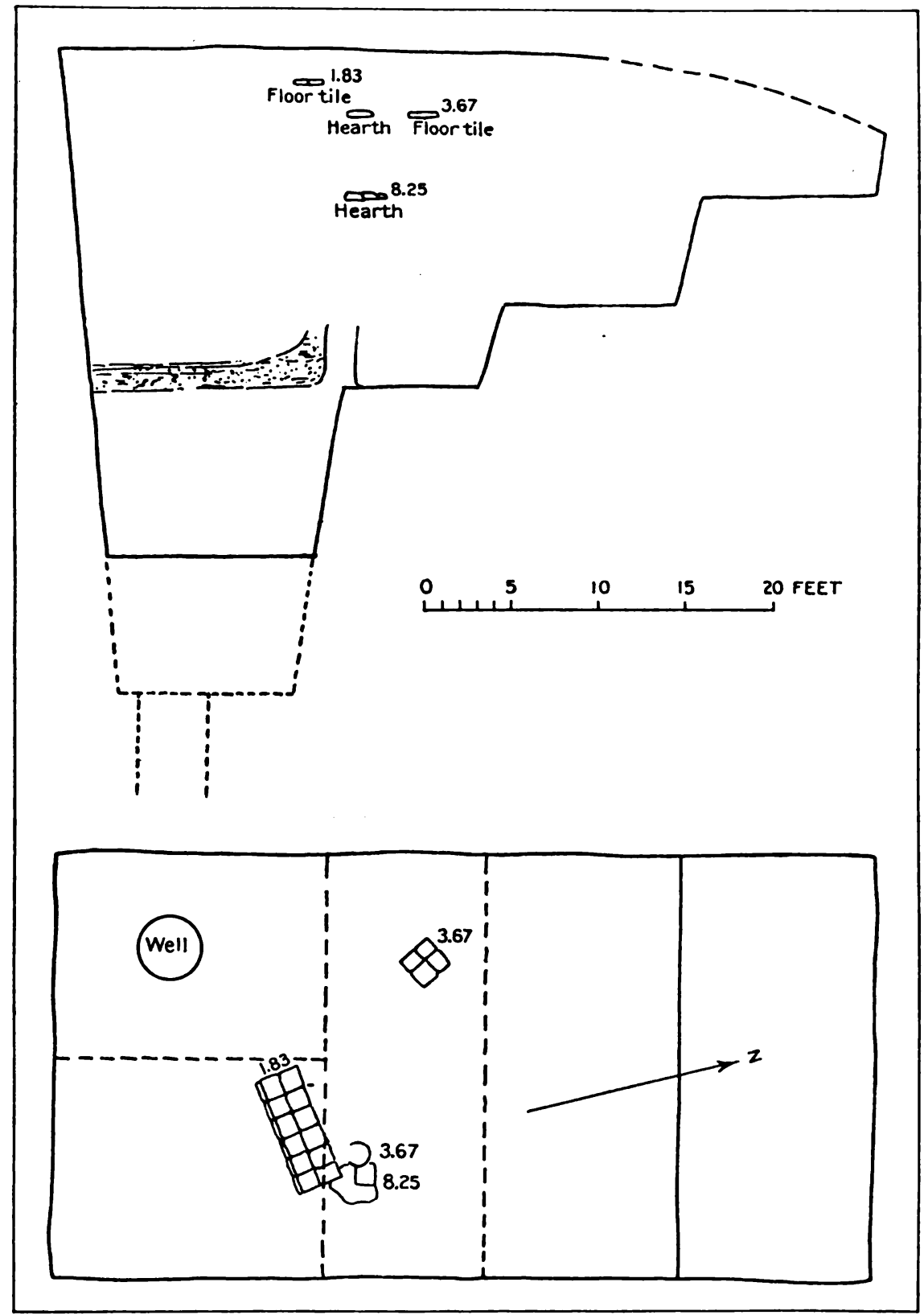

Fig. 422.-Plan and Vertical Section of Upper Digging on the Citadel.

Thus we have to distinguish in the upper strata of the hill three apparently similar periods lying one above the other. The three brick pavements may belong either to a court or to a room. In the deeper layers such bricks were not found. 
Indeed, the remains of structures were wanting. Between the depth of 17 feet 5 inches and 20.5 feet, there were found two bronze (?) arrow-points, one of them of the three-edged type, which we had already found at Anau.

At a depth of 20 feet 6 inches, a second terrace of 7 feet width was established. At 21 feet 4 inches there came to light the remains of a house with walls of sundried bricks, with a horizontal layer of ashes and charcoal extending through it. The accompanying sketch (fig. 423) represents the section clearly marked on the three walls of the excavation. The burnt layer represents the level of the floor of the house.

At a depth of 26 feet it was necessary to establish a smaller terrace on the east side. On the west side of the now restricted excavation very loose earth was encountered, causing the workmen to suspect the presence of a caved-in well. Lastly, at 40 feet 4 inches, there occurred a well-shaped depression, which at a depth of 7 feet opened into a horizontal subterranean passage, 7 to 8 feet wide and of unequal height, though apparently not more than from 3 to 3.5 feet high. This passage ran first for 12 feet in a north-northwest direction, then in a general northnortheast direction, and, as is clearly visible, is connected with the floor of the

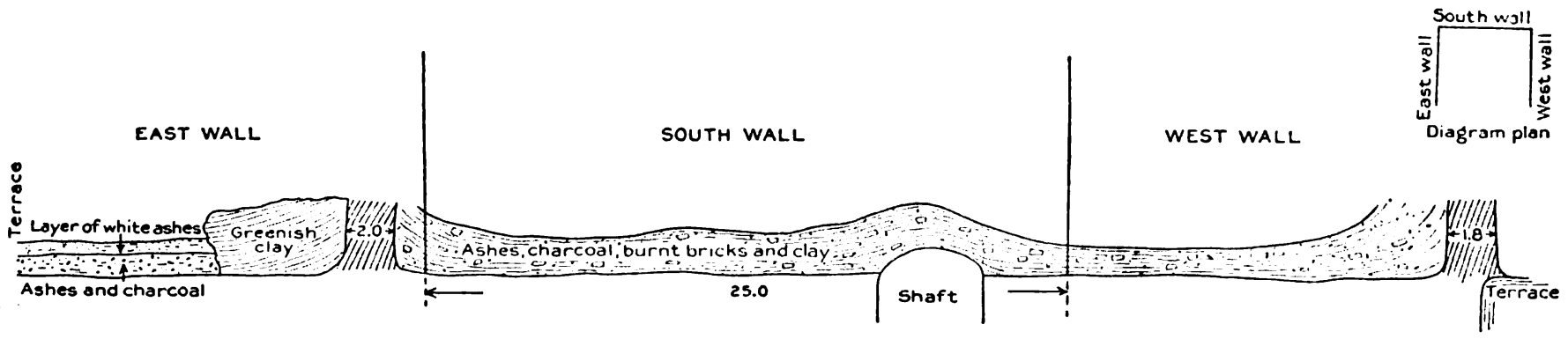

Fig. 423. - Elevation of Sides of Upper Digging at Depth of 21 feet, to show Layer of Ash and Rubbish at Bottom of Excavation.

house above by means of the well-shaped depression already mentioned. In the section one can see clearly how this depression was filled in from above. It must formerly have been empty and have formed a means of communication with the subterranean passage. That this passage is the work of man is shown by the traces of the instruments with which the walls were made. In places it is cut through walls of sunburnt bricks. Fragments of sunburnt bricks lie scattered in the dried mud left by the occasional passage of water. Besides these, there are also the teeth of camels and a human skull. These were probably brought in by animals which in later times may have used the passage as a cave or place of refuge. Our attempt to reach the passage by gallery IV, on the declivity of the hill, did not succeed. After the examination of the subterranean passage, work was stopped in the upper digging.

To the three periods of the upper layers we must therefore add a fourth. As it lies considerably-approximately $\mathrm{I} 3$ feet-deeper than the brick pavement, it becomes a question whether it belongs in an older culture epoch. Such excavation problems can be solved only through the pottery. Now, the pottery that is represented in the upper layers occurs also in the middle layers, the masses 
of pottery fragments down to the depth of 40 feet 4 inches belonging to the same ceramic group as regards forms and technique. Therefore we can not avoid referring all four periods of construction to the same culture efoch, concerning which the coins will give us more exact information.

A culture-stratum of 40 feet thickness is no longer surprising, since we found in the kurgans at Anau numerous periods of a uniform development superimposed upon one another.

\section{LOWER DIGGING.}

The sinking of the lower digging contributed nothing to the solution of the problem of the upper digging (fig. 424). After a terrace 9 feet wide had been established at a depth of 8 feet 7 inches the work entered, at 12 feet, on the south side of

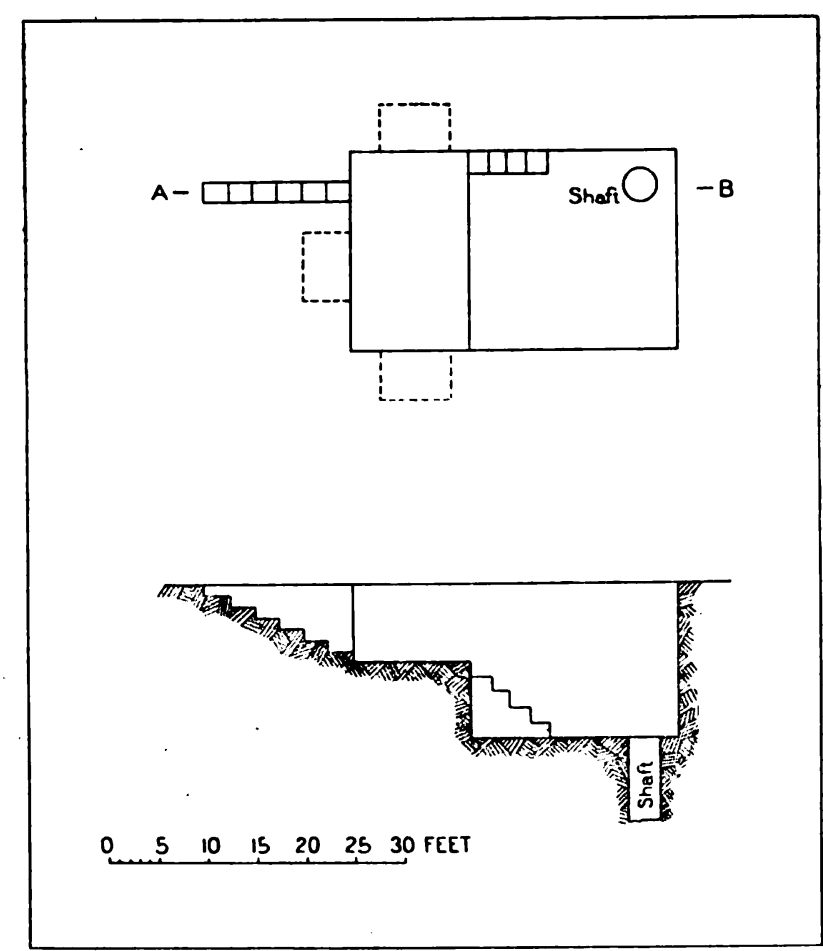

Fig. 424. - Plan and Vertical Section of Lower Digging in Inner City. the pit, a bed of sand which extended with increasing depth more and more to the north; that is, it was a sandhill such as belong to the dunes of the desert. On account of this, further examination in depth was left to be done by shafts.

\section{OUTER DIGGING I.}

At a slight depth below the surface, at the level of 2 feet (fig. 425), there was uncovered the edge of a square construction built of square bricks set on edge. Near it there was exposed, oppo site the longer side, a clay pipe standing erect and in connection with a cavity. The suspicion that we had here to do with a well and water basin was confirmed on the following day.

The well was of the most primitive construction. The shaft is a simple cylindrical pit, only 7 feet 8 inches deep, the walls of which are not even curbed with stones. The pire which leads into this is surrounded by square bricks and fragments of bricks, which are stuck in edgeways and both support the pipe and close the well at the top (fig. 426). There is nothing to show in what manner the basin was connected with the pipe. The basin stands without foundation immediately upon the earthen floor. The burnt bricks used in its construction, 8 by 8 by I. 5 inches, are made of greenish-white clay. Both the bottom and the sides are formed of a single thickness of brick, set with a mortar or cement with which the whole interior is plastered over. The whole border was originally surrounded with square red bricks laid flat upon the earthen floor and flush with the inner edge of the basin. The basin has a discharge passage at the short northwest 
PLATE 52.

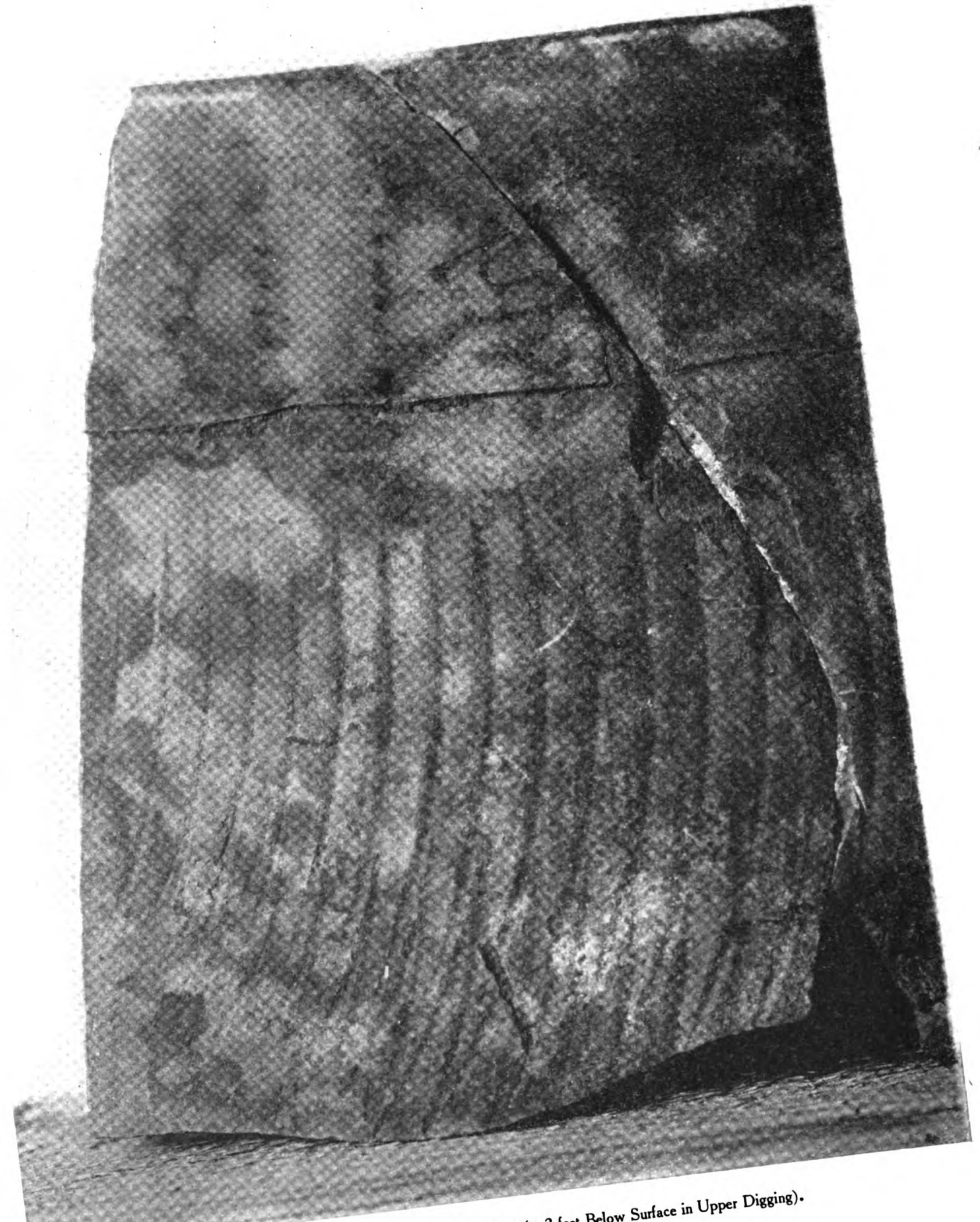

With Inscription in Pehlevi (at 2 feet Below Surface in Upper Digging)

Digitized by GOOgle 
Digitized by GOOgle 


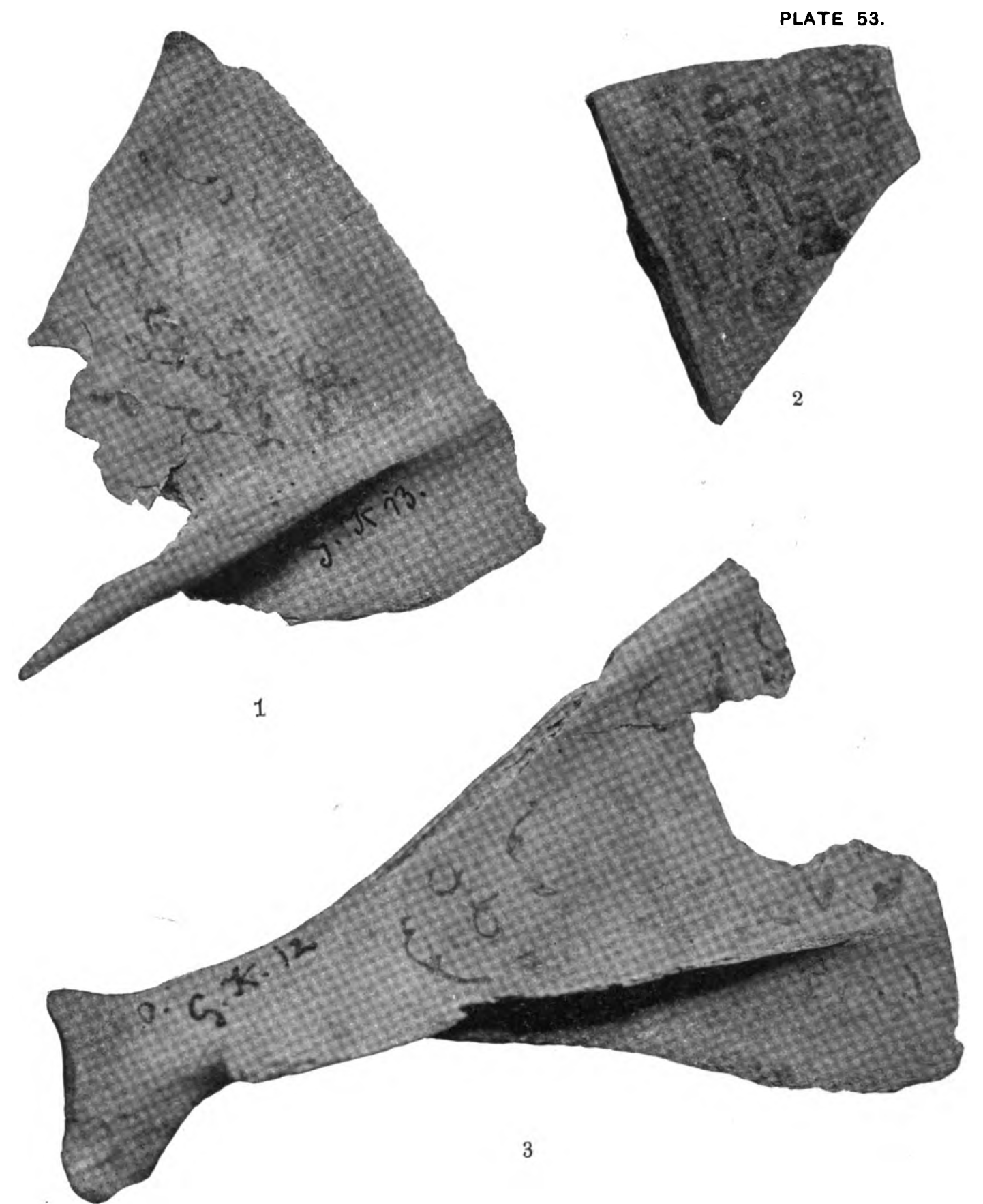

Inscriptions. The smaller Bone (G. K. 13) and the Small Piece of Pottery Bear Writing in Pehlevi; the Larger Bone has Uigur Characters (2 teet below Surface at Upper Digging). 
side, towards which the floor is gently inclined. It consists of a channel put together with red brick fragments and covered at the top. It is continued in a clay pipe. The upper edge of this pipe stands at about the same level as the bottom of the basin. Thus the discharge has a proper fall and was in all probability a part of a drainage system. The remains of such pipe-systems were also found at other points in the excavation, similar clay pipes occurring in different depths ( 3 feet 4 inches and 8.5 feet) on the longer side of the pit (fig. 427).

After the removal of the construction just described, the excavation was deepened by the establishment of two terraces, respectively 15 and 8 feet long, at the respective depths of II.5 feet and 17 feet. An older layer was reached at a depth of 20 feet 5 inches, where, in the southeast corner of the digging, there stood a cylindrical pithos in situ.

Still deeper, at 23 feet 4 inches, was found the head of a female clay figure. At a depth of 27 feet, work was stopped on June 7 .

It is naturally of interest to compare the culture layers opened upon the plateau of the outer city with those of the acropolis hill. The pottery found in outer digging $I$ is the same in all the layers and corresponds to that of the upper digging. We must therefore refer the plateau and the acropolis hill, in so far as they have been explored, to the same

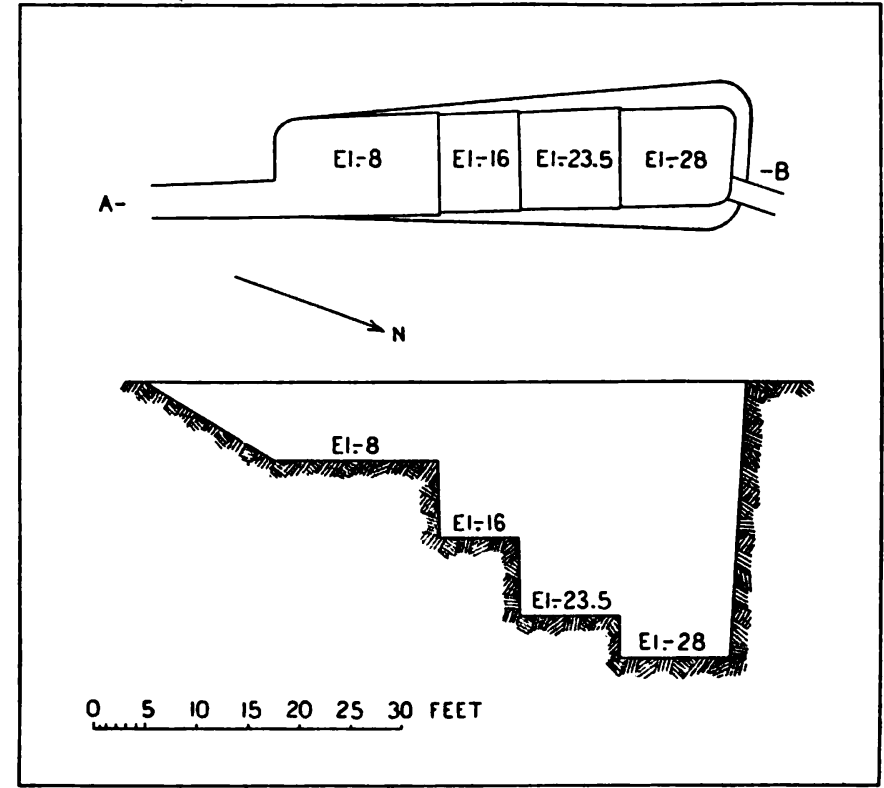

Fig. 425.-Plan and Vertical Section of Outer Digging I in the Outer City. great culture epoch. The numerous coins found in outer digging $I$ will aid in determining the age of this epoch.

OUTER DIGGING II.

For the characterizing of this culture, the supply-vessels found in outer digging II are of great significance. (See the special report of Homer Kidder.) They belong to the same class as the large marginal fragments of the upper digging which were covered with inscriptions. These finds will be discussed later.

GALLERIES I TO III.

The examination of the galleries, which were intended to penetrate the heart of the acropolis at different levels, led to no decisive results. In the two upper galleries, I and II, it was necessary to cut through very thick walls of sun-dried bricks, but very few pottery fragments were brought out, and these, as regards form and workmanship, belong to the same pottery as that from the upper digging. 


\section{SPECIAL FINDS.}

The determination of the character of the exposed culture layers is dependent wholly upon two groups of finds-the pottery and the discovered coins. Both will here be treated more fully than the other special finds.

\section{(a) POTTERY.}

It has been already remarked that the pottery fragments found in the upper and outer diggings belong to one and the same ware, for the greater part a light, grayish-greenish-white pottery of very common workmanship and made on the

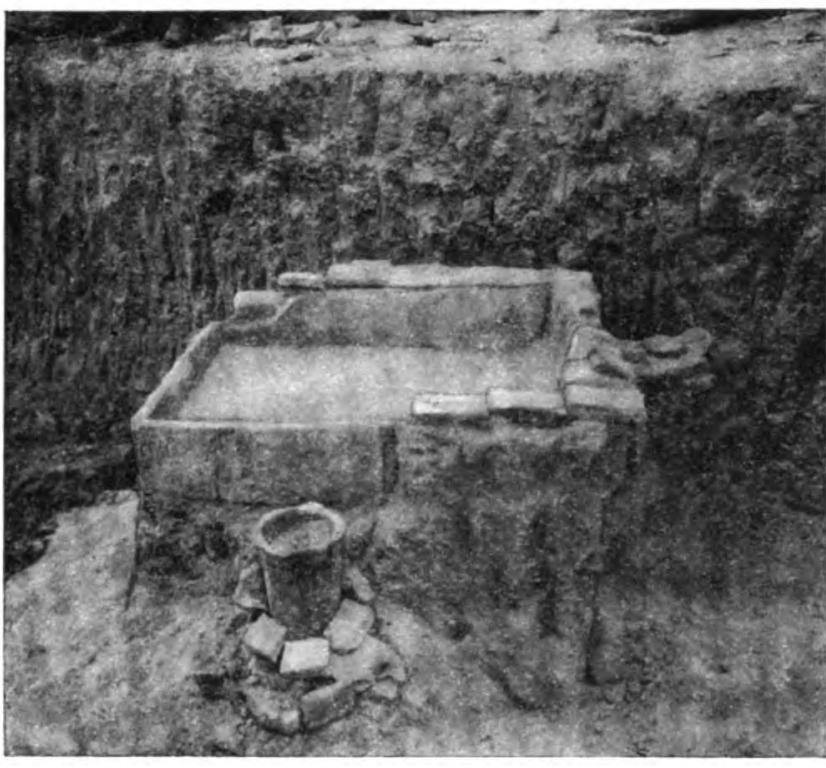

Fig. 426. - Water-basin found in Outer Digging $I$. wheel. With it occur red clay vessels with a light-yellow or greenish-white slip. The most common forms are kettles, cups, and pitchers, with a sharp and, in part, rich profiling. Fragments of handles of different forms are numerous.

The decoration of this simple pottery consists of incised or impressed ornamentation. In the larger vessels it consists of oblique or vertical lines, with contiguous parallel crescentshaped lines, which are pressed in with a sharp instrument and are broader and deeper in the middle, running out to points towards the surface on the ends.

This motif is shown also on the large pithoi of the outer digging II and on the fragments with inscriptions, although in coarser execution; and in very fine workmanship on smaller and more delicate vessels. Besides this, there is a band of wavy lines which is produced with a comb-like instrument. The following illustrations of separately observed vessels will give a general representation of this pottery:

G.K. 107 (plate 49, fig. I), from outer digging I, between 4 and 9 feet-a small jug with a broken margin, height $10 \mathrm{~cm}$.

Plate 49, fig. 2, from the upper digging, between 9 and ro feet-a high, slender jug with shoulder handle; height $23.5 \mathrm{~cm}$.

G.K. I 44 (plate 49, fig. 3), from outer digging I, between II feet 6 inches and 14 feet 4 inches-a small vase or pot without handle; height $7.4 \mathrm{~cm}$.

G.K. I64 (plate 49, fig. 4), from outer digging I, between 14 feet 4 inches and 17 feet -an egg-shaped pitcher with a small foot and a shoulder handle; height $13.5 \mathrm{~cm}$.

G.K. 176 (plate 49, fig. 5), a small pitcher with a narrow throat, height $10.4 \mathrm{~cm}$., from the same point as the one above. 
G.K. II (plate 50, fig. I), $70 \mathrm{~cm}$. below the surface of the hill, at the entrance to gallery $111-$ a slender jug with narrow throat, with broken-off handle and margin; height $12.6 \mathrm{~cm}$.

G.K. 205 (plate 50, fig. 3), from the outer digging II, together with the great pithoi-a deep, broad cup with the margin rising vertically from the somewhat in-drawn top of the belly, and two handles; height $16.6 \mathrm{~cm}$.

Plate 50, fig. 2, from the upper digging - a slender pear-shaped jug with small foot and narrow throat; handle and margin broken off; height $20.2 \mathrm{~cm}$.

G.K. 207 (plate 5I, fig. I), from 12 feet deep, in a shaft on the plateau of the outer city-the body of an ornamented pitcher with a broad throat and large bottom.

Besides this rough service pottery, glazed fragments were also found, but they were relatively rare. Among these glazed clay lamps are noticeable. As is shown in G.K. 77 (plate $5 \mathrm{I}$, fig. 2), they are little depressed bowls, with a small foot surface, clover-leaf shaped opening, contracted in front, and with a high,
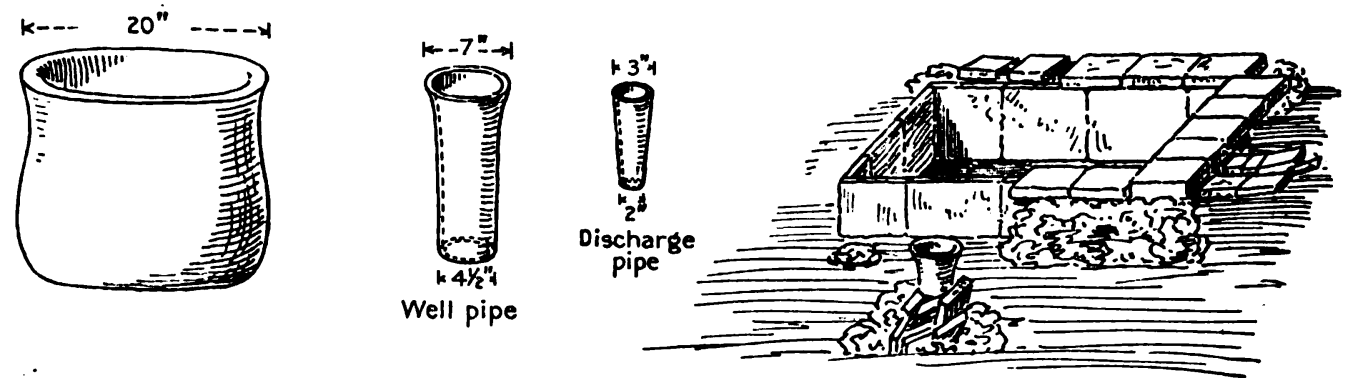

Basin in outer digging

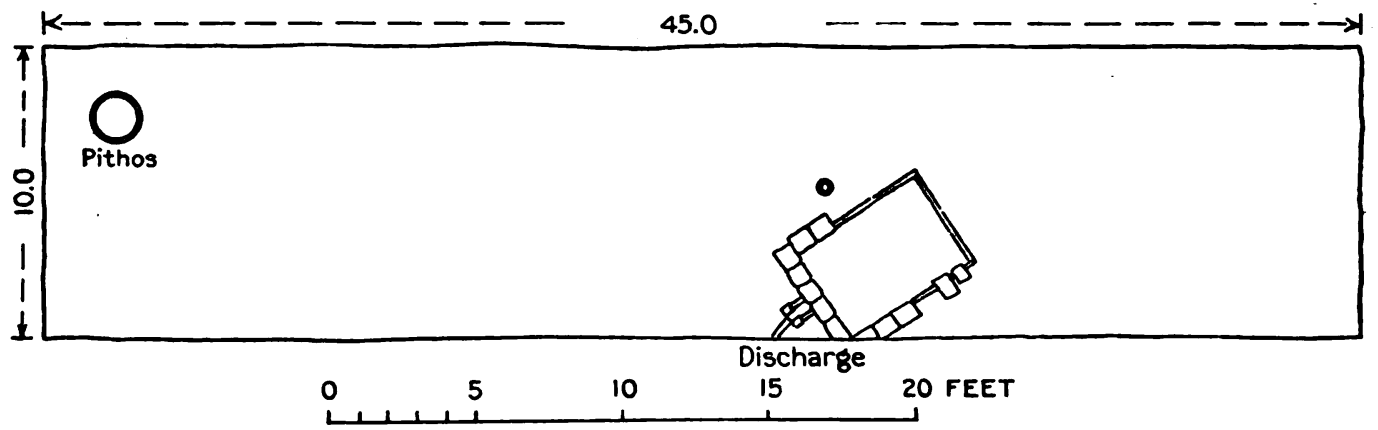

Fig. 427. -Details of the Water-basin in Outer Digging I.

narrow handle. The glaze is of one color-yellow or green. The specimen represented was found in outer digging II with a great pithos, many fragments also being collected. Besides this a specimen was found in outer digging $I$, between the surface and 4 feet depth. In the upper digging they were entirely wanting.

\section{(b) GLAZED POTTERY.}

To be carefully distinguished from the technique of glazed lamps are the other finds of glazed pottery. Five different kinds of glazed pottery are distinguishable:

(a) With incised patterns. The glazes, which run together in the grooves, are of several colors-green, yellow, and white (G.K. 65, I I 9 to I 2 I, I23, 155, I88, 190). 
(b) Without incision; glaze yellow, white, black, green (G.K. 66, 84, 95, 102, II 2, I1 $3,122,150,187,193$ ).

(c) With one-colored glaze, whitish-yellow, on which are superimposed ornamental Cufic inscriptions in black-brown (G.K. 125).

(d) On a white ground, green, yellow, and red-brown shades, with luster (G.K. 83).

(e) Green-glazed, with scalloped ornament over which the glaze extends (G.K. I49).

\section{(c) PAINTED WARE.}

In addition to these glazed fragments, there is a particular group of painted ware. The patterns are laid upon the clay ground in dead-black color. Besides this there occur yellow or red spots (G.K. 64, 82, 85, 100 to 105, I I I I I 20, I 33, I 5 I to $154,189,191,192)$. However, the painted fragments can not be separated from the glazed ware as regards locality. Their different groups are associated with each other. The greater number were found in outer digging $\mathrm{I}$, and in all layers, to a depth of 20 feet 5 inches. In comparison with the ordinary service pottery, however, they are of rare occurrence. It is worthy of remark that the three groups $c, d$, and $e$ were represented by only one fragment each.

It is equally surprising that on the upper digging on the acropolis only two fragments of the painted group were observed-one between 2 feet 4 inches and 5 feet, the other between I I. 5 feet and 15 feet 5 inches. The glazed ware is entirely wanting.

$$
\text { (d) coins. }
$$

The determination of the coins found in all the excavations of Ghiaur Kala was very kindly undertaken by Mr. Markof, Conservator of the Imperial Cabinet of Coins of the Ermitage in St. Petersburg. The results of his investigation are given here. The determination of the coins was rendered very difficult by the strong oxidation which many of them have undergone.

Two coins are eliminated as useless for dating purposes-an Afghan coin of the eighteenth century (G.K. 7I) and an Ilek khan of the eleventh century (G.K.2). The first is modern; the other was found on the surface of the upper digging. The remaining coins fall into two categories-the younger and the older coins.

(a) The younger coins. - These belong to three different groups, which I will enumerate in the following manner, together with the points at which they were found:

Samanide, tenth century: G.K. I16, outer digging I, 9 to 11.5 feet.

Abbasside, eighth century: G.K. 106, outer digging I, 4 to 9 feet; G.K. 23, upper digging $2 \frac{1}{3}$ to 5 feet. Justinian I ( 527 to 565$)$ : G.K. 23; compare above.

But these younger coins were found together with the older ones of the first to the third century. Under No. 23 are marked at the same time Sassanide coins of the third century; and in the same way Nos. 106 and 116 . There is also a Parthian coin of the second century.

(b) The older coins. - The greater number belong to the third century and are Sassanide, and even the indeterminable ones are, according to Markof, of a Sassanide coinage. They are classified here according to the different rulers. 
Ardeschir I (226-240):

G.K. 4I, upper digging, 8 feet to II.5 feet.

G.K. 49, upper digging, II.5 feet to 15 feet 5 inches.

G.K. 78 , outer digging II.

Sapor I (240-270):

G.K. 19, lower digging, 8 feet.

G.K. 58 , outer digging $\mathrm{II}$.

G.K. 70, outer digging 1,4 to 9 feet.

G.K. 180 , outer digging 1,17 feet to 20 feet 5 inches.

G.K. 186, outer digging I, 17 feet to 20 feet 5 inches (dump).
Sassanide (third century):

G.K. 31, lower digging, 12 feet.

G.K. 198, outer digging 1,20 feet 5 inches to $23 \xi$ feet.

Indeterminable, probably Sassanide (third century):

G.K. 18, upper digging, $2 \frac{1}{3}$ feet to 5 feet.

G.K. 68, upper digging, II.5 feet to 15 feet 5 inches.

G.K. I 30, upper digging, 17 feet 5 inches to 20.5 feet.

G.K. 167, upper digging, 26 feet to 32 feet 7 inches.

G.K. I48, outer digging I, 11.5 feet to $14 \frac{1}{3}$ feet.

G.K. 173 , outer digging $1,14 \frac{1}{3}$ feet to 17 feet.

To the Sassanide are to be added some Parthian coins, partly of still older age.

Parthian (third century): G.K. 152, outer digging 1,14 feet to 17 feet.

Parthian (second century): G.K. II6 (compare above).

King Sanabares (first century, A. D.): G.K. 185 , outer digging 1,17 feet to 20 feet 5 inches.

Which of these coins shall guide us in dating the finds of Ghiaur Kala? Shall it be the younger, which occur in the outer digging to a depth of II.5 feet below the surface?

The great number of coins of the third century prevent this conclusion. We would have to assume that these coins had continued in circulation till the tenth and eleventh centuries, and this, according to Mr. Markof, is improbable, if not out of the question. On the other hand, it may be mentioned that on the acropolis, where in the upper digging the earth layers were exposed to a depth of 40 feet below the top, the younger coins, that is, the Abbassides of the eighth century, were found only to a depth of 5 feet and that below this no younger coins occurred.

We have, therefore, the right to assign to the great number of Sassanide coins of the third century the same significance as to the ordinary service pottery that showed a uniform character in all the exposed layers. In the light of these two groups of finds, we can determine the culture of Ghiaur Kala, i. e., the coins of the third century establish the terminus post quem for the use of all the pottery.

The culture of Ghiaur Kala was Sassanide. This makes it necessary to separate the younger finds, such as the younger coins and the glazed pottery, from the general mass of the other finds. Their appearance also in deeper layers can be explained through the many kinds of accidents to which the long-trodden soil of Ghiaur Kala was exposed, even if a settlement may have no longer existed there at the end of the first millennium.

\section{(e) ' INSCRIPTIONS.}

A knowledge of the inscriptions is of importance in judging the potteries that were discovered. This depends upon whether we have to assume that the inscriptions, as in the ostraka, were made only upon any fragment of pottery that came to hand, or whether they were written upon entire vessels in use at the time. In the first case they might be classed among the accidental finds of the 
younger epoch and would have no significance in connection with the culture proper of Ghiaur Kala. In the second case we would have to take into consideration the fact that the large marginal pieces bearing the inscriptions belong to vessels of the same type as those found in larger quantities in situ in outer digging II. In this case they would become an essential factor in determining the culture of Ghiaur Kala.

The study of the inscriptions has been undertaken by the distinguished academicians, Professors Radlof and Salemann in St. Petersburg. Unfortunately, however, owing to the bad condition of the characters, the results are not sufficiently certain to solve the problem in hand. Concerning one kind of writing, however, there can be no doubt. The fragments of pottery (G.K. Ioa, Iob, plate 52), as well as two pieces of bone (G.K. II, I3; plate 53), are, according to Professor Salemann, undoubtedly inscribed in Pehlevi character. On the other hand, a bone (G.K. 12) bears, according to Professor Radlof, Uigurian characters. The Pehlevi writing, according to Professor Salemann, is "cursive book-writing (in contrast to the characters on coins and gems). It appears similarly on some silver bowls, and can not be determined chronologically. It may go up to the tenth and eleventh century of our era, perhaps it is still younger. It is easily a couple of centuries earlier, but is not more closely determinable." Concerning the meaning of the inscriptions, it is not possible to say anything "even approximately," because "while single letters are clear, they can not be formed into words." If, therefore, the inscriptions belong to the end of the first millennium of our era, or still later, we would have to assume that they were made on old ostraka, and their significance would be similar to that of the younger coins and glazed fragments. In any event they are the first traces of Pehlevi writing found in Turkestan, and lead to the hope of further finds.

As regards the other small finds, I will describe here the separate groups which appear worthy of observation.

\section{(f) METAL OBJECTS: GOLD, BRONZE, IRON.}

Of gold, there are to be noted two small pieces of jewelry: (a) A golden pendant in the form of a small vessel of sheet gold, with a flattened bottom and made in two parts-it is crushed (G.K. I 70; plate 51 , fig. 3)-from the upper digging, between 26 feet and 32 feet 7 inches deep; $(b)$ a small piece of a golden clasp or band for the end of a strap, probably formerly provided with a hook in front, which is now broken off (G.K. 33; plate $5 \mathrm{I}$, fig. 4), from the upper digging, between 5 and 8.75 feet deep.

Worthy of remark are arrow-points of bronze of different types: ( $\mathrm{I}$ ) Threeedged arrow-points with three strikingly long points which form the projecting continuation of the three edges (G.K. I09; plate 5I, fig. 7). (2) Smaller three-edged arrow-points with small side-wings and a short shaft-socket (G.K. I Io; plate $5 \mathrm{I}$, fig. 6). Both of these arrow-points were found in the upper digging, between the depths of $I_{7}$ feet 5 inches and 20.5 feet. A little deeper, between 20.5 
and 26 feet, was exposed a specimen (G.K. I40) of the same type as G.K. rog (plate 5I, fig. 7). To these there is to be added a third type: (3) fragment of a leaf-shaped arrow-point, strongly oxidized (G.K. 138; plate 5I, fig. 5), from the wash on the surface near gallery Ir.

Like the three-edged arrow-points, the following finds also recall the excavations at the South Kurgan of Anau:

A bronze stamp with a semiannular eye on the back, decorated in front with four curves bent inward (G.K. 4; plate $5 \mathrm{I}$, fig. 8), from the upper digging, between 10 inches and 2 feet 4 inches. A bronze object (G.K. 178; plate 5I, fig. 9), is probably the foot of an implement. It was found in the outer digging II. Indeterminable is a small bronze plate with two holes for attachment and a comb-like edge (G.K. 59; plate $5 \mathrm{I}$, fig. Io), also from the outer digging.

A remarkable object (G.K. 87) is an iron seal-ring ornamented with figures (plate 5I, fig. II). It was found on the surface of the city plateau near outer digging $\mathrm{I}$. In the ornamentation one can recognize a sitting and a standing figure.

(g) BEADS OF STONE, CLAY, GLASS, AND FAIENCE.

Numerous beads were found in the excavation, and are enumerated according to material and form. They are all brought together on plate 54 .

Beads of turquoise having different forms were often found: (a) Cylindrical (figs. I-4) from the upper digging, between 20.5 feet and 32 feet 7 inches, and on the declivity; (b) barrel-shaped (G.K. I 43, fig. 5), upper digging between 20.5 and 26 feet; $(c)$ annular (G.K. 45; fig. 6), upper digging, between 11.5 feet and 15 feet 5 inches; $(d)$ disk-shaped; green (G.K. 47 ; fig. 7 ) from the same place.

Of lapis lazuli, three pendants (G.K. I26, I29; figs. 8 and 9) found in the wall of sun-dried brick in gallery $I$.

Of carnelian, an elongated pendant (G.K. 20; fig. Io), from the upper digging, between 2 feet 4 inches and 5 feet; a spherical bead (G.K. 88; fig. II), from the upper digging, between 15 feet 5 inches and 17 feet 5 inches.

Of agate, a large spherical bead (G.K. I; fig. 12), from the upper digging, under the surface in the uppermost layer; a long cask-shaped bead (G.K. 204; fig. 13), from outer digging I, between 23 feet 4 inches and 27 feet.

Of stone, of very different kinds-gray with yellow spots (G.K. 174; fig. 14) from outer digging $\mathrm{I}$, between $\mathrm{I} 4$ feet 4 inches and $\mathrm{I} 7$ feet; whitish-green, doubleconical; (G.K. 32; fig. I5), from the upper digging, between 5 and 8.75 feet; violet, variously jointed pendants (G.K. 88 ; fig. II) from the upper digging, between 15 feet 5 inches and 17 feet 5 inches; gray, disk-shaped (G.K. I 75; fig. I6), from the upper digging, in débris; yellowish-red, disk-shaped (faience?) (G.K. 88; fig. I I), from the upper digging, between ${ }_{5}$ feet 5 inches and 17 feet 5 inches.

Of coral, six small cylindrical beads (G.K. I46; fig. 17) from the outer digging, between II.5 feet and 14 feet 4 inches.

Of glass: White with yellow, band-shaped inlays, cask-shape (G.K. 20; fig. 10), from the upper digging, between 2 feet 4 inches and 5 feet; spherical, sea-green, (G.K. 7 ; fig. 18), from the upper digging, between ro inches and 2 feet 4 inches; annular, water-clear (G.K. 136; fig. 19), from the south shaft. 
Faience: Blue-glazed with deep grooves (G.K. I47; fig. 20), from outer digging I, between II. 5 feet and 14 feet 4 inches.

Clay: Cylindrical, blue, imitation of turquoise (G.K. 184; fig. 2I), from the declivity in gallery IV; spherical, covered with gold (G.K. 202), from outer digging $I$, between 20 feet 5 inches and 23 feet 4 inches.

\section{(h) TERRA-COTTA FIGURES.}

Figures of both human and animal form, made from burnt clay, were found in the excavations on the acropolis and in those on the plateau of the main city. I enumerate them as follows:

A torso of a naked figure with a bent back (sitting?) (G.K. 99; plate 55, fig. I), from the surface near outer digging $I$.

The lower part of a bulky, naked male figure, painted black, red, and yellow (G.K. 44 ; plate 55 , fig. 2), from the upper digging, between 8.75 and I I.5 feet.

A female head with short locks and ornaments for the hair, probably with a kerchief (G.K. 201 ; plate 55, fig. 3), from the outer digging between 20 feet 5 inches and 23 feet 4 inches.

Female figure in relief, standing in a long robe, with rich neck ornaments, holding a mirror in the right hand before the breast, the left hand placed lower down and the head wanting; made in a mold (G.K. 63; plate 55, fig. 4); found on the surface near outer digging $I$.

Male figure in relief, bearded, with high pointed cap, and holding a band or chain in both hands. The lower part is wanting (G.K. I $7 a$; plate 55, fig. 5). This also was pressed in a mold. From the upper digging within 2 feet 4 inches of surface.

The animal figures are very numerous. In so far as any determination is possible, they are representations of horses. G.K. I 8 (plate 56, fig. 2) may serve as an example. It was found in outer digging I, between 9 feet and II.5 feet, as was also an isolated specimen-a mounted figure-painted in black and red. The rider is broken off, except a part of the left leg (G.K. I77; plate 56, fig. I). It is from outer digging II, near the large supply vessels.

(i) STONE VESSELS.

A small cup of soapstone with four feet (G.K. 135; plate 56, fig. 3), from near the great pithoi in outer digging $\mathrm{II}$, is worthy of remark. The exterior of the object is adorned with engraving. Vertical bands decorate the feet, with concentric circles surrounding a central point, and crescent-like between. Fragments of other stone vessels without ornamentation (G.K. 43, 44b) were found in the upper digging, between 8.75 and $\mathrm{I} .5$ feet.

(k) SLING IMPLEMENTS.

As in the North and South Kurgans of Anau, so also here in Ghiaur Kala there were found numerous sling implements of stone and clay. We will have to assume that they had remained in use since antiquity. Their forms are not 


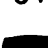

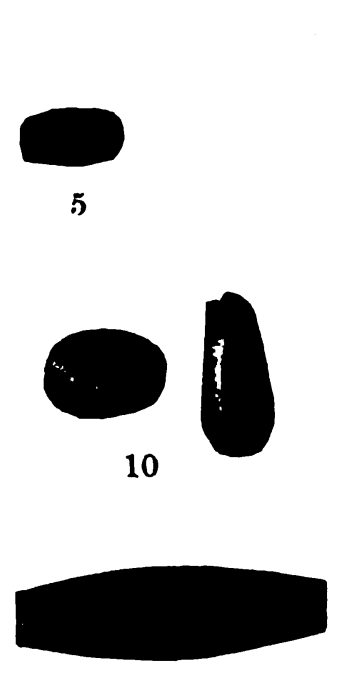

13
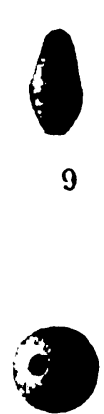

15
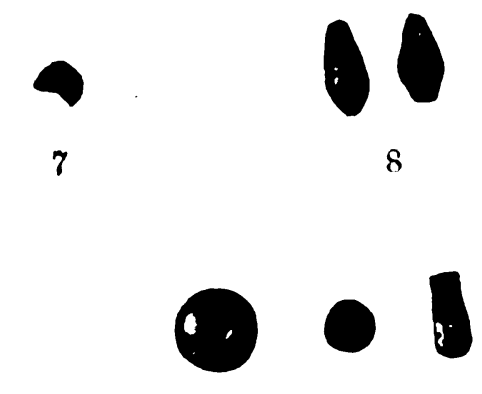

11

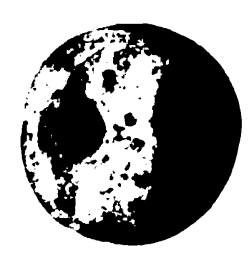

12

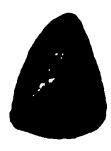

14

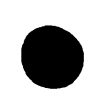

18

Beads from Ghiaur Kala (Old Merv).

Fic3. 1-5 (S.K. 141, 166, 163, 182, 143). Upper Dizzinz. between 23 and 32 feet deep.

6 (G.K. 45). Turgupise Beid, Upper Dizzinz, 11.5 to 15.5 feet deep.

8 (G.K. 125). Pend ant of L23i: Lazuli, found in Wall of Air-dried Bricks in Gallery I.

9 (G.K. 129). Pend int of Lapis Lazuli. found with No. 8 .

10 (G.K. 20). Carnelian Pendant and Glass Beas, Upper Digging. at 2.5 to 5 feet deep

11 (G.K. 88). Carnelian Bead, Upper Digging. 15.5 to 17.5 feet deep.

12 (G.K. 1). Large Agate Bead. Near Surface in Upper Digging.

13 (G.K. 201). Long Agate Bead. Outer Digging 1, 23.5 to 27 feet deep.

15 (G.K. 32). Greenish-white Double-conicail Stone Bead. Upper Digging. between 55 and 9 leet deep

16 (G.K. 175). Gray Disk-shaped Stone Bead. Upper Digging Dump.
17 (G.K. 146). 6 Coral Beads, Outer Digging II. between 11.5 and 14.5 feet deep

18 (G.K. 7). Spherical Sea-green Glass Bead. Near surface in Upper Digging.

19 (G.K. 136). Annular Bead of Clear White Glass, from South Shaft.

21 (G.K 184) Turquoise Bead from Gallery IV. 
Digitized by GoOgle 
PLATE 55.

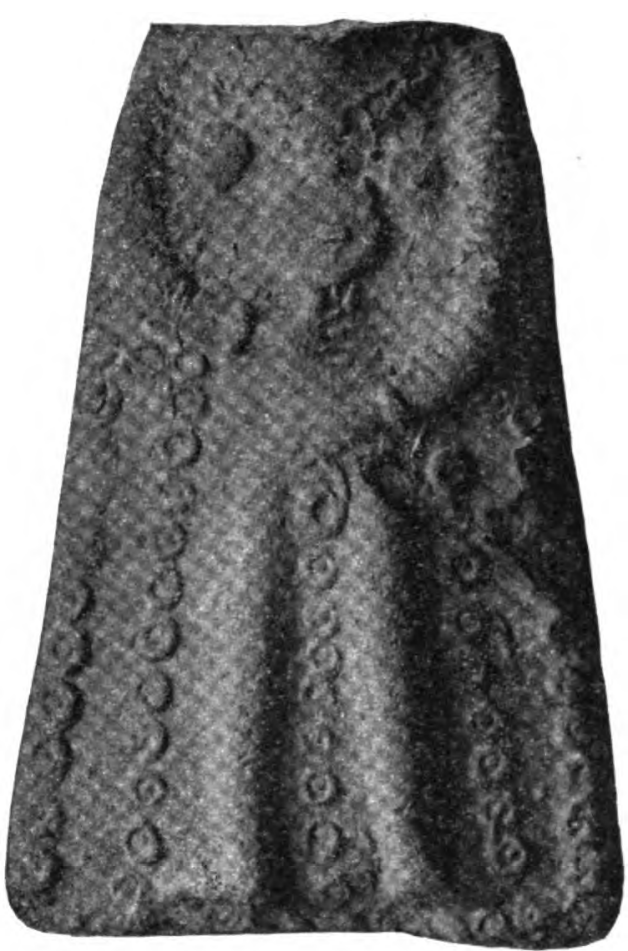

4

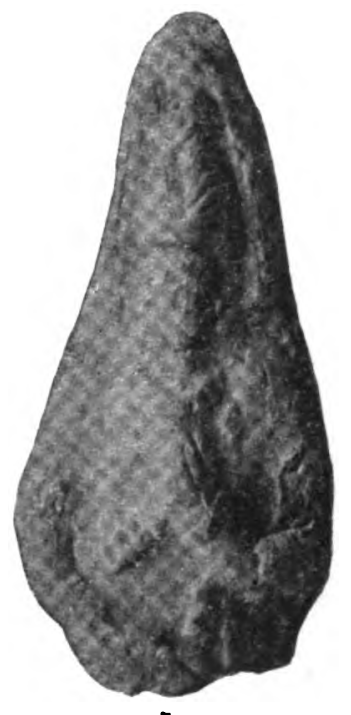

5

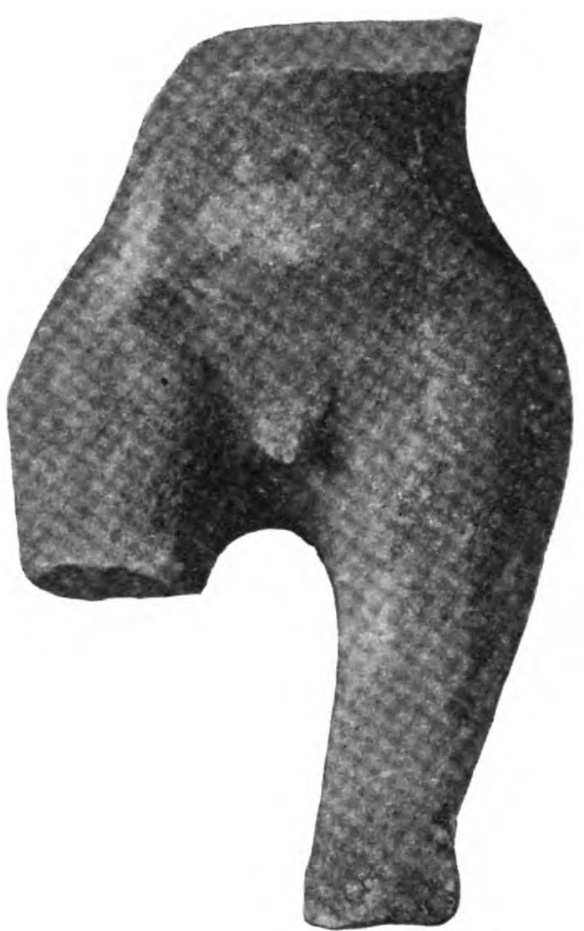

2
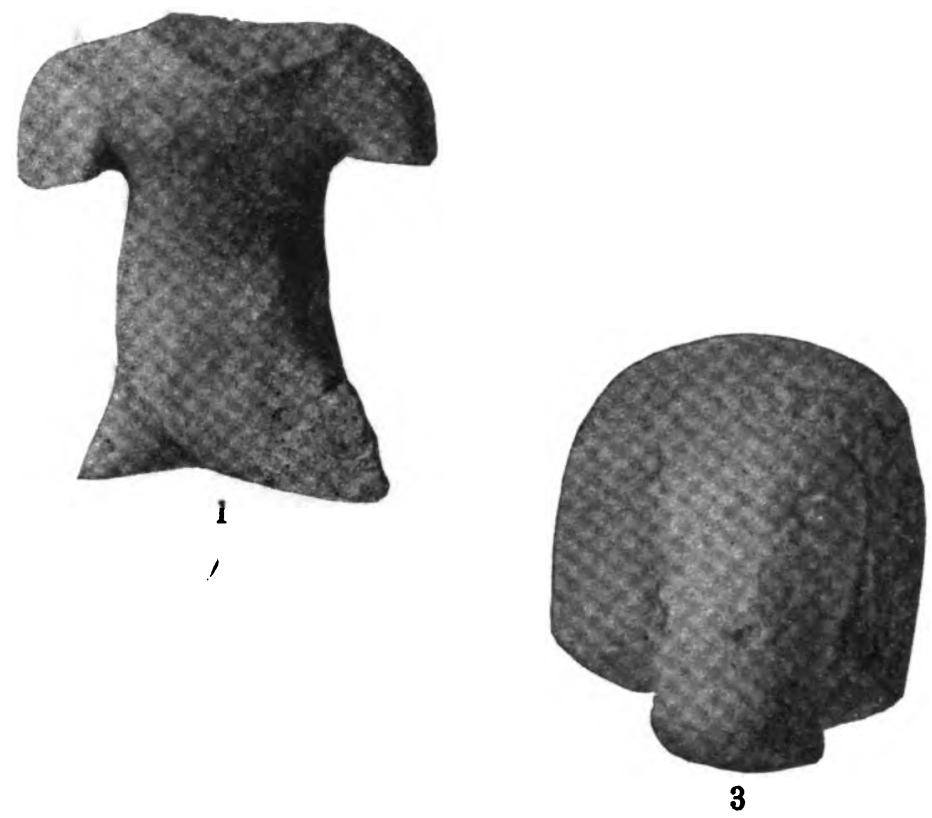

Terra-cotta Figures from Ghiaur Kala (Old Merv).

FiG. 1-(G.K. 99). Trunk of a Naked Figure with Bent Back, from Surface near Outer Digging $I$. 2 (G.K. 44). Lower Part of Male Figure, Painted Black, Red, and Yellow. Upper Digging, 8.5 to 11.5 3 feet deep.

Feart with Short Locks. Outer Digging I, 20.5 to 23.5 feet deep.

4 (G.K. 63). Female Figure in Relief. Made in a Mold. Found on surface near Outer Digging II.
(G.K. 17a). Male Figure (?). Made in a Mold. Upper Digsing, within 2.5 feet of Surface. 
Digitized by GOOgle 


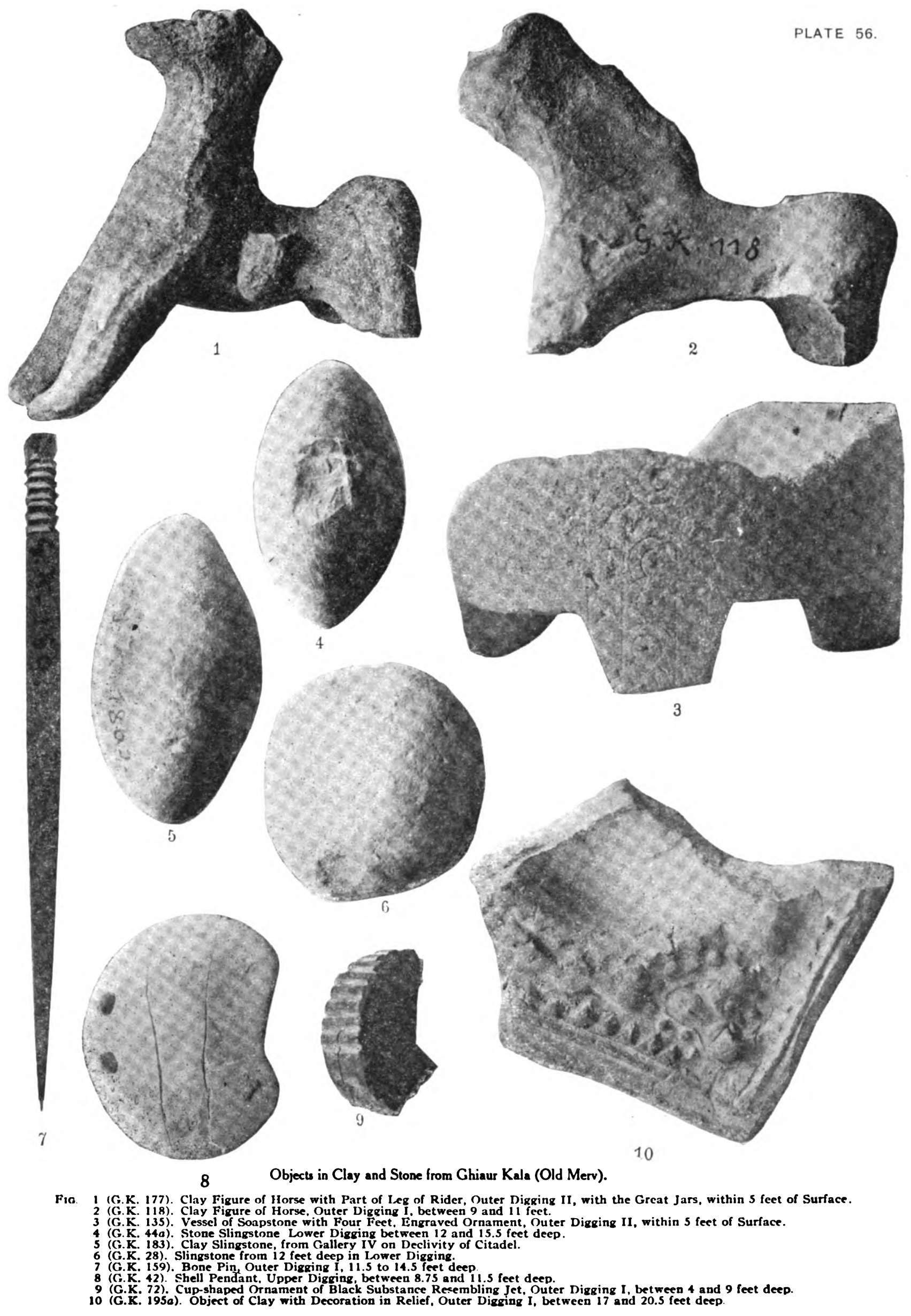

Digitized by GOOgle 
Digitized by GoOgle 
as diverse as at Anau. For the most part they are plum shape; spherical forms were more rarely noticed. As examples, we may indicate G.K. $44 a$ (plate 56 , fig. 4), which is of stone and was found in the lower digging, between 12 and 15.25 feet; also G.K. I83 (plate 56, fig. 5), of clay and found on the declivity of the acropolis in gallery IV; and lastly, the spherical example G.K. 28 (plate 56, fig. 6) at 12 feet, in the lower digging.

\section{(l) MISCELLANEOUS.}

Of other small finds there are a few pieces which are worthy of remark.

A bone pin, four-edged, at the head, ornamented with notches (G.K. 159; plate 56, fig. 7), from outer digging I, between II.5 feet and 14 feet 4 inches.

A pendant with two holes, cut from a shell (G.K. 42 ; plate 56 , fig. 8), found in the upper digging, between 8.75 and 11.5 feet.

An ornament (?) of cup form, with longitudinal ribs on the margin, made from a coal-like material, probably jet (G.K. 72 ; plate 56 , fig. 9), from outer digging $I$, between 4 and 9 feet.

Lastly, the fragment of a clay object, cup-shaped, with a plastically modeled margin (G.K. 195a; plate 56 , fig. 10). It was found in outer digging $\mathrm{I}$, between 17 feet and 20 feet 5 inches.

It is to be hoped that the work done and the finds made at Ghiaur Kala will furnish the groundwork for further investigations. The ancient soil of Merv, in which so many historical and archeological problems lie buried, offers a tempting field to the archeologist. 


\section{SPECIAL FINDS CATALOGUE.}

\section{NORTH KURGAN.}

March 26, 1904:

I. 2 carnelian beads, I blue-white bead, 2 pendants, found together, terrace 1, n:ar the skeletons that lay south of the cross wall 30 to $31.5 \mathrm{ft}$.

2. Copper fragment, from refuse in bottom of Komorof's trench.

3. Copper fragment, above terrace $\mathrm{r},+3 \mathrm{I} .5 \mathrm{ft}$.

4. Fragment copper ring, terrace $\mathrm{I},+3 \mathrm{I} .5 \mathrm{ft}$

5. Spindle whorl in refuse.

March 28, 1904:

5a. Blue glazed potsherd, west pit in cut (in refuse).

6. Spindle, cut (in refuse)

7. Flint knife (?) west pit, cut (in refuse).

8. Flint knife, animal tooth, same place (in refuse).

9. Flint nucleus, same place, $+9 \mathrm{ft}$.

10. 2 fragments flint knives, north digging.

I1. Clay bead, same place.

12. Flint flakes, same place.

1 2a. Piece hematite, gallery, $+9 \mathrm{ft}$

13. 2 flint flakes, no data.

March 29, 1904:

14. Clay marble, terrace $\mathrm{I},+30 \mathrm{ft}$.

March 30, 1904:

15. Fragment clay form, east pit, in refuse (?)

16. Nucleus and fint knife, same place (?).

17. Flint nucleus, cut, west gallery, o to $+7 \mathrm{ft}$

18. 2 fragments polished bone implements, same, 0 to $+7 \mathrm{ft}$.

19. Flint knife, west pit, in refuse (?)

20. Copper pin, west pit, in refuse.

2 I. Iron band, suspiciously modern, same place.

22. Human tooth, same place.

23. Piece hematite (has been ground down), west digging, +13 to $+18 \mathrm{ft}$.

24. Clay bead, west digging, +13 to $+\mathrm{r} 8 \mathrm{ft}$.

25. Egg-shaped clay object, found near child's skeleton, terrace $\mathrm{I},+30 \mathrm{ft}$.

26. Lapis-lazuli bead, deposit in child's grave, terrace $I(c f .50)+30 \mathrm{ft}$.

March 3I, 1904.

27. 3 flint knives, 5 flakes, cut, east gallery, -3 to $+2.5 \mathrm{ft}$.

28. Half of a perforated stone sphere, same place, -3 to $+2.5 \mathrm{ft}$.

29. Flint knife, west gallery, o to $-7 \mathrm{ft}$.

30. Flint knife, same, $-3 \mathrm{ft}$.

3I. Nucleus, same, -2 to $-3 \mathrm{ft}$.

32. Clay bead, same, -2 to $-3 \mathrm{ft}$.

33. Piece ocher, same, $-7 \mathrm{ft}$.

34. Fragment copper pin, terrace $r$, south cross wall, supposed to come out of freshly turned earth, $i$. $e_{\text {., }}$ from under the skeletons, +28 to $+30 \mathrm{ft}$
March 31, 1904-Continued.

35. Flint knife, north digging $\mathrm{I},-10$ to $-12 \mathrm{ft}$.

36. Flint knife, same, $-8 \mathrm{ft}$.

37. Fragment spindle, same, $-8 \mathrm{ft}$

38. 2 snail shells, same (cf. 53), $-8 \mathrm{ft}$.

39. Piece ocher, same, $-8 \mathrm{ft}$.

40. 3 animal teeth, cut, west gallery, $-3 \mathrm{ft}$.

4I. 2 fragments spindles, north digging II, -8 to - I I ft.

42. Clay knob, same, -8 to - I f ft.

43. Half of small vessel of crystallized gypsum, same, -8 to - I I ft.

44. Chisel-form implement of slate, same, -8 to - I I ft.

45. Implement of slaty stone, same, -8 to -1 I $\mathrm{ft}$

46. Knob-like worked stone fragment, north digging $\mathrm{II},-8$ to $-1 \mathrm{Ift}$.

47. Kaolin-like stone, same, -8 to - I I ft.

48. Fragment bronze implement, same, -8 to - I I ft.

49. Painted potsherd, well south of mound, $-7 \mathrm{ft}$.

50. 4 lapis-lazuli beads, child's burial, terrace I (cf. No. 26), +28 to $+30 \mathrm{ft}$.

$5 \mathrm{r}$. Spinbob, clay, terrace II, found beside metate, +22 to $+25 \mathrm{ft}$

52. Fragment spinbobs, clay, terrace III, $+21.5 \mathrm{ft}$.

53. Snail shell, north digging ( $c f .38),-$ io $\mathrm{ft}$.

54. Galena, terrace II, east corner, $+25 \mathrm{ft}$.

55. Flint flake, terrace 1 , south of cross wall, +28 to $+30 \mathrm{ft}$.

55a. Snail shell, cut, west gallery, o to $-7 \mathrm{ft}$.

April 1, 1904.

North digging, I and II, - 10 to $-12 \mathrm{ft}$.

56. Small knife, chalcedony.

57. Clay knob.

58. Flint.

59. Flint knife.

6o. Spinbob.

61. Fragment of handle, clay.

62. Galena (?)

63. Calcite crystal.

64. Painted potsherd.

East gallery, -3 to $-6 \mathrm{ft}$.

65. Flint knife.

66. Spinbob, stone.

67. Spinbob, clay.

West gallery, -7 to $-14.8 \mathrm{ft}$.

68. Ocher, 2 pieces.

69. Spinbob, clay.

7o. Snail shell.

Terrace $\mathrm{r},+27$ to $+28 \mathrm{ft}$

71. 3 spinbobs.

72. Fragment clay animal form, found near surface on south side of mound.

April 2, 1904.

73. Flint knife, terrace $\mathrm{I},+27 \mathrm{ft}$.

74. 2 spinbobs, terrace $\mathrm{II},+22.5 \mathrm{ft}$. 
April 2, 1904-Continued.

75. Fragment copper pin, surface near terrace viI, at $+28 \mathrm{ft}$.

76. 3 spinbobs, terrace vi, in the strata below fireplaces, $+29 \mathrm{ft}$.

77. Spinbobs, terrace $v$, below level of skeleton, +32 to $+36 \mathrm{ft}$.

78. Polished stone, terrace $\mathrm{v},+32$ to $+36 \mathrm{ft}$.

79. Petrified shell, terrace $v,+32$ to $+36 \mathrm{ft}$.

8o. Flint, terrace $v_{1}+32$ to $+36 \mathrm{ft}$.

81. Copper fragment, spirals and sheaths, burial object, terrace iI (cf. special report of $L$. Warner) $+22.5 \mathrm{ft}$.

82. 2 fragments bronze pin, terrace vir, $+28 \mathrm{ft}$.

83. Copper spear-head or dagger-blade, terrace vI ("on the surface of"-H. S.), level with fireplace, $+30 \mathrm{ft} .6$ in.

84. Fragments stone slab, colored with ocher, north digging, -12 to $+13 \mathrm{ft}$.

85. 2 flints, north digging, -12 to $13-\mathrm{ft}$.

86. 2 spinbobs, north digging, -12 to $-13 \mathrm{ft}$.

87. Small piece bronze, north digging, -12 to $-13 \mathrm{ft}$.

88. 2 fragments spinbobs, east gallery (?), -6 to $-8 \mathrm{ft}$

89. Flint arrow-head, east gallery, -6 to $-8 \mathrm{ft}$.

90. Marble, west gallery well, $-20 \mathrm{ft}$.

9r. 2 flint knives, west gallery shaft, $-20 \mathrm{ft}$.

\section{April 4, 1904.}

92. Flint knives, fragments and flakes, north digging, -13 to $-16 \mathrm{ft}$.

93. Copper pin, terrace v, $20 \mathrm{~cm}$. under stone ball, +28.5 to $+32 \mathrm{ft}$.

94. Perforated stone ball, terrace $v$, found $90 \mathrm{~cm}$. under rim of pot in situ, +28.5 to $+32 \mathrm{ft}$.

95. 2 painted potsherds, found with No. $94,+28.5$ to $+32 \mathrm{ft}$.

96. Spinbobs and fragments, terrace III, +18 to $+20 \mathrm{ft}$.

97. Small piece crystalline gypsum, terrace III +18 to $+20 \mathrm{ft}$

98. Copper awl, terrace III, +18 to $+20 \mathrm{ft}$.

99. Flint knife, terrace III, +18 to $+20 \mathrm{ft}$.

100. Fragment cylindrical stone implement, centrally perforated, terrace $\mathrm{v},+28$ to $+32 \mathrm{ft}$.

ror. 2 small flint knives, terrace $v,+28$ to $+32 \mathrm{ft}$.

102. Spinbobs and fragments, terrace vi, +25 to $+29 \mathrm{ft}$.

103. Fragments spinbobs, terrace vir, +26 to $+28 \mathrm{ft}$.

104. Spinbobs, terrace VII, +26 to $+28 \mathrm{ft}$

105. Fragments painted potsherds, found with 104 +26 to $28 \mathrm{ft}$

106. Fragments spinbobs, found terrace virI, $+28 \mathrm{ft}$

107. Fragments spinbobs, north digging, $-14 \mathrm{ft}$

108. Flint knife and fragments, north digging, $-14 \mathrm{ft}$

109. Round worked potsherd, painted black, east gallery (?), $-8 \mathrm{ft}$

I ro. Flints, east gallery, $-9 \mathrm{ft}$.

I1 1 . Fragments spinbob, east gallery, $-9 \mathrm{ft}$.

I 12. Half-perforated disk of crystalline gypsum, place uncertain.

113. Beads, turquoise (6), perforated snail shells (2), east gallery with skeleton $17,-8 \mathrm{ft}$.

114. White stone beads (58), I large white stone bead, I I red stone beads, terrace II, skeleton $1 \mathrm{I},+20.5$ to $+22.5 \mathrm{ft}$.

115. Spinbob, two fragments, broken out of a clay brick, terrace II, $+24.5 \mathrm{ft}$

116. Fragment spinbob, terrace II, +20.5 to $+22.5 \mathrm{ft}$

117. Same, east gallery, -8 to - ro ft.
April 4, 1904-Continued.

118. Small bone awl, east gallery, -8 to $-10 \mathrm{ft}$.

April 5, 1904.

II. Fragments spinbobs, terrace $I+25$ to $+27 \mathrm{ft}$.

120. Same, terrace $v,+27$ to $+28.5 \mathrm{ft}$.

12I. Same, terrace viII, +24 to $+28 \mathrm{ft}$.

122. Same, terrace II, $+20.5 \mathrm{ft}$.

123. Same, terrace viI, +24 to $+26 \mathrm{ft}$

124. Half ornamented spinbob, terrace III, +16 to $+17 \mathrm{ft}$.

125. Spinbob, terrace vi, +24 to $+25 \mathrm{ft}$.

126. Fragment spinbob (?) terrace I, +25 to $+27 \mathrm{ft}$.

127. Marble of stone, terrace vII, +24 to $+26 \mathrm{ft}$.

128. Flint knife and fragments, north digging, -16 to $-19 \mathrm{ft}$.

129. Flint pieces, terrace vi, +24 to $+25 \mathrm{ft}$.

130. Fragments of flint borer, north digging, $-17 \mathrm{ft}$.

131. 2 chalcedony pieces, north digging, -16 to $-19 \mathrm{ft}$.

132. Round, perforated potsherd, -16 to $-19 \mathrm{ft}$.

133. Calespar, north digging, -16 to $-19 \mathrm{ft}$.

134. 3 snail shells, north digging, -17 to $-19 \mathrm{ft}$.

135. Perforated shell, north digging, -17 to $-19 \mathrm{ft}$.

136. Worked piece of turquoise, north digging, -17 to $-19 \mathrm{ft}$.

137. Fragment of whetstone, terrace Ir, beside skeleton near the pithos, $+25 \mathrm{ft}$.

138. Flint, terrace vir, +24 to $+26 \mathrm{ft}$

139. 2 stones, terrace II, $+20.5 \mathrm{ft}$.

140. Cylindrical stone bead, terrace II, $+25.5 \mathrm{ft}$

141. Rim fragment of feeding-cup, terrace $1,+25$ to $+27 \mathrm{ft}$.

142. Clay plastering with imprint of reeds, terrace viII +24 to $+28 \mathrm{ft}$.

143. Lead spirals, burial object of disturbed skeleton, terrace Ir, also 2 stone beads and a ball of uncertain material, $+22 \mathrm{ft}$.

144. 67 stone beads, terrace II, skeleton No. 12, $+22.5 \mathrm{ft}$.

145. Fragment copper implement, terrace vir, +24 to $+26 \mathrm{ft}$

146. Stone with traces of being worked, east gallery, -10 to $-15 \mathrm{ft}$.

147. Stone fragment, possibly worked, east gallery, -10 to $-15 \mathrm{ft}$.

April 6, 1904.

148. Spinbobs and fragments, terrace $I,+23$ to $+25 \mathrm{ft}$.

149. Same, terrace $\mathrm{II},+22$ to $+24 \mathrm{ft}$.

I50. Same, terrace $\mathrm{v},+25$ to $+27 \mathrm{ft}$.

15I. Same, terrace vI, +22 to $+24 \mathrm{ft}$.

152. Same, terrace vIr, $+23 \mathrm{ft}$.

153. Same, terrace viII, +23 to $+24 \mathrm{ft}$.

154. Same, north digging, -19 to $-20.5 \mathrm{ft}$.

155. Same, place uncertain.

156. Flints, north digging, -19 to $-20.5 \mathrm{ft}$.

157. Flint, terrace $\mathrm{I},+23$ to $+25 \mathrm{ft}$.

158. Same, terrace II, +19 to $+20 \mathrm{ft}$

159. Flint, terrace $\mathrm{III},+16$ to $+17 \mathrm{ft}$.

160. Flint knife, terrace $v,+25$ to $+27 \mathrm{ft}$.

16r. Flint, terrace vi, +22 to $+24 \mathrm{ft}$.

162. Flint knife, terrace vir, +23 to $+24 \mathrm{ft}$

163. Flint, east gallery, -15 to $-17 \mathrm{ft}$.

164. Same, terrace $v,+25$ to $+27 \mathrm{ft}$.

165. Hematite, terrace vi, +22 to $+24 \mathrm{ft}$.

166. Clay marble, terrace $v,+25$ to $+27 \mathrm{ft}$.

167. Copper pin-head, +24 to $+24.8 \mathrm{ft}$.

168. Clay plastering with imprint of reeds, terrace vili, +23 to $+24 \mathrm{ft}$.

169. Fruit seed, terrace viII, +23 to $+24 \mathrm{ft}$. 
April 6, 1904.-Continued.

170. Fruit seed, terrace II, $+20.5 \mathrm{ft}$.

171. Bits of fruit seeds, bedded in clay, north digging, -19 to $-20 \mathrm{ft}$.

172. Pieces of ocher, north digging, -19 to $-20 \mathrm{ft}$.

173. Flints, terrace $v,+25$ to $+27 \mathrm{ft}$.

174. Crystalline gypsum (?) terrace vir, +23 to $+24 \mathrm{ft}$.

175. Hematite, terrace vir, +23 to $+24 \mathrm{ft}$.

176. Flint, terrace vII, +23 to $+24 \mathrm{ft}$.

177. Resinous mineral, north digging, $-20 \mathrm{ft}$.

178. Gypsum, north digging, -19 to $-20 \mathrm{ft}$.

179. Ocher, north digging, -19 to $-20 \mathrm{ft}$

180. 2 snail shells, one perforated, north digging, -19 to $-20 \mathrm{ft}$.

181. Perforated slate disk, terrace $\mathrm{I},+23$ to $+25 \mathrm{ft}$.

182. Clay rod, north digging, -19 to $-20 \mathrm{ft}$.

183. Small knife of chalcedony, north digying (found April 2), -11 to $-13 \mathrm{ft}$.

184. Stone marble, east gallery, -15 to $-17 \mathrm{ft}$.

185. Fragments copper and lead tubes, small flint knife, burial object child's skeleton No. 14 , terrace II (4 copper, 2 lead), $+20 \mathrm{ft}$.

186. Small fint knife, terrace vII, +23 to $+24 \mathrm{ft}$.

187. Copper pin-head, terrace viII, +23 to $+24 \mathrm{ft}$.

188. Fragment copper weapon, probably spearhead, terrace $1 I_{1}+19$ to $+20 \mathrm{ft}$.

189. Fragment small copper knife (?) terrace I, +23 to $+25 \mathrm{ft}$.

April $7,1904$.

190. Fragments spinbobs, terrace $I,+22$ to $+23 \mathrm{ft}$.

191. Same, terrace $\mathrm{II},+19$ to $+20 \mathrm{ft}$.

192. Same, terrace $v,+23$ to $+25 \mathrm{ft}$.

193. Same, terrace vi, +19.5 to $+22 \mathrm{ft}$.

194. Same, terrace vir.

195. Same, terrace viII, $+22.5 \mathrm{ft}$

196. Spinbob, north digging, -20.5 to $-24.5 \mathrm{ft}$.

197. Clay knob, form two cones, terrace $11,+19$ to $+20 \mathrm{ft}$.

198. Copper fragment, terrace $\mathrm{II},+19$ to $+20 \mathrm{ft}$.

199. Flints, terrace vi, +19.5 to $+22 \mathrm{ft}$.

200. Same, north digging, -20.5 to $-24.5 \mathrm{ft}$.

201. Same, north digging III.

202. Flint scraper, terrace III, +15 to $+17 \mathrm{ft}$.

203. 3 uncertain minerals, terrace $\mathrm{II},+19$ to $+20 \mathrm{ft}$.

204. Piece of marble, terrace vir, +21 to $+23 \mathrm{ft}$.

205. Polishing stone, terrace vII, +21 to $+23 \mathrm{ft}$.

206. Fragment clay spoon (place uncertain).

207. Small clay object (German zaepfchen), terrace II +19 to $+20 \mathrm{ft}$

208. Clay lid handle, terrace $\mathrm{II},+\mathrm{Ig}$ to $+20 \mathrm{ft}$.

209. Chalk (?) north digging, -20 to $-24 \mathrm{ft}$.

210 . Fruit seeds, terrace I, +22 to $+23 \mathrm{ft}$

2 II. Same, terrace $v,+23$ to $+25 \mathrm{ft}$.

212. Bone, possibly worked (place uncertain).

213 . Whetstone, north digging, $-22 \mathrm{ft}$.

214. Perforated potsherd, terrace $\mathrm{I},+22$ to $+23 \mathrm{ft}$.

215. Slag, terrace II, +19 to $+20 \mathrm{ft}$.

216. Ocher, east gallery, -17 to $-19 \mathrm{ft}$.

217. Snail shells, north digging, -20.5 to $-24.5 \mathrm{ft}$.

218 . Ocher, north digging, -20.5 to $-24.5 \mathrm{ft}$.

219. Clay bead, north digging, -20.5 to $-24.5 \mathrm{ft}$.

220. Gypsum, north digging, -20.5 to $-24.5 \mathrm{ft}$.

221. Hematite, north digging, -20.5 to $-24.5 \mathrm{ft}$.

222. Small cylindrical beads about 1065 in number burial object child's skelet on 9 , terrace $v$ (some wrapped separately), $+29 \mathrm{ft}$.

223. Fruit seed, north digging, $-22 \mathrm{ft}$.

April 8, 1904.

224. Fragments spinbobs, terrace $v,+22$ to $+23 \mathrm{ft}$.

225. Same, terrace vir, +20 to $+21 \mathrm{ft}$
April 8, 1904.-Continued.

226. Fragment spinbob, north digging III (place uncertain).

227. Flint knife and fragments, terrace $v,+22$ to $+23 \mathrm{ft}$.

228. Round potsherd, terrace vir, +20 to $+2 \mathrm{ft}$

229. Round, perforated potsherd, terrace viI, +20 to $+2 \mathrm{Ift}$.

230. Clay marble, terrace $v,+22$ to $+23 \mathrm{ft}$.

231. Fragment flint knife, terrace III, $+15 \mathrm{ft}$.

232. 2 snail shells, north digging, -24.5 to $-26.5 \mathrm{ft}$.

(Manuscript containing several numbers was lost in transmission.)

\section{SOUTH KURGAN.}

April 8, 1904.

I. Clay lamp (?), below surface.

2. Fragment iron knife, upper digging, $55 \mathrm{~cm}$. below surface, $+50 \mathrm{ft}$.

3. Spinbob, upper digging, $50 \mathrm{~cm}$. below surface. $+50 \mathrm{ft}$.

4. Lid handle of clay vessel.

5. Polishing stone, north terrace, below surface.

6. Metal tube, upper digging, below surface.

7. Slag, below surface.

8. Three-edged copper arrow-head, north terrace, I $\mathrm{m} .60 \mathrm{~cm}$. below highest margin, $+50 \mathrm{ft}$.

9. Small clay jar, below surface, upper digging. 10. Fragment ornamented spinbob, upper digging, $1 \mathrm{~m}$.

11. Copper wire, upper digging, I m., $+49 \mathrm{ft}$.

12. Polishing stone, upper digging, $1 \mathrm{~m}$.

13. Flint saw, in dump of an older digging.

14. Flint flake, upper digging, $1 \mathrm{~m}$.

15. Fragment perforated disk of white stone, upper digging, $1 \mathrm{~m} .20 \mathrm{~cm}$.

16. Whetstone, dump of older digging.

17. Fragment bone awl, dump of older digging.

18. Kalkspat (German), upper digging, $1 \mathrm{~m}$.

19. Fragment polished basalt, dump older digging. April 9, 1904.

20. Gypsum, upper digging, I $\mathrm{m}$.

21. Fragment flint knife, north terrace, $2 \mathrm{~m} .60$ $\mathrm{cm}$. below highest margin, $+3 \mathrm{Ift}$.

22. Two fragments iron sickle, north terrace, $2 \mathrm{~m}$. $60 \mathrm{~cm}$. below highest margin $+31 \mathrm{ft}$. April II, 1904 .

23. Stone pestle, south terrace, I $\mathrm{m}$. below highest margin, $+38 \mathrm{ft}$.

24. Bead, material undetermined, south terrace, $1 \mathrm{~m}$. below highest margin, $+38 \mathrm{ft}$.

25. Small iron rod, north terrace, $3 \mathrm{~m} .50 \mathrm{~cm}$ below highest margin, $+27 \mathrm{ft}$.

26. Flint knife, north terrace, $3 \mathrm{~m}$. $50 \mathrm{~cm}$. below highest margin, $+27 \mathrm{ft}$.

27. Stone mortar, upper digging, I m. $45 \mathrm{~cm}$., +48 ft. 5 in.

28. Small cylindrical bead, turquoise, north terrace, $3 \mathrm{~m}$. $50 \mathrm{~cm}$. below high margin, $+27 \mathrm{ft}$.

29. Flints, north terrace, $3 \mathrm{~m}$. $50 \mathrm{~cm}$. below high margin, $+27 \mathrm{ft}$.

30. Fragment spinbob, upper digging, from dump.

31. Ornamented spinbob, north terrace, $3 \mathrm{~m}$. 50 $\mathrm{cm}$. below highest margin, $+27 \mathrm{ft}$

32. Large stone bead, surface.

33. Spinbob, from dump.

34. Flint knife, from dump.

35. Pieces iron, north terrace, $3 \mathrm{~m}$. $50 \mathrm{~cm}$. below highest margin, $+27 \mathrm{ft}$. 
April in 1004-Continued.

35-37. Mortar and pastle, found together (stone) upper digging, $1 \mathrm{~m} .45 \mathrm{~cm}$. $+48 \mathrm{ft}$. 5 in,

38. Lenticular stone implement, with incomplete perforation, upper digging, from dump.

39. Fragment bone awl, upper digging, $1 \mathrm{~m} .5^{8} \mathrm{~cm}$. $+48 \mathrm{ft}$.

April 12, 1904.

40. Copper awl south terrace, $2 \mathrm{~m} .60 \mathrm{~cm}$; below highest margin, $+38 \mathrm{ft}$

41. Two fragments iron knife, north terrace, $+27 \mathrm{ft}$.

42. Two flint knives, north terrace, $+27 \mathrm{ft}$

43. Flint, upper digging, $+43 \mathrm{ft}$.

44. Bone awl, upper digging, from dump.

45. Fragment perforated marble (?) disk, upper digging, $+43 \mathrm{ft}$.

46. Piece marble, upper digging, $+43 \mathrm{ft}$.

47 . Round, chipped and perforated potsherd, upper digging, $+43 \mathrm{ft}$.

48. Clay tube (small) upper digging, $+43 \mathrm{ft}$.

49. Slingstone of sandstone, upper digging, $+43 \mathrm{ft}$.

April 14, 1904.

50. Spinbob, upper digging, $+40 \mathrm{ft}$

51. Same, south terrace, $+28 \mathrm{ft}$.

52. Same, north terrace, $+25 \mathrm{ft}$

53. Flint knife, upper digging, + $40 \mathrm{ft}$.

54. Piece of flint, north terrace, $+25 \mathrm{ft}$.

55. Metal tube, north terrace, $+25 \mathrm{ft}$.

56. 2 fragments of a curiously ribbed stone article, north terrace, $+25 \mathrm{ft}$.

57. Clay idol, upper digging, + to ft.

58. Fragment clay article, with two hooks, undetermined, south shaft, $+2 \mathrm{ft}$.

59. Clay bottle, south terrace, $+28 \mathrm{ft}$.

60. Clay article, shaped like spinbob, south shaft, $+2 \mathrm{ft}$.

6r. 3 fragments of copper dagger, upper digging. t to ft.

62. Copper band, bent over at end and perforated, upper digging, $+40 \mathrm{ft}$.

63. 2 snail shells, upper digging, + to $\mathrm{ft}$.

64. Snail shell, south terrace, $+28 \mathrm{ft}$.

65. Long glass bead, upper digging, +40 to $+43 \mathrm{ft}$.

66. Clay tube, south terrace, $+28 \mathrm{ft}$.

67. Small stone pestle, upper digging, $+40 \mathrm{ft}$.

68. Ocher, north terrace, $+25 \mathrm{ft}$.

69. Missing.

70. Turquoise bead, north terrace, $+25 \mathrm{ft}$.

7oa. Flattened sphere with two depressions, stone, south terrace, $+28 \mathrm{ft}$.

71. Red jasper, upper digging, + to ft.

72. Tooth, animal, upper digging, $+40 \mathrm{ft}$

73. Three-sided seal with figured carvings, south terrace (= terrace $\mathrm{B}),+28.25 \mathrm{ft}$. April 15, 1904.

74. Fragment copper dagger-blade, upper digging, $+37 \mathrm{ft} .7 \mathrm{in}$, to $+40 \mathrm{ft}$.

75. Copper button with eye, upper digging, +37 ft. 7 in. to $+40 \mathrm{ft}$.

76. Fragment copper pin, south terrace, $+26.25 \mathrm{ft}$.

77. Fragment copper, north terrace, $+23 \mathrm{ft}$

78. Quartz slingstone (?), upper digging, $+37 \mathrm{ft}$. 7 in. to $+40 \mathrm{ft}$.

79. Flint knife, upper digging, $+37 \mathrm{ft} .7$ in. to $+40 \mathrm{ft}$.

8o. Flint scraper, dump.

81. Flint knife, small, north terrace, $+23 \mathrm{ft}$.

82. Quartz pendant with "groove," upper digging, $+37 \mathrm{ft} .7$ in. to $+40 \mathrm{ft}$.
April 15, 1904-Continucd.

83. Image of bull, clay, upper digging, $+37 \mathrm{ft}$. 7 in. to $+40 \mathrm{ft}$.

84. Clay knob, north terrace, $+23 \mathrm{ft}$.

85. Muller, upper digging, $+37 \mathrm{ft} .7$ in. to + to $\mathrm{ft}$

86. Slide, faience, north terrace, $+23 \mathrm{ft}$.

87. Copper fragment, north terrace, $+23 \mathrm{ft}$.

88. 2 small shells, north terrace, $+23 \mathrm{ft}$.

89. Turquoise bead, north terrace, $+23 \mathrm{ft}$.

90. Cut piece of calcspar, north terrace, $+23 \mathrm{ft}$.

91. Muller, upper digging, $+37 \mathrm{ft}$. 7 in. to $+40 \mathrm{ft}$.

92. Clay implement, spinbob-shaped, upper diging, $+37 \mathrm{ft} .7 \mathrm{in}$. to $+40 \mathrm{ft}$.

93. Round, chipped potsherd, upper digging, +37 7 in. to $+40 \mathrm{ft}$.

94. Lid handle, upper digging, $+37 \mathrm{ft} .7$ in. to $+40 \mathrm{ft}$.

95. Perforated copper coin, said to come from upper digging, $+37 \mathrm{ft} .7$ in. to $+40 \mathrm{ft}$.

April 16, 1904

96. Copper fragment, north terrace, $+22 \mathrm{ft}$

97. Copper awl, upper digging, $+33 \mathrm{ft}$

98. Copper sheath, fragment, upper digging, $+33 \mathrm{ft}$.

99. Copper fragment, upper digging, $+33 \mathrm{ft}$.

100. Flints, north terrace, $+22 \mathrm{ft}$.

101. Flints, upper digging, $+33 \mathrm{ft}$.

102. Spinbobs, upper digging, $+33 \mathrm{ft}$

103. One spinbob, north terrace, $+22 \mathrm{ft}$.

104. Two stone beads, south terrace, $+25 \mathrm{ft}$.

105. Square stamp, clay, south terrace, $+25 \mathrm{ft}$.

106. Two spinbobs, south terrace, $+25 \mathrm{ft}$.

107. Tip of bone awl, upper digging, $+33 \mathrm{ft}$.

108. Calcspar, north terrace, $+22 \mathrm{ft}$.

109. Pieces iron, outer digging, about $+17 \mathrm{ft}$.

1 ro. Calcspar, upper digging, $+33 \mathrm{ft}$.

I 1 . Five slingstones, upper digging, $+33 \mathrm{ft}$.

112. Stone implement, upper digging, $+33 \mathrm{ft}$.

April 18, 1904.

113. Fragment spinbob, upper digging, +32 to $+33 \mathrm{ft}$.

114. Same, south terrace (B), $+2+$ to $+25 \mathrm{ft}$.

115. Slingst one, upper digging, +32 to $+33 \mathrm{ft}$.

116. Trapezoidal, chipped potsherd, painted, north terrace $(A),+21$ to $+22 \mathrm{ft}$.

117 . Fragment small copper dish, upper digging, +32 to $+33 \mathrm{ft}$.

1 18 . Small copper ring, upper digging, +32 to $+33 \mathrm{ft}$.

119. Stone hammer, short-handled, in one piece, terrace B dump, +24 to $+25 \mathrm{ft}$.

120. Finely worked flint arrow-head, terrace $B$, fresh dump, +24 to $+25 \mathrm{ft}$.

April 19, 1904.

121. Spinbobs (5) and I fragment, upper digging, +29 to $+32 \mathrm{ft}$

I22. Spinbobs (2), fragment (1), terrace B.

123. Spinbob, terrace $C+26$ to $+29 \mathrm{ft}$.

124. Double-conical, decorated stone beads (2), terrace $B$, dump.

125. Blue glass bead, terrace $B$, dump.

126. Flint knives $(5)$, terrace $C,+26$ to $+29 \mathrm{ft}$.

127. Flint knife, terrace $B$, dump.

128. Oval, worked piece of marble, upper digging, +29 to $+32 \mathrm{ft}$.

129.. Piece marble slab, terrace $B$, dump

130. Calcspar, upper digging, +29 to $+32 \mathrm{ft}$.

131. Calcspar, terrace $B$, dump.

132. Half of perforated stone club

I33. Small clay cup, upper digging, +29 to $+32 \mathrm{ft}$. 
April 19, 1904.-Continued.

134. Clay disk with central perforation, terrace $B$, dump.

135. Small clay pipe, upper digging, +29 to $+32 \mathrm{ft}$. 136. Slingstones (5), terrace $B$, dump.

137. Marble knob, upper digging, +29 to $+32 \mathrm{ft}$.

138. Pestle, terrace $B$, dump, $+23 \mathrm{ft}$.

139. Fragment copper, terrace $B$, dump, $+23 \mathrm{ft}$.

140. Copper wire, upper digging, +29 to $+32 \mathrm{ft}$.

I4I. Small copper dagger-blade, near terrace $B$, $+32 \mathrm{ft}$.

142. Copper dagger-blade, large, no tin, +29 to +32 feet.

143. Copper razor, upper digging, no tin, +29 to $+32 \mathrm{ft}$. 142 and 143 found in same strata with fragment of vessel wheel-made and decorated with wave pattern.

144. Needle-like copper implement, upper digging, +29 to $+32 \mathrm{ft}$.

145. Small copper rod, outer digging, +6.5 to + to $\mathrm{ft}$.

\section{April 20, 1904.}

146. Copper sickle with bent handle, upper digging, +25 to $+29 \mathrm{ft}$

147. Spinbob, upper digging, +25 to $+29 \mathrm{ft}$.

148. Spinbobs (3) and fragments (2), terrace B.

149. Spinbobs (2), terrace $\mathrm{C},+23$ to $+26 \mathrm{ft}$.

150. Clay beads (2), upper digging, +25 to $+29 \mathrm{ft}$.

15I. Clay beads (I), terrace $B, \pm+23 \mathrm{ft}$.

152. Stone bead, terrace $B$.

153 Stone bead, upper digging, +25 to $+29 \mathrm{ft}$.

154. Double-conical glazed clay bead, upper digging, +25 to $+29 \mathrm{ft}$.

155. Clay marble, terrace $\mathrm{C},+23$ to $+26 \mathrm{ft}$

156. Perforated stone club, terrace $\mathrm{C},+23$ to $+26 \mathrm{ft}$.

157. Stone bead, terrace $\mathrm{C},+23$ to $+26 \mathrm{ft}$.

158. Rim-piece alabaster vessel, terrace $B,+20$ to $+23 \mathrm{ft}$.

159. Fragments of two marble vessels, terrace $B$, +20 to $+23 \mathrm{ft}$.

160. Fragment alabaster vessel.

16I. Perforated clay disk, terrace $\mathrm{C}+23$ to $+26 \mathrm{ft}$.

162. Flint knives (2), terrace $B, \pm+23 \mathrm{ft}$.

163. Flint fragments, terrace $B, \pm+23$ ft.

164. Flint knives (2), terrace $C$, +23 to $+26 \mathrm{ft}$.

165. Fragments of copper, upper digging, +25 to $+29 \mathrm{ft}$.

166. Fragment copper awl, terrace $B, \pm+23 \mathrm{ft}$.

167. Copper fragment, terrace $B, \pm+23 \mathrm{ft}$.

168. Same, terrace $C,+23$ to $+26 \mathrm{ft}$.

169. Fragment decorated stone vessel, upper digging, near pithos $b,+25$ to $+29 \mathrm{ft}$.

170. Fragment stone stamp, star pattern, upper digging, +25 to $+29 \mathrm{ft}$.

17r. Miniature spinbob, upper digging, +25 to $+29 \mathrm{ft}$.

172. Perforated clay implement, upper digging, +25 to $+29 \mathrm{ft}$.

173. Clay disk, several perforations, upper digging, +25 to $+29 \mathrm{ft}$.

174. Clay idol, terrace $B, \pm+23 \mathrm{ft}$

175. Upper portion of large clay idol (?), upper digging, +25 to $+29 \mathrm{ft}$.

176. Slingstones (2), terrace $B, \pm+23 \mathrm{ft}$

177. Perforated stone disk, terrace $B,+23 \mathrm{ft}$.

178. Conical stone, terrace $B,+23 \mathrm{ft}$

179. Whetstone, terrace $B,+23 \mathrm{ft}$.

180. Petrifaction, terrace $C$, dump, +23 to $+26 \mathrm{ft}$.

181. Fragments (2) clay cylinder, foot of chalice (?) upper digging, +25 to $+29 \mathrm{ft}$.

182. Bone implement, upper digging, +25 to $+29 \mathrm{ft}$.
April 20, 1904.-Continued.

183. Fragments (2) of pestle, +25 to $+29 \mathrm{ft}$.

184. Sinter (?) terrace $B$

185. Snail shell, terrace $B$.

186. Snail shell, terrace $C$.

187. Flint knife, terrace $C,+23$ to $+25 \mathrm{ft}$.

April 21, 1904.

188. Spinbobs (3), fragments (2), upper digging, + 21 to $+25 \mathrm{ft}$

189. Spinbob and fragments (4)

190. Spinbob, terrace C, +21 to $+23 \mathrm{ft}$.

191. Flint scraper, terrace $B, \pm+23 \mathrm{ft}$.

192. Flint scraper, terrace $C,+21$ to $+23 \mathrm{ft}$.

193. Double-conical stone bead, terrace $B, \pm+23 \mathrm{ft}$.

194. Double-conical stone bead, terrace $C,+21$ to $+23 \mathrm{ft}$.

195. Slingstones (7), terrace $\mathrm{C},+2 \mathrm{I}$ to $+23 \mathrm{ft}$.

196. Fragment pestle, terrace $\mathrm{C},+2 \mathrm{I}$ to $+23 \mathrm{ft}$.

197. Fragment copper pin, terrace $C,+2 I$ to $+23 \mathrm{ft}$.

198. Fragment of copper implement, upper digging, +21 to $+25 \mathrm{ft}$

199. Fragment copper pin, terrace $B, \pm+23 \mathrm{ft}$.

200. Copper awl in (2) fragments, terrace $C,+21$ to $+23 \mathrm{ft}$.

201. Copper knob (?), terrace $B, \pm+21.5$ to $+23.7 \mathrm{ft}$.

202. Copper stamp (?) fragment, terrace $B, \pm+21.5$ to $+23.7 \mathrm{ft}$.

203. Fragment copper ring, terrace $B,+21.5$ to $+23.7 \mathrm{ft}$.

204. Copper band, fragment, upper digging, $+2 \mathrm{I}$ to $+25 \mathrm{ft}$.

205. Copper arrow-head, outer digging, +2 to $+4 \mathrm{ft}$. 206. Bone awl, fragment, terrace $B, \pm+23 \mathrm{ft}$.

207. Rosette ornament, bronze, with loop or eyelet (2 fragments), terrace $B, \pm+23$ feet (cf. 202).

208. Bone arrow-heads, terrace $B,+20$ to $+23 \mathrm{ft}$ 209. Decorated spinbob, terrace $B$, near pot under skeletons.

2 10. Stone implement, terrace $B$, from same place.

211 . Fragment clay toy wagon-box, terrace $C,+21$ to $+23 \mathrm{ft}$.

212. Round-chipped potsherd, terrace $C,+21$ to $+23 \mathrm{ft}$.

213. "Marble," clay, terrace $C_{,}+21$ to $+23 \mathrm{ft}$.

214. Conical, worked piece of marble, terrace $\mathrm{C}$, +21 to $+23 \mathrm{ft}$.

215. "Marble" of clay, terrace B.

216. Stone "marble," terrace B.

217. Whetstone, terrace $B$.

218. Carnelian bean and lapis-lazuli pendant, terrace $\mathrm{C}+2 \mathrm{r}$ to $+23 \mathrm{ft}$.

219. Lapis-lazuli button, outer digging, +2 to $+3 \mathrm{ft}$.

220. Stone hammer, terrace $B$.

$22 \mathrm{I}$. Stone pestle, upper digging, $+2 \mathrm{r}$ to $+25 \mathrm{ft}$.

222. Same (fragment), upper digging, +21 to $+25 \mathrm{ft}$.

223. Same (fragment), terrace $B,+20$ to $+23 \mathrm{ft}$.

224. Marble pendant, terrace $B,+20$ to $+23 \mathrm{ft}$.

225. Polishing stone, upper digging, +21 to $+25 \mathrm{ft}$.

226. Potsherd, perforated like a strainer, upper digging, $+2 x$ to $+25 \mathrm{ft}$.

227. Iron oxide, upper digging, $+2 \mathrm{r}$ to $+25 \mathrm{ft}$

228. Potsherd, stamped with decoration, said to be from dump.

April 22, 1904.

229. Spinbobs (3), fragments (5), terrace $B,+20$ to $+23 \mathrm{ft}$.

230. Fragment, spinbob, terrace $C,+19.5$ to $+21 \mathrm{ft}$. 
April 22, 1904.-Continued.

231. Clay wheels (2), terrace $B,+20$ to $+23 \mathrm{ft}$.

232. Clay marbles (6), fragments (I).

233. Clay marble, terrace $C$, +19.5 to $+21 \mathrm{ft}$.

234. Flint knives (2), terrace $B,+20$ to $+23 \mathrm{ft}$.

235. Same, terrace $C,+19.5$ to $+21 \mathrm{ft}$.

236. Stone bead, terrace $C_{\text {, }}+19.5$ to $+2 \mathrm{It}$.

237. Clay bead, terrace $B,+20$ to $+23 \mathrm{ft}$.

238. Metal tube, * terrace $B,+20$ to $+23 \mathrm{ft}$

239. Fragment, marble vessel, terrace $\mathrm{B},+20$ to $+23 \mathrm{ft}$.

240. Fragment cut stone slab, terrace $B,+20$ to $+23 \mathrm{ft}$.

241. Slingstones (4), terrace $C_{1}+19.5$ to $+21 \mathrm{ft}$.

242. Egg-shaped stone, terrace $\mathrm{C},+19.5$ to $+21 \mathrm{ft}$.

243. Flattened marble bead, terrace $C,+19.5$ to $+21 \mathrm{ft}$.

244. Stone bead, burial object, wrist of skeleton $\alpha$, terrace $\mathrm{B},+20$ to $+23 \mathrm{ft}$.

245. Turquoise bead, terrace $C$, +19.5 to $+21 \mathrm{ft}$.

246. Agate bead, terrace $C$, +19.5 to $+21 \mathrm{ft}$.

247. Fragment copper dagger-blade, terrace $B,+20$ to $+25 \mathrm{ft}$.

248. Fragment copper knife-blade, terrace $C,+19.5$ to $+21 \mathrm{ft}$.

249. Copper pin-head, terrace $C,+19.5$ to $+2 \mathrm{Ift}$.

250. Fragments (2) of a copper pin, terrace $C,+19.5$ to $+2 \mathrm{It}$.

251. Same, terrace $C$, +19.5 to $+2 \mathrm{rt}$.

252. Fragment (2) female figure of unburnt clay from clay box, terrace $B, 20$ to $+23 \mathrm{ft}$.

253. Decorated stone bead, found like 252 , terrace $\mathrm{B},+20$ to $+23 \mathrm{ft}$.

254. Stone pestle, terrace $C,+19.5$ to $+2 \mathrm{Ift}$.

255. Fragment perforated clay weight, terrace $C$, +19.5 to $+2 \mathrm{rt}$.

256. Rim-piece marble vessel, terrace $B,+20$ to $+23 \mathrm{ft}$.

257. Round chipped potsherds (2), terrace $C,+19.5$ to $+2 \mathrm{It}$.

258. Fragment of handle to some vessel, terrace $C$, +19.5 to $+21 \mathrm{ft}$.

259. Petrifaction, outer digging, $+2 \mathrm{ft}$. to $-1 \mathrm{ft}$.

260. Fragment clay implement, terrace $B,+20$ to $+23 \mathrm{ft}$.

26r. Whetstones (3), terrace $\mathrm{C},+19.5$ to $+2 \mathrm{It}$.

262. Handle of large stone weight, terrace $B,+20$ to $+23 \mathrm{ft}$.

April 23, 1904.

263. Spinbobs (5), terrace $B,+20$ to $+23 \mathrm{ft}$.

264. Spinbobs (4), terrace $B,+20$ to $+23 \mathrm{ft}$

265. Miniature spinbob, terrace $B,+20$ to $+23 \mathrm{ft}$. 266. Spinbob fragments (6), terrace $B,+20$ to $+23 \mathrm{ft}$. 267. Same (7), terrace $B,+20$ to $+23 \mathrm{ft}$.

268. Fragment clay rattle, terrace $B,+20$ to $+23 \mathrm{ft}$.

269. Clay marbles (II), fragments (3), terrace $B$, +20 to $+23 \mathrm{ft}$.

270. Fragment clay wheel, terrace $\mathrm{B},+20$ to $+23 \mathrm{ft}$. 271. Slingstones (2), terrace $B,+20$ to $+23 \mathrm{ft}$.

272. Spinbobs, upper digging, shaft $\mathrm{C},+15$ to $+18 \mathrm{ft}$.

273. Stone bead, terrace $C,+18.5$ to $+19.5 \mathrm{ft}$.

274. Copper chisel, terrace $B,+19 \mathrm{ft}$.

275. Fragment copper pin, terrace $B,+19 \mathrm{ft}$.

276. Fragment copper chisel, terrace $B,+19 \mathrm{ft}$.

277. Copper awl, terrace $B,+19 \mathrm{ft}$.

278. Copper pin, terrace $B,+19 \mathrm{ft}$.

279. Ocher, terrace $B,+19 \mathrm{ft}$.

280. Fragment copper pin, terrace $B,+19 \mathrm{ft}$.

281. Same, terrace $B,+19 \mathrm{ft}$.

282. Clay marbles (2), terrace $B,+20$ to $+23 \mathrm{ft}$.
April 23, 1904-Continued.

283. Spinbob fragments (2), terrace $B,+20$ to $+23 \mathrm{ft}$. 284. Clay animal figures, fragments (3), terrace $B$, +20 to $+23 \mathrm{ft}$.

285. Clay idol, terrace $B,+20$ to $+23 \mathrm{ft}$

286. Fragment female figure with necklace, clay, terrace $\mathrm{B},+20$ to $+23 \mathrm{ft}$.

287. Bead made of fossil, terrace $B,+20$ to $+23 \mathrm{ft}$. 288. Fossilized shell, terrace $B,+20$ to $+23 \mathrm{ft}$.

289. Fragment round-chipped, perforated potsherd, terrace $\mathrm{B},+20$ to $+23 \mathrm{ft}$.

290. Small clay lid with knob, terrace $B,+20$ to $+23 \mathrm{ft}$.

291. Clay handle, terrace $B,+20$ to $+23 \mathrm{ft}$.

292. Horn-shaped object of clay, terrace $B_{1}+20$ to $+23 \mathrm{ft}$.

293. Greenstone, terrace $B,+20$ to $+23 \mathrm{ft}$.

294. Piece of clay, terrace $B,+20$ to $+23 \mathrm{ft}$.

295. Spinbobs (2), terrace $B,+20$ to $+23 \mathrm{ft}$.

296. Spinbob, terrace $C,+18.5$ to $+19.5 \mathrm{ft}$.

297. Clay ball, terrace $B,+20$ to $+23 \mathrm{ft}$.

298. Potsherd with perforation, terrace $C_{1}+18.5$ to $+19.5 \mathrm{ft}$.

299. Stone bead, terrace $C_{1}+18.5$ to $+19.5 \mathrm{ft}$.

300. Small marble tube, terrace $C,+18.5$ to $+19.5 \mathrm{ft}$.

301. Copper ring fragment, terrace $\mathrm{C}$, +18.5 to $+19.5 \mathrm{ft}$.

302. Small copper chisel, terrace $B,+20$ to $+23 \mathrm{ft}$.

303. Flint knife, terrace $C,+18.5$ to $+19.5 \mathrm{ft}$.

304. Clay object, terrace $B,+20$ to $+23 \mathrm{ft}$.

305. Potsherd perforated like a strainer, terrace $B$, +20 to $+23 \mathrm{ft}$.

306. Mineral, terrace $\mathrm{C},+18.5$ to $+19.5 \mathrm{ft}$.

April 25, 1904.

All terrace $B=+20$ to $+23 \mathrm{ft}$.

307. Spinbobs (8).

308. Spinbobs.

309. Spinbob fragments.

3 ro. Miniature spinbob.

311. Clay animal figures (2).

312. Fragment same.

313. Clay human figures, fragments (3).

314. Clay marbles (6).

315. Same, fragments (4).

316. Flint knives (2).

317. Flint scraper.

3 18. Round, scalloped potsherd.

319. Clay disk.

320. Clay object.

321. Fragment clay,wheel.

322. Fragment of $\mathbf{a}$ handle (?)

323. Clay handle.

324. Cone of clay, fragment.

325. Stone disk with grooves.

April 26, 1904.

All terrace $B=+20$ to $+23 \mathrm{ft}$.

326. Spinbobs (4) fragments (20), smaller fragments.

327. Animal figures and fragments (16).

328. Clay marbles ( 7 ), fragment.

329. Clay object like animal head with horns, fragments; cf. 345.

330. Clay wheels (2), fragments.

331. Clay cone.

332. Copper spear-head, $+19 \mathrm{ft}$.

333. Copper fragment.

334. Pendant with eyelet, bronze, $+2 \mathrm{It}$.

335. Flint flake (4).

336. Ocher. 
April 26, 1904.-Continued.

337 Fragment whetstone.

338. Fragment colored cut glass, said to be from fresh dump, modern (?).

339. Clay idol (head and right arm missing).

Upper digging, shaft $\mathrm{C}$.

340. Clay wheel

341. Clay stamp.

342. Fragments (2) of a broad decorated handle of badly burnt clay.

April 27, 1904.

All terrace $B=+20$ to $+23 \mathrm{ft}$.

343. Spinbobs (5), fragments ( 13 large, 7 small)

344. Clay animal figures, fragments (I I).

345. Clay object like animal head and fragment, cf. 329 .

346. Clay marbles (8) and fragments (2).

347. Stone beads (2).

348. Fragments clay wheel.

349. Perforated disk.

350. Lump of clay with fine incisions.

35 I. Beautifully worked obsidian arrow-head, found under skelet on $\gamma$.

352. Stone hammer found under clay box.

353. Fragment ornamental disk, found under strata of skeletons.

354. Fragments (2), bronze pin found under pithos $d$. 355. Natica (removed for determination).

April 28, 1904

All terrace $B$.

356. Fragment flying bird, clay.

357. Spinbobs (5), fragments (12 large, 4 small)

358. Clay animal figures in fragments (12).

359. Clay marbles (4).

360. Clay wheels (2), fragments.

361 . Fragments (2) of human figures, clay.

362. Fragment marble vessel.

363. Fragment decorated clay slab.

Upper digging. shaft $\mathrm{C}$.

364. Fragment clay wheel.

April 30, 1904.

365. Finely worked flint arrow-head, shaft $\mathrm{C}$, probably from between $o$ and - ro $\mathrm{ft}$.

May 4, 1904

366. Half decorated spinbob, $-14 \mathrm{ft}$, in shaft $\mathrm{C}$.

\section{GHIAUR KALA (OLD MERV).}

May 24, 1904.

1. Spherical agate bead, upper digging

ia. Fragment of a clay animal figurine, upper digging.

May 25, 1904.

2. Copper coins, mostly of unrecognizable date, upper digging.

3. Iron ring, upper digging.

4. Bronze stamp, upper digging.

5. Fragment of a bronze plate, upper digging.

6. Fragments of glass, upper digging.

7. Glass bead, upper digging.

8. Bronze fragment (arrow-point ?), upper digging.

9. Fragment of bronze, upper digging.

Ioa, b. Fragment of a large vase with inscriptions in Pehlevi, upper digging.

11. Same, upper digging.
May 25, 1904.-Continued.

12-13. 2 bones with inscriptions in Pehlevi and one in Uigur, upper digging

14-16. 3 clay knobs, probably lid handles, upper digging.

17. Spindle-whorls, upper digging

17a. Piece of a male terra-cotta figurine, upper digging.

May 26, 1904.

Upper digging $2 \mathrm{ft}$. 4 in. to $5 \mathrm{ft}$. below surface; lower digging $5 \mathrm{ft} .7$ in. to $9 \mathrm{ft} .5$ in below surface.

18. Copper coin, upper digging near the round hearth.

19. Copper coin, lower digging, $-8 \mathrm{ft}$.

20. I glass and I stone bead, upper digging.

21 . Round pierced potsherd, upper digging.

22. Piece of an iron knife, upper digging.

23. 4 copper coins, upper digging.

24. Piece of bronze, upper digging.

25. Pieces of glass, upper digging.

$25 a$. Rounded and pierced potsherd, upper digging.

May 27, 1904.

Upper digging. $5 \mathrm{ft}$. to $8 \mathrm{ft}$. 9 in. below surface; lower digging, $9 \mathrm{ft}$. 5 in. to $12 \mathrm{ft}$. below surface.

26. Bronze fragment, upper digging.

27. Rounded pierced shards, lower digging, $-12 \mathrm{ft}$. 28-30. Balls of burnt clay, lower digging, $-12 \mathrm{ft}$.

31. 2 copper coins, lower digging, $-12 \mathrm{ft}$

32. Beads of green stone, upper digging.

33. Gold ornament, piece of an animal pendant, upper digging

34. Piece of a ring of alabaster, upper digging.

35. Pieces of variegated glass, upper digging.

36. Smoothing stone, upper digging.

37. Piece of whetstone, upper digging.

37a. Whorls, upper digging.

$37 b$. Animal figurine, lower digging.

May 28, 1904.

Upper digging, $8 \mathrm{ft}$. 9 in. to $\mathrm{I} \mathrm{ft}$. 6 in. below surface; lower digging, i $2 \mathrm{ft}$. to $15.25 \mathrm{ft}$. below surface.

38. Clay ball, upper digging.

39. Fragment of an animal figurine, lower digging.

40. Piece of vessel of well-polished black stone, lower digging.

41. 2 copper coins, upper digging

42. Round animal figure of shell with two holes, upper digging.

43. Rectangular pipe of black polished stone in 3 pieces, upper digging.

44. Lower part of male figure of burnt clay, painted red, yellow, and black, upper digging.

44a. Slingstones (cf. South Kurgan, Anau), lower digging.

$44 b$. Fragment of a stone vessel, upper digging.

May 30, 1904.

Upper digging, $11.5 \mathrm{ft}$. to $15 \mathrm{ft} .5$ in. deep; lower digging, $15.25 \mathrm{ft}$. to $16 \mathrm{ft}$. deep; cuter digging $I, 0$ to $4 \mathrm{ft}$. deep.

45. Small turquoise beads, upper digging.

46. Slingstones, upper digging (cf. Anau).

47. Broken turquoise beads, upper digging.

48. Slingstones of burnt clay, lower digging.

49. Piece of copper coin, upper digging.

50. Piece of copper, upper digging.

51. Glazed lamp, outer digging $I$. 
May 30, 1904.-Continued.

52-56. Glazed clay lamps and pieces, outer digging II.

57. Piece of a glazed bead, outer digging II, (cf. Anau).

58. 2 copper coins, outer digging II.

59. Rectangular copper plate, toothed, like a comb on one side with 2 holes, outer digging II.

6o. Pieces of copper, outer digging II.

61. Fragment of glass, outer digging II.

62. Piece of glass with impressed ornament, outer digging $\mathrm{I}$.

63. Lower part of a female figure, surface near outer digging $\mathrm{I}$.

64-66. Glazed and painted potsherd, surface near outer digging 1 .

67. Whorls, outer digging I

68. Copper coins, upper digging.

69. Potsherd with dots, upper digging.

May 31, 1904.

Upper digging. $15 \mathrm{ft} .5$ in. to $17 \mathrm{ft} .5$ in. deep; outer digging $\mathrm{I}, 4 \mathrm{ft}$. to $9 \mathrm{ft}$. deep.

70. 2 copper coins, outer digging $\mathrm{I}$.

71. Piece of copper coin, outer digging $I$.

72. Fragment of a black substance (jet), outer digging $\mathrm{r}$.

73. Ornament of jet, outer digging 1 .

74. Piece of disk of white stone, outer digging $\mathrm{I}$.

75-77. Glazed clay lamp, outer digging II.

78. Copper coin, outer digging II.

79. Same, outer digging II.

80. Glass fragments, outer digging II.

$8 \mathrm{I}$. Small clay ball, outer digging $\mathrm{I}$.

82-85. Glazed and painted potsherds, outer digging $\mathrm{I}$.

86. Piece of an animal figurine, surface near outer digging $\mathrm{I}$.

87. Piece of an iron seal-ring with figures, surface near outer digging $\mathrm{I}$.

88. 3 beads, upper digging.

89. Piece of a glazed lamp, outer digging Ir.

9o. Piece of a glass ring, outer digging II.

91. Thick bronze disk, pierced in center, outer digging $I I$.

92. Bronze nail-head, outer digging II.

93. Piece of copper, outer digging II.

94. Pieces of glass, outer digging $\mathrm{II}$.

95. Glazed pottery, outer digging Ir.

96. Pieces of copper, outer digging 1 .

97. Fragments of a horned pin, outer digging $I$.

98. Copper coin, outer digging I.

99. Piece of a clay figurine, surface near outer digging $\mathbf{~}$.

100-105. Glazed and painted potsherds, outer digging 1 .

ro6. 3 copper coins, outer digging $I$.

107. Clay ball, outer digging $\mathrm{I}$.

108. Whorls from south shaft on citadel.

June 1, 1904

Upper digging, $17 \mathrm{ft}$. 5 in. to $20 \mathrm{ft} .6 \mathrm{in}$. deep outer digging $\mathrm{I}, 9 \mathrm{ft}$. to $11.5 \mathrm{ft}$. deep.

rog. 3-edged arrow-point of bronze (cf. South Kurgan, Anau), upper digging.

1 10. 3-edged arrow-point with short shaft socket, upper digging.

III-II3. Glazed and painted potsherds, outer digging 1.

114. Piece of a bronze mirror, gallery $\mathrm{II}, 70 \mathrm{~cm}$. under the surface at entrance.
June 1, 1904.-Continued.

115. Lower part of a small jug, gallery III, under the surface at entrance.

I 16.3 copper coins, possibly legible, outer digging I. I 17 . A pierced potsherd, outer digging 1 .

I 8 . Animal clay figurine, outer digging $I$.

I I9-124. Glazed and painted potsherds, found deeper than 111 to 113 , outer digging $I$.

125. Glazed potsherd, outer digging II.

126. 2 blue stone beads (lapis lazuli), gallery $\mathbf{~}$.

127. Slingstone of clay.

128. Bronze fragment, gallery III, uncertain.

129. Beads of lapis lazuli like 126; this is suspicious, since they are said to have been found in the heart of a wall.

130. Copper coin, upper digging.

1 31-132. 2 animal figures, burnt clay, upper digging.

133. Painted potsherd, dump of outer digging $I$.

134. Clay balls, south shaft on citadel.

r35. Stone cup with four feet, ornamented on the outside, outer digging Ir.

136. Small white beads, south shaft, citadel.

137. Bronze fragment, south shaft, citadel. June 2, 1904

Upper digging, $20.5 \mathrm{ft}$. to $26 \mathrm{ft}$. deep; outer digging $1,11.5 \mathrm{ft}$. to $14 \mathrm{ft}$. 4 in. deep.

138. Pieces of bronze arrow-point, gallery II, surface débris.

139. Piece of an iron knife, outer digging 1.

140. Piece of an arrow-point like 109.

141. Turquoise bead, upper digging.

142. Piece of a variegated stone plate, upper digging.

143. Turquoise beads (cf. South Kurgan, Anau), upper digging.

144. Green-colored implement, outer digging I.

145. Fragment of a vase of alabaster, outer digging 1 .

146. 6 coral beads, outer digging 1 .

147. Half a glazed bead, outer digging 1 .

148. Copper coin, outer digging 1 .

149-155. Painted and glazed potsherds, outer digging 1.

156. Whorl-like disk (clay), outer digging I.

157. Copper fragment, outer digging $I$.

158. Animal figure of clay, outer digging $r$.

159. Bone pin, outer digging 1 .

160. Piece of bronze pin and rock crystal, gallery $\mathbf{r}$.

161. Clay knob, upper digging.

162. Clay disk, outer digging 1 .

163. Fragment of stone vessel, outer digging $\mathrm{I}$. June 3, 1904.

Upper digging, 26 to $32 \mathrm{ft}$. 7 in. deep; outer digging $1, I_{4} \mathrm{ft} .4$ in. to $17 \mathrm{ft}$. deep.

164. A jug with handle, in pieces, outer digging I.

165. Fragment of bronze ring, upper digging.

166. Turquoise beads, upper digging

167. Copper coin, dump of upper digging.

168. A sieve-like pierced potslierd, upper digging.

169. Turquoise beads, dump of upper digging.

170. Gold ornament, hollow, upper digging, said to be from fresh dump.

17 I. Slingstones of burnt clay, upper digging.

172. 3 copper coins, from the fresh bottom dirt of outer digging $\mathrm{I}$.

173. 6 copper coins, upper digging

174. Stone beads, dump outer digging $I$.

175. Stone beads, dump of upper digging.

176. Small handled jug, outer digging 1 .

177. Little clay horse with remains of a rider, painted, outer digging II.

178. Bronze knob, outer digging II.

$178 a$. Slingstone of clay, upper digging. 
June 4,1904

Upper digging, $32 \mathrm{ft} .7$ in. to $40 \mathrm{ft}$. 4 in. deep; outer digging $x, 17 \mathrm{ft}$. $20 \mathrm{ft}$. 5 in. deep. 179. Slingstone, burnt clay, dump of upper digging. 180. 5 copper coins, outer digging 1 .

181. Animal figure, outer digging 1 .

182. Blue bead (turquoise), upper digging in dump.

183. Slingstone of burnt clay from gallery iv.

184. Light blue bead (faience ?) found near 183

185. 3 copper coins, outer digging 1 , in situ on the bottom.

186. Copper coin, outer digging $I$, in dump.

187-192. Painted and glazed potsherds, outer digging $I$.

193. Glazed potsherds, surface near outer digging $I$.

194. Ball of burnt clay, outer digging $I$.

195. Handle of glass (blue), outer digging r.

195a. Terra-cotta pressed in a mold, outer digging $I$.

June 6, 1904 .

Upper digging, 40 ft. 4 in. deep; outer digging $20 \mathrm{ft} .5$ in. to $23 \mathrm{ft}$. 4 in. deep.

196. Capsule of sheet bronze, gallery. IV.

197. A whorl-shaped object of clay, near gallery II.
June 6, 1904-Continued.

198. 4 copper coins, outer digging $I$, from the lowest layer.

199. Little bronze plates, outer digging 1 .

200. Copper fragment, upper digging, from the well-like depression.

201. Head of a female terra-cotta figure, bottom of outer digging.

202. Fragments of a gilded bead in outer digging $\mathrm{I}$.

June 7,1904 .

Upper digging, $40 \mathrm{ft} .4$ in. deep; outer digging I, $23 \mathrm{ft}$. 4 in. to $27 \mathrm{ft}$. deep.

203. Slingstone of clay, outer digging $\mathrm{I}$.

204. Elongated barrel-shaped agate bead, outer digging $I$ (?).

205. High and deep cup, 2 fragments, outer digging II near the jars.

206. Fragment of a jug with incised wavy-form decoration, outer digging II, near the jars.

207-213. Larger fragments of a handled jug, ornamented in part, found in the shaft I foot deep (the fragments kept separate in a small bag). 
NOTE ON THE OCCURRENCE OF GLAZED WARE AT AFROSIAB, AND OF LARGE JARS AT GHIAUR KALA.

BY HOMER H. KIDDER.

[CHAPTER XI.] 
、

Digitized by GOOgle 


\section{CHAPTER XI. \\ DEPTH OF THE GLAZED WARE IN THE CULTURE OF AFROSIAB, ANCIENT SAMARKAND.}

As I was requested to ascertain the depth of glazed ware in the culture of Afrosiab, the site was examined in July and again in November. In almost all quarters the site is furrowed by steep-sided gullies, many of which cut through the culture into the underlying loess; and though in some of these gullies a certain amount of digging would be necessary to determine accurately the total depth of culture, their sides give ample opportunity to measure the depth of glazed ware.* In the second examination, also, data were obtained in trenches dug in the summer of 1904 by Dr. Barthold.

The surface is so complex and the systems of gullies are so numerous that without the map of Afrosiab it will be impossible to designate here the loci of observations. Therefore, a general statement of findings must do, with a number of illustrative measurements.

In neighboring gullies on the east side of the high middle ground that extends towards the citadel $\dagger$ were noted: ( 1 ) Depth of culture, 15 feet 7 inches; depth of glazed ware, 3 feet. (2) Depth of culture, 9 feet 7 inches; depth of glazed ware, 3 feet 2 inches. (3) Depth of culture, 35 feet + ; depth of glazed ware, 4 feet I I inches.

Near the east wall: Depth of culture, 9 feet + ; depth of glazed ware, 5 feet.

On the west side of the middle ground: (I) Depth of culture, 2I feet; depth of glazed ware, 3.3 feet. (2) Depth of culture, 25.5 feet; depth of glazed ware, 2 feet Io inches. (3) Depth of culture, 13 feet 5 inches; depth of glazed ware, 3.5 fect.

Dr. Barthold's shallow trench at the west of the citadel does not show the bottom of culture. Along its sides the lowest fragments of glazed ware noted were from 2.75 feet to 3.5 feet deep.

The culture, which from the bottom up contains broken unglazed pottery (often in large quantities), shows great variations in depth. Glazed ware, on the other hand, shows but slight variations in its extreme depth at different points. But all fragments found at a depth of more than 3 feet or so were isolated in culture containing many fragments of unglazed ware; and it should be added that, compared with the quantity of unglazed pottery, glazed ware was nowhere found in abundance at much more than a foot below surface. Here, perhaps, is evidence that glazed ware, as we might expect, continued for some time after its introduction to be extremely rare.

* In places, however, care was needed not to mistake for culture a thin coating of mud which, having washed down the side of the gully from the surface, sometimes contains bits of glazed ware at points below the occurrence of such ware in the culture proper. My first note here in July recorded as lying in culture 16.25 feet helow the surface a fragment of glazed ware which I was afterwards convinced must have been embedded in surface-wash.

t On the citadel itself no relevant data can be obtained without digging, and the sane is true of the modern Sart cemetery in the southeast corner along part of the south side, where the condition of the surface ground is very different from that in the anciently abandoned quarters. 
Allowing for denudation, the few feet of culture in which glazed ware appears represents the whole period during which Afrosiab continued to be occupied after the introduction of glazed ware. In other words, after the date at which glazed ware was introduced, Afrosiab continued to be occupied only during a period long enough for the growth of the few feet of culture in which glazed ware occurs; and before that date it had been occupied a sufficient length of time for the accumulation of the total depth of culture minus the number of feet containing glazed ware.

\section{RECORD OF THE EXCAVATION AT OUTER DIGGING II, GHIAUR KALA.}

Dr. Schmidt has asked me to report on the excavation of a group of nine jars found in the central mound of the outer inclosure of Ghiaur Kala.

In beginning a shaft there, May 27, the men came upon the top of a large earthenware jar, 3 inches below the surface, and exposed its side to a depth of 2.5

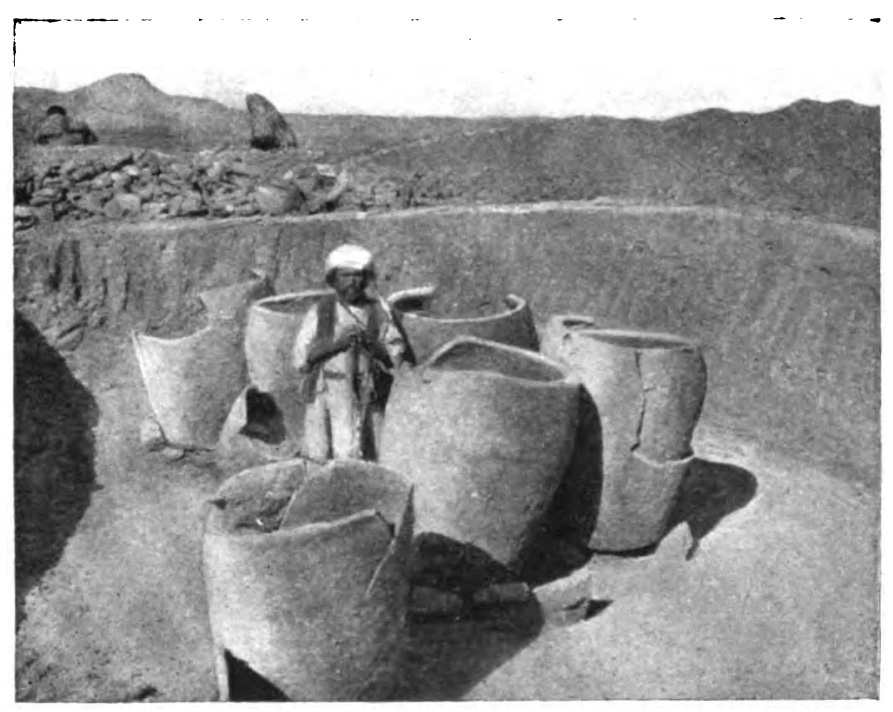

Fig. 428.-Great Jars found in Outer Digging II.

feet. Digging was then stopped, and a new shaft was started, 8 paces northeast. The following night, someone broke open the side of the jar, probably hoping to find treasure, and removed part of its contents of mixed earth and wood-ashes. On May 30 this jar was unearthed. A digging about 7 feet square disclosed the rims of three more jars an inch or two lower, and when the digging was enlarged to 6 by 7 yards, four more jars came to light at 3 to 6 inches below the surface, besides another tipped on its side. The work was continued May $3 \mathrm{I}$ and June I, till all the jars were exposed to the bottom (fig. 428).

Except the one that was tipped on its side the jars stood in two lines, northsouth and east-west, meeting in a corner where two of them had apparently been slightly displaced. The bottom of the jars stood approximately on a level. The surface, however, slopes here from east to west, and while five jars along the east 
or higher side, stood their full height, each having all or part of its rim, three jars towards the west side, where the ground is more than a foot lower, had been exposed above the surface and were found with their tops irregularly broken off. Of the jars on the east side, also, several had lost parts of their rims, and all were badly cracked. To keep them from falling to pieces it was necessary to leave supporting ground, in some cases between the jars, in others against the weakest parts of their exposed sides; and this prevented the taking of full measurements. The measurements taken were:

Jar 1: Height 49 inches; diameter of rim, 32.5 inches (taken from the middle of the rim); thickness of rim, 2.5 inches; thickness of jar, 1.5 inches.

Jar 2: Height, 47.5 inches; diameter of rim, 31.25 inches.

Jar 3: Height 47 inches; diameter of rim, 34 inches; thickness of rim, 3 inches; thickness of jar, 1.5 inches. Jar 4: Height 47.75 inches; diameter of rim, 33 inches; thickness of rim, 2.5 inches; thickness of jar, 1.375 inches; greatest circumference, 121.2 inches.

Jar 5: Height, 48 inches; greatest diameter, 40.25 inches; circumference at base, 94 inches.

Jar 7 : Circumference at base, 96.75 inches.

Jar 8: Circumference at base, 94.5 inches.

Jar 9: Diameter at base, 13.5 inches.

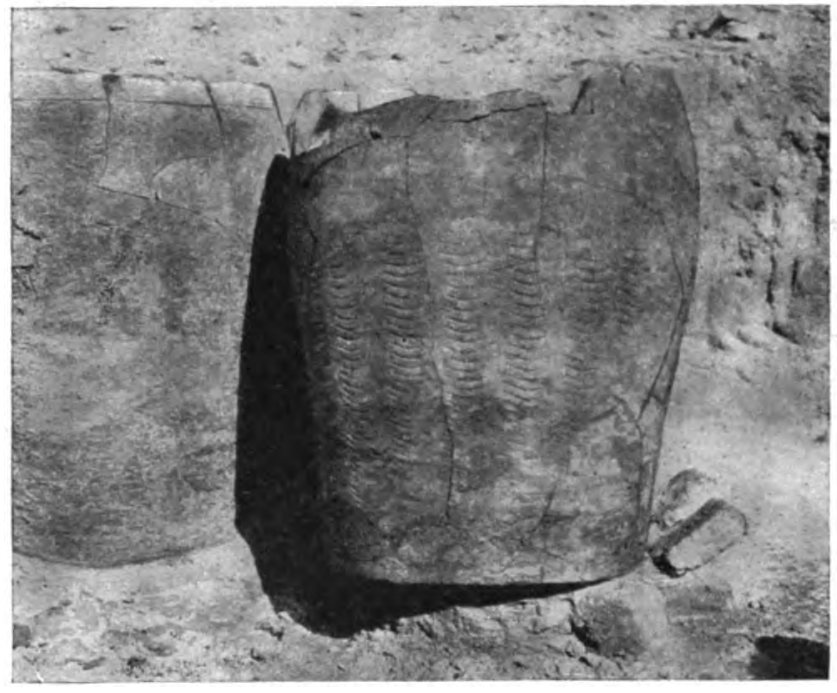

Fig. 429. - Ornamentation of the Great Jars.

All the jars, except the one mentioned as tipped, stood upright or but slightly tilted; their bottoms, being convex, rested each on three wedge-shaped burnt bricks, set in a triangle, some of these slightly displaced; and in several cases the wedge-bricks rested in turn on square burnt bricks. A similar wedge-brick was found on the surface in the citadel.

The exterior surfaces of the jars bore incised designs, consisting of parallel rows of short arcs (scratched on the clay when wet) in two arrangements. In one kind (fig. 429) for 2 inches from the top, the jar is encircled by a band ( 12 to 14 inches broad) of three horizontal rows, from which vertical rows run to the base. The other arrangement is similar except that the lower rows are diagonal. Most 
of these jars have the former arrangement (a), which occurred also on several fragments of similar jars found here. One large fragment of the top of a jar, without horizontal rows, had the diagonal arrangement extending to within an inch or so of the rim. The jar lying half on its side was of a different character. It was flat-bottomed, had no design, and though so badly broken that its height and girth could not be determined, was obviously smaller than the rest.

Among the other objects found in this digging were beads, fragments of colored glass, baked bricks, a large quantity of broken pottery, some of it glazed, one or two pieces of miniature animal sculpture in baked clay, several small earthenware lamps, of which only one was intact, odd bits of copper, and some corroded copper coins whose impressions were wholly effaced. The contents of several of the jars were sifted without finding anything more important than bits of pottery, chicken bones, and wood-ashes.

Six or eight feet from the corner, in the angle formed by the two lines of jars, was found a piece of uneven flooring ( 70 by 42 inches) of square baked bricks ( 6 inches to 1 foot square). It was on a level with the bottoms of the jars; and this fact, taken in connection with their peculiar arrangement, suggested that the jars had stood in the corner of a room, court, or terrace, in which case an interval observed between two of the jars may have given access to a doorway. On June 4 the jars were reburied. The pit measured 6 by 7 yards, 5.5 feet deep on the east side, 3.75 feet on the west.

I may here add a note on the only other large jar that was found this year in Ghiaur Kala. It came to light June 8, in digging along the side of the smaller of Mr. Djukowsky's trenches in the citadel; height, 29 inches; diameter of rim, I6.25 inches. It bore an incised design like that on the fragment mentioned above - parallel rows of short arcs running diagonally from the bottom to within an inch or so of the top. This jar, being intact, was sent to the Askhabad Museum. 
PART III.

DESCRIPTION OF THE KURGANS OF THE MERV OASIS.

By Elisworth Huntington.

[Chapter Xit. Plates 57-60.] 


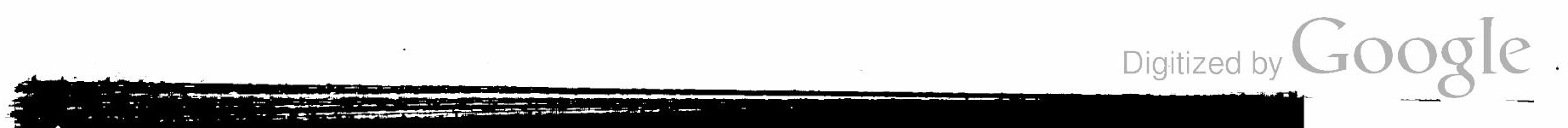




\section{CHAPTER XII.-A RECONNAISSANCE OF THE KURGANS OF THE MERV OASIS.}

As one looks northward from the great citadel of Ghiaur Kala in the center of the ruins of ancient Merv, the monotonous expanse of the flat sunny plain is broken here and there in the shimmering distance by pale gray mounds, or kurgans, of large dimensions. For a space of fifty miles from north to south and of forty from east to west they form one of the most marked features of the otherwise level landscape. A brief reconnaissance among them indicates that the old cities of Merv were surrounded by a dense suburban and presumably agricultural population which clustered around the kurgans. Fruitful fields and teeming villages appear to have been supported by the Murg-ab river, not only in the districts now under cultivation, but also in regions at present waterless. The distribution of the kurgans suggests that their future study will not only throw much light upon the civilization of the ancient people of Transcaspia, but will be of especial service in elucidating the physical changes, climatic or otherwise, which are sometimes thought to have been the cause of the decay of the ancient empires of the arid regions of Asia.

Outside the cities of the ancient Merv Oasis the relics of the former inhabitants are of two distinct types, characteristic of two quite different periods. The more recent ruins, which are fairly well preserved, are built almost entirely of sun-dried mud bricks, and consist of old houses and castles, rectangular forts with very thick walls, round towers to protect the fields and villages, and old canals guarded by mile after mile of walls flanked with square towers. The date at which they were built is in many cases historically known, and there is good reason for believing that they all belong to the latter half of the Mohammedan era. With these more recent ruins we are not now concerned, although a study of their extent and distribution would probably lead to significant results as to the water-supply of the Middle Ages.

The older ruins are of a distinctly different type. Chief among them are numerous flat-topped kurgans, or tepes* as the Turkomans call them, which are so abundant that in eight days the writer was able to visit and examine 28 , and might have made the number larger if it had not seemed advisable to visit those lying on the extreme outskirts of the oasis. The distribution of most of those investigated and of a few others is shown on the accompanying revised copy of the Russian 5-verst map (fig. 430), where it will be seen that they are most abundant in the region directly north of Bairam Ali and the various ruined cities of ancient Merv. In addition to the kurgans, there are a number of large rectangular forts, the thick and lofty mud walls of which have been reduced either to mere rows of hillocks, as at Kirk Tepe, or to rounded ridges, as at Yasi Tepe. Houses of the

*Tepe (pronounced tě'pā) means an isolated hill. 
ordinary sort must have existed, but they have utterly disappeared, and their sites are marked only by low mounds, or by an accumulation of pottery strewing the surface of the ground. Canals, too, must have abounded, but their traces are rare and hard to follow, and it is exceedingly difficult to determine their age.

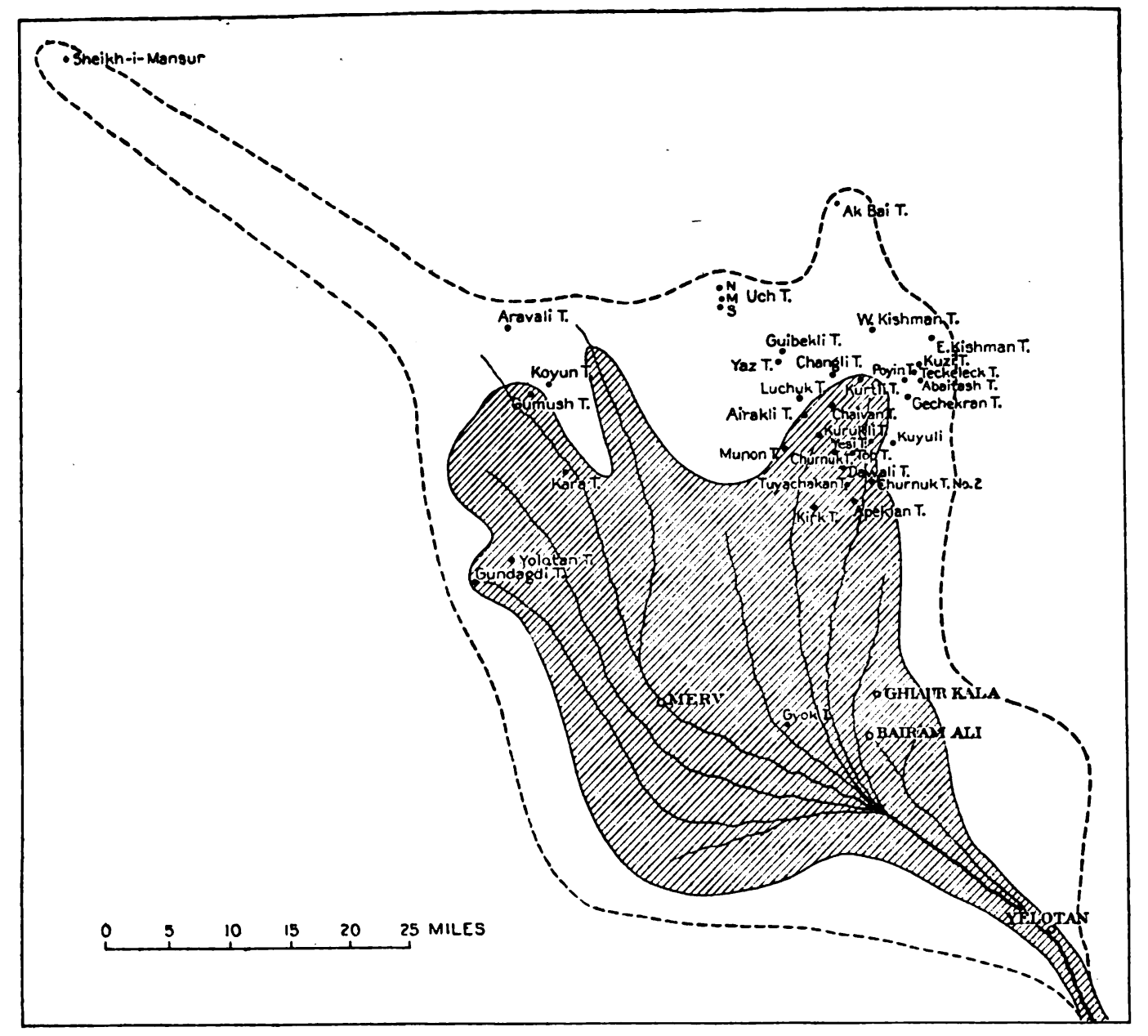

Fig. 430.-Sketch Map of the Merv Oasis. $\mathrm{T}=$ Tepe $=$ Kurgan.

THE KURGANS.

In spite of great diversity the kurgans as a whole are modeled upon a single plan. All have flat tops, all are symmetrical in vertical section, and most are rectangular in plan. They vary greatly in size, however, the heights ranging from 15 to 80 feet, and the diameter from 65 to 480 feet. In age, too, and in the amount of weathering to which they have been subjected, there are equally important differences. The older kurgans, which generally are also the smaller, are so far reduced in size and height that their sides have a slope of only $15^{\circ}$ or $20^{\circ}$, and can be climbed on horseback almost anywhere. The newer ones, on the other 
PLATE 57

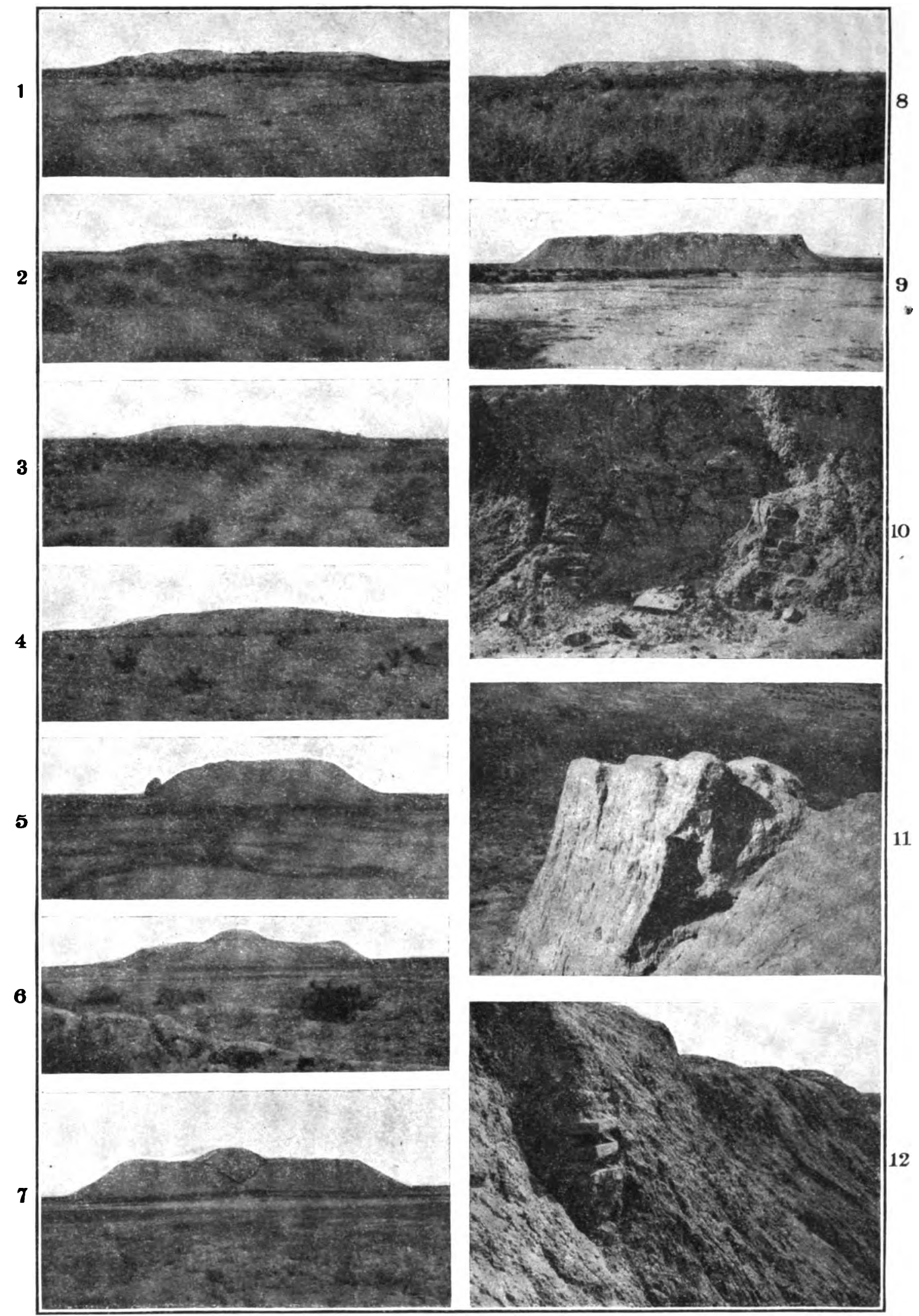

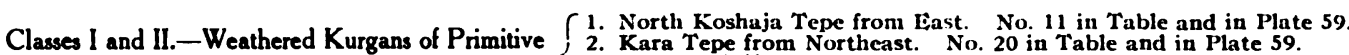
and Transition Types.

Class II.-Kurgans of Transition Type. 3. North Uch Tepe from Southwest. 20 in Table and in Plate 39. 4. Yaz Tepe from South No 6 in Table and in Plate 59 .

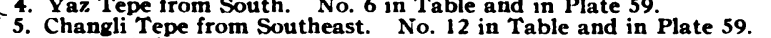
5. Changli Tepe from Southeast. No. 12 in Table and in Plate 59.

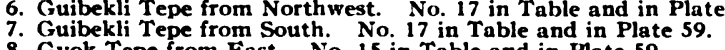

8. Gyok Tepe from East. No. 15 in Table and in Plate 59.

9. Kuyuli Tepe from North. No. 25 in Table and in Plate 60

Class III.-Kurgans of Highly Developed Type.

10. Brick Wall at Kuyuli Tepe.

11. Tower at Southeast Corner of Kuyuli Tepe slowing Sun-dried Bricks.
12. Southwest Wall of Kuyuli Tepe showing Burnt Brick. 
Digitized by GoOgle 
PLATE 58.

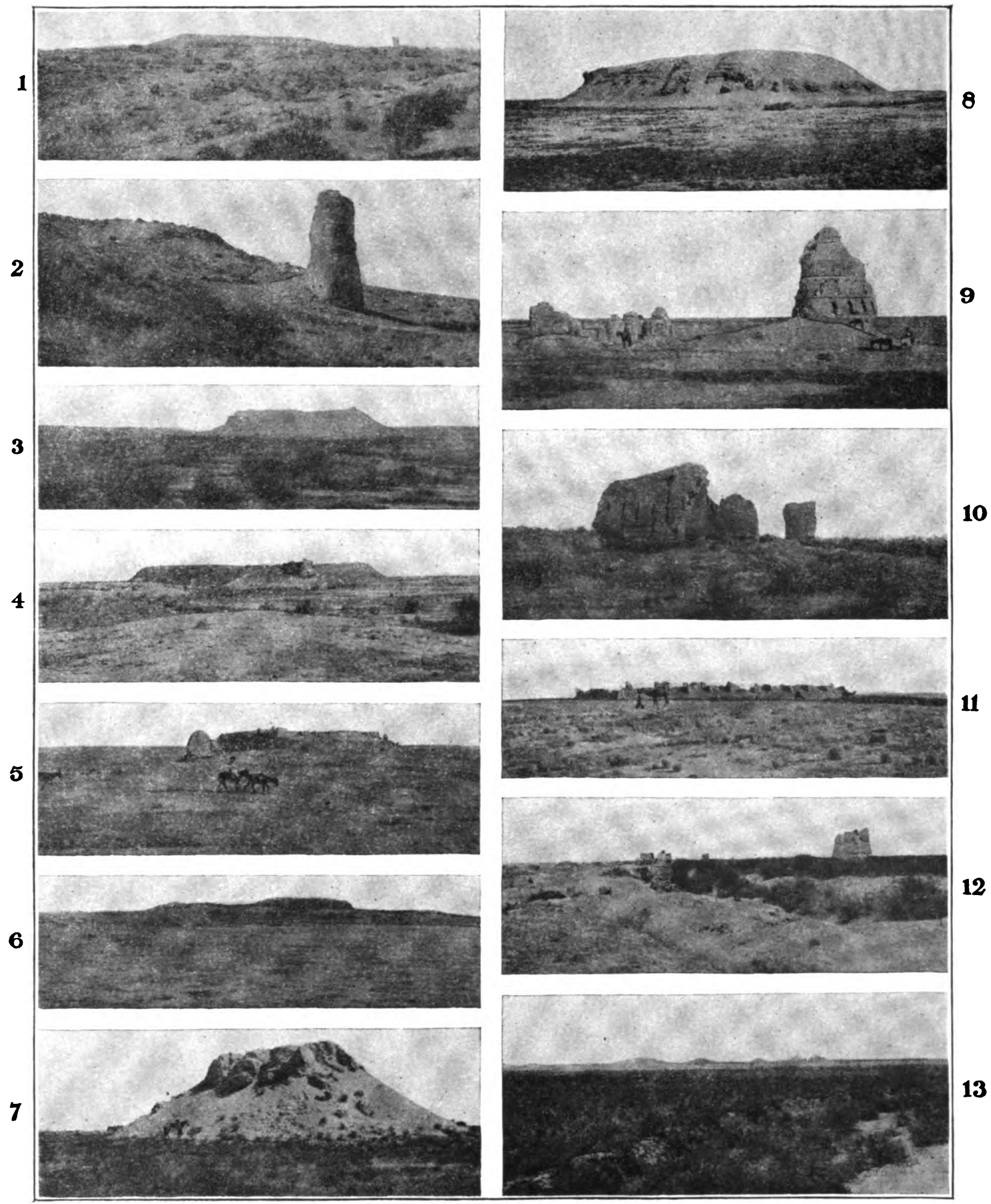

\footnotetext{
1 and 2. Two views of East Kishman Tepe and a Tower of Bricks,

3. West Kishman Tepe from East. No. 24 in Table and in Plate 60 .

4. Gechekran Tepe from South, showing Southern Tower, and smaller

5. Kurtli Teap of ruins in foreground. No. 26 in Table and in Plate 60 .

6. Kurukli Tepe from Northwest. No. 22 in Table and in Plate 60.

7. Churnuk Tepe from South. No. 28 in Table and in Plate 60.

8. Top Tepe from South. No. 21 in Table and in Plate 60.

10. Old Mosoue (?) at East Kishman Tepe.

11. Chilburg Kala a Ruined Fort near Kirt Tepe.

12. Ruins of Towers and Walls along Old Main Canal of Bairnm Ali, South

13. Kirk Tepe, looking from Southeastern Wall toward Citadel. See Plate 60.
} 
Digitized by GOOgle 
hand, have sides that rarely slope less than $30^{\circ}$, and sometimes, where bits of old wall still remain, are almost perpendicular. On horseback they can be ascended only at the places where the ancient gateways appear to have been located, one gate in each mound. Most of the mounds do not seem to be old village sites, like those of Anau, built up aimlessly and slowly, through many centuries by the accumulations of generation after generation. On the contrary, many appear to have been constructed in exactly the opposite manner, by the rapid building of thick adobe walls of sun-dried bricks. The space within the walls was filled with mud and refuse until a broad elevated platform was produced. On this the builders dwelt; and there we find to-day bits of the pottery, bricks, glazed ware, glass, and stone, which formed the necessities or the luxuries of their daily life.

\section{CLASSIFICATION OF THE KURGANS.}

Throughout the kurgans there is such a degree of unity of form and structure that it seems legitimate to assume that all are the work of one people, or, at least, of people of one stock. There are, however, such marked differences, and such clear evidences of development, that it seems advisable to divide them, tentatively at least, into three groups. The basis of classification is, first and most roughly, outward appearance and amount of weathering and erosion; second, ground plan and orientation; and third, and far the most important, contents, such as pottery, bricks, glass, glazed ware, and stone. The first two criteria are, it is true, very untrustworthy, but they become of importance when it is found that they agree with one another and with the third criterion.

A classification based merely on a hasty reconnaissance of the surface of the kurgans is, of necessity, highly tentative, but the principle of division is a true one. Even if many mounds should later be transferred from one class to another, or if the classes themselves should be modified, the present tentative grouping will at least be an aid to description, and will give some suggestion of the very interesting development that appears to have taken place during the centuries which must have intervened between the building of the first kurgan and the last.

The accompanying table contains a classified list of 28 kurgans, with the most essential data as to their size, contents, and other peculiarities. The appearance of some of the kurgans and other ruins is shown in the series of photographs reproduced on plates 57 and 58 . The two following plates, 59 and 60 , show roughly the plan and cross-section of each kurgan. The plans show the size and shape at the top of the kurgans, not at the base. The sections are drawn to scale and are oriented with north at the top of the page. An examination of the plates brings out many salient features, far better than can be done by verbal description. 
Kurgans of the Merv Oasis (see plates 57-60).

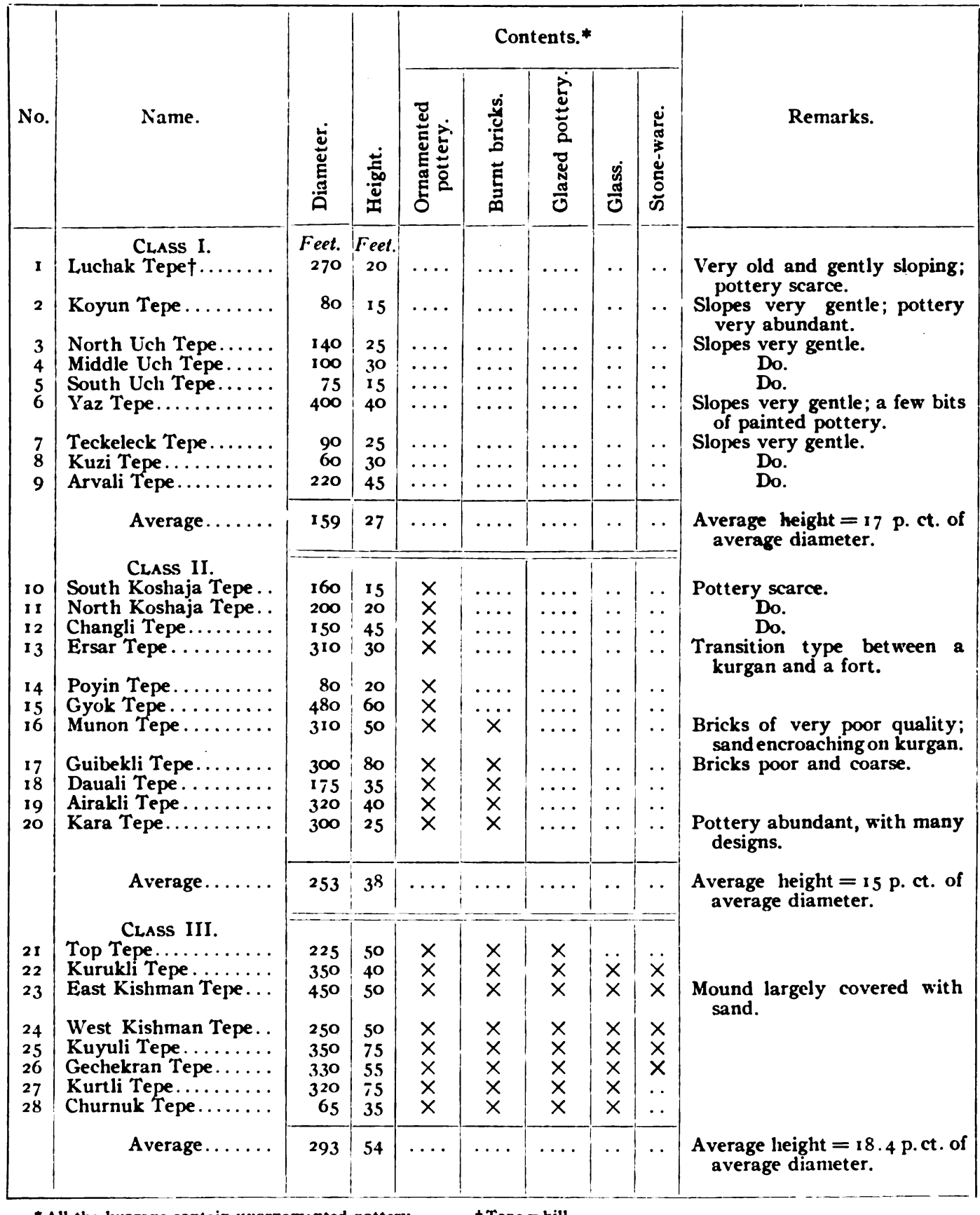

* All the kurgans contain unornamented pottery.

† Tepe $=$ hill.

CLASS I. KURGANS OF THE PRIMITIVE TYPE.

The oldest kurgans, those of the primitive type, are usually rather small and low, with rounded outlines and with gently sloping sides. They have a distinctly old appearance, although this statement must be qualified by saying 
that in spite of considerable erosion they have not lost the outlines of their original form, nor have they acquired so old an appearance as the kurgans at Anau, near Askhabàd, for instance. The Merv kurgans vary in shape from heptagonal in the case of Munon Tepe, to square, although the latter is the prevailing shape, and the variation may be due to erosion. Those of the primitive type seem to have been built without special reference to the points of the compass. The only work of human hands that is found on the surface is pottery, the commonest red and green wheel-made varieties for the most part, without a trace of ornament. Occasionally a finer gray variety, also unornamented, is found; and at one place, Yaz Tepe (No. 6 in the table and No. 4 on plate 57), three pieces of painted pottery were secured. These latter may be of significance as aids in the dating of the kurgans, and will be referred to again. Each kurgan appears to have been originally surrounded by a moat, but in most cases this is largely filled up.

CLASS II. KURGANS OF THE TRANSITION TYPE.

The kurgans of the transition type are often indistinguishable in outward form from their primitive prototypes, yet on the whole they are larger and more steep-sided. Most of them were originally rectangular, and several have their sides or axes oriented north and south. More generally than in Class I the remains of moats surround the eminences. Outer walls, too, are an occasional feature, either hemming in the whole of the summit of the hill, as at Ersar Tepe (No. 13), or surrounding an inclosure in the center of which rises a higher square, as at Guibekli Tepe (Navel Hill, No. 77 in the table and Nos. 6 and 7 on plate 57), and at Kuzi Tepe (No. 8), a kurgan of the primitive class. The pottery is of the same common sorts as in the preceding type, but in the gray variety there is less of the fine-grained type and more that is coarse and common. One great difference distinguishes the transition pottery from its predecessor. The older sort is without incised ornament; its successor of the transition type is characterized by it. In the oldest mounds of the second class incised ornamentation is rare and consists chiefly of vertical lines, either parallel on the sides of a jar, or radiating out and down from the base of the neck. In the more highly developed mounds ornamented pottery is exceedingly abundant. In addition to the simple designs just mentioned there are various others, such as parallel horizontal lines, oblique lines or scallops around the neck, the wave ornament in various designs made with implements of from five to ten teeth, and lastly the criss-cross pattern. In some places the ground is almost covered with pottery bearing this last design, and invariably the pieces are fragments of large, thick jars like those that bear the same ornament in the old city of Ghiaur Kala. In this connection it is interesting to note that among the modern Turkomans of the Merv Oasis the most common form of large jar bears an incised ornament of the same character. The modern jars are covered with a crude green glaze and the design is smaller and closer in pattern, more generally vertical, and far less ornamental and less carefully made than in former times, but nevertheless it may be a degenerate descendant.

In addition to the art of ornamenting pottery the people of the transition period had learned another, that of burning bricks with straw. At first the bricks 
were very coarse and rough, and were usually 3 inches thick, although a few were thinner. Later the brick-makers appear to have settled upon a standard size2.5 inches thick by about $\mathrm{I}$ inches square.

CLASS III. KURGANS OF THE HIGHLY DEVELOPED TYPE.

The structure, contents, shape, and size of the kurgans of the third class indicate that as time went on old arts were improved and new ones were developed. The people learned to make their hills higher and larger, and began to orient them with care. Some built kurgans with the sides running directly north and south, while others, carrying the idea of orientation farther, put the axes north and south, and even went so far as to make diamond-shaped parallelograms instead of squares. It was apparently no accident, this gradual turning of the mounds more and more to the north and south, for of the nine kurgans of the third class at least four have projecting towers at the most southern point, as appears in the diagrams of plate 60 . Possibly these have a religious significance, but of this we have no proof. Not only did the outer form of the kurgans become more highly developed, but the manner of building the interior advanced equally. Baked bricks were used in addition to sun-dried bricks, and in one case, Kuyuli Tepe, i. e., the Well Hill (plate 57, Nos. 9 to 12 ), a round well of baked brick is built into the wall of the mound. In other lines, also, there was progress. Pottery was decorated with incised designs more frequently than ever; a new method of ornamentation was developed; and glazed ware was introduced. The glazing, very simple at first, became so far developed that six or eight colors were employed and elaborate designs were produced.

Hand in hand with the art of glazing, or at least not far behind it, came the sister art of glass-making, so that now the people had at their disposal many methods of manufacturing ornamental utensils. Still another followed when the craftsmen learned to put stone upon the turning lathe and produce vessels like those still in use in Persia. Among other things lamps were made of stone. One such was found at East Kishman Tepe, while in other places fragments of brown, slightly glazed pottery lamps were found, like those at Ghiaur Kala, the capital of the oasis. On the whole, the state of culture evidenced by the kurgans of the highly developed class must have been very much higher than that which prevailed when the primitive kurgans were constructed. Yet the transition from the earlier to the later stages is so gradual and so completely exemplified, step by step, that it seems highly probable that the whole series is the work of one people.

\section{STRUCTURE OF THE KURGANS.}

In all the kurgans of the primitive type and in most of those of the transition type, the slopes are so gentle and the gullies have been so far widened and graded that the inner structure is not disclosed. In a few of the transition kurgans, and in most of those of the still later type, the steepness of the sides has caused the cutting of sharp gullies that disclose the internal composition. Nowhere does one discover any layers of ashes or of burnt earth, or any bones and charcoal, 


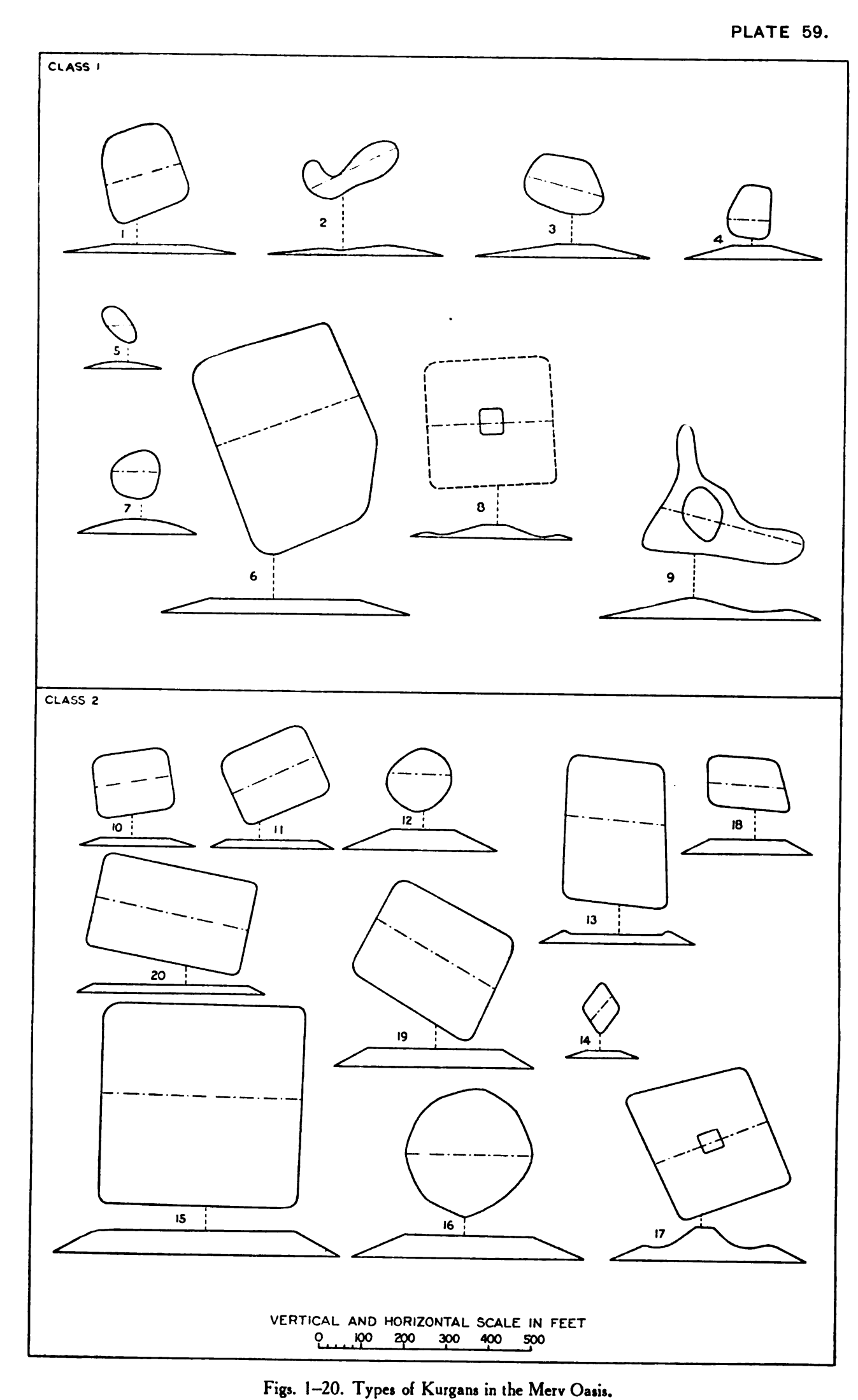


Digitized by GoOgle 
PLATE 60.

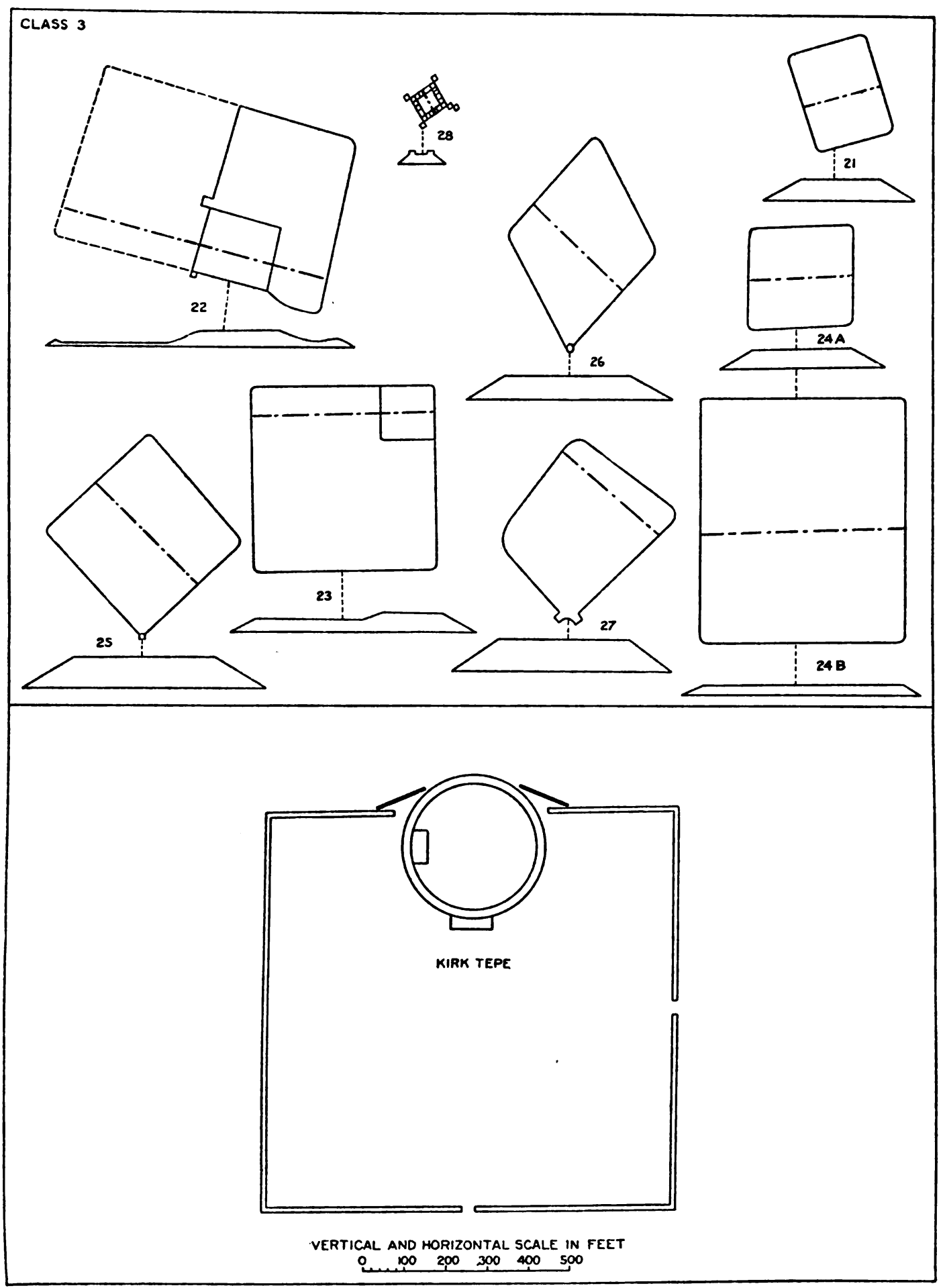

Figs. 21-23. Types of Kurgans in the Merv Oasis. 

or other evidences that the mounds were built up gradually by people who lived upon them year after year and century after century. The main mass of the mounds consists of mud, which, toward the edges, seems always to have been made into sun-dried bricks which were laid in courses. Here and there these somewhat unstable bricks are strengthened by a layer, or a little group, of burnt bricks, or even by a few large pieces of heavy red pottery. Toward the center of the mounds, and to a less extent in other places, the regularly laid bricks give place to more carelessly laid crude clay, mixed more or less with smaller potsherds. Apparently the idea was that the outer walls and any other portions that required extra strength should be built of sun-dried bricks, strengthened with burnt bricks and large potsherds, while the interior, wherever strength was not required, was filled with looser mud until a smooth-topped platform was obtained. Possibly the mounds were built partially and then inhabited for a time before they were built to their full height. No single mound has been so completely examined that we can say with certainty just how it was built, but the piecing together of the fragmentary evidence from many mounds makes it probable that the above conclusion is correct. Moreover, this seems to be the way in which the mounds and platforms of the citadel at Ghiaur Kala were constructed, and there is good reason for thinking that the builders of that city were the same people as the builders of the kurgans. Whether this style of architecture was indigenous we do not yet know. It is closely similar to that of many of the ancient mounds of Babylonia on the one hand, and to that of the old Buddhist "stupas" and lamaseries of Chinese Turkestan, on the other.

\section{PURPOSES OF THE KURGANS.}

At first sight the thought presents itself that these platforms were erected for purposes of defense, and probably such was in part the case. The strong outer walls surrounding Guibekli, Ersar, and Kuzi Tepe could hardly be for any other purpose. The absence of massive walls in the majority of cases, however, makes it probable that defense can not have been the chief or only purpose. Gechekran Tepe, better than any other, shows the normal condition of one of the recent kurgans. Although erosion has not yet proceeded far, all trace of houses has been removed. The surface of the top is almost smooth, except that from every side there is a gentle slope inward to a slight depression, where water stands during rain. If a flat-topped kurgan were capped with ordinary mudwalled houses, standing around the edges of the top and facing toward an inner inclosed courtyard, the weathering action of rain and wind would, in course of time, wear away the walls and partly fill the courtyard, producing a surface like that of Gechekran Tepe.

It seems probable that the kurgans were, in the main, erected as sites for the dwellings of princes and their retinues. Such a course would have eminent advantages; it would render the occupants relatively free from hostile attack, and would isolate them from the common crowd of laboring humanity; and it would provide the coolest possible summer dwelling-place. During the rainless period 
from the first of June to the end of September, Merv suffers under almost tropical heat, the thermometer day after day rising to $100^{\circ} \mathrm{F}$. or more in the shade. The ground becomes so hot that one can scarcely touch it, and to lie upon it is torture. At even a slight elevation, however, the radiation from the ground is robbed of its effect, and the wind, whose evaporating power brings coolness and comfort so quickly in this dry atmosphere, has opportunity to play. An elevation of only Io feet makes a great difference, and at a height of from 30 to 60 feet the heat is quite bearable. The rulers, it would seem, lived in comfort on the tops of their hills, while down below in the heat and dust labored the common people, the ruins of whose small dwellings can be seen as little heaps clustering at the foot of the great kurgans, or stretched in lines along the courses of the canals.

One kurgan, more than any other, lends credence to the theory that has just been suggested. Churnuk Tepe (No. 28 in the table), one of the several that go by that name, is the smallest, the youngest, and the best preserved of all the kurgans of the last period. It alone shows abundant ruins of a superstructure, a thick-walled mud house surrounding a small courtyard. With the extreme elaboration that so often marks the last days of any line of development, the architect not only adopted the square form with the axis almost north and south, and the square tower projecting toward the south, but added to his design the touch that made the house almost bizarre, the square rooms projecting at the ends of the diagonals, one each to the north, south, and west, and two to the east. The main body of the structure consisted of a courtyard, on either side of which were ranged from four to six rooms. Beneath the rooms ran broad, arched passages, which may have been divided into apartments for storerooms or for the use of servants.

\section{AGE OF THE KURGANS.}

The dating of ruins is at best a difficult matter, and in the case of a reconnaissance like the present it is well-nigh impossible. One thing, however, can be stated, tentatively at least. The kurgans of the highly developed type appear to belong to the same era as Ghiaur Kala. The basis for this statement has already been mentioned. The pottery, with its characteristic designs, the glazed ware, the glass, and the stone-ware are of identically the same sort in the old city and in the mounds. At Gechekran Tepe a portion of a brown glazed lamp was found, identical in material and apparently in form with those found so abundantly in what seems to have been an old shop at Ghiaur Kala. Then, again, the peculiar method of construction with sun-dried bricks is identical in both cases, and is so unusual as to be significant. The beginnings of Ghiaur Kala may date back to the time of some of the earlier kurgans, but its final greatness appears to have been coincident with the construction of the kurgans of the highly developed type.

In this connection the old ruin of Kirk Tepe is of interest. Here, 15 miles north-northwest of Ghiaur Kala, we have what seems like a small imitation of that ancient capital. Kirk Tepe is a square inclosure, $I, 000$ feet on a side, with thick mud walls which in their present ruined state are 20 or more feet high. In the course of centuries they have been worn down into the form of rounded and semi- 
isolated hillocks; hence the name "Kirk Tepe," or the "Forty Hills." The inclosure inside the walls is practically level and contains but a small amount of pottery. What few potsherds there are consist partly of glazed ware. The resemblance to Ghiaur Kala lies in the fact that here, as in the great city, the northwestern wall is interrupted by an inner circular inclosure with higher walls-an inclosure which appears to have been built before the main walls were erected, as may be seen from the way in which the line of the large square is interrupted in the lower figure of plate 60 . Adjoining the walls of this acropolis are two small platforms, the sites, perhaps, of houses or palaces. In every respect Kirk Tepe seems to be a small and ephemeral imitation of Ghiaur Kala.

The dating of the primitive mounds is even more doubtful than that of the highly developed type. The great change and development that took place from the time of the earliest kurgans, with their unadorned pottery, to the time of the latest, with their glass and glaze, must indicate a considerable lapse of time, measured by many centuries. The most feasible means of dating the earlier ruins seems to lie in connecting them with the remains of other civilizations. At Yaz Tepe, the largest kurgan of the primitive type, three bits of pottery were found bearing a painted design, a sort of highly developed tent pattern, done in brown. The style of pottery and the style of ornament are both quite different from anything else found in the kurgans or in Ghiaur Kala, and the fragments seem like remnants preserved from an earlier time, or else stray bits imported from a distance. To an eye unskilled in ceramics, they appear to belong to the same type as the pottery of the oldest culture-stratum of the older village kurgan at Anau.

This raises the question of the relation between the people who quickly built the kurgans of sun-dried brick at Merv and elsewhere, and those who in neighboring regions slowly built the larger kurgans of ashes, bones, walls of houses, and other remnants of human occupation. At Merv both sorts of mounds have not been discovered. In the vicinity of Lutfabad and Kaaka, however, between Merv and Askhabad the writer noted that along the base of Kopet Dagh in the "atok" or "skirt" of the mountains of northern Persia, two sorts of kurgans exist side by side. The older and larger have very gentle slopes and rounded tops, and show no evidence of any special plan in their construction. They seem to be like those of Anau. The others are, on the whole, smaller, and, by their steeper sides, show that they are younger. Their flat tops and apparently square form show a distinct plan in their erection, and the hasty views obtained from passing railroad trains suggest that they belong to the same class as those at Merv.

Near Askhabad kurgans of the two types exist more clearly side by side. At Anau, it is needless to say, are the two large mounds of the old village type. Half a mile to the southeast of the center of Askhabad stands another smaller kurgan, flat-topped and rather steep-sided, while a mile or more to the east is a second of the same sort that appears flat-topped from below, but is really surmounted by a wall like Ersar Tepe (No. 13) at Merv. These last two kurgans are square in plan and seem very much like the smaller kurgans at Merv. The exact relation of the various types of mounds can not be determined without extensive excavation. 


\section{THE DISTRIBUTION OF THE ANCIENT POPULATION OF THE MERV OASIS.}

In examining the ruins of the Merv Oasis one of the most striking features is the apparent density and wide distribution of the population in the past as compared with the present. Wherever villages exist to-day there are traces of ancient occupation; but, more than this, there are also large areas which must once have been densely peopled, although now they are deserted. From Gechekran and Kurtli Tepes, out northward past the two Kishmans to Ak Bai and Takir Bai in the midst of the sand, or westward beyond Luchuk Tepe, and northwestward past Yaz and Guibekli Tepes to Uch Tepe with its three mounds in the sand, and thence westward to Arvali Tepe, there is to-day no sign of habitation. Yet this whole region must for the most part have been thickly populated at one time, as is evident rot only from the mounds, but also from the great amount of pottery that covers the ground. For instance, among the low sand-dunes between the two Kishmans, or between Uch and Guibekli Tepes and on over the deserted clay plains to Airakli and Munon Tepes lie great tracts where the ground is covered with potsherds far more thickly than in any of the modern villages. Such, too, is the case west of Uch Tepe for 2 or 3 miles, till the sand-dunes begin, and east of Kara Tepe, where the main distributary of the Murg-ab flows out to lose itself in the desert. North of Yelotan, according to the Russian superintendent of the dam at that place, ruins are abundant for a distance of 15 or 20 miles, while west of the Murg-ab they extend nearly half as far.

In all these places and many others sand is encroaching steadily over what were once cultivated fields. Nowhere, so far as has been noticed, is land being recovered from the sand, although the opposite process is taking place rapidly. Year by year the outposts of humanity are being drawn inward toward the centers of Merv and Bairam Ali, and the Turkomans who formerly watared their flocks and cultivated a few fields at the extremities of the distributaries of the Murg-ab are obliged either to betake themselves to wells and become wholly pastoral, or else to move inward and become agricultural. Thirty years ago the water of the main distributary is said to have reached Sheik-i-Mansur, although now Top Taranchi, 40 miles upstream near Gumush Tepe, is the limit. Another branch reached Kara Burun at every flood-time ro years ago, but now it flows only to Aravali, 45 miles farther upstream, and even at that point the people are obliged to depend on wells for their main water-supply. In the same way it is only seven years since the canal that now ends at Kurtli Tepe flowed 4 miles farther to West Kishman.

These facts do not necessarily mean that the total amount of water has decreased during the last quarter of a century. They show nothing as to that question, either one way or the other. What they indicate is a change on the part of the people from a state of semi-nomadic pastoralism to one of sedentary agriculture by reason of the changes that have followed the Russian occupation of $\mathrm{r} 884$. In the old days the nomads allowed the water to flow nearly at will in almost the natural channels, and the villages and fields were located along the 
extended watercourses, while strips of desert lay between. In the case of a sedentary agricultural population like that which is now coming to occupy the oasis on the other hand, especially where, as at Merv, the water-supply is strictly limited and all parts of the level plain are equally fertile, the invariable tendency is to utilize the land lying close below the center where the distribution of the water begins to take place. From there outward the land will be used in a nearly continuous body, although, of course, along the main canals detached tongues will stretch out into the untilled wastes beyond.

This is what is taking place at Merv-the people are moving into the upper portion of the delta of the Murg-ab, and the Imperial Estate at Bairam Ali, with its new dams and reservoirs, is hastening the process and at the same time making it possible for a greater number of people to be supported by the same amount of water. In the course of another generation it is probable that the change from semi-nomadism to agriculture will have been completed, a larger population will be supported by the oasis, and a larger number of acres of land will be under cultivation, but the outposts of civilization will have been drawn inward, and the size of the cultivated delta, as measured by a mere inspection of the map, will have decreased. It is conditions such as these, rather than those of the immediate transition period of to-day, which should be looked at in comparing the distribution and magnitude of the ancient population with that of the present; for the ancient times were days of intensive agriculture, when, as the ruins show, the people lived close together, and most of the land between the villages must have been cultivated.

Any attempt to compare the area of the land under cultivation at the time of the kurgans with that under cultivation to-day is liable to error because of the limited study that has been given to the question. The best that can be done is to indicate the general direction in which the truth seems to lie. For the sake of conservatism we will disregard the important differences between the transition state of to-day with its large remnants of semi-nomadism and the state of intensive agriculture of the past, and will compare the limits of irrigation in 1904 with those at the time of the kurgans. Such a comparison indicates that the amount of irrigated land has decidedly decreased since the kurgans were abandoned. This is roughly shown on the accompanying sketch-map, where the limit of the present irrigated area is drawn through the ends of the canals without regard to the very extensive unoccupied lacunæ that lie between. The lacunæ are so large that much of the region presents the aspect of a desert in which there are mere patches of cultivation. The limits of the formerly irrigated areas are drawn just beyond the outmost ruins, but it is hardly probable that the ancient inhabitants built large and important villages at the extreme limit of cultivation. Outside of these places there must have been a strip of cultivated land where the villages were so small that they have left no noticeable traces.

In view of all the facts we should probably be justified in diminishing the area represented as now under irrigation, and, perhaps, in extending that represented as under irrigation during the earlier period. Yet even as the map stands, it is 
evident that at the time of the kurgans, say 1,000 or 2,000 years ago, the Merv Oasis was more extensive than it is to-day. That this decrease is due to changes in the methods of irrigation is hardly possible. The earlier times, as we have seen, were characterized by a highly developed system of intensive irrigation, under which the distributaries were short, but highly branched, while the present is characterized by a poor system, now in process of rectification, under which the distributaries are long and but slightly branched.

In other words, the change in the system of irrigation has been one which, other conditions remaining unchanged, would have caused an apparent increase in the size of the delta. Yet exactly the opposite result has taken place. The limits of the main canals have been drawn inward in spite of the fact that the number of side canals has decreased. Above Yelotan, so far as we know, the country along the upper Murg-ab is no more densely populated now than formerly. Therefore, the diminution in the cultivated area can not be due to the lessening of the water-supply of the Merv Oasis by the diversion of water farther upstream. Neither such diversion nor a change in the irrigation system can account for the lessening of the area capable of cultivation. The only other competent cause for such a diminution would seem to be a change in the amount of water furnished by the Murg-ab. Such a change would seem to require a corresponding variation in the climate of the mountains of northern Afghanistan, where the Murg-ab takes its rise. A change in the climate of northern Afghanistan would probably involve a similar change at Merv and elsewhere. Accordingly the ruins of Merv seem to be explicable only on the theory that in ancient times the climate of the country as a whole was more humid than it is to-day.

If we approach the subject from another point of view, we arrive at the same result. The present population of the oasis of Merv below Yelotan comprises about 65,000 Turkomans, mostly cultivators of the soil who have recently given up nomadism, and a considerable number of townspeople of other nationalities, so that, at a liberal estimate, the total reaches 100,000 . In ancient times the oasis is said to have contained a million people, and the size of Ghiaur Kala and of the other old cities, the number and character of the outlying and apparently contemporaneous ruins, and the degree to which the traces of thickly populated villages extend into the desert, make this seem highly probable. Assuming, however, that the true figures are but half a million, could the oasis to-day support so large a number of people?

At Bairam Ali on the Imperial Domain, under the direction, formerly of Mr. Dubosof, and now of Mr. Yeremief and Mr. Von Brandt, there is a portion of the oasis where the most modern and economical system of irrigation prevails, and where a given amount of water supports the maximum population. The water for the Domain is diverted from the Murg-ab by means of the Hindu-Kush dam, just south of Yelotan, which was completed in 1894. According to Mr. Nikrashevich, the superintendent of the dam, the minimum flow of the river at this point, before any of the canals of the oasis are taken off, amounts to 1,500 cubic feet per second, and of this the Imperial Domain has the right to divert ro per cent. 
In times of flood, however, when the flow per second has been known to rise to 17,000 cubic feet, the Domain is allowed to divert as much of the surplus as it can use or store, provided always that 90 per cent of the minimum amount remains in the main stream. Accordingly the Domain receives more than ro per cent of the total flow-from 20 per cent to 25 per cent according to Mr. Nikrashevich. For the sake of being on the safe side, let us call it 15 per cent of the total. This amount of water supports to-day an agricultural population numbering 15,000 souls and a further body of workmen, artisans, and tradespeople, numbering with their families not over ro,ooo.

In 1904 there was danger that the available water-supply would prove somewhat scanty for the thorough irrigation of the crops of even this number of people. In other words 15 per cent of the water under the most favorable conditions of irrigation can not support over 25,000 people; and all the water can not support over 166,000 , or in round numbers 200,000 people, twice the present population. But even this liberal estimate leaves us with a deficit of 300,000 souls, when compared with the 500,000 whom we have taken as the population of the oasis in antiquity. Whatever the exact figures may be, it seems highly probable that the present water of the Murg-ab can not possibly support so large a population as that which actually peopled the oasis in antiquity. There appears to be no way of explaining this discrepancy except by supposing that in earlier times the flow of the Murg-ab was larger because of greater rainfall, or because of less rapid evaporation due to lower temperature.

Note to Chapter XII.-This chapter was written in September, 1904, and is here printed in its original form, the only changes being a recasting of the first paragraph, and a few verbal alterations. During the three years and a half which have intervened between the writing of the chapter and the time of going to press, March, I908, the writer has had the opportunity to make a somewhat extensive study of the climatic problems here touched upon. The results of the later studies are set forth in a volume entitled "The Pulse of Asia" (Houghton, Mifflin, and Company, 1907). Evidence gathered from the ruins of Chinese Turkestan and from the fluctuations of the Caspian Sea, as well as from other sources, indicates that in the regions from the Caspian on the west to China Proper on the east all Central Asia has undergone a series of climatic pulsations during historic times. There seems to be strong evidence that at the time of Christ or earlier the climate was much moister and more propitious than it now is. Then during the first few centuries of the Christian era there appears to have been an epoch of increasing aridity. It culminated about 500 A. D., at which time the climate appears to have been drier than at present. Next came an epoch of more propitious climate which reached its acme about $900 \mathrm{~A}$. D. There is a little evidence of a second epoch of aridity which was especially marked in the twelfth century. Finally, in the later Middle Ages, a rise in the level of the Caspian Sea and the condition of certain ruins render it probable that climatic conditions once again became somewhat favorable, only to give place ere long to the present aridity.

It is not possible in this note to point out the various lines of evidence upon which the conclusions are based. They are given in full in the work referred to above. It is evident that if the conclusions are valid, the Merv Oasis must have passed through several climatic vicissitudes since the time of the earliest kurgans. In that case it should have experienced a corresponding series of epochs of expansion and prosperity during times of more propitious climate, and of contraction, distress and retrogression during times of unpropitious climate. No definite conclusion as to the matter can be reached as yet, since our knowledge of the history of Merv is still fragmentary, and especially since there has never been any full study of the distribution of ruins of different ages, whereby 
we may know exactly how, when, and why the limits of cultivation expanded and contracted. In general, however, it appears that the history of the rise and fall of successive phases of civilization in Merv corresponds to what would be expected in view of the theory of climatic changes outlined above. A fuller study of the region will afford one of the best possible tests of the theory. The matter is referred to here thus briefly in order to explain why it is that the writer, having advanced a climatic theory in explanation of certain great historic events, such as the barbarian invasion of Europe in the Dark Ages, here publishes a chapter upon one of the most critical regions to be found anywhere in the world, and devotes only a page or two to the most elementary phases of the question. The chapter is one of the steps which led to the theory, and therefore takes up only the rudiments of the subject. 


\section{PART IV. \\ CHEMICAL ANALYSES OF METALLIC IMPLEMENTS. \\ By F. A. Gooch. \\ [Chapter XiII.]}


Digitized by GoOgle 


\section{CHAPTER XIII.-THE ANALYSIS OF THE METALLIC IMPLEMENTS AND PRODUCTS OF CORROSION.}

In making choice of methods for the analysis of the metallic implements and products of corrosion, the purpose has been to secure results as accurate and comprehensive as may be with the least expenditure of valuable and unique material. In many cases the quantity of material employed did not exceed a half gram, and in some cases was less than that amount. The sample was taken from the implement in some cases by means of a lathe center-bit without disturbing exterior outlines, in some cases was broken from an end or edge, and in many cases was scraped or flaked off from the surface of the implement or broken from a mass of corroded material.

\section{THE ANALYTICAL PROCEDURE.}

\section{Treatment of Material.}

Of the material an amount approximating 0.5 gram, if so much was available, was carefully weighed, placed in a small covered beaker, and treated with $10 \mathrm{c.cm}$. of nitric acid (sp. gr. 1.42), the action being moderated by cooling when the sample was metallic and quickly acted upon, and accelerated by warming when the sample represented corroded material and was slowly attacked. When the action was complete, it was usual to evaporate the liquid, desiccate the residue at $110^{\circ} \mathrm{C}$, moisten with nitric acid, take up soluble material in $50 \mathrm{c.cm}$. of water, treat with ammonium hydroxide to formation of the soluble copper-ammonium compounds, heat to boiling, add nitric acid in excess, and filter the insoluble material upon ashless paper and wash, reserving residue and filtrate for separate treatment.

By desiccating silica was made insoluble, and by treatment with ammonium hydroxide complete hydrolysis of soluble tin compounds was effected. In some of the earlier analyses of pure metal the process of desiccation was omitted, and for the formation of the insoluble metastannic acid reliance was placed upon dilution and boiling. Experience showed, however, that all the tin is found in the residue when the ammonium hydroxide treatment is employed, and this treatment was followed in nearly all the work.

II. The Insoluble Residue after Treatment with Nitric Acid

The insoluble residue, consisting possibly of antinony oxide, metastannic acid, silica, undecomposed material, and lead sulphate in case lead and sulphur were present, was collected upon ashless paper, washed, ignited in porcelain, and weighed.

The residue was covered with a mixture of sodium carbonate and sulphur in equal parts, and the mass was heated in the covered crucible until the preliminary fusion was over and sulphur ceased to be volatilized. The mass was boiled 
out with water, and the solution filtered upon ashless paper; and when the residue was large the process of fusing and extracting was repeated. If the operation was successful, the solution now contained as sodium sulpho-salts all the tin, antimony, and arsenic of the insoluble residue. The residue and filtrate were treated separately.

III. Treatment of the Regidue apter the SUlphur Fusion and Extraction.

(a) If the original material was pure metal, the material upon the filter, containing possibly sulphides of lead, copper, and iron, was ignited, and the residue was treated with aqua regia and a little sulphuric acid. The mixture was heated to the fuming point of sulphuric acid, cooled, and treated with a little water. Any precipitate of lead sulphate at this point was filtered off on asbestos and weighed.

The solution, filtered if necessary from precipitated lead sulphate, was treated with ammonium hydroxide and any precipitated ferric hydroxide was filtered off and weighed as ferric oxide.

The solution containing no ferric salt, or filtered from the precipitated ferric hydroxide, was treated with hydrogen sulphide and any precipitated copper sulphide was filtered off, ignited, and weighed as copper oxide.

(b) In case the original material was corroded material contaminated with siliceous and earthy substance, the procedure in treating the residue after the sulphur fusion and extraction was varied. In this event, the material remaining upon the filter might consist of siliceous and earthy substance as well as small amounts of copper, lead, and iron sulphides. This residue was ignited with the filter, in platinum, and treated with hydrofluoric acid and a few drops of sulphuric acid. The mixture was heated until the free acid had been removed and was then ignited and weighed. The loss of weight under the treatment with hydrofluoric acid should be silica, in the absence of material capable of yielding undecomposable sulphates. If the material contained bases, like lime or soda, which formed with sulphuric acid refractory sulphates, this measure of the silica was only approximate.

The residue after the volatilization of silica was fused with sodium carbonate, the mass after fusion was treated with hydrochloric acid, and hydrogen sulphide was passed into the solution. Any precipitate of sulphides thus obtained was filtered off, ignited, and treated for the formation of lead sulphate, ferric oxide, and copper oxide, according to method described in the preceding paragraph $(a)$.

IV. Treatment of the Solution Obtaingd after the SUl,phur Fusion and Extraction.

The solution obtained by extracting with water the mass remaining after the fusion with sodium carbonate and sulphur was acidified with hydrochloric acid. The precipitate containing sulphur, and possibly sulphides of antimony, arsenic, and tin, was collected upon a small filter, the filtrate being rejected. The precipitate upon the filter was dissolved in the least possible amount of a warm solution of sodium sulphide. The solution was concentrated, cooled, and treated gradually with sodium dioxide until the liquid became colorless and oxygen was liber- 
ated freely. To this solution was added alcohol of sp. gr. 0.84 , amounting to a third of the entire volume. The precipitate was filtered off on paper and washed with dilute alcohol of gradually increasing strength-first, a mixture of one of alcohol to two of water, and then, successively, mixtures of one to two, one to one, and finally three to one of alcohol and water. The precipitate should contain the antimony as sodium antimonate, and the filtrate should contain sodium arsenate and sodium stannate in solution.

The precipitated sodium antimonate was dissolved from the filter in a mixture containing dilute hydrochloric acid ( $\mathrm{I}$ to 4 ) and 5 to ro per cent of its weight of tartaric acid, the solution was diluted, and hydrogen sulphide passed to complete precipitation. The precipitate was filtered on asbestos, dried in an atmosphere of carbon dioxide (Paul's apparatus) at $240^{\circ} \mathrm{C}$., and weighed as antimony trisulphide.

The solution, possibly containing sodium arsenate and sodium stannate, was acidulated with hydrochloric acid, cooled to $0^{\circ}$, treated with twice its volume of hydrochloric acid of sp. gr. 1.20, also cooled to $0^{\circ}$. Into the solution, filtered on asbestos, from precipitated sodium chloride, if necessary, hydrogen sulphide was passed for an hour and a half. After standing for two hours the precipitate was filtered off on asbestos, washed with hydrochloric acid ( 1 to 2 ) and then with hot alcohol, dried at $110^{\circ} \mathrm{C}$., and weighed as arsenic pentasulphide.

From the filtrate separated from the arsenic pentasulphide nearly all free acid was removed by evaporation and the well-diluted solution was saturated with hydrogen sulphide. After addition of ammonium nitrate to aid coagulation, the precipitate was filtered off, washed with a solution of ammonium nitrate, ignited with ammonium carbonate, and weighed as stannic oxide. The residue was identified as stannic oxide by fusion with sodium carbonate, treatment of the mass with dilute hydrochloric acid and zinc, and testing of separate portions of the solution with mercuric chloride and, after addition of potassium hydroxide in excess, with an ammoniacal solution of silver nitrate.

V. Treatment of the Filtrate from the Residue Insoluble in Nitric Acid.

To the filtrate obtained after removal of the residue left after treatment of the original material with nitric acid was added sulphuric acid, about $5 \mathrm{c.cm}$. The liquid was evaporated to the fuming point of sulphuric acid, diluted to a volume of $50 \mathrm{c.cm}$., filtered on a weighed asbestos filter, and washed with dilute sulphuric acid ( $I$ to 3 ). The filtrate was reserved. The precipitate was ignited upon the asbestos filter and weighed as lead sulphate.

\section{Treatment of the Filtrate from Lead Sulphate.}

To the filtrate from lead sulphate were added I gram of tartaric acid and ammonium hydroxide nearly to neutralization. The solution was heated to boiling and $5 \mathrm{c} . \mathrm{cm}$. of dilute sulphuric acid ( $\mathrm{I}$ to 4 ), $5 \mathrm{c.cm}$. of a saturated solution of ammonium acid sulphide, and $100 \mathrm{c} . \mathrm{cm}$. of $\mathrm{N}$ Io ammonium sulphocyanide,* were added. The whole was allowed to stand over night and the precipitated cuprous

* Van Name, Am. Jour. Sci., xIII, 138 (1902). 
sulphocyanide was filtered off upon asbestos in a perforated crucible provided with a subsidiary perforated disk (Gooch, Am. Jour. Sci., XX, I I [1905]) to facilitate the removal of material from the filter.

No attempt was made to transfer all the precipitate to the filter, but the containing beaker and adherent material with the precipitate upon the filter were washed twice. The filtrate was reserved for treatment. The crucible was placed inside the beaker, the disk with the adherent precipitate removed and placed outside the crucible within the beaker, the beaker was covered with a watch-glass, and the cuprous sulphocyanide adhering to beaker, crucible, and disk was treated with a mixture of sulphuric acid and nitric acid. Water was added after complete solution of the precipitate had taken place. The solution was filtered from the asbestos and evaporated to the fuming-point of the sulphuric acid, neutralized with ammonium hydroxide, acidified with a few drops of sulphuric acid, and electrolyzed with the use of the rotary cathode. (Gooch and Medway, Am. Jour. Sci., $\mathrm{XV}, 320$ [1903].) The deposit of copper was weighed.

Analyses of the Copper Implements from the North and South Kurgan, Cultures I, II, and III.

\begin{tabular}{|c|c|c|c|c|c|}
\hline No. of sample. & & Locality. & Character of sample. & $\begin{array}{l}\text { Weight } \\
\text { taken for } \\
\text { analysis. }\end{array}$ & $\begin{array}{c}\text { Silica and } \\
\text { insoluble } \\
\text { material } \\
\text { in nitric } \\
\text { acid. }\end{array}$ \\
\hline 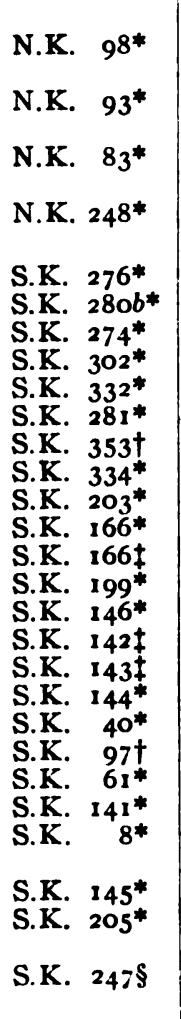 & 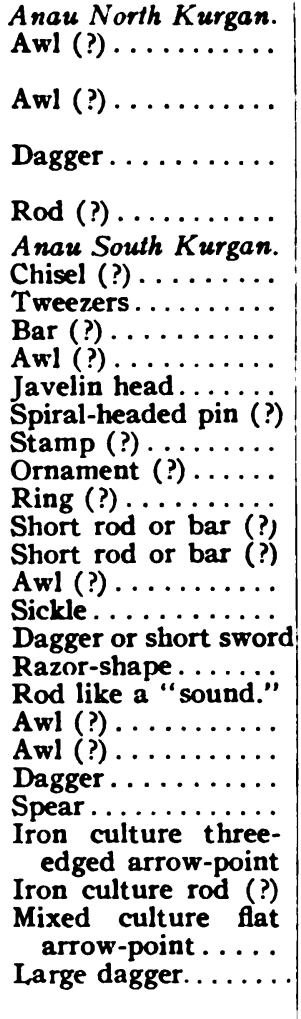 & 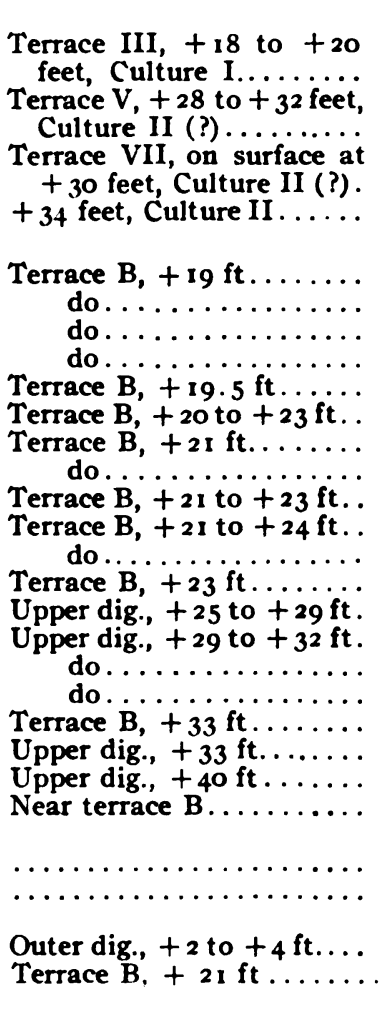 & 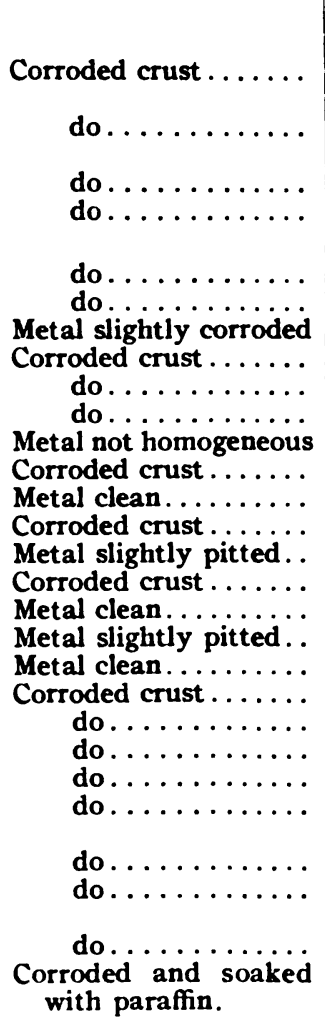 & $\begin{array}{l}\text { Grams. } \\
0.1303 \\
0.1627 \\
0.3626 \\
0.3413 \\
0.1173 \\
0.2036 \\
0.5780 \\
0.0428 \\
0.2220 \\
0.1290 \\
0.5219 \\
0.2009 \\
0.6569 \\
0.1807 \\
0.8136 \\
0.3480 \\
0.6474 \\
0.6883 \\
0.5052 \\
0.2390 \\
0.4599 \\
0.3939 \\
0.5793 \\
0.5999 \\
0.0616 \\
0.8988 \\
0.4400 \\
1.0957\end{array}$ & $\begin{array}{l}\text { Grams. } \\
\text { o.0060 } \\
0.0116 \\
\\
0.0062 \\
0.0182 \\
\\
0.0221 \\
0.0105 \\
00014 \\
0.0040 \\
0.0280 \\
\text { None. } \\
0.0012 \\
0.0162 \\
\ldots \ldots \ldots \\
0.0272 \\
0.0041 \\
0.0166 \\
\ldots \ldots \ldots \\
0.0010 \\
0.0002 \\
0.0175 \\
0.0440 \\
0.0319 \\
0.0131 \\
0.0331 \\
0.0052 \\
0.0236 \\
0.0615 \\
\ldots \ldots \ldots\end{array}$ \\
\hline
\end{tabular}

* M. A. Phelps, unalyst. †F. A. Gooch. analyst. ¥C. P. Flora. analyst.

This specimen was not examined by Professor Gooch till after paraffin had been applied as a preservative. 
Analyses of the Copper Implements. - Continued.

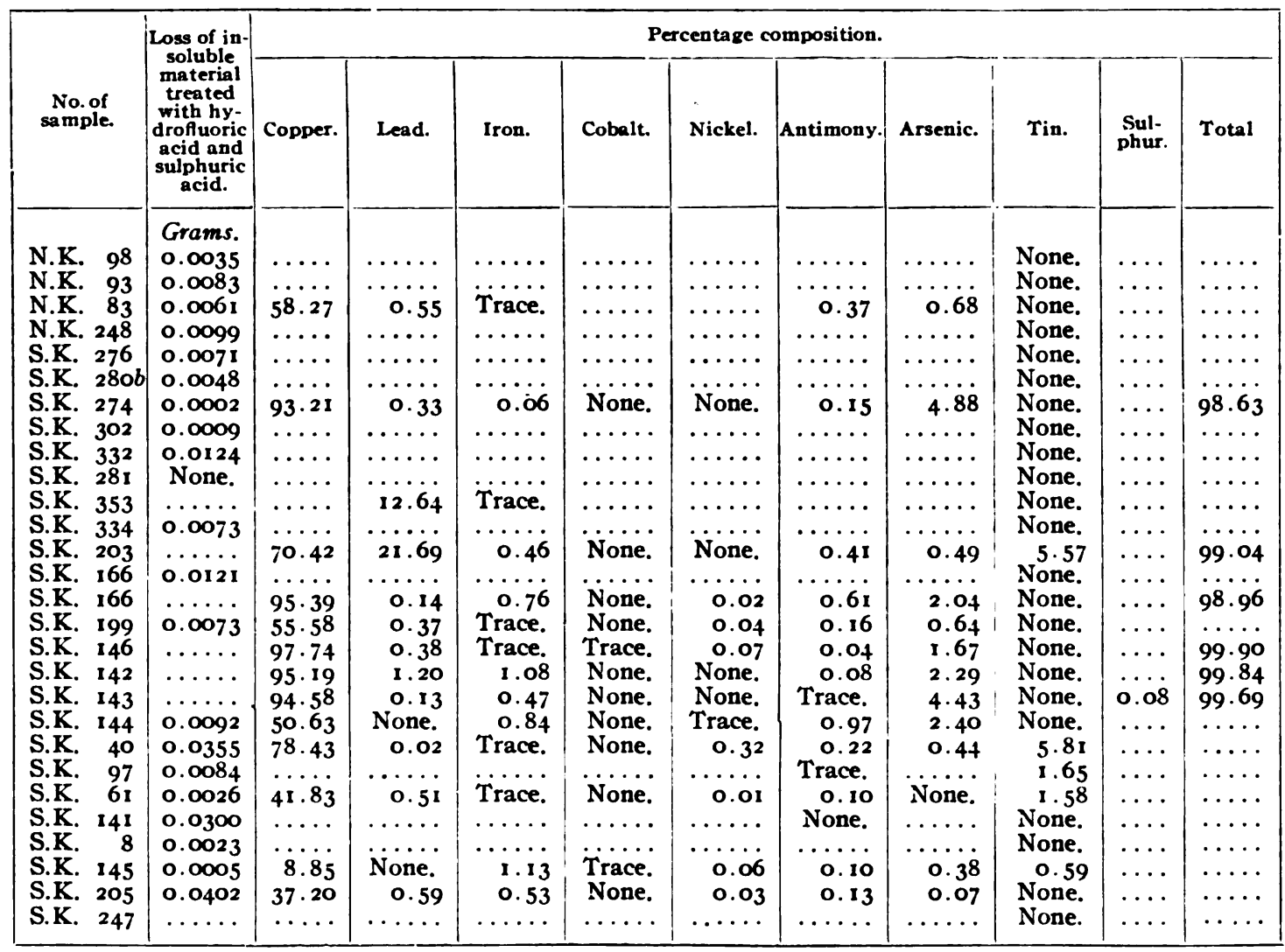

ViI. Treatment of the Filtrate from Cuprous Sulphocyanide.

The filtrate from the precipitated cuprous sulphocyanide was boiled down to a third of its volume to remove sulphur dioxide, and hydrogen sulphide was passed into the hot solution. The precipitate (which might contain sulphides of antimony and arsenic with traces of sulphides of lead and copper and possibly of tin in case ammonium hydroxide had not been used in I to effect complete hydrolysis of the salts) was collected upon paper and washed. The filtrate was reserved.

Vili. Treatment of the Precipitate by Hydrogen Sulphide in Presence of Lead.

The precipitate by hydrogen sulphide in the acidulated and concentrated solution left after removal of cuprous sulphocyanide was treated on the filter with sodium sulphide, and the filter was washed. The solution, which might contain sodium arsenate and sodium antimonate and traces of sodium stannate in case ammonium hydroxide had not been used to complete the formation of metastannic acid in the first nitric acid treatment, was treated according to the methods of section IV for the determination of antimony as antimony trisulphide, of arsenic as arsenic pentasulphide, and (if necessary) of tin as stannic oxide. The residue left upon the filter after treatment of precipitated sulphides with sodium sulphide was ignited with the filter and treated for the determination of lead as lead sulphate, and for copper as copper oxide, according to the methods of section III. 
IX. Treatment of the Filtrate from Precipitates pormed by Hydrogen Sulphide in Presence OP ACID.

The filtrate from the sulphides precipitated by hydrogen sulphide in the acidified solution from which copper had been removed as cuprous sulphocyanide was neutralized carefully with ammonium hydroxide (no precipitation taking place in the presence of tartaric acid) and treated with hydrogen sulphide. The precipitate should contain the sulphides of iron, nickel, cobalt, and possibly copper in traces, if compounds of these elements are present. The filtrate was rejected. The precipitate was treated on the filter with dilute hydrochloric acid and the residue washed. The filtrate was reserved for the estimation of iron. The insoluble precipitate was ignited with the filter and the residue dissolved in aqua regia, the solution evaporated to dryness, the residue taken up in hydrochloric acid, the solution treated with hydrogen sulphide, and any precipitate filtered off, ignited, and weighed as copper oxide.

The filtrate from the copper sulphide, or the solution in which hydrogen sulphide gave no precipitate in presence of hydrochloric acid, was carefully made alkaline with ammonium hydroxide, and hydrogen sulphide was passed in. The precipitate, filtered off and ignited, was weighed as nickelous oxide and cobaltic oxide. Any considerable residue obtained at this point should be treated for the separation of nickel and cobalt by the double nitrite process; in the case of the very small residues actually obtained in this work, the simple test for cobalt with the borax lead was all that could be made.

The filtrate reserved after treatment of the sulphides of iron, nickel, cobalt, and copper with hydrochloric acid, was boiled, treated with bromine water, and made alkaline with ammonium hydroxide. The precipitate was filtered off, washed, ignited, and weighed as ferric oxide.

\section{Special Tests for Tin.}

In the special tests for tin alone, it was usual to attack the material with nitric acid, desiccate, take up into nitric acid and water, boil, heat with ammonium hydroxide, and then with nitric acid, filter off the insoluble material, ignite and weigh. By this treatment all the tin originally present was gathered in the residue. The residue was fused with a mixture of sodium carbonate and sulphur, the melt extracted with water. The extract was acidified, and the precipitate thus obtained collected, washed with ammonium nitrate, ignited and weighed. In the ignition any arsenic present would be volatilized, so that the residue should consist only of stannic oxide and possibly antimony oxide. If the residue was considerable, the separation of antimony and tin was effected by the method previously described in section IV. If the residue was inconsiderable and no indication of antimony had been noted in the color of the sulphide, the qualitative confirmatory test for tin was made at once.

In the main, the procedure outlined above was followed closely; but great care was taken in the scrutiny of final products, which were often subjected to special analysis to make sure that the separations had been as nearly complete as possible. The analyses were made, almost entirely, by Dr. Martha Austin Phelps and Dr. Charles Paxson Flora. 


\section{N DEX.}

(Roman numerals refer to the successive cultures of Anau.)

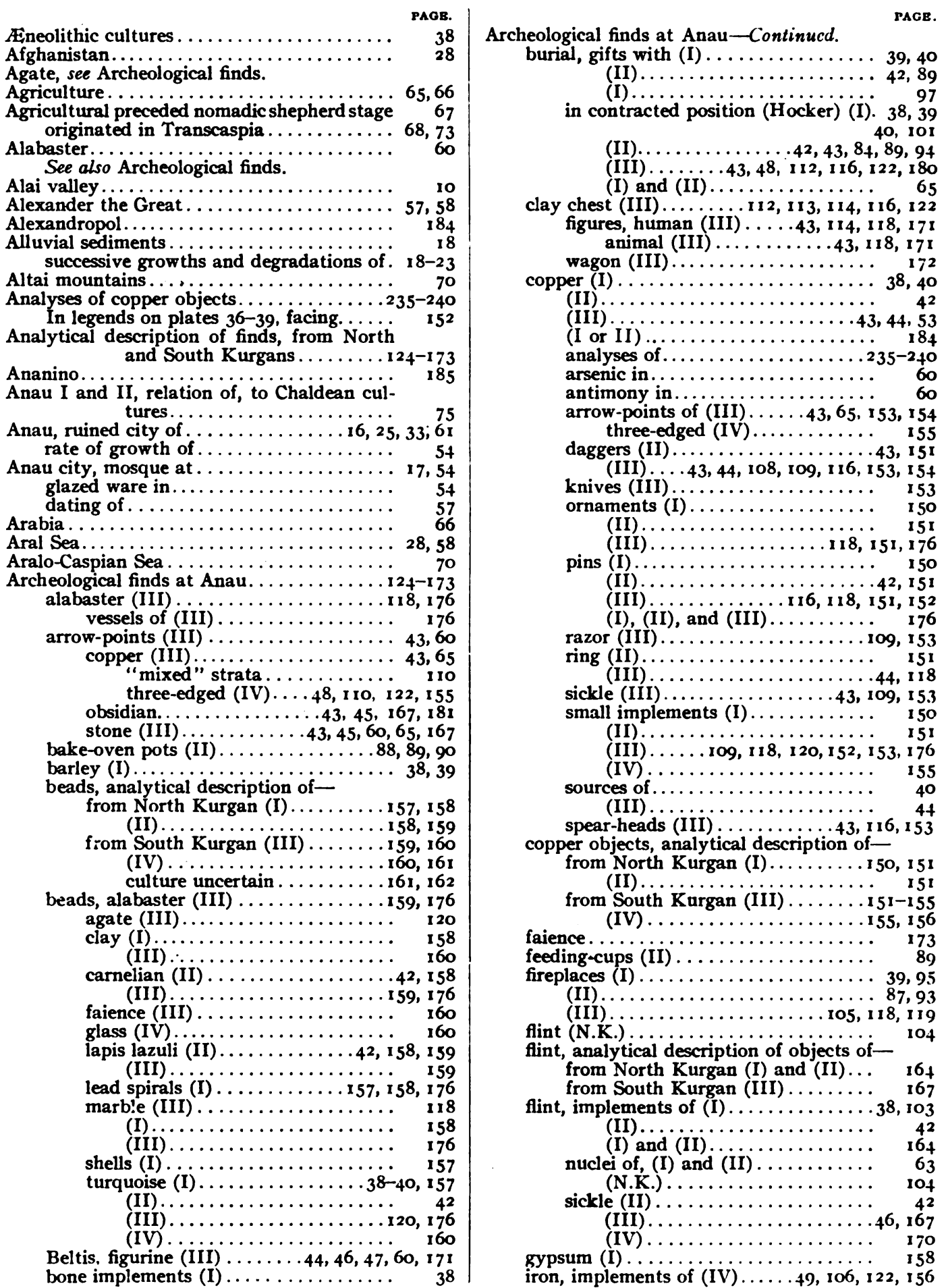


Archeological finds at Anau-Conlinucd. iron sickles (IV). analytical description of objects of, from South Kurgan (IV)...

Ishtar, figurine (III) . ..............4, $46,60,174$ lapis lazuli (II) $\ldots \ldots \ldots \ldots \ldots \ldots . \ldots \ldots, 8,158,159$ (III) $\ldots \ldots \ldots \ldots \ldots \ldots \ldots 159,176$

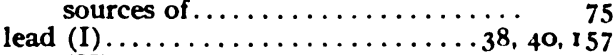
(II).

lead, analytical description of objects of, from North Kurgan (I)....

mace-heads (I) (II) $\ldots \ldots \ldots \ldots \ldots \ldots \ldots \ldots \ldots \ldots \ldots, 42,64,165$

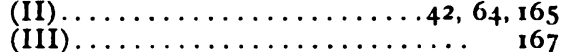
marble vessels (III) $\ldots \ldots \ldots \ldots \ldots \ldots \ldots, \quad 176$ mealing-stones (I) .............. 38 (II) . . 42,90 (I) and (II)

obsidian arrow-points (Iii) .....43, 45, 60, 167 pivotal door-stones............... 74 (II)

(III)

pottery, handmade (I) $\ldots \ldots \ldots \ldots \ldots \ldots, 58,51,64$

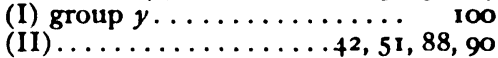
(IV) $\ldots \ldots \cdots \cdots \cdots \cdots \cdots \cdots+4,5,51,108,149$ (N.K.) ................ 10 wheelmade (III) $\ldots \ldots \ldots \ldots 43,65,104,106$ (IV). 109, $110,113,120,122$ monochrome (II) $\ldots \ldots \ldots \ldots \ldots \ldots \ldots \ldots \ldots \ldots, 92,90,919$ group $x \ldots \ldots \ldots \ldots 97,132-135,175$ painted (I) $\ldots \ldots \ldots \ldots .38,90,94,124-132$ (I) group $y \ldots \ldots .90,94,97,100,102$

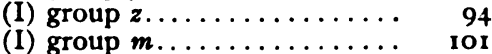
(II) $\ldots \ldots \ldots \ldots \ldots \ldots 4^{2}, 94,135^{-1} 37$ (II) group $x \ldots \ldots \ldots \ldots \ldots, 90$, 102 (III) $\ldots \ldots \ldots \ldots \ldots \ldots 43,143,145$ (IV) $\ldots \ldots \ldots \ldots \ldots \ldots \ldots$ I $\quad 149$ polychrome (II) $\ldots \ldots \ldots \ldots \ldots \ldots, \quad{ }_{136}$ incised (III) $\ldots \ldots \ldots \ldots \cdots \cdots \cdots+43,145,175$ decoration (I) $\ldots \ldots \ldots \ldots \ldots \ldots \ldots, 38,40$ (II) ... glazed (I) and (III)

"mixed strata" $\cdots \cdots \cdots \cdots \cdots$, 54 pottery, analytical description of -

North Kurgan (I) ...........124-132

(II) ........124-132

South Kurgan (III) ........... $\ldots \ldots \ldots 3^{3}-145$ (IV) $\ldots \ldots \ldots \ldots \ldots \ldots \ldots \ldots \ldots \ldots \ldots \ldots \ldots+149$ razor (III) -faced, with man, lion, and

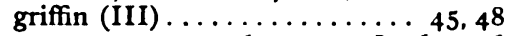
$60,112,118,169,176$

sickle, copper (III) lint (III)

skeletons (I)

(II) $\ldots \ldots \ldots \ldots \ldots \ldots \ldots \ldots \ldots 8_{4}, 89$, ff.

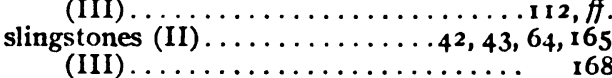
e-whorls $(\mathrm{I}) \ldots \ldots \ldots \ldots \ldots \ldots \ldots \ldots \ldots \ldots \ldots, 103$ (II) $\ldots \ldots \ldots \ldots \ldots \ldots \ldots \ldots \ldots \ldots \ldots \ldots \ldots \ldots, 4^{2}$ (I) and (II) $\ldots \ldots \ldots \ldots \ldots \ldots \ldots \ldots \ldots \ldots,{ }_{65}{ }^{42}$ (II) and (II) $\ldots \ldots \ldots \ldots \ldots \ldots \ldots \ldots \ldots \ldots \ldots \ldots \ldots, 166,1636$

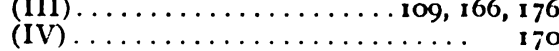
stamps (III) ............. 169, 176
Archeological finds at Anau-Continued.

PAGR. stone implements, perforated, etc., analytical description of, from
North and South Kurgans. 165, 167 stone ornaments (III) .......... 157-162 stone vessels (III) . . . . . . . . . I 8 , 120 described from South Kurgan (III) 169,176 terra-cotta figures, of woman (III) . 43, 46, 60$$
\text { of animals (III) } 114,118,171
$$
of animals (III) (I) .... 43, 46, 118,171 urquoise, objects of (I) $\ldots \ldots \ldots \ldots \ldots \ldots \ldots, 40,64$
(III) $\ldots \ldots \ldots \ldots \ldots \ldots \ldots \ldots \ldots \ldots \ldots$ wagon, clay (III) $\ldots \ldots \ldots \ldots \ldots \ldots \ldots \ldots \ldots$ wheat (I) $\ldots \ldots \ldots \ldots \ldots \ldots \ldots \ldots \ldots$ 38, 39

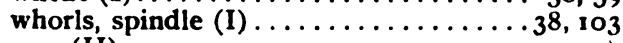
(II) and (II) $\ldots \ldots \ldots \ldots \ldots \ldots \ldots \ldots \ldots 65,163$

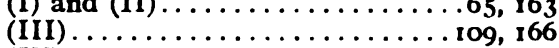

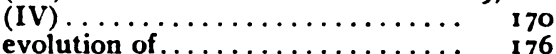
whorls, analytical description of-

from North Kurgan (I) and (II) ... $\quad 163$

from South Kurgan (III) $\ldots \ldots \ldots \ldots, 166$

Archeological (IV) ................ 170

Archeological finds at Ghiaur Kala (Oid

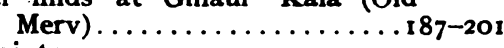

arrow-points . three-edged . . . . . . . . .

beads, agate $\ldots$. carnelian ............... 199

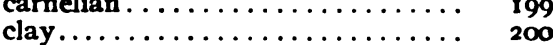

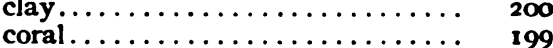

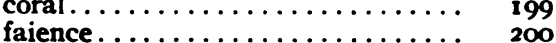
glass ................... 199

lapis lazuli............... 199 turquoise . . . . . . . . . . . 199 bronze objects............... 198, 199 coins . . . . . . . . . . . . $\ldots \ldots \ldots 188,196$

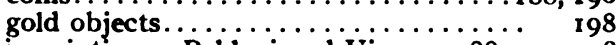
inscriptions-Pehlevi and Uigur . . 188, 197, 198 lamps .................... 195, 216 pottery................. 194-196, 214 glazed.................. 195 painted................. 196 sling implements............... 200 terra-cotta figures.............. 200 water basin . . . . . . . . . . . 192 Arctic Ocean . . . . . . . . . . $5 \ldots \ldots \ldots \ldots, 5$ Armenia .................. 70 Arrow-points and spear-heads . . . . . . . . Arrow-points, absence of, (I) and (II) ..... 63 appear in (III) $\ldots \ldots \ldots \ldots \ldots \ldots \ldots \ldots 60,65$ obsidian (III) $\ldots \ldots \ldots \ldots \ldots \ldots .43,45,167,181$ stone, absent in early Susiana....... 73 three-edged - at Anau. ........... 49 at Ghiaur Kala.............. 191, 198 distribution of .............. 183 comparatively discussed .......... $183-186$ Arrow-points, see also Archeological finds.

Askhabad, artesian well ............. 27

discussed $\ldots \ldots \ldots \ldots \ldots \ldots \ldots \ldots, 31,61$

a quaternary time scale........... 62

sinking of plains shown in ........ 27 Aspelin, J. R.................. Attica.......... ${ }^{85}$

Babylonia ................... 53, 72

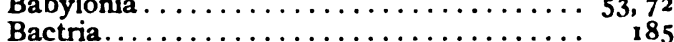

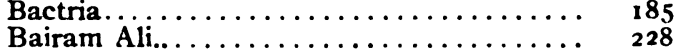
Bake-oven pots. $\ldots \ldots \ldots \ldots \ldots \ldots \ldots \ldots \ldots \ldots, \quad 8{ }^{28}$ See also Archeological finds. 
INDEX.

Balkash Sea.

Bal Kuwi. See also Archeological finds.

Barley, brought to Europe...

Beads, see Archeological finds.

Beltis.

See also Archeological finds.

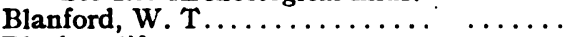

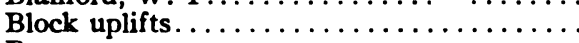

Boar.

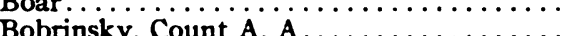

Bokhara..........................

Bos namadicus . . . . . . . . . . . . . . . . . . . .

Bosporus

Cimmerian

von Brandt, Mr.

Breeding, initiated by long-b ided people on oases

Bronze from Ghiaur Kala $\ldots \ldots \ldots \ldots \ldots \ldots$

Bronze, full, absent

Burials in contracted position (Hocker), geographical distribution of. .....

in early Europe

See also Archeological finds.

Camel.. See also Archeological finds.

Carter, J. B

40

Cattle, long

short-horned $\ldots \ldots \ldots \ldots \ldots \ldots \ldots \ldots \ldots \ldots, 180,181,184$
$4^{2}$

Central Asia, evolution of

a series of landlocked basins $\ldots \ldots \ldots$

climatic factors in . . . . . . . . . . . . . .

residuary seas of

列

crich-basins of . . . . . . . . . . . . .

trend of climatic conditions in........

grassy plains of.

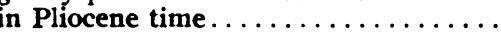

effect of regional desiccation in. . . . . . .

advent of glacial period in . . . . . . . .

subaerial processes in

loess in

a cycle of controlling agencies in, during Quaternary time.

delta-oases of.

animal life in - during glacial period.

zone of vegetation in

genera'ized culture of.....

genera.ized culture of . . . . . . . . . . . relation of Anau (I) and (II) to cultures of

Chaldean influence in Anau (III) . . . . . . .

Châlons-sur-Saône . . . . . . . . . . . .

Chantre, E..................180, 18

Child burials . . . . . . . . . . . . . . . 64, 65

Chosroes I (Anu-shirvan) $\ldots \ldots \ldots \ldots \ldots \ldots \ldots$

Chosroes I (Anu-shirvan) $\ldots \ldots \ldots \ldots \ldots \ldots$

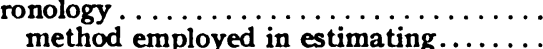

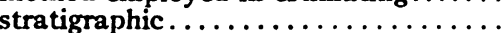

rate of growth of culture-strata per

rate determined in Egyptian village

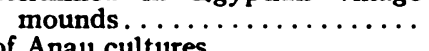

dating of Anau cultures . . . . . . . .

Dr. H. Schmidt on, of Anau.

foot-note on-by R. Pumpelly : . ....

Civilizations, sec Cultures.
58
29

73

69

60

75

184

184

72

184

230

71

198
53

180

80

75

|

Clay chest in South Kurgan.......... PAOE.

Clay chest in South Kurgan.............112-116

Clay figures, see Archeological finds.

Climate, relation of, to cultures.....43,44, 49, 50

Climatic oscillations..............6,67 relation of, to cultures....43,44, 49, 50, 57-60

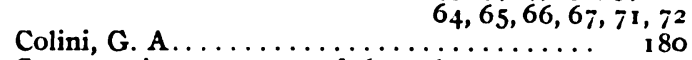

Comparative summary of the cultures.....

Contracted burials (Hocker)........... See also Archeological finds.

Copper......................60, 64, 66 localities of ores, in Persia and Siberia. . 44 ornaments, comparative discussion of . . $\quad$ I $8 \mathrm{I}$ objects, analytical description of, sce Archeological finds.

chemical analyses of . . . . . . . 235-240

In legends of plates $36-39$, facing.

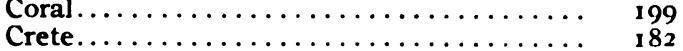

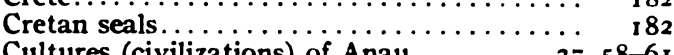

Cultures (civilizations) of Anau...........

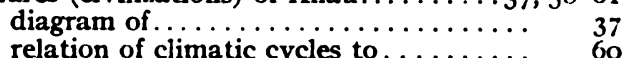

I and II, relation of, to early Babylonia of Central Asia, early differentiation of $\quad 64$

Culture (civilization) I of Anau........ 38,60 characteristics of $\ldots \ldots \ldots \ldots \ldots \ldots \ldots, 38,121$ animals known in ............. 38 animals domesticated in .......... 38 houses of . . . . . . . . . . .

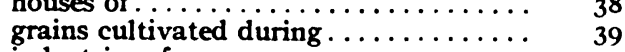
industries of $\ldots \ldots \ldots \ldots \ldots \ldots \ldots \ldots .39$

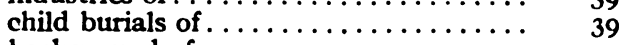
background of $\ldots \ldots \ldots \ldots \ldots \ldots \ldots \ldots, 49$ initiated domestication of animals . . . . . end of $\ldots \ldots \ldots \ldots \ldots \ldots \ldots \ldots \ldots$

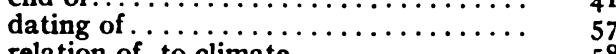
relation of, to climate $\ldots \ldots \ldots \ldots \ldots \ldots \quad 58$

Culture II of Anau...............4 42, 60 characteristics of $\ldots \ldots \ldots \ldots \ldots \ldots \cdots \cdots, 4^{42,}, 121$

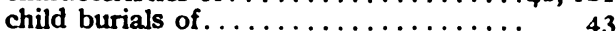
industries of $\ldots \ldots \ldots \ldots \ldots \ldots \ldots, 43$ animals bred in ................ 43 dating of $\ldots \ldots \ldots \ldots \ldots \ldots \ldots \ldots \ldots \ldots \ldots, \quad 437$ relation of, to climate . . . . . . . . 59 end of $\ldots \ldots \ldots \ldots \ldots \ldots \ldots \ldots \ldots \ldots$

Culture III of Anau. . . . . . characteristics of $\ldots \ldots \ldots \ldots \ldots \ldots \ldots, 4,122$ distinctly a copper culture........... 44 child burials of $\ldots \ldots \ldots \ldots \ldots \ldots \ldots 43,47$ relation of, to climate $\ldots \ldots \ldots \ldots \ldots 44,59$ ignorance of bronze during .......... 44.44 Ishtar cult ...................... $\quad 46$ ends about 2000 B. C........... 57

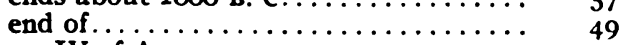

Culture IV of Anau. . $\ldots \ldots \ldots \ldots \ldots \ldots \ldots \ldots, 122$ an iron culture $\ldots \ldots \ldots \ldots \ldots \ldots \ldots \ldots, 49$ relation of, to climate $\ldots \ldots \ldots \ldots \ldots \ldots \ldots \ldots, 5 \%, 59$ dating of by $R . P \ldots \ldots \ldots \ldots \ldots$ by $\mathrm{H} . \mathbf{S} \ldots \ldots \ldots \ldots \ldots \ldots \ldots \ldots \ldots \ldots, \quad 576$ Culture gaps ....................... between III and IV $\ldots \ldots \ldots \ldots \ldots \ldots \ldots \ldots$
between II and III $\ldots \ldots \ldots \ldots \ldots \ldots \ldots$

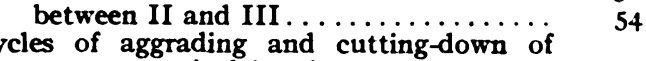

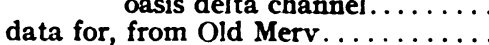

parallel with climatic and culture and biological changes........ 58,59 
Daggers. see Archeological finds.

Davis, W. M.

Decius

Deer.

Delta-oases.

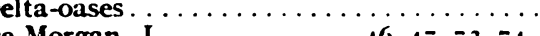

De Morgan. J $\ldots \ldots \ldots \ldots \ldots 46,47,73,74,179,180$

Deserts, progressive expansion of ....... I3

Djungarian gate. ................ ;o

Dog....................... 48,60, it

Domesticated animals, breeds produced of $.+1,4.3$ stunting of

Domestication of animals. and breeding originated in Transcaspia breeds prod

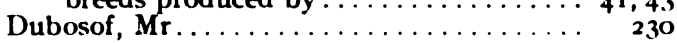

Duerst, J.U. . . . . .

Edfu.

Egypt

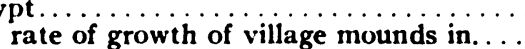

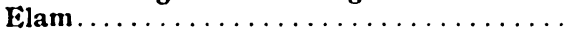

Elburz

Esneh.

Euergetes II

Euplirates.

Evans, A. J

cavations at North Kurgan ..............

summary $\ldots \ldots \ldots \ldots \ldots \ldots \ldots \ldots \ldots \ldots \ldots \ldots \ldots \ldots \ldots$
details of $\ldots \ldots \ldots \ldots \ldots$

Excavations at South Kurgan .......... 104-120

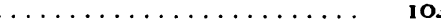
details of . ................ 106-120 See also Table of Contents.

Excavations, at Ghiaur Ka!a (Old Merv) ...187-20r general summary $\ldots \ldots \ldots \ldots \ldots \ldots \ldots 18$ details of $\ldots \ldots \ldots \ldots \ldots \ldots \ldots \ldots \ldots \ldots \ldots$ r8 89.193 special finds from............

Faience, see Archeological finds.

Feeding-cups, see Archeological finds.

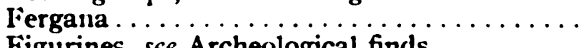

Figurines, sce Archeological finds.

Fireplaces, see Archeological finds.

Flint. implements .

$\ldots \ldots \ldots \ldots \ldots$

Sce also Archeological finds.

Fox.

Friederichs . . . . $\ldots \ldots \ldots \ldots \ldots \ldots \ldots \ldots \ldots \ldots \ldots \ldots$

Furtwaengler.................

Galchas .

Gautier, j. E

Gezer. climatic changes at $\ldots 57-59,18, \ldots \ldots \ldots$. excavations at

pottery in

glazed ware in.

Pehlevi and Uigur inscriptions in . . . . .

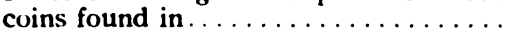

archeological finds at $\ldots \ldots \ldots \ldots \ldots \ldots \ldots$ 194-20 pottery at ........................

Glacial period, in central Asia . . . . . . 6 , conditions during phases of $\ldots \ldots \ldots \ldots$ I $2 \mathrm{ff}$. moraines of, on Pamir.............. oscillations of iso!ation of Central Asia caused by..... 63, 70 Glass. see Archeo.ogical finds.

Glazed ware...............

Gobi .........
PAGE.

.... 19.9

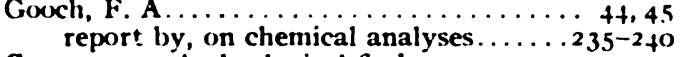
Gypsum, sce Archeological finds.

Hallstadt period $\ldots \ldots \ldots \ldots \ldots \ldots \ldots \ldots \ldots \quad 185$

Hamadan................. 185

Helbig $\ldots \ldots \ldots \ldots \ldots \ldots \ldots \ldots \ldots \ldots \ldots 185,186$

Hindu-Kush $\ldots \ldots \ldots \ldots \ldots \ldots \ldots \ldots \ldots \ldots$;o

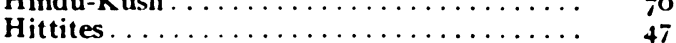

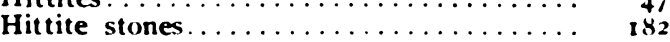

Hoernes, M................... 46

Hohenzollern-in-Sigmeringen, Prince..... 185

Homer...................... 186

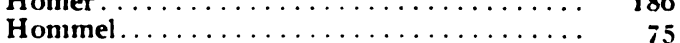

$\underset{\text { Horodnika . . . } \ldots \ldots \ldots \ldots \ldots \ldots \ldots \ldots \ldots \ldots \ldots \ldots}{\mathbf{7 5}}$

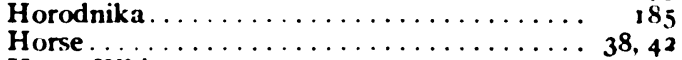

Huns, White $\ldots \ldots \ldots \ldots \ldots \ldots \ldots \ldots \ldots \ldots \ldots \ldots \ldots$ 38, $^{42}$

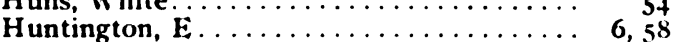

on distribution of Kurgans on Merv

()asis................219-232

Inscriptions, Peh'evi and Ligur, at Ghiaur Kala (Ancient Merv) .......197, 198

Iranian plateau...............6.

Iron culture (Anau IV) ...................
Objects from, see Archeological finds.

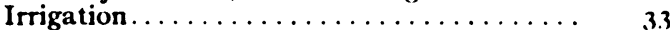

when begun $\ldots \ldots \ldots \ldots \ldots \ldots \ldots \ldots \ldots \ldots$

canals for ...............

formerly more extensive . . . . . . . . . 34

reverses natural order of de! ta-building. 34

Irrigation sediments $\ldots \ldots \ldots \ldots \ldots \ldots \ldots 18,19,22$ thickness of $\ldots \ldots \ldots \ldots \ldots \ldots \ldots \ldots \ldots$

rate of growth of $\ldots \ldots \ldots \ldots \ldots \ldots \ldots \quad \mathbf{3 5}$

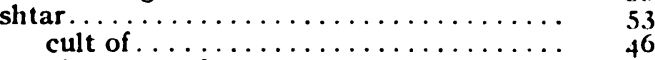

Isolation, area of $\ldots \ldots \ldots \ldots \ldots \ldots \ldots \ldots, 70$

Istakri. ................. ${ }_{5} \mathrm{~s}$

Jequier.................. 47

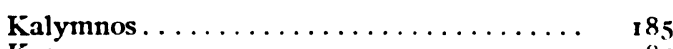

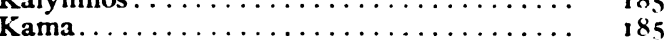

Karagodeuachkh $\ldots \ldots \ldots \ldots \ldots \ldots \ldots \ldots \quad 18_{4}$

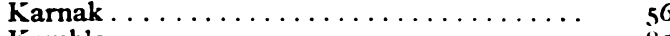

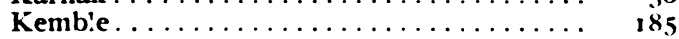

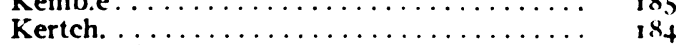

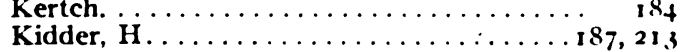

Kidder, H. $\ldots \ldots \ldots \ldots \ldots \ldots \ldots \ldots \ldots \ldots \ldots \ldots \ldots \ldots \ldots \ldots \ldots \ldots \ldots \ldots$
Kieff $\ldots \ldots \ldots \ldots \ldots \ldots \ldots$

Knife . . . . . . See also Archeological finds

Koban . .............

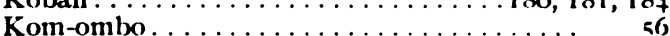

Komorof, General..............

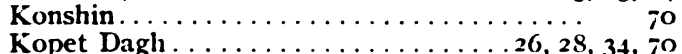

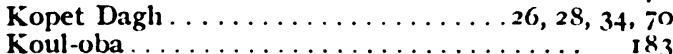

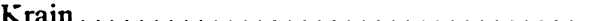

Kuban ................... I $8+$

Kurgans, of Anau, structure of . . . . . . . method of excavating .......... 16 relative ages of . . . . . . .
stratified débris of $\ldots \ldots \ldots \ldots \ldots$ strata)....

earthen house floors in . . . . . . . . . . .

child skeletons in. . .

child skeletons in .

hases of, buried. . . .

deformation of $\ldots \ldots \ldots \ldots \ldots \ldots \ldots \ldots$

relative rate of growth of . . . . . . . 22

evidence from shafts at ........... $19-23$

are on zone of alternate aggrading and

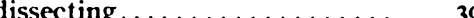

analytical description of finds from.... $124-173$ 
Kurgan, the North, at Anau, physical events during life of

animal bones collected from

characleristics of Culture I of .

1 of characteristics of Culture II of ..........

size of $\ldots \ldots \ldots \ldots \ldots \ldots \ldots \ldots \ldots$.

excavations at ..................... Kurgan, the South, at Anau, characteristics characteristics of Culture IV of .......... excavations at .................. 10+-1

Kurgans of the Merv oasis ................. 219

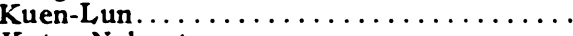

Kutur-Nahunte . . . . . . . . . . . . . .

I.ake-dwellings, Swiss............... 67 Lamp, at Ghiaur Kala ............... 195, 216

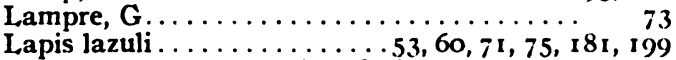
See also Archeological finds.

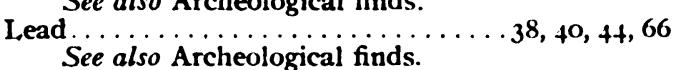

Lemberg........................... $\quad \mathbf{I}_{55}$ Lindenschmidt, L ..................... 185

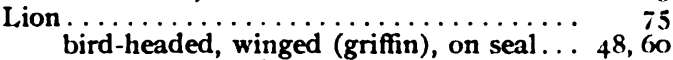

Loess, in Central Asia ................. 10, 12 description of . . . . . . . in China....................... in Europe and America.............. 8 Richthofen's theory of $\ldots \ldots \ldots \ldots \ldots \ldots$
R. Pumpelly on $\ldots \ldots \ldots \ldots \ldots \ldots$ R. Pumpelly on ................. $\begin{array}{lll}\text { sources and transporting agents of ..... } & 9.12 \\ \text { on the Pamirs } & \end{array}$ relation of shrinkage of, on cultures....

v. Luschan $\ldots \ldots \ldots \ldots \ldots \ldots \ldots \ldots \ldots \ldots, \quad \mathbf{1}_{5}$

Luxor....................... ${ }_{56}$

Mace-heads.................... 60, 64 See also Archeological finds

Marb'e, objects of, see Archeological finds.

Markof, determination of coins by . . . . . . 196, 197

Mealing-stones . . . . o. cha 38,42 See also Archeological finds.

Medinet -habu ........................ $\quad 56$

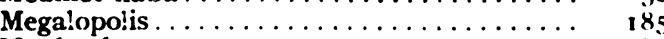

Merdescht $\ldots \ldots \ldots \ldots \ldots \ldots \ldots \ldots \ldots, \quad 185$

Merseburg ...................... $\quad 182$

Merv, excavations at ancient .......... 187 glazed ware at, with Sassanian coins... $5+$ kurgans on oasis of $\ldots \ldots \ldots \ldots 26,58,219-232$
. Mesopotamia, bronze in ........ $\ldots \ldots \ldots \ldots \ldots, 53,66$
Metallic implements, analyses of $\ldots \ldots \ldots 235-239$ Metallic implements. analyses of $\ldots \ldots \ldots \ldots 235^{-239}$ in first c.imatic cycle........... it great, and routes.................... of oasis peoples......................

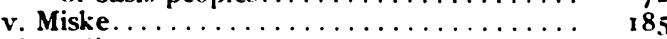
Mongolia $\ldots \ldots \ldots \ldots \ldots \ldots \ldots \ldots \ldots \ldots, 5,5,66$

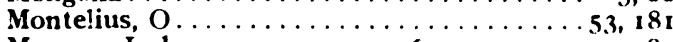
in early cultures of $\ldots \ldots \ldots \ldots$. pottery of $\ldots \ldots \ldots \ldots \ldots \ldots \ldots \ldots \ldots \ldots \ldots \ldots \ldots, 18,7_{13}^{73}$

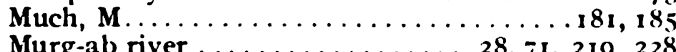
Muschketof, J. V..................... 27,70

Nehring

Nikrashevich, Mr......................

Nile............................

Novilara....................... $\quad 180$
Oases, delta.............................. early home of man ........ channels on ........ aggrading and dissecting agencies on ...23, 24 aggring sinking while mountains rise. ....... evidence from Askhabad well......... 27 zones of deposition on .............. 27 résumé of essential factors in building of 29 streams on ................. 27 alluvial shoreline on ................

Oasis of Anau.................... is the forming of $\ldots \ldots \ldots \ldots \ldots \ldots \ldots \ldots$ is town sites of ................. 15 evidence from shafts on ............ $19^{-23}$ ratios of growth, alluvial sediments and culture-strata.

table of physiographic history of .........

Oasis-world, lypothesis of . ............... isolation of, since giacial period............ comparison of cultures of ............. differentiation of cultures of .............. forced initiation of agriculture in..... the birthplace of sett!ed civilization... Oberthau......................... 182

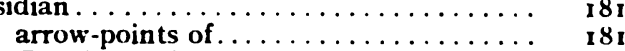
See also Archeological finds.

Odessa....................... $18_{t}$

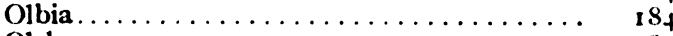

Olshausen........................... 18

Olympia............................ 185

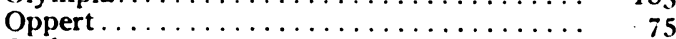

Orchomenos..............

Ornaments, see Archeological finds.

Ovis vignei..................

Ox, wild ........................ $\mathbf{3 8}_{\mathbf{3 8}}$ Sumerian character for $\ldots \ldots \ldots \ldots \ldots \ldots, 7_{2}$ domestication of $\ldots \ldots \ldots \ldots \ldots \ldots \ldots, 38,41$

Ox, domesticated................... Sumerian character for ............ 72 late arrival of, in Babylonia........... $7^{2}$ long-horned .................. $38,42,60$

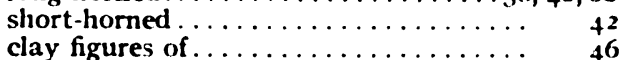
Oxus river $\ldots \ldots \ldots \ldots \ldots \ldots \ldots \ldots \ldots \ldots, 28,76$

Painted pottery of Anau I, II, III, and IV, see Archeological finds.

Painted pottery of Anau and Susiana . . . . . $\quad 179$

Palestine . . . . . . . . . $\ldots \ldots \ldots \ldots \ldots \ldots$

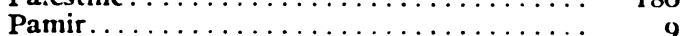
deflation on $\ldots \ldots \ldots \ldots \ldots \ldots \ldots \ldots \ldots \ldots,{ }_{10}^{9}$ loess on $\ldots \ldots \ldots \ldots \ldots \ldots \ldots \ldots \ldots \ldots \ldots \ldots$ r.

Panticapxum. $\ldots \ldots \ldots \ldots \ldots \ldots \ldots \ldots, \quad 1_{4}$ Pehlevi inscriptions................197, 198 Penck, A..................... 59 Persepolis....................... $\quad 185$ Persia, painted pottery of $\ldots \ldots \ldots \ldots \ldots \ldots \ldots$. 179

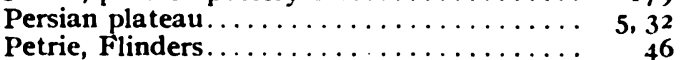

Pig, domestication of $\ldots \ldots \ldots \ldots \ldots \ldots \ldots, 38,41$ domesticated $\ldots \ldots \ldots \ldots \ldots \ldots \ldots, 3_{8,2,60}$

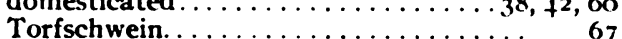

Pins, see Archeological finds.

Pivotal door-stones. . . . . . . . . . . . . . 4,43

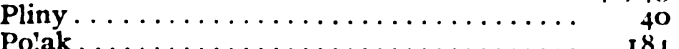

Potters' wheel...................... 43,4t Pottery whed................... 430 of Cultures I, II, III, and IV. See Archeological finds and in Table of Contents. use in dating. $\ldots \ldots \ldots \ldots \ldots \ldots 20,21,23,5$ painted pottery......................64, 65,66 See also Archeological finds. 


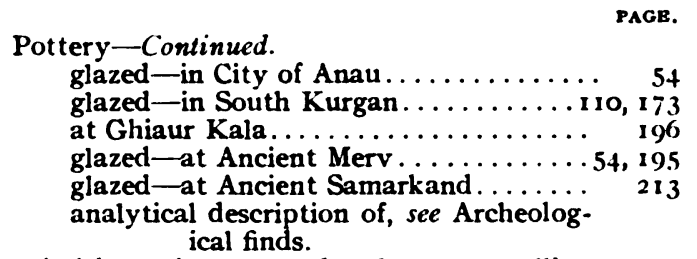

Primitive city mounds, law controlling

Ptolemy VI.

Pumpelly, $\mathbf{R} \ldots \ldots \ldots \ldots \ldots \ldots \ldots \ldots \ldots$

note on dating .............. 186

Pumpelly, R. W. . . . . . . . 6, 10, 15, 19, 23,29

note by $32,57,102,114,115$

Quatrefages.

Radlof, W

Ramses III .

Ratio of growth of alluvial sediments and culture-strata.

Razor, sce Archeological finds.

Reclus, Elisée.

Reinach, S.

Results from North and South Kurgans . .121-173

Richthofen, F. von ...

Ring, see Archeological finds.

v. Sacken.

Sahara.

St. John, O

Salemann.

Salmanesar II

Samarkand

ware at.............................

depth of glazed ware at $\ldots \ldots \ldots \ldots \ldots$

Samthawro. .

Sargon of Accad

Sarmatic Sea.

Schellenberg, H. C..

Schliemann collectic

.

Schmidt, H . . . . . I 5, 37, 40, 44, 48, 49,

Seal, three-faced, with winged and birdheaded lion-griffin ......... 48,60 discussion of ... Cretan. See also Archeological finds.

\section{Sellin}

Sergi, G . . . . . . .

Shafts at Anau, A . . . . . . . . $\ldots \ldots \ldots \ldots 21,22,25,33,35,52$

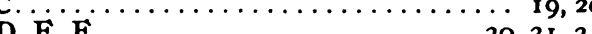

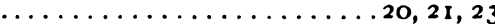
N.K.W. I $\ldots \ldots \ldots \ldots \ldots \ldots \ldots \ldots \ldots \ldots, \quad$ I9 N.K.W. II . . . . . . . . . . . . . . 23 the evidence from........... $19,20,21,23,51$

Sheep, wild. domesticated ........................ domestication of . . . . . . . . . . . . large-horned ................. 6

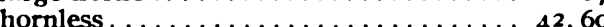
Torfschaf .................6. Torfschaf .................. expansion of ................ 67,71 Shell ornaments, see Archeological finds.

Sickle $\ldots \ldots \ldots \ldots \ldots \ldots \ldots \ldots \ldots 43,45,48,63$ foreign analogies of copper, Culture III 182 Sickle flints $\ldots \ldots \ldots \ldots \ldots \ldots \ldots \ldots \ldots 6,73,74$

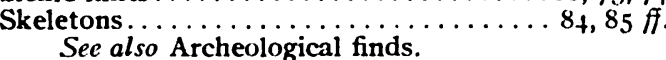

Skulls from Anau, dolichocephalic
Sling implements from Ghiaur Kala ...... PAGB.

Slingstones.................... See also Archeological finds.

Smjela ...................... 18

Spear-heads of stone............. 70 absence of, in Cultures I and II...... 63 absence of, in early Susiana........ 73

Spindle-whorls ................ 65 See Archeological finds.

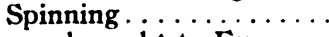

brought to Europe

Stamps, see Archeological finds.

Stone, implements and vessels of, sce Archeological finds.

Susa, first appearance of proto-cuneiform

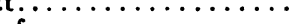

pottery of ............ 179

usiana.............................

flint implements of ............... 73

absence of stone arrow-points and spearheads in ............. 73

flint workshop in ............

analogies of early cultures of, to Anau

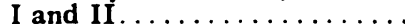

Syr-darya river...............

Tachmurez................ 5

Tadjiks............

Tepe Mohamed Djaffar, flint workshop at...

$\begin{array}{ll}\text { Tepe Mohamed Djaffar, flint workshop at... } & 73 \\ \text { Terra-cotta figures, from Anau III......... } & 46\end{array}$

See also Archeological finds and pls. 46,47 .

from Ghiaur Kala.................

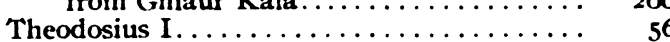

Thotmes III ................ ${ }_{56}$

Tian Shan ...................

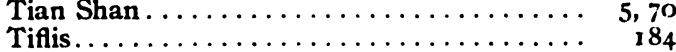

Tin, in Anau III....................... absent in Anau $I$ and II $\ldots \ldots \ldots \ldots . \ldots, 48,42$

Tin ores in Khorassan and Afghanistan.... 44

Torfschaf, see Turbary sheep.

Troja-Hissarlik .................. I8I

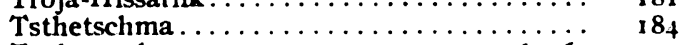

Turbary sheep................6. $69,71,72$

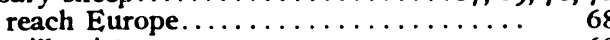

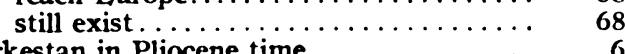

Turkestan in Pliocene time..........60, 64, 199 See also Archeological finds.

Uigur inscriptions at Ghiaur Kala....... 197, 198 Ujfalvy.................. 69 Ur......................... 53 Urus................

Villach.................. 185 Virchow, $\mathbf{R} \ldots \ldots \ldots \ldots \ldots \ldots \ldots \ldots \ldots \ldots \ldots \ldots \ldots \ldots, 181,184$

Waatsch................. 185

Wagon, clay (III) $\ldots \ldots \ldots \ldots \ldots \ldots \ldots \ldots$ 172

Warner, L...............68, 69, 85, 91 Wheat . . . . . . . . . . . . . . brought to Europe............. 69 Whorls, spindle..............................
See also Archeological finds.

W jatka.................... 185

Yellow river.................

Yeremief, $\mathrm{Mr} \ldots \ldots \ldots \ldots \ldots \ldots \ldots \ldots \ldots \ldots \ldots$

Zerafshan river. $\ldots \ldots \ldots \ldots \ldots \ldots \ldots \ldots \ldots \ldots \ldots \ldots \ldots \ldots \ldots \ldots \ldots \ldots$
Zichy, Count $\ldots \ldots \ldots \ldots \ldots \ldots$ 



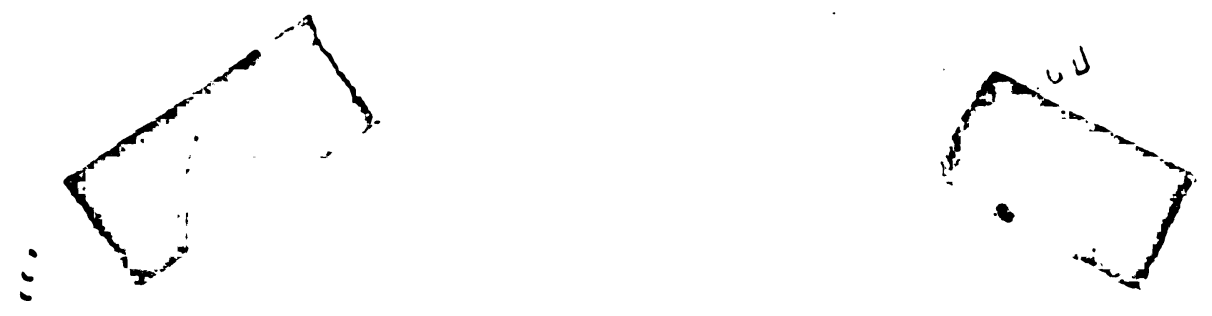

$r$

Digitized by Google 
lis:

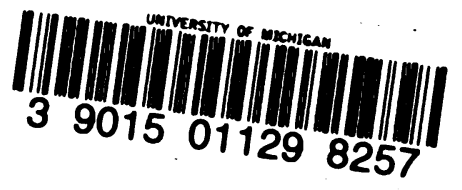

.

$\hat{x}^{\bar{n}}$.

DO NOT REMOVE

OR

MUTILATE CARD 
